\title{
Towards E-compliance
}

Citation for published version (APA):

Okuda, A. (2021). Towards E-compliance: Exploring the role of compliance and E-governance initiatives in the case of Bhutan. [Doctoral Thesis, Maastricht University]. Boekenplan.

https://doi.org/10.26481/dis.20211116ao

Document status and date:

Published: 01/01/2021

DOI:

10.26481/dis.20211116ao

Document Version:

Publisher's PDF, also known as Version of record

\section{Please check the document version of this publication:}

- A submitted manuscript is the version of the article upon submission and before peer-review. There can be important differences between the submitted version and the official published version of record.

People interested in the research are advised to contact the author for the final version of the publication, or visit the DOI to the publisher's website.

- The final author version and the galley proof are versions of the publication after peer review.

- The final published version features the final layout of the paper including the volume, issue and page numbers.

Link to publication

\footnotetext{
General rights rights.

- You may freely distribute the URL identifying the publication in the public portal. please follow below link for the End User Agreement:

www.umlib.nl/taverne-license

Take down policy

If you believe that this document breaches copyright please contact us at:

repository@maastrichtuniversity.nl

providing details and we will investigate your claim.
}

Copyright and moral rights for the publications made accessible in the public portal are retained by the authors and/or other copyright owners and it is a condition of accessing publications that users recognise and abide by the legal requirements associated with these

- Users may download and print one copy of any publication from the public portal for the purpose of private study or research.

- You may not further distribute the material or use it for any profit-making activity or commercial gain

If the publication is distributed under the terms of Article $25 \mathrm{fa}$ of the Dutch Copyright Act, indicated by the "Taverne" license above, 


\title{
Towards e-compliance:
}

\section{Exploring the role of compliance and}

\author{
e-governance initiatives
}

in the case of Bhutan 
(C)2021, Atsuko Okuda

Publisher: Boekenplan, Maastricht

\section{ISBN 9789086665280}

All rights reserved. No part of this publication may be reproduced in any form by print, photoprint, microfilm, electronic or any other means without written permission from the author. 


\section{TOWARDS E-COMPLIANCE: Exploring the Role of Compliance and E-Governance Initiatives in the Case of Bhutan}

\section{DISSERTATION}

To obtain the degree of Doctor at Maastricht University, on the authority of Rector Magnificus Prof. dr. Rianne $M$. Letschert, in accordance with the decision of the Board of Deans, to be defended in public on Tuesday,

16 November, 2021 at 10:00 hours

BY

Atsuko Okuda 


\section{SUPERVISOR}

Prof. dr. Baharul Islam, Indian Institute of Management Kashipur

\section{CO-SUPERVISOR}

Dr. Mindel van de Laar, Maastricht University

Dr. Antonio Cordella, London School of Economics

\section{ASSESSMENT COMMITTEE}

Prof. dr. Harro can Lente (Chair)

Prof. dr. Elsa Estevez, Universidad Nacional de la Plata

Prof. dr. Lalitha Fernando, University of Sri Jayewardenepura

Prof. dr. Rita Walczuch 
First, I wish to thank my supervisory team at the UNU-MERIT, Dr. Mindel van de Laar, Director of the GPAC ${ }^{2}$ Program, Dr. Antonio Cordella, Associate Professor at the London School of Economics and Dr. Baharul Islam, Professor and Chair, Centre of Excellence in Public Policy and Government, the Indian Institute of Management Kashipur. Without their insightful advice, continuous guidance and unwavering encouragement, this study would not have been possible.

I can't thank enough the government officials and experts who supported my research in Bhutan. My immense gratitude. They are the true heroes of Bhutan's digital transformation, upholding the vision of His Majesty the King and country and making tireless efforts towards corruption-free society. They were truly inspirational.

I am eternally grateful to my family who supported my journey from Day 1 . My husband, Karma Sangay Phuntsho, and two daughters, Sonam Pelzom Misaki Okuda and Samdrup Dolma Miyuki Okuda. I know that my decision to pursue $\mathrm{PhD}$ research came as a bewilderment to them. When I was taking econometric courses, my daughters asked me what I was studying at the university. When I said math, they looked confused. Why would I "pay" to study "math" in the "Netherlands"? Wouldn't I have a better thing to do in my leisure time?

My decision to pursue research was not out of necessity. It was rather my curiosity and conviction that we as ICT for development practitioners should do better. We have many questions but few answers. I believe that ICT can solve many development challenges we face, but we also face unexpected and unexplained obstacles in implementing ICT initiatives, such as e-governance. Can we really leave it at that, or shall we better challenge ourselves to find an answer, one answer at a time, to untangle the mysterious challenges and move forward? So my answer to that was, yeah, why not?

Like all the other brave researchers, I encountered changes, challenges, surprises and setbacks in the process. A happy note in this regard was that I was appointed as the Regional Director of the International Telecommunication Union (ITU) Regional Office for Asia and the Pacific in April 2020 in the middle of this journey. But this happened at the height of COVID-19 lockdown, which complicated my transition, and pushed my research to the backburner at the time. Soon after my transition, I then had to undergo a serious eye operation. I still remember the day when I couldn't see well enough but needed to present this research to an international academic conference in June 2020. The organizer was kind enough to arrange my presentation to be pre-recorded; so I managed. 
Like many would-be researchers, I could have given up my research and move on to "life". But these were not unsurmountable challenges, because, in all honesty, I enjoyed the journey itself and doing research. I was also encouraged and inspired by a lot of colleagues in the UN who deeply care about people and countries around the world.

On that note, I express my sincere appreciation to the UN Office of Human Resource Management (OHRM) for giving me the opportunity to take the sabbatical leave from September to December 2019 and enabled me to conduct the fieldwork in Bhutan. The outcome of this fieldwork constitutes the backbone of this study and hope that the findings are also useful to the work of the UN and other development agencies alike. I am also grateful to the management of the Telecommunication Development Bureau of ITU, Ms. Doreen Bogdan-Martin and Mr. Stephen Bereaux, who kindly gave the space for me to pursue the research and encouraged me to complete it.

I am hoping that this research, although a small step, will pave the way and stimulate debates and actions to carry forward the research agenda to make the world a better place.

Thank you all, and Tashi Delek! 


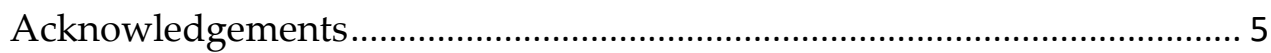

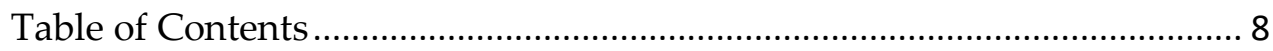

List of Figures, Tables and Images............................................................ 14

List of Abbreviations and Acronyms.......................................................... 16

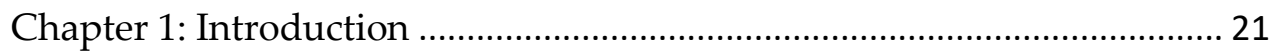

1.1 E-governance as Anti-Corruption Vehicle.......................................... 21

1.2 Compliance as a Conduit to Analyze E-governance Initiatives........ 23

1.3 Concepts and Definitions ................................................................. 24

1.4. Research Questions ........................................................................ 26

Chapter 2: Literature Review …………………....................................... 29

2.1 Literature Review Strategy............................................................... 29

2.2 Literature Review: E-governance, Compliance and Corruption ...... 30

2.2.1. E-governance as a Vehicle to Reduce Corruption in Government

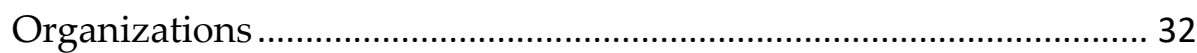

2.2.2. Empirical Evidence: Relationships between E-governance and

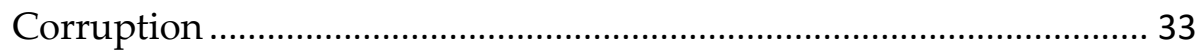

2.2.3. E-governance Initiatives and Case Studies .................................. 34

2.2.4. Openness and E-governance Implementation ............................ 35

2.2.5. E-governance and Institutions .................................................... 36

2.2.6. Existing Information Systems Theories ...................................... 37

2.2.7. Ownership in Information Systems Development .................... 38

2.2.8. Research Gaps: E-governance, Compliance and Corruption .... 38

2.3 Literature Review: Compliance and Technology................................ 40

2.3.1. Strategy for Second Literature Review ....................................... 41 
2.3.2. Overview of Selected Literature

2.3.3. Institutional Instruments and Compliance Determinants..... 44

2.3.4. Research Gaps: Role of ICT and E-governance in Compliance

Literature 49

2.4 Research Gap Summary .................................................................. 50

Chapter 3: Research Methodology, Method and Design ............................. 53

3.1 Methodological Orientation ............................................................... 53

3.2 Research Strategy and Design ............................................................ 54

3.3 Case Study Country Selection Criteria ............................................... 55

3.4 Bhutan as a Case Study Country ………………………………....... 57

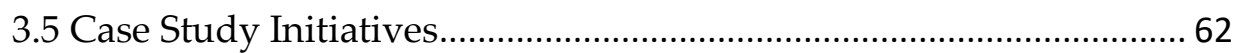

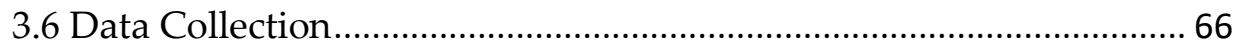

3.6.1. Data Collection Method Overview .............................................. 66

3.6.2 Semi-structured Interview as Data Collection Method................ 69

3.6.3 Interviewee Profile .................................................................... 71

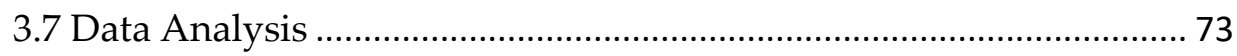

Chapter 4: Case Study Initiative: the Online Asset Declaration System of the Anti-Corruption Commission .............................................................. 77

4.1 Background of the Asset Declaration System..................................... 78

4.2 The ADS as ICT System Innovation..................................................... 84

4.3 Compliance in the Implementation of the Asset Declaration System

4.4. Drivers of Compliance among ADS Users......................................... 97

4.4.1 Credibility and Trust in ACC........................................................ 98

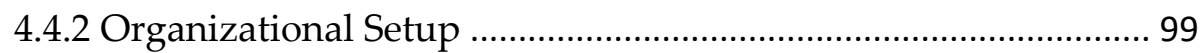

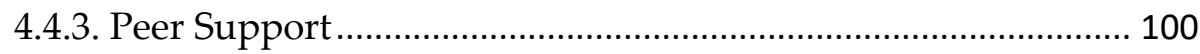




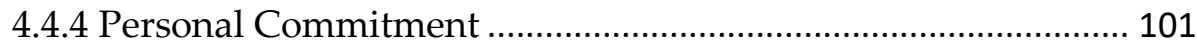

4.4.5. Training and Awareness........................................................... 102

4.4.6. The role of His Majesty the King ............................................... 103

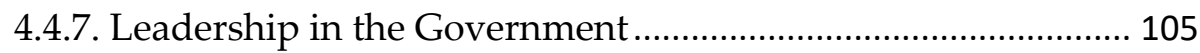

4.4.8. Technology-enabled Ease of Use ............................................... 106

4.4.9. Technical Support and Responsiveness of the ACC Team...... 107

4.4.10. Monitoring, Verification and Follow-up ................................. 108

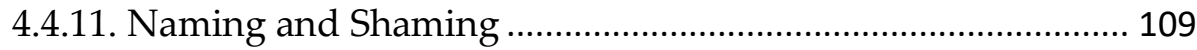

4.4.12. The Role of Media and Social Media ..................................... 110

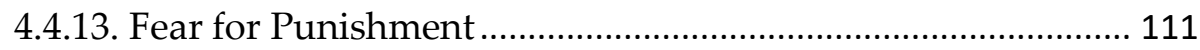

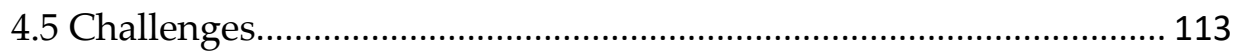

4.5.1. Application of Advanced Technology ...................................... 113

4.5.2. Doubt in the EFFectiveness of ADS ........................................... 114

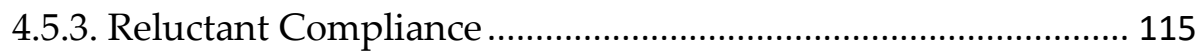

4.6. Summary: ADS Compliance Drivers ............................................... 115

Chapter 5: Case Study Initiative: Electronic Public Expenditure

Management System (e-PEMS) of the Ministry of Finance ...................... 119

5.1. Background of the electronic Public Expenditure Management

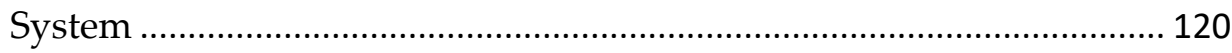

5.2. The electronic Public Expenditure Management System (e-PEMS) as

ICT System Innovation ...................................................................... 125

5.3. e-PEMS Compliance .................................................................... 132

5.4. Analysis on e-PEMS Compliance Drivers....................................... 135

5.4.1. The Role of His Majesty the King ............................................. 135

5.4.2. Leadership in the Goverment ................................................. 136

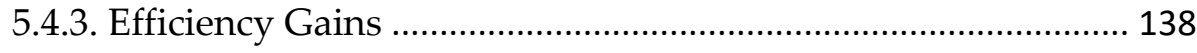


5.4.4. Familiarity with the Existing System and Ease of Use...... 139

5.4.5. Centralized Master Data Management and Monitoring .......... 140

5.4.6. Technology and Automation .................................................... 141

5.4.7. Transparency, Visibility and Traceability ............................... 142

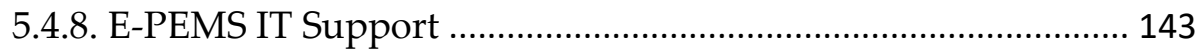

5.4.9. Peer Support and Parenting Arrangement .............................. 144

5.4.10. Personal Commitment ........................................................... 145

5.4.11. Fear for Punishment ................................................................... 146

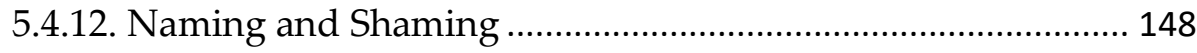

5.4.13. The Role of Media and Social Media ...................................... 148

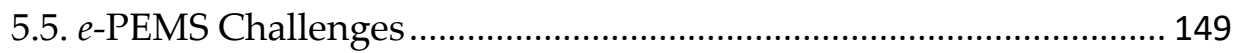

5.5.1. Consultation and Coordination among Finance Officers and

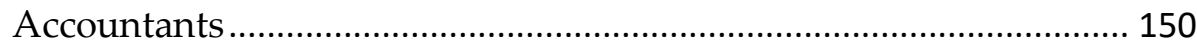

5.5.2. Design and Implementation........................................................ 151

5.5.3. Application of Advanced Technology ….................................... 152

5.5.4. Training and Sensitization........................................................ 154

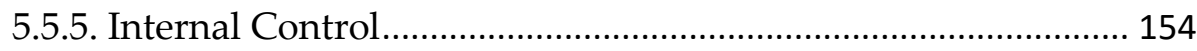

5.6. Summary: e-PEMS Compliance Drivers ......................................... 155

Chapter 6: Compliance in ADS and e-PEMS Systems: Cross-Case Synthesis 159

6.1. Overview of the Cross-Case Synthesis ............................................ 159

6.2. Overview of Similarities and Dissimilarities between ADS and E-

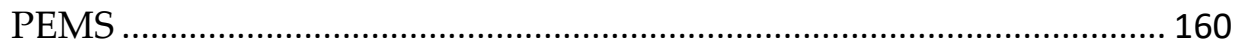

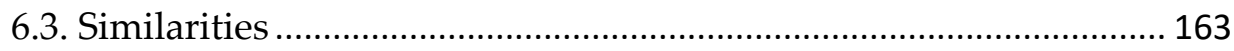

6.3.1. Leadership Category …............................................................ 163

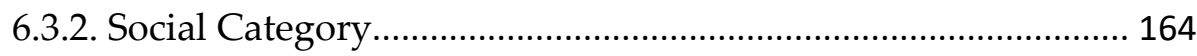




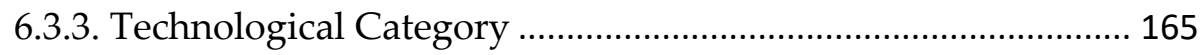

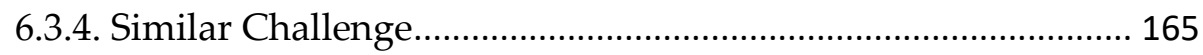

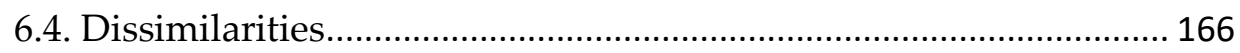

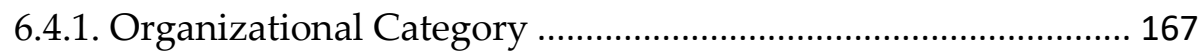

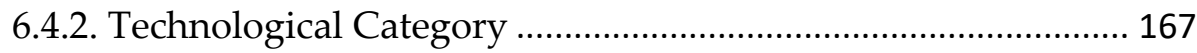

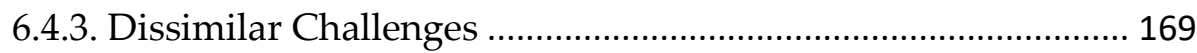

6.5. Conditions, Mechanism and Context ............................................... 171

6.5.1. Dependence among Compliance Drivers as a Condition ......... 171

6.5.2. Inter-Dependence among Compliance Drivers as a Condition 175

6.5.3. Mechanism of Compliance Drivers......................................... 177

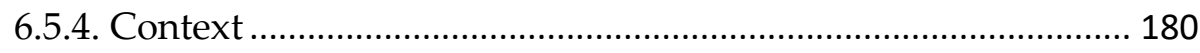

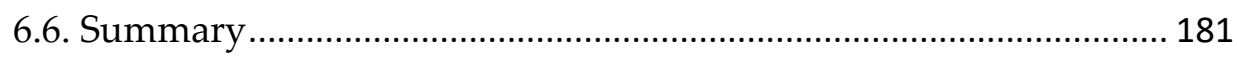

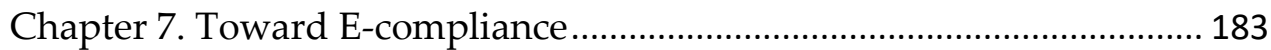

7.1. Compliance Drivers against the Existing Literature ....................... 184

7.1.1. Leadership Compliance Drivers................................................ 185

7.1.2. Social Compliance Drivers ........................................................ 186

7.1.3. Organizational Compliance Drivers .......................................... 190

7.1.4. Technological Compliance Drivers .......................................... 191

7.2. Gaps between Case Study Initiatives and Existing Literature....... 193

7.2.1. E-Governance Compliance Drivers: Ownership, Leadership and

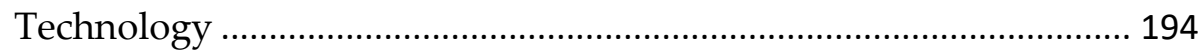

7.2.2. Unique Features in the Case of Bhutan .................................... 196

7.3. Existing Compliance Model ............................................................ 199

7.4. E-Compliance as the Conceptual Framework ................................. 200

7.5. E-compliance in the Theory of Sociomateriality ………….............. 204 
7.5.1. Theoretical Relevance of Sociomateriality to E-compliance.... 205 7.5.2. Explaining and Applying E-compliance within Sociomateriality Theory 207

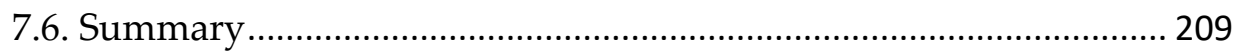

Chapter 8: Conclusion and Policy Recommendations ............................... 211

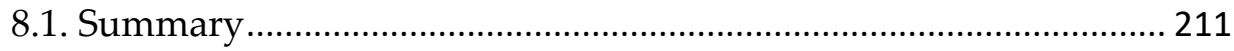

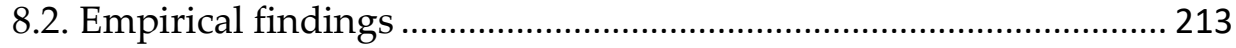

8.3. Theoretical Contributions............................................................. 214

8.4. Research Limitations ................................................................... 216

8.5. Policy Recommendations .............................................................. 217

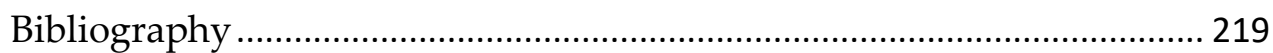

Annex 1: Literature Review: E-governance and Corruption..................... 240

Annex 2: Literature Review: Compliance and Technology ....................... 292

Annex 3: Institutional Instruments and Compliance Determinants

Identified in the Literature Review ......................................................... 351

Annex 4: Interview Protocol for ICT, HR and Finance Officers................ 397

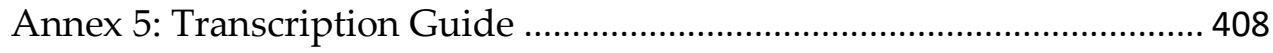

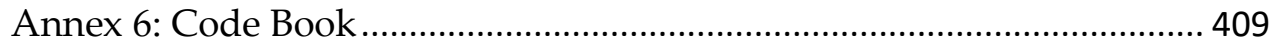

Annex 7 The names of the agencies covered by ACC AD System ........... 415

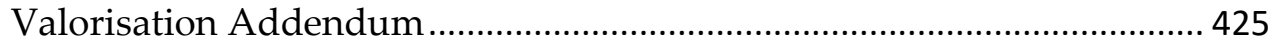

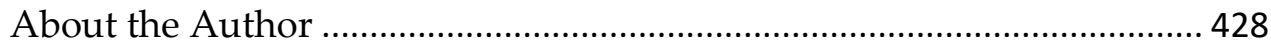




\section{Figures}

Figure 1: The Relationship of compliance and corruption in e-governance initiatives 26

Figure 2: Overview of the first round of systematic literature review...... 31

Figure 3: Overview of the second round of systematic literature review . 41 Figure 4: Illustration of a case study country, constant factors and egovernance initiatives 63

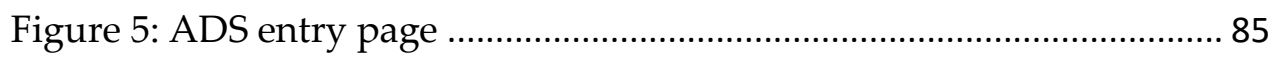

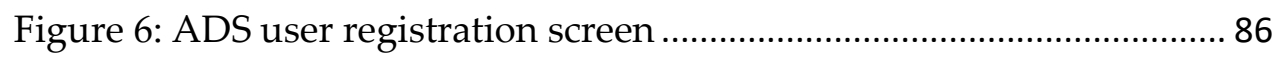

Figure 7: ADS personal information screen ............................................... 86

Figure 8: ADS reasons for declaration screen.......................................... 87

Figure 9: ADS personal and family information screen.............................. 87

Figure 10: ADS additional jobs/employment income screen ..................... 88

Figure 11: ADS post-employment arrangement and plan screen............... 89

Figure 12: ADS immovable property entry screen ..................................... 90

Figure 13: ADS submission screen ........................................................... 90

Figure 14: Relationships between PEMS and other financial management systems implemented by MoF 123

Figure 15: Relationships between e-PEMS and Bank of Bhutan (BoB) .... 128

Figure 16: Dependence and Inter-dependence among compliance drivers

Figure 17: Conceptual framework of e-compliance. 202

Figure 18: Example of compliance drivers and their relationships in the case of Bhutan 203

\section{Tables}

Table 1: Article breakdown by function 43

Table 2: Summary of institutional instruments and compliance determinants in anti-corruption efforts 45

Table 3: Matrix of countries along WGI CC and EGOV. 56 
Table 4: The number of Internet users in selected countries in South Asia from 2000 to 2017

Table 5: The number of mobile-cellular telephone subscribers per 100 in selected South Asian countries, 2000-2018 60 Table 6: The number of fixed broadband subscribers per 100 inhabitants in selected South Asian countries, 2000-2018

Table 7: List of 30 e-government initiatives listed in the Bhutan E-

Government Master Plan 64

Table 8: Comparison of identified case study initiatives 66

Table 9: Summary of collected documents for document analysis 67

Table 10: Number of interviewees by sex .72

Table 11: Number of interviewees by profession. .72

Table 12: Number of interviewees by initiative .72

Table 13: Schedule II compliance rates by type of organisation, 2017 and 2018 95

Table 14: Types of users and level of authorization 129

Table 15: Similarities and dissimilarities between ADS and e-PEMS compliance drivers 161

Table 16: Comparison of challenges 162

Table 17: Direct dependence relationships among the compliance drivers

Table 18: Inter-dependence relationship among the compliance 175

\section{Images}

Image 1: Map of Bhutan. 59 
LIST OF ABBREVIATIONS AND ACRONYMS

\begin{tabular}{|l|l|}
\hline ACC & Anti-Corruption Commission \\
\hline ACAB & Anti-Corruption Act of Bhutan \\
\hline AD & Asset Declaration \\
\hline ADB & Asian Development Bank \\
\hline ADA & Asset Declaration Administrator \\
\hline ADS & Asset Declaration System \\
\hline AFIS & Automated Fingerprint Identification System \\
\hline ATR & Action Taken Report \\
\hline BBSC & Bhutan Broadcasting Service Corporation \\
\hline BDBL & Bhutan Development Bank \\
\hline BIG & Basel Institute on Governance \\
\hline BNBL & Bhutan National Bank \\
\hline BOB & Bank of Bhutan \\
\hline BTI & Bhutan Transparency Initiative \\
\hline BTR & Backward Tracing Research \\
\hline BUP & Budget Utilization Plan \\
\hline CADA & Central Asset Declaration Administrator \\
\hline CC & Control of Corruption \\
\hline CCA & Central Coordination Audit \\
\hline CIRT & Cyber Incident Response Team \\
\hline CSIS & \\
\hline
\end{tabular}




\begin{tabular}{|c|c|}
\hline $\mathrm{CSO}$ & Civil Society Organisation \\
\hline $\mathrm{DA}$ & Disproportionate Asset \\
\hline DCRC & Department of Civil Registration and Census \\
\hline DITT & $\begin{array}{l}\text { Department of Information Technology and Telecommunica- } \\
\text { tion }\end{array}$ \\
\hline DNB & Department of National Budget \\
\hline DOI & Diffusion of Innovation \\
\hline DoIM & Department of Information and Media \\
\hline DPA & Department of Public Accounts \\
\hline DPNB & Druk Punjab National Bank \\
\hline DRC & Department of Revenue and Customs \\
\hline DV & Dependent Variable \\
\hline EFT & Electronic Fund Transfer \\
\hline e-GIF & eGovernment Interoperability Framework \\
\hline EGOV & E-government Survey \\
\hline EID & Employee Identification Number \\
\hline$e$-PEMS & Electronic Public Expenditure Management System \\
\hline EU & European Union \\
\hline FCPA & Foreign Corrupt Practices Act \\
\hline FMIS & Financial Management Information System \\
\hline FTMA & Fiscal Transfer and Monitoring Division \\
\hline G2B & Government to Business \\
\hline $\mathrm{G} 2 \mathrm{C}$ & Government to Citizen \\
\hline
\end{tabular}




\begin{tabular}{|c|c|}
\hline GAM & e-Government Adoption Model \\
\hline GIFT & Global Interchange for Financial Transaction \\
\hline GIS & Geographic Information System \\
\hline GNH & Gross National Happiness \\
\hline GNHC & Gross National Happiness Commission \\
\hline HR & Human Resources \\
\hline ICM & Information Communications and Media \\
\hline ICT & Information and Communication Technology \\
\hline IMF & International Monetary Fund \\
\hline IS & Information Systems \\
\hline ISS & Delone and McLEAN IS Success Model \\
\hline IT & Information Technology \\
\hline IV & Independent Variable \\
\hline JV & Journal Voucher \\
\hline LC/PLC & Letter of Credit/Project Letter of Credit \\
\hline MERCOSUR & Mercado Común del Sur \\
\hline $\mathrm{MoE}$ & Ministry of Education \\
\hline MoEA & Ministry of Economic Affairs \\
\hline MoF & Ministry of Finance \\
\hline MoAF & Ministry of Agriculture and Forests \\
\hline $\mathrm{MoH}$ & Ministry of Health \\
\hline $\mathrm{MoHCA}$ & Ministry of Home and Cultural Affairs \\
\hline MoIC & Ministry of Information and Communication \\
\hline
\end{tabular}




\begin{tabular}{|l|l|}
\hline MoLHR & Minitry of Labour and Human Resources \\
\hline MoWHS & Ministry of Works and Human Settlement \\
\hline MYRB & Multi-Year Rolling Budget \\
\hline NACS & National Anti-Corruption Strategy \\
\hline NC & National Council \\
\hline NGO & Non-Governmental Organization \\
\hline Nu & Ngultrum \\
\hline LDC & Least Developed Countries \\
\hline OAG & Office of Attorney-General \\
\hline OECD & Organisation for Economic Cooperation and Development \\
\hline OPEN & Online Procedures Enhancement for Civil Applications \\
\hline PEFA & Public Expenditure and Financial Accountability \\
\hline PLaMS & Planning and Monitoring System \\
\hline RAA & Royal Audit Authority \\
\hline RAMIS & Revenue Administration Management Information System \\
\hline RBG & Royal Body Guard \\
\hline RCSC & Royal Civil Service Commission \\
\hline RIM & Royal Institute of Management \\
\hline RMA & Royal Monetary Authority \\
\hline RO & Religious Organisation \\
\hline RSTA & Road Safety and Transport Authority \\
\hline SRS & Swiss Agency for Development Cooperation \\
\hline
\end{tabular}




\begin{tabular}{|l|l|}
\hline TAM & Technology Acceptance Model \\
\hline TBANK & Tashi Bank \\
\hline TCB & Tourist Council of Bhutan \\
\hline TI & Transparency International \\
\hline TMD & Treasury Management Division \\
\hline TOE & Technology-Organization-Environment Framework \\
\hline TPB & Theory of Planned Behavior \\
\hline TPN & Taxpayer Number \\
\hline TRA & Theory of Reasoned Action \\
\hline TWAN & Thimphu-wide Area Network \\
\hline UN & United Nations \\
\hline UNDESA & United Nations Department of Economic and Social Affairs \\
\hline UNDP & United Nations Development Programme \\
\hline UNESCO & $\begin{array}{l}\text { United Nations Educational, Scientific and Cultural Organiza- } \\
\text { tion }\end{array}$ \\
\hline UNODC & United Nations Office on Drugs and Crime \\
\hline US & United States \\
\hline WTAUT & United Theory of Acceptance and Use of Technology \\
\hline & Worldwide Governance Indicators \\
\hline
\end{tabular}


"That is my biggest emphasis to government from Prime Minister down to everyone; ICT is not about technology, it's about people. We have to change the way we think, particularly the way we do things. Otherwise, ICT or technology helps you to do the wrong things more efficiently". (G1)

\subsection{E-GOVERNANCE AS ANTI-CORRUPTION VEHICLE}

E-governance initiatives are increasingly seen as a vehicle to tackle corruption across the globe. They offer an unprecedented amount and visibility of data and information which can be aggregated, disaggregated, and analyzed to identify patterns of fraudulent practices and help improve policies, procedures, and processes to curb corruption. Such e-governance systems include tax management (Al-Madi, Al-Shraideh \& Khrais 2016), public service transactions and process management (Kim, Kim \& Lee 2009; Kumar \& Best 2006), online public information services (Bearfield \& Bowman 2017), public grievance system (Rana, Dwivedi, Yogesh \& Michael 2015), monitoring system (Xinli 2015) and transportation systems (Samuel \& Lowen 2010).

But the systems alone are insufficient to reduce corruption (Bertot, Jaeger \& Grimes 2010; Benson, Torres, Royo \& Flores 2012; Kumar \& Best 2006; Jun, Wang \& Wang 2014). Otherwise, we would have seen corresponding decreases in corruption along with the increasing number and scale of e-governance initiatives worldwide. Furthermore, despite the fact that similar e-governance functions and initiatives have been implemented around the globe, the evidenced outcomes seem to vary markedly from country to country (Lee 2010; Kumar \& Best 2006; Jun, Wang \& Wang 2014; Bolivar, Perez \& Lopez-Hernandez 2015).

A related consideration is how the the context in which e-governance initiatives are implemented influences their outcomes. The few successful cases, such as the Online Procedures Enhancement for Civil Applications (OPEN) in the Republic of Korea which evidenced "positive impact on the reduction of corruption" (Kim, Kim \& Lee 2009, p.48), were implemented in a context where technology, governance, and social enablers already exist. However, e-governance initiatives are particularly important in the context of developing countries where governance deficits and resource constraints are more pronounced and systemic corruption widely observed (Grindle 2007; Srivastava, Teo \& Devaraj 2016). In such countries, simply 
enabling access to government information and data may not be enough for citizens to hold governments accountable and lead to a reduction in corruption (Bertot, Jaeger \& Grimes 2010).

By contrast, an overload of government information on a website may lead to increased inefficiency. (Halachmi \& Greiling 2013) The role of e-governance in reducing corruption has been touted in qualitative and quantitative studies (Kim, Kim \& Lee 2009; Shim \& Eom 2009; Lio, Liu \& Qu 2011; Elbahnasawy 2014; Krishnan, Teo \& Lim 2013), but how that reduction actually happens has not been adequately researched (Andersen 2009; Starke, Naab \& Scherer 2016), especially from the perspectives of government employee users of e-governance systems.

An increasing number of people are resorting to additional innovative measures, including social media campaigns and online leaks, to shed light on corruption (Mazzarella 2006; Fenster 2012; Starke, Naab \& Scherer 2016). But we do not yet know the magnitude, conduit and level of influence of social media and its impact on government officials who are the users of e-governance systems and who contemplate corrupt behaviors. It could be that officials now feel cornered by the increasing transparency, visibility, and traceability of their acts in e-governance systems and potential scrutiny on social media. They may be less inclined to bend rules for their own personal benefits. Alternatively, it could be that they always find a way to circumvent such visibility and scrutiny, convinced that impunity and invincibility will continue to protect them (Starke, Naab \& Scherer 2016). That is possible given that technology has been regarded as favoring those in power (Bertot, Jaeger \& Grimes 2010; Aladwani 2016; Samuel \& Lowen 2010). Indeed, technology may be the key in empowering those government employees in both scenarios when they comply or circumvent the rules for their personal benefits

Against this background, this exploratory, inductive research studies the concept of compliance among government employee users in the implementation of e-governance initiatives. More specifically, this research answers the questions on how compliance manifests in e-governance implementation and what are the determinants of compliance among the government employee users in a digitally mediated environment. It is expected that corruption would be eventually reduced once the government employee users comply with the requirements of e-governance systems which are designed to control corruption, especially systemic corruption.

The findings of this research provide evidence of e-governance implementation in the case of Bhutan and offers an analysis on the unfolding dynamics among technology, institution and human agency which constitute a compliance mechanism. 


\subsection{COMPLIANCE AS A CONDUIT TO ANALYZE E-GOVERNANCE INITIATIVES}

This section explains the rationale of choosing compliance as a conduit to analyze e-governance implementation. E-governance implementation is typically accompanied by new policies, regulations and/or organisational setups to integrate new functions, processes and procedures in the existing organisational context. An example could be a new financial management system, which is designed to increase transparency and reduce unauthorised transactions in financial management. The new financial management system may require the use of e-signatures in authoring payments through updated financial management policies and regulations with new functions, processes and approvers. When government employee users comply with the new policies, regulations and organisational setups and duly process all transactions in the system, it is likely that the e-governance initiative succeeds in addressing the pre-existing challenges, increases transparency, and reduces unauthorised transactions.

The assumption is that when government employee users comply with e-governance policies and system requirements, which are designed to curb corruption, their compliance will lead to eventual control of corruption. In a country where corruption level is low, compliance in e-governance implementation will not likely bring a change in the level of corruption (in which case it could be considered prevention). Conversely, if government employee users decide not to comply where a corrupt practice is not prevalent, introduction of an e-governance system may lead to an eventual increase in corruption. In a country where corruption is already rampant, the compliance of government employee users is expected to lead to a decrease in corruption. If the users decide to not comply with e-governance initiatives in a corruption rampant environment, it will not bring any change in the level of corruption. Understanding compliance and identifying the determinant factors of compliance among government employee users, therefore, is expected to provide a new avenue to explain the mechanism between e-governance implementation and eventual changes in the level of corruption.

As the literature review in Chapter 2 elaborates, the concept of compliance has not been systematically researched in e-governance literature. It becomes clear that the compliance literature does not yet include explorations to the effects of technology or e-governance in a comprehensive manner either. Therefore, my study contributes evidence to the existing literature on e-governance and compliance, while simultaneously, stimulating academic discourse on the validity of using compliance as 
a conduit to analyze e-governance implementation. By understanding such discourse in the case of Bhutan and potentially more case studies in other global contexts and situations, this research may assist in designing and implementing effective e-governance initiatives for better results and impact in controlling corruption.

\subsection{CONCEPTS AND DEFINITIONS}

This section defines the key concepts of this study, highlighting specifically the way the terms are used in this research. The below section builds on the concepts and definitions developed and presented in a conference paper on e-compliance (Okuda 2020a)

Banniter and Connolly (2012) define e-governance as "the use of ICT in government in ways that lead to genuinely different structures or processes a consequence of which may be the greater effectuation of or changes in norms and public values" (p. 21). With emphasis on various stakeholders' involvement, the United Nations Educational, Scientific and Cultural Organization or UNESCO (2005) defines egovernance as "the application of ICT to the system of governance to ensure a wider participation and deeper involvement of citizens, institutions, $\mathrm{NGO}^{1} \mathrm{~s}$ as well as private firms in the decision-making process". E-governance, therefore, covers a wider scope than e-government (Radhikaashree \& Balakrishnan 2015).

My research uses the extended terms, e-governance policies, regulations and organisational setups, to denote the policies, regulations and organisational setups, which are newly established or are updates to the existing ones, due to the implementation of e-governance initiatives. In the afore-mentioned example of a financial management system, an e-governance policy introduces the objective and use of an e-signature as the legitimate means of financial transactions in the government. E-governance regulations could indicate responsible agencies, where and how an e-signature could be used, including types of transgressions, monitoring and reporting, among others. E-governance organisational setups could include the new workflow, assignment of e-signature approvers, technical support functions, project management team, oversight, and reporting lines. However, there could be e-governance initiatives, which are successfully implemented without codified policies, regulations and organisational setups. This exploratory study will investigate such cases in an adaptable manner so as to understand how compliance takes place with determinant factors in such a situation.

${ }^{1}$ Non-governmental organisation 
Government employee users in my research refer to government officials, who directly or indirectly use the e-governance system under investigation. They could include heads of government organisations, managers of administration functions, such as human resource, finance and budget, ICT officials, e-governance project managers and users, who enter and retrieve data and information as part of their daily work.

Compliance is defined as "the mutual consistency of legal requirements and enterprise requirements" (Hassan \& Logrippo 2008) with "the target acting in accordance with an influence attempt from the source" (Payan and McFarland, 2005). Sundstrum (2016) equates non-compliance to legal violation, as both denote deviation from formal rules. Compliance is also expressed as a degree of adherence, in such cases as not complying with all the rules (only some) or not complying all the time (only sometimes). Compliance may contrast with enthusiastic commitment or reluctant obedience (Yukl, 1989) and may convey a negative connotation associated with involuntary action (Gelderman, Ghijsen \& Bruman 2006). The term "willing compliance" (Navarra \& Cornford 2011) and "voluntary self-compliance" (Avgerou, Ciborra, Cordella, Kallinikos \& Smith 2005) are used to describe the voluntary nature of action.

As detailed in Chapter 7, compliance also takes the form of value-based/dispositional compliance and rule-based compliance (Batory 2012 and Webb 2012). According to several scholars (Webb 2012; Van del Wal, Graycar \& Kelly 2016; Alon and Hageman 2017; Williams and Horodnic 2015), both types of compliance are needed to ensure sustainable compliance in society. Building on the general definitions of compliance by Hassan \& Logrippo (2008) and Payan and McFarland (2005), in this present research, compliance in e-governance implementation is defined as "adherence to new policies, regulations and/or organisational setups, or updates to existing ones, and performing new functions, processes and procedures when e-governance systems are introduced and implemented".

Corruption is defined as "the abuse of public power for private benefit" (Tanzi 1998, p. 8). Søreide (2009), Tjen \& Evans (2017) add that corruption is, in essence, trade which should not be for sale, including extortion, bribery, collusion and negligence. Based on the typology of corruption defined by Bryne (2007), this present research focuses on systemic corruption within government entities and does not cover other types of corruption, such as ad hoc, petty, grand, political or legal/moral corruption. Systemic corruption within the government may have a wider impact than isolated, ad hoc corruption (Boisvert, Dent \& Quraishi 2014; Byrne 2007; Aladwani 2016), because it tends to undermine formal institutions when enforcing their own policies, rules and regulations and trying to achieve public policy goals for the public good (Coicaud 2016). 


\subsection{RESEARCH QUESTIONS}

In this inductive exploratory research, compliance is used as a conduit and part of the mechanism to explain the phenomena of e-governance implementation. When government employee users comply with e-governance system requirements, it is expected that the system will achieve the objectives the system is designed for and contribute to overall control of corruption in the government. The research questions of this study are:

\section{How does compliance manifest in e-governance implementation?}

\section{What are the determinants of compliance among government employee users in e-governance implementation?}

The relationships explored are shown in Figure 1. The unit of analysis is an e-governance initiative, and the level of analysis is the institutional level. My research will use a comparative case study as a research method and select e-governance initiatives which aim to reduce corruption in a purposefully selected case study country. Although there are references to eventual change in the level of systemic corruption as a result of compliance, it is not the main aim of this research to understand how compliance influences corruption. The focus is to better understand what drives and holds compliance.

Figure 1: The Relationship of compliance and corruption in e-governance initiatives

E-governance implementation

Determinants which influence compliance

Compliance among government employee users

Change in the level of systemic corruption

In the investigation, it is important to understand the context of the e-governance initiatives, the reasons why the e-governance initiative has been initiated as well as the identified challenges and opportunities at the time of initiation. Determinants 
which influence compliance among government employee users are expected to include e-governance policies, regulations and organizational setups, in addition to technological functionalities and capabilities; these factors were identified based on the literature review detailed in Chapter 2. However, it is also possible for an egovernance initiative to be successfully implemented with more informal arrangements. Some of the determinant factors may be specific to the organization where e-governance implementation takes place or the country as a whole where similar factors are identified across organizations and initiatives.

Chapter 2 is a literature review, identifying the existing research and evidence on compliance in e-governance implementation and role of ICT in compliance efforts. Chapter 3 discusses the methodological orientation chosen to answer the research questions, including the criteria used for the selection of case study country, Bhutan, and two case study initiatives. Chapter 4 and 5 present the findings emanating from the examination of the two case study initiatives and identification of compliance drivers, followed by the cross-case synthesis and analysis in Chapter 6 . The findings of this present research are contrasted with the existing literature and evidence, which then leads to theorizing in Chapter 7. Based on the empirical evidence in this present research and lack of existing literature, evidence and compliance model, a new conceptual framework of $e$-compliance is proposed. The empirical and theoretical contributions of this present research is summarized, together with policy recommendations, in Chapter 8 . 
"I think everyone in the world including Bhutan wants a corruption free society. We want a society where we can be free, where we can be happy with each other, where we don't have to fear". (O2)

\subsection{LITERATURE REVIEW STRATEGY}

In this chapter, through a systematic literature review, I identify relevant research and research gaps with regards to where and how compliance manifests in e-governance implementation and what have been identified as the compliance determinants. Bryman (2016) lists the following 5 iterative steps to conduct systematic review: 1 ) statement of scope and purpose; 2 ) search for existing studies; 3 ) review of the studies; 4) appraisal of quality and quantity and 5) extraction and synthetization. The systematic review was enabled with access to electronic databases, such as the Web of Science, assisted with keywords, citations, and parameters to narrow the search.

In order to identify the relevant research and research gaps, two rounds of systematic literature review were conducted. The first round aimed to identify instances of compliance and compliance determinants in the Information Systems (IS) and, more specifically, e-governance literature. This round of literature review focused on research and implementation of e-governance initiatives which were designed to control corruption. As the first round of review found little evidence and research done on compliance in the IS and e-governance literature, the second round of literature review explored the compliance literature and how ICT and e-governance initiatives appeared in the context of discussing general compliance and compliance determinants.

The main findings of the first round of systematic literature review are synthesized and analyzed around the key topics of this research in Section 2.2. The findings of the second literature review are then analyzed and presented in Section 2.3. Section 2.4 consolidates the findings of both rounds of literature review and concludes with the combined results of what was found in the literature review as well as the identified research gaps. 
Based on the research questions posed in this present research, the first round of systematic literature review identified relevant research and research gaps on where and how compliance was evidenced to manifest in the implementation of egovernance initiatives and the compliance determinants.

In order to develop an overview of the topic and conduct an initial round of literature review, the Web of Science Core Collection was accessed on 2 April 2017. The key words, "e-governance", "e-government", "corruption" and "government", were used to elicit a broad overview of the topic from the perspectives of governance, institutionalism, information system (IS), and compliance. This search resulted in a selection of 187 articles published since 2005 in selected disciplines of social sciences. The 187 articles were then ranked by the level of citation and screened by the relevance with focus on e-governance/e-government, corruption, compliance, as summarized in Annex 1. Backward and forward referencing was also used to obtain critical case studies, additional research findings and related IS theories. 
Figure 2: Overview of the first round of systematic literature review

\section{Identification of studies via databases and registers}

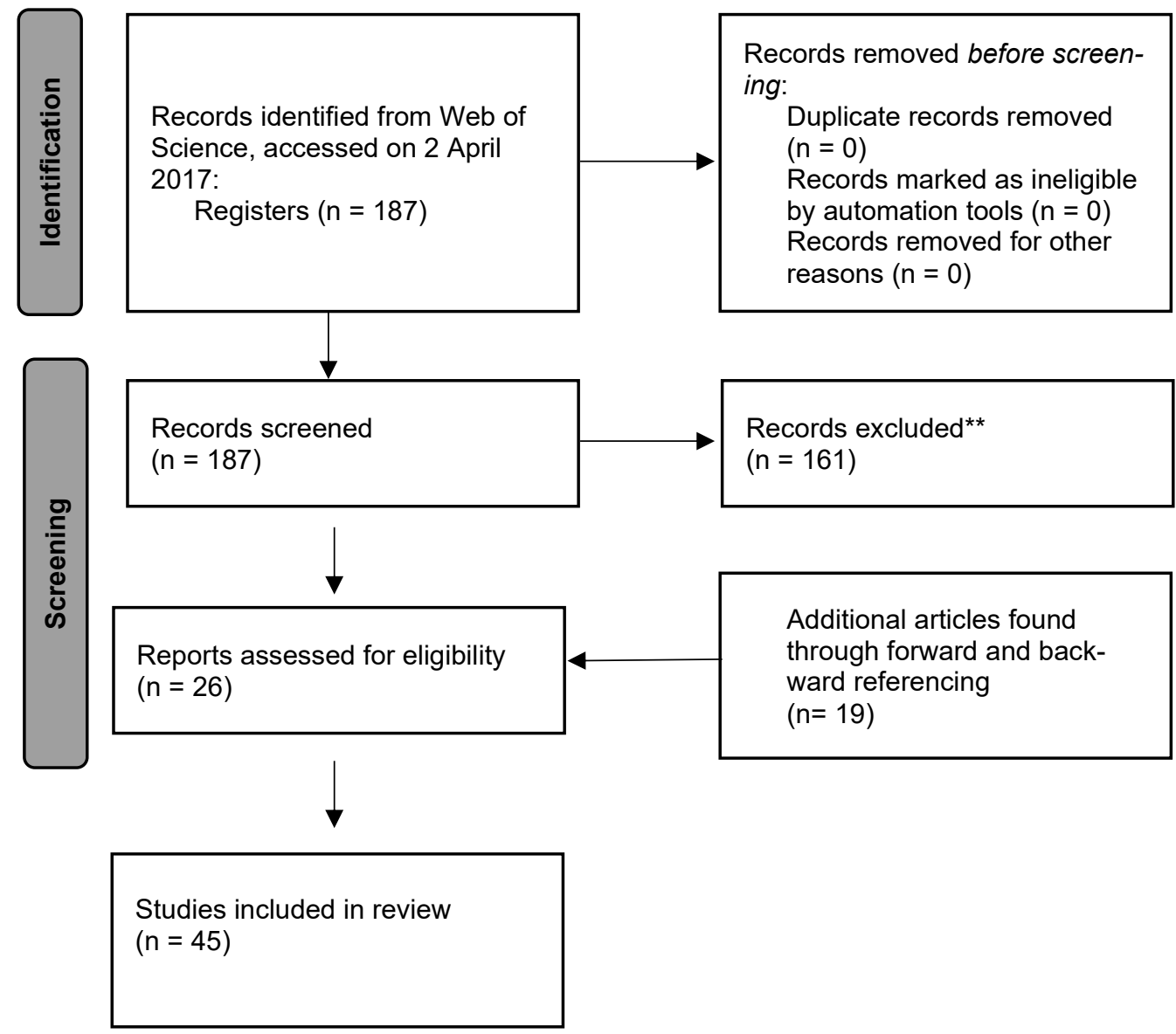

This section groups the relevant articles based on thematic, methodological and theoretical similarities and linkages and presents the findings around the topics of 1) e-governance as a vehicle to reduce corruption in government organizations (Section 2.2.1), 2) empirical evidence between e-governance and corruption (Section 2.2.2), 3) e-governance case studies (Section 2.2.3), 4) openness and e-governance implementation (Section 2.2.4), 5) e-governance and institutions (Section 2.2.5), 6) existing Information Systems (IS) theories (Section 2.2.6) and 7) ownership in IS development (Section 2.2.7). The section concludes with a synthesis of research gaps emanating from the first round of literature review in Section 2.2.8. 


\subsubsection{E-GOVERNANCE AS A VEHICLE TO REDUCE CORRUPTION IN GOVERNMENT ORGANIZATIONS}

This section groups the existing studies and research which demonstrated thematic similarities around the implementation of wide-ranging e-governance initiatives which were designed to reduce corruption. Some articles also investigated the emerging influence of social media on corruption.

On the topic of e-governance as anti-corruption measures, Bertot, Jaeger \& Grimes (2010) concluded that ICT-enabled initiatives, such as e-governance, were evidently successful in reducing corruption, especially in areas of taxation and government contracts in larger and wealthier countries. They identified three effective anti-corruption approaches; administrative reform, regulation, and social change. The authors acknowledged that e-government approaches of providing public information as a means to holding government to account would not work in places where censorship and online information filtering were in place. They also stated that "ICT can reduce corruption by promoting good governance, strengthening reform-oriented initiatives, reducing potential for corrupt behaviors, enhancing relationships between government employees and citizens, allowing for citizen tracking of activities, and by monitoring and controlling behaviors of government employees" (p. 265). However, they did not adequately explore the perspectives of government employees in this research. Government officials were not portrayed as active players, despite the bureaucratic acceptance being cited as a key success factor, together with leadership and political will.

Another study by Benson, Torres, Royo \& Flores (2012) provided an overview of the use of social media by local administrations in EU countries, emphasizing the importance of corresponding changes in leadership and governance with ICT introduction. Starke, Naab \& Scherer (2016) emphasized the importance of social media in putting pressure on government and mobilizing people. The potential exposure of misconducts, as exemplified by the Panama Paper and WikiLeaks, was also identified as an example of the power of social media (Fenster 2012). Bannister \& Connolly (2014) noted the emergence of literature on the impact of e-government and the Internet on government corruption, but concluded that it was still at an early stage and expected different ways ICT could have transformative impacts. He then cautioned that not all ICT-inspired transformations were for the better and concluded that there was scope for extensive research into this subject.

The reviewed articles provided the evidence of e-governance initiatives, Internet and ICT which were found effective to control corruption. They also indicated possible factors and channels through which such effects were transmitted. However, 
the e-governance initiatives covered in the reviewed articles were mostly implemented in OECD countries and with specific e-governance functions. Furthermore, the perspectives of government employee users were found largely missing. Future research could shed light on different contexts and e-governance functions to deepen our understandings.

\subsubsection{EMPIRICAL EVIDENCE: RELATIONSHIPS BETWEEN E-GOV- ERNANCE AND CORRUPTION}

Another group of articles used similar methodological approaches and provided empirical evidence of the relationships between ICT and corruption. This section reviews the findings of the existing quantitative studies and where and how ICT, and e-governance initiatives, were found effective in reducing corruption.

Shim \& Eom (2009) examined ICT and social capital as major factors in reducing corruption in their quantitative study, while another empirical study by Lio, Liu \& $\mathrm{Ou}$ (2011) analyzed the relationship between ICT and corruption using panel data of 70 countries from 1998 to 2005. The latter concluded that the Internet had statistically significant effects on corruption reduction, but the potential was not yet fully realized.

On a similar vein, Elbahnasawy (2014) analyzed the relationships between e-government, Internet adoption and corruption using a large panel data. Krishnan, Teo \& Lim (2013) also validated their assumption in their quantitative research that egovernment initiatives were evidenced to reduce corruption. The relationship was not unidirectional: Aladwani (2016) empirically examined the impact of corruption on e-government implementation through various government institutions, while Starke, Naab \& Scherer (2016) analyzed free media, Internet and e-government in addressing corruption.

Andersen (2009) assessed the impact of e-government on control of corruption, using the Worldwide Governance Indicators (WGI) panel data of 149 countries in 1996 and 2006, and found that improvements in e-government had correlating improvements in the corruption indicator. At the same time, he pointed out the limitation of quantitative approach in that there might be general equilibrium effects. E-government was not reducing corruption at the macro level and may be shifting the effect to some other parts of society. The research confirmed that the Organisation of Economic Cooperation and Development (OECD) countries had less corruption with a larger number of e-government implementation than non-OECD countries. Therefore, the importance of analyzing OECD and non-OECD countries 
separately was underlined, as e-government seems to have clearer impact on nonOCED countries between 1996 and 2006.

The reviewed articles empirically evidenced the effects of ICT, e-governance and Internet on reducing corruption, using longitudinal and panel data of various sources. However, they also revealed some limitations of quantitative approaches. The empirical evidence of the impact of e-governance on corruption was still scant and the mechanisms of how ICT or e-governance initiatives reduced corruption are not yet fully understood, in particular in non-OECD countries.

\subsubsection{E-GOVERNANCE INITIATIVES AND CASE STUDIES}

Another group of articles used case studies as research methods and analyzed egovernance implementation in various contexts, including in non-OECD countries. The reviewed case studies provided rich descriptions and contexts where e-governance initiatives were implemented.

A single case study conducted by Kim, Kim \& Lee (2009) examined the case of the Online Procedures Enhancement for Civil Application (OPEN) of the Seoul Metropolitan Administration in the Republic of Korea. The authors concluded that regulatory/coercive factors were found most effective to the success of this anti-corruption initiative, guided by the political leadership of the mayor. Other success factors included enabling IT infrastructure, training, resources and Internet literacy among citizens. The case study on OPEN was most interesting, as it illustrated the struggle between the organization's leadership and employees in the introduction and implementation of the system.

In addition, the following e-government case studies were conducted in the developing country context: India by Rana, Dwivedi \& Williams et al (2015); Lebanon by Alaaraj \& Hassan (2016); Jordan by Al-Madi, Al-Shraideh \& Khrais (2016); Cyprus by Sari (2016) and China by Jun, Wang and Wang (2014) and Xinli (2015). While successful case studies have emerged, Heeks (2002) pointed out a high rate of failure in implementing e-government initiatives in developing countries, which he argued was caused by mismatch between design and local user actuality, as evidenced in an example in India (Kumar \& Best 2006). Aladwani (2016) argued that corruption itself could be a source of e-government failures, while Kalsi and Kiran (2015) identified resistance by political leaders and bureaucrats as a major challenge. 
While providing insights, success factors and evidence in e-governance implementation including in non-OECD contexts, the review also elicited research gaps. Despite the fact that corruption often involves government officials, there was little systematic research found to understand government employee users' perspectives and internal mechanisms of where and how e-governance was effective to reduce corruption.

\subsubsection{OPENNESS AND E-GOVERNANCE IMPLEMENTATION}

Several articles embedded the discussions of e-governance implementation in various societal factors, such as openness and democracy, which were considered as essential to reducing corruption. The thematically linked articles identified conditions and prerequisites for e-governance initiatives to be effective and successful.

Bhuiyan (2011) pointed out that some regimes in developing countries were not fully open to public scrutiny and engagement. In such a circumstance it is expected that the e-governance introduction would be resisted because it can promote unintended flow of information and openness. Elbahnasawy (2014) noted that the empirical evidence of the impact of e-government on corruption was scant, despite micro-level evidence such as the case of OPEN in the Republic of Korea. Furthermore, citing the reference to the United Nations Development Programme (UNDP), Elbahnasawy asserted that the e-government cases which evidenced a reduction in corruption were largely anecdotal. He suggested for future research to investigate "alternative forms of e-government in combating corruption and the extent to which democracies are likely to create these forms of e-government" (p. 123) as well as the impact of e-government on various forms of corruption independently.

The review identified important considerations and several gaps in the existing literature. Where openness and access to information are limited and people can not hold governments accountable, the effect of e-governance initiatives on control of corruption may also be limited. Future research should take into account the societal factors, such as openness and access to information, especially in the context of non-OECD countries when discussing where and how e-governance initiatives are effective. 


\subsubsection{E-GOVERNANCE AND INSTITUTIONS}

Another group of articles analyzed the existing IS and e-governance research which developed theoretical frameworks to understand and analyze e-governance within organization and institution.

Heeks \& Bailur (2007) analyzed 84 articles on e-government and identified several research gaps, such as predominant IS focus, lack of philosophical and epistemological underpinnings, limited empirical studies and general methodological weaknesses. In relation to IS-based e-government models, Heeks (2002) highlighted "relatively poor conception of organizational change" (p.103) in the existing literature. Fountain (2007) noted that existing literature focused on government's efforts to make information public, provide public services online and citizen's reactions to the information and services. She then called for more research into internal mechanics of government through the lenses of formal and informal institutions and advocated for an approach to examine mediating factors between formal and informal institutions, such as "management practices, task structures and operating routines" (p. 3). The organizational, institutional and technological change across various layers of government was termed as "the technology enactment framework" by Fountain. Based on her work, Cordella and Iannacci (2010) developed the e-government enactment framework to examine the interplay among ICT, e-government policy and organizational form/bureaucratic network, while the need for taking into account institutional dynamics was stressed by Lanzara (2009).

E-governance-related organizational and institutional factors which were evidenced effective in reducing corruption included leadership (Kim, Kim \& Lee 2009; Kumar \& Best 2006; Aladwani 2016; Xinli 2015), quality of managers (Fukuyama 2004; Aladwani 2016), organizational culture (Fountain 2007; Bertot, Jaeger \& Grimes 2010; Alaaraj \& Hassan 2016), anti-corruption drive (Bhargava 2006), enforcement capacity (Kim, Kim \& Lee 2009), internal control (Fountain 2007; Shim \& Eom 2009) and regulation (Bertot, Jaeger \& Grimes 2010). ICT also developed capacity of staff who performed new tasks and duties for compliance (Giesbrecht, Scholl \& Schwabe 2016; UNDESA 2016; Kumar \& Best 2006; Jun, Wang \& Wang 2014), including what Heeks (2002) called hybrid and improvisation capacity.

The review highlighted the need for more research into internal mechanisms within organization and government as well as the interactions of e-governance initiatives with government employee users. The review also confirmed that there was little research done on compliance in the IS and e-governance literature. 


\subsubsection{EXISTING INFORMATION SYSTEMS THEORIES}

In addition to the above literature, I reviewed the existing IS theories and research which may explain the determinants for using the IT systems among the users by applying back and forward referencing. Rad, Nilashi \& Dahlan (2017) conducted a review of literature and classification of research which focused on IT adoption, in particular rejection and acceptance of information systems by users. The authors found that the majority of the research between 2006 and 2015 covered theoretical frameworks, such as technology acceptance model (TAM), diffusion of innovations (DOI), united theory of acceptance and use of technology (UTAUT), theory of planned behavior (TPB), technology-organization-environment framework (TOE), theory of reasoned action (TRA) and Delone and McLean IS success model (ISS) among other theories.

While TAM focuses mainly on technology adoption by users through ease of use and usefulness, DOI emphasizes innovation characteristics. UTAUT has been used to assess technology adoption from 7 main channels, including performance expectancy, social influence, price value and habit. Dwivedi, Rana et.al (2017) found that attitude was a critical factor for IT adoption in their study using UTAUT. TPB is a model which investigates user intention and perceived behaviors (Jokonya 2017), while ToE underlines the importance of innovation, organization and technology. The ISS Model, on the other hand, integrates new dimensions of impact of information systems, delivery of meanings as well as user satisfactions. Acknowledging the popularity of TAM and other theories, Rad, Nilashi \& Dalhan (2017) urged the development of new theories to deepen understandings of complex challenges the IS researchers witnessed, including the measurement and assessment of actual system uses, instead of intension to use.

Some of the research applied TAM to determine voluntary and non-voluntary use of technology among users. Hwang, Al-Arabiat \& Shin (2015) conducted a critical literature review of studies on mandatory use of technology and acceptance. In a non-voluntary environment, normative influence, attitude, interpretation of mandate were found effective for user's technology adoption, but it was acknowledged that IS literature has not fully accounted for the role of leadership. Based on TAM, DOI and TPB, Shareef, Kumar et.al. (2011) developed the e-Government Adoption Model (GAM) in an empirical study in Canada to assess adoption of technology at different service maturity levels among user citizens.

However, the existing IS models aim to understand and analyze technology acceptance in various environments, which may or may not materialize in action and outcomes beyond intention. Compliance in e-government implementation is more 
complex than mere technology adoption among users, which is often seen as linear, causal relationships. If a user accepts prescribed technology with corrupt intent, such technology acceptance and adoption in fact may result in an increase in fraud cases. Furthermore, context and dynamics evolve over times. The existing theories, therefore, do not provide adequate tools to account for dynamic evolution of egovernance implementation and compliance.

\subsubsection{OWNERSHIP IN INFORMATION SYSTEMS DEVELOPMENT}

For this present research, the case variation is determined by the ownership of egovernance systems. The ownership, defined in this study as funding source (local or donor funding) and development (local or external expert development), was identified as an important factor during a case selection visit to Bhutan between July and August 2019. This section synthesizes and presents the existing literature and empirical evidence of where and how the concept of ownership was found effective in e-governance implementation.

The existing research has evidenced effects of some elements of ownership on system development projects. Gu, Hu \& Hemple (2021) analysed the effect of psychology ownership among software development teams on team performance. Similarly, the sense of ownership among users and system development teams was evidenced to have impact on the adoption of various information system (Paré, Sicotte \& Jacque 2006; Maruping, M. L., Zhang, X. \& Venkatesh, V. 2009). In discussing country ownership and sustainability of health information management systems, Watson-Grant, Xiong \& Thomas (2017) identified four dimensions of country ownership (partnership, commitment and responsibility, capacity and accountability). Based on the findings, it is concluded that the concept of ownership is an effective factor in information systems development among system development teams and users alike.

\subsubsection{RESEARCH GAPS: E-GOVERNANCE, COMPLIANCE AND CORRUPTION}

The first round of systematic literature review aimed to answer the research questions on where and how compliance was evidenced to manifest in the implementation of e-governance initiatives and associated compliance determinants. As Section 2.2 detailed, very few studies were found to have investigated the topic of compliance in the existing IS and e-governance literature. 
This first round of literature review identified relevant studies conducted on e-governance and corruption in OCED and non-OECD countries. Although the literature review so far provided valuable evidence, case studies and insights and confirmed the importance of certain factors in implementing e-governance initiatives in government organizations, several research gaps emerged in relation to my research questions:

- Few studies systematically analyzed compliance as a mechanism to explain the phenomena of e-governance implementation (Rana, Dwivedi and Williams et al. 2015; Alaaraj and Hassan 2016; Al-Madi, AlShraideh and Khrais 2016; Sari 2016);

- Government employee users of e-governance initiatives are important actors but their perspectives were not adequately researched in existing studies on e-governance (Kim, Kim \& Lee 2009; Rana, Dwivedi and Williams et al 2015; Alaaraj and Hassan 2016; Al-Madi, Al-Shraideh and Khrais 2016; Sari 2016; Kumar \& Best 2006; Kalsi \& Kiran 2015), especially from the compliance perspective;

- Heeks (2002), Fountain (2007), Lanzara (2009), Srivastava, Teo \& Devaraj (2016) and Bearfield and Bowman (2017) pointed out a greater need to take into account internal mechanisms and organizational structures to explain the phenomana of e-governance implementation;

- Some of the above cited articles (Kim, Kim \& Lee 2009; Rana, Dwivedi and Williams et al 2015; Bearfield and Bowman 2017) assumed that providing access to government information through e-governance initiatives would empower citizens to hold government officials accountable but the existing literature does not fully explain how this happens in developing countries with less institutional and individual capacity (Fukuyama 2004; Grindle 2007).

- Insufficient research has been conducted on how e-governance initiatives could bring about changes within governments without fully functional democratic oversight mechanisms (Andersen 2009; Bertot, Jaeger \& Grimes 2010).

- Limitation of quantitative approach was recognized, as there might be general equilibrium effects (Andersen 2009) and we do not know the mechanics of how ICT or e-governance initiatives reduced corruption: in addition, empirical evidence on the impact of e-governance on corruption was scant and anecdotal (Elbahnasawy 2014);

- Insufficient research was conducted systematically on e-governance, compliance and corruption in non-OECD contexts (Bertot, Jaeger \& Grimes 2010; Andersen 2009); 
- Research on the impact of e-governance and Internet on corruption was at an early stage and more research is needed on different transformative factors (Bannister \& Connolly 2014)

The identified research gaps were instrumental in designing the second round of systematic literature review, discussed in Section 2.3, as well as in developing research design, data collection and analysis, detailed in Chapter 3.

\subsection{LITERATURE REVIEW: COMPLIANCE AND TECHNOLOGY}

The first round of systematic literature review was not successful in identifying relevant research on compliance in the existing IS and e-governance literature in Section 2.2. Based on the identified research gaps, a second round of systematic literature review was conducted with the aim to discern the effect of ICT and egovernance on compliance and where and how such ICT-enabled compliance was evidenced in the existing compliance literature.

In this literature review, an institutional instrument is used as a basis for general compliance and is defined to "lay(s) down the general rules governing the functioning of the organisation". (Amr 2003, p. 129) In explaining institutional instruments, Mingaleva \& Mirskikh (2014) identified 1) legislation activities, 2) creation and development of organisations and 3) effective systems for regulation as the constituting factors.

In order to identify the institutional instruments (policies, regulations, strategies, and organizational setups) and the compliance determinants, the Web of Science was accessed for the second round of systematic literature review. The findings of the review are synthesized in Section 2.3. The Section first outlines the strategy for the literature review in Section 2.3.1, followed by the overview of identified articles and studies by region and sectors/functions in Section 2.3.2. Using framework analysis, Section 2.3.3 analyzes the institutional instruments and the associated compliance determinants identified in the existing literature and presented the findings. Section 2.3.4 then discusses the role and effect of ICT and e-governance in the existing compliance literature, which led to the identification of research gaps. 
Using the Web of Science with key words "compliance" and "corruption", 142 relevant articles were found among the relevant categories of journals as of 20 June 2018. The assumption was that a search with specific and narrow key words will not produce any meaningful results and could miss important findings. As my research is inductive in nature, the purpose of this systematic review was to capture a wide range of institutional instruments and compliance determinants which are relevant to my research questions. The overview of the second round of literature review is found in Figure 3.

Figure 3: Overview of the second round of systematic literature review

\section{Identification of studies via databases and registers}

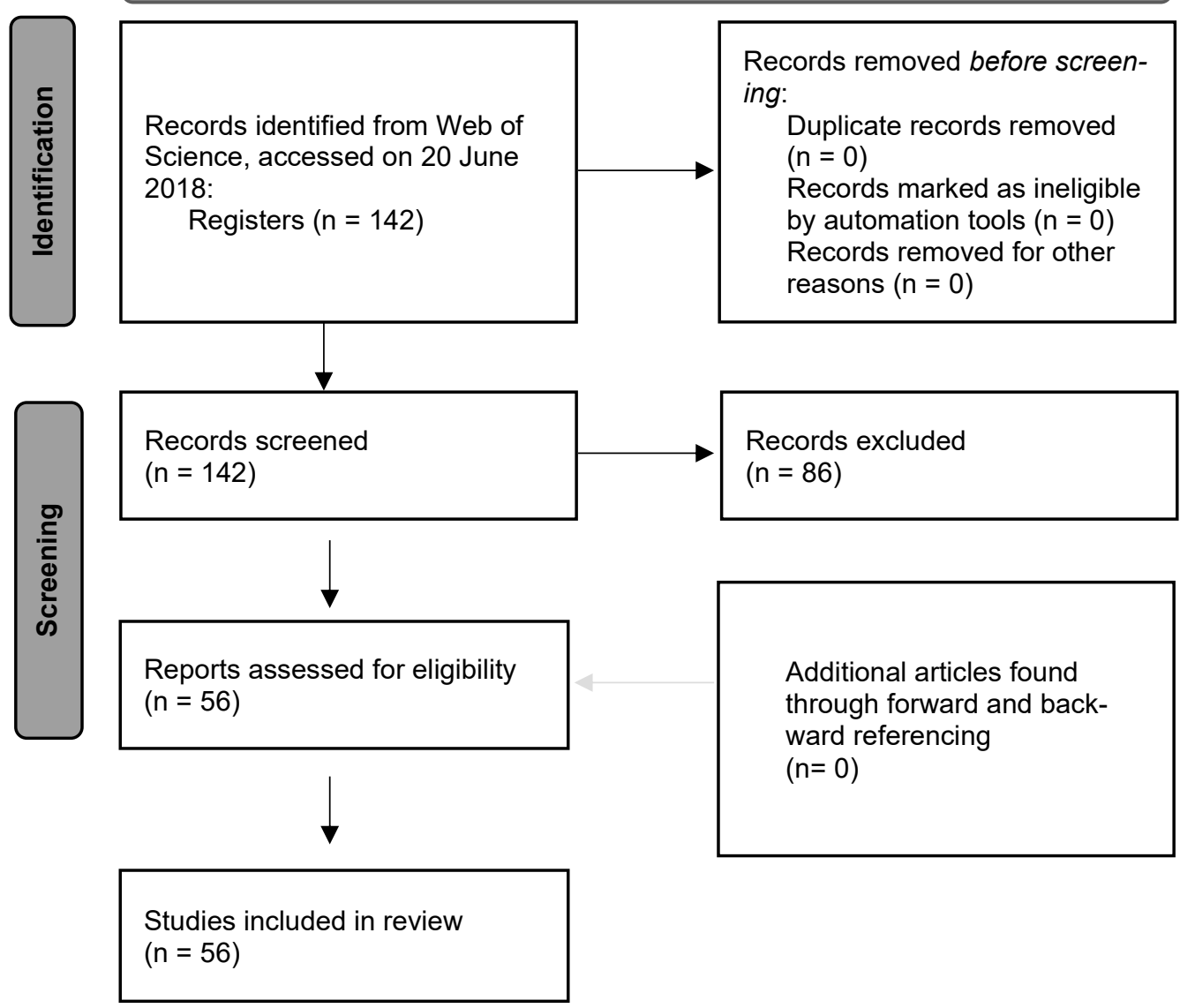


The detailed parameters for the search as well as the comprehensive list and summary of the articles are attached as Annex 2: Literature Review: Compliance and Technology. The 142 articles were manually screened to identify articles which contained the above-mentioned institutional instruments relevant to my research questions and compliance determinants. The manual screening was done based on the review of abstract of each paper and their focus on public sector, compliance, corruption and institutional instruments. Articles, which focused primarily on the private sector and specific technical and legal issues, and those without reference to compliance, government or corruption, were excluded.

As a result of the manual screening, 56 articles were found containing relevant institutional instruments and compliance determinants as summarized in Annex 3. The findings of the included articles were then categorized by theme, attributes of institutional instruments and elements of compliance determinants emanating from the literature review. The selected 56 articles covered national/international compliance cases, different industries/functions and institutional instruments, which are summarized in Table 2 in Section 2.3.3. The reference to ICT is highlighted and marked in red in Annex 3.

\subsubsection{OVERVIEW OF SELECTED LITERATURE}

The 56 articles cover various geographical regions. It was found that $29 \%$ of the articles focused on Europe (16 articles), $21 \%$ on Asia (12 articles), $11 \%$ on Americas ( 6 articles), $7 \%$ on Africa ( 4 articles) and $4 \%$ on Oceania ( 2 articles), thus covering evidence of compliance in wide geographic areas. In addition, 29\% (or 16 articles) investigated global and theoretical matters in their articles (Okuda 2020a).

As Table 1 shows, the identified articles investigated various aspects and functions of public administration ( $41 \%$ or 23 articles), enforcement (11\% or six articles), international instruments ( $7 \%$ or four articles), taxation ( $20 \%$ or 11 articles) and migration and energy, extractive industry and labour (4\% or two articles each). The review also included one article ( $2 \%$ ) each on correctional services, military, fisheries, conservation, health and education (Okuda 2020a). Thus, the reviewed articles cover a wide range of regions, functions and incidences of compliance with a likelihood of finding e-governance and ICT effects on compliance, where and how compliance manifests and the associated compliance determinants. 
Table 1: Article breakdown by function

\begin{tabular}{|c|c|}
\hline Sector (\#) & Function (authors) \\
\hline $\begin{array}{l}\text { Cross-cutting } \\
\text { functions in } \\
\text { public admin- } \\
\text { istration (5) }\end{array}$ & $\begin{array}{l}\text { - Public service and administrations (Darden 2008, Ba- } \\
\text { tory 2012), } \\
\text { - Public procurement (Rodriguez-Arana 2017, } \\
\text { Popescu, Onofrei \& Kelley 2016) } \\
\text { - Dispositional trust in institutions (Alon \& Hageman } \\
\text { 2017) }\end{array}$ \\
\hline $\begin{array}{l}\text { Access to infor- } \\
\text { mation (4) }\end{array}$ & $\begin{array}{l}\text { - Information disclosure (Garcia-Tabuyo et al. 2016, } \\
\text { Camaj 2016, Garcia-Tabuyo, Saez-Martin \& Caba-Pe- } \\
\text { rez 2015, Kotzian 2011) }\end{array}$ \\
\hline $\begin{array}{l}\text { Anti-corrup- } \\
\text { tion control } \\
\text { and regulation } \\
(14)\end{array}$ & $\begin{array}{ll}\text { - } & \text { Regulations and red tape (Mendez \& Sepulveda } \\
\text { 2013) } \\
\text { - } & \text { Audit (Kantsir \& Plekan 2017) } \\
\text { - } & \text { Fight against corruption (Tavits 2010, Ozarslan 2016, } \\
& \text { Rodriguez 2016), } \\
\text { - } & \text { Administrative control at local level (Osipian 2010) } \\
\text { - } & \text { Institution and corruption (Schlenther 2017, Tjen \& } \\
\text { - } & \text { Anans 2017) } \\
\text { - } & \text { Public orruption infrastructure and bodies (Hough } \\
\text { - Samuel \& Lowen 2010) } \\
\text { Code of conduct (Michael 2012) }\end{array}$ \\
\hline $\begin{array}{l}\text { Enforcement } \\
\text { (6) }\end{array}$ & $\begin{array}{ll}\text { - } & \text { Cartel (Sokol 2012) } \\
\text { - } & \text { Enforcement and persecution (Galiot 2017) } \\
\text { - } & \text { Rule violations (Akerlof 2016) } \\
\text { - } & \text { Bribery and enforcement (Cleveland et al. 2009, } \\
& \text { Berghoff 2018, Gilbert \& Sharman 2016) }\end{array}$ \\
\hline $\begin{array}{l}\text { International } \\
\text { instruments (4) }\end{array}$ & $\begin{array}{l}\text { Compliance with European Union (EU) anti-corrup- } \\
\text { tion requirements (Yilmaz \& Soyaltin 2014) } \\
\text { Foreign Corrupt Practices Act (FCPA) compliance } \\
\text { and implementation (Weismann, Buscaglia \& Peter- } \\
\text { son 2014, Jiang 2017) } \\
\text { - Special Data Dissemination Standard (Vadlaman- } \\
\text { nati, Cooray \& Brazys 2018) }\end{array}$ \\
\hline Taxation (11) & $\begin{array}{l}\text { Tax compliance (Ali 2014, Alon \& Hageman 2013, } \\
\text { Schueth 2012, Rosid, Evans \& Binh 2016, Baum, } \\
\text { Gupta, Kimani \& Tapsoba 2017) }\end{array}$ \\
\hline
\end{tabular}




\begin{tabular}{|c|c|}
\hline & $\begin{array}{ll}- & \text { Tax evasion (Williams \& Horodnic 2015) } \\
\text { - } & \text { Corruption reporting (Timmons \& Garfias 2015) } \\
\text { - } & \text { Gender (D'Attoma, Volintiru \& Steinmo 2017) } \\
\text { - } & \text { Culture (Varvarigos 2017) } \\
\text { - } & \text { Tax morale (Williams \& Krasniqi 2017, Cyan, } \\
& \text { Koumpias \& Martinez-Vazquez 2016) } \\
\end{array}$ \\
\hline $\begin{array}{l}\text { Migration and } \\
\text { energy ( } 2)\end{array}$ & $\begin{array}{l}\text { - Anti-corruption (Ademmer \& Börzel 2013), } \\
\text { - Anti-trafficking policies (Cho, Dreher \& Neumayer } \\
\text { 2014) }\end{array}$ \\
\hline $\begin{array}{l}\text { Extractive in- } \\
\text { dustry (2) }\end{array}$ & $\begin{array}{l}\text { - Compliance with international standards (Sovacool } \\
\text { 2016, Papyrakis, Rieger \& Gilberthorpe 2017) }\end{array}$ \\
\hline Labour (2) & $\begin{array}{l}\text { - Wages and harassment (Bac 2018) } \\
\text { - Undeclared work (Perez-Magro et al. 2017) }\end{array}$ \\
\hline $\begin{array}{l}\text { Correctional } \\
\text { services (1) }\end{array}$ & - $\quad$ Prison management (Webb 2012) \\
\hline Military (1) & - Conscription (Lokshin \& Yemtsov 2008) \\
\hline Fisheries (1) & - $\quad$ Regulation and compliance (Sok 2014) \\
\hline $\begin{array}{l}\text { Conservation } \\
\text { (1) }\end{array}$ & - $\quad$ Regulation and corruption (Sundstrom 2016) \\
\hline Health (1) & - Compliance with aid requirements (Dietrich 2011) \\
\hline Education (1) & $\begin{array}{l}\text { - Perception of corruption (Van der Wal, Graycar \& } \\
\text { Kelly 2016) }\end{array}$ \\
\hline
\end{tabular}

Source: Okuda 2020a

\subsubsection{INSTITUTIONAL INSTRUMENTS AND COMPLIANCE DETER-} MINANTS

This section analyzes the findings of the second-round literature review, more specifically instances of compliance and compliance determinants. In addition to the instances of general compliance, compliance determinants, associated institutional instruments and the effect of e-governance and ICT were discerned when reviewing the identified articles and studies. The comprehensive list and narratives are found in Annex 3 which highlighted compliance determinants in bold and the effects of ICT and e-governance in red and Table 2 presents the summary of the findings. 
For this exercise of categorizing compliance determinants, I selected framework analysis as the method. As Silvermann (2016) mentioned, framework analysis is one of the methods where "close inspection is used to discover, explore and generate an increasingly refined conceptual description of the phenomena" (p.332). The method enables a researcher to collect data (the level of description and summary) and then move on to "exploring and explaining what is 'underlying' or 'broader' (mechanism) or to 'distil' essence, meaning, norms, orders, patterns, rules, structures etc. (the level of concepts and themes)" (p. 332). The method also enables a researcher to establish a thematic and sub-thematic cluster which is to be refined through increasingly abstract codes in an iterative manner.

Using this framework analysis strategy, I categorized institutional instruments (themes) and compliance determinants associated with the identified institutional instruments (sub-themes) in a progressively abstract and iterative manner as presented in Table 2.

Table 2: Summary of institutional instruments and compliance determinants in anti-corruption efforts

\begin{tabular}{|c|c|}
\hline $\begin{array}{l}\text { Institutional Instru- } \\
\text { ments }\end{array}$ & Compliance determinants \\
\hline Access to information & $\begin{array}{l}\text { Collecting and disseminating information } \\
\text { about corrupt practices (Cleveland, Favo, } \\
\text { Frecka, et al. 2010; Webb 2012; Garcia- } \\
\text { Tabuyo, Saez-Marin, Caba-Perez 2015; Alon } \\
\text { and Hageman 2017) } \\
\text { - Disseminating information on public ser- } \\
\text { vices (Batory 2012; Schlenther 2017; Ali, } \\
\text { Fjeldstad, Sjursen 2014; Camaj 2016; Garcia- } \\
\text { Tabuyo, Saez-Marin, Caba-Perez 2016) } \\
\text { - Organising public campaigns against cor- } \\
\text { ruption (Schlenther 2017; Sokol 2014; Bina } \\
\text { and Yinghong 2016; Akerlof 2017) }\end{array}$ \\
\hline $\begin{array}{l}\text { Anti-Corruption pol- } \\
\text { icy, legal and regula- } \\
\text { tory frameworks }\end{array}$ & $\begin{array}{l}\text { - Anti-Corruption policies, laws and regula- } \\
\text { tions (Schlenther 2017; Tjen and Evans 2017; } \\
\text { Webb 2012; Travits 2010; Batory 2012; } \\
\text { Popescu, Onofrei \& Kelley 2016; Schueth } \\
\text { 2012; Yilmaz 2014; Ozarslan 2016) }\end{array}$ \\
\hline
\end{tabular}




\begin{tabular}{|c|c|}
\hline & $\begin{array}{l}\text { - Administrable compliance guidelines and } \\
\text { code of conduct (Sokol 2014; Van del Wal, } \\
\text { Graycar \& Kelly 2016) } \\
\text { - Anti-Corruption programmes (Van del Wal, } \\
\text { Graycar \& Kelly 2016; Tjen and Evans 2017) } \\
\text { - Risk assessment and management (Van del } \\
\text { Wal, Graycar \& Kelly 2016; Cleveland, Favo, } \\
\text { Frecka, et al. 2010; Tjen and Evans 2017) } \\
\text { - Monitoring programme (Schlenther 2017) }\end{array}$ \\
\hline $\begin{array}{l}\text { Anti-Corruption-cen- } \\
\text { tered organisational } \\
\text { reforms }\end{array}$ & $\begin{array}{l}\text { - Anti-Corruption bodies and compliance } \\
\text { and disciplinary offices (Schlenther 2017; } \\
\text { Tjen and Evans 2017; Van del Wal, Graycar } \\
\text { \& Kelly 2016; Bina and Yinghong 2016; } \\
\text { Villagrasa 2016; Baum, Gupta, Kimani et al. } \\
\text { 2017; Hough 2017; Ozarslan 2016) } \\
\text { - Resource allocation (Webb 2012; Van del } \\
\text { Wal, Graycar \& Kelly 2016) } \\
\text { - Internal accounting and audit (Kantsir \& } \\
\text { Plekan 2017; Van del Wal, Graycar \& Kelly } \\
\text { 2016; Akerlof 2017) } \\
\text { - Reducing compliance costs (Tjen and Evans } \\
\text { 2017; Bac 2018) } \\
\text { Anti-Corruption Tools (Tjen and Evans } \\
\text { 2017; Schlenther 2017; Camaj 2016; Popescu, } \\
\text { Onofrei \& Kelley 2016; Samuel \& Lowen } \\
\text { 2010) }\end{array}$ \\
\hline $\begin{array}{l}\text { Anti-Corruption re- } \\
\text { porting and enforce- } \\
\text { ment }\end{array}$ & $\begin{array}{l}\text { - Whistle-blower protection (Sokol 2014; } \\
\text { Schlenter 2017; Webb 2012; Batory 2012; Gil- } \\
\text { bert and Sharman 2016; Michael 2012) } \\
\text { - } \quad \text { Confidential reporting (Schlenther 2017; } \\
\text { Akerlof 2017; Ozarslan 2016; Van del Wal, } \\
\text { Graycar \& Kelly 2016) } \\
\text { - } \quad \text { Rewards and penalties (Sokol 2014; Batory } \\
\text { 2012; Berghoff 2018; Akerlof 2017; Jiang } \\
\text { 2017; Galiot 2017; Sokol 2014) } \\
\text { - Control of violations (Batory 2012; Tjen and } \\
\text { Evans 2017; Bac 2018; Alon and Hageman } \\
\text { 2017; Akerlof 2017; Ali, Fjeldstad, Sjursen } \\
\text { 2014; Gilbert \& Sharman 2016) }\end{array}$ \\
\hline
\end{tabular}




\begin{tabular}{|c|c|}
\hline & $\begin{array}{l}\text { Detection, investigation and prosecution } \\
\text { (Sokol 2014; Webb 2012; Cleveland, Favo, } \\
\text { Frecka, et al. 2010; Gilbert and Sharman } \\
\text { 2016; Ozarslan 2016) }\end{array}$ \\
\hline Public sector reforms & $\begin{array}{l}\text { - } \quad \text { Efficient judiciary (Williams and Horodnic } \\
\text { 2015; Ozarslan 2016; Sundstrum 2016) } \\
\text { Less interactions with government officials, } \\
\text { including automation (Baum, Gupta, Ki- } \\
\text { mani et al. 2017; Schlenther 2017; Tjen and } \\
\text { Evans 2017) } \\
\text { - Institutional and individual capacity } \\
\text { (Schlenther 2017; Popescu, Onofrei \& Kelley } \\
\text { 2016; Sok 2014; Akerlof 2017; Cho, Dreher \& } \\
\text { Neumayer 2014; Ozarslan 2016; Camaj 2016; } \\
\text { Sokol 2014) } \\
\text { - Simpler procedures (Tjen and Evans 2017; } \\
\text { Schlenther 2017; Popescu, Onofrei \& Kelley } \\
\text { 2016) } \\
\text { - Sectoral reforms (Schenther 2017; Ali, Fjeld- } \\
\text { stad, Sjursen 2014; Cyan, Koumpias \& Mar- } \\
\text { tinez-Vazquez 2016; Van del Wal, Graycar } \\
\text { \& Kelly 2016) } \\
\text { Introducing value-based approach (Webb } \\
\text { 2012; Van del Wal, Graycar \& Kelly 2016) } \\
\text { Civil service reform (Webb 2012; Cleveland, } \\
\text { Favo, Frecka, et al. 2010; Michael 2012; } \\
\text { Schueth 2012; Osipian 2010) } \\
\text { Less organisational complexity (Camaj 2016; } \\
\text { Mendez \& Sepulveda 2013; Darden 2008) }\end{array}$ \\
\hline $\begin{array}{l}\text { Trust and social } \\
\text { norms }\end{array}$ & $\begin{array}{l}\text { Trust in government (Tavits 2010; Timmons } \\
\text { and Garfias 2015; Webb 2012; Williams and } \\
\text { Horodnic 2015; Alon and Hageman 2017; } \\
\text { Ali, Fjeldstad \& Sjursen 2014; Cyan, } \\
\text { Koumpias \& Martinez-Vazquez 2016; Aker- } \\
\text { lof 2017) } \\
\text { - Trust heuristics (Tavits 2010; Sundstrum } \\
\text { 2016) } \\
\text { - Peer influence and stigma (Batory 2012; } \\
\text { Tavits 2010; Akerlof 2017; Cyan, Koumpias } \\
\text { \& Martinez-Vazquez 2016; Kotzian 2011; }\end{array}$ \\
\hline
\end{tabular}




\begin{tabular}{|l|l|}
\hline & Rosid, Evans \& Binh 2016; Sundstrum 2016; \\
& Ali, Fjeldstad \& Sjursen 2014) \\
\hline & Leadership (Webb 2012; Schlenther 2017) \\
- & Individual motivation (Tavits 2010; Webb \\
& 2012; D'Attoma, Volintiru \& Steinmo 2017: \\
& De Figueiredo 2013; Rosid, Evans \& Binh \\
& 2016; Williams \& Krasniqi 2017) \\
- & Organisational culture (Sokol 2014; Webb \\
& 2012; Schlenther 2017; Osipian 2010) \\
- & Training and education (Schlenther 2017; \\
& Cleveland, Favo, Frecka, et al. 2010; Tjen \\
& and Evans 2017; Cyan, Koumpias \& Mar- \\
& tinez-Vazquez 2016) \\
\hline International instru- & Role of foreign entities, such as companies \\
ments & (Schlenther 2017; Dietrich 2011) \\
International conventions and foreign laws \\
and legislations against corruption (Schlen- \\
ther 2017; Jiang 2017; Cleveland, Favo, \\
Frecka, et al. 2010; Gilbert and Sharman \\
2016; Ozarslan 2016; Popescu, Onofrei \& \\
Kelley 2016; Buscaglia \& Peterson 2014) \\
International standards (Papyrakis, Rieger \\
and Gilberthorpe 2017; Sovacool et al. 2016; \\
Vadlamannati, Cooray \& Brazys 2018; \\
Camaj 2016; Garcia-Tabuyo, Saez-Marin, \\
Caba-Perez 2015) \\
\hline
\end{tabular}

Source: Okuda 2020a

The thematic analysis identified seven institutional instruments, which are broadly categorized into six domestic and one international institutional instruments and associated compliance determinants. The domestic institutional instruments were found inter-linked with each other, and focus on institutional and organizational setups, policy and regulatory frameworks, enforcement, reporting, and general reforms, supplemented with more social aspects of trust and norms. The international institutional instrument is associated with the implicit and explicit presence of foreign entities, interactions, frameworks in the country. In the case of e-governance implementation, the international instrument may manifest in the form of donor funding as well as the use of external experts in system development. 
There were 32 compliance determinants identified with domestic institutional instruments, while there were three compliance determinants associated with the international institutional instrument. Among them, ICT-enabled compliance determinants, such as the role of Internet in disseminating information on public services as well as IT systems such as financial management, payment, procurement and taxation, were referenced in some studies, but e-governance initiatives and ICT did not appear as a main compliance determinant based on the findings of this second round of literature review.

The identified compliance determinants will inform the selection of case study initiatives and help develop interview instruments, which will be discussed in more detail in Chapter 3 on the methodological orientation. Furthermore, the compliance determinants in Table 2 will be used to compare the findings of case study initiatives against the existing literature and determine the uniqueness and salient features of case study country and initiatives in Chapter 7.

\subsubsection{RESEARCH GAPS: ROLE OF ICT AND E-GOVERNANCE IN COMPLIANCE LITERATURE}

This section elaborates how ICT and e-governance were featured in the existing compliance literature, which again confirmed the lack of literature and evidence to answer my research questions. Several compliance studies made references to ICT and e-governance, which are found in Annex 3 and discussed in Section 2.3.3, but there were few studies which conducted systematic review on the subject.

DeNardis (2010) examined legal and executive instruments which need to be put in place to ensure operational compliance for e-governance interoperability. Other means to enhance compliance were identified as budgets, incentives/bonuses, peer working group and compliance monitoring by chief executive officers in the article. Peristeras \& Tarabanis (2004) emphasized the control aspect of compliance in the implementation of Governance Enterprise Architecture of e-government initiatives and how to treat non-compliance. Based on the assumption that ICT improves government efficiency and reduces corruption by curtailing the discretionary power of government officials, Samuel \& Lowen (2010) examined the relationships between bribery, compliance and social welfare through a Principal-Supervisor-Agent model. Based on the findings, the authors concluded that ICT can substitute or complement anti-corruption policy. 
The existing literature thus helped provide initial insights into compliance and the linkage between compliance and ICT/ e-governance. However, the existing articles focus more on technical compliance of e-governance initiatives, such as interoperability and enterprise architecture (DeNardis 2010; Peristeras \& Tarabanis 2004) than internal mechanisms of e-governance implementation, although the studies were conducted in relation to corruption.

The second round of literature review was instrumental in obtaining valuable insights, instances of general compliance, institutional instruments and compliance determinants. However, it also revealed that there was little evidence and literature which help answer my research questions, namely where and how compliance manifests in e-governance implementation and associated compliance determinants.

\subsection{RESEARCH GAP SUMMARY}

Based on the discussions in Section 2.2 and 2.3, this section synthesizes the research gaps identified in the first and second rounds of systematic literature review.

The first round of literature review analyzed 45 articles and studies on compliance and corruption in the existing IS and e-governance literature. The literature review found that few studies investigated compliance in the IS and e-governance literature, although there was a sizeable body of studies which evidenced the effect of egovernance and ICT on reduction in corruption through empirical research and case studies. In particular, there was a lack of research on internal mechanisms, government employee perspectives and understanding of non-OECD contexts in discussing e-governance and corruption.

The second round of literature review then focused on 52 relevant articles from the existing compliance literature and identified general compliance determinants as well as some effects of ICT and e-governance on compliance. Against the seven domestic and international institutional instruments, 35 compliance determinants were identified, as listed in Table 3 . While these determinants will be useful in selecting case studies and developing interview instruments, the second round of the literature review did not find systematic and relevant studies on compliance in egovernance implementation.

The empirical research of this present research will use the concept of compliance among government employee users to understand the internal mechanisms of egovernance within the overall framework of anti-corruption efforts. The case study 
country will be purposefully selected from non-OECD countries. Based on the research gaps identified in Chapter 2, Chapter 3 discusses research methodology, method and design in more detail. 
"For a small country, as we function within limited resources, the efficiency of our governance will diminish should we not counter the prevalence of corruption." - Mr. Lotey Tshering, Prime Minister of the Royal Government of Bhutan (Anti-Corruption Commission 2019, p. 4)

This chapter explains the methodological orientation and research design, which enables to answer the research questions:

\section{How does compliance manifest in e-governance implementation?}

\section{What are the determinants of compliance among government employee users in e-governance implementation?}

Section 3.1 presents a methodological orientation of this present research and justification for the selection of research method, followed by research strategy and design using comparative case study in Section 3.2. The selection criteria for case study country are then discussed in Section 3.3. Based on the criteria, Bhutan was selected as the case study country. Section 3.4 then describes Bhutan in more detail. The case study initiatives are selected among the 30 initiatives listed in the Bhutan E-government Master Plan (Ministry of Information and Communication 2014) based on the pre-set criteria. The Asset Declaration System (ADS) of the Anti-Corruption Commission (ACC) and the electronic Public Expenditure Management System (e-PEMS) of the Ministry of Finance (MoF) are selected based on the criteria in Section 3.5. Section 3.6 then discusses the methods and procedures used to conduct the research. The chapter concludes with the discussion on steps and approaches to be taken for data analysis and interpretation in Section 3.7.

\subsection{METHODOLOGICAL ORIENTATION}

This exploratory research uses qualitative inductive methods, based on constructivist/interpretivist approach (Bryman 2016; Moses \& Knutsen 2012; Matthews \& Ross 2010). The phenomena of compliance are not always materially observable and "should be considered social constructions built up from the perceptions and actions of social actors" (Bryman 2016, p.28). Furthermore, compliance is not static: 
it is constructed and reconstructed as determinants and actors evolve in dynamically evolving context to focus on "people's interpretations and understandings of social phenomena and their own actions" (Matthew 2010 p. 28).

The phenomena surrounding e-governance compliance among government officials is complex and relevant empirical data are not readily available. An inductive research strategy is suitable to "establish limited generalizations about the distributions of, and patterns of association amongst, observed or measured characteristics of individuals and social phenomena" (Blaikie 2010, p. 83). Additionally, the literature review in Chapter 2 revealed that the mechanism of how e-governance initiatives work through the lens of compliance has not been sufficiently researched, in particular, from government employee users' perspectives and in the context of non-OECD country. According to Blaikie (2010), "(e)xploratory research is necessary when very little is known about the topic being investigated, or about the context in which the research is to be conducted" (p.70).

\subsection{RESEARCH STRATEGY AND DESIGN}

The research questions aim at identifying possible multiple determinants of compliance and use multiple sources of evidence. A case study approach is selected as the research design. According to Yin (2013), a case study is appropriate when the inquiry "copes with the technically distinctive situation in which there will be many more variables of interests than data points, and as one result relies on multiple sources of evidence, with data needing to converge in a triangulation fashion" (Yin 2003: p. 13-14).

Additionally, comparative case study fits the criteria developed by Goodrick (2014) as it is:

- exploratory, inductive research with little empirical evidence;

- a complex phenomenon, where the boundary between context and phenomenon is not known;

- research, which benefits from rich description and an in-depth interpretation of the case, and;

- intended to explain why and how in addition to the outcomes.

More specifically, a synchronic comparison for cross-case variation at one point in time (Panke 2018) is found suitable. In my research, a multiple case study will help provide a detailed description of each case and theme within a case and across cases (cross-case analysis) for interpretation (Creswell \& Poth 2016, p.100). Cross- 
case questions for a multiple case study could help contrast differences and identify similarities across cases, initiatives and organisations under investigation (Yin 2013). In each case, converging evidence is sought from facts and conclusions, which will then inform the conduct and focus of the other cases (Okuda 2020a).

\subsection{CASE STUDY COUNTRY SELECTION CRITERIA}

As Chapter 2 has shown, the existing literature has not produced sufficient empirical evidence on e-governance implementation in non-OECD, developing countries to answer my research questions. Non-OECD countries are generally characterized by a lower level of control of corruption than OECD countries, as demonstrated in Table 3. For this present research, it is important to understand the level and nature of compliance and the determinant factors in a non-OECD country, where institutional, human and financial resources are more constrained and phenomena of compliance can be observed in e-government implementation (Okuda 2020a).

In this research, the following factors determined the selection of a case study country (Okuda 2020a):

- Country with High Control of Corruption (CC) Indicators of the Worldwide Governance Indicator (WGI): compliance was found associated with the existence of various CC frameworks, instruments and infrastructure, such as anti-corruption infrastructure and bodies (Hough 2017, Villagrasa 2016, Bina \& Yinghong 2016) and enforcement (Cleveland et al. 2009, Berghoff 2018, Gilbert \& Sharman 2016), as detailed in Chapter 2.

- Country in the category of medium-level e-government development, with the assumption that the majority of high-level e-government countries are OECD countries with many other compliance determinants in place and their compliance level may be high with or without e-governance initiatives, while low-level e-government countries may not have a sufficient number of operational e-government initiatives in place where compliance can be observed.

- Case study country should be implementing a variety of e-governance initiatives for at least 5 years to enable the examination of compliance determinants.

- Case study country should have improved ranking in various corruption indices and surveys, such as Transparency International perception surveys, which indicates the likelihood of finding instances of compliance. 
- This qualitative research intends to select an English-speaking country which is accessible and open to research and provides a safe environment, without the need for interpretation.

Table 3 mapped all countries included in Worldwide Governance Indicators (WGI) 2016 on the vertical column and United Nations Department of Economic and Social Affairs (UNDESA) E-government Survey (EGOV) 2016 on the horizontal row. Countries were categorised either in WGI CC High (with scores higher than 0.5) or Low (with scores lower than 0.5). The EGOV categorization of countries followed the approach used in the UNDESA Survey (UNDESA 2016) for the selection of case study country in this present research (Okuda 2020a).

Table 3: Matrix of countries along WGI CC and EGOV

\begin{tabular}{|c|c|c|}
\hline & WGI CC High & WGI CC Low \\
\hline $\begin{array}{l}\text { EGOV Very } \\
\text { High }\end{array}$ & $\begin{array}{l}\text { AUS, AUT, BHR, BEL, } \\
\text { CAN, DNK, EST, FIN, } \\
\text { FRA, DEU, ISL, IRL, ISR, } \\
\text { JPN, KOR, LTU, LUX, } \\
\text { NLD, NZL, NOR, SGP, } \\
\text { SNV, ESP, SWE, CHE, } \\
\text { ARE, GBR, USA }\end{array}$ & ITA \\
\hline EGOV High & $\begin{array}{l}\text { ADO, BHS, BRB, BRN, } \\
\text { CHL, CRI, HRV, CYP, CZE, } \\
\text { GEO, GRD, HUN, JOR, } \\
\text { LVA, LIE, MYS, MLT, } \\
\text { MUS, OMN, POL, PRT, } \\
\text { QAT, SAU, SYC, SVK, UGY }\end{array}$ & $\begin{array}{l}\text { ALB, ARG, ARM, AZE, BLR, } \\
\text { BIH, BRA, BGR, CHN, COL, } \\
\text { ECU, GRC, KAZ, KWT, LBN, } \\
\text { MEX, MNG, MNE, MAR, PER, } \\
\text { PHL, MDA, ROM, RUS, SRB, } \\
\text { ZAF, LKA, THA, MKD, TTO, } \\
\text { TUN, TUR, UKR, UZB, VEN, } \\
\text { VNM }\end{array}$ \\
\hline $\begin{array}{l}\text { EGOV Me- } \\
\text { dium }\end{array}$ & $\begin{array}{l}\text { ANT, BTN, BWA, CPV, } \\
\text { CUB, DMA, KIR, LSO, } \\
\text { FSM, NAM, RWA, WSM, } \\
\text { SEN }\end{array}$ & $\begin{array}{l}\text { DZA, AGO, BGD, BLZ, BOL, } \\
\text { KHM, CMR, DOM, EGY, SLV, } \\
\text { ETH, FJI, GAB, GHA, GTM, } \\
\text { GUY, HND, IND, IDN, IRN, } \\
\text { IRQ, JAM, KEN, PRK, KGZ, } \\
\text { LAO, LBY, MDV, MHL, NRU, } \\
\text { NPL, NIC, NGA, PAK, PLW, } \\
\text { PAN, PRY, SDN, SUR, SWZ, } \\
\text { SYR, TJK, TZA, TMP, TGO, } \\
\text { TON, TKM, TUV, UGA, VUT, } \\
\text { ZMB, ZWE }\end{array}$ \\
\hline
\end{tabular}




\begin{tabular}{|c|c|}
\hline EGOV Low & $\begin{array}{l}\text { AFG, BEN, BFA, BDI, CAF, } \\
\text { TCD, COM, CIV, DJI, GNQ, } \\
\text { ERI, GMB, GIN, GNB, HTI, } \\
\text { LBR, MDG, MWI, MLI, MRT, } \\
\text { MOZ, MMR, NEG, PNG, STP, } \\
\text { SLE, SLB, SOM, SSD, YEM }\end{array}$ \\
\hline
\end{tabular}

Source: compiled by author (Okuda 2020a) based on data from WGI 2016 at https://datacatalog.worldbank.org/dataset/worldwide-governance-indicators and from UNDESA E-government Survey 2016 at https://publicadministration.un.org/egovkb/en-us/Reports/UN-E-Government-Survey-2016

Out of 13 countries in the category of Medium EGOV/High CC in Table 32, Bhutan, Botswana, Lesotho and Samoa meet the criteria in the order of suitability, also based on the country ranking of Transparency International Perception Survey $2019^{3}$ and language requirements. All countries were considered carefully against the pre-set criteria, before the case study country was selected. According to the Bhutan E-government Master Plan (Ministry of Information and Communication 2014), the country has been implementing e-government initiatives for more than five years, with the objective of promoting ICT for good governance. Botswana has developed its e-government strategy 2015-20214, while Samoa and Lesotho do not have approved e-government strategies. Unlike the master plan in Bhutan, Botswana's e-government strategy does not focus on anti-corruption or good governance as an objective, which makes Botswana less compelling as a case study country for this present research. The Bhutanese government provided access and supported the research design. Based on suitability and feasibility, the case of Bhutan was selected.

\subsection{BHUTAN AS A CASE STUDY COUNTRY}

This section describes Bhutan as the case study country and provides the overall context. Bhutan is a kingdom, clasped in the Himalayan mountains, with a population of about 736,000 people (National Statistical Bureau 2018) that are governed under the constitutional democratic monarchy. It is categorised as a Least

\footnotetext{
2 These 13 countries are Netherlands Antilles, Bhutan, Botswana, Cape Verde, Cuba, Dominica, Kiribati, Lesotho, Federated States of Micronesia, Namibia, Rwanda, Samoa and Senegal.

${ }^{3}$ The improvements in ranking is most pronounced in Bhutan (25th), Botswana (34th), Lesotho (85th) and Samoa (NA)

${ }^{4}$ Available at https://www.ellipsis.co.za/wp-content/uploads/2016/07/Botswana.pdf
} 
Developed Country (LDC), on the path to graduation from the LDC status in 2023 (Bhutan Broadcasting System 2018).

His Majesty the King, Jigme Khesar Namgyel Wacngchuck, assumed the throne as the fifth King in 2008 (Wangchuck 2017). His father, the fourth King, Jigme Singye Wangchuck, initiated various modernization efforts, including the concept of Gross National Happiness (GNH) to guide the government's development efforts, instead of Gross National Income or Gross National Product (Mitra \& Jeong 2017). Introduced in 1972, GNH aims to view development in a holistic manner, encompassing "(1) equitable socio-economic development; (2) preservation and promotion of culture, (3) environmental conservation and sustainability and (4) good governance" (Allay 2016, p.119).

What is also unique about Bhutan is that democratization was initiated by the monarchy. The fourth King devolved his executive power to the elected cabinet in his Royal Edict called Kasho in 1998, which led to the first National Council election in 2007 and National Assembly election in 2008 (Sebastian 2015). The country's constitution was enacted in the same year 2008 (Gallenkamp 2013). The latest national election of 2018 led to the formation of Cabinet under the current Prime Minister, Dr. Lotay Tshering. Under the leadership of the Prime Minister, there are $10 \mathrm{~min}-$ istries in the government: Agriculture and Forest, Economic Affairs, Education, Finance, Foreign Affairs, Health, Home and Cultural Affairs, Information and Communications, Labour and Human resources, and Works and Human Settlement. (Wachgchuk 2017)

The national language of Bhutan is Dzongkha and English is widely spoken and used in township and schools. In addition to Dzongkha, there are three dominant languages: Bumthangkha in central Bhutan, Tshanglakha in eastern Bhutan and Lhotshamkha, or Nepali, in the South (Wangchuk, 2017).

Bhutan has 20 districts called Dzongkhag as shown in Image 1. Each Dzongkhag is then divided into block or Gewog and sub-district of Dungkhag. The district administrator is called Dzongda. Dzongda is responsible for government officials in each sector, such as administration, finance, education, agriculture and health. The second level local administrative unit is called Thromde. The Bhutanese parliament consists of three pillars: His Majesty, National Council and National Assembly. (Wancghuk 2017) 


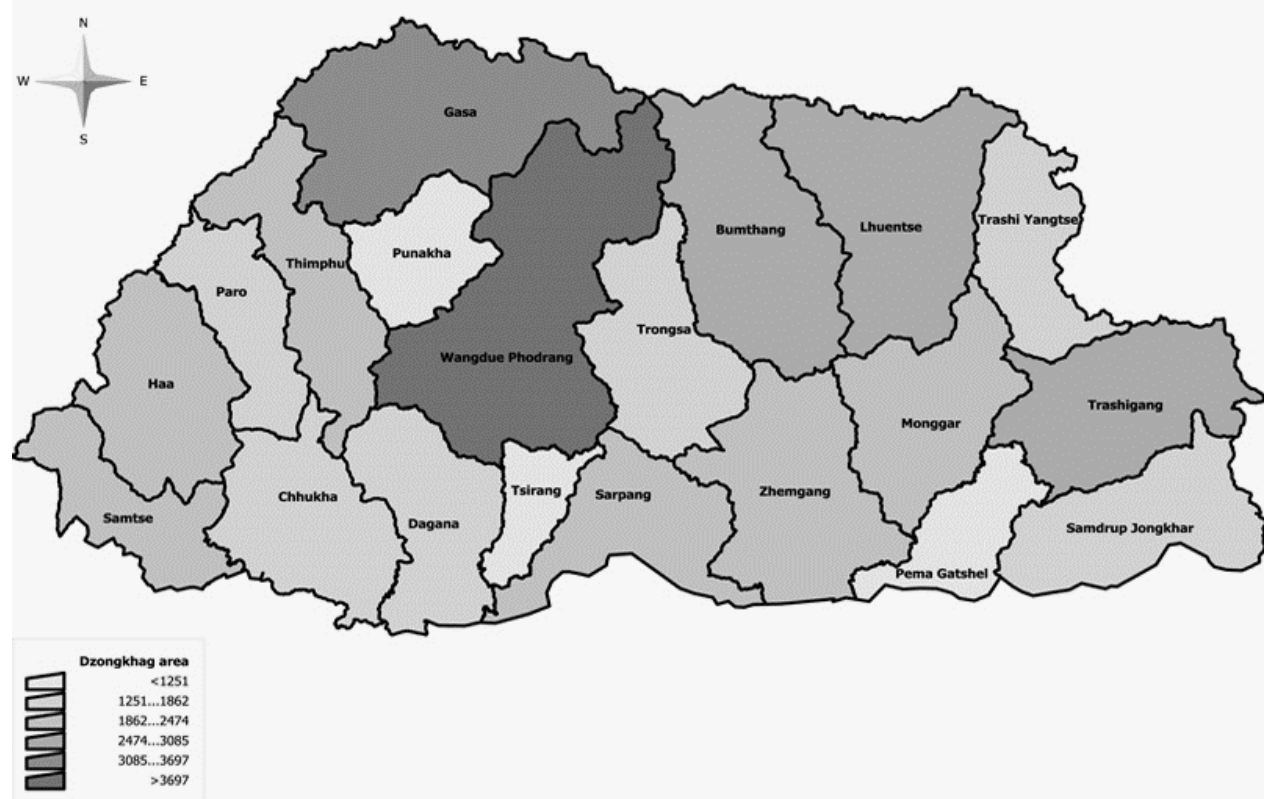

Source: National Statistics Bureau of Bhutan at http://www.nsb.gov.bt/map/thematic/dzongkhag.php?id=26

Based on the data from the corruption perception surveys of Transparency International (TI), it is clear that Bhutan scores high on the ranking. Despite being an LDC, Bhutan is ranked 25th out of 180 countries assessed in the 2019 TI Corruption Perceptions Index ${ }^{5}$. In TI's regional analysis, Bhutan was compared with five other countries in the region (Bangladesh, Indonesia, Maldives, Pakistan and Sri Lanka) on the strength of their anti-corruption agencies (Transparency International 2017). Bhutan was scored the highest among the six assessed countries in four out of the eight indicators of legal independence, financial and human resources, detection and investigation, prevention, education and outreach. What it scored low was in the public perceptions and accountability and oversight (Okuda 2020a).

In terms of the ICT infrastructure, Bhutan has expanded the Internet usage, fixed and mobile broadband networks across the countries despite the mountainous terrain. However, while Internet users and mobile subscribers have increased dramatically, the fixed broadband networks are only slowly expanding as shown in Table

${ }^{5}$ https://www.transparency.org/en/cpi/2019/index/btn, accessed on 17 February 2021. 
4, 5 and 6 (Okuda 2020). The lack of sufficient Internet connectivity was mentioned as a bottleneck by users of the ADS, as detailed in Section 4.5.

Table 4: The number of Internet users in selected countries in South Asia from 2000 to 2017

\begin{tabular}{|c|c|c|c|c|c|c|}
\hline & \multicolumn{6}{|c|}{ Percentage of Individuals using the Internet } \\
\hline & 2000 & 2005 & 2010 & 2015 & 2016 & 2017 \\
\hline Bangladesh & 0.07 & 0.24 & 3.70 & 14.40 & 18.02 & 15.00 \\
\hline Bhutan & 0.40 & 3.85 & 13.60 & 39.80 & 41.77 & 48.11 \\
\hline India & 0.53 & 2.39 & 7.50 & 17.00 & 22.00 & 34.45 \\
\hline $\begin{array}{l}\text { Nepal (Repub- } \\
\text { lic of) }\end{array}$ & 0.20 & 0.83 & 7.93 & 17.58 & 19.69 & 34.00 \\
\hline Sri Lanka & 0.65 & 1.79 & 12.00 & 12.10 & 16.40 & 34.11 \\
\hline
\end{tabular}

Source: ITU world telecommunications indicators, at https://www.itu.int/en/ITUD/Statistics/Pages/stat/default.aspx, accessed on 10 February 2020

Table 5: The number of mobile-cellular telephone subscribers per 100 in selected South Asian countries, 2000-2018

\begin{tabular}{|c|c|c|c|c|c|c|c|}
\hline & \multicolumn{7}{|c|}{$\begin{array}{l}\text { Mobile-cellular telephone subscriptions per } 100 \text { inha- } \\
\text { bitants }\end{array}$} \\
\hline & 2000 & 2005 & 2010 & 2015 & 2016 & 2017 & 2018 \\
\hline Bangladesh & 0.22 & 6.47 & 46.03 & 84.08 & 86.08 & 94.53 & 100.24 \\
\hline Bhutan & 0.00 & 5.55 & 57.52 & 92.84 & 94.80 & 98.00 & 93.26 \\
\hline India & 0.34 & 7.85 & 60.94 & 76.41 & 85.15 & 87.32 & 86.94 \\
\hline $\begin{array}{l}\text { Nepal (Re- } \\
\text { public of) }\end{array}$ & 0.04 & 0.88 & 34.04 & 101.85 & 117.81 & 130.63 & 139.45 \\
\hline Sri Lanka & 2.29 & 17.20 & 85.68 & 114.31 & 122.72 & 133.47 & 142.65 \\
\hline
\end{tabular}

Source: ITU world telecommunications indicators, at https://www.itu.int/en/ITUD/Statistics/Pages/stat/default.aspx, accessed on 10 February 2020 
Table 6: The number of fixed broadband subscribers per 100 inhabitants in selected South Asian countries, 2000-2018

Fixed-broadband subscriptions per 100 inhabit-

ants

\begin{tabular}{|c|c|c|c|c|c|c|}
\hline & & & & \multirow{2}{*}{2016} & \multirow{2}{*}{2017} & \multirow{2}{*}{2018} \\
\hline & 2005 & 2010 & 2015 & & & \\
\hline Bangladesh & & 0.28 & 3.13 & 4.17 & 4.57 & 6.34 \\
\hline Bhutan & & 1.27 & 3.83 & 2.24 & 2.24 & 1.43 \\
\hline India & 0.12 & 0.89 & 1.29 & 1.41 & 1.33 & 1.34 \\
\hline $\begin{array}{l}\text { Nepal (Re- } \\
\text { public of) }\end{array}$ & & 0.22 & 1.12 & 0.82 & 1.82 & 2.82 \\
\hline Sri Lanka & 0.11 & 1.13 & 2.99 & 4.24 & 5.78 & 7.27 \\
\hline
\end{tabular}

Source: ITU world telecommunications indicators, at https://www.itu.int/en/ITUD/Statistics/Pages/stat/default.aspx, accessed on 10 February 2020

When the implementation of e-government initiatives started, government employee users raised various concerns. Some of the reported concerns here form the context and are related to challenges the case study initiatives were expected to address (Okuda 2020a). They ranged from the need for reliable Internet connectivity, back up of sensitive online documents and cybersecurity to proper infrastructure in offices in earlier years (Kuensel 2016b). Other issues emerging in the course of e-government implementation included lack of coordination for implementing ICT initiatives, low adoption rate among government agencies, lack of sufficient budget and human resource capabilities. A policy was suggested to be developed to provide clear guidance in coordination and implementation of e-government initiatives. Such a guidance was expected to enable the government to leverage existing and emerging technologies and avoid multiple and redundant investments and infrastructure (Kuensel 2017a).

During the course of conducting this present research, I found only one research paper on e-governance conducted on Bhutan. Miyata (2011) examined the vehicle registration system developed by the Road Safety and Transport Authority (RSTA) of the Ministry of Information and Communication (MoIC) of Bhutan and its 
impact, including on corruption, in the country. She concluded that governance benefits outweighed cost efficiency, as computerisation in a small LDC such as Bhutan is costly. While the system was not evidenced to reduce costs, survey respondents stated that the time needed for registration was reduced and adherence to rules increased significantly (Okuda 2020a).

Due to the fact that there is an academic gap and Bhutan is a good case to study egovernance and compliance, this present research is expected to make a good scholarly contribution. Since there are very few studies conducted on e-governance in Bhutan before, it adds value both academically to deepen an understanding of e-governance and compliance, and societally as it informs the government of Bhutan and ICT for development practitioners of compliance as an important conduit to consider.

\subsection{CASE STUDY INITIATIVES}

This section discusses the selection criteria and process of selection of case study initiatives in Bhutan. The Royal Government of Bhutan developed its first E-government Master Plan in 2014 (Ministry of Information and Communication 2014), but some e-governance initiatives dated earlier than 2014. The Master Plan was developed with the objective of achieving Gross National Happiness (GNH) and promoting ICT for information society, good governance and sustainable socioeconomic development in the country (Okuda 2020a).

For this present research, the case variation is driven by the ownership of systems. The factor was identified during a case selection visit to Bhutan between July and August 2019. Several key informants indicated that the ownership of the initiatives in the forms of 1) government or external funding and 2) local or external system design and implementation of e-governance initiatives could be the key determinants of compliance, with possible influence of size and complexity of implementing and user organizations. Based on the literature review presented in Section 2.2.7, the use of two dimensions of ownership (funding and design/implementation) in this research as case study initiative selection criteria is aligned with the existing research findings and therefore is justified.

Therefore, the case study initiative selection was finalised, taking into account the ownership factor, as shown in Figure 4. 


\begin{tabular}{|l|l|}
\hline Ownership & \\
\hline Local & Case 1 \\
\hline Donor-funded & Case 2 \\
\hline
\end{tabular}

Constant factors in the environment include political stability, national development plan, general ICT connectivity, macro-level fiscal stability, quality of overall political leadership.

Source: Okuda (2020a)

This case study design maintains constant several factors, such as political stability, national development plan, general ICT connectivity, macro-level fiscal stability and quality of overall political leadership. With the introduction of ownership as a case selection criterion, the case study presents a most similar systems design with most different ownership structure. The compliance levels of the case study initiatives are first assessed, based on which compliance drivers are inductively explored (Panke 2018) to identify the most likely factors which explain the phenomena of compliance.

To fit the most similar systems design, we select one case with local ownership and one case with donor ownership, within the most similar government setting of Bhutan. The case study initiatives were selected from the 30 e-government initiatives listed in the Bhutan E-government Master Plan. The initiative had to have the following elements to be eligible as a case study initiative to ensure a most similar system, with most different case, from which one local and one donor funded case would be selected (Okuda 2020a):

1) Initiatives which are not for policy or strategy development;

2) Initiatives which are not infrastructure, facilities or hardware-related;

3) Initiatives with an objective of increasing transparency and reducing corruption;

4) Initiatives which are not designed for the entire government, so as to identify e-governance managers and government officials within a ministry or agency at the institutional level;

5) Initiatives which process transactions within the government;

6) Sectors where corrupt behaviors were evidenced in the literature review in Chapter 2; 
7) One initiative implemented with national and local resources (local ownership) and the other with donor funds (donor-funded ownership);

8) The implementing agencies agree to take part in the research.

In this context, the below Table 7 tabulates the steps taken to identify eligible initiatives out of the 30 e-government initiatives listed in the Bhutan E-government Master Plan (Okuda 2020a);

- 22 initiatives relate to cross-sectoral, infrastructure, data and service facility and policy development, identified in column (1), and therefore eliminated as not relevant to my research questions.

- The remaining 8 sectoral initiatives focus on providing applications and services for transactions in various sectoral ministries, as show in column (2) and

- Further reviewed against the findings of the literature review on compliance, as detailed in Chapter 2, in column (3) which resulted in 5 initiatives.

Table 7: List of 30 e-government initiatives listed in the Bhutan E-Government Master Plan

\begin{tabular}{|l|l|l|l|l|}
\hline Name & Responsible Agency & $\begin{array}{l}\text { Cross- } \\
\text { sec- } \\
\text { toral } \\
\mathbf{( 1 )}\end{array}$ & $\begin{array}{l}\text { Sec- } \\
\text { toral } \\
\text { ser- } \\
\text { vices } \\
\text { (2) }\end{array}$ & $\begin{array}{l}\text { Lit } \\
\text { re- } \\
\text { view } \\
\mathbf{( 3 )}\end{array}$ \\
\hline P1. National Broadband Network (last mile) & DITT/MoIC & $\mathrm{x}$ & & \\
\hline P2, Government Intranet (TWAN ${ }^{7}$ ) & DITT/MoIC & $\mathrm{x}$ & & \\
\hline P3. BhutanCIRT* & DITT/MoIC & $\mathrm{x}$ & & \\
\hline P4. e-Government Policy & DITT/MoIC & $\mathrm{x}$ & & \\
\hline P5. Telecom and Broadband Policy & DITT/MoIC & $\mathrm{x}$ & & \\
\hline P6. ICM ${ }^{8}$ Act & DoIM/DITT/MoIC & $\mathrm{x}$ & & \\
\hline P7. Parenting of ICT Professionals & DITT/MoIC & $\mathrm{x}$ & & \\
\hline $\begin{array}{l}\text { P8. Development of Leadership and non-ICT } \\
\text { Professionals }\end{array}$ & $\begin{array}{l}\text { DITT/MoIC, Chiphen } \\
\text { Rigpel }^{* *}\end{array}$ & $\mathrm{x}$ & & \\
\hline P9. ICT Masterplan for MoE & $\mathrm{MoE}^{10}$ & $\mathrm{x}$ & & \\
\hline P10. ICT Masterplan for MoF & $\mathrm{MoF}^{11}$ & $\mathrm{x}$ & & \\
\hline P11. ICT Masterplan for Health & $\mathrm{MoH}^{12}$ & $\mathrm{x}$ & & \\
\hline
\end{tabular}

${ }^{6}$ Department of Information Technology and Telecommunication, Ministry of Information and Communications

${ }^{7}$ Thimphu-wide Area Network

${ }^{8}$ Information communications and Media

${ }^{9}$ Department of Information and Media

${ }^{10}$ Ministry of Education

${ }^{11}$ Ministry of Finance

${ }^{12}$ Ministry of Health 


\begin{tabular}{|c|c|c|c|c|}
\hline P12. ICT Masterplan for Agriculture & MoAF13 & $x$ & & \\
\hline P13. ICT Masterplan for Tourism & $\mathrm{TCB}^{14}$ & $x$ & & \\
\hline P14. e-GIF15 & DITT/MoIC & $\mathrm{x}$ & & \\
\hline P15. Common Data Hubs & DITT/MoIC & $\mathrm{x}$ & & \\
\hline $\begin{array}{l}\text { P16. Common Systems (Govt email, e-Procu- } \\
\text { rement etc) }\end{array}$ & $\begin{array}{l}\text { Respective System } \\
\text { Owners }\end{array}$ & $\mathrm{x}$ & & \\
\hline P17. Government Data Centre & DITT/MoIC & $\mathrm{x}$ & & \\
\hline P18. G2C Services & G2C***, DITT/MoIC & $\mathrm{x}$ & & \\
\hline P19. G2B ${ }^{16}$ Services & $\mathrm{MoEA}^{17}$ & $\mathrm{x}$ & & \\
\hline P20. Natl. e-Commerce Framework & MoEA & $\mathrm{x}$ & & \\
\hline $\begin{array}{l}\text { P21. Public Financial System (MYRB }{ }^{18} \text {, } \\
\left.\text { PEMS }^{19}, \text { PLaMS }^{20}\right)\end{array}$ & MoF & & $\mathrm{x}$ & $\mathrm{x}$ \\
\hline $\begin{array}{l}\text { P22. E-Medical Records, Health Mgmt Info } \\
\text { System }\end{array}$ & $\mathrm{MoH}$ & & $\mathrm{x}$ & $\mathrm{x}$ \\
\hline $\begin{array}{l}\text { P23. Civil Registration System (AFIS }{ }^{21} \text {, bilin- } \\
\text { gual) }\end{array}$ & DCRC/MoHCA ${ }^{22}$ & & $\mathrm{x}$ & \\
\hline P24. Labornet, Job Portal (Enhancement) & MoLHR $^{23}$ & & $\mathrm{x}$ & \\
\hline $\begin{array}{l}\text { P25. GIS24 Digitised Road Network Map\& } \\
\text { GIS-based maps }\end{array}$ & MoWHS25 & $\mathrm{x}$ & & \\
\hline P26. Intelligent Transport System & RSTA $^{26} / \mathrm{MoIC}$ & & $\mathrm{x}$ & \\
\hline P27. Corruption Compliant Mgt System & $\mathrm{ACC}^{27}$ & & $\mathrm{x}$ & $\mathrm{x}$ \\
\hline P28. Terrestrial Network & $\mathrm{BBSC}^{28}$ & $\mathrm{x}$ & & \\
\hline P29. Audit Information Mgt System & RAA $^{29}$ & & $\mathrm{x}$ & $\mathrm{x}$ \\
\hline P30. e-Filing System for Judiciary & Royal Court of Justice & & $\mathrm{x}$ & $\mathrm{x}$ \\
\hline
\end{tabular}

Source: Okuda 2020a

* Cyber Incident Response Team

** This is a project supported by the Government of India for human capacity development in all sectors.

*** Government-to-Citizen (G2C) project located in the Cabinet Secretariat: available at https://www.citizenservices.gov.bt/home

From the eligible cases, when exploring the possibilities for the fieldwork, the Royal Court of Justice, Ministry of Health and Royal Audit Authority could not be approached to provide access to examine their systems and therefore the initiatives

\footnotetext{
${ }^{13}$ Ministry of Agriculture and Forests

${ }^{14}$ Tourism Council of Bhutan

15 eGovernment Interoperability Framework

${ }^{16}$ Government-to-Business

${ }^{17}$ Ministry of Economic Affairs

${ }^{18}$ Multi-Year Rolling Budget

${ }^{19}$ Public Expenditure Management System

${ }^{20}$ Planning and Monitoring System

${ }^{21}$ Automated Fingerprint Identification System

${ }^{22}$ Department of Civil Registration and Census, Ministry of Home and Cultural Affairs

${ }^{23}$ Ministry of Labour and Human Resources

${ }^{24}$ Geographic Information System

${ }^{25}$ Ministry of Works and Human Settlement

${ }^{26}$ Road Safety and Transport Authority

${ }^{27}$ Anti-Corruption Authority

${ }^{28}$ Bhutan Broadcasting Service Corporation

${ }^{29}$ Royal Audit Authority
} 
are not included in the Table 8 for comparison. In this context, my research selected two initiatives (P21 and P27 in the Table 7), namely 1) online ADS 30 of the AntiCorruption Commission (ACC) and 2) e-PEMS of the Ministry of Finance (MoF) which held the required variation in terms of ownership. While the government funded and managed ACC's online ADS, a multi-donor fund, administered by the World Bank, funded and technically supported e-PEMS (Okuda 2020a). The ADS was developed by the government employees, while the e-PEMS recruited an external expert to advise the system design and assist the development.

Table 8: Comparison of identified case study initiatives

\begin{tabular}{|l|l|l|}
\hline & Local ownership & $\begin{array}{l}\text { Donor-funded } \\
\text { ownership }\end{array}$ \\
\hline $\begin{array}{l}\text { Initiative/Implementing } \\
\text { agency }\end{array}$ & Online ADS/ ACC & e-PEMS/MoF \\
\hline
\end{tabular}

Source: Okuda (2020a)

\subsection{DATA COLLECTION}

This section details the methods and procedures of collecting the data. Data collection was planned through document analysis, observations and semi-structured interviews, which are expected to render a broader account of events and behaviours and develop a converging line of inquiry (Yin 2013). The data collection will be split into three components: 1) information system descriptions based on document analysis and observations; 2) obtaining evidence of compliance among government employee users through semi-structured interviews and observations; and 3) data triangulation using document analysis (newspaper articles, project documents, information on the Internet among others) and external expert views (Okuda 2020a).

\subsubsection{DATA COLLECTION METHOD OVERVIEW}

This section presents the overview of data collection method used to answer the research questions, supplemented by details on respective data collected for document analysis, observations and semi-structured interviews.

\footnotetext{
${ }^{30}$ As part of ACC's corruption management system which has evolved into several systems since the inception of the Bhutan E-government Master Plan of 2014.
} 
For document analysis, secondary data, such as e-governance policy and strategy documents, project documents, problem analysis reports, evaluation reports, user feedback and articles of various newspaper companies were gathered to be used. The collected data helped enhance an understanding of the country and organisational context, nature of the identified e-governance initiatives, political and socioeconomic environment and settings where the identified two initiatives are implemented. The document analysis is also used to triangulate data collected from semi-structured interviews (Okuda 2020a). The overview of collected documents are listed in Table 9.

Table 9: Summary of collected documents for document analysis

\begin{tabular}{|l|l|l|}
\hline Agency & $\begin{array}{l}\text { No of } \\
\text { items }\end{array}$ & Summary of collected documents \\
\hline ACC & 45 & $\begin{array}{l}\text { ACC annual reports, NACSF }{ }^{31}, \text { workshop reports, NIA }{ }^{32}, \\
\text { procedures to report corruption, compliance reports since } \\
\text { 2012, ACC annual reports, asset verification protocols, penal } \\
\text { codes }\end{array}$ \\
\hline MoF & 49 & $\begin{array}{l}\text { Project reports, budget reports, national revenue reports and } \\
\text { manuals, tax system related instructions, e-PEMS user man- } \\
\text { uals, brochures, system requirements specification docu- } \\
\text { ments, financial rules, public finance act, e-PEMS notifica- } \\
\text { tions }\end{array}$ \\
\hline MoIC & 2 & E-government Master Plan and performance agreement \\
\hline RAA & 16 & $\begin{array}{l}\text { Audit reports, strategic plan, handbook on quality assur- } \\
\text { ance, audit manuals }\end{array}$ \\
\hline
\end{tabular}

ACC: Anti-Corruption Commission; MoF: Ministry of Finance; MoIC: Ministry of Information and Communication; RAA: Royal Audit Authority

In addition, 185 news articles were collected from main newspapers and broadcasters in Bhutan as follows: Kuensel (63 items), BBS (2), Bhutan Times (1), Business Bhutan (26), Daily Bhutan (4), The Bhutanese (89).

This present research used unstructured observation to "record in as much detail as possible the behavior of participants with the aim of developing a narrative

\footnotetext{
${ }^{31}$ National Anti-Corruption Strategy Framework

${ }^{32}$ National Integrity Assessment
} 
account of that behavior" with focal sampling (Bryman 2016 p. 270). I observed interactions as a non-participating observer in both case study organisations to obtain evidence of how the systems were actually used and managed. I visited the ACC and MoF in October and November 2019. My observations took place at management meetings, IT team rooms and users' offices in ACC, MoF and various agencies where interviews took place. In total, approximately 40 hours were spent to observe office environments, interactions of the teams with users and how systems were used and integrated in their daily operations. Such observations were helpful to identify factors which did not appear in documents and semi-structured interviews and triangulate data from other sources, and notes on my observations were constructed. During the observation sessions, participants were informed of my role as researcher and observer. For example, I observed that $e$-PEMS users kept a large number of folders in their respective offices, while finance officers and accountants were constantly coming and going from each other's offices to obtain signatures on hard copy papers. The fact that a paper trail was still needed to process e-payment did not appear in e-PEMS documentation, and my observation was helpful to refine semi-structure interview questions and explore the lack of system functions further.

Thirty three semi-structured interviews were conducted with interviewees identified based on their roles and functions in organisations implementing the identified e-governance initiatives and the Ministry of Information and Communication (MoIC), which coordinates and oversees the overall implementation of e-governance initiatives in Bhutan. They included e-governance project managers, ICT team members and functional managers among others (Okuda 2020a). The details of the interviewee profiles are found in Section 3.6.3.

Additionally, I conducted 7 semi-structured interviews with opinion leaders in society, who played an instrumental role in promoting, developing and implementing e-governance initiatives. During the case selection visit in July-August 2019, I introduced the research plans and goals to key focal points and influential individuals in the country. As a result, access to documents, interviewees and case study initiative implementers was obtained, including access to pertinent insights needed to deepen understanding of the current political, social and economic context. Based on this visit, the actual data collection visits were carried out in September 2019 - January 2020 (Okuda 2020a). 


\subsubsection{SEMI-STRUCTURED INTERVIEW AS DATA COLLECTION METHOD}

This section details the design of semi-structured interview method used in my research. The semi-structured interview as a data collection method lends the flexibility to identify new determinants, which the current literature or research might not have identified yet.

Data collection by means of semi-structured interview was guided by the interview protocol developed for this research ${ }^{33}$. The protocol articulated interviewees' rights, questionnaires for interviews and interview guide to ensure the same topic is covered in a similar format (Annex 4). Questionnaires were developed based on the research questions, roles and functions of interviewees, literature reviews, observations, document analysis and the initial visit to Bhutan in July-August 2019. The interview protocol was tested on 21 September 2019 on a Bhutanese ICT professional who was not interviewed for this present research to identify any unclear language and question formulation. The interview protocol was accordingly revised based on feedback and suggestions received during the pilot testing (Okuda 2020a).

The interview questions were sequenced from introductory general questions to questions aligned with research objectives, leading to consolidation questions, as per the interview protocol. Interviews were conducted in the natural environment of offices, except when interviewees requested other venues such as café, or interviews needed to be conducted outside office hours. The interview reports also contain researcher's observations and descriptive notes, open to all perspectives to gain insights. The questions were updated after each interview to focus on emerging and recurrent topics, while ensuring comparability across interviews. Interviews were carried out after obtaining informed consent from the interviewees. I explained the confidentiality requirements, set forth in relevant Dutch research codes of conduct, in addition to the provision that a copy of my research could be provided (Okuda 2020a).

The semi-structured interviews were sequenced to obtain data and information and gradually narrow down the scope of possible determinants in a logical manner. First, semi-structured interviews were conducted among four officials involve in the development and implementation of the E-Governance Master Plan in MoIC and four opinion leaders/experts outside the government to gain deeper insights on political, economic and technological contexts in which the two initiatives were

\footnotetext{
${ }^{33}$ The Ethics Committee approval from the University of Maastricht (UM) was obtained in June 2019. The UM ethics board requirements are available at https://www.maastrichtuniversity.nl/research/integrity-ethics/ethical-review/ethical-review-committee-inner-city-faculties-ercic
} 
implemented. In particular, the latest information on the status of E-government Master Plan implementation, ICT infrastructure, programme, regulations and capacity was helpful to understand and inquire some of the phenomena (Okuda 2020a). They were also the users of the ADS. Furthermore, I gained more nuanced accounts to what I had found in the document analysis, together with the information on corruption perceptions and government's anti-corruption efforts.

Second, semi-structured interviews were conducted among government officials involved in the implementation and use of the two case study initiatives based on their roles and functions (e-governance project manager, functional and ICT team members and users of the systems). I started the semi-structured interviews at ACC and then proceeded to MoF. This sequence was intended to start with a locally owned initiative and identify possible determinants. The preliminary findings then guided the subsequent semi-structured interview questions for the MoF initiative, which is more complex with donor-funded ownership (Okuda 2020a).

In the case of ADS of ACC, primary users were human resource officers (Asset Declaration Administrator, or ADA) and secondary users were Schedule I and Schedule II officers of ministries ${ }^{34}$, autonomous agencies ${ }^{35}$ and constitutional bodies $^{36}$ (Okuda 2020a). Schedule I public servants include leaders of monastic bodies, Prime Minister, Ministers, Justices, Members of National Assembly, heads of agencies and army, among other high-level position holders. Schedule II public servants include those on contract longer than one year and in position level of civil service P5 and above, except teachers. In the case of $e$-PEMS of MoF, the users were over 700 finance officers and accountants of ministries and agencies, called budgetary agencies ${ }^{37}$ who process financial transactions in all ministries and agencies (Okuda 2020a).

The government users for both initiatives were selected from ministries and agencies, based on the criteria of size and complexity of organization (measured by budget size) as well as its statute (autonomous or constitutional body). Size and complexity of user organisations were identified as a possible compliance determinant during my case selection visit to Bhutan in July-August 2019. In addition to ministries, a constitutional body ${ }^{38}$ which also promotes compliance was selected for the likelihood that it has evidence of compliance drivers. Among the 10 ministries of Bhutan, the education sector received the largest share of national budget

\footnotetext{
${ }^{34}$ The list of all 10 ministries can be found at http://www.bhutan.gov.bt/government/ministries.php.

35 They can be found at https://www.nlcs.gov.bt/?page id=103.

${ }^{36}$ Online ADS covers other entities, such as religious organizations, army, police, corporations and civil society organizations, but for the purpose of this research, I included only government agencies relevant to my research questions.

${ }^{37}$ All the government agencies covered by the government budget, except the Army.

${ }^{38}$ All the constitutional bodies can be found at https://www.nlcs.gov.bt/?page id=115.
} 
(16\%), while the sector covered by MoIC received the smallest ${ }^{39}$ (3\%) (Ministry of Finance 2019c, p. 43). However, a sizeable number of officials submit their asset declarations through Dzongkhag (district) administrations and, therefore, the Ministry of Education in the capital may not have a comprehensive picture of asset declaration compliance of all the government employee users under the Ministry. Therefore, the second largest budgetary agency, the Ministry of Agriculture and Forests (MoAF), was selected for the government user interviews. In terms of the constitutional body, the Royal Audit Authority (RAA) is selected for the relevance of the agencies' work to compliance. Therefore, MoAF, MoIC and RAA were selected for the semi-structured interviews intended for end users (Okuda 2020a).

The data saturation was considered to be reached when there was no new information and coding which can be obtained from interviews (Fusch \& Ness 2015; Saunders, Sim, Kingstone, et al 2017). Furthermore, this research adopted the thematic relevance approach in which the number of interviewees expressing their independent opinions is considered more important than the number of times the idea was expressed and coded per interviewee (Guest, Bunce \& Johnson 2006).

\subsubsection{INTERVIEWEE PROFILE}

In total, 32 officials and experts were interviewed for this research, which resulted in 33 interview transcripts. One official was interviewed twice for verification and additional information at the end of fieldwork. Out of the 32 interviewees, 23 were male and 9 were female. As to the occupational category of the interviewees, 13 worked in the ICT sector, 5 engaged in the ADS and as the asset declaration administrators (ADA), 8 were finance officers and accountants, while 6 belonged to other categories representing public corporation, civil society and private sector. In terms of the user categories, 11 were e-PEMS users, while 31 were the ADS users. The asset declaration is also submitted by users outside the government, and therefore the below number includes the total number of ADS users inside and outside the government. Due to the sensitivity of the topic and confidentiality and privacy reasons, Table 10, 11 and 12 present a high-level summary of the interviewee profiles.

\footnotetext{
${ }^{39}$ Energy received 1\%, but both Energy and Mining/Manufacturing (3\%) are covered by the Ministry of Economic Affairs. In combination, the budgetary share of the ministry is larger than that of the Ministry of Information and Communication (MolC).
} 
Table 10: Number of interviewees by sex

\begin{tabular}{|c|c|c|}
\hline Sex & Male & Female \\
\hline Number & 23 & 9 \\
\hline
\end{tabular}

Table 11: Number of interviewees by profession

\begin{tabular}{|l|r|}
\hline Profession & Number \\
\hline ICT & 13 \\
\hline ADA & 5 \\
\hline Finance & 8 \\
\hline Others & 6 \\
\hline
\end{tabular}

Table 12: Number of interviewees by initiative

\begin{tabular}{|r|r|l|}
\hline Initiative & E-PEMS & ADS \\
\hline Number & 11 & 31 \\
\hline
\end{tabular}

In order to maximize internal reliability (to avoid a time lapse and impact of additional development and events during the interval between interviews), all the semi-structured interviews were conducted during the same period of September 2019 to January 2020 to hold constant the factors in the environment, as discussed in Section 3.5. Any discrepancy or divergent views within the case study initiative were addressed as much as possible within the same time frame, before moving on to the next unit data collection. I completed all the data collection for the ADS at ACC on 30 October 2019, and then started collecting data for the $e$-PEMS on 5 November 2019. The data collection for the $e$-PEMS built on what emerged from the previous data collection for the ADS, taking into account agency specific conditions and circumstances.

The first unit analysis on the ADS helped produce preliminary findings, which were subsequently validated or expanded in the second unit analysis on the $e$ PEMS. While the collected data on the ADS was used to refine and narrow the interview questions on e-PEMS, the data collection was conducted separately. By using the same/similar set of questions across the units, common and differing factors were identified. 
All interviews, except 2, were conducted in their offices or nearby offices in the same building. The two interviews took place outside their offices, due to the convenience (at a hotel business center) and the fact that an interview needed to be organized over the weekend (in a cafe). Two interviews took place in their offices over Skype, due to the fact that the interviewees were not available at the time I conducted the field research. The interviews were sometimes interrupted due to urgent matters which required interviewee's immediate attention, but otherwise, the interviews took place in a safe, secure and natural environment. In order to reduce social pressure to answer the interview questions, I asked interviewees to feel free not to answer any questions they didn't feel comfortable and correct my understandings if they didn't represent their views. Most of the semi-structured interviews exceeded the allocated time.

Detailed notes were prepared for interviews. The note was used to distill learning after each interview and to adjust questions in the following interview so as to systematically narrow down to key factors. Enough materials were considered to be collected when no new item came up and there was an agreement on the situations.

All the interviewees agreed on the recording of the interviews. All interviews were conducted in English. Due to the confidential nature of the interviews, the transcription was conducted using the machine-led transcription of NVIVO from October 2019 to August 2020. I checked each transcript and the audio recording against the set criteria of transcription process for this interview, as listed in the transcription guide (Annex 5).

\subsection{DATA ANALYSIS}

This section provides steps and approaches to be taken for data analysis and interpretation, including the use of multiple triangulations to verify findings (Denzin \& Lincoln 2012). Triangulation refers to "using more than one method or source of data in the study of social phenomena" (Bryman 2016, p.386). Yin (2013) notes that data triangulation will increase the concept validity with the use of different data sources to evidence the same phenomenon. The results of semi-structured interviews in my research were triangulated by information and data obtained from document analysis and observations (Okuda 2020a). By comparing the results, common and differing elements across case study initiatives emerged as discussed in Chapter 6.

The interview results were coded to identify emerging patterns of compliance determinants. Coding is considered as "a transitional process between data collection 
and a more extensive data analysis" (Saldana 2015, p. 5) and is a cyclical act. The first cycle coding process involves coding a single word to an entire paragraph, followed by the second cycle coding process for generating categories, themes and concepts. Coding helps identify different patterns, such as similarity, difference, frequency, sequence and causation, while taking into consideration the complexity of social reality (Saldana 2015, p.7), which was applied to the inductive coding in this present research (Okuda 2020a). I developed the Code Book to capture the definition and parameters of each code, as attached in Annex 6. All the codes were developed in vivo.

The documents, such as laws, policies, newspaper articles and evaluation reports, as well as interview transcripts were included in the coding. The first round of coding helped to develop an initial set of compliance drivers and define the parameters, attributes and forms which describe the compliance drivers. In contrast to the term, compliance determinant, used in the two rounds of literature reviews in Chapter 2, the concept of compliance driver is used for operationalization in the investigation of the phenomena in the case study initiatives. In this present research, a compliance driver is defined as a group of inter-linked factors and attributes which are evidenced to have direct impact on compliance of government employee users in using e-governance systems.

Some interviewees repeated one driver several times for emphasis in the interviews, while several interviewees mentioned same driver only once. Both accounts were included and used if corroborated by other data sources, including document analysis and observations. The importance was placed on the accounts which were corroborated by interviewees' accounts from other organizations and functions and from experts outside the government, such as private sector and media, supported by document analysis. This phase of coding established and fine-tuned the categories of compliance drivers and the coherence of accounts and attributes across different data sources within a compliance driver for each case study initiative independently.

Due to the sensitivity of the topic, not many interviewees may have felt confident to speak up during the interviews. Therefore, in this present research, a compliance driver was developed using triangulation of data from multiple sources. Even if only one interviewee mentioned a factor several times as an important factor, it was taken into account as far as it was triangulated with analyzed documents and observations. When two interviewees mentioned them and they were triangulated with other data sources, they were taken in. Additionally, factors, attributes and conditions were taken into consideration when more than three interviewees mentioned the same without any conflict. 
In the second round of coding, partial pattern matching (Sinkovics 2018; Almutairi, Gardner \& McCarthy 2014) was used to identify emerging commonalities and divergence across the two cases. Cross-case synthesis was developed based on the thick description emanating from each case study initiative, which provided sufficient details to determine similarities, dissimilarities and transferability to the other context and setting (Guba \& Lincoln 1994; Miles, Huberman \& Saldana 2018; Okuda 2020a).

In analysing data, stakeholder analysis and process tracing methods were applied to establish more nuanced perspectives of various actors and understand institutional dynamics. Hermans and Thissen (2009) analysed 18 actor analysis methods. Out of the 18 methods, stakeholder analysis was found suitable for this present research, as it is applied to analyse "stakeholder environments to assess cooperative potential and threat of obstruction" with the assumption that stakeholders exist with influence on and interest in the success of the initiatives. (p. 811) (Okuda 2020a) In this present research, accounts of different functional groups, such as ICT, finance, and HR officials, were carefully analysed, taking into account their organizational contexts and functional interests in the success of the cases study initiatives. Taking into account possible resistance to compliance and relationships between the government employee users and the case initiative management teams, the method was also useful to disaggregate and analyze challenges which emerged in the document analysis, semi-structured interviews and observations. For instance, the lack of consultation in the design phase was mentioned by several $e$ PEMS users and therefore was added as a challenge in Section 5.5.3. In building the narratives, stakeholder analysis and institutional dynamics were taken into account, so as to provide a more nuanced account of the phenomena at hand. Interview accounts of experts as external stakeholders were also applied to validate the accounts of government employee users of the selected case study initiatives.

Bennett and Checkel (2014) underlined the use of process tracing method as a means to provide explanations in some cases and cast doubts in others. This method was instrumental in connecting the compliance levels to compliance drivers in the two case studies. For example, several interviewees mentioned that organizational setup, more specifically the appointment of additional ADA, was an effective compliance driver. I could trace the intervention and an increase in compliance level in the organization where the intervention was introduced, using document analysis (Okuda 2020a). 
"Gasa NC (National Council) member Sangay Khandu said that fighting corruption should not occur only when complaints are lodged but must begin systematically. "ACC's access to information on transaction of assets indiscriminate of private and public servants is a must to fight and curtail corruption," " (Kuensel 2016a)

One of the e-governance systems identified in my research is the Asset Declaration System (ADS) of the Anti-Corruption Commission (ACC) of Bhutan. In this chapter, I discuss the background in which the ADS is situated in Section 4.1. The background information includes a brief introduction of the ACC, type of corruption reported in various ACC reports, legal frameworks, asset declaration (AD) objectives, type of declarants, asset declaration management functions, processes and timelines. Section 4.2 then explains the ADS as ICT system innovation and how it was designed and deployed to address the challenges. The level of ADS compliance is discussed in Section 4.3, followed by the identified compliance drivers in Section 4.4. The semi-structured interviews, observation and document analysis also revealed challenges associated with the ADS as a system as well as compliance among government employee users, detailed in Section 4.5. The chapter concludes with a summary in Section 4.6.

In this present research, a compliance driver is defined as a category and group of inter-linked factors, attributes and conditions which are evidenced to have direct impact on compliance of government employee users in using e-governance systems. Each compliance driver is explained with data from semi-structured interviews, document analysis and observations. The quotes which best describes the factors, attributes and conditions of a compliance driver was added to the narrative as the evidence ${ }^{40}$. The data derived from document analysis, including the newspaper articles of Kuensel and Business Bhutan, was used for the purpose of triangulation.

While the preliminary results of the semi-structured interviews on the ADS informed some of the questions used later during the examination of the electronic

\footnotetext{
40 Some quotes contained grammatical errors, repetitions and unclear terms. Such errors, repetitions and unclear terms were corrected in this Chapter to enhance the readability.
} 
Public Expenditure Management System (e-PEMS), the data collection and analysis on each initiative was conducted separately and independently.

\subsection{BACKGROUND OF THE ASSET DECLARATION SYSTEM}

This section describes the background in which the ADS was developed and implemented. The ADS was developed internally by the ACC. The Commission was established in 2006 under a Royal decree as an independent authority, reporting to the National Assembly. With a total of 106 staff, the ACC is mandated to carry out three core functions of educating the public, preventing and investigating cases of corruption. The ACC developed the National Integrity and Anti-Corruption Strategies (NIACS) 2014-2018 and 2019-2023, which aligns the Commission's work with the country's Five-Year Plans (Anti-Corruption Commission 2018; Okuda 2020a).

As narrated in Okuda (2020a), fight against corruption has been a major development agenda and a Key Performance Indicator in the Government Performance Management System (Anti-Corruption Commission 2016). The latter was introduced by the Cabinet and has been managed under the Prime Minister's Office to monitor the performance of ministries and agencies against agreed milestones and deliverables ${ }^{41}$. The reduction of corruption was also a National Key Result Area in the $12^{\text {th }}$ Five-Year Plan (Anti-Corruption Commission 2018) and ICT is seen as key to increasing transparency, efficiency and effectiveness of service delivery on the e-governance platform in the National Integrity and Anti-Corruption Strategy 2019-2023 (Anti-Corruption Commission 2019).

Despite these efforts by the government and high-ranking in the Transparency International's Corruption Perception Survey (25 th in 2019), there have been allegations of fraud, embezzlement, mismanagement and abuse of authority. According to ACC's 2018 Annual Report, 141 complaints were submitted to the ACC e-mail account, 109 complaints were submitted by post and 73 by walk-in. Abuse of functions is the most often reported cases $(54.7 \%)$, followed by alleged embezzlement (6.9\%) and other alleged offenses. Complaints against ministries increased from 52 in 2017 to 84 in 2018, out of which most complaints were lodged against the Ministry of Education (28) and Ministry of Agriculture and Forests (23) during the reporting year (Anti-Corruption Commission 2018). According to an evaluation conducted in 2013 by the Basel Institute on Governance (BIG) and the Royal Institute of Management (RIM) of Bhutan, while the public perception on cash-based petty

\footnotetext{
${ }^{41}$ The site is found at http://www.gpms.gov.bt/
} 
corruption improved, more sophisticated forms of corruption were emerging, which was difficult to prove (Anti-Corruption Commission 2013), as narrated in Okuda (2020a).

One form of corruption, which characterizes Bhutan's corruption landscape, is policy corruption, developed from land-transaction-based corruption cases. Policy corruption is defined as "the misuse of privileged information or the misuse of office and power by a public official for private gain" (Anti-Corruption Commission 2013 , p. 12). The privileged information is then used to influence policy and decision making, which is intended to benefit the involved public officials (Okuda 2020a).

One of the notorious land grab cases was reported by the newspaper, Business Bhutan (2019a). A former Finance Minister was alleged to have converted 10 decimal government land into private property. The anonymous source brought the case to the ACC in 2017, which triggered an investigation. In 2019, the ACC forward the case to the Office of Attorney-General (OAG), after the ACC interviewed the village representatives, examined land records and verified that the conversion appeared not within the government rules and regulations. There have been similar cases involving influential figures, such as Dzongda (district administrator), and transfer of land ownership (The Bhutanese 2016)

Another form of corruption prevalent in Bhutan was identified as nepotism and favoritism, often found in recruitment, promotion, training and any other human resource related matters. It is also linked to conflict of interest in the context of Bhutan, which would require enhanced control and enforcement of standards (Okuda 2020a). An ACC 2013 report underlined the importance of encouraging whistle-blowers to come forward, ensuring checks and balance and establishing quality assurance and control in detecting fraud and corruption (Anti-Corruption Commission 2013).

The prevalent favoritism and nepotism in organizations was corroborated in the semi-structured interviews. The interviewees shared their concerns over what they experience and witness in their daily lives. In particular, Bhutan being a small country and people knowing each other seem to create a futile ground for nepotism and favoritism. Some even felt that such cases were increasing.

"Our population is hardly around 800,000, so we knew one another well. The favoritism and nepotism have been the concerning issue, which has been increasing in Bhutan." (R3) 
This view was corroborated in the National Corruption Barometer Report 2020 conducted by Bhutan Transparency Initiative. Increasing corruption was perceived as a growing concern and the most prevalent forms of corruption in Bhutan was identified as trading influence, conflict of interest, abuse of function, bribery and embezzlement. (Bhutan Transparency Initiative 2020)

Such cases of nepotism and favoritism are often found in the construction sector, procurement and HR decisions. As Bhutan is one of the least developed countries, the Bhutanese people do not have many opportunities to travel abroad. Therefore, an opportunity to attend training abroad or obtain a scholarship to study at a foreign university is much sought after among government employees. The screening and selection of government employee applicants for training abroad and scholarships is conducted by various human resources units. Due to the competitiveness, government employees often perceive the influence of nepotism and favoritism. The other sectors associated with nepotism and favoritism were procurement and construction where a large amount of financial transactions are involved.

The competitive process for training and scholarship contributes to the fear captured in Section 4.4.11 "Fear for Punishment". Invariably, the interviewed government employee users expressed their fear for non-compliance and being implicated in an audit case which results in losing the opportunity for training and scholarship.

As discussed in Section 1.3, systemic corruption constrains the government ability to enforce its own rules and regulations, which would then cascade into significant impact on overall control of corruption of a country. To reduce the systemic corruption, the ACC believes that the government needs to strengthen internal control, which consists of systems, policies, procedures and practices. Internal controls are seen as the foundation for adherence to policies, laws, rules and regulations (AntiCorruption Commission 2016). This recommendation is in line with the findings of the National Integrity Assessment 2016 which was conducted by ACC and the National Statistics Bureau of Bhutan with funding from the Swiss Agency for Development and Cooperation (SDC). The 2016 assessment report noted that available measures for corruption control in Bhutan, such as whistle-blower protection, internal checks and balance and internal audit system, were found ineffective. The report concluded that additional measures, such as e-services and guidelines to manage conflict of interest in the public sector, are needed (Anti-Corruption Commission $2017 \mathrm{~d}$ ). The nature of systemic corruption in Bhutan, findings and recommendations from various assessment reports formed the background to the current configuration and functionalities of the ADS. 
The ADS has been in place since the establishment of ACC in 2006 and was developed to implement AD Rules 2008 and 2012 as the legal framework (Anti-Corruption Commission 2015a and 2016). These Rules were further updated to form AD Rules 2017 which was derived from Section 38 (8) and Section 171 of the Anti-Corruption Act of Bhutan (ACAB) 2011. Section 38 of the ACAB 2011 specifically stipulates that civil servants or individuals who consume public funds "shall prepare, declare accurately and truly and file their personal assets, income and liabilities, as well as, those of their spouses and/or dependents" (Anti-Corruption Commission 2017b, p. 1), as detailed in Okuda (2020a).

According to the AD Rules 2017, the ADS is recognized as one of the anti-corruption instruments to

- detect and deter illicit enrichment;

- ensure public trust through accountability;

- manage conflict of interest by monitoring outside positions, post-employment arrangements and assets and income of family members, among other purposes (Okuda 20201).

The ADS is not intended to be a tool to detect fraud or investigate cases, but rather to enhance transparency and accountability and prevent corruption among the government employee declarants. The positive views towards the ADS were expressed during the interviews, highlighting how the system can help enhance transparency and accountability and prevent corruption, while safeguarding the individuals from unwarranted allegations and consequences.

The ADS is managed by ACC's Prevention and Education Department where the Asset Declaration and Management Division is housed (Anti-Corruption Commission 2019a). The asset declaration function was recently upgraded to a full-fledged division with additional resources which had been approved by the Royal Civil Service Commission (RCSC) - a clear indication of government's commitment to the asset declaration system (Source: own observations and interviews).

Furthermore, Article 9 of the AD Rules 2017 stipulates that concerned government officials register with the ADS, through which he or she can file his or her declaration as per the Rules. The frequency of the filing is mandated as, 1) within three months for those who newly join the office, 2) within one month before leaving the government service and within one month after leaving the service for those who make planned or unforeseen exits and, 3) from 1 February to 31 March annually for government officials, who fall in the category of "covered persons". If a covered person fails to submit the annual declaration within the specified time, he or she 
will be allowed to submit from 1 May to 31 May with fines for late declaration. If a covered person fails to submit by 31 May, he or she will be considered a non-declarant with stipulated fines imposed (Anti-Corruption Commission 2017a), as described in Okuda (2020a).

There are two categories of "covered persons" for asset declaration, Schedule I and II. Schedule I public servants ${ }^{42}$. Public servants in certain sectors ${ }^{43}$ are required to submit the declaration, irrespective of their levels. The intention is to target sectors, which could provide a potential opportunity for illicit enrichment (Anti-Corruption Commission 2017a).

Schedule I public servants submit the declaration to the ACC, while Schedule II declarants do so to the Asset Declaration Administrator (ADA) of the respective agency he or she belongs to. The Central Asset Declaration Administrator (CADA) monitors the overall administration of AD at the ACC. ADA is the agency focal point in all asset declaration matters and provides support, such as new user registration, regular updates on declarants, receiving and maintaining the submissions. In case the submission to the ADS is not possible, ADA distributes hard copy forms to declarants and enters the information on the hard copy into the ADS. In case fines are imposed, ADA ensures that the decision is properly implemented. ADA supports the head of agency in his or her reporting and implements decisions and actions (Anti-Corruption Commission 2017a), as highlighted in Okuda (2020a)

The CADA is responsible for updating and maintaining the list and information of Schedule I declarants and ensuring that new declarants are registered with the ADS. The responsibilities are similar to ADA, but as the central coordinator of the entire process, he or she also submits the asset declaration report for Schedule I and II to ACC within a set timeframe. CADA is also responsible for identifying and verifying Disproportionate Asset (DA) cases and coordinates meetings of the DA Committee established under the ACC. In case fines are imposed, CADA ensures they are collected and deposited into the Government Revenue Account (Anti-Corruption Commission 2017a), as summarised in Okuda (2020a). In an interview, it was clarified that there are 205 ADAs across ministries, agencies, Dzongkhags, corporations and CSOs where covered persons belong to.

\footnotetext{
42 More details on the definition of Schedule I and II is available in Section 3.6.2.

${ }^{43}$ Administration, agriculture, architecture, engineering, land services, finance, audit, foreign services, forestry, environmental protection, human resource, legal, judiciary, legislative services, media and health services, trade, industry and tourism, transport and aviation services, among others.
} 
The head of agency is responsible for assigning ADA, ensuring that declarations are kept in a secure location and examining asset declaration submissions for possible conflict of interest. The head of agency is also required to integrate disciplinary actions in the agency's code of conduct. In case of breach, he or she imposes penalties in accordance with the Asset Declaration Rules. He or she submits the asset declaration report and the Action Taken Report (ATR) to ACC within a preset timeframe (Anti-Corruption Commission 2017a), as one of the responsibilities of the head of agency in asset declaration (Okuda 2020a).

An asset declaration report contains a list of declarants, late declarants, non-declarants and DA cases with a master list of declarants. The ACC then takes decisions on late declarants, non-declarants and DA cases, which the CADA are to implement. CADA also presents DA cases to the DA Committee during the first week of October and for the ACC's final decisions within the third week of October. CADA then prepares the final asset declaration report by 30 November to conclude a round of the asset declaration. The public can request for information on certain declarant in writing, which is duly reviewed by the ACC according to the Asset Declaration Rules (Anti-Commission Commission 2017a) as part of the asset declaration cycle (Okuda 2020a).

The penalty for late submission is a fine equivalent to daily national minimum wage for the duration between the submission deadline and the date of submission. A non-declarant is asked to pay one-year national minimum wage. In case a government official fails to comply with the imposed penalty, it is considered an obstruction of justice. If ADA, CADA or the head of the agency fails to fulfil his or her duties, a fine of one month's national minimum wage is imposed, and for repeated failures, additional disciplinary actions are taken (Anti-Corruption Commission 2017a), as mentioned in Okuda (2020a).

As described above, CADA and ADAs in agencies and ministries play an essential role and provide an interface between the system requirements and declarants. They need to review the declarations for their correctness, while sending followup and reminder e-mail messages and providing hands-on support when the declarants submit their declarations in the system. The work does not end at the time of submission. A proactive ADA conducts an induction programme which includes an explanation on the asset declaration requirements to newcomers. Additionally, they have to be an interface between the agency and ACC in case a penalty is imposed, as corroborated by interviews with ADAs. 
Some ADAs were found proactive and keep reminding the declarants of the deadlines until the last day of submission, while others were not. Because of the ineffectiveness of some ADAs, some declarants missed the submission deadline and complained that they did not get an adequate level of information, although the declarants should know the submission deadline which never changes every year.

During the declaration period, the role of ADAs is tested. If an ADA gets to know that a declarant bought a car but did not declare it, what would be the response of ADA? Should he or she ask the declarant to declare the car? What would happen if the declarant is later found guilty of concealing his or her asset? Would the ADA be found guilty too? It was clarified in one interview that the responsibility falls on the declarant and not on the ADA.

The roles of ADA and CADA were evolved in the current form because of the realization on the part of ACC that the asset declaration as a prevention tool would not be effective without the support and good will of the declarants. The Anti-Corruption Act and other legal instruments are not sufficient to garner the cooperation of the declarants, let alone the system.

"In prevention (department), we cannot throw the Anti-Corruption Act in your face. I have to get the good will and build the rapport". (B1)

\subsection{THE ADS AS ICT SYSTEM INNOVATION}

This section explains the ADS as a system innovation and how it functions in the context described in Section 4.1 and supports the achievement of policy goals described in the Anti-Corruption Act 2017 with the built-in technology.

In order to understand the original design and system development, I searched for documented records but they were not available at the time of my fieldwork in the fall of 2019 and the spring of 2020. The interviewees clarified that it was estimated to have been developed around 2007-2008. After the Asset Declaration Rule 2012 was adopted, the system was then revamped on the .Net programming language and the system design document was accordingly developed by a private sector company, although the document lacks the information on when exactly the document was developed (Anti-Corruption Commission N/A). The system design document has been used as a basis for continuous development until now. The ADS was funded by the government and was developed and is maintained by the ICT 
Unit of ACC and the business owner is the newly created Asset Declaration and Management Division of ACC. ${ }^{44}$

Since the revamping of the system after 2012, ACC continuously enhanced the system based on user feedback and received comments. ACC has conducted periodic training for ADAs and users. ACC also plans to share information through system interfaces with oversight institutions, tax authorities and property registration authorities (Anti-Corruption Commission 2016). The system is accessible from the ACC ADS site at http://adsnew.acc.org.bt:88/adsnew/UI/default.aspx (Okuda 2020a).

The system usage starts with user registration. A new user is asked to create an account. Figure 5 illustrates the homepage of the ADS.

Figure 5: ADS entry page

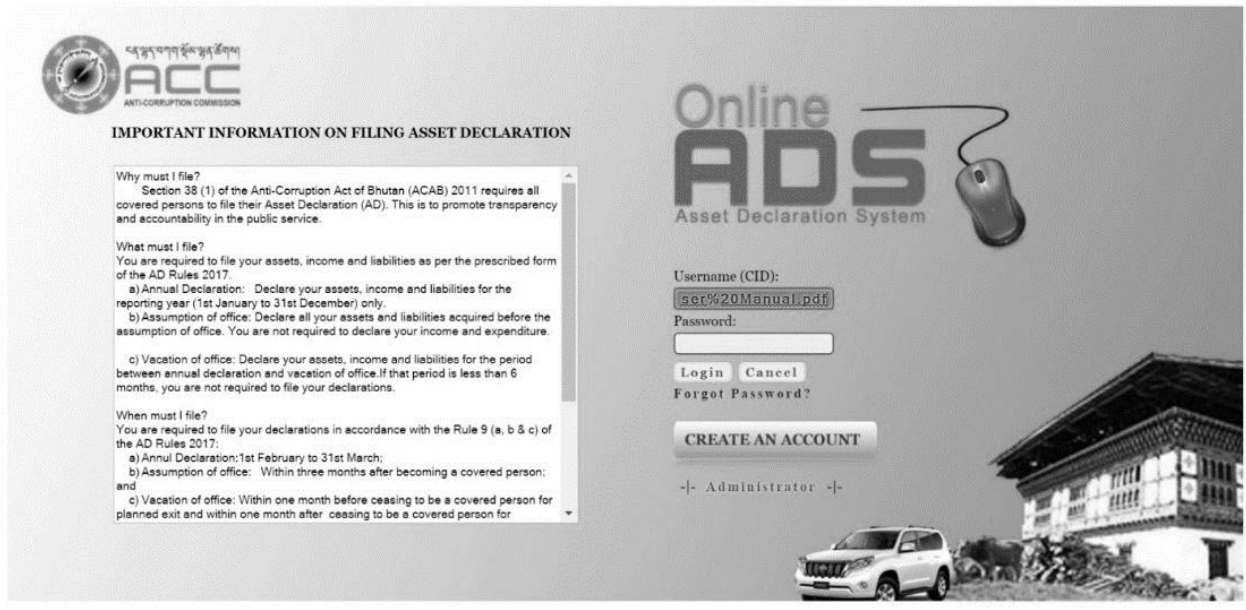

Source: http://adsnew.acc.org.bt:88/adsnew/UI/default.aspx, accessed on 1 October 2019

The user registration example is found in Figure 6.

\footnotetext{
${ }^{44}$ Please refer to the ACC organogram at https://www.acc.org.bt/sites/default/files/Organogram\%20\%28Aug\%206\%2C\%202019\%29.pdf.
} 
Figure 6: ADS user registration screen

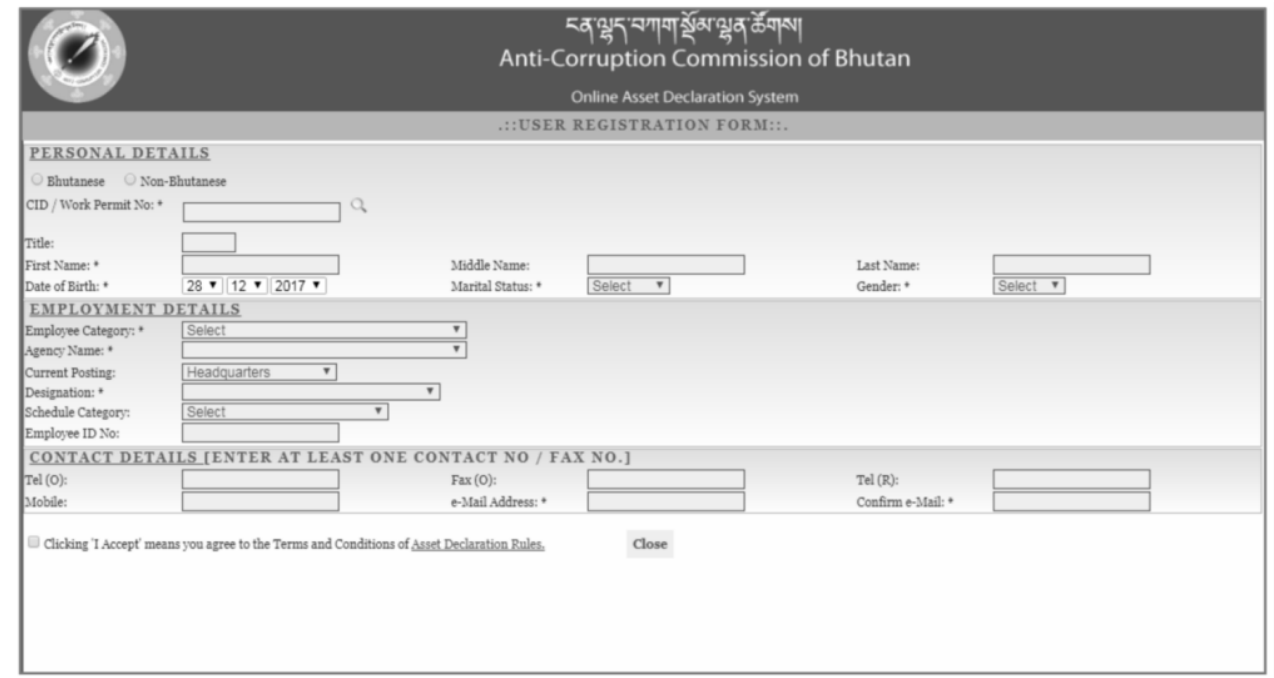

Source: Anti-Corruption Commission User Manual for Asset Declaration (2017b), p. 2 at https://www.acc.org.bt/sites/AD\%20User\%20Manual.pdf, accessed on 1 October 2019

Once the user completes the form, it is submitted to the ADA of the user's agency and the user receives an e-mail notification on successful registration. When the ADA accepts the registration, another e-mail notification is sent with the user name and default password (Okuda 2020a). Figure 7 is a sample of user personal information screen (Anti-Corruption Commission 2017b).

Figure 7: ADS personal information screen

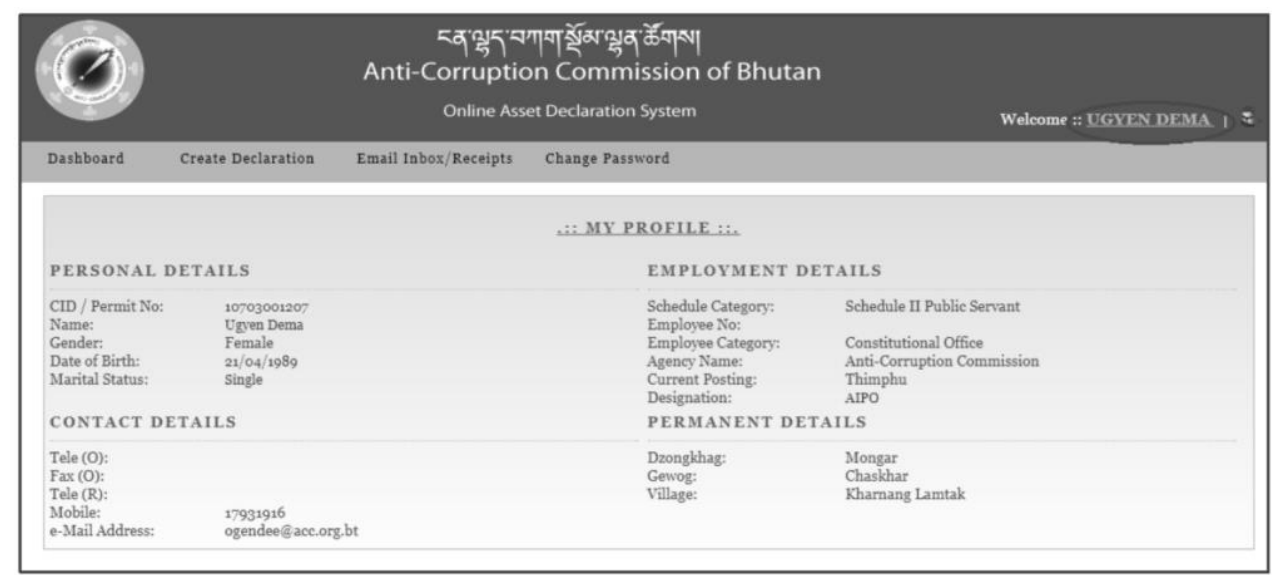


Source: Anti-Corruption Commission User Manual for Asset Declaration (2017b), p. 4 at https://www.acc.org.bt/sites/AD\%20User\%20Manual.pdf, accessed on 1 October 2019

Once a new declaration is created by clicking the menu bar, the screen as shown in Figure 8 appears to select the reason for declaration. A first-time user will select assumption of office, while officials leaving the office will select vacation of office (Okuda 2020a).

Figure 8: ADS reasons for declaration screen

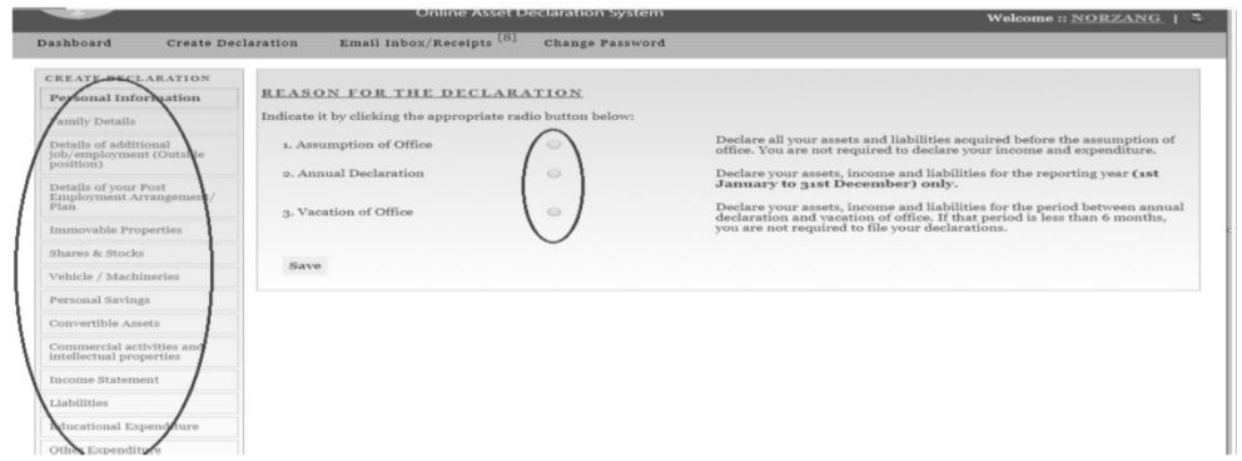

Source: Anti-Corruption Commission User Manual for Asset Declaration (2017b), p. 5 at https://www.acc.org.bt/sites/AD\%20User\%20Manual.pdf, accessed on 1 October 2019

The system then asks a user to add himself or herself and family members under the created declaration as displayed in Figure 9.

Figure 9: ADS personal and family information screen 


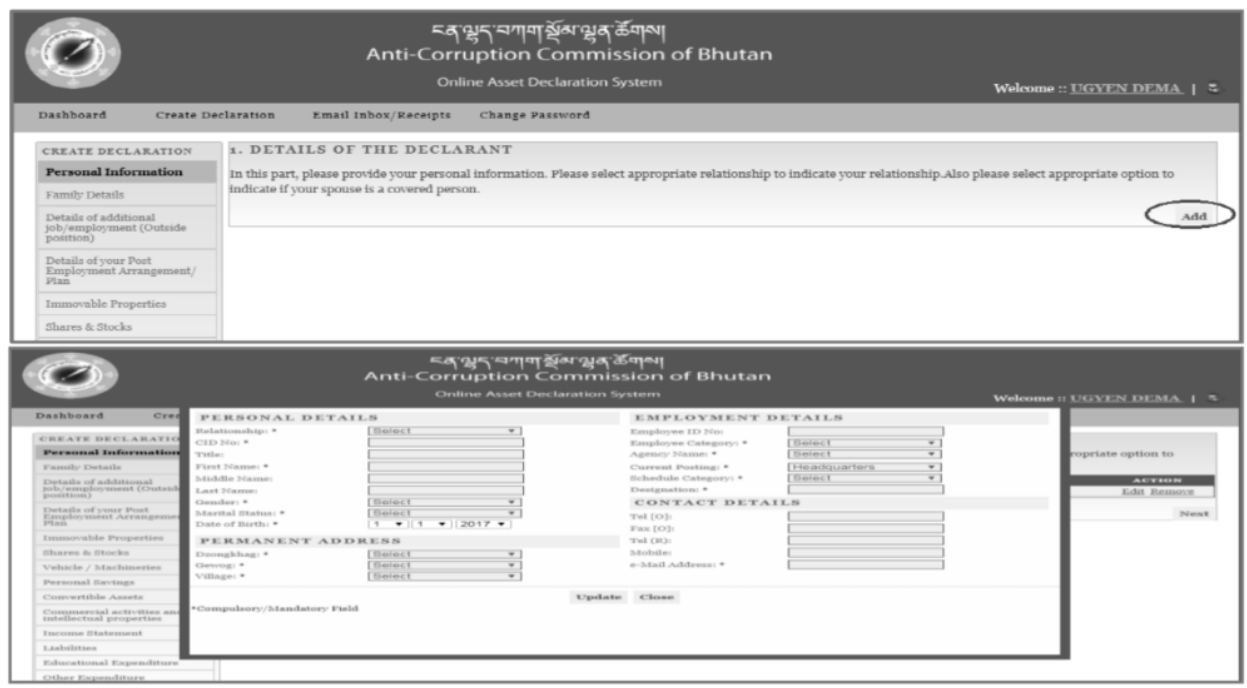

Source: Anti-Corruption Commission User Manual for Asset Declaration (2017b), p. 6 at https://www.acc.org.bt/sites/AD\%20User\%20Manual.pdf, accessed on 1 October 2019

For every individual, employment and income (for outside positions) details will then be asked as displayed in Figure 10.

Figure 10: ADS additional jobs/employment income screen

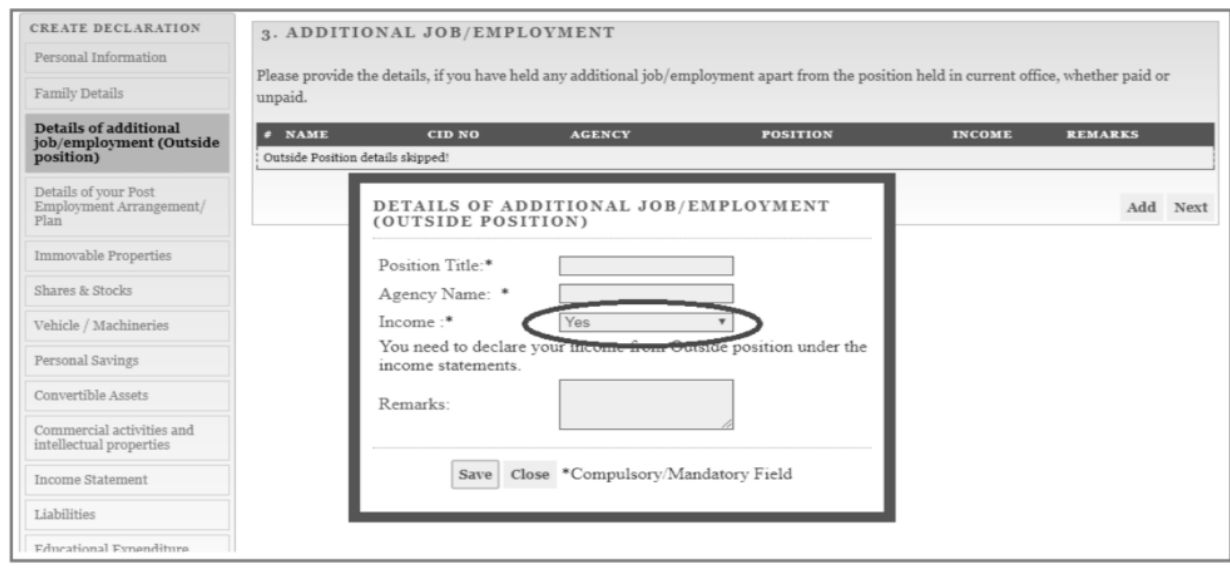

Source: Anti-Corruption Commission User Manual for Asset Declaration (2017b), p. 8 at https://www.acc.org.bt/sites/AD\%20User\%20Manual.pdf, accessed on 1 October 2019 
The system also asks the user to specify any post-employment arrangements and plans, if applicable (see in Figure 11).

Figure 11: ADS post-employment arrangement and plan screen

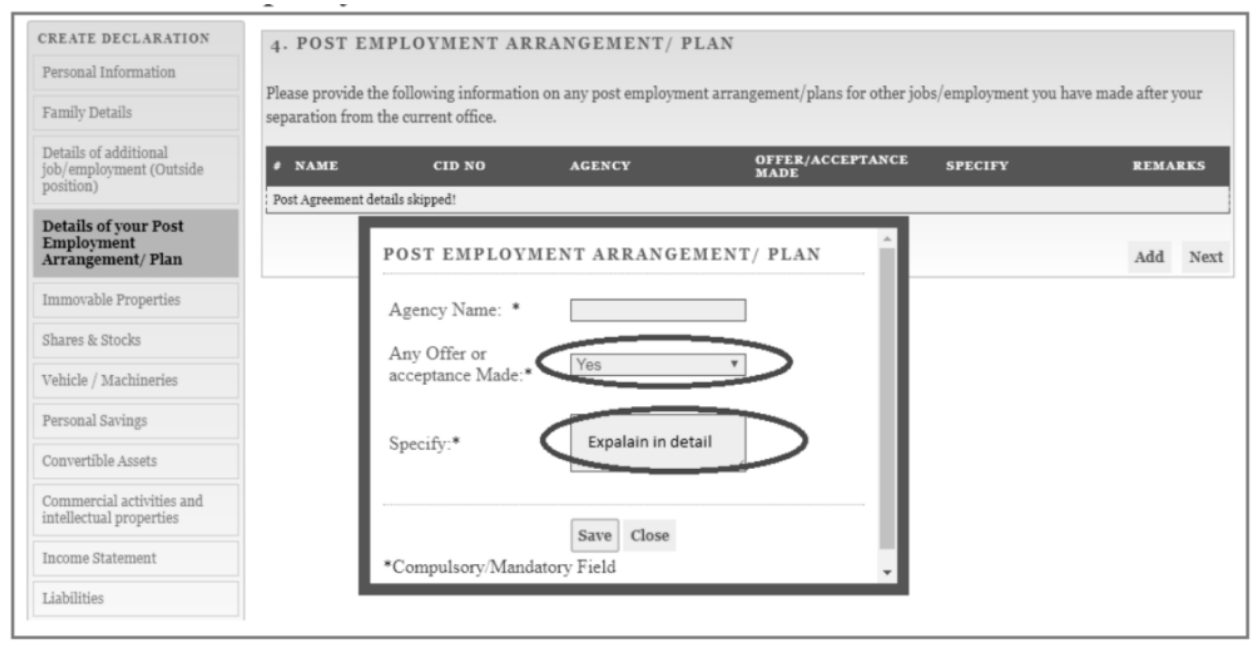

Source: Anti-Corruption Commission User Manual for Asset Declaration (2017b), p. 9 at https://www.acc.org.bt/sites/AD\%20User\%20Manual.pdf, accessed on 1 October 2019

The system requires users to enter details of immovable properties, such as land and building, including transaction status and payment made as in Figure 12. 
Figure 12: ADS immovable property entry screen

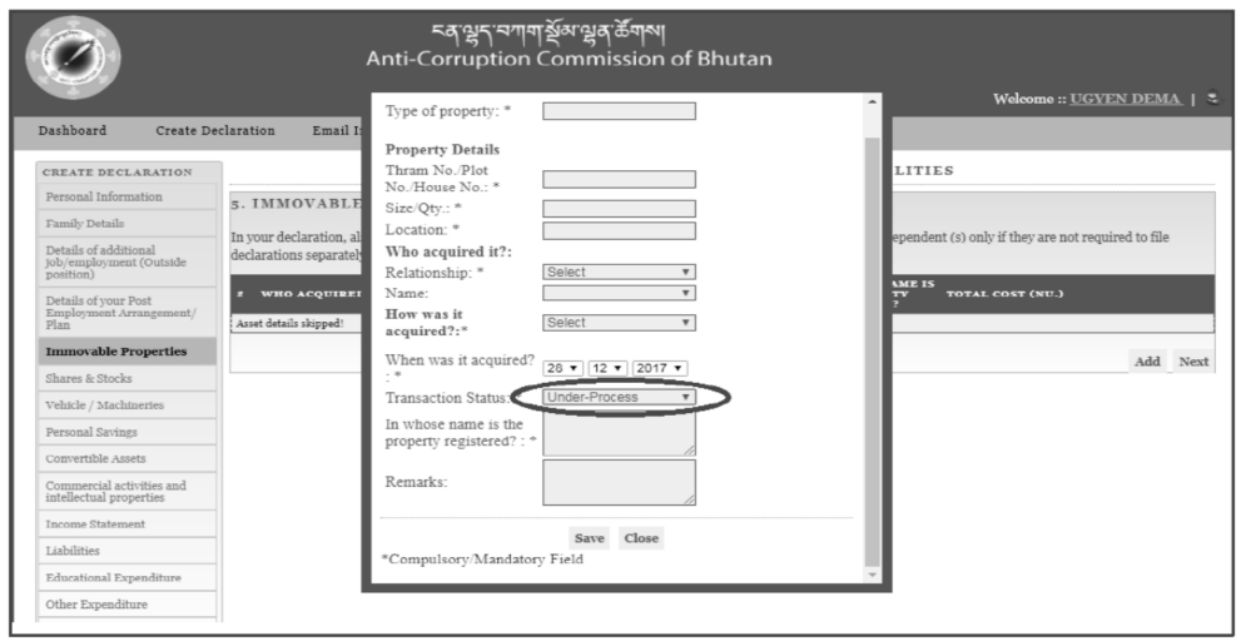

Source: Anti-Corruption Commission User Manual for Asset Declaration (2017b), p. 10 at https://www.acc.org.bt/sites/AD\%20User\%20Manual.pdf, accessed on 1 October 2019

Similar information is requested for ownership of shares and stocks, vehicles/machineries, personal savings, convertible assets, commercial activities and intellectual properties. The system then requires the user to enter income statement, liabilities, educational expenditures and other expenditures (Okuda 2020a). If the declaration is correctly entered, the final submission page in Figure 13 allows the user to submit the declaration.

Figure 13: ADS submission screen

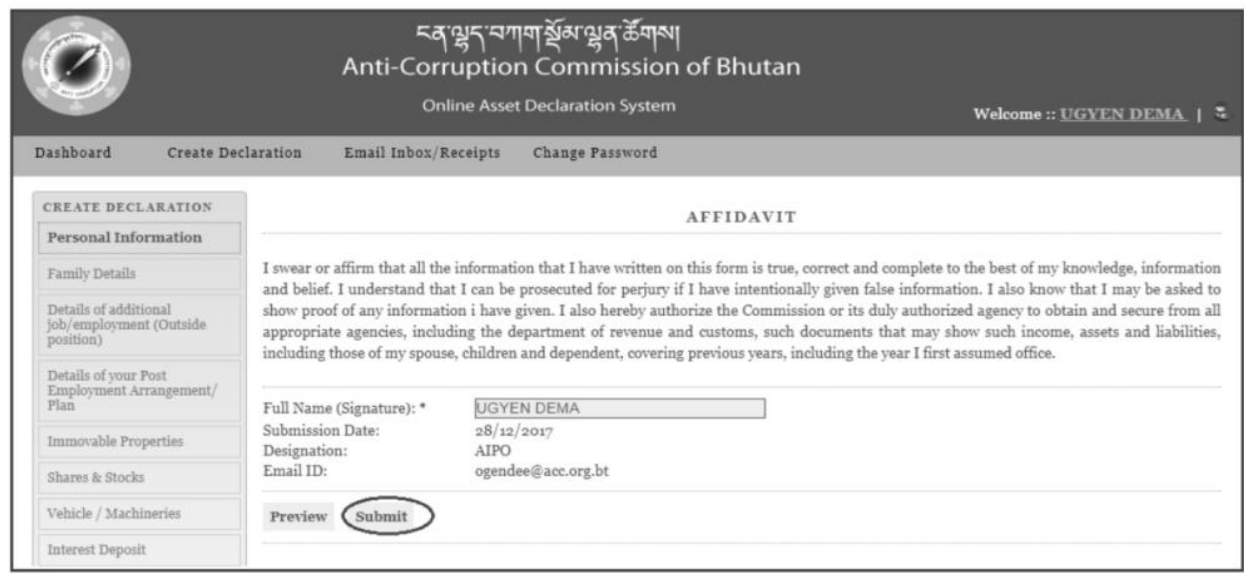


Source: Anti-Corruption Commission User Manual for Asset Declaration (2017b), p. 19 at https://www.acc.org.bt/sites/AD\%20User\%20Manual.pdf, accessed on 1 October 2019

A successful declarant receives an acknowledgement e-mail. In case of an error or correction, the declaration is returned to the declarant, who then updates the information as per the reasons for return specified in the e-mail notification. Common errors observed in submissions include calculation of salary by month instead of year, following old rules and spelling mistakes. These errors are pointed out by ADA and CADA against the user guide which derives from the Asset Declaration Rules 2017 and ACC orders. Once the declaration is accepted and verified, the declarant receives the final confirmation e-mail (Anti-Corruption Commission 2017b; Okuda 2020a).

The ADS is also used to flag potential DA cases by detecting a sudden increase in asset and income. In the 2016 ACC Annual Report, 157 declarations, or 34\% of the total Schedule I declarations, were flagged by the system for suspected disproportionate asset among the Schedule I declarants for the asset declaration cycle of 2015. These cases were later dropped in the verification process in the same year. The sudden increases were explained as import of vehicles (an entitlement for parliamentarians), increase in property values and typology errors. Among Schedule II declarations, 3,169 cases, or $16 \%$ of the total Schedule II declarations, were similarly flagged by the system for the 2015 asset declaration cycle, but only 1,500 could be verified due to shortage of resources. Among the cases, 1,446, or $96.4 \%$, were dropped and 54 cases, or 3.6\%, were identified for Discreet Enquiry (DE) or further action (Anti-Corruption Commission 2016; Okuda 2020a).

The ACC Annual Report 2017 reported on the results of the 2016 asset declaration exercise. The report mentioned that 99 disproportionate asset cases were flagged among the Schedule I declarations in 2016, a decrease from 157 the year before. Out of the 99 cases, 97 were dropped and two were forwarded for further inquiry. Among the Schedule II declarations, 4,596 cases were flagged in 2016. Although not all cases were reviewed due to human resource constraints, the reviewed 3,462 cases were dropped. The 54 DA cases which had been identified for further action in the previous year of 2015 were cleared after finding no issues in the subsequent declarations (Anti-Corruption Commission 2017e).

Although most DA cases seem to be dropped, there was a recent case where the DA function played an instrumental role in a large investigation (Okuda 2020a). A former Labour Minister was found to have concealed his asset, income and 
liabilities in his asset declaration in 2017 and had solicited and accepted investment from a foreign national to set up a partnership business using proxies (Business Bhutan 2019b; Kuensel 2018c). According to the revised Asset Declaration Rules 2017, if a covered person makes a false statement with the intent to conceal his or her asset, income or liabilities, it is considered an offence according to Section 64 of the Anti-Corruption Act of Bhutan (ACAB) (Kuensel 2017b). The Section 64 stipulates that public servants "shall be guilty of an offence if they knowingly make false declarations with a view to conceal their assets, income and liabilities" and the offense is considered as a misdemeanor (Anti-Corruption Commission 2011a, p. 54), punishable according to the Penal Code (Parliament of Bhutan 2011).

In this particular case of former Labour Minister, I asked interviewees how the information in his declarations helped in the investigation and how the access to his declarations was initiated. As described earlier, interviewees confirmed that the ADS was not an investigation tool but rather for prevention of corruption. Another interviewee elaborated that the data and information collected in the declaration, or intelligence, may be used as evidence when there is an investigation or complaint. The information in the declaration then serves as evidence of concealing his or her asset in a larger investigation effort. Although such illicit asset enrichment could be detected as disproportionate asset, there is another way to detect, as demonstrated in this case of former Labour Minister.

The National Council (NC) members of the Parliament also view the ADS as a way to detect policy corruption and fake asset declaration. They recommended strengthening the ADS and developing an integrated IT system, which enables automatic information sharing on properties, liabilities and tax contributions of government officials and employees (Okuda 2020a). A National Assembly (NA) member from the Gasa Dzongkhag (district) was quoted as saying that "ACC's access to information on transaction of assets, indiscriminate of private and public servants, is a must to fight and curtail corruption" (Kuensel 2016a). The ADS integration with existing systems is expected to enhance information and data consistency and ensure checks and balance. For that reason, ACC's work in using advanced technologies for anti-corruption efforts is expected to expand (Anti-Corruption Commission 2019).

Initially, the ADS encountered wide-ranging challenges in verifying submitted information as the storage of declaration documents was not centralised and the declarants' information not updated in time, in addition to territorialism and lack of information sharing policy (Anti-Corruption Commission NA). In 2013, 12 agencies were reported to have failed in the submission, which is considered a breach of responsibility of heads of agencies and ADAs at that time. Since then, a number 
of measures have been implemented, which led to the improved level of compliance (Anti-Corruption Commission 2015a) as reported by Okuda (2020a).

What is unique about the ADS is the well-established and documented change management to the system and responsiveness to the user feedback. Recognizing the need for system improvements, ACC accommodates feedback and suggestions and discusses them at Commission meetings. The decisions, in the form of minutes and meeting records, are the basis for the technical updates in the system. The changes are then channeled to the ICT unit of the ACC for effecting the approved changes, and this workflow and collaboration between the ICT unit and the business owner division were found very smooth.

What also emerged from the interviews was the frequent ACC consultations with users and stakeholders and communication with them. After the Asset Declaration Rule 2012 was revised in 2017 the ADS team initiated a series of consultations with ADAs, heads of agencies and other stakeholders. It was believed that listening to the users would yield insights and good ideas which would then help improve the system for the users. When the ADS team received good feedback and suggestions for improvement, the team reported to the Commission. Upon the approval, the changes were introduced to the system.

The ACC and stakeholders are consulted when major changes, such as system enhancements and amendments to the Asset Declaration Rules, take place. The system has evolved as an outcome of the accumulated feedback and suggestions from the users and stakeholders.

"We do consultative meetings with the stakeholders. We also collect feedbacks from the users, from the AD focal persons. We incorporate all their feedbacks. In fact, the system (has been developed with) all through their feedbacks". (B5)

The implementation of the changes also seems well planned and coordinated by ACC in the form of training, media notifications and other notification means. The training is organized for the purpose of raising awareness and building common understanding between ACC, ADA and users, so that later there won't be any disagreement on what entails the declaration submission. Although desirable, it is not possible to train all 24,000 declarants. Therefore, ACC uses the strategy of training ADAs, so that they can then reach all the declarants in their ministries and train them on new functionalities and features in the system, if any. 
In addition to training, ACC reaches out to media to notify ADAs and users on the annual declaration cycle. For the media notifications, ACC resorts to the only TV channel in the country, Bhutan Broadcasting Service (BBS), as well as other print media.

\subsection{COMPLIANCE IN THE IMPLEMENTATION OF THE ASSET DEC- LARATION SYSTEM}

This section discusses the level of compliance among the government employee users of ADS, based on the data obtained specifically for this present research and compare it with historical data obtained by document analysis. The historical trends narrated in this section seem to verify the effectiveness of incremental measures the ACC introduced to enhance the system and system usage, such as consultations, training, feedback, media notifications, discussed in Section 4.2.

The latest compliance level is high among both Schedule I and II declarants (98.9\% and $98.97 \%$ respectively, based on the 2018 data), but it was not always the case, judging from the document analysis and interviews. According to the 2012 Compliance Report of Asset Declaration, 85.97\% for Schedule I public servants (325 out of 378) submitted their declarations on time, with 27 declarants (8.3\%) submitting after the submission deadline in April. Among Schedule I declarants, 204, or $62.77 \%$, submitted their declarations online, while the rest submitted on hard copies. Prime Minister, ministers, secretaries, head of agencies, heads of army and district governors all complied and submitted their AD by the end of April. Nonetheless, 53 Schedule I officials failed to declare their assets and liability within the deadline (Anti-Corruption Commission 2012) as also reported in Okuda (2020a).

Since 2012, the level of compliance improved steadily. According to the 2015 AD compliance report, the compliance rate among Schedule I officials increased to $92.60 \%$ in 2015 . Out of the 428 Schedule I declarants, $90.58 \%$ submitted their declarations online. Out of the submitted declarations, 15 were returned for incomplete information (Anti-Corruption Commission 2015b). Similar trends continued in 2017. (Anti-Corruption Commission 2017c; Okuda 2020a)

For this study, the latest 2018 figures were extracted by the ACC. The Schedule I compliance for the reporting year 2018 was $98.9 \%$ and for 2017 it was $94.2 \%$. For Schedule II, compliance in 2018 was $98.97 \%$ and an increase form $96.93 \%$ in 2017. In total, there were 23,409 covered persons, or declarants, among Schedule II from 209 organisations in 2018. In 2017, the total number was less, 21,640 from 198 
organisations (Okuda 2020a). As incomplete submissions are returned to the declarants, properly filled and complete submissions are considered as compliance in the case of ADS. Table 13 summarises the disaggregated compliance rates by type of organisation for 2018 and 2017. The names of agencies under each category are found in Annex 7. The ACC does not publish an agency-wide compliance list.

Table 13: Schedule II compliance rates by type of organisation, 2017 and 2018

\begin{tabular}{|c|c|c|c|c|c|c|c|}
\hline & & \multicolumn{3}{|c|}{2018} & \multicolumn{3}{|c|}{2017} \\
\hline SN & $\begin{array}{l}\text { Parent } \\
\text { Agency }\end{array}$ & $\begin{array}{l}\text { No. of } \\
\text { Agen- } \\
\text { cies }\end{array}$ & $\begin{array}{l}\text { Total } \\
\text { Covered } \\
\text { Person }\end{array}$ & $\begin{array}{c}\text { Compli- } \\
\text { ance \% }\end{array}$ & $\begin{array}{l}\text { No. of } \\
\text { Agen- } \\
\text { cies }\end{array}$ & $\begin{array}{l}\text { Total } \\
\text { Cov- } \\
\text { ered } \\
\text { Person }\end{array}$ & $\begin{array}{l}\text { Com- } \\
\text { pli- } \\
\text { ance } \\
\%\end{array}$ \\
\hline 1 & $\begin{array}{l}\text { Armed } \\
\text { Forces }\end{array}$ & 3 & 1248 & 100 & 3 & 1149 & 99.56 \\
\hline 2 & $\begin{array}{l}\text { Autono- } \\
\text { mous agen- } \\
\text { cies }\end{array}$ & 40 & 1800 & 97.67 & 41 & 1634 & 98.71 \\
\hline 3 & $\begin{array}{l}\text { Constitu- } \\
\text { tional bod- } \\
\text { ies }\end{array}$ & 6 & 519 & 99.81 & 6 & 470 & 99.36 \\
\hline 4 & $\begin{array}{l}\text { Corpora- } \\
\text { tions }\end{array}$ & 55 & 4957 & 99.7 & 51 & 4533 & 98.32 \\
\hline 5 & CSOs/NGOs & 35 & 262 & 98.47 & 27 & 207 & 100 \\
\hline 6 & $\begin{array}{l}\text { Dzongkhag } \\
\text { (district) } \\
\text { Administra- } \\
\text { tions }\end{array}$ & 20 & 4351 & 97.47 & 20 & 3944 & 94.5 \\
\hline 7 & $\begin{array}{l}\text { Dzongkhag } \\
\text { (district) } \\
\text { Courts }\end{array}$ & 22 & 276 & 99.28 & 22 & 247 & 99.19 \\
\hline 8 & $\begin{array}{l}\text { Financial In- } \\
\text { stitutions }\end{array}$ & 10 & 2800 & 99.39 & 10 & 2510 & 98.01 \\
\hline
\end{tabular}




\begin{tabular}{|c|l|c|c|c|c|c|c|}
$\mathbf{9}$ & Ministries & 14 & 6775 & 99.11 & 14 & 6561 & 95.67 \\
\hline 10 & $\begin{array}{l}\text { Thromdes } \\
\text { (city corpo- } \\
\text { rations) }\end{array}$ & 4 & 421 & 98.81 & 4 & 385 & 98.18 \\
\hline Total & $\mathbf{2 0 9}$ & $\mathbf{2 3 4 0 9}$ & $\mathbf{9 8 . 9 7}$ & $\mathbf{1 9 8}$ & $\mathbf{2 1 6 4 0}$ & $\mathbf{9 6 . 9 3}$ \\
\hline
\end{tabular}

Source: ACC. The data was extracted from the ADS by ACC in November 2019; Okuda 2020a

When asked about salient features of the ADS compliance, interviewee noted that declarants from religious organizations, or ROs, tend to submit hard copies which requires typing-in, takes time and may introduce errors, when the data is entered. The system is available only in English, not in the national language (Dzongkha), and there are non-English speakers in ROs. When I asked about a systematic language barrier for non-English speaking declarants outside the capital to submit declarations in English, it was clarified that the technical, infrastructure issue would be a main cause of challenge, not the language issue. Non-English speaking declarants would approach respective ADA and submit the declarations.

Despite the improving compliance rate, there have been late and non-declarants who had to pay fines over the years. According to the ACC Annual Report 2017, $\mathrm{Nu}$. 33,250 (\$468) from Schedule I and $\mathrm{Nu} .703,106(\$ 9,888)$ from Schedule II were collected in fines for late and non-declarations in 2016 (Anti-Corruption Commission 2017e). I asked interviewees their opinions on the reasons for late and nondeclarations. According to the interviewees, the reason was not medical condition, or some emergencies, but the carelessness on the part of declarants. One example was explained as a transfer from another region to the capital, but the transfer took place in January, while the declaration started from February to March. Therefore, the transfer was not considered as a valid reason to explain the late submission and waive off the penalty for the late declaration.

It was explained during the interviews that there had been late declarations, but no non-declarants had ever repeated the mistake or offense in the subsequent years. The interviewee speculated that the late declarants work in remote areas with poor Internet connectivity and do not get information on declaration in time. Some ADAs may not be proactive and they themselves may not be informed of the declaration deadlines, as reasons for the late declarations. 
These accounts were supported by an explanation by another interviewee who underlined the lack of seriousness on the part of declarants as the reason for late or non-declaration, despite the numerous attempts by ADAs. The reason for this lack of seriousness was then explained as not being aware of the existence and severity of penalty.

"Lack of seriousness could be because they are not aware on the penalty that is there". (B2)

If the declarant is not a first-time declarant, the submission takes about 20 minutes. That requirement of a limited time investment may be the reason why several interviewees considered lack of seriousness as a reason for non-compliance. Another reason was the return of the submitted declaration for correction. The returned declaration and request for updates may not have been acted on in time by the declarants, because they believed that their declarations had been submitted successfully.

Some late declarants asked for an extension of penalty payment until December, based on the action taken report prepared by the concerned ADA and submitted in September. A non-declarant is handled directly by the ACC and the ADA in the concerned agency will not take actions for non-declarants. A letter is issued by the ACC with a copy to the concerned ADA.

During the interviews, it was also explained that 16-17 cases are forwarded to the Office of the Attorney-General (OAG) every year, when late or non-declarants refuse to pay the penalty or the follow up actions did not yield any concrete outcomes, as per the Asset Declaration Rules. Such cases will first be presented to the Disproportionate Committee at the ACC, and then to the ACC Legal team, after which to the OAG for prosecution.

\subsection{DRIVERS OF COMPLIANCE AMONG ADS USERS}

It is important to understand what drives the 24,000 government employee users to comply with the ADS requirements year after year. This section summarises 13 key compliance drivers found in the document analysis, my observations and semistructured interviews. The order of these compliance drivers is not intended to imply the importance or any other meaning. In this present research, a compliance driver is defined as a category and group of inter-linked factors, attributes and 
conditions which are evidenced to have direct impact on compliance of government employee users in using e-governance systems. The factors, attributes and conditions were identified from interviews, document analysis, such as newspaper articles and reports, and my observations.

In some cases, there were both positive and negative accounts towards the same compliance driver. Positive accounts explained that some factors triggered positive outcomes, while the lack of the same factors led to less compliance. Some accounts were nuanced, reflecting personal experiences and perspectives, which were triangulated with other data sources. The names of compliance drivers were developed using inductive coding. The detailed definition of each compliance driver as well as what it includes and excludes are listed in Codebook in Annex 6.

\subsubsection{CREDIBILITY AND TRUST IN ACC}

An evaluation conducted on the National Anti-Corruption Strategy (NACS) by the Basil Institute of Governance and the Royal Institute of Management of Bhutan noted that " $(t) h e$ ACC and its leadership are highly respected in the Bhutanese society, though also somewhat feared still due to the perceived focus on punishment" (Anti-Corruption Commission 2013, p.5; Basil Institute of Governance 2013). The 2016 National Integrity Assessment report corroborated the findings. Among the respondents, $52 \%$ reported that ACC is doing very well and $41 \%$ fairly well (AntiCorruption Commission 2017d).

During the interviews, some ADS users attributed the level of compliance to trust in the ACC as an organization. The Commission is a constitutional body responsible for anti-corruption, because of which people respect and trust the ACC and comply with whatever rules and policies the ACC comes up with. Such high regard by the people extends to the ADS and confidence bestowed in the system.

Corroborating accounts were found in various documents. The Prime Minister of Bhutan referenced to the critical role the ACC plays in the country's anti-corruption efforts in endorsing the National Integrity and Anti-Corruption Strategy (20192023) as follows:

"Today, as the ACC continues to lead the anti-corruption drive in the country, it is critical for all of us to complement the efforts. Therefore, by way of endorsing this strategy, we commit to abide by its objectives." (AntiCorruption Commission 2019, p. 4) 
The trust the users have in the ACC is translated in the information security. The users believe that the information provided in declarations is safe and secure and will not be misused, which contributed to compliance. Additionally, the ACC is an oversight agency with a leverage to enforce other agencies to comply. Such leverage includes naming and shaming, as elaborated in Section 4.4.10.

"As an oversight agency, they have, to some degree, leverage over enforcing agencies to adopt certain things, right. And they also have the ability to do naming and shaming". (A1)

The credibility and trust in ACC have influenced other compliance drivers, such as fear for punishment, which was expressed vividly by several interviewees, confirmed by my observations during the fieldwork. Fear for punishment as a compliance driver is detailed in below Section 4.4.13.

\subsubsection{ORGANIZATIONAL SETUP}

Some ministries decided to go beyond what was required by the ACC and make their own organizational arrangements to encourage compliance by employee users. These measures included appointing additional ADAs, organizing annual conferences and allocating resources, which have been implemented by some ministries, such as the Ministry of Agriculture and Forests. Some agencies and ministries have a large number of declarants who are spread out into remote and rural areas. It made sense to the interviewees that these large ministries and agencies appointed additional ADAs. It was believed that such measures had direct and indirect impact on compliance among the government employee users.

In one ministry, over 90 additional asset declaration focal points were appointed. These additional focal points were helpful to manage declarations in central and regional offices. Furthermore, this ministry in question organized annual conferences and conducted training on asset declaration as ministry's own initiative. It may not be a coincidence that this ministry in question recorded one of the highest compliance rates, despite the size and geographical spread.

One ministry requested for training from the ACC, which demonstrated its proactiveness. That ministry in question previously had a poor compliance rate. After 
the training was conducted for ADAs, the compliance rate jumped to $100 \%$ the following year.

"Because prior to that, they had a very low compliance. Then they requested us to give training. So we conducted a series of training for the ADAs. The next year, they had the hundred percent compliance". (B4)

One interviewee shared a negative example where lack of such organizational setup was perceived as leading to poor compliance. The Dzongkhag (district) administrations were seen by some interviewees as having lower compliance rates than others, and the reason was explained that there were only one or two ADAs who were busy human resource (HR) officers and covered a large number of declarants, including at the lower gewog, or block, level.

There were other similar accounts without any conflicts. The above-mentioned accounts provided interviewees' view on causal pathways between the organizational setup and level of compliance, across different government entities and functions. Where the organizational setup was instituted, the compliance rate increased, while where it was perceived lacking, the compliance rate was considered low.

\subsubsection{PEER SUPPORT}

In addition to the organizational setup, peer support emerged as an important factor among the ADAs in fulfilling their function. A ministry established ADA's WeChat group to share updates and information on the ADS, which was reported as effective for ADAs to facilitate declaration submissions among the end users in the ministry. If one ADA had a question on the asset declaration, he or she can quickly ask it and receive an answer from peers in the WeChat group. If no one knew, the group would contact the ACC for clarification. The group was also useful in reminding members of the rules and regulations associated with the asset declaration, how to go about it as ADAs and what to do to prepare for the declaration cycle the following year.

"We already have a WeChat group, including all the ADAs of the Ministry. If they have any confusion regarding asset declaration, they can ask in the group. Anybody who knows the answer can answer. If not, we can facilitate. We have even conducted the ADA program. We have made ( $A D A s$ ) aware of the rules and regulations. And when we have the opportunity to gather all those ADAs 
together, we always remind them on the ADA rules for next year, how to go about (it), what to do and all". (P6)

The secretary of the ministry also participated in the WeChat group, which conveyed the seriousness the Ministry attached to the asset declaration. The secretary monitored what was discussed in the group and was updated on the status of asset declaration of the ministry during the asset declaration period of 2 months. The secretary would then be asked to sign the asset declaration report for the ministry, with the list of who declared, late declarants and non-declarants. If follow up actions needed to be taken, the Action Take Report would also need to be generated and signed by the secretary.

Some agencies and ministries didn't have such a peer support group and do not discuss asset declaration beyond training and meetings, but still managed to achieve high compliance rates. Although such an informal peer support group is found effective in agencies where it existed, it seems that there are other compliance drivers which may be effective in other agencies with high compliance. In fact, there may be multiple drivers which played effective roles in ensuring compliance. However, Bhutan is a small country and personal relationships are often valued in every day social settings. Therefore, peer support seemed effective where it existed.

\subsubsection{PERSONAL COMMITMENT}

A sizeable number of interviewees in various agencies and ministries identified personal commitment of ADAs as a distinct compliance driver. The interviewees shared positive examples of where such personal commitment ensured high compliance, whereas lack of such personal commitment led to a low compliance rate. There was no disagreement on the importance of ADA's personal commitment among all interviewees.

The fact that ADAs were human resource officers may also have influence on the government employee users, as some may fear negative repercussions of late or non-declaration on their career development, promotion and training opportunities abroad, as described in Section 4.1.

The personal commitment of ADAs was explained as his or her proactiveness and how serious they were towards their responsibilities as ADAs. ADA's attitude may also convey the importance of asset declaration to the declarants. The compliance rates were poor in the agencies where the ADAs did not take the responsibility seriously. Where the ADA is proactive, he or she will take actions, such as conducting sensitization and advocacy. Furthermore, the declarants were notified of the 
deadlines and requirements properly and in time. Because the awareness among the end users was high, they tended to file the declarations in time and of good quality. Such proactive ADAs sent the asset declaration report on time and informed the head of the agency of the status and update.

"It depends on the proactiveness of the ADA. How serious he takes his roles and responsibilities. Even if he is appointed, if he doesn't take it seriously, compliance will not really be good. So basically, if he performs his roles and responsibilities seriously, compliance will be very high". (B2)

Personal commitment also applied to other government officials who were involved in the management, upgrade and maintenance of the ADS. One interviewee expressed the heightened anxiety in making sure that the system functioned and performed during the declaration period.

"If they say that oh this (system) is not working, then I feel pressured. My system is not working. I can not sleep on Sunday. And I dream about this system (being) not working. Maybe during the declaration period, I will have such tension. Or something may go wrong and I have to be prepared". (B4)

There was a unanimous agreement that personal commitment was an important compliance driver across functions, organizations and seniority of interviewees. Personal commitment manifested in the work of ADAs, IT support and users at large. Some interviewees shared their views that when the personal commitment was lacking, it inevitably led to late- and non-compliance, as a negative example. The above accounts were corroborated by my observations during the fieldwork.

\subsubsection{TRAINING AND AWARENESS}

Additionally, several interviewees cited training, advocacy, sensitization and eventual awareness among ADAs and declarants as one of the key compliance drivers. These activities were normally conducted by the ACC. As explained in Section 4.4.2, some proactive organizations and ADAs conducted such activities independently of the ACC or requested for additional support from the ACC.

Several interviewees cited sensitization, awareness raisin and training as a reason for compliance because the declarants would know what to do and when through the ADAs who received the training and sensitization.

"(The reason for compliance) will be the public sensitization, awareness, training, the frequent training, and then notification ADA sends". (B4) 
The sensitization included and prioritized the explanation of the consequences and penalties, placing the importance on raising awareness on the implications of being a late or non-declarant.

During the interviews, it was explained that the declarants would not consult the ADS user manuals, although it detailed the steps and requirements of the asset declaration. The demonstration of how the ADS works in a meeting was found more effective than the manuals or just presentation materials. Some declarants claimed that they were not aware of the asset declaration requirements and deadlines, despite the media outreach through the national newspapers, Kuensel, and Bhutan Broadcasting Service (BBS), during the declaration period starting January every year. The importance of sensitizing ADAs was underlined, as they guided the declarants on the submission deadlines and requirements based on the asset declaration rules and regulations. These accounts were closely linked to peer support in Section 4.4.3 and personal commitment in Section 4.4.4.

The efforts by ACC in conducting training, educational and advocacy programs was recognized as effective in the National Corruption Barometer Report 2020 (Bhutan Transparency Initiative 2020). During the fieldwork, several interviewees referred to the training conducted by ACC outside the semi-structured interviews, which evidenced the effectiveness and impact of training on the users' mind.

\subsubsection{THE ROLE OF HIS MAJESTY THE KING}

The role of His Majesty the King is a very unique feature specific to Bhutan. In several interviews, the reverence towards him and his words echoed loud and clear. His drive to digitization and anti-corruption seemed ingrained in people's minds and had an overarching effect on government officials' belief, attitudes and behaviors.

His Majesty the King's determination to anti-corruption was found in numerous documents analyzed for this present research. One example was his address delivered on the occasion of the $104^{\text {th }}$ National Day in 2014:

"Corruption is unambiguous- there is no great or small corruption. And no one can be above the law. But there is an even greater threat - ignoring corruption. When the corrupt are not held to account, those who observe due diligence, work hard and professionally are most likely to be discouraged. We mustn't allow the latter to lose morale by rewarding everyone indiscriminately, irrespective of his or her performance. That is why, corruption must be curtailed and, more than ever before, extraordinary 
service must be recognized and rewarded." (Anti-Corruption Commission 2019, p. 5)

Several interviewees shared their reverence in their accounts. The head of ACC, the Commissioner, is appointed by His Majesty the King45, out of 22,000 civil servants. Because His Majesty the King trusted the Commissioner, he or she was trusted by the people.

"All these important posts, the heads of RAA (Royal Audit Authority) and ACC, were hand-picked by him among all these 22,000 civil servants and they were given that heavy responsibility. The system (such as ADS) cannot be compromised. These people (ACC Commissioner and other appointees) directly work under HM". (A2)

His Majesty the King's words were most effective, as he was revered and his selfless service respected by the Bhutanese people. His Majesty the King lived in a humble setting and served the people with the people's welfare in mind, unlike in other countries. He demonstrated the simple lifestyle, while visiting even remote villages across the country and got to know and solved the problems people faced first-hand. It was widely believed that the people in Bhutan were very fortunate to have His Majesty the King and their special relationships.

"In my own experience, I don't see anyone who works like His Majesty. Day and night. Always there. One outstanding factor is the special relationship between the public and His Majesty. There is a very special bonding, that is something that is very difficult to describe. (F2)

Several interviewees across functions and organizations expressed similar views, reverence and respect towards His Majesty the King and the role he played in ensuing compliance among the government employee users. There was no conflict across the accounts and analyzed documents confirmed the same.

\footnotetext{
45 The latest appointment was announced in October 2020, available at https://thebhutanese.bt/ecb-acc-and-raa-get-new-heads/
} 


\subsubsection{LEADERSHIP IN THE GOVERNMENT}

There was a unanimous agreement on the importance of leadership as a critical compliance driver. In the agencies and ministries where the compliance was high, the leadership was invariably supportive to ADA's work and created an enabling environment for them. This leadership took a variety of forms of verbal encouragement, taking responsibilities, and demonstrated commitment to anti-corruption.

The leader played a pivotal role in supporting ADA's work. Without such support, ADAs would not be able to convince and encourage the declarants to take action as required. According to one interviewee, the formal appointment of ADA sends a clear message to the declarants. In an agency or ministry where an ADA is not formally appointed, the compliance was invariably poor.

"If the support is not there from the head, ADA will not be able to do much, because even for appointing $A D A$, the head has to appoint an $A D A$.

If leaders didn't support ADA's work to conduct sensitization and training within the ministry, there was no incentive for ADAs to do the work or more work. The lack of such support conveyed the message that the asset declaration was not important and was not part of ADAs job. The leadership support and encouragement from the top were critical to the success of ADAs work and compliance.

"I think the encouragement from the top is very very crucial". (P6)

In addition, the leadership in asset declaration took the form of verbal encouragement to staff in regular meetings. Some leaders brought up the asset declaration in regular quarterly and monthly meetings and asked if it was the declaration time, to draw staff attention and stimulate discussions. He or she then provided the rationale and reasons why the staff needed to declare, what happened if they didn't and legal consequences in his or her own words.

Another interviewee went further and cited an example of a leader who explained the concept and root cases of corruption, showing that he or she was serious about fighting corruption. When such determination was demonstrated, it was found effective to encourage compliance among the government employee users. The role of leadership was found particularly important, as the National Corruption Barometer Report 2020 found that corruption was concentrated predominantly at the executive level of all organizations in the case of Bhutan. (Bhutan Transparency Initiative 2020)

Some leaders were also afraid of being caught by the ACC for doing something improperly. Such leaders would make sure that such a situation would not arise and do things right. Leaders were conscious of his or her reputation and what was 
reported about his or her organization. The leaders were responsible for what happened in the organizations they were managing. In case of low compliance, the leaders, or heads of organizations, would be impacted and his or her leadership capabilities could be questioned.

However, when asked about technical awareness among the leadership, interviewees invariably responded that the leaders were not keen to go into technical details for decision making, as some leaders may not have had sufficient IT knowledge.

"Yes, it is very difficult (to explain technical details). The management do not have the IT knowledge". (B5)

However, it didn't mean that there was a leadership void on technical and systemrelated matters. The type of leadership found in the ADS implementation was more enabling than technically managing or leading the initiative themselves. When system updates and changes were needed and presented by the ADS team, the leaders welcomed and were supportive to such proposals.

This model seemed to work where there was trust between top-level decision makers and functional and technical teams. The compliance driver around leadership was developed based on various factors, attributes and conditions specific to the case study initiative of the ADS, without any conflicting accounts.

\subsubsection{TECHNOLOGY-ENABLED EASE OF USE}

The interviews also identified the ease of use as a compliance driver. Unless a declarant had a lot of assets to declare, which was not the case for most of the government officials, it was reported to not take time. This was explained as a reason for the high compliance by several interviewees. Filing the declaration would not take more than 10 minutes according to several interviewees, although the verification of information, such as salary, may take time.

It was widely reported that the system was easy to use and efficient, and the declarants had positive experience in declaring assets.

"Yes, we have personally used the online asset declaration of the ACC. And so far the experience has been very good. I think it was quite efficient". (F2)

In addition, the automated functions, including password generation and notification, and retaining the past declaration records were compliance enabling factors. One of the most frequently encountered problems was that declarants forget their passwords, but the system had the automated function to send the forgotten 
passwords without human interventions. The declaration notification was automatically sent by e-mail when the declaration was submitted. Most users didn't have to update the asset records, and therefore, could use the previous records to submit the declarations.

"It's mostly automated. When you forget a password, it comes back to you and then after declared, another e-mail comes to you. That's why people go easy. My previous data (is) already there. I just have to say, the same, press, press, imported". (P4)

Although the ADS was not a tool to catch fraud, the records maintained in the system was expected to serve as evidence and keep users honest. One interviewee had asked the ACC the question on what if declarants were not honest and did not declare their assets. The response of the ACC was that since the record was kept in the system, those who did not declare honestly may be caught in the future, which may be an effective compliance driver.

The ADS was revamped almost 10 years ago. Therefore, despite the challenges government employee users may have encountered at the initial deployment stage, most users were by now accustomed to the system and procedures and there was a familiarity, which were found helpful.

Despite some sense of resignation that all the declarants had to file the declaration, there was a unanimous agreement across accounts and data sources that technology-enabled ease of use contributed directly to compliance of the government employee users. If the system was more complex and required more efforts and data in filing the declarations, it is easy to expect that less declarants would be able to complete the accurate filing in time.

\subsubsection{TECHNICAL SUPPORT AND RESPONSIVENESS OF THE ACC TEAM}

Lack of responsiveness from the technical team could be discouraging and demotivating to comply with the system requirements. In this regard, there was a unanimous view that the ACC's ICT Team was helpful, accessible and responsive to the questions and feedback from the users.

The responsiveness did not stop at the technical aspects, but the functional team was also found supportive and listened to the problems and concerns of the users. The feedbacks were sought not only from users but also from the ACC staff and Commission. Based on such feedback, the system was updated regularly. This 
made the ADS more user friendly and effective and better achieved what the system was intended to do.

"The overall objective is to make the system more user friendly, more effective, comprehensive and more practical. So that it serves what it is supposed to do and it enables compliance from the declarants". (B2)

The ACC also sent e-mail and actively solicited suggestions for system improvements. The above user orientation was corroborated and appreciated by other interviewees and ADS users.

The ACC also organized meetings to discuss system updates and changes. Such meetings further prompted a number of recommendations from the participants. What was found useful by the participants was that the changes could be made to accommodate the recommendations, because the system was developed in-house.

"There were a lot of recommendations from the participants. Because of being (developed) in house, the amendments were made (to the system). That was useful to the users in the pursuit of developing the system". (Q1)

The fact that the system was developed and maintained at the ACC seemed to give the flexibility to make changes when the feedback and requests were received and approved regularly. This is linked to the discussion on ownership in Section 4.6.

There was no conflict across data sources regarding the effectiveness of technical support and their responsiveness as a compliance driver. It was a team effort between the IT and functional teams, supported by the overall guidance and direction by the ACC leadership, as mentioned under Section 4.4.7.

\subsubsection{MONITORING, VERIFICATION AND FOLLOW-UP}

The ADS users were aware that the ACC reviewed the submitted declarations and identified possible cases of illicit enrichment of asset and sudden increase in assets and incomes. The monitoring, verification and follow-ups by the ACC asset declaration team seemed effective in encouraging compliance among users.

One interviewee bought a house and declared it one year. The interviewee received a letter from the ACC inquiring how the interviewee managed to buy a house with the income he earned. He had to explain in writing indicating that he had gone to study abroad and obtained a loan to buy a house. According to him, such encounter increased his confidence in the ACC and the asset declaration system, because it showed that the ACC did monitor and verify the declarations carefully. 
Another interviewee was also contacted by the ACC after the declaration was submitted. The interviewee was convinced that the ACC was carefully checking the declaration. In case of land purchase, for example, the declarant was asked how much, from where the funds came from, among other questions. Such follow ups enhanced the perception of the declarants towards ACC and ADS as effective.

"If I don't declare it, how much, how I acquired the land, they question us. It shows that it's being effective, they are using this system effectively. (P4)

However, a report on ethics and integrity infrastructure noted limitations in the current system, namely, the declarants were unaware that the ACC verified information with concerned authorities, such as the Royal Audit Authority, the National Land Commission Secretariat, the Road Safety and Transport Authorities and banks (Anti-Corruption Commission 2015a). The verification was conducted against the Asset Verification Protocol (Anti-Corruption Commission 2011b), which was published online but not many users were aware of the document nor its verification methodology.

The fact that the ACC monitored, verified and followed up based on the data in the ADS and used the system to identify possible illicit enrichment was found effective. Although there were doubts among the declarants, detailed as a challenge under Doubt in the Effectiveness of ADS in 4.5.2., the compliance driver was found compelling among the government employee users.

\subsubsection{NAMING AND SHAMING}

Every year, the ACC compliance report published the functions of non-declarants on the ACC website, which produced the "name and shame" effects. The outcomes of the asset declaration, especially the names of non-declarants, were regularly reported in newspapers (Kuensel 2018b). In addition to the penalties and fines, the name and shame effect may be an effective factor in encouraging compliance among government employee users.

The effectiveness of naming and shaming was evident in the fact that the named non-declarants got in touch with concerned ACC offices immediately when the information was made public. Most people were sensitive to the fact that their name appeared negatively in the media, and because of the fear, they complied.

"I think, yes, it will impact them very much because as soon as we publish their name as non- declarant on the website, we get a call". (B4) 
As Bhutan is a small country, the naming and shaming effect leads to social stigma, according to interviewees. Because of that, the majority of government officials preferred to remain anonymous and avoid being non-declarants. Famous persons and politicians were particularly sensitive to the naming and shaming effect due to the sensational impact. The fear would remind all that they had to be better, good people and less corrupt. Otherwise, they would be reported in the media and their life would be ruined.

The naming and shaming effect affected not only the concerned non-declarants but also others in the organization, such as the head of agency and ADA, as it implied that the latter failed to ensure compliance. The negative impact on others seemed to be effective and led to improved compliance among the declarants in the following year if one failed to declare on time or did not declare at all.

"It would also affect the head of the agency that I was working for. One of his staff has not declared on time and because of that, that employee's name has appeared on the media. That would mean that the head of the agency has failed somehow. That does impact the agency and the ADAs. And overall compliance would have improved the following year onwards". (B3)

There was no conflict across the accounts regarding the effectiveness of naming and shaming as a compliance driver. Some interviewees commented that the effectiveness was $100 \%$ in the context of Bhutan which is a small country and where social stigma is long lasting. The naming and shaming effects are intrinsically linked to the role of media and social media discussed in Section 4.4.12 and fear for punishment in Section 4.4.13. Together they created an effective mechanism to expose and report on non-compliance, which triggered cascading social impact on the lives of government employee users.

\subsubsection{THE ROLE OF MEDIA AND SOCIAL MEDIA}

In addressing corrupt practices and creating the naming and shaming effect, the role of media and social in Bhutan can't be overemphasized. There was a unanimous view that the media was keeping a check on corruption cases. One interviewee attributed the high ranking of Bhutan in the Transparency International's corruption perception survey to the role of media.

Bhutan has several newspaper companies as well as broadcasting services. The interviews revealed the view that the more media Bhutan has, the more corruption cases can be uncovered, which will deter people from corrupt practices. This present research corroborated the accounts with a number of media reporting by the 
Bhutanese media, such as Kuensel and the Bhutanese, on corruptions cases which involved high-level government officials and politicians. One interviewee agreed that the ACC work and media coverage thereof revealed cases publicly that in the past would have been hidden.

While social media was still largely seen as a medium for gossiping by interviewees, it has increasingly become a tool the society and media can not ignore, due to its geographical reach and speed in conveying messages. People started asking government officials questions on social media. As such, social media may be providing additional accountability mechanism and be playing a more important role than traditional media.

"I think media including social media is playing a very good role here (in addressing corruption and promoting compliance)." (F3)

The increasing importance of social media was reported by a newspaper article in The Bhutanese. The article highlighted that with the help of social media and technology, a private media company can compete with the established media companies, better understand people's grievances and reach more people across the countries. (The Bhutanese 2018) The role of media and social media in preventing corruption was also recognized as effective in the National Corruption Barometer Report 2020. (Bhutan Transparency Initiative 2020)

However, the above accounts would need to be placed in the context. The government acknowledged that Bhutan was ranked at $80^{\text {th }}$ out of $180^{\text {th }}$ in the World Press Freedom Index 2019 and there was a call to create a more conducive environment for a free and fair media in the National Integrity and Anti-Corruption Strategy 2019-2023. (Anti-Corruption Commission 2019)

There was no conflicting account across different data sources and different accounts which converged into the important role media and social media played as a compliance driver.

\subsubsection{FEAR FOR PUNISHMENT}

Fear of sanctions, the ACC prosecution and other punishments associated with non-compliance, especially fines, were some of additional reasons for high compliance rates. A number of interviewees shared various types of fear they had in case they failed to declare in time. 
The fear may have originated from the ACC and its investigation, interrogation and prosecution authorities. People knew that the ACC went after people and took them to court. In some cases, those in question were penalized for the crimes. Such news generated fear among the people, much like the fear the police generated. That's the reason why people felt fear when they received a call from the ACC.

"A lot of people were taken to the court and even penalized for the crime (by ACC). It generated a fear among the public. A lot of people have this fear when ACC calls". (F3)

Most cases were dismissed after clarifications were provided by the declarants, but the mere fact that the ACC was checking and verifying the declaration with other systems for disproportionate asset triggered fear in the declarants. The fear also represented what it could mean to one's stable life, jobs and families, if the ACC found him or her guilty by not complying.

The declarants also felt that the ACC may find hidden assets and inaccurate declarations 4-5 years later, if not now, and the penalties would be more severe. In fact, an ACC investigation led to a discovery of past false declaration in the case of the former Labour Minister (Kuensel 2019e). Due to such fear, it was speculated that declarants would be honest in their declarations. This fear for punishment is therefore closely linked to the compliance driver on monitoring and verifying discussed under Section 4.4.10, which provided technological capabilities to detect false or inaccurate declarations in the past.

Fear for penalty, in particular fines, also appeared prominently in the interviews. The fine was introduced in 2017 along with the revised Asset Declaration Rules 2017 (Anti-Corruption Commission 2017a). This monetary punishment was an effective compliance driver among government employee users.

"The penalty for the late declarants may not be too much, but for the non-declarant, it's a very high amount, especially in the Bhutanese context. And that does play a very important role on the compliance". (B3)

Several interviewees confirmed that non and late declarants who had to pay penalties didn't repeat the offence in the following years, which indicates the effectiveness of penalty as a deterrent measures. This fact may explain the improvement in compliance over the years, when declarants learned the hard way after being forced to pay penalties. All the accounts confirmed the effectiveness of fear for punishment as a compliance driver. 


\subsection{CHALLENGES}

The above sections narrated the ADS as system innovation and success in ensuring compliance among the government employee users. Various types of compliance drivers were identified by document analysis, observations and semi-structured interviews. However, it does not mean that the ADS didn't encounter challenges. Unaddressed, the challenges may undermine the legitimacy of the system and asset declaration as a function in the future. The next section identifies some of the major challenges which were identified in the interviews, observations and document analysis.

\subsubsection{APPLICATION OF ADVANCED TECHNOLOGY}

Several interviewees perceived that the system would benefit from technological upgrades and advancements, which was supported by my observations during the field study. One respondent assumed that the ADS interfaced with other systems and verified the accuracy of submitted data and information against the data stored in other systems, such as vehicle and land registration systems. Systematically interfaced with other systems, the ADS could have compelled declarants to submit comprehensive and accurate information.

In particular, some interviewees believed that the ADS should get data from other systems so that users didn't have to populate assets one by one, and at the same time should be easy to validate the information and further increase transparency.

"ACC needs to be high tech. They need all the expertise and they should be able to look into (all systems). If they encourage some of these systems (to interface), their work will be easier". (G1)

But the above-mentioned integration with other systems has other ethical, legal and data privacy implications. A common policy framework among agencies and systems may be needed to enable data sharing and verifications more efficiently and effectively. Additionally, the ADS declarants encountered Internet connectivity challenges, especially in remote districts, such as Trashi Yangtse and Zemgang. The connectivity problem frustrated the declarants and may impact on the compliance rates in the future.

The need for exploring systems and mechanisms to encourage proactive sharing of information across agencies was recognized in the National Corruption Barometer 
Report 2020 (Bhutan Transparency Initiative 2020) and in the National Integrity and Anti-Corruption Strategy (2019-2023) (Anti-Corruption Commission 2019).

\subsubsection{DOUBT IN THE EFFECTIVENESS OF ADS}

Although compliance was high, some thought that the system was not enough to prevent corruption. Even if the tool was developed for prevention, the users expected corruption to reduce with such systems as ADS, as the users felt that there were still lots of corrupt practices in the country.

The interviewees generally perceived the system and asset declaration as good initiatives, but it was not sufficient to control corruption. There were declarants who did not declare assets and income honestly, while the interviewees felt that they were witnessing a number of corrupt behaviors. Therefore, the asset declaration may be perceived as a mere formality.

"Well, it is a good initiative, I must say that. But it is not foolproof system to control the corruption, because despite having the system, there is lot of corruption going on. A lot of people don't declare their assets, income. I feel it is just mere formality to update". (R3)

But there was a more nuanced view from another interviewee. Although some directors and managers may not have shared the same level of awareness and motivation, this interviewee felt that some professional groups were more committed to conscientiously submitting their declarations without errors and in time.

In response to my question on the recent arrest of the former Labour Minister partly due to the false declaration in the past, which was maintained in the system, the interviewees felt that the part played by the ADS was not significant. A complaint triggered the ACC investigation which then cross-checked his past declarations. However, he would have been arrested for accepting bribery any way, with or without the charges for false declarations. Without such a complain and investigation, false and inaccurate declaration would remain undetected. In fact, the former Labour Minister submitted the declaration in time and it was accepted at the time of submission.

Another challenge lied in how the verification of submitted declarations was structured. The ADA was expected to examine the submitted declarations and notify the head of agency in case of DA or complaint. However, not all ADAs were equipped to verify DA. The afore-mentioned report on ethics and integrity infrastructure recommended that decentralised verification should be strengthened 
with random audits and checks by the ACC. To overcome the challenge and ensure detection of illicit enrichment, the same report suggested the development of relevant indicators, such as disciplinary actions, prosecutions and public requests for asset declaration, in addition to the level of compliance (Anti-Corruption Commission 2015a).

\subsubsection{RELUCTANT COMPLIANCE}

Although all the interviewee declarants complied with the asset declaration requirements, there was a level of reluctance among some declarants, which may erode confidence and compliance in the future. Some felt that the asset declaration was a burden, and did not take it seriously, because they saw the declaration as a routine, administrative procedure, and were unable to see it as a means to ensure integrity among the government employees and control corruption.

"Another reason for poor compliance could be that the civil servants don't take the declaration seriously. It's a mentality issue. They think that it is a routine, administrative procedure, instead of ensuring the integrity among the employees and control corruption". (R1)

Despite all the listed wide-ranging challenges, the ADS and the ACC managed to achieve a high level of compliance. It could be summarized that the compliance drivers outweighed and outnumbered the challenges. However, unless the challenges are addressed, confidence in the system may be eroded and compliance may reduce in the future.

\subsection{SUMMARY: ADS COMPLIANCE DRIVERS}

Section 4.4 identified 13 compliance drivers in using the ADS. Guided by a similar structure and logic used in the categorization of compliance determinants in Table 2, the ADS compliance drivers can be grouped into Organizational, Leadership, Social and Technological categories as listed below.

- Organizational compliance drivers: credibility and trust in the ACC, organizational setup, training and awareness;

- Leadership compliance drivers: the role of His Majesty the King and leadership;

- Social compliance drivers: peer support, personal commitment, naming 
and shaming, the role of media and social media, and fear for punishment;

- Technological compliance drivers; technology-enabled ease of use, monitoring, verification and follow up, technical support and responsiveness of the ACC team.

Interviewees identified formal organizational compliance drivers, such as credibility and trust in ACC, organizational setup and training and awareness, as effective and the accounts were corroborated with document analysis and observations. The ACC was widely respected and at the same time feared for its investigation and prosecution functions. The declarants felt that the ACC was doing a good job and therefore, the ADS as a system was trusted. Some ministries and agencies took initiatives to appoint additional ADAs, while allocating ministry and agency budget to organize conferences and meetings specific to asset declaration. The ACC also organized a series of training, awareness raising and sensitization activities across the government, which was found essential for compliance. The compliance rate was reported low where the ADAs and declarants didn't know asset declaration, the ADS system function and penalties.

Another compliance driver group centered on leadership. The role played by His Majesty the King was significant and agreed upon by interviewees and corroborated by other data sources. His commitments to promote ICT and eradicate corruption resonated across the government employee users as a strong driver of compliance. Leadership in the context of compliance took the form of supporting the ADA's work, encouragement and confirming the importance in meetings. Additionally, some leaders could link the ADS and asset declaration to overall anti-corruption efforts. The fact that leaders owned the asset declaration and responsibilities seemed to have conveyed unequivocal messages to declarants. It was also speculated that leaders didn't want to be seen as failing in ensuring compliance for their own reputation. However, the leadership in the implementation of ADS was not seen technologically aware, but provided an enabling environment for agile and timely system updates and changes.

The fieldwork also found social compliance drivers as important and effective. Peer support was rendered through various mechanisms such as a WeChat group. Equally important was personal commitment of ADAs. Where ADAs were active, the compliance rates were reported to be high. Most interviewees agreed that punitive aspects of asset declaration were found effective in ensuring compliance. The naming and shaming in the media was found particularly compelling, although it may trigger negative emotions by those affected by naming and shaming. If one's name appears in the media, others in the organization, such as the head of the agency and ADAs, would also be affected by the media coverage. In the process, the role of media and social media was found effective as a compliance driver. The declarants were additionally fearful of penalties and fines. The fines for non- 
declaration amounted to a significant sum in the Bhutanese context and the fear for fines was palatable during the interviews. The fact that no non-declarants repeated the offence was another indication of the effectiveness of penalty as a compliance driver.

Technology played a critical role in ensuring compliance. Interviewees confirmed that the ADS, as an established system, was easy to use and several functions were automated. Most declarants didn't have many assets to declare, and therefore, the filing did not take more than 10 minutes because past records were made available to declarants. Many users tended to forget their passwords but the retrieval was made automated, and so was the e-mail notification upon submission. Another technological contribution to compliance was monitoring, verification and followup. Although the declarants may try to hide assets, the system maintained the records over years, and the declarants feared that the ACC would discover the discrepancies eventually.

Several interviewees commented on the technical support and responsiveness of the ACC ICT and functional teams. In particular, the concerned officials made consistent efforts to reach out to users and ADAs for comments and feedback, for the improvement of the ADS. The interviewees reported that a number of recommendations were made by users and were implemented as system updates. Several interviewees appreciated such efforts by the ACC.

Finally, the chapter ended with the description of identified challenges the ADS faced in ensuring the compliance among the government employee users. While the compliance rates were high, the confidence and compliance may be eroded in a future if the identified challenges were not addressed in time. These challenges included lack of advanced technology to further automate and enhance verification and monitoring, doubts in the effectiveness of ADS and reluctant compliance. Some employee users believed that the asset declaration was a mere formality, because the system was perceived as not effective in reducing corruption in the country.

The case study initiatives were selected with the criteria of local ownership and donor-funded ownership as detailed in Section 3.5. Local ownership was defined with government funding and system development by government employees. Donor-funded ownership was characterized by external donor funding and system development with external experts. The ADS was selected as an example of local ownership, while the $e$-PEMS was selected for donor-funded ownership.

When asked about local ownership of the ADS and how important it was to interviewees, they had mixed responses: several confirmed that local ownership could increase their trust in the system, while the others would have preferred that external experts develop the system. However, all interviewees recognized the 
importance of the system having been developed with the government funding and expertise, although they were not aware that the ADS had been developed with local ownership, before the interviews. Therefore, ownership may not have had direct impact on compliance among the government employee users.

However, there were indirect impacts of local ownership. Some indirect benefits of an in-house development included the ability of the ADS IT team to change and update the system flexibly and nimbly as requested by the ADS functional team, users and management, as elaborated under Technical Support and Responsiveness of the ACC Team in Section 4.4.9. The newly introduced feature of automation was appreciated by the interviewees, as detailed under Technology-enabled East of Use in Section 4.4.8. The system was developed by the government employees in the IT team, which demonstrated strong personal commitment to ensure that the system functioned optimally, evidenced under Personal Commitment in Section 4.4.4. The interviewees may not have connected local ownership as a concept and how it impacts different aspects of compliance during the interviews, but the indirect effects of local ownership were wide-ranging and significant. 
"Majesty has been reminding the people that being small is an opportunity that makes the country smart. Technology, according to His Majesty The King, is an indispensable tool necessary to realize this aspiration" (Kuensel 2019d)

This chapter discusses the second case initiative, the electronic Public Expenditure Management (e-PEMS) of the Ministry of Finance (MoF). The chapter first describes the context in which the $e$-PEMS is situated in Section 5.1. The $e$-PEMS is at the heart of the government's efforts to modernize public financial management and control corruption. Before detailing the functionality of the system, this chapter introduces some of the recent fraud cases and incidents that form the context in which the system operates and what the system is expected to do to prevent the recurrence of such systemic corruption in Bhutan (Okuda 2020a). The chapter then describes $e$-PEMS as ICT system innovation in Section 5.2, followed by Section 5.3 on the level of $e$-PEMS compliance. The chapter describes the identified compliance drivers in Section 5.4, followed by the challenges associated with the e-PEMS in Section 5.5, before concluding with the summary in Section 5.6.

In the same manner as in Chapter 4, a compliance driver is defined as a category and group of inter-linked factors, attributes and conditions which are evidenced to have direct impact on compliance of government employee users in using e-governance systems. Each compliance driver is explained with data from semi-structured interviews, document analysis and observations. The quotes which best describes the factors, attributes and conditions of a compliance driver was added to the narrative as the evidence ${ }^{46}$. The data derived from document analysis, including the newspaper articles of Kuensel and Business Bhutan, was used for the purpose of triangulation.

While the preliminary results of the semi-structured interviews on the Asset Declaration System (ADS) informed some of the questions used to examine the $e$-PEMS, the data collection and analysis on each initiative was conducted separately and independently.

\footnotetext{
${ }^{46}$ Some quotes contained grammatical errors, repetitions and unclear terms. Such errors, repetitions and unclear terms were corrected in this Chapter to enhance the readability.
} 


\subsection{BACKGROUND OF THE ELECTRONIC PUBLIC EXPENDITURE MANAGEMENT SYSTEM}

This section first introduces prominent fraud cases which were reported by the Bhutanese media over the recent years as the background. The cases illuminate the context in which the public expenditure management systems operate in the country. The section also describes the financial information management system as well as public expenditure management system in general and what is expected of such an IT system. That is followed by a brief introduction of PEMS and why it needed to be upgraded to $e$-PEMS.

In 2018, the Anti-Corruption Commission (ACC) found eight government employees working at the Paro International Airport involved in the embezzlement of Nu. 7.278 million $(\$ 102,348)$ between 2013 and 2017. These were immigration officers who had been responsible for collecting visa fees at the airport. They were provided booklets to issue receipts for visa fees received from foreign visitors. Internal audits by the Ministry of Home and Cultural Affairs (MoHCA) found that 1,300 pages from the booklets were missing and alleged that they were used for the purpose of embezzlement. The fact that this case implicated as many as eight employees in a crime that had spanned four years attracted media attention (Business Bhu$\tan 2018 \mathrm{a}$; Okuda 2020a).

A second example was covered in newspaper articles from Business Bhutan and Kuensel, exposing government employees who had reported false travel claims as reported in an article (Okuda 2020a). The Royal Audit Authority (RAA) reviewed travel and daily allowance claims by officials of the Ministry of Agriculture and Forests (MoAF) and Dzongkhag (district) Administrations of Thimphu, Paro and Punakha districts between 2012 and 2017. The authorities found that $\mathrm{Nu} 1.110$ million $(\$ 15,610)$ had been claimed without undertaking or substantiated travel in 2016 and 2017. Significant deficiencies and weaknesses were reported over travel budget use, such as non-compliance with travel procedures, inadequate controls over processing and scrutiny of travel claims, despite travel being the second highest budget expenditure item (Business Bhutan 2018b). A Kuensel article on the same topic reported that from the lowest position to the highest, everyone seemed to be involved in such inflated claims, which left no one to file a complaint, while previous audit observations seemed to have gone unheeded (Kuensel 2018a). The RAA report concluded that effective coordination between controlling and disbursing officers and closer monitoring would be essential to ensure that travel budget was spent prudently and in compliance with travel rules (Royal Audit Authority 2018). 
In 2019, RAA published its 2018 annual report and revealed that the authority had recovered $\mathrm{Nu} 106.368$ million (\$1.5 million) after issuing 597 audit reports to government agencies and public corporations. Unresolved audit cases still amount to $\mathrm{Nu} 604.380$ million (\$8.5 million), up from $\mathrm{Nu} 407$ million (\$5.7 million) in 2017. The irregularities were caused by shortfall, lapses, deficiencies, non-compliance with laws and rules, mismanagement, fraud, corruption and embezzlement. One official was quoted as saying that despite improvements in internal management systems, there remained weaknesses in internal control and management and a lack of experienced employees (Kuensel 2019c, The Bhutanese 2019; Okuda 2020a).

In Spring 2020, Kuensel published another news article on the case of misappropriation by a Gewog (block) accountant in the Trashigang Dzongkhag (district) (Kuensel 2020a). She was alleged to have embezzled $\mathrm{Nu} .10$ million $(\$ 140,485)$ between 2016 and 2018 manipulating the checks and vouchers in the Public Expenditure Management System (PEMS). The article pointed out weak supervision, monitoring and verification at various levels as a cause of incident, as she could create fake names and other details in the vouchers. The Gewog (block) leaders were quoted as saying that they were operating under trust. The case was found by RAA in an audit. There was another similar case where an accountant in the Samdrup Jonkar Dzongkhag (district) was alleged to have embezzled Nu.8.4 million $(\$ 118,309)$, found again by auditors. Another Kuensel article cited a weak supervision and monitoring as a cause (Kuensel 2020b).

The above examples illustrate some of the challenges encountered when the previous Public Expenditure Management System (PEMS) were operational in managing government funds. They suggest underlying challenges associated with the use of information technology systems in managing public funds and expenditure and detecting fraudulent practices. In 2020, Bhutan Transparency Initiative (BTI) published the National Corruption Barometer Report 2020 which was funded by the ACC. The total of 1,152 respondents confirmed that corruption has been an increasing concern, driven by "trading influence, failure to declare conflict of interest, abuse of function, bribery, and embezzlement". The report cited that perceived corruption was the highest at the ministries and in particular at the executive level. (Bhutan Transparency Initiative 2020, p.ix)

To prevent fraud and enhance and enforce internal control, a financial management information system (FMIS) plays an increasingly important role. One of the functions FMIS normally undertakes is payment. A payment order authorises a payment after available funds have been checked and designated officials approve 
of it. Payment instruments include cheques, electronic fund transfer (EFT), and cash. In a centralised system, an accounts department issues payment orders for payments. The accounts department at the Ministry of Finance establishes relevant regulations and guidelines by issuing instructions related to preparation of financial accounts, financial reports and bank reconciliations. Lines ministries execute the budget allocated to them by procuring goods and services and making payments, and report to the Ministry of Finance on their financial operations. FMIS eases transaction processes, consolidates data, implements control and produces management and financial reports at the Ministry of Finance (International Monetary Fund 2016). If an FMIS is well designed and functions optimally and the government employee users comply with the system requirements, it is speculated that it is difficult to embezzle funds or hide discrepancies unaddressed, because of the transparency and traceability in the system (Okuda 2020a).

In Bhutan, government revenues and expenditures have been managed by several IT systems, such as the Planning and Monitoring System (PlaMS) of the Gross National Happiness Commission (GNHC), the Multi-Year Rolling Budget (MYRB) System of the Department of National Budget under MoF, as well as, the Public Expenditure Management System (PEMS) (Okuda 2020a). According to the RAA audit report, PEMS was developed during the fiscal year 2008-2009 and the records in PEMS are available from July 2010 (Royal Audit Authority 2016). The Department of Revenue and Customs manages the Revenue Administration Management Information System (RAMIS), which was developed with Asian Development Bank (ADB) funding. Payroll accounting also uses the data from the Civil Service Information System (CSIS) of the Royal Civil Service Commission (RCSC) (Royal Audit Authority 2016).

As illustrated in Figure 14 below, the Public Expenditure Management System (PEMS) obtains budget data from the Multi-Year Rolling Budget (MYRB) System that the Department of Budget maintains. PEMS provides the functionality of budget execution and reporting by booking expenditures and providing the basis to monitor the budget, including at municipal levels. All budgetary agencies, or agencies covered in the government budget, are required to initiate and execute transactions in PEMS. The system also captures closing cash balances on a daily basis. The year-end closing cash balance is reported through the Department of Public Accounts (DPA) in July every year. Each budgetary agency submits its Budget Utilization Plan (BUP) for approval of its budget to the DPA through PEMS. Based on the Budget Utilization Plan (BUP), agencies then submit fund release requests in the system. Funds are released to agencies through Letter of 
Credit/Project Letter of Credit (LC/PLC) ${ }^{47}$ authorisations to the agencies' LC/PLC accounts. Subsequently, payments are made by respective agencies according to BUP. Various control functions are embedded in the PEMS to mitigate risks of errors in financial statement, fraud and other irregularities (Okuda 2020a). For example, PEMS restricts disbursements beyond budget appropriations (Royal Audit Authority 2016).

Figure 14: Relationships between PEMS and other financial management systems implemented by $\mathrm{MoF}$

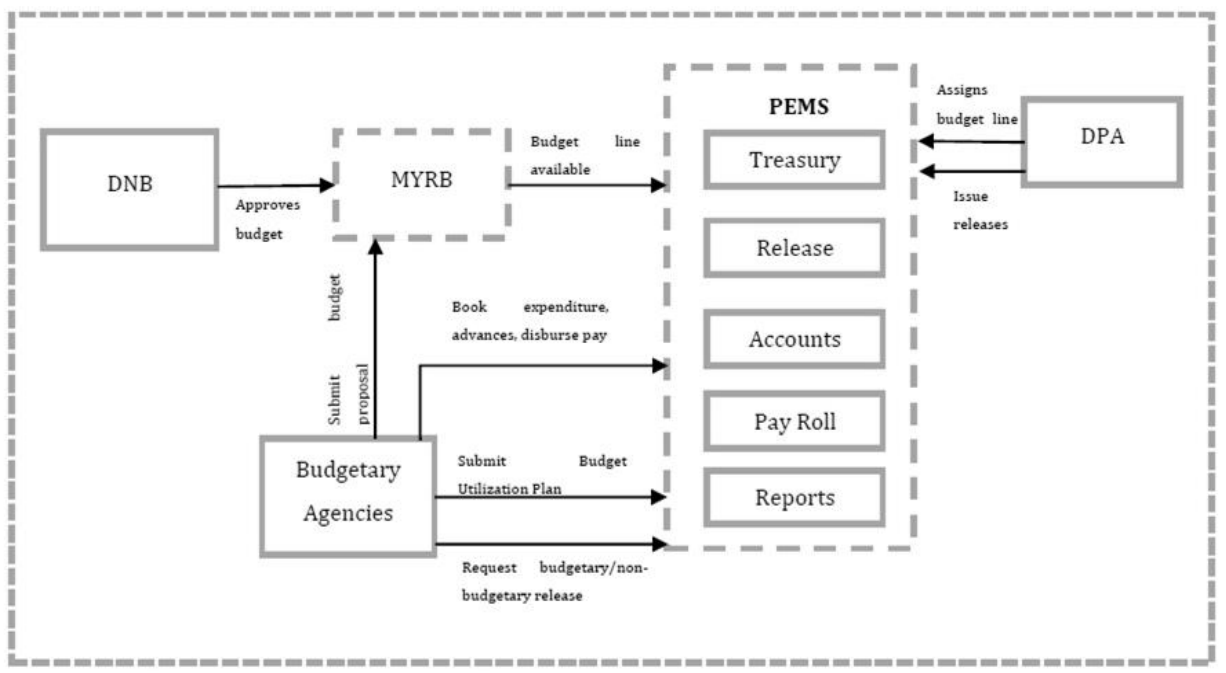

Source: Business process flow in PEMS, prepared by DPA, MoF

Access and privileges to financial records and information are granted as per the Public Finance Act of 2007 and 2012 and Financial Rules and Regulations. A user is given a unique identity with a password and different levels of access depending on the individuals' roles and responsibilities, such as System Administrator, agency heads, division chief, supervisor, verifying officer and approving officer. Access level is controlled by role management in the system and user identity is recorded with each transaction, thus enabling an audit trail to identify each user and transaction in the system. Each agency has an internal audit unit, which is given read-only access to records and information of the agency, while external auditors are given full read-only access to conduct audits. Changes to financial records are restricted by level of access and associated privileges and such changes are maintained in the system for audit trail. PEMS has the functionality to generate

${ }^{47}$ LC and PLC are sub-accounts of the Government Consolidated Accounts. 
reports on all financial transactions for further review and analysis (World Bank 2016; Okuda 2020a).

In this context, the World Bank conducted an evaluation of Bhutan's PEMS in 2016 using the Public Expenditure and Financial Accountability Framework (PEFA). It rated key functions of Bhutan's public expenditure management and financial accountability from A to D, with A being satisfactory and D unsatisfactory. In the evaluation, internal control in PEMS was rated as D with a comment stating that "(t)here are serious weaknesses in internal controls in PEMS payroll module and significant observations are made by the auditor on the adequacy of controls to ensure integrity of the payroll data" (World Bank 2016, p. 88). Public asset management, regularity of reconciliation and clearance of suspense accounts and that of advance accounts, all done in PEMS, were rated as B, C, and B respectively (World Bank 2016; Okuda 2020a).

Additionally, discrepancies and non-compliance in using PEMS have been observed and reported by both the World Bank and the RAA. One of the observations was made in the payroll function. Monthly payroll was processed in PEMS, which triggered direct bank transfers to government employees' bank accounts. The World Bank report took note of the existence of maker-checker control in the PEMS payroll module, but smaller agencies were found not following this control requirement. In particular, non-finance employees were unfamiliar with the PEMS and could not operate it meaningfully. Therefore, a finance officer implemented all transaction steps, including creating and approving transactions, regardless of the internal control requirements. In the case of payroll processing, the finance staff generated a payroll voucher in PEMS and a hard copy had to be signed by supervisors for approval, but the voucher did not contain the details of individual employees. This segregation of duty is established on paper, but not in the system, and could pose a weakness in internal control. As a consequence of such practices, the World Bank report noted that inconsistent numbers of employees and their contributions to the Provident Fund had been found in PEMS and other records (World Bank 2016; Okuda 2020a). Furthermore, the RAA had found payroll irregularities of $\mathrm{Nu} 9.6$ million $(\$ 135,002)$, including duplicate payments, in 2013-2014 (World Bank 2016).

The RAA conducted an audit, specifically on PEMS, to determine "the existence, adequacy, and effectiveness of controls in PEMS in relation to financial management" (p.1), while aiming to identify vulnerabilities in the system, which could be exploited for manipulations and fraud. More specifically, the audit reviewed policy and procedures to safeguard financial data from unauthorised access, documentation to enable future enhancements and system upgrades. The audit identified 
several weaknesses in PEMS, including non-segregation of duties, weak input control, inadequate audit logs and trails to record information about activities and transactions, weak master file controls, limited ICT security policy and a lack of change management process (Royal Audit Authority 2016; Okuda 2020a).

The semi-structured interviews corroborated how such fraud happened prior to the introduction of e-PEMS, due to weak internal control as well as limited audit logs and trails. Cheques were issued as payment instruments under PEMS and finance officers or accountants used to sign a check. But the process provided opportunities for manipulation, including cutting the name in the check and replacing it with someone else's name. Although a bank statement should enable the reconciliation between who was supposed to receive the check and who actually received it, it was found difficult to trace who cashed the check.

"Cutting the name on the check and writing (someone else's) names. These things had happened in the past. Most of the corruption was because of that check (manipulation)". (Q1)

Furthermore, the RAA auditor mentioned that PEMS project documents or systems documents were unavailable at the time of audit and that the PEMS IT personnel performed the maintenance and enhancement based on their tacit knowledge, not based on technical documentation. Subsequently, the RAA made audit recommendations to address the identified weaknesses, including improving controls and implementing electronic fund transfer, such as an electronic payment gateway (Royal Audit Authority 2016; Okuda 2020a). Based on the audit observations, the MoF established a Technical Working Group at the DPA and was working on improving the PEMS in consultation with various agencies (World Bank 2016).

\subsection{THE ELECTRONIC PUBLIC EXPENDITURE MANAGEMENT SYS- TEM (E-PEMS) AS ICT SYSTEM INNOVATION}

This section describes the $e$-PEMS as ICT system innovation to prevent the recurrence of irregularities, overcome the shortcomings emanating from PEMS and address audit observations and recommendations which were detailed in Section 5.1. In addition to the overview of the system, this section focuses on three functionalities of $e$-PEMS, namely master file management, voucher preparation and makerchecker concept, which are integral parts of internal control in any FMIS. 
In recognition of the PEMS shortcomings and audit observations and recommendations, the e-PEMS was developed based on the Public Finance Act 2007, its amendment 2012 as well as Financial Rules and Regulations of the Royal Government of Bhutan 2016. The Finance Secretary established the $e$-PEMS team comprising staff from the Department of Public Accounts, ICT Section and consultant (Ministry of Finance 2019a: Okuda 2020a).

At the launching of the system in July 2019, the Finance Secretary, Mr. Nim Dorji, was quoted as saying that a strong public expenditure management system was a necessity for Bhutan to graduate from the status of the least developed country, as the system would nurture a culture of fiscal discipline and ensure sensible utilization of public resources.

"Since Bhutan is preparing to graduate from its least developed country status, strong Public Expenditure Management System was critical in providing a culture of fiscal discipline for sensible utilization of public resources". (World Bank 2019)

According to Okuda (2020a), the functional and technical requirements of $e$-PEMS were developed using the International Monetary Fund report entitled "Shifting expenditure control to the Public Expenditure Management System" (International Monetary Fund 2016). The functional specifications were developed around the major objectives of

1. Enabling real-time inter-banking settlements for all types of transactions

2. Issuing acknowledgements for payment orders and for payments by payees and suppliers

3. Enabling correction of wrong transactions

4. Meeting audit requirements

5. Automating links among the e-PEMS, Bank of Bhutan (BoB) and Royal Monetary Authority (RMA) systems

6. Ensuring approval of payments with authorised signatories

7. Improving payroll and remittance payments

8. Enhancing system security and reliability

The system was developed by the DPA in collaboration with Bank of Bhutan (BoB), Royal Monetary Authority (RMA), Department of Revenue and Customs (DRC) and the Department of Information Technology and Telecom (DITT), funded by a multi-donor trust fund with contributions from the European Union and Austrian Development Agency, administered by the World Bank. There was an external 
expert onboard to update the system. The training was provided to users with 24/7 technical support system (Ministry of Finance 2019a and 2019b; Okuda 2020a). All $e$-PEMS transactions have to be routed through the $\mathrm{BoB}$, which manages the government accounts. Therefore, the development of the Global Interchange for Financial Transaction (GIFT) by RMA enabled e-PEMS transactions with non-BoB banks (Kuensel 2019d).

Figure 15 illustrates interactions between the $e$-PEMS and a vendor who needs to be paid as well as interfaces among different government IT systems. A vendor interacts with the budgetary bodies or the government agencies which execute the government budget in $e$-PEMS. The vendor data is sent to the concerned budgetary body which then passes the verified data onto the DPA to enter to the master file in $e$-PEMS. The taxpayer number and other details derive from another system called RAMIS, or Revenue Administration Management Information System. The transactions and payment instructions are sent first to $\mathrm{BoB}$, a commercial bank which manages government accounts. The Figure 15 shows one to one and one to many transactions going to $\mathrm{BoB}$, while $\mathrm{BoB}$ returns acknowledgement, or Ack, in the diagram. For a vendor which has an account with $\mathrm{BoB}$, the fund is deposited directly into its $\mathrm{BoB}$ account. There are other commercial banks operating in Bhutan, such as Bhutan National Bank (BNBL), Bhutan Development Bank (BDBL), Tashi Bank (TBANK) and Druk Punjab National Bank (DPNB). For a vendor which has an account with one of the non-BoB banks in Bhutan, the transaction passes through an interface called GIFT, managed by the RMA. 


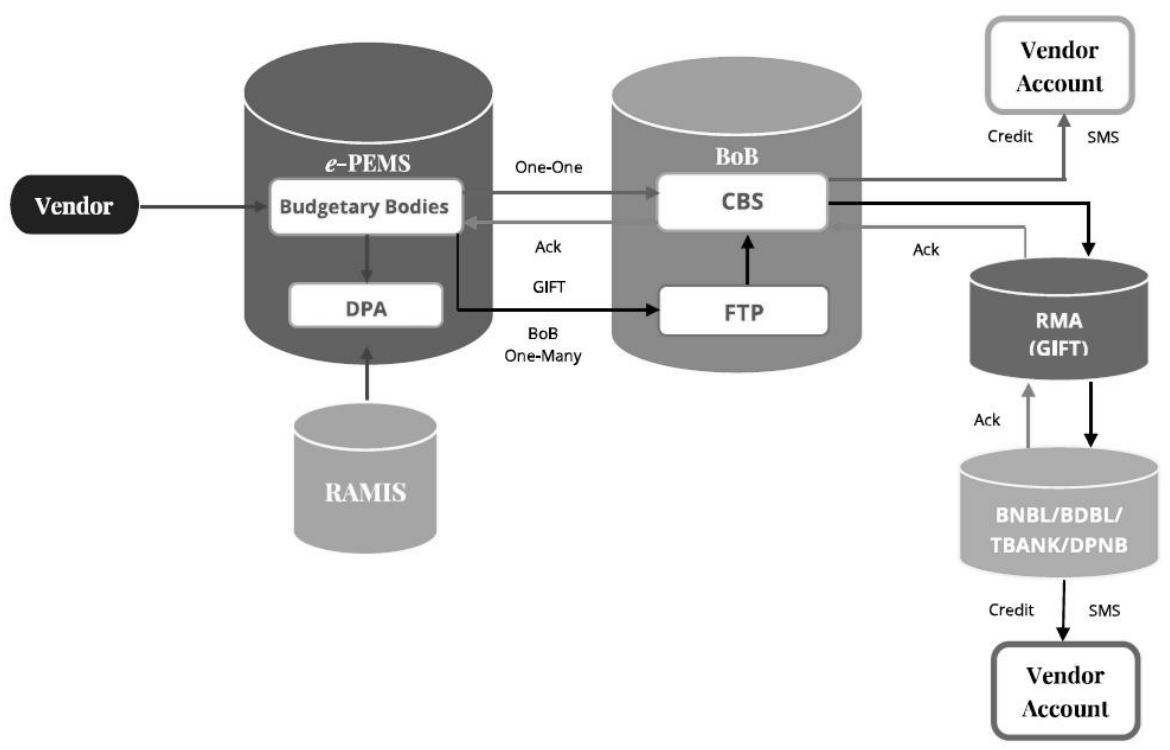

Source: Ministry of Finance (2019b)

This present research focuses specifically on the electronic payment part of $e$-PEMS implementation as it has direct relevance to control of corruption, internal control and compliance among government employee users (Okuda 2020a). More specifically, this research examines the three functional and technical features, namely

- User management

- Voucher preparation, verification, approval and reversal with payment instructions and

- Maker-checker processes.

The three functionalities were selected based also on the findings of the World Bank evaluation and the Royal Audit Authority's audit observations and recommendations detailed in Section 5.1.

\section{$\underline{\text { User Management }}$}

As RAA audit findings and World Bank evaluation indicated, a weak user management would undermine efforts for establishing audit trails, while enabling 
unauthorised access to the system and then financial transactions. The previous user management in PEMS allowed duplicate and generic user names to be created in a decentralised manner. In the $e$-PEMS, there was a one-time user creation, managed centrally by the DPA $e$-PEMS administrator according to a new User Management policy and naming convention. A finance officer or any other designated officer was assigned as agency administrator in the e-PEMS. He or she assigned agency users to the LC/PLC accounts of the agency, created payroll departments and assigned the users to the payroll departments in the e-PEMS (Okuda 2020a). Different levels of authorisations (voucher verification, voucher approval, payment instruction, release request approval and release approval) were given to users as detailed in Table 14.

Table 14: Types of users and level of authorization

\begin{tabular}{|l|l|l|l|l|l|}
\hline \multirow{2}{*}{ Roles } & \multicolumn{5}{|c|}{ Authorized Signatory } \\
\cline { 2 - 6 } & $\begin{array}{l}\text { Voucher } \\
\text { verifica- } \\
\text { tion }\end{array}$ & $\begin{array}{l}\text { Voucher } \\
\text { Approval }\end{array}$ & $\begin{array}{l}\text { Payment } \\
\text { Instruc- } \\
\text { tion }\end{array}$ & $\begin{array}{l}\text { Release } \\
\text { Request } \\
\text { Approval }\end{array}$ & $\begin{array}{l}\text { Release } \\
\text { Ap- } \\
\text { proval }\end{array}$ \\
\hline System Admin & No & No & No & No & No \\
\hline Agency Admin & Yes & Yes & Yes & Yes & No \\
\hline FTMD ${ }^{48}$ Chief & No & No & No & No & Yes \\
\hline TMD $^{49}$ Chief & No & No & No & No & No \\
\hline $\begin{array}{l}\text { Account Divi- } \\
\text { sion Chief }\end{array}$ & Yes & Yes & Yes & Yes & No \\
\hline Agency User & Yes & Yes & Yes & Yes & No \\
\hline TMD User & No & No & No & No & No \\
\hline FTMD User & No & No & No & No & No \\
\hline Director & Yes & Yes & Yes & Yes & Yes \\
\hline $\begin{array}{l}\text { PEMS Client } \\
\text { Support }\end{array}$ & No & No & No & No & No \\
\hline $\begin{array}{l}\text { Agency Report } \\
\text { View }\end{array}$ & No & No & No & No & No \\
\hline DNB ${ }^{50}$ User & No & No & No & No & No \\
\hline
\end{tabular}

\footnotetext{
${ }^{48}$ Fiscal Transfer and Monitoring Division of the Department of Public Accounts, MOF

${ }^{49}$ Treasury Management Division of the Department of Public Accounts, MOF

${ }^{50}$ Department of National Budget, MOF
} 


\begin{tabular}{|l|l|l|l|l|l|} 
PEMS SDS head & No & No & No & No & No \\
\hline RAA User & No & No & No & No & No \\
\hline GNHC $^{51}$ User & No & No & No & No & No \\
\hline
\end{tabular}

Source: Reconstructed from Ministry of Finance (2019a), p. 21; Okuda 2020a

The process of centrally managed user management and master file creation was explained in detail and corroborated during the interviews. The user and vendor data was mapped against 13 party types, such as employee and supplier, in the system. The system was set up to make 15 types of transactions, such as salary payment. The user or vendor data was matched with the appropriate transaction type when a transaction was processed. This account was largely corroborated in the e-PEMS user manuals on party master (Ministry of Finance 2019d), user management (Ministry of Finance 2019e) and account payee master. (Ministry of Finance 2019f)

\section{Voucher}

This $e$-PEMS module was used to post transactions and disburse public funds in accordance with the applicable financial rules and regulations. If government employee users ignore the system requirements in creating, verifying and approving vouchers, it might be easy to embezzle funds and initiate frauds. There were four types of vouchers in the $e$-PEMS, namely, disbursement, journal, reversal and others. Disbursement vouchers were used to process payments and was linked to LC/PLC accounts. Both bank and cash transactions were previously processed in the PEMS. Journal vouchers were used to correct errors to already processed disbursement, journal and other vouchers. Reversal vouchers were used to cancel disbursement, journal and other vouchers. When a voucher was reversed, a reverse voucher was automatically generated. Other vouchers were used to record cash receipts, recovery of advances and other types of deposit. These vouchers were verified and approved by the verifying and approving officers. E-mail notifications were sent to verifying officer when an accountant submitted vouchers for verification (Okuda 2020a).

In the $e$-PEMS environment, payees' details in voucher documents were derived from a master file with an option of manually uploading information for special transactions. The payment modes were expanded into bank, cash and direct transactions. Cheques were fully eliminated in the $e$-PEMS, and cash was allowed only for advance adjustments and the recovery of excess payments. Direct transactions

${ }^{51}$ Gross National Happiness Commission 
were possible only for payment for fuel, official credit card transactions and bank charges. A voucher was then submitted for verification and approval. The voucher was rejected in case of a mistake. If it was approved, payment instruction was generated along with the accompanying reference code. The payment instruction was then validated before being sent to $\mathrm{BoB}$ online. In the case of a correction of disbursement, journal or other voucher, reversal took place by selecting LC/PLC, months and voucher number and providing justification for reversal (Okuda 2020a).

During the interviews, the process of voucher preparation, verification and approval in the e-PEMS was explained and corroborated. First, an accountant prepared a voucher, using the budget line and selecting payee. The voucher was then submitted to the verifying officer to check the accuracy of the budget lines, payees, amount and any errors. The verified voucher was then submitted to the approving officer for cross-check, after which it was submitted for e-payment. The authorized official was given a one-time password to finally process the e-payment (Okuda 2020a).

The $e$-PEMS still relied on paper-based approval. The accountants needed to present supporting papers, such as invoices, in the voucher preparation process in $e$ PEMS. The supporting papers were approved, if they were in good order, and were sent back to the accountant who presented the paper for approval. Based on the approval, the accountant prepared the voucher and sent it to the verifying officer in $e$-PEMS. Most of the $e$-PEMS users who participated in the interviews appreciated the fact that the check was eliminated. The rest of the steps basically were found the same as in PEMS.

"The only difference is that the check part is eliminated. That is, the rest is all the same". (Q1)

\section{Maker-checker processes}

The maker-checker concept aims to prevent one person from creating and approving a voucher, thus establishing checks and balance in the process, which is an essential internal control mechanism. Before the e-PEMS was implemented, there were three levels of checks, namely, voucher preparation, voucher verification and voucher approval. In the $e$-PEMS, an accountant prepared a voucher and submitted it for verification. In case the voucher was rejected by the verifying or approving officer, the same person that originally submitted the voucher would create a new one. When a new voucher was submitted after rejection, the same verifying or 
approving officer would verify or approve the new voucher. Once approved, the approving officer generated the payment instruction and validated it before sending it to the bank. If $\mathrm{BoB}$ rejected the payment instruction, it was returned to $e$ PEMS with a pre-established rejection code. Only the DPA can modify the instruction and then return it to the approver for approval before sending it back to $\mathrm{BoB}$ (Ministry of Finance 2019a; Okuda 2020a).

\subsection{E-PEMS COMPLIANCE}

Following the overview of $e$-PEMS as ICT system innovation, this section assesses the level of compliance among the $e$-PEMS users who are accountants and finance officers within the government. The system was launched in July 2019. When the interviews were conducted from September 2019 to January 2020, the system was still in the process of being stabilized. However, since the users were familiar with the previous PEMS and the steps required for $e$-PEMS transactions were largely the same, the level of $e$-PEMS compliance was high and financial transactions continued without major disruptions.

Within a month of its introduction, e-PEMS recorded 17,923 transactions worth over $\mathrm{Nu} 3$ billion ( $\$ 42.19$ million). The RMA governor was quoted as saying that $e$ PEMS would promote transparency and accountability because the centralised database was available to policy makers, legislators and auditors to examine government expenditures, while the process of manually writing and processing cheques were made redundant (Kuensel 2019d; Okuda 2020a).

As a newly revamped system, delays were inevitable and led to unwanted consequences. Indeed, one delay in e-PEMS reportedly led to the death of a baby in a remote district of the Dagana district. The district health officer was quoted in a newspaper article saying that when $e$-PEMS was introduced, it took time to obtain budget, which was supposed to be used to buy ambulance fuel. By the time the ambulance reached the village, it was too late and the baby had died. The story written by the father of the deceased baby went viral on Bhutanese social media (Kuensel 2019a). However, MoF officials responded that training on the use of $e$ PEMS had been provided to officials including those at the Dzongkhag or district levels (Okuda 2020a).

In addition to the above incident of baby's death, issues were also reported in relation to government employee salary payments. In the previous PEMS, monthly 
loan and insurance payments from government employees had been deducted at source, but $e$-PEMS facilitated only statutory deductions, such as taxes, health contributions, among others. Personal loans were now to be paid by the government employees themselves, using available mobile banking applications. Initially, there was insufficient awareness among the government employees on the new procedures, which resulted in loan defaults, but the problem had subsided by September 2019 (Okuda 2020a).

In the first two months, the volume of $e$-PEMS transactions exceeded $\mathrm{Nu} 6.3$ billion (\$88.6 million). Transparency and accountability were expected to increase as vendors and service providers needed to be registered centrally by the DPA and be paid directly without having an accountant issuing a cheque (Kuensel 2019b; Okuda 2020a).

In terms of the transaction volume, it was estimated that 500 transactions were processed by $e$-PEMS daily.

"If I talk about daily basis, the number of transactions for one to one (transaction) is definitely more than 500". (C3)

Despite the initial deployment problems, the system has been used by over 700 accountants and financial officers posted in all ministries and Dzongkhag (district) administrations including sub-unit of Gewogs (block). At the same time, the use of $e$-PEMS was compulsory, as the accountants and finance officers had to process transactions and payments in $e$-PEMS to do their work. However, the compliance level could have been lower for technical and other reasons, although it was compulsory.

The high compliance and e-PEMS success were cited from various angles during the interviews. One example was salary payment. In the PEMS, checks were issued for the payment of salary of government employees. Inevitably, there had been long queues at the banks to cash the checks at the time of salary payment. Now, with the electronic payment introduced by $e$-PMES, not many people were found lining up in the banks and payments were processed electronically and instantly. This helped agencies and ministries to use staff time more efficiently and the organizations to grow.

"The first week of August, people were saying that not many people (were) in the bank, now that everything is electronically happening". (C3) 
During the interviews, it was also corroborated that all the accountants and finance officers were using $e$-PEMS to make transactions, including salary payment of government employees. They had to use $e$-PEMS to process payments and salaries.

"Even those who haven't received training, they are using. You have to use the system to pass any transition". (C8)

The use of checks provided opportunities for manipulation and was considered as one of the challenges encountered in PEMS, detailed in the above Section 5.1. During the interview, it was corroborated that the use of checks was discontinued in $e$ PEMS. Previously, some checks had been issued without any corresponding records in the PEMS, which must have created discrepancies between available funds in the system and bank statements. It was speculated that such discrepancies were not identified because the bank reconciliation was somehow manipulated. Therefore, in addition to the introduction of e-payment, elimination of checks was touted as a success.

There were also other questionable practices using checks in PEMS. Some accountants and finance officers withdrew a large amount of cash under their names and kept it with them for the purpose of bill payments. However, there were cases of allegedly misuse by some accountants and finance officers and financial records were "adjusted" when it happened. With the introduction of $e$-PEMS, such a practice was now controlled.

However, despite the high number of successful transactions, there was an incidence where an accountant in the Trashigang Dzongkhag (district) did not comply and transferred over Nu. 3 million, or $\$ 42,253$, of government funds into her personal account via e-PEMS, as corroborated by several interviewees. It was possible because she was the one who created, verified and approved the transactions without oversight and internal control.

"I believe in one place in Trashigang (district) or somewhere, it happened. That lady, that particular accountant has cashed around $(\mathrm{Nu}) 3$ million $(\$ 42,253)$ and put in her account because she is the one who verifies and approves (in the) $e$ PEMS. There's nobody to monitor. She has the power to do whatever she likes. It is risky. It is very very risky". (Q1)

Despite the high level of compliance and wide-spread use of the $e$-PEMS among the accountants and finance officers, internal control and checks and balance continued to be a challenge and in fact came up as a risk in various interviews. The details of limited internal control and how the e-PEMS team was addressing the challenge are described in Section 5.5.5. 


\subsection{ANALYSIS ON E-PEMS COMPLIANCE DRIVERS}

Although it is mandatory for accountants and finance officers to use the $e$-PEMS to do their jobs, there could be workarounds and other ways to manipulate the system. In fact, there are a wide variety of technological and other challenges in the e-PEMS that were mentioned during the interviews, as summarized in Section 5.5. It is therefore important to analyze why the vast majority of government employee users comply with the $e$-PEMS requirements and achieved the high compliance level, despite the challenges and opportunities for manipulation and fraudulent practices.

This section summarises the 13 key compliance drivers found in the document analysis, my observations and semi-structured interviews in the examination of the $e$-PEMS implementation. The order of these compliance drivers is not intended to imply the importance or any other meaning. In the same manner as in Chapter 4, a compliance driver is defined as a category and group of inter-linked factors, attributes and conditions which are evidenced to have direct impact on compliance of government employee users in using e-governance systems. The factors, attributes and conditions were identified from interviews, document analysis, such as newspaper articles and reports, and my observations.

This present research adopted the thematic relevance approach in which the number of interviewees expressing their independent opinions is considered more important than the number of times the idea was expressed and coded per interviewee.

There were both positive and negative accounts towards the importance of the same compliance driver. Positive accounts explained that some factors triggered positive outcomes, while the lack of the same factors led to less compliance. Some accounts were nuanced, reflecting personal experiences and perspectives, which were triangulated with other data sources. The names of compliance drivers were developed using inductive coding. The detailed definition of each compliance driver as well as what it includes and excludes are listed in Code Book in Annex 6.

\subsubsection{THE ROLE OF HIS MAJESTY THE KING}

His Majesty the King is deeply respected in Bhutan. In several interviews, the reverence towards him and his words manifested and his resolve and commitment to 
anti-corruption seemed ingrained in people's minds and had an overarching effect on government officials belief, attitudes and behaviors.

One example of His Majesty the King's resolve to anti-corruption and better management of resources is cited in the national budget of financial year 2019-2020. While underlining the importance of prudent financial resource management, His Majesty the King placed the responsibility squarely on the shoulders of civil servants.

\footnotetext{
"As a developing country, we have limited resources. We must manage our available resources wisely, minimize waste, and ensure that all our resources are directed at improving the well being of the people, and in fulfilling our national vision. The civil service is tasked with the oversight, management, administration, and disbursement of funds for governance. So the responsibility falls squarely on the shoulders of our civil servants to ensure efficiency and effectiveness in utilizing our scarce resources." (Ministry of Finance 2019c, p.1)
}

The interviewees believed that Bhutan was fortunate to have the monarchy who kept an eye on everything and His Majesty promoted anti-corruption efforts. With the help of IT system and because the people respected His Majesty, there was a hope that corruption may be reduced in Bhutan soon.

"I think the good thing about Bhutan is that we have a monarchy who keeps an eye on everything and I'm sure because wherever His Majesty goes, he always talks about corruption and being a good human being helping each other. And I'm hopeful that people will respect his wishes with the intervention of IT services". (O2)

The respect and reverence towards His Majesty the King was unanimous among the interviewees. His resolve to control corruption and drive for digitization seemed to have guided compliance among the government employee users.

\subsubsection{LEADERSHIP IN THE GOVERMENT}

During the interviews, leadership was frequently cited as an important compliance driver in the context of $e$-PEMS implementation. The trust the users had with the leader, in particular the Finance Secretary, was identified as a compliance driver. Together with the director of the DPA, he travelled around the country and advocated for the use and benefit of e-PEMS among accountants and finance officers. The Finance Secretary also talked about $e$-PEMS, its benefits, needed reform and support from accountants and finance officers in every finance meeting, which ensured their compliance. 
The statement of Finance Minister was also quoted in a World Bank blog which summarized the development of Bhutan's financial information systems.

"'This is a historic move in terms of structural and systemic changes in streamlining the Public Financial Management (PFM) system in Bhutan" said Honorable Finance Minister Namgay Tshering, adding that as the country progresses, the use of IT [Information Technologies] tools has become inevitable". (World Bank 2019)

The leadership commitment to upgrade the financial information system and demonstrate fiscal discipline should also be seen in the context of Bhutan's efforts to graduate from the status of the least developed countries (World Bank 2019).

At the same time, the interviewed $e$-PEMS users felt proud of being a finance officer and a representative of the Ministry of Finance in a working agency (a line ministry or agency he or she is posted in). When the MoF, the parent agency, initiated a system like $e$-PEMS, it was expressed during the interviews that all finance staff should appreciate and support the initiative.

"As a finance (officer), I take pride in that (system), because I'm also a representative of the Ministry of Finance. When the Ministry of Finance have initiated, we should all appreciate and take (pride) of all the positive". (Q1)

Additionally, MoF had credibility, budget and authority to command compliance among the government employee users. One interviewee commented that the users had to comply because the system was initiated by the person the users were reporting to.

The leadership which emerged in the case of $e$-PEMS took a very specific and unique form. On the one hand, there was a strong drive to digitize from leaders, but on the other hand, the leaders were not seen as ICT-ready and savvy across the government. This specific aspect of leadership was expressed frequently during the interviews.

"And the issue we are facing is, the higher management are not IT related. They don't understand (IT)". (R3)

When asked about the level of awareness on e-PEMS and if e-PEMS training was arranged specifically for leaders, it was confirmed that there was no such training. It was speculated that the decision makers, such as ministers and prime minister, should be aware of the existence of the system as it was widely reported by media. It was widely assumed that the decision-makers were aware of $e$-PEMS functionality, but the officers would not be able to go and check with the ministers. 
It was relevant officers' duty to appraise the ministers and secretaries in their ministries on e-PEMS and any updates or issues with the system. However, the interviews revealed that challenges and opportunities related to $e$-PEMS were not reported to secretaries and ministers. The technical issues encountered by the $e$-PEMS users were considered trivial, not the type of issues which warranted the highestlevel attention.

Additionally, e-PEMS was considered as an operational matter and the minister and secretary didn't ask questions on the system, either. Therefore, the responsibility and accountability fell on the finance officers and accountants in the case of $e$ PEMS, based on the mutual trust between decision makers and e-PEMS users.

"I must say frankly, till now I haven't apprised the minister. And since it is more operational, the responsibility, accountability falls on us, (in) using, making and dispersing funds. That way I think they fully trust us. They don't even ask much about this". (Q2)

There was no conflict across all data sources regarding the effectiveness of leadership as a compliance driver. However, what emerged in the interviews were more nuanced accounts of leadership and their relationships with the e-PEMS users, namely accountants and financial officers across the government.

\subsubsection{EFFICIENCY GAINS}

Most e-PEMS users cited efficiency gains as a motivation to use $e$-PEMS. The system was able to process payments and transactions faster and more transparently, with reduced time and efforts by accountants and finance officers. For example, the government had previously processed individual loans through PEMS. If an officer had a personal bank loan, the loan payment was processed at the time of salary payment as part of the payroll system. This was a complex operation, which many finance officers confided was the case.

The accountants and finance officers were happy that the personal loan payment was now removed from the government payroll function in the e-PEMS, and this was a much-needed reform. Some of these officials had complained to the Finance Ministry in the past that processing government officials' personal loan payment should not be the duty of accountants and finance officers. Previously, the month end salary disbursement had to start as early as $5^{\text {th }}$ of each month due to the complexity of processing personal loan payment. Now, with the removal of personal loan payment in e-PEMS, the complex task and workload on accountants and finance officers was reduced. 
Furthermore, electronic payment transactions reached the payees faster. In the check systems under PEMS, the payee had to wait and received the cash the next day or after, but the e-PEMS payments were processed instantly, in a minute or two, if there was no technical issue. The payees were naturally happy to receive the payment quickly.

"Now in our system, if there's no technical issue, they get the payment on time. Instantly after one to two minutes. I think for that the users are happy. They get the payments very fast". (C8)

The elimination of checks had another efficiency gain. Vendors and suppliers didn't have to come to the ministries and agencies to receive checks. It was particularly daunting for payees from other districts, such as Bumthang and Trongsa. Check books also cost: Nu. 50 (USD 0.7) per booklet. Electronic payments also eliminated the need to purchase the check booklets from the respective banks.

"They (payees) don't have to come to follow up on the thing. Some vendors from Bumthang and Trsongsa (districts), and all. We send e-mail". (P5)

The efficiency gains brought by the $e$-PEMS was an effective compliance driver, as the users were convinced that the system brought benefits not only to themselves but also to vendors and payees, according to the accounts from several interviewees. Despite the initial technical hiccups which were reported by newspaper articles (Kuensel 2019a and 2019b), the technical problems seemed largely subsided after October 2019.

\subsubsection{FAMILIARITY WITH THE EXISTING SYSTEM AND EASE OF USE}

Since e-PEMS was an upgrade to PEMS and was not an entirely new system, it was easy to transition, use and comply with the system requirements. It was commented during the interviews that most of the functionalities were the same between the two systems, and most users were familiar with the steps and procedures, which helped the transition to the e-PEMS and might have helped convince the users to comply.

The two systems were almost the same, except the check elimination and automated bank statement reconciliation, which was an improvement and upgrade.

"PEMS and e-PEMS (are) almost the same. Inside it's all the same but in e-PEMS, we don't write checks. That's the only difference. Then bank statement 
reconciliation, we don't need to punch manually. That's one improvement for ePEMS". (P5)

The e-PEMS was found easy to use and does not require extensive financial knowledge to operate, because all the necessary information was already built in the system. A user just needed to know the account, category of payee and transaction type, as described in Section 5.2. The system automated the rest of transactions, such as debit and credit in the accounting.

"They really do not have to be so financially sound to use the system because everything is in the system. You just have to go through each category and just go on doing the transaction. The system takes care of everything else; which side has to be credited, which side has to be debited. Now (it is) so much simpler". (C3)

The similarities between PEMS and e-PEMS were detailed in Section 5.2. There was no conflict across various data sources regarding the familiarity with the existing system and ease of use as a compliance driver. If the systems were dissimilar and users needed time and efforts to learn the steps and procedures, compliance might have been lower.

5.4.5. CENTRALIZED MASTER DATA MANAGEMENT AND MONITORING

The DPA team in the capital now managed the master file of vendors and employees with centralized access control and kept an eye on the financial activities in various parts of the government agencies across the country. Such features were expected to help prevent e-PEMS users from not complying and misusing the system.

With the effective and centralized management of the master file by the DPA team, the government users would not be able to manipulate the payee information at the agency level, as was done in the previous check system. The vendor payee information needed to be sent to the DPA for their entry in the system as an internal control mechanism.

"If I have to make payment to you, I cannot punch your details here (in an agency). I have to take all this information from you and get the information punched in the system from the Public Accounts (DPA). And then only I can make the payment. So those rights and restrictions are there, for the internal control system". (P2) 
The DPA has access to centrally monitor activities in other ministries, agencies and district administrations in the e-PEMS, regardless of the physical location of the office. This visibility and central monitoring capability seemed also effective to encourage compliance among the government employee users.

"Only the Ministry of Finance, those who are developing the system can have the access to all the information. They are given the rights. And if something is wrong in place like Luntshi or Trashigang (district), they will just send a mail and through the mail, they can have access to everything. What is wrong there and could make the correction". (P2)

These accounts were corroborated by the system documents, such as System Business Requirement Document (Ministry of Finance 2019a) and the e-PEMS user manual on party master (Ministry of Finance 2019d), user management (Ministry of Finance 2019e) and account payee master. (Ministry of Finance 2019f) The interview accounts detailed the steps and procedures to centrally update the master file in Section 5.2.

What is noteworthy on this compliance driver is that in addition to the central oversight capabilities in managing the master file, each transaction made in all offices across the country, regardless of location, can be accessed by the DPA team in the capital. It was a compelling factor to prompt compliance among the government employee users, especially in districts.

\subsubsection{TECHNOLOGY AND AUTOMATION}

Furthermore, the $e$-PEMS users underlined several technological features and automation in $e$-PEMS as compliance drivers. The e-PEMS compliance rate was $100 \%$ and it was because the system automated functions and services and was a realtime system, without delays in transactions which had been experienced in the previous check-based system.

"Why they are 100 percent compliant in the system is mainly because it is automated more or less, (it is) a real time system compared to the check system". (C8)

Transparency in transactions increased with the $e$-PEMS introduction and automation. Once the payee was selected and transaction was made in the system, the transfer was automatically effected to the payees account. Therefore, there was no space to manipulate.

"I think, now the fraud will be reduced, because we have all the list of vendors, list 
of employees working here. Once we punch in the names, (the payment) will go automatically to their respective account. There is no chance of manipulation or fraud or something like that. (R2)

Such technological features and automation generated fear, caution and carefulness among the $e$-PEMS users. Because the transaction and payment were electronic, it was processed instantly. Once the payment was processed from the respective account, there was no way to make a correction. Previously, passwords of staff had been shared, but now the password management was enforced and complied strictly by the $e$-PEMS users.

Automation in utility payment in the $e$-PEMS was cited as another example. Ministries and agencies had to pay various utility bills, such as electricity, telecommunications among others. The $e$-PEMS automated the process and generated the bill payment amount as some utility companies created an interface with $e$-PEMS, although, as detailed in Section 5.5, not all attempts to interface with external parties were successful.

The technology and automation introduced by the e-PEMS enabled instant electronic transactions and kept their records in the system in a systematic manner. This compliance driver led to adjustments on the government employee users' attitudes and behaviors and their enhanced compliance. There was no conflicting account across various data sources.

\subsubsection{TRANSPARENCY, VISIBILITY AND TRACEABILITY}

Additionally, several interviewees voiced transparency, visibility and traceability $e$-PEMS introduced as a compliance driver. Previously, the PEMS made unnecessary deductions and payments, as the system could have the same employee's information in two organizations and the system did not have the technology to detect the duplicate employee records. With the e-PEMS' new payroll module, the issue was resolved.

Another transparency brought by e-PEMS was the bank statement and reconciliation. In the previous check system, the actual cashing took time, sometimes months, after the issuance of checks. It was also challenging to identify who cashed the check, against the records available at the ministry and agency, as such cases could accumulate. Now, with the instantaneous payments and electronic records in the bank statement, any discrepancies could be spotted and tackled within the month, thus leaving little room for manipulation. 
"With the e-payment, what is most transparent is the bank statements. There is very little room for corruption. We know who has withdrawn the money". (Q1)

Previously, a possible manipulation had involved changing the payment amount on the check. In the new system and transparency it brought, such a practice was no longer possible.

Another feature the e-PEMS brought in was traceability, in addition to transparency. In PEMS, tracking and tracing was time consuming and almost impossible, when bank reconciliation was a complex task. In the new e-PEMS, the account information and payee can be easily tracked with the employee ID (EID) and tax payer's number (TPN) from the master file, which was centrally managed. Such transparency and traceability seemed to deter manipulation attempts and encourage compliance.

"If there is corruption, we have to go and search for the people; whose account is this and whose number is this. For e-payment, all the accounts are tracked and TPN (tax payer number) is tracked. I think there is transparency." (P5)

There was no conflict across data sources. It was clear in the interviews that the government employee users understood that there was no room for manipulation in the e-PEMS and they had to comply.

\subsubsection{E-PEMS IT SUPPORT}

Despite numerous issues the e-PEMS users encountered especially at the beginning of the deployment, the responsive IT support helped ensure user compliance. When technical and functional issues remained unanswered, it would be difficult for users to comply. In the case of e-PEMS, the interviews revealed that the IT support was responsive and resolved issues as they were reported.

When there were issues, the users sent e-mail to a group e-mail account which was established for the purpose and the issues were resolved in a time manner. User manuals and periodic information sharing and official notification upon system upgrades were also found useful. The same information and documents were also uploaded to the website. In addition to the official letters, they kept the accountants and finance officers in the loop on the system upgrades and changes.

When a user reported an issue, some corrections were normally made quickly, but at other times, it took longer, such as 2-3 days. Although the user would not know 
what was being done, what was reassuring to him or her was that the actions were being taken by the team to address the issue.

Reporting and explaining technical issues in e-mail was a challenge. In such a situation, accountants and finance officers personally went to the DPA office with their laptops.

"You have to write mail. Sometimes we had to take our laptops and go. Because through mail they (IT support team) don't understand much. Then you go personally down there (DPA) to solve our problems". (P5)

The last statement corroborated my observations at DPA where finance officers and accountants frequented to bring errors to the e-PEMS team physically during my fieldwork. There was no conflict across data sources.

\subsubsection{PEER SUPPORT AND PARENTING ARRANGEMENT}

One of the most striking features in the e-PEMS implementation is the sense of community, comradery and commitments to the profession, developed by the peer support and parenting concept of the Ministry of Finance. Facilitated by institutional instruments, such as promotion and transfer, these elements seemed to encourage mutual compliance among the e-PEMS users.

The strong bond, culture and traditions among accountants and finance officers also manifested as commitment to work. They set up an informal WeChat group and provided support to each other when they encountered problems in the $e$ PEMS use. By doing so, they were all able to learn from each other. The accounts were corroborated by other interviewees who said that issues were raised, discussed and resolved in that WeChat group.

"We have our (WeChat) group here, national accounts group. We discuss there. They (express) their own views and we'll solve the problem". (P5)

As the WeChat group included the officers from the Ministry of Finance, the support team also got to know the issues the users were facing.

As the system development and stabilization continued, the manuals and written materials became obsolete and the update did not catch up and keep pace with the fixing and therefore, the WeChat group turned out to be a very effective way to get things done for the users. The user manual was increasingly considered merely as broad guidance. 
All the accountants and finance officers reported to the MoF for transfer and promotion and to the working agency (where they are placed) for day to day financial management. One interviewee was happy to assist the working agency to disburse and manage funds, but they considered the Ministry of Finance as their parent agency where they belong to.

"All of us, all accountants are directly under the Ministry of Finance. We have to report to the Finance for transfer and promotion. We consider the Ministry of Finance as our parent ministry". (Q2)

Among the accountants and finance officers, the fact that the MoF, their parent agency, initiated the system seemed to have decisive impact on the level of compliance. Some interviewees shared that accountants and finance officers belonged to one professional category, according to the Civil Service Rules of Bhutan and promotion and transfers took place within the occupational group every five years. The view on this compliance driver among the e-PEMS users was very similar and seemed to ensure compliance among themselves.

\subsubsection{PERSONAL COMMITMENT}

It was not only the leadership and peer support which compelled compliance, but also individual commitment. What came out clearly during the interviews was the personal commitment of finance officers and accountants to doing the job well. Sometimes they had to reconcile between what the system required and the reality where not all financial decisions made at the working agencies conformed to the rules and regulations.

In response to a question on compliance across ministries and agencies, the interviews revealed that the compliance level indeed varied. In some agencies, when finance officers and accountants tried to comply and enforce internal checks, the other officers smartly found workarounds and different ways. The interviewees commented that the level of compliance depended largely on supervisors, finance officers and chief finance officers who should persevere and insist on compliance. In the lower administrative level of Gewog, or block, compliance depended fully on the accountants and their personal commitment.

"I don't think that the compliance is the same throughout the agencies. It will depend on the financial officer or the chief financial officer. They're the main people who should be complying, whether it's in the rules or through the system". (C4)

But internal checks and compliance were not always easy to ensure. It was the 
mandate of finance officers to follow the rules and regulations which was developed and sent by the Ministry of Finance, their parent agency. If the head of the working agency approved something beyond what the rules and regulations stipulated, it was the responsibility of the finance officers to advise the head of the agency. If the advice was not heeded, discrepancies may occur between the parent agency and working agency, and it took personal commitment to ensure the compliance.

"As a finance adviser or a finance personnel out here, it is our mandate to confine to the rules. Rules and regulations were framed and sent by the Ministry of Finance. We are here to apply that. When the approving authorities approved and sent to us (instruction), it is our mandate to check and advise the head, the one who approved, that something has gone wrong, you have approved beyond what is there in the rules". (Q1)

Sometimes, personal commitment also appeared in case of problems. As detailed in Section 5.5.2, the system has encountered a number of technical issues and the users demonstrated personal commitment to persist and resolve the issues.

"Sometime I send email. If that does not work, I go (to DPA) personally, because there are issues where e-mail cannot capture. If that (issue) is being kept pending for longer duration, party will make a complaint, (saying) that you have started epayment system. You are saying on press of a button, you will give the payment and you are taking 2 months and 3 months (to process a single payment). What is the use of implementing this system?". (P2)

In a small country like Bhutan, personal commitment detailed above is difficult to exercise on a daily basis, if a supervisor or head of agency do not comply with financial rules or e-PEMS steps and requirements. Several interviewees shared similar views on challenges they faced, across organizations and ranks in the hierarchy.

\subsubsection{FEAR FOR PUNISHMENT}

The finance officers and accountants feared that auditors would eventually find a misuse or fraud, if there was any such incidence, due to the transparency, visibility and traceability the $e$-PEMS introduced. In addition to the fear towards the ACC, the government employees respected and feared the audit authority for different reasons. The RAA conducted compliance audits among ministries and agencies, which provided additional impetus to enhance compliance (Anti-Corruption Commission 2015a). 
The interviews detailed how irregularities and lapses were found by the RAA and affected the finance officers and accountants in multiple ways. When the auditor found irregularities and lapses, the finance officer and head of the agency were held accountable and their names were recorded in the audit system. Bhutanese civil servants needed an audit clearance for wide ranging HR actions, such as promotion, transfer, training and scholarships to study abroad. If one's name was recorded in the audit system, an audit clearance would not be granted, and the opportunities for promotion, training and scholarships would be lost. As such, possible irregularities and lapses the audit may finds were a real cause of fear for finance officers and accountants.

Some ministries, such as MoF, have prominent posts abroad, such as in embassies, consulates and missions, for the service of three years. In the selection for these posts, the panel reviewed all aspects of candidates, including the audit clearance and any issue at the working agencies. Therefore, all finance officers and accountants were careful with their reputations and tended to comply, so as not to miss such opportunities.

"Now we have foreign postings and we get three years to serve in the embassies, consulates and missions. When panelists select (candidates) for foreign postings, they consider all those factors. So if there's any issue encountered in those agencies and if finance officers involved, then surely his selection will be affected. So yes they have to be careful with the reputation". (C4)

During the interviews, an actual example of punishment against a government official who stole government funds was shared.

"As time went by, it got accumulated. Today, Nu. 100,000 (\$1408), tomorrow Nu. 50,000 (\$704) and it got accumulated and then ultimately the audit (discovered it). And now she's is bearing the blunt of what she has done. She has been terminated, suspended. Now she has to refund all the money, with penalty interest and even face charges". (Q1)

In this case, the audit ultimately discovered the embezzlement, and the concerned government official was terminated and asked to refund all the money with penalty interests, while facing criminal charges. Such examples and cases triggered fear among the finance officers and accountants and encouraged them to comply. There was a unanimous fear for punishment among the e-PEMS users, without any conflict across data sources. 
Some interviewees mentioned the fear of their names appearing on the media, so called naming and shaming, as a major compliance factor and deterrent from corruption and fraud. In the past, some accountants were named in fraud and misuse cases in the media. That had impact on other finance officers and accountants.

"Because in the past there were cases, similar cases where accountants have misused the money. Their names appeared in the media. I think they (finance officers and accountants) fear of that". (C8)

The fear for naming and shaming affected the mindset of finance officers and accountants. Once someone or some cases got media attention, they were put under scrutiny, exposed. Other people may have compromising information related to fraud or misuse. It could easily be leaked to the media. When that happened, the names of the finance officer and head of the organization may appear in the media. Finance officers and heads of sectors had significant roles to play in the offices, and they did care if their names appeared in the media. Their reputations would be tattered and the Ministry of Finance would get to know the problem.

"If they don't comply and if there is an issue reported in the media, their reputation will be affected. And when their reputation is affected, it would be noticed by the Ministry of Finance." (C4)

The interview accounts were similar without any conflicting views on the effect of naming and shaming on compliance. It was the matter of not only their own reputation and opportunities but also impact on other people, including the head of agency, and the MoF, their parent agency.

\subsubsection{THE ROLE OF MEDIA AND SOCIAL MEDIA}

The fear for naming and shaming also impacted the government employees' relationship to media and discouraged whistleblowers to approach media. Because they were afraid of upsetting bosses or undermining his or her future career prospect, the government employees normally didn't wish to talk to the media even if he or she knew that something was wrong. Instead, they tended to resort to social media and hinted the wrongdoing, which could then be picked up by the mainstream media. But such cases were still rare. 
"Sometimes they use social media to hint people that there's something going on. Sometimes they give tip off to media but it is very rare. They (government officials) are really protective". (F3)

Social media provided an important platform for whistleblowers to raise awareness on corruption, which was then taken up by traditional print media in Bhutan. One whistleblower created a fake account on social media and posted the evidence of fraud. It prompted the ACC to initiate an investigation. The person in question, an administrator, was caught and eventually imprisoned, but it took the whistleblower more than two years.

"What happened is he created a fake account and put everything on social media. That prompted the ACC to investigate and that administrator was imprisoned. His case is still in the high court. But it took that whistle blower more than two years". (F4)

This new role of social media, providing a platform for whistleblowers, was also changing the relationship between traditional media and social media and the way traditional print media got news. Increasingly, the traditional mainstream media verified what was reported on social media. Initially, it was the broadcaster which broke news and print media would follow up. Now, the news was broken on social media first, and mainstream media then verified what was reported was true or not and produced an investigative report.

The interviewees from different organizations and functions provided consistent and similar views regarding the role of social media and media as a compliance driver. Because any irregularities and non-compliance could now be easily reported to social media, the employee users have become cognizant of the implications.

\subsection{E-PEMS CHALLENGES}

While it was widely acknowledged that the system has brought a significant level of efficiency, transparency and traceability, not everyone was onboard from the beginning and at the time of my fieldwork, challenges and shortcomings also surfaced in the interviews as well as during the observation period. The main challenges were categorized into 1) consultation and coordination among finance officers and accountants, 2) design and implementation, 3) application of advanced technology, 4) training and sensitization, and 5) internal control. 


\subsubsection{CONSULTATION AND COORDINATION AMONG FINANCE OFFICERS AND ACCOUNTANTS}

Several interviewees indicated that they had not been involved or consulted in advance, which perhaps led to some of the dissatisfactions expressed by some interviewees. Initial and iterative consultations and coordination may have been effective in addressing gaps and challenges identified by the RAA, such as internal control.

Some interviewees were not involved in the designing or re-designing of the system as well as development of functional specifications and requirements. Only after the launching, an order came to start using the system.

"I wasn't involved in any of the initial inception period. It was the mandate of the Department of Public Accounts. They had the core team there, e-PEMS support. Only after July when it was launched, it came as an order to us to start practicing, following the process, the payment systems". (Q1)

It was corroborated by other interviewees that consultation and coordination took place only with a few agencies based in the capital, due to the time limitation and completing requirements.

"To be frank, we had no discussion as such. Even when we developed this system, we had only a consultative meeting with the few agencies based in Thimphu, so just to check the readiness of going with the e-payment." (C4)

User and stakeholder consultations as well as consolidation of user requirements are fundamental steps for an ICT system design and implementation, supported by testing, user acceptance and communication. In the case of $e$-PEMS, several interviewees expressed their concerns on this point, taking into account the critical role the $e$-PEMS played in the public expenditure management for the entire government and country. In addition to consultation and coordination, one interviewee wondered if experienced developers should had been brought onboard and if proper testing had been conducted early on in the development process, as the interviewee was just informed that the system had been rolled out, without such information.

After the launch in July 2019, a series of technical and functional problems started surfacing, including in the payroll module of $e$-PEMS, such as the elimination of personal loan payment, as described in the Section 5.4. While the efficiency gains were recognized, several interviewees commented that the consultation and user outreach was not sufficient, and caused loan non-payment and defaults at agency banks. These issues could have been identified and addressed before the launch. 
What is striking about the e-PEMS development is that the design and implementation went through an unconventional system development approach of learning by doing. For instance, for the critical interface with banks and the RMA, normally a few rounds of testing would be expected. However, on the day I conducted interviews, I observed that there was a tense commotion among the key interviewees because the payment instructions sent to a bank from e-PEMS did not go through and there were complaints from users, evidenced also by the below account.

When the system was rolled out, the team did not have the clarity in some of the processes and detailed requirements to develop interfaces to external systems, such as utility companies. The e-PEMS development was characterized as agile, learning by doing. When the team encountered technical and functional issues, they consulted with the stakeholders and team members and fixed the issues in the system as they went.

"When in the initial phase, we rolled out the system, we were not clear about some of the processes because some of the processes are dependent on other stakeholders like utility payments. It was kind of a learning through doing. Whenever we faced issues, we consulted stakeholders and if we had to make changes in our system, we immediately discussed in our team and then we made changes". (C4)

The technical hiccups were also reported in newspaper articles. The notification in changes in personal loan deduction was made on 16 August, but the government employees were not sufficiently aware of the change, which led to loan defaults.

"The finance ministry has issued a notification on August 16 stating that only statutory and common deductions like taxes, health contribution, provident fund, house rent for government quarters, GIS and welfare fund would be facilitated by ePEMS." (Kuensel 2019b)

When system changes were introduced incrementally, they inevitably affected different parts of the system which were not designed to function and perform the way the new changes required the system to perform. If not carefully planned and orchestrated from the beginning, these new changes could trigger cascading and multiplying technical problems.

The system was just launched at the time of my fieldwork and since then, a number of improvements were introduced and the system was stabilized. However, unaddressed, such technical problem would no doubt undermine the confidence users may have in the system and increase doubt on why they have to use the system.

The unconventional development also manifested in the lack of documentation, 
such as System Requirement Specifications (SRS) documents and user manuals, and frequent changes to the design without change management governance, while already solutioning and after rollout. The interviews revealed that the team did not have time to update the SRS, while major changes were introduced to the system. Although the SRS was considered as a living document, it did not reflect even $50 \%$ of the system specifications.

There was an $e$-PEMS user manual, but because system changes were frequently made, the user manual could not be consulted when they were using the system, because these changes were not reflected in the document, either. Therefore, the WeChat group, mentioned in Section 5.4.9, may have been found most effective in addressing problems the users encountered in their daily operations.

Due to the frequent changes, it is uncertain if the fundamental principles of internal control and checks and balance were maintained or not, due also to lack of documentation and change control mechanism. When asked about the impact of these changes to the system design and development on internal control intended in the initial design, one interviewee had a doubt and there was no clear answer. The system was initially designed to put in place internal control and prevent misuse, but if the design was reopened and all the pieces in the system depended on each other, it was not sure how the internal control function would eventually work.

The implementation challenge was summarized well by one interviewee who compared the design and development experience to clinging to a floating boat and managed to stay afloat on the surface in the middle of the ocean.

"I felt that I was in the middle of the ocean. Maybe one boat was floating there. I just climbed on that and steered and stayed onto the surface. (C7)

\subsubsection{APPLICATION OF ADVANCED TECHNOLOGY}

Technology can do more to further enhance transparency, visibility and traceability as well as achieving the e-PEMS objectives, including recording user activities using logs. When inquired about these opportunities and potentials during the interviews and observations, I was informed that MoF was planning to implement a more comprehensive system and that the team was aware of the potential utility of advanced technology and the e-PEMS was a transitional measure.

"If you're talking about the kind of activity the person is doing (to track) we cannot (do that) as of now. We only know when he has logged in and he has logged out". (C3) 
The maker-checker concept was not entirely materialized in the current e-PEMS design, either. The current system has implemented 4 steps of maker-checker concept: voucher preparation, verification and approval, followed by the payment instruction to the bank. The design anticipated 4 different individuals to perform each step, but in reality, in smaller agencies, one person performed all steps, which created risks, as the below Section 5.5.5. detailed. The technology used was not able to accommodate different levels of internal checks (among central, district and block levels, or across budget entities and agencies).

"There are smaller agencies, like regional offices and Gewongs, or blocks. There, only one finance person is working. We are not able to put (4 steps) in the system. We do have provision, but we are not able to restrict it in the system". (C4)

Furthermore, the e-PEMS relied on hard copy and finance officers and accountants were still required to obtain approval on hard copies, in addition to the approval of vouchers in the system. When asked why the accompanying hard copies were needed in addition to the approval in the system, one interviewee responded by saying that it was an audit requirement, but the audit requirements could have been included in the design phase.

"When the audit people come, all they want is the documentation. That's why in the designing phase, we should have informed the audit". (P4)

To my question on the system capability to manage documentation trails, one interviewee explained that the details of the approval were not captured and were not available in the system. Without hard copy trails, an e-PEMS user would not be able to determine if the approval was obtained based on the supporting documents or not. What an e-PEMS user could see in the system was how much was transferred to which account and when, which was considered as a limitation in the current system.

"Because without those papers uploaded in the system, I cannot determine whether the approval is there or not. At the moment what I can say is okay on this day this much amount has been passed to this account number. I think here I can see one limitation (in the system)". (Q2)

Related to the issue of information and system security, some interviewees expressed concerns about the perceptions on system's security risks. Even banks suffered from hacking and banks normally have more secure systems. What about the government systems, an interviewee asked. It was the mandate of the finance personnel to secure the systems and make sure that the government funds were sent to the right destinations. 
In contrast to the ADS, the training and sensitization efforts of e-PEMS seemed limited. Although the $e$-PEMS functionalities were similar to those of PEMS, user training and sensitization among finance officers and accountants may have provided information and skills to address technical and user problems which followed the rollout of the e-PEMS in July 2019.

"They (government officials) are very much aware that government has initiated this e-PEMS system. We had one launching ceremony e-PEMS. We're in Thim$p h u$, we were called to the launching ceremony. And all the finance officers (attended). So that was the sensitization at the national level". (Q2)

Some $e$-PEMS users shared their experiences and felt that more sensitization, advocacy and training could be helpful, especially in the payroll module.

"One of the problems was that the Ministry of Finance has not done enough advocacy in terms of our finances (officials), regarding the payroll system". (Q1)

The training conducted by the $e$-PEMS team in Tsirang district in June 2019 seemed to have identified a number of functional and design challenges, after which the system was further enhanced, changed and updated, as corroborated by interviewee's accounts. It was believed that the shared comments and issues were being used for system design enhancement and development. There was no training after the 2019 training in Tsirang. Therefore, the effective functional training was not conducted for the numerous changes introduced before and after the launching of the system for the government employee users.

\subsubsection{INTERNAL CONTROL}

Despite the RAA audit observations, internal control appeared still weak in the $e$ PEMS. It was confirmed by several interviewees and evidenced by an incident. In a smaller organization, there was only one accountant who performed all the steps of voucher preparation, verification and approval in the system. In a larger organization, different officials were appointed to take each step, so as to enforce internal control. The interviews confirmed that there had to be a clear line and delineation of responsibilities for internal control to work.

In fact, the risk was widely recognized by most of e-PEMS user interviewees, if not all. In response, several interviewees shared the proposal of clustering accountants 
under one finance officer to add a supervision and oversight layer. One chief accounts officer could monitor and oversee all the accountants in the cluster, which should strengthen internal control in the districts.

"As far as I understand, there's a floating idea that the cluster system will be introduced in the districts, so that under one umbrella of accountants, its chief accounts officer will take care and monitor all the accounts (of the districts). In that case, the monitoring system will be stronger there". (Q1)

I asked various interviewees how the e-PEMS was technically set up to accommodate such an umbrella arrangement in providing monitoring functions across organizational units and accounts and enabling appropriate access. For example, one accountant is responsible for particular accounts in particular ministry or district, and not in other ministries and organizational units. If accountants were clustered and one chief accounts officer or finance officer needed to have access to all the accounts in the cluster, would the system be able to accommodate such a change and provide appropriate access to the chief accounts officer or finance officer in a flexible manner? The interviewees were not aware that the system needed to change the workflow in the system to accommodate such clustering or were not sure if the e-PEMS could technologically manage the clustering, as it was not designed from the beginning.

\subsection{SUMMARY: E-PEMS COMPLIANCE DRIVERS}

This Section 5.6. aims to list and summarise the compliance drivers associated with the $e$-PEMS implementation, followed by the challenges identified during the semistructured interviews. There were 13 compliance drivers identified as essential in the case study initiative of the e-PEMS. The drivers can be grouped into the leadership, social and technological compliance categories.

- $\quad$ Leadership compliance drivers: the role of His Majesty the King and leadership;

- Social compliance drivers: peer support and parenting arrangement, personal commitment, naming and shaming, the role of media and social media, fear for punishment;

- Technological compliance drivers; efficiency gains, familiarity with the existing system and east of use, centralized master data management and monitoring, technology and automation, transparency, visibility and traceability, e-PEMS IT support 
The first compliance driver was the role His Majesty the King played in promoting anti-corruption. Because he was revered and respected widely among the people, his words were found having overarching effects on government employee users' compliance. Another compliance driver identified during the interviews was leadership and credibility and authority commanded by the (MoF. Interviewees felt the need to heed the call from the MoF leadership and felt proud as a representative of MoF in the working agency. Particularly appreciated was the role the Secretary of Finance played in advocating for the e-PEMS around the country. Another interesting leadership attribute which emerged from the interviews was that ministers and secretaries across the government may not have been aware of the system functionalities and operations beyond the headlines, as the interviews confirmed that officers did not report to them how the system was operating in the respective ministries and agencies. Therefore, the responsibilities and accountability in managing the disbursement of financial resources and addressing the challenges fell on finance officers and accountants based on the mutual trust between the decision makers and e-PEMS users.

What was unique and distinctive about the e-PEMS users was the strong sense of belongings to the professional group under the Ministry of Finance, their parent agency. All the accountants and finance officers used a WeChat group where technical problems were shared and responded to by the peers. The Ministry of Finance as a parent agency had significant influence over the finance officers and accountants, although they were posted in different ministries and agencies, or working agencies, through their transfer and promotion. Such peer support was effective in ensuring compliance among the users.

Another compliance driver was associated with personal commitment of finance officers and accountants. They were mandated to follow financial rules and regulations, because of which the finance officers and accountants were occasionally placed in a difficult situation when the decisions made by the working agencies did not conform with the financial rules and regulations. This was the time when their personal commitment were tested. Personal commitment also appeared at a time when the finance officers and accountants faced technical problems and they had to persist and solve the problems for the benefit of payees and external parties.

There were two punitive measures which were found effective in encouraging compliance. One was the fear for punishment. Finance officers and accountants feared that the audit find irregularities and lapses, because of which they would not be able to obtain an audit clearance. It was needed for various HR related actions, such as transfer, promotion, training and scholarships to study abroad. An actual case of fund misuse and punishment imposed on an accountant was shared 
by interviewees, which seemed to enhance their fear for punishment. Associated fear among the finance officers and accountants was naming and shaming in the media. They feared that such exposure in the media would tatter their reputations and have negative implications professionally and personally. Thus, the finance officers and accountants were compelled to comply with the e-PEMS requirements. The media and social media were found playing a critical role. Social media provided a platform for whistleblowers who were otherwise unable to bring issues to the public. Some cases which were shared by whistleblowers on social media led to the ACC investigations as well as reporting on traditional mainstream media.

The $e$-PEMS examination discovered several technology and system related compliance drivers. Some interviewees cited efficiency gains from the introduction of electronic payments and elimination of manual checks. In particular, the removal of personal loan payment from the payroll module significantly reduced the workload of accountants and finance officers. Unlike manual checks, the new electronic payment was processed instantaneously, and saved costs. The payees didn't have to come from other districts and visit ministries and agencies to receive a check. There was a comment that people now didn't have to queue up at banks to receive cash from the salary and other payments in check. Another compliance driver was the familiarity with the system and ease of use. Most of the functionalities were similar between the previous PEMS and e-PEMS. Many interviewees felt that ePEMS was an upgrade to PEMS, because of the new technological features, such as more efficient bank statement reconciliation and utility bill payment.

The master file, including the employee, vendor and supplier data, was now managed centrally by the Department of Public Accounts e-PEMS team and therefore, there was little scope to manipulate transfer of funds to someone else's account which was not duly registered. Additionally, the DPA e-PEMS team was believed to have access to data and activities across organizations, and thus, any potential misuse and fraud could be identified centrally. Because of the transparency, visibility and traceability introduced by e-PEMS, the scope for corrupt and fraudulent practices diminished significantly. The problems associated with duplicate employees in the system, manipulation of manual checks and reconciliation between payments and bank statement were all resolved.

The e-PEMS IT support was responsive to the issues the users encountered in processing transactions. Manuals, notifications and common e-mail accounts were found useful, although some interviewees noted that the users didn't consult the manual, as changes were introduced to the systems and the manual was not updated to document these changes. Some said that they had to visit the DPA officer personally, as it was difficult to describe technical problems in e-mail. 
The $e$-PEMS users encountered a series of challenges in the designing and implementation phases. The main challenges were categorized into 1) consultation and coordination among finance officers and accountants, 2) design and implementation, 3) application of advanced technology, 4) training and sensitization, and 5) internal control. Unaddressed, these challenges may underline the credibility of the system and compliance level may decrease in a future.

The case study initiatives were selected with the criteria of local ownership and donor-funded ownership as detailed in Section 3.6. Local ownership was defined with government funding and system development by government employees. Donor-funded ownership is characterized by external donor funding and system development with external experts. The e-PEMS was selected as an example of donor-funded ownership, while the ACC was selected for local ownership.

When asked about donor-funded ownership of the e-PEMS and how important it was to interviewees, they had mixed responses and the accounts were not conclusive. The interviewees were aware that the development had been funded by the World Bank and there was an external consultant who was advising and participated in the system development. However, it did not appear to be a factor which came to their minds immediately as a distinctive factor. Several confirmed that donor-funded ownership could increase their trust in the system, while the others had no particular preference between local and donor-funded ownerships. Therefore, ownership may not have direct impact on compliance among the e-PEMS users. 
"We say that bad devil watching over you. And on the left shoulder there is like the good god. There is bad god and there is good god. His work is to advise you to do good things. And his work is to, you know, advise you (to) do good things he's recording" (A2)

\subsection{OVERVIEW OF THE CROSS-CASE SYNTHESIS}

Across the two case study initiatives examined in Chapter 4 and Chapter 5, similar and dissimilar compliance drivers emerged. This section contrasts similar and dissimilar compliance drivers to identify the determinants of compliance among the government employee users in the implementation of the two e-governance initia-

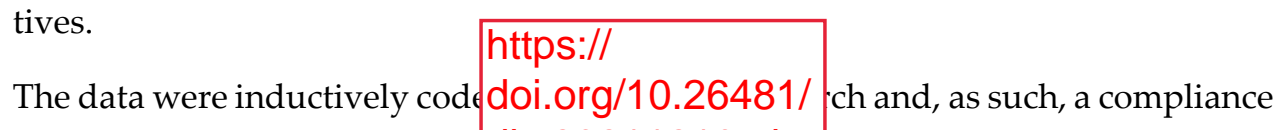
driver within each case study dis.20211210mh he interviewees referred to it. Therefore, within each case $\mathrm{s}$ named differently. Therefore, different case study initiative.

In this present research, a com erms were similar but were ay be termed differently in a inter-linked factors, attributes and conditions which are evidenced to have direct impact on compliance of government employee users in using e-governance systems. A compliance driver was developed using triangulation of data from multiple sources. A factor is considered a compliance driver when a) one interviewee mentioned a factor several times as an important factor and the driver was confirmed as existing through documents and observations; b) two interviewees mentioned a factor and other data sources confirmed the factor relevant; and c) when more than 3 interviewees mentioned the same driver with similar supporting mechanisms during the interviews. The category of the compliance drivers used in Section 4.6 and 5.6 followed a similar logic used to categorize compliance determinants identified in the existing literature review, detailed in Table 2 in page 44.

Some drivers were identical and interchangeable between the case study initiatives, despite the different case configurations. The others demonstrated dissimilar characteristics, partly because of the context surrounding the respective organizations and initiatives. Some drivers appeared both in positive and negative examples, but 
nonetheless, pointing to the same effect as a compliance driver. For example, training and awareness emerged as a compliance driver in the ADS but not in the $e$ PEMS. However, the lack of training was identified as a challenge in the $e$-PEMS. Therefore, although training and awareness are described in the below Sections 6.4 as dissimilarities, this present research concluded that it is a valid and effective compliance driver.

After the overview of the cross-case synthesis in Section 6.1, Section 6.2 presents and compares the 2 sets of compliance drivers as well as challenges identified in Chapter 4 and 5. The compliance drivers were grouped in the 4 categories of organizational, leadership, social and technological compliance drivers.

Section 6.3 then discusses in more details the similarities. All the compliance drivers in the leadership and social categories were very similar, identical or interchangeable across the two case study initiatives. Another compliance driver from the technological category also exhibited similarities. There was one similar challenge which was identified both in the ADS and e-PEMS.

The dissimilarities are then argued in Section 6.4. They are found predominantly in the organizational and technological categories as well as in challenges. This section also identifies positive and negative examples of the same compliance drivers, which may be presented as dissimilar compliance drivers and challenges.

The subsequent Section 6.5 explains the conditions, mechanism and context of compliance drivers in the case study country of Bhutan. In Chapter 4 and 5, dependence and inter-dependence were narrated among compliance drivers, which are synthesized as a condition of compliance driver in Section 6.5.1 and 6.5.2 respectively. The relationships among compliance drivers and the nature of the relationships derived from the interview accounts and document analysis. Section 6.5.3 then explores the mechanism which may explain the functioning of compliance drivers, mechanism and space. Section 6.5.4 places the compliance drivers, mechanism and space in the Bhutanese context. The chapter concludes with the summary of the Chapter 6 in Section 6.6.

\subsection{OVERVIEW OF SIMILARITIES AND DISSIMILARITIES BETWEEN ADS AND E-PEMS}

This section compares the similar and dissimilar compliance drivers which emerged from the two case study initiatives of the ADS of the ACC and the e-PEMS 
of the Ministry of Finance $(\mathrm{MoF})$ in Bhutan. Similar compliance drivers are placed side by side in the summary Table 15, followed by comparison of similar and dissimilar challenges identified in Section 4.5 and Section 5.5. The similarities and dissimilarities are discussed in more detail in Section 6.3 and 6.4 respectively.

Compliance drivers of the two case study initiatives are grouped by the categories used in Section 4.6 for the ADS and Section 5.6. for e-PEMS, namely organizational, leadership, social and technological. Table 15 presents the overview of compliance drivers under each of the 4 categories.

Table 15: Similarities and dissimilarities between ADS and e-PEMS compliance drivers

\begin{tabular}{|c|c|c|}
\hline Category & ADS Compliance Drivers & E-PEMS Compliance Drivers \\
\hline $\begin{array}{l}\text { Organiza- } \\
\text { tional }\end{array}$ & $\begin{array}{l}\text { Credibility and Trust in the } \\
\text { Organization } \\
\text { Organizational Setup } \\
\text { Training and Awareness }\end{array}$ & \\
\hline Leadership & $\begin{array}{l}\text { The Role of His Majesty the } \\
\text { King } \\
\text { Leadership in the Govern- } \\
\text { ment }\end{array}$ & $\begin{array}{l}\text { The Role of His Majesty the } \\
\text { King } \\
\text { Leadership in the Government }\end{array}$ \\
\hline Social & $\begin{array}{l}\text { Peer Support } \\
\text { Personal Commitment } \\
\text { Naming and Shaming } \\
\text { The Role of Media and So- } \\
\text { cial Media } \\
\text { Fear for Punishment }\end{array}$ & $\begin{array}{l}\text { Peer Support and Parenting Ar- } \\
\text { rangement } \\
\text { Personal Commitment } \\
\text { Naming and Shaming } \\
\text { The Role of Media and Social } \\
\text { Media } \\
\text { Fear for Punishment }\end{array}$ \\
\hline Technological & $\begin{array}{l}\text { Technology-enabled Ease of } \\
\text { Use } \\
\text { Monitoring, Verification } \\
\text { and Follow-up }\end{array}$ & $\begin{array}{l}\text { Efficiency Gains } \\
\text { Familiarity with the Existing } \\
\text { System and Ease of Use } \\
\text { Technology and Automation }\end{array}$ \\
\hline
\end{tabular}




\begin{tabular}{|l|l|l|}
\hline & $\begin{array}{l}\text { Technical Support and Re- } \\
\text { sponsiveness of the ACC } \\
\text { Team }\end{array}$ & $\begin{array}{l}\text { Centralized Master Data Man- } \\
\text { agement and Monitoring }\end{array}$ \\
& $\begin{array}{l}\text { Transparency, Visibility and } \\
\text { Traceability }\end{array}$ \\
& E-PEMS IT Support \\
\hline
\end{tabular}

One salient feature which emerged from the comparison between the 2 sets of compliance drivers is that there was no $e$-PEMS-related compliance driver under the organizational category. Although parenting arrangement was mentioned by interviewees, it was referenced in the context of describing their attachment and professional belongings to the Ministry of Finance which was their motivation to comply with the $e$-PEMS.

Another interesting feature in Table 15 is that there are more technological compliance drivers in the $e$-PEMS than in the ADS. What is equally interesting is the fact that leadership and social compliance drivers are almost identical and interchangeable, as elaborated in the Section 6.3.

In addition, Table 16 lists the challenges identified between the ADS and e-PEMS.

Table 16: Comparison of challenges

\begin{tabular}{|l|l|}
\hline ADS Challenges & E-PEMS Challenges \\
\hline Application of Advanced Technology & Application of Advanced Technology \\
\hline Doubt in the Effectiveness of ADS & $\begin{array}{l}\text { Consultation and Coordination among } \\
\text { Finance Officers and Accountants }\end{array}$ \\
\hline Reluctant Compliance & Design and implementation \\
\hline & Training and Sensitization \\
\hline & Internal Control \\
\hline
\end{tabular}

The only similar challenge found in the 2 case studies is the need for application of advanced technology, as both systems would benefit from using more advanced technologies to further encourage compliance. However, the other differences are dissimilar and not comparable. 
Section 6.31 discusses the details of similar compliance drivers under the Leadership and Social categories as well as one similar challenge, namely application of advanced technology. One exceptional addition to similarity is the compliance around technology-enabled east of use (ADS) and familiarity with the existing system and ease of use /Technology and Automation (e-PEMS) which demonstrated very similar characteristics. Section 6.4 details the dissimilarities found in the organizational and technological categories as well as dissimilar challenges in the two case study initiatives.

\subsection{SIMILARITIES}

This section provides detailed accounts of similarities along the category and where and how they were found similar.

\subsubsection{LEADERSHIP CATEGORY}

The reverence expressed towards His Majesty the King was identical and interchangeable between the case study initiatives. His efforts to promote digitization and anti-corruption had an overarching and profound effect on the government employee users' believe, attitudes and behaviors. The reverence and respect were also frequently found in documents and newspaper articles related to the ADS and $e$-PEMS. It was explained in a significant number of interviews that no one would go against the words of His Majesty the King, and a significant amount of interview time was spent on the government employees describing their admiration towards Majesty the King.

Leadership in the respective agencies was also identified as an essential compliance driver. The ADS compliance was invariably high where the leadership was supportive to the work of the Asset Declaration Administrators (ADA) and the interviews also discovered that the leadership in the Ministry of Finance (MoF) had positive impact on the compliance among the $e$-PEMS users.

Interestingly, in both case study initiatives, leaders were referenced as not technologically aware and were not involved in technical and technological discussions, guidance and decisions. Leadership in both initiatives instead created enabling environments where timely system changes and urgent updates could take place nimbly and flexibly, based on the trust between leadership and technical and functional team members. 
The compliance drivers in the social category were very similar, identical or interchangeable between the two case study initiatives. Proactive ADAs created a peer support mechanism within agency, such as an informal WeChat group, to fulfill their functions. The WeChat group was found effective to ask and answer questions among the members and remind each other the concerned rules and regulations. The immediate responses and advice from the WeChat membership were found effective to facilitate the ADS compliance. The $e$-PEMS users also established a WeChat group among finance officers and accountants. The group was particularly useful to address technical issues the e-PEMS users encountered on a daily basis. When the e-governance system was updated and upgraded continuously, the documentation, such as policies, regulations, system requirement documents, manuals, guidelines and instructions, may not have always reflected the latest and new system features. In the absence of such reference documents, the group was one of the few sources which could help address the issues and ensure the continuation of daily operations.

In addition, the proactiveness of ADAs was a frequently cited compliance driver, whereas the compliance level of agencies with inactive ADAs was reported low. ADAs were HR officers and therefore, the declarants feared that late- or non-declarations would affect the declarants' career, such as promotion and transfer. The personal commitment also appeared within the ADS support team. Despite the time pressures and intensified workload at the time of declaration, the team made sure that the system was up and running.

The e-PEMS users, on the other hand, had to reconcile the system's requirements and what the working agencies decided on. Finance officers had a difficult task of advising the head of working agency if he or she approved beyond the financial rules and regulations stipulated. It took personal commitment to ensure the compliance in such scenarios. The e-PEMS users' commitment also appeared in their commitment and persistence in addressing numerous technical issues they encountered in the system. They personally and frequently visited the DPA to solve the problems. They feared that if they did not address the issues in a timely manner, the payees would complain and cast doubt on the benefits of $e$-PEMS which was launched and initiated by their parent agency, the Ministry of Finance (MoF).

Another effective compliance driver was naming and shaming, as the government employee users were very sensitive to being implicated negatively in the media. ACC published the non-declarants' functions and organizations on their website, which were subsequently reported in the mainstream media. In the case of $e$-PEMS, some accountants were named in fraud and misuse cases in the media, which had 
noticeable impact not only on the named accountants but also on other finance officers and heads of organizations alike. The naming and shaming were intrinsically inter-linked with the role played by media and social media. The interviewees felt that the media was keeping a check on corruption cases. Social media was increasingly becoming popular in Bhutan with a wide geographical coverage. Social media now provided a platform for whistleblowers, which was then picked up by mainstream media for more investigative reporting.

Fear for sanctions, ACC investigation, interrogation, prosecution and other punishment associated with non-compliance were frequently expressed as an effective compliance driver. Especially feared were the fines imposed for late and non-declarants of ADS. Such penalty was believed to destabilize otherwise stable lives of the government employee users. The ADS declarants also feared that hidden assets and inaccurate declarations would be uncovered in future, if not now. The e-PEMS users also feared that any misuse would eventually be discovered by the Royal Audit Authority (RAA). There were previous cases where accountants were found guilty for embezzlement and frauds. The accountants in question were terminated, prosecuted and asked to return the money with interests.

\subsubsection{TECHNOLOGICAL CATEGORY}

The government employee users commented that both systems were easy to use. In the case of ADS, the declaration took only 10-20 minutes for the majority of declarants, which generated positive experience among the users. The ADS has been in use for 10 years and the familiarity with the system grew steadily among the users. Password generation and notification were automated, while the previous records were maintained in the system as reference. Similarly, the e-PEMS was an upgrade to PEMS and therefore, the users were familiar with most of the steps and functionalities in the system. Additionally, technology and automation were found effective and certain functions, such as electronic payments and utility payments, were automated by e-PEMS.

\subsubsection{SIMILAR CHALLENGE}

There was a similarity in an identified challenge. In both case study initiatives, limited application of advanced technology was identified as a challenge, as 
contrasted in Table 16, although where and how the advanced technology should be applied varied to reflect the realities surrounding the initiatives.

The ADS was found limited in interfacing with other systems which managed land records, banks, vehicle registrations, among others. With such interfaces, the declarants would not need to enter the data and information in ADS, and the data would be accurate and would not need verification. The Internet connectivity was also identified a challenge for declarants in remote and rural areas.

The advanced technology could do more to enhance transparency, visibility and traceability of $e$-PEMS. The current design and technology did not accommodate the clustering arrangement of flexibly assigning verifying and approving officers across organizational boundaries, while internal control and security could be further strengthened with advanced technology with user and activity logs. The system could also integrate associated documentation capabilities in the system instead of relying on hard copy for physical approval.

This limitation in the use of advanced technology is not a surprise, as Bhutan was selected from the category of countries with High Control of Corruption by the Worldwide Governance Indicators (WGI) and Medium in UNDESA E-government Survey in Section 3.3. The analyzed data presented in this chapter validated the assumption used in the selection of the case study country and matched the expectations of Bhutan being high in control of corruption and medium in the use of egovernment technology.

The identical and inter-changeable compliance drivers may be found in other initiatives in Bhutan, and/or similar initiatives of other countries where compliance is high. This could be a topic of future research.

\subsection{DISSIMILARITIES}

This section now turns to the dissimilar compliance drivers identified in Chapters 4 and 5. Some compliance drivers show distinctive features, unique to the respective organizations, initiatives and contexts where the systems were situated in. Using the same method to illustrate similarities in Section 6.3, this section explains dissimilarities and offers insights on where and how they manifested. 
In ADS, the credibility in ACC was accompanied by fear for its investigation and interrogation functions, although it was well respected and considered as doing a good job. The ACC is a constitutional body mandated to tackle corruption and the Chair was appointed by His Majesty the King. Therefore, the ACC could command respect and compliance among the ADS users. Besides, ACC is an oversight agency which could enforce other agencies to comply, including through naming and shaming. The MoF has the credibility, budget and authority to command compliance among the finance officers and accountants, because they report to MoF, but the level and reach of influence, respect and fear ACC generated across the government was not comparable.

Some ministries went beyond what was required and made additional organizational arrangements and setups to ensure ADS compliance. These measures had direct and indirect impact on the government employee users despite the size, complexity and geographical spread of the organizations. However, unlike the e-PEMS users, ADAs and ADS users were diverse, which necessitated these additional organizational arrangements and there was no parenting arrangement among ADAs who were mainly HR officers.

Training, awareness raising and advocacy were effective compliance driver of ADS, while the lack thereof was identified as a challenge in the case of $e$-PEMS. The ADS users informed during the interviews that they would not consult the ADS user manuals and preferred more inter-personal information sharing, despite the fact that the user manuals detailed the steps and what needed to be done. The sensitisation, advocacy and awareness raising demonstrated what to do and not to do in the way users understood. The notification was also sent out widely on traditional print media and broadcasting services every year from January. Interestingly, the lack of training and awareness was identified as a challenge in the $e$-PEMS. It will be discussed in more detail in Section 6.4.3.

\subsubsection{TECHNOLOGICAL CATEGORY}

More diverse technology-related compliance drivers were found in the e-PEMS than in the ADS. The $e$-PEMS users cited efficiency gains as a compliance driver, which did not appear in the case of the ADS. With the introduction of $e$-PEMS, the monthly payroll was run more efficiently, while electronic payment transactions replaced time-consuming manual check systems. The efficiency gains were 
reported not only among the $e$-PEMS users but also government employees at large who received salary deposited electronically into their accounts and payees who received payment instantaneously.

Monitoring, Verification and Follow-up (ADS) and Transparency, Visibility and Traceability (e-PEMS) could be comparable compliance drivers but presented significant dissimilarities. The declarations submitted to ADS were monitored, verified and followed up to identify possible illicit enrichment of asset by the asset declaration team at ACC, which was found effective to convince the declarants to declare honestly, but the majority of the steps still relied on human interventions and the ADS did not offer transparency, visibility and traceability at the time of the fieldwork.

The transparency, visibility and traceability brought by $e$-PEMS were very effective to compel compliance. Transparency and traceability manifested in the bank statement and reconciliation. Unlike the previous check system, it was now faster and easier to identify payments, payees and dates of payments to track the movement of money, leaving little room for manipulation. Any discrepancies in payment could be spotted in a timely manner in the e-PEMS.

Centralized Master Data Management and Centralized Monitoring was a unique feature of $e$-PEMS. The creation of employees and vendor payees in master data or file was now centrally managed by DPA. The centralized control and monitoring were effective in deterring users from non-compliance and attempting misuse and manipulation in the system. There was no centralized master data management function in the ADS.

Technical Support and Responsiveness of the ACC Team (ADS) and E-PEMS IT Support (e-PEMS) demonstrated dissimilarities in many different aspects. The ADS IT support team was found helpful in responding to the user inquiries quickly. The ADS functional team was supportive and actively reached out to users for any areas of improvements, thus working in tandem with the IT support team. The feedback was productively used to improve the systems continuously, so that it has become more user-friendly and responsive to users' needs and requirements.

The value of $e$-PEMS support team was found in responding to and resolving bugs and technical issues. Although not all the technical issues were resolved instantly, the users were comforted by the fact that the IT support team was taking action to address the issues and complied, despite numerous challenges the users faced. However, the functional and IT teams of the $e$-PEMS operated differently and were less responsive to the users than the ADS teams. The lack of consultations and coordination among accountants and finance officers, as well as unconventional system design and implementation triggered a number of challenges, as detailed in the below Section 6.4.3. 
There were several initiative specific, dissimilar challenges identified in the examination of the 2 initiatives. The ADS related challenges centered on how effective the asset declaration and ADS were to actually prevent corruption, while the $e$ PEMS related challenges were more on technical in nature and related to system development.

While the e-PEMS users demonstrated little doubt about the utility of $e$-PEMS, the ADS users expressed doubts about how useful the system and asset declaration were to reduce actual corruption. While the majority of users thought that the ADS was a good initiative and some professional groups were more committed than others, they believed that the system was not sufficient to prevent corruption and not all users declared their assets honestly. The interviews also revealed that the verification of declarations was not sufficiently rigorous so as to fulfill the mandate of detecting illicit enrichment.

Unlike the $e$-PEMS users, some ADS users considered the asset declaration in the system more of a burden, formality and bureaucratic and administrative requirements. The others did not take the asset declaration seriously and did not see how the system was a means to ensure integrity and prevent corruption among the government employee users. Thus, the system so far did not provide satisfactory answers to the questions and doubts of declarants in a concrete manner, other than a broad anti-corruption strategy and drive.

While the above ADS challenges are initiative specific, the following challenges identified in the e-PEMS were something the ADS users found as compliance drivers in the above Section 6.4.2. Unlike the ADS upgrades and improvements, the revamping of e-PEMS did not involve a wide consultation and coordination of finance officers, accountants and key stakeholders in advance. The consultation and coordination to develop functional and technical requirements seems to have been limited due to time and resource constraints, which later manifested in the gaps and technical issues at the implementation stage. The challenge also manifested in limited testing, outreach and communication to government employees at large when the personal loan payments were discontinued in July and August 2019. In contrast to this negative example, the ADS presented a positive example as ADS IT Teams responsiveness to the users, described in Section 6.4.2. Therefore, despite the fact that the IT teams and their responsiveness was discussed as a dissimilarity, it will be included as an effective compliance driver in the present research.

As the PEMS and e-PEMS were similar, large scale efforts might not have been required. However, training and sensitization may have equipped users with 
information and skills needed to address the numerous technical issues which surfaced after the rollout in July 2019. This contrasted with the fact that training and awareness was a compliance driver under the ADS, while the lack thereof under the $e$-PEMS was identified as a challenge.

There were unique challenges applicable only to the e-PEMS, which concerned design and implementation in revamping the system. Critical features in electronic payments, namely the interfaces with BoB and other banks, were at times not functioning when the fieldwork was conducted. The interviews revealed that there was not sufficient clarity in some of the processes and requirements. Rather, the development of e-PEMS, which was the critical backbone of the government financial management, was described as learning by doing and the team fixed the technical issues as they went along. This incremental development approach was found risking the design integrity and internal control embedded in the system design from the beginning. This unintended development approach also appeared in the lack of documentation which should normally guide and document the system features, functionalities, changes made to the design and why.

Unique to the e-PEMS, weak internal control was identified as a challenge. The maker-checker concept did not always apply in smaller agencies and some accountants in remote locations worked independently without much supervision. Without embedded internal control in the system, such a situation provided opportunities for fraud and misuse despite the improved transparency, traceability and visibility and other benefits of $e$-PEMS, evidenced by several incidents of misuse.

Despite the challenges, the compliance levels in both case study initiatives were high at the time of the fieldwork. This signifies that the challenges were not unsurmountable and in fact they were overcome by the positive, enabling compliance drivers detailed in Section 6.3 and 6.4. Additionally, Bhutan has potential internal resources to address some of the identified challenges, as will be detailed in Section 6.5 .

In the future, however, the above-mentioned challenges could become more detrimental bottlenecks or hinderances which may affect the functioning of enabling compliance drivers and eventually decrease the level of compliance, if unaddressed. For example, less effective leadership or limited credibility and trust in the ACC or MoF could increase doubt on the merits in declaring assets among the declarants and on e-PEMS among finance officers and accountants. Unaddressed, lack of internal control may lead to fraud and misuse among finance officers and accountants, which may then lead to less personal commitment and peer support. 
The above Section 6.3 and 6.4 identified similar and dissimilar compliance drivers and challenges. Similar compliance drivers were found in the leadership and social categories, with some technological compliance drivers as well as training and sensitization and responsive IT teams as evidenced by positive and negative examples. There is a likelihood that these similar compliance drivers would be found in other initiatives in the context of Bhutan or in similar initiatives in other countries that meet the country selection criteria. Dissimilar compliance drivers, found in the organizational and part of technological categories, are effective to the specific contexts of the respective organizations and initiatives.

Some compliance drivers are dependent on other drivers to be effective. This section discusses the relationships between compliance drivers, mechanism for the compliance drivers to work and context in which the compliance drivers and mechanisms are placed. This section thus explains the dependence and inter-dependence among compliance drivers and how the compliance drivers function as a mechanism in the Bhutanese context. In this research, dependence is defined as a uni-directional dependence, while inter-dependence is defined as a relationship where dependence is mutual and runs in both directions. The former is detailed in Section 6.5.1 and the latter in Section 6.5.2.

This present research then proposes that the aggregation of dependence and interdependence relationships constitutes the compliance mechanism, while the number of compliance drivers constitutes the compliance space. The mechanism of compliance drives is elaborated in Section 6.5.3, followed by Section 6.5.4 which extends the narrative to contextualize the compliance mechanism in the Bhutanese context.

6.5.1. DEPENDENCE AMONG COMPLIANCE DRIVERS AS A CONDITION

The accounts emanating from Section 4.4 and 4.5 elicited a number of dependence relationships among the compliance drivers. In this present research, a compliance driver is defined as a group of inter-linked factors and attributes which are evidenced to have direct impact on compliance of government employee users in using e-governance systems. This section identifies the main dependence relationships to help construct the compliance mechanism. The nature of the relationships of compliance drivers were derived from the interview accounts and document 
analysis. The special emphasis is placed on similar compliance drivers, as they are likely to be widely found in the Bhutanese context, while dissimilar compliance drivers may only be found in that particular organization and initiative. In particular, I will describe the dependence of leadership on naming and sharing, peer support on social media, ease of use on responsive IT team. There was dependence among technology-related compliance drivers: efficiency gains, transparency, visibility, traceability, monitoring and verification all depended on technology and automation as well as fear for punishment on technology.

Each dependence is listed in Table 17. When Compliance Driver A depends on Compliance Driver B, a uni-directional arrow points from B to A to illustrate the relationship of which compliance driver should be in place first.

Table 17: Direct dependence relationships among the compliance drivers

\begin{tabular}{|c|c|}
\hline Dependence relationships & Narratives \\
\hline $\begin{array}{l}\text { Social } \\
\text { Media }\end{array}$ & $\begin{array}{l}\text { Peer support depended on social } \\
\text { media, such as WeChat groups, } \\
\text { which enabled a large number of } \\
\text { peer to join on a common platform } \\
\text { to exchange information and ask } \\
\text { questions, regardless of where the } \\
\text { peer was. In the absence of docu- } \\
\text { mentation and guidelines, social } \\
\text { media provided an essential ave- } \\
\text { nue to peer support on a sustaina- } \\
\text { ble basis. }\end{array}$ \\
\hline $\begin{array}{c}\text { Respon- } \\
\text { sive IT } \\
\text { Support }\end{array}$ & $\begin{array}{l}\text { The ease of use of the systems was } \\
\text { dependent on the responsiveness of } \\
\text { IT support. Not all systems are easy } \\
\text { to use, without responsive IT sup- } \\
\text { port team and their efforts towards } \\
\text { improvements in the systems. In } \\
\text { both ADS and e-PEMS, there were } \\
\text { significant efforts made by their re- } \\
\text { spective IT support teams to ensure } \\
\text { the optimal functioning of the }\end{array}$ \\
\hline
\end{tabular}




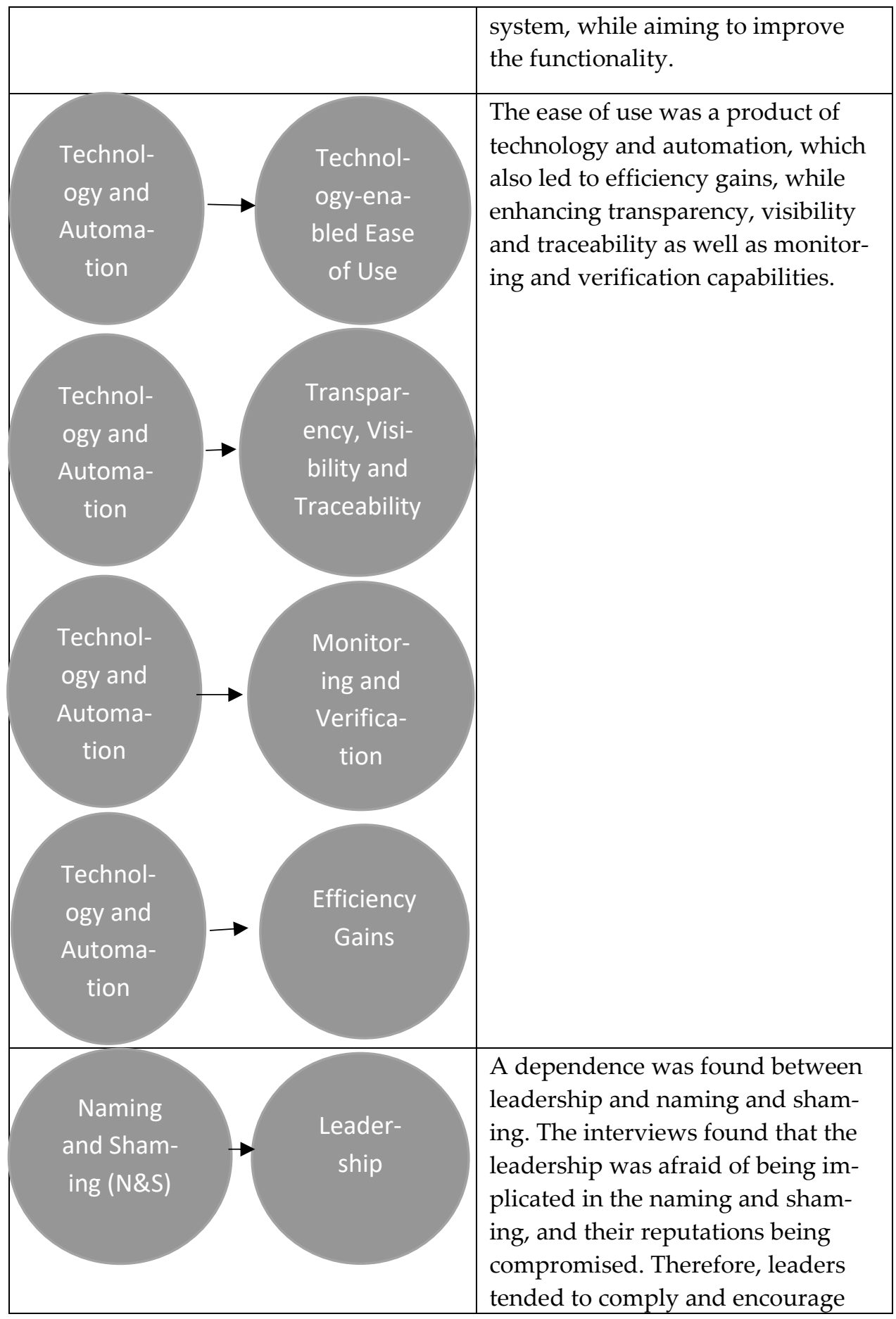




\begin{tabular}{|c|l|}
\hline \begin{tabular}{|l|} 
Technol- \\
ogy and
\end{tabular} & $\begin{array}{l}\text { the staff to comply, due to the fear } \\
\text { for naming and shaming. }\end{array}$ \\
\hline $\begin{array}{l}\text { Automa- } \\
\text { tion }\end{array}$ & $\begin{array}{l}\text { Fear for } \\
\text { Punish- } \\
\text { on technology which provided } \\
\text { monitoring capability and traceabil- } \\
\text { ity in the system. The users knew } \\
\text { that those who had committed } \\
\text { fraud were found due to the tech- } \\
\text { nology and were penalized previ- } \\
\text { ously, which served as an effective } \\
\text { deterrence and compliance driver. }\end{array}$ \\
\hline $\begin{array}{l}\text { Transpar- } \\
\text { ency, Visi- } \\
\text { bility and }\end{array}$ & $\begin{array}{l}\text { The users also feared that they } \\
\text { Traceabil- } \\
\text { ity }\end{array}$ \\
\hline
\end{tabular}

One of the criteria used to select case study initiative was the concept of ownership, defined in this study as funding source (government funded or donor funded) and developers (local or foreign). Section 4.6 and 5.6 explained that the ownership did not appear as a direct compliance driver, but an indirect compliance driver which created dependency relationships with several compliance drivers.

As part of the examination of the ADS, Section 4.6 referenced to the ownership's impact on other compliance drivers related to the responsiveness of ADS IT support team, technology and automation, technology-enabled ease of use and personal commitment, thus clearly evidencing the dependence. The ADS was selected as a case study initiative for its government funding and system development by government officials. There were fewer challenges identified by the government employee users than the $e$-PEMS.

Similarly, Section 5.6 examined the effect of ownership on other compliance drivers in the case of e-PEMS. While several interviewees mentioned that donor funding and foreign experts would increase trust in the system, there were conflicting accounts and the dependence did not emerge as clearly as in the case of ADS. At the same time, a number of coordination, design and development and 
training/awareness issues surfaced during the examination of this case study initiative, unlike the case of the ADS. The e-PEMS was selected as a case study initiative for donor funding and development with foreign expertise.

Thus, it is inferred that ownership is an effective, indirect compliance driver which functions through dependence with other compliance drivers in the case of initiative with local ownership. However, an initiative of donor funding does not exhibit similar traits and trigger similar impacts, which may manifest in qualitatively less personal commitment, responsiveness of the IT team and technology-enable ease of use. Subsequently, they are translated into more challenges which may negatively affect the level compliance.

\subsubsection{INTER-DEPENDENCE AMONG COMPLIANCE DRIVERS AS A CONDITION}

Similarly, a number of inter-dependences were identified among the compliance drivers in Section 4.4 and 5.4. The nature of the relationships of compliance drivers were derived from the interview accounts and document analysis and listed in Table 18 .

Table 18: Inter-dependence relationship among the compliance

\begin{tabular}{|l|l|}
\hline Leader- & $\begin{array}{l}\text { In the case study initiatives, leader- } \\
\text { ship took a form of providing an en- } \\
\text { abling environment where the } \\
\text { changes and initiatives can be pro- } \\
\text { posed and implemented by the IT } \\
\text { and functional teams. The leaders } \\
\text { may not have sufficient IT } \\
\text { knowledge to lead development and } \\
\text { implementation of IT systems, but } \\
\text { the inter-dependence between }\end{array}$ \\
\hline
\end{tabular}




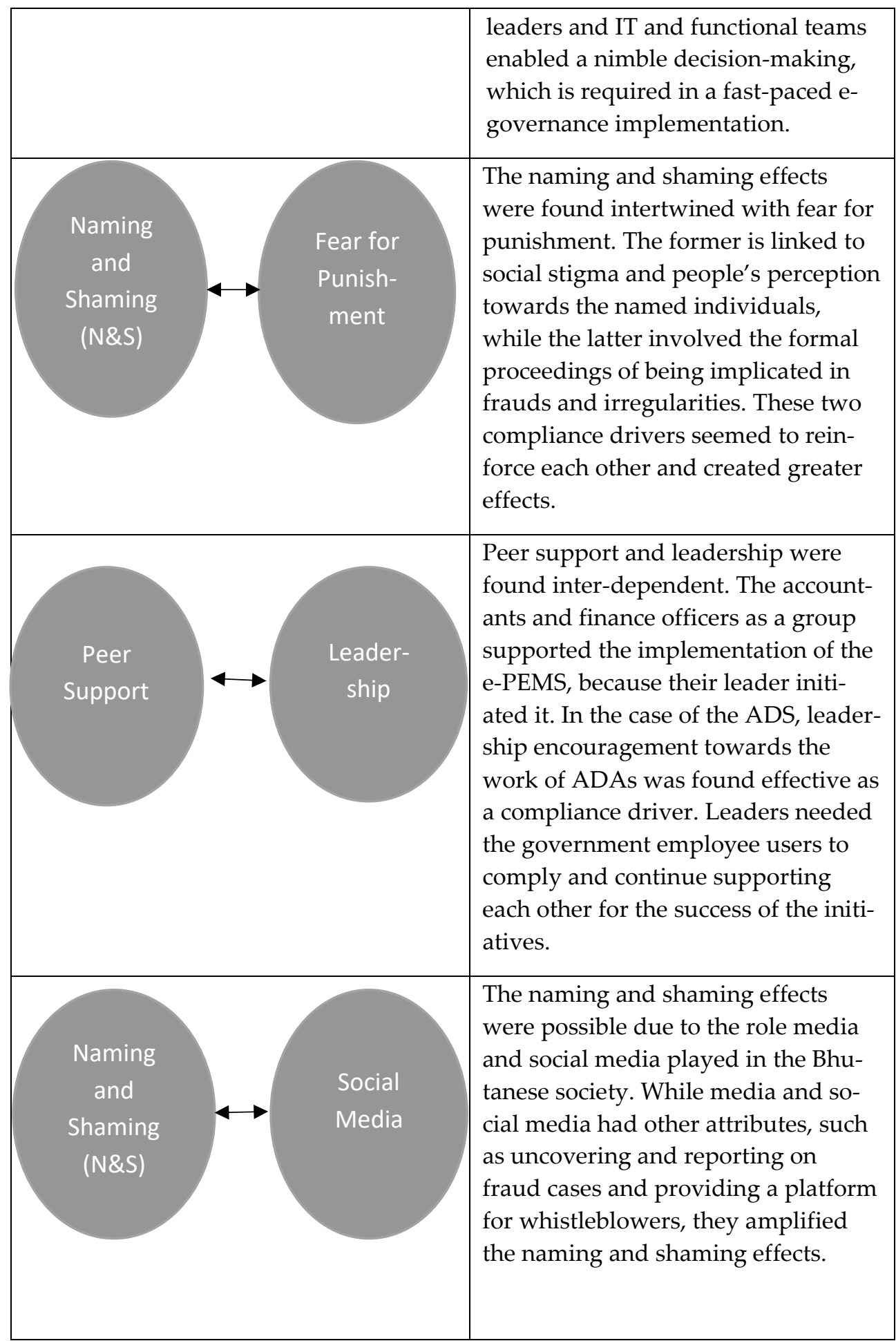




\begin{tabular}{|l|l|}
\hline Training, & $\begin{array}{l}\text { Peer support, personal commitment } \\
\text { and training/sensitization were } \\
\text { found inter-dependent, supporting } \\
\text { each other. Each compliance driver } \\
\text { was effective but the combination of } \\
\text { the three inter-linked compliance } \\
\text { drivers may have been more resilient } \\
\text { to setbacks and lack of one of the } \\
\text { compliance drivers may not signifi- } \\
\text { cantly affect overall compliance. } \\
\text { Training and awareness was identi- } \\
\text { fied as a challenge and negative ex- } \\
\text { ample in the } e \text {-PEMS. }\end{array}$ \\
\hline
\end{tabular}

\subsubsection{MECHANISM OF COMPLIANCE DRIVERS}

In this section, the above dependence and inter-dependence relationships are aggregated into Figure 16 to illustrate the overview of compliance mechanism, followed by the detailed narratives of the mechanisms. Although there were more relationships, this section focused on relationships centered around similar compliance drivers. Dependence is depicted with a unidirectional arrow, while interdependence with a bi-directional arrow in Figure 16. Where Compliance Driver A depended on Compliance Driver B, the uni-directional arrow points from B to A to illustrate the relationship of which compliance driver should be in place first. 


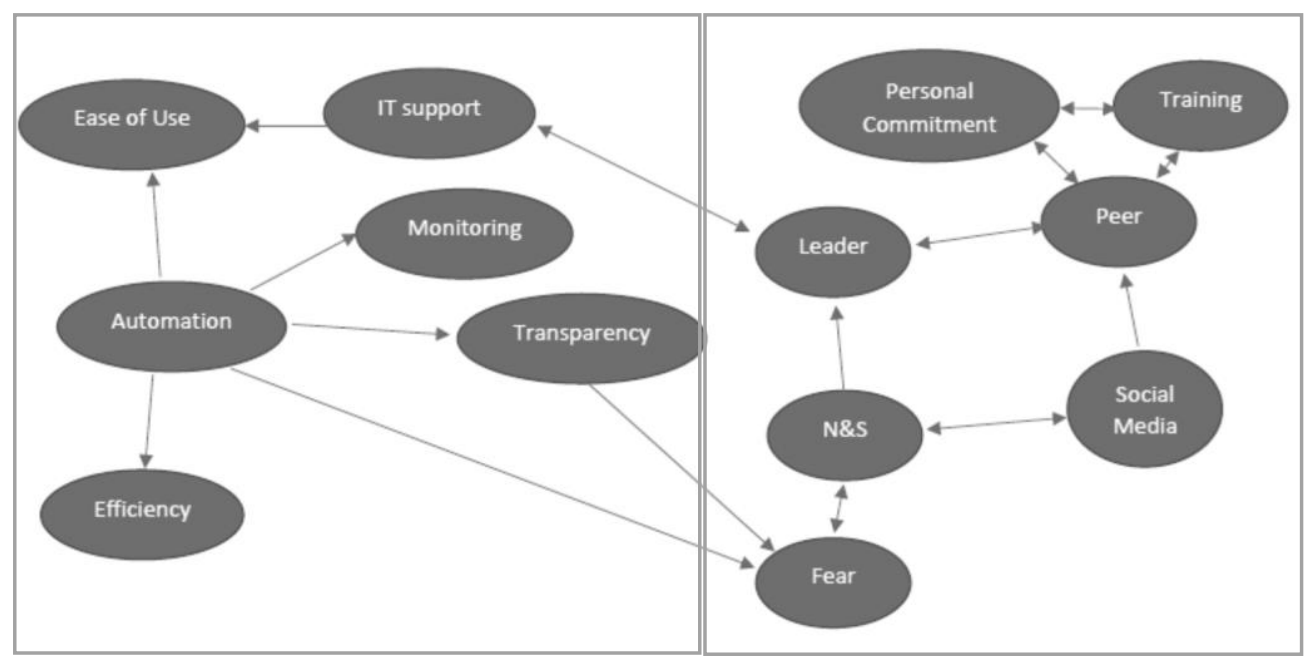

Figure 16 clearly shows the importance and influence of technology-related compliance drivers such as automation, ease of use, monitoring and transparency, which are clustered on the left-band box. The other social, organizational and leadership compliance drivers are clustered on the right-hand box in Figure 16. It illustrates how compliance drivers reinforce each other through their dependence and inter-dependence with other compliance drivers.

One distinctive feature of compliance emerged in the case study initiatives was the horizontal and vertical leadership. While the traditional vertical leadership existed as ministers, secretaries and chairpersons in the case study initiatives, their leadership role in ensuring compliance and implementing e-governance implementation was found more indirect and supportive than conventionally expected. Their support prominently appeared in advocacy, organizational setup and resource allocation needed for the initiatives, but the interviews revealed that the leaders were not particularly technology-aware and did not lead and manage the e-governance initiatives themselves. They did not receive the report or update on the overview, functionality and issues associated with the two systems. Rather, the leadership provided the framework where the changes were approved and necessary resources allocated, based on the trust with the technical and functional teams managing the initiatives. 
This vertical leadership supplemented the horizontal leadership where the technical and functional teams as well as users interacted. The system design, changes, development and directions were initiated and proposed by the teams based on user feedbacks and the horizontal leadership was maintained among the members of the teams and users via peer support. Although not designed intentionally for compliance purposes, the combination of the vertical and horizontal leaderships enabled the flexible, agile and responsive system development and update, in the absence of system related documentation, especially when the necessary updates to policies, rules and regulations took time.

The relationship between social media and traditional media as well as their impact on government employee users were equally unique to Bhutan. Bhutan being a small country, whistleblowers tended to hesitate to come forward with possible misuse and fraud cases directly to the ACC and media in fear of their identities being exposed. Instead, the whistleblowers created fake accounts in social media to upload the information, which was then picked up by the traditional media for the investigative reporting. People trusted the traditional media which reported relentlessly on fraud cases in Bhutan, which may be a flip side of fear factor of naming and shaming the government employee users had.

Another factor emerged in the examination was the fact that the high compliance level was associated with the long-term efforts and effects of ADS and e-PEMS in the form of familiarity and ease of use. More advanced features may be lacking from the systems, but both evolved to adequately respond to the changing context and user feedback.

At the moment, the identified challenges have not so far affected compliance levels in both initiatives, judging from the high compliance rates. However, as some of the compliance drivers are dependent on others and inter-dependent, any change in the existence and effectiveness of one compliance driver may affect cascading changes in the entire compliance landscape.

In this scenario, the depended upon and inter-dependent compliance drivers are particularly important. If the media and social media were to be prevented from reporting on fraud cases, there would be less naming and shaming and whistleblowers who wish to expose frauds and misuse of funds. If technology and automation does not function optimally, it would impact technology-enabled ease of use, monitoring capabilities and transparency among others.

This present research infers that the number of compliance drivers matters and the complexity of mechanism matters. However, this would need to be examined in future research with more case studies in other e-governance initiatives in Bhutan as well as in similar initiatives of other countries. 
This section places the similar and dissimilar compliance drivers in the national context of Bhutan for the contextualization and discusses how the intertwined compliance drivers produced compliance in reality. As this is an inductive exploratory study which employed constructionism/interpretative approach, this section discusses internal and external validity and reliability based on the criteria developed by Bryman (2016), namely trustworthiness. Trustworthiness has 4 components of credibility, transferability, dependability and confirmability. This section will discuss how the above-mentioned trustworthiness was applied in this study with a view to identifying essential elements for theorizing in Chapter 7.

Based on the ontological and epistemological notion that there can be more than one account of social reality, one of the criteria to establish trustworthiness of this present study is credibility which is ascertained by respondent validation and triangulation. As discussed in Section 3.6.2 on semi-structured interview as data collection method, interview questions were updated after each interview to focus on emerging and recurrent topics. The subsequent interviews formulated interview questions to validate or update the accounts, while triangulating the accounts with document analysis and observations.

Another criterion to measure trustworthiness is transferability, while the present research is oriented to focus on the uniqueness in the context and significant phenomena in the case of Bhutan. One of the means to ascertain transferability is thick description which facilitates the judgement to determine transferrable elements.

One unique aspect of the case study country is the fact that Bhutan is one of the least developed countries and at the same time a landlocked developing country, with the approximate population size of 800,000 . Thus, the available human and financial resources are limited to advance anti-corruption and implement the latest technologies across the government. Despite the formidable limitations, the country has steadily improved in the ranking of corruption perception survey of Transparency International (TI). The selected two e-governance initiatives in Bhutan, which were designed to prevent frauds and misuse, found high compliance rates among the government employee users, which provided evidence to support the TI corruption perception survey ranking. While similar cases and conditions may be rare, if not non-existent, the thick description obtained in the document analysis, semi-structured interviews and observations of this research provided evidence and elements which may be transferrable to other contexts and initiatives.

Additionally, the fieldwork took place between September 2019 to January 2021 to ensure that there was no major incident, policy development and organizational 
changes in the country context. The fact that the fieldwork was conducted in a relatively short period of time helped hold the context constant.

The following Chapter 7 will compare what was found in this present research with the existing literature with a view to identifying what is missing in the case of Bhutan and in the existing literature and determining the level of transferability. Dependability and confirmability are established in this research though auditable collection of materials and evidence.

\subsection{SUMMARY}

Based on the detailed case study specific analyses of the ADS and e-PEMS in Chapter 4 and 5, the Chapter 6 presented and compared the 2 sets of compliance drivers and challenges along the 4 categories of organizational, leadership, social and technological compliance drivers. Similarities were identified predominantly in the leadership and social categories with several compliance drivers from the technology categories. There was only one challenge which was similar between the two case study initiatives. Dissimilarities were found mostly in the organizational and technological categories as well as among challenges.

The chapter then discussed the conditions, mechanism and context in which the compliance drivers were situated. In this present research, a compliance driver is defined as a group of inter-linked factors and attributes which are evidenced to have direct impact on compliance of government employee users in using e-governance systems. The conditions were identified in the relationships of dependence and inter-dependence among the compliance drivers. The relationships derived from the interview accounts, observations and document analysis. The chapter explained the compliance mechanism as an aggregation of inter-linked relationships among the compliance drivers in the compliance space where all the compliance drivers operated and functioned.

In the process of discerning dependence and inter-dependence and developing a distilled account of compliance mechanism and context, two important factors emerged, which had widespread impact on several other compliance drivers and challenges. First, Figure 16 illustrated the impact of technology-related compliance drivers on other compliance drivers as an enabler of other compliance drivers. Second, ownership, as defined by funding source and developer, was instrumental with its indirect influence on several other compliance drivers to explain differences between the ADS and e-PEMS. 
The chapter then explained validity in the section on the context. As an inductive exploratory study with constructionism and interpretative approach, validity was explained through various facets of trustworthiness. 
"That is why, corruption must be curtailed and, more than ever before, extraordinary service must be recognized and rewarded." - His Majesty the King (Anti-Corruption Commission 2019, p. 5)

The previous Chapter 6 presented the cross-case synthesis with a discussion on similar and dissimilar compliance drivers. Similarities were found predominantly in the leadership and social categories, with some from the technological category. Dissimilarities concentrated in the organizational category, with some compliance drivers from the technological category. Most challenges were also dissimilar. Chapter 6 then discussed conditions, mechanism and context, and concluded that technology was an overarching enabler of compliance drivers, while ownership had an effective yet indirect impact on several compliance drivers.

Chapter 7 examines the identified compliance drivers against the existing literature detailed in Chapter 2 and develops a conceptual framework which explains the phenomena of compliance in e-governance implementation. This chapter begins by discussing what the existing literature says about the identified compliance drivers, if there are close enough similarities with what was found in case study initiatives.

Using the pattern matching method referenced in Section 3.7, the comparisons with the existing literature will focus on the 4 categories of compliance drivers, namely organizational, leadership, social and technological categories in Section 7.1. The reason for the category level matching is that there were very few studies conducted on the topic of compliance in e-governance implementation and one-to-one match between the identified compliance drivers and existing literature would not yield meaningful results.

There are compliance determinants that are present in the existing literature which were found absent in the case study initiatives in Bhutan, as elaborated in Section 7.2. The main focus of that section is to examine what compliance drivers were present in the case studies in Bhutan, but not in the literature, and which compliance determinants were found in the literature that were absent in the case study initiatives.

Section 7.3 then discusses relevant compliance models found in the existing literature, such as the Outcome and Output model. The compliance drivers identified in this present research could not be well explained by the existing compliance models. A reason for this gap was that the case selection was made based on variation in ownership. This present research aimed to examine the relationship of 
ownership on compliance, whereas ownership is largely missing in the existing compliance models. Furthermore, technology-related compliance drivers were found effective in this present research, but the existing model do not adequately explain the role of technology in ensuring compliance. This may be due to the fact that compliance in e-governance implementation has not been adequately researched and therefore has not been included in the existing compliance models.

Building on the identified gaps between the case study initiatives and the literature and in recognition of the lack of appropriate compliance models in the existing literature, Section 7.4 advocates for a new conceptual framework to understand and analyze compliance specific to the implementation of e-governance. In view of the increasing number of e-governance initiatives worldwide, which are introduced to tackle corruption in various sectors, this section explores the construction of a concept, e-compliance, which integrates technology with other compliance drivers in egovernance implementation.

Section 7.5 then examines e-compliance in the theory of sociomateriality which provides the analytical tool. Based on the empirical data and analysis, this section discusses essential parameters required for future studies on e-compliance and the theoretical anchoring in the theory of sociomateriality in the Information System (IS) literature. Section 7.6 summarises and concludes the discussion.

\subsection{COMPLIANCE DRIVERS AGAINST THE EXISTING LITERATURE}

The aim of this section is to compare the compliance driver categories and what was found in the existing literature. Table 2 in Section 2.3.3 summarises the literature review conducted to identify the role of ICT in the general compliance literature. The detailed narrative of Table 2 is found in Annex 3, Institutional Instruments and Compliance Determinants Identified in the Literature Review.

The two rounds of the literature review were conducted for this research, as elaborated in Chapter 2. The first round of literature review did not yield relevant insights and evidence to answer the research questions on compliance determinants in e-governance implementation, as summarised in Section 2.2.8. Therefore, the second round of literature review was conducted to understand the role of ICT in the compliance literature. The second review was designed to use institutional instruments, such as legislative activities, creation and development of organizations and effective system for regulations (Amr 2003; Mingaleva \& Mirskikh 2014), as a basis for compliance. The review identified general compliance determinants and how ICT was referenced in the literature. 
The compliance drivers identified in the case studies (Chapter 4 and 5), were matched with the compliance determinants from the literature (see Annex 3), following the categories that were inductively created for compliance drivers in case study initiatives and the categories used for compliance determinants in Annex 3. However, not all compliance drivers found matching narratives in the existing literature. The case study initiatives also shed light on the lack of effective use cases of ICT and lack of inclusion of e-governance initiatives in the existing compliance literature.

\subsubsection{LEADERSHIP COMPLIANCE DRIVERS}

The leadership category includes 2 compliance drivers, namely the role of His Majesty the King and leadership in the government. There was a unanimous agreement among all interviewees on the importance of both compliance drivers. However, the type and nature of the leadership found in both the ADS and e-PEMS are different from the leadership found in the literature review (see Annex 3).

His Majesty the King played an important role in promoting anti-corruption and digitization in Bhutan. Because he is revered and respected widely among the people, his words were found having overarching effects on government employee users' compliance. Another compliance driver identified during the interviews was leadership in the government which supported the officials, encouraged compliance and demonstrated his or her commitment in various actions.

The congruence between words and actions of leadership was found important in the existing literature as well as in the case study initiatives. Leadership support to anti-corruption agency was also referenced as effective to encourage compliance. Schlenther (2017) cited an example of Botswana, which was a top performer in terms of anti-corruption efforts, judging from the Corruption Perception Index ranking ${ }^{52}$. The success was attributed to "the implementation of ethics and anticorruption initiatives that are supported by the country's leaders" (p.223). The leadership and political will was "supported by a dedicated anti-corruption agency that has been able to translate political talk into action" (p.223). These aspects of leadership are well aligned with some elements of the leadership compliance driver identified in the case study initiatives.

\footnotetext{
${ }^{52}$ Boswana is $34^{\text {th }}$ in the Transparency International Corruption Perception Survey in 2019.
} 
The reverence and respect commanded by His Majesty the King was mentioned in both case study initiatives in Bhutan. Because the head of the ACC was appointed by His Majesty the King, the policies and rules the ACC developed were seen as legitimate and to be complied with. The e-PEMS users also reported their respect towards His Majesty the King and the leadership in the Ministry of Finance. Using the same logic, it could be expected that non-compliance be observed if people do not consider policies and regulations legitimate. A case in point is the study on forest nationalisation and reverse effects the policies triggered. Akerlof (2017) concluded that people did not report non-compliance or violations because they considered the rule illegitimate, which resulted in a high non-compliance rate.

However, the literature review did not yield a close alignment on the dual leadership of His Majesty the King as constitutional monarchy and leadership in the government. In the case of Bhutan, the words and resolve of His Majesty the King had an overarching impact on the government employee users, while leaders in the government demonstrated their commitments in their actions and put necessary resources in place. Even if a leadership in the government decides not to prioritize anti-corruption, His Majesty the King would still play a critical role. Therefore, this dual leadership model is expected to be more effective and enduring in ensuring compliance than relying solely on the quality and decision of elected officials in the government. The existing literature does refer to leadership in the government, and some literature explains some aspects of leadership compliance drivers as mentioned in this section. However, this dual leadership model is not found in the existing literature.

There is a general lack of reference to e-governance, and more specifically how leadership makes decisions and takes actions in promoting compliance in e-governance implementation, in the existing compliance literature. In addition to the dual leadership model, the case of Bhutan presented an interesting leadership model where the leaders were not technology aware, but where based on trust with technical and functional teams, they enabled rapid system development and updates which served the intended policy objectives. The horizontal leadership model between leaders and IT and functional teams based on trust supplemented a traditional vertical leadership model. Such horizontal and vertical leaderships have proven effective in encouraging and ensuring compliance and rapid system development in the case study initiatives.

\subsubsection{SOCIAL COMPLIANCE DRIVERS}

The social compliance drivers found in the case study initiatives included personal 
commitment, peer support, naming and shaming, fear for punishment and the role of media and social media. Personal commitment appeared in both initiatives as an effective compliance driver. Proactive ADAs created a peer support mechanism within the agency, such as an informal WeChat group, to fulfill their functions. The $e$-PEMS users also established a WeChat group among finance officers and accountants. In the absence of documentation, updated policy and regulations, the group was one of the few resources which could help address the issues and ensure the continuation of daily operations among the government employee users. Another effective compliance driver was naming and shaming, as the government employee users were very sensitive to being implicated negatively in the media. The naming and shaming was intrinsically inter-linked with the role played by media and social media. Fear for punishment, ACC investigation, interrogation, prosecution and other punishment associated with non-compliance were frequently expressed as an effective compliance driver.

Some research findings explained personal commitment exhibited by the ADA, finance officers and accountants to their duties and compliance in both case study initiatives. Akerlof (2017) examined internal values of law enforcement officials as well as social stigma associated with crimes. Using the definition of norms as "internalized views regarding duty and obligations" (P. 112), he argued that the feeling of duty triggered compliance as well as motivations to punish others' non-compliance behaviors. This study explains some aspects of personal commitments identified in the case study initiatives in Bhutan.

Peer support may be considered as an effective mechanism to acquire, sustain and reinforce such behaviors among the peers in the case study initiatives in Bhutan. Tavits (2010) referred to social behavior to be "acquired and sustained through imitation or modelling of others' behaviors" (p.1260). Using social learning theory, Tavits explained how people acquired behaviors through, 1) definition, 2) imitating behaviors and 3) positive reinforcement. This explains the phenomena of informal WeChat groups and how the conversations helped imitate behaviours and created positive enforcement for compliance among peers. Ali, Fjeldstad \& Sjursen (2014) also discussed that behaviors and attitudes would be influenced by those of their reference groups. In addition to the social influence theory, herd behaviors were evidenced to influence compliance, possibly through the perceived probability of detection. Those who complied with taxation had peers and friends who also complied, and vice versa. These findings seem to adequately explain the nature and type of peer support found in the two initiatives in Bhutan.

Media and social media as a separate compliance driver augmented peer support and provided vital information needed to internalize norms for compliance. Media and social media conveyed the messages of His Majesty the King and relentlessly 
reported on corruption cases which must have helped internalize the norms among the government employee users. Similar findings have been reported by Kotzian (2011) who introduced the role of information in compliance with norms. The author proved that individuals complied when others complied and that beliefs about the validity of norms were developed based on public and private information. Individuals adjust their beliefs according to that information. Sociologists have argued that "compliance with norms is not a result of rational calculation, but occurs because the norm is internalized" (p. 159).

Naming and shaming found in Bhutan doesn't fit well in any particular category of Table 2 and Annex 3. Following Kotzian (2011), naming and shaming would deserve to be included. The closest alignment may be found in the category "peer influence and stigma" under "social norms". Batory (2012) identified two factors in compliance: 1) instrumental (people act as dictated by self-interest, rewards and punishments) and 2) normative (moral judgements). Naming and shaming could be considered as instrumental compliance, but it is not a close alignment between the compliance driver and existing literature, as naming and shaming have wider social implications on the part of implicated government employee users, other officials and head of the agencies.

In the case study initiatives, various aspects of fear for punishment surfaced, including penalty. Penalty was imposed for late- and non-compliance among asset declarants and e-EPMS users were deprived of various career opportunities in case of non-compliance. Considering budget limitations in most developing countries, cost-effective ways to promote compliance include penalty for non-compliant behaviors. Batory explained that a typical policy reaction for compliance was deterrence "to try to change the individual's strategic calculus by increasing the costs of socially harmful behavior as well as the likelihood that those costs will indeed need to be borne" (p.72) (Batory 2012).

In addition, the role of audit was mentioned when fear for punishment was discussed in the case study initiatives in Bhutan. Misuse, corrupt behaviors and internal control risks were often discovered by the audit, especially in the case of the $e$ PEMS. The existing literature reported similar findings., Van del Wal, Graycar \& Kelly (2016) cited the important role auditors played in control and risk management by reviewing control and risk management systems and operations. Applying a concept of corruption trap, Akerlof (2017) cited that a high rate of corruption tended to lead to more corruption and it was found difficult to undertake an audit in a highly corrupt society. The fact that the audit function was found effective in Bhutan may indeed corroborate the Transparency International's high raking. 
In the case of Bhutan, the government officials were afraid to officially report on possible allegations and misconduct. However, it does not mean that they didn't take action on possible allegations and misconduct. They anonymously shared information on alleged misconduct on social media, which often led to ACC investigations and reporting of corruption cases by print media. Similar examples were identified in the existing compliance literature. Schlenther (2017) argued for the utility of increased transparency through public disclosure of information on social media, as symbolised in the Luxemburg Leaks, Panama Pa-pers and Paradise Papers. Whistleblowing and other institutional instruments rely on public awareness and understanding via social and print media, as "transparency supports measures to combat corruption and importantly increases public pressure on the government to fully address the problem of corruption" (p.231).

This section found several matching narratives between the social compliance drivers and existing compliance literature. The role of media and social media, in particular in the context of whistleblowing, was well documented in the existing compliance literature. Fear for punishment was also well described by various compliance research, together with the effectiveness of audit. However, there were several gaps between the identified social compliance drives and compliance literature.

First, peer support was found necessary because of the lack of documentation, updated policies and regulations in e-governance implementation, supported by the use of social media, such as WeChat group. In the context of Bhutan, this is an ingenious arrangement developed by the government employee users in response to the emerging situation. However, the existing literature did not investigate such a scenario or rationale for peer support mediated by social media.

Second, naming and shaming was another compliance driver which did not find a close alignment with the existing literature and the existing models and theories did not adequately explain the phenomena at hand. In Bhutan's small society, naming and shaming has a wide-ranging and long-lasting effect not only on the part of the non-compliant officials but also those surrounding them.

Another missing factor in the existing compliance literature is the concept and application of ownership. In this present research, ownership is defined by funding source for system development (government or donor funding) and development team (government officials with or without external consultants). The concept of ownership was applied in the selection of case study initiatives, with the assumption that it would play a major role in determining the level of compliance. However, as Chapter 4 and 5 detailed, the effect of ownership was found indirect, with links to a wide range of compliance drivers, such as peer support, personal commitment and responsiveness of the IT team. Due to the fact that the ADS was 
developed in-house and with government resources, the IT and functional teams exhibited outstanding personal commitment and peer support, which led to cascading positive impacts on compliance among the government employee users at large. However, in the case of $e$-PEMS, which was selected for its external ownership (donor funding and presence of external consultant), similar effects were limited, and the system design, coordination, development and deployment encountered a series of challenges as elaborated in Section 5.5. This phenomenon surrounding ownership may be specific to system development and e-governance implementation or to the context of Bhutan.

\subsubsection{ORGANIZATIONAL COMPLIANCE DRIVERS}

The organizational compliance drivers were found in the case of ADS. They include the credibility and trust in the organization, organizational setup and training and awareness. In the ADS implementation, the credibility in ACC was accompanied by a sense of fear for its investigation and interrogation functions, although it was well respected and considered as doing a good job by the public at large. Some ministries went beyond what was required for asset declaration and made additional organizational arrangements and setups to ensure high compliance. These measures had direct and indirect impact on the government employee users regardless of the size, complexity and geographical spread of the organizations. Training, awareness raising and sensitization were found an effective compliance driver of ADS, while the lack thereof was identified as a challenge in the case of $e$ PEMS.

In both case study initiatives, the ACC and its policies and rules related to asset declaration were seen as legitimate, which encouraged compliance among the government employee users. In line with Batory (2012), people obeyed the rules as they believed that 1) "the law is just", 2) the authority had the right to dictate behaviors and 3) obedience was driven by procedural fairness, with the perception that law was formulated with full authority. Thus, legitimacy of the sources of legal obligations was found as the basis for rule-conforming behavior. (Batory 2012).

As Bhutan is a least developed country and landlocked developing country at the same time, the available budget has been limited. But some organizations made available human and financial resources through various means, and those organizations were found with a high level of compliance in the case of ADS. Webb (2012) noted that resource scarcity and workload could be negative determinants, which may lead to an environment for cheating to occur. Webb added "adequate time, budgets, equipment, information and authority to execute their responsibilities" ( $p$. 
99) as key ingredients for compliance. This finding explains the importance of organizational setups the ADAs reported on during the interviews.

The effectiveness of training and advocacy was also found in the compliance literature. In the case of tax compliance, tax education and integrity efforts were found effective in influencing compliance behavior and reducing incidents (Schlenther 2017). Cleveland, Favo, Frecka, et al. (2010) underlined the importance of education and training in reducing bribery, accompanied by robust ethics and compliance programme. Tjen and Evans (2017) studied the Gayus case in Indonesia, and found that taxpayer outreach and education was one of the key pillars for their anti-corruption strategies. These findings are largely in line with the compliance driver on training and sensitization identified in the case study initiatives.

The organizational compliance drivers, found in the case of ADS, were adequately explained by the existing compliance literature. Credibility and trust in ACC was similar to what was found in a case study on Hungary conducted by Batory (2012). Another compliance driver, organizational setup, was also found in a study conducted by Webb (2012) which emphasized the need for adequate budget, equipment and authority for compliance. Education, sentisation and awareness raising, found in the case study initiative of ADS, also appeared in various studies in the existing literature.

\subsubsection{TECHNOLOGICAL COMPLIANCE DRIVERS}

The technological compliance drivers played an important role in ensuring compliance in the two case study initiatives. Despite the existence of fragmented narratives and references to ICT, however, the literature review in Chapter 2 does not fully explain the technological compliance drivers identified in the two case study initiatives or compliance in the context of e-governance implementation. Judging also from Annex 3, it is evident that the existing compliance literature does not provide sufficient coverage and explanation to understand the role of technology .

The two case study initiatives identified several compliance drivers in the domain of technology. More technological compliance drivers were found in the $e$-PEMS than in the ADS implementation. Technology-enabled ease of use in the ADS and familiarity with the existing system in the $e$-PEMS were essential in the studied cases. In addition, monitoring, verification and follow-ups and responsive IT support in the case of the ADS were found effective compliance drivers. In the e-PEMS initiative, efficiency gains, technology/automation, centralized master data management and monitoring, transparency, visibility and traceability and IT support 
were technology-related compliance drivers.

The government employee users commented that both systems were easy to use. Additionally, technology and automation were found effective and certain functions, such as password generation and submission confirmation in the ADS and electronic payments in the $e$-PEMS, were automated. The $e$-PEMS users cited efficiency gains as a compliance driver, which did not appear in the case of the ADS. Monitoring, Verification and Follow-up (ADS) and Transparency, Visibility and Traceability (e-PEMS) could be comparable compliance drivers but presented notable dissimilarities. The transparency, visibility and traceability brought by $e$ PEMS were very effective to compel compliance. Centralized Master Data Management and Centralized Monitoring was a unique feature of the $e$-PEMS, too. The creation of employees and vendor payees in master data or file was now centrally managed by the Department of Public Accounts (DPA) of the Ministry of Finance $(\mathrm{MoF})$ and was effective in deterring users from non-compliance and attempting misuse and manipulation in the system. Technical Support and Responsiveness of the ACC Team (ADS) and E-PEMS IT Support (e-PEMS) demonstrated dissimilarities in many different aspects but the importance of the IT support to the government employee users was recognized widely during the fieldwork.

The above-mentioned technological compliance drivers are largely missing from the existing literature. While automation, system design and efficiency were broadly referenced in Annex 3, the existing compliance literature did not sufficiently explain most of the technological compliance drivers and their effectiveness. More specifically, the existing literature focused on automation, transparency, minimizing compliance costs and positive roles of ICT in detecting corruption, but the literature did not find the role of ICT beyond detecting corruption and not as a compliance driver. The rest of the technological compliance drivers did not find a matching narrative which can explain the phenomena in the case of Bhutan.

The importance of robust information systems and transparency it brings was underlined in negative case studies in the existing literature. Schlenther (2017) cited a case of Kenya, where the president was alleged to be involved in a corruption case. In a similar case in Malawi, a computer-based financial system was compromised by government officials to divert funds and an arrest warrant was eventually issued to the former president. Citing IMF recommendations, Schlenther highlighted the importance of "simple transparency and to the extent possible automated procedures, strong information systems and high profile prosecutions" (p.234). . Webb (2012) elaborated on the merit of transparency by which "managers are able to observe the unethical conduct of the employees and its consequences, and vice versa" 
(p. 99), thus serving as a deterrent to unethical behaviors, but not in the context of use of ICT and e-governance implementation.

In the case of Bhutan, the elimination of checks and introduction of electronic payment reduced the scope for fraud and misuse of public funds in the case of $e$-PEMS. The logic and rationale applied for the introduction of automation and e-payment in e-PEMS were similar to what was found in the literature. Manual registration and process of filing and payment, which involved person to person transactions, were found to be an opportunity for corruption in several case studies. (Schlenther 2017; Tjen and Evans 2017).

The technological aspects of compliance may be unique and specific to the context of Bhutan and e-governance implementation, but further research would be needed to deepen an understanding of the relationship between technology and compliance. Covered channels are 1) efficiency gains, 2) technology-enabled ease of use, 3) the chain of monitoring, verification and followup, 4) transparency, visibility and traceability, 5) a centralized master data management or monitoring system and 6) the role of IT support as drivers of compliance. Despite the existence of fragmented references to technology, the compliance literature does not fully explain the technological compliance drivers or compliance in the context of e-governance implementation in the case of Bhutan.

\subsection{GAPS BETWEEN CASE STUDY INITIATIVES AND EXISTING LIT- ERATURE}

Some compliance drivers identified in the case study initiatives were well aligned with case studies and evidence found in the existing literature, as discussed in the above Section 7.1. However, some of the channels found present in Bhutan cannot be explained by the existing literature. These unique channels may be attributable to the fact that Bhutan is a unique case. The alignments were identified mainly in the social and organizational compliance driver categories. The existing literature did not yield good and suitable alignments to adequately explain the compliance drivers under the leadership category. Even more scant were the alignment between the technological compliance drivers and the existing literature. The examples and narratives related to ownership did not appear in the existing literature.

Interestingly, this present research discovered that various compliance determinants found in the existing compliance literature did not appear in the case study initiatives at all. Compliance triggered by international instruments, such as the role of foreign entities, international conventions and international standards, was 
found entirely absent in the case studies in Bhutan. Similarly, access to information and anti-corruption policy, legal and regulatory frameworks were largely absent from the case study initiatives.

Against this background, the below Section 7.2.1 examines the missing elements in the existing literature based on the case study initiatives in Bhutan, followed by Section 7.2.2 which examines the missing elements in the case of Bhutan based on the literature review.

\subsubsection{E-GOVERNANCE COMPLIANCE DRIVERS: OWNERSHIP, LEADERSHIP AND TECHNOLOGY}

The compliance drivers within categories organizational and social compliance found good alignments in the existing literature. However, the existing research and studies do not adequately explain the e-governance categories of compliance drivers, ownership, leadership and technology. Due to the lack of evidence, concepts and theories, this present research advocates for the need for theorizing and understanding the e-governance compliance phenomena at hand.

In addition to the lack of reference to the effects of ownership on other compliance drivers, there were several unique compliance drivers on leadership and technology which did not find good alignments as listed below:

Indirect effects of ownership on

- Peer support

- Personal commitment

- Responsive IT support

Leadership compliance drivers

- The Role of His Majesty the King

Technological compliance drivers

- Efficiency Gains

- Technology-enabled Ease of Use/ Familiarity with the Existing System

- Centralized Master Data Management and Monitoring

- Monitoring, Verification and Follow-up

- Transparency, Visibility and Traceability

First, the most obvious gap in the existing Information System (IS) literature is the lack of evidence and research on compliance in e-governance implementation. It is 
corroborated by the conclusion made based on the first round of literature review, detailed in Section 2.2.8. Second, the existing compliance literature did not adequately study e-governance either, beyond treating ICT as a tool to improve access to information, enhance transparency and detecting corruption, as elaborated in Section 2.3. Third, although some fragmented references were found, the abovementioned ownership, leadership and technologies are not well explained in the existing IS or compliance literature.

There was no study or research found in either IS or compliance literature which focused on the concept or application of ownership to understand compliance and e-governance implementation. This present research identified the channels through which ownership exerted its wide-ranging indirect effects to encourage compliance. Future research may be conducted to examine different e-governance initiatives in Bhutan or similar e-governance initiative in other comparable countries so as to deepen an understanding of the effects of ownership and channels thereof. Such evidence is expected to assist in the further development of $e$-compliance as a conceptual framework.

As to leadership, the role played by His Majesty the King and dual leadership found in the leadership category is unique to Bhutan and was not found in the existing IS or compliance literature. Particularly interesting and missing in the existing literature is the role of horizonal leadership found in e-governance implementation in Bhutan. Leadership was found not technology aware but based on the trust between leaders and IT and functional teams, the system development, update and upgrade were implemented with agility. More substantive and technical leadership roles were played by lower level officials in implementing both initiatives, while the secretaries and ministers created an enabling environment for such rapid system development. Thus, in addition to the traditional vertical leadership model, the horizontal, collaborative and collective leadership model may be in place in these two case studies.

What was also unique to the e-PEMS and did not appear in the literature is the parenting arrangement of the Ministry of Finance $(\mathrm{MoF})$ and personal commitment generated by the parenting arrangement. The $700 e$-PEMS users were scattered across the government agencies and Dzongkhags, or district, administrations in Bhutan. However, under the parenting arrangement, all of them felt that they belonged to the Ministry of Finance (MoF), the parent agency, which managed their promotions, transfers, and various opportunities. The e-PEMS was the initiative introduced by the MoF and therefore, the users felt that they had to comply.

Regarding technology, the existing literature did not explain the technological compliance drivers sufficiently. As illustrated in Graph 6.1, technological 
compliance drivers exhibited important dependence and interdependence among the compliance drivers. The most depended on compliance driver was technology/automation. The existing literature did refer to automation, but not as a compliance driver or its dependent and inter-dependent relationships with the other compliance drivers.

Additionally, other technological compliance drivers, such as 1) efficiency gains, 2) technology-enabled ease of use, 3) central master data management and monitoring, 4) monitoring, verification, follow-ups and 5) transparency, visibility, and traceability, were not studied as compliance drivers among the government employee users in either IS or compliance literature. The dependence and inter-dependence among the technological compliance drivers and with other compliance drivers could be studied in Bhutan and other contexts, so as to further develop $e^{-}$ compliance as a conceptual framework.

\subsubsection{UNIQUE FEATURES IN THE CASE OF BHUTAN}

This present research also discerned the absence of various compliance determinants in the case of Bhutan. The existing literature review places emphasis on transparency, in the forms of collecting and publishing information on public services and organizing public campaigns against corruption, with the ultimate aim of providing citizens with access to information. A number of existing studies and researches focus on the access to information when it comes to ICT and anti-corruption institutional instruments. The assumption is that once citizens at large are empowered with access to information, mediated by ICT, the citizens can confront corrupt practices and hold government officials to account (Camaj 2016; Popescu, Onofrei \& Kelley 2016). In the case study initiatives which focused on the perspectives of the government employee users, the citizen-centered transparency did not come up as a factor.

The existing literature also produced a number of studies around the topic of anticorruption policy, legal and regulatory frameworks. Included in the existing literature were not only policies, but also administrative compliance guidelines, code of conduct, anti-corruption programmes, risk assessment and management and monitoring programme of the anti-corruption efforts. In this present research, these institutional aspects of compliance determinants were studied to describe the initiatives and background through document analysis in the case of Bhutan. But as illustrated in the Figure 16, institutional aspects did not feature prominently as compliance drivers found in the case study initiatives. These policies, frameworks and programmes have been put in place and may be effective and functional in the context of Bhutan. If a lack of such institutional instruments was identified as a 
cause of non-compliance or source of corruption, these instruments would have been referenced in the data collection stage. Therefore, such institutional factors did not come to the fore in the case study initiatives. These factors which existed but were taken for granted emerged only when the evidence was contrasted with the existing literature which investigated the cases or contexts where such institutional instruments were found missing or not effective.

Additionally, what was found missing from the case study initiatives were public sector reforms, civil service reforms and less organizational complexity in the existing literature. Interestingly, these aspects were mentioned by some of the interviewees as missing in Bhutan or case study initiatives. For example, the parenting arrangement was found effective among the accountants and finance officers, but such arrangements were not instituted among the HR officers who were ADAs and IT officers. Such systematic organizational arrangement could have supported the government employee users better and addressed the challenges identified in both initiatives. Similarly, there were several interviewees who thought that integration of compliance as a performance appraisal criterion of civil servants would have been effective. The lack of various reforms may be related to the findings of this present research which found high compliance among government employee users as well as government leadership which may not be technology aware. Due to the high compliance rates, the government may not have felt urgent need for compliance-enabling reforms, as the specific policy objectives of the case study initiatives have been largely met. However, future studies in Bhutan and other countries are expected to inform the importance and effectiveness of public sector reforms and lessened organizational complexity in enhancing compliance and help further develop the conceptual framework of e-compliance.

Equally absent were the compliance determinants associated with international institutional instruments, such as role of foreign entities in the country, international conventions and foreign laws and legislations and international standards. When foreign companies and entities are present in the country, various policies, regulations and laws of the countries where the companies and entities are registered influence the investments and dealings. The examples of such policies, legislations and laws include the US Foreign Account Tax Compliance Act (FACTA), Foreign Corrupt Practice Act (FCPA) and UK Bribery Act of 2010. International conventions include the UN Convention against Corruption, UN Global Compact, OECD Convention, among others. Donors also impose transparency and accountability clauses in supporting the recipient countries. However, these international dimensions of compliance determinant did not appear in the case studies, because there are very few foreign companies and investment in Bhutan. While the e-PEMS was donor-funded, transparency and accountability in managing the project was not a major concern. Additionally, this lack of international dimension is corroborated 
with the findings of this present research: the government approach to compliance is motivated by domestic concerns over corruption rather than by international considerations.

What is perhaps most interesting in discussing the missing determinants in the case of Bhutan is the fact that corruption-related political, institutional and societal deficits the literature evidenced in other countries were largely absent. Citing a case of Kenya, Schlenther (2017) noted that "the deliberate undermining of the basic institutions that underpin and support the rule of law and good government" (P.224) explained a high-level and pervasive corruption in the country. Citing a concept of corruption trap, Akerlof (2017) cited that a high rate of corruption tended to lead to more corruption, and it was difficult to undertake an audit in a highly corrupt society. Lack of legitimacy made rule-compliance more difficult, leading to the need for coercive forces. Such coercive measures were evidenced to lead to resistance, in the form of not only rule violations but also non-reporting of such violations to authorities. It then led to a "noncompliance trap" with high non-compliance, spiraling down to more non-compliance.

The case studies in Bhutan did not find the indications of pervasive and widespread corruption and associated political, institutional and social deficits. This absence of pervasive corruption could be considered as a unique feature of Bhutan, which also corroborates the ranking of Transparency International's corruption perception surveys over the years. In addition, the basic institutional capacity needed to support the rule of law and good governance was not mentioned by the interviewees. It may be because the people in Bhutan have taken them for granted. However, the existence of such factors becomes obvious only when the cases were compared with the examples of other countries and the existing literature.

From the comparison with the existing literature, it has become apparent that compliance in the e-governance implementation can not be sustained in an environment where corruption is rampant. This enabling environment did not come out clearly in the interviews or document analysis in the case of Bhutan, due perhaps to the fact that this environmental aspect was taken for granted. The existing literature on institutional instruments and compliance did reference to the role of ICT, but they reflected a static view of ICT, external to the phenomena, while technology was found an integral and dynamically intertwined part of compliance in the case of Bhutan. 


\subsection{EXISTING COMPLIANCE MODEL}

The existing literature also provided various models of compliance which explained the type and nature of compliance in various sectors and functions in government and society. Some scholars developed concepts and types of compliance, such as rule-based and trust-based dispositional compliance as well as output/outcome compliance. Although these concepts and theories were developed without examining or referencing ICT and e-governance, some aspects of compliance models and channels may be applicable to explain the case study initiatives in this present research. This Section 7.3 discusses the most relevant models to this present research, the applicability of compliance models and gaps identified in the process.

Webb (2012) argued that compliance-based approach needed to be supplemented by value-based approach to reduce public service malfeasance, using analysis on South Africa's Department of Correctional Services. His study evidenced that compliance-based approach of creating more regulations and oversights impacted public service efficiency and effectiveness, and created additional opportunities for corruption. The value-based approach aimed to create an ethical culture within the organisation and enhance implementation of anti-corruption policies. Such an approach included "communicating moral expectations with employees, visible punishing (of) offenders, ethics training, and appraising ethics performance of employees by making it a stand-alone key performance area" (p. 97). Similarly, several other scholars (Van del Wal, Graycar \& Kelly 2016; Alon and Hageman 2017; Williams and Horodnic 2015) argued the importance of both types of compliance, namely rule-based compliance and value-based compliance, to ensure sustainable compliance in society.

Similarly, Van del Wal, Graycar \& Kelly (2016) contrasted the compliance-based approach with the integrity or value-based approach. The former focused on laws, rules and regulations through supervision, control and punishment of offenders. The associated institutional instruments included asset declaration, screening of employees, penal code on corruption and disciplinary measures and procedures. The latter strategy focused on bottom-up formulation of organisational aspirations, promotion of ethical behaviors and code of conduct, ethical behaviors and training. A direct, more formal approach created the structures and standards in support of ethical conducts of employees, while an implicit, culture-oriented approach targeted at behaviors of peers and supervisors, creation of shared values, fair renumeration, appraisal and promotion systems, which rewarded good behaviors.

In the domain of formal mechanisms, Alon and Hageman (2017) focused on enforcement with the intention of enhancing tax compliance. The success was 
influenced by the combination of institutional determinants, in particular, 1) dispositional trust (culturally-based) and 2) rule-based trust (including regulation). Trust was "seen as a necessary component to lower transaction costs and constrain opportunistic behaviors" (p. 156) According to Alon and Hageman, effective institutional structure was shaped by enforcement and regulation, which had complementary effects on rule-based environment and curb discretionary power. A wellfunctioning rule of law may act as a trust enhancing mechanism, which created higher dispositional trust that was culturally based, shaped by trust-related experience.

Ademmer and Börzel (2013) identified 2 types of compliance: outcome and output. While outcome compliance required behavioral changes, output compliance manifested in policies and political decisions. Using the combination of these two types of compliance, 4 expected compliance tendencies were detected by the authors. These included 1) compliance (high output/ high outcome), 2) shallow (increased output/ low to no outcome), 3) emerging (increased output/ increased outcome) and 4 ) inertia (low to no output/ low to no outcome).

All the examined compliance models consisted of a variation of 1) rule-based institutionalized compliance determinants and 2) trust- and social-norm based compliance determinants. No model identified in the literature review examined technology-based compliance model or compliance model in e-governance implementation. This conclusion points to the need for theorizing compliance in e-governance implementation and constructing a new conceptual framework of $e$-compliance.

\subsection{E-COMPLIANCE AS THE CONCEPTUAL FRAMEWORK}

Based on the review done in section 7.3, it is evident that the existing compliance models are insufficient to explain the phenomena of compliance in e-governance implementation in the case of Bhutan. In addition, the analysis of the two case study initiatives elaborated in Chapter 4, 5 and 6 indicated that technology played a significant role in enhancing compliance, supported by other compliance drivers and ownership. Yet, the technological compliance drivers and the concept of ownership do not fit into either rule-based compliance or trust-based compliance, nor the outcome-output based compliance model. In order to explain the phenomena of compliance in e-governance implementation and take into account technology and ownership, a new conceptual framework is needed. This section proposes the new conceptual framework of e-compliance based on the analysis of the case study initiatives and existing compliance models (Webb 2012; Van del Wal, Graycar \& 
Kelly 2016; Alon \& Hageman 2017; Ademmer and Börzel 2013). Chapter 6 presented the cross-case synthesis as well as the conditions, mechanism and context surrounding the case study initiatives. The importance of dependence and interdependence among compliance drivers was underlined in Section 6.5.1 and 6.5.2. The relationships were aggregated and illustrated in Figure 14. These inter-linked compliance drivers have created a compliance mechanism and compliance space where the compliance drivers interact with each other and lead to high compliance. If compliance is low, it indicates that the functioning compliance mechanism might not be in place, there may be few and ineffective compliance drivers, and/or the compliance space too narrow.

At the same time, it is expected that the compliance drivers and mechanism evolve in response to a dynamically evolving context and background. For example, new technological compliance drivers may emerge, while other drivers may disappear when there are some incidents, shock or changes in the context, such as changes in leadership, organizational structure and budget availability. If there are many inter-linked compliance drivers in a complex e-compliance system, the influence of one compliance driver is of limited power. If one compliance driver disappears, while other compliance drivers remain intact, it is unlikely that the compliance level decreases much, because other inter-linked compliance drivers would remain effective. However, if an e-compliance system is built on only a few compliance drivers, the influence of each driver is high and the absence of one driver would negatively impact other connected drivers and decrease the compliance level considerably.

In addition to the compliance mechanism, which consists of inter-linked and mutually supportive compliance drivers, the compliance space, which consists of the number of compliance driver, helps explain the phenomena of compliance in the e-governance implementation.

Based on the need to develop a new compliance model which takes into account technology, ownership, inter-linked compliance drivers in e-governance implementation, and the existing compliance models, this research proposes a conceptual framework, e-compliance, which consists of

1) rule-based compliance determinants, represented by the organizational compliance drivers

2) trust-based, dispositional compliance determinants, represented by the social and leadership compliance drivers and

3) technology-based compliance determinants, represented by the technological compliance drivers. 
In the conceptual framework of e-compliance, the compliance space is explained by the number of identified compliance drivers and the compliance mechanism by the dependence and inter-dependence among the compliance drivers.

Figure 17: Conceptual framework of e-compliance

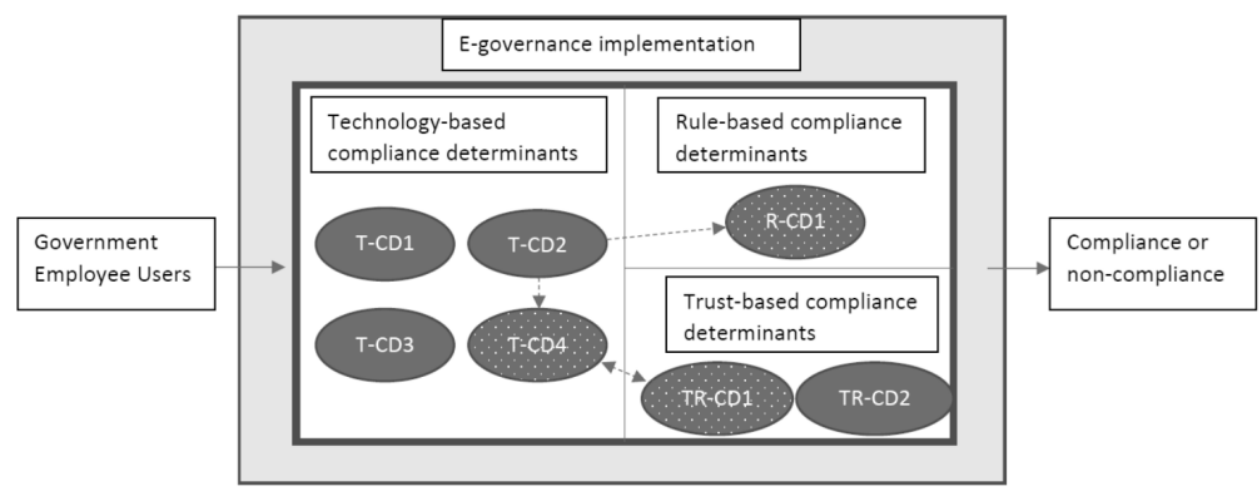

T-CD: Technology-based compliance driver; R-CD: Rule-based compliance driver; TR-CD: Trust-based compliance driver

Figure 17 illustrates the compliance mechanism and compliance space which form e-compliance. E-compliance is represented by an inner rectangular within e-governance implementation, and the compliance mechanism by the dependence and inter-dependence among compliance drivers. The compliance space contains compliance drivers under the three compliance determinants. In Figure 17, T-CD, R$\mathrm{CD}$ and TR-CD represent examples of compliance drivers under technology-base, rule-based, and trust-based compliance determinants respectively.

The number of compliance drivers constitutes the compliance space. In each context, there would be different compliance drivers, but the three compliance determinants would remain the same based on the findings of this research. Dotted compliance drivers are the examples of drivers influenced by the ownership effect. Dotted arrows are the examples of possible dependence and inter-dependence among compliance drivers. The aggregation of the dependence and inter-dependence relationships among compliance drivers forms the compliance mechanism.

When a government employee user interacts with an e-governance initiative, ecompliance depicted in the middle of Figure 17 is expected to influence the course of action and behavior of the user through the compliance space and mechanism, and lead to higher, lower or non- compliance. 


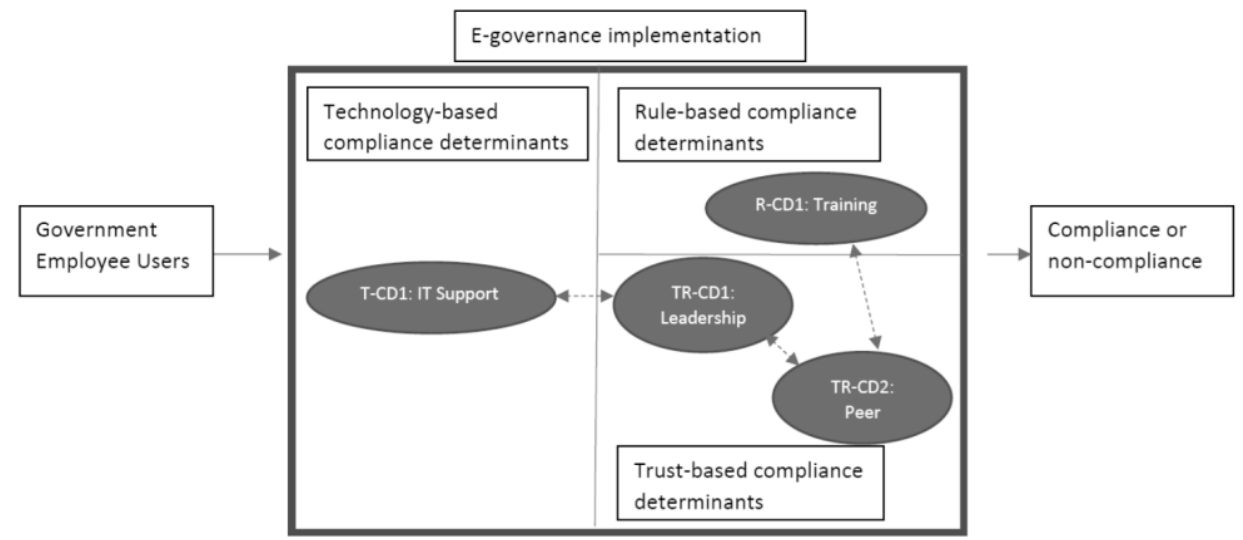

An example of a compliance mechanism in Bhutan is included in Figure 18, through the arrows in the Figure. IT Support is assigned as T-CD1, while Leadership as TR-CD1, Peer Support as TR-CD2 and Training as R-CD1. Responsive IT Support was inter-dependent with Leadership: Leadership provided an enabling environment for the IT team's nimble decision-making and actions, and in turn the IT Support implemented the initiatives where Leadership's technical knowledge was limited. Similarly, Leadership and Peer Support were inter-dependent: the encouragement of Leadership was found influential on how IT and functional team members supported the initiatives, while Leadership needed their support to implement and update system functionalities and ensure user compliance. Another inter-dependence was found between Peer Support and Training. Where the level of Peer Support was high, the organizations tended to allocate resources for Training, which then motivated the IT and functional team members.

The conceptual framework of e-compliance offers guidance to explain compliance among government employee users in e-governance implementation through ecompliance consisting of compliance space and compliance mechanism. It was developed to explain determinants of compliance among government employee users of e-governance initiatives which are designed to prevent fraud and control corruption. However, it could be used to assess compliance in other types of egovernance initiatives. The framework would not only offer the logic and category of contextual and relevant compliance drivers under each compliance determinant and their dependent and inter-dependent relationships, but also explain the role of technology which strengthens other compliance drivers and improves compliance in e-governance implementation.

The conceptual framework of e-compliance presents unique characteristics which require careful theoretical considerations. First, the compliance drivers discussed 
in Chapter 6 include technology-enabled as well as institutional, social and human agency-related drivers. Second, Chapter 6 underlined the dependence and interdependence among compliance drivers, which constitute a compliance mechanism. The present research also acknowledges the dynamic development of systems and technology, due to and leading to interactions with government employee users via various compliance drivers in a compliance space. E-compliance requires a specific analytical took to fully understand such unique characteristics. The below Section 7.5 discusses theoretical anchoring and analytical tools suitable to further examine e-compliance in the future.

\subsection{E-COMPLIANCE IN THE THEORY OF SOCIOMATERIALITY}

This section explains the theoretical foundation underpinning the conceptual framework of e-compliance and the theoretical anchoring in sociomateriality in the Information System (IS) literature, followed by a discussion on essential parameters required for future studies on e-compliance.

The literature review in Section 2.2.6 identified IS theories, such as TAM, DOI, UTAUT, TPB, TOE, TRA and ISS. However, they were found not suitable to adequately explain the complex, multi-facetted phenomena of compliance in e-governance implementation, beyond technological adoption, or intention to adopt. Many of the existing IS frameworks position technology in linear relationships, as a starting point of investigation or the adoption of technology as a goal, and would not be suitable for an investigation of dependent and inter-dependent relationships of social, organizational and leadership factors, together with technological factors. In addition, people may adopt and use e-governance initiatives as technology, but may misuse it for their personal benefits, as Chapters 4 and 5 evidenced. The adoption of technology alone would not help explain the phenomena of compliance and determinants of compliance in implementing e-governance which are designed for control of corruption.

As Section 7.4 detailed, e-compliance consists of compliance mechanism and compliance space in e-governance implementation. What characterizes e-compliance is the entanglement of the structural facets, social actors and technological artefacts which influence each other. Over time, the entanglement started shaping structures, such as vertical and horizontal leaderships, practices such as technology-mediated peer support, and development of systems which are continuously updated in response to the user needs and requirements. These are some of the features best examined by the theory and methodology of sociomateriality. It was identified as the best tool by which the social, organizational and leadership compliance drivers 
can be analysed with the technological compliance drivers without tilting to the former or the latter, and the inter-linked relationships among the compliance drivers can be explained.

\subsubsection{THEORETICAL RELEVANCE OF SOCIOMATERIALITY TO E-}

\section{COMPLIANCE}

This section explains the relevance of sociomateriality theory as a tool to analyze ecompliance, considering the social, organizational, leadership and technological entanglement that structures the compliance mechanism identified in this present research. According to Orlikowski (2007), traditional organizational studies focused on either technology-centric or human-centric perspective. On the one hand, the technology-centric studies assumed that technologies are "exogenous, homogeneous, predictable, and stable, performing as intended and designed across time and place" (p.1437), and "leverages human action" (p.1436). On the other hand, the human centric approaches are concerned with "how humans make sense of and interact with technology in various circumstances". (p.1437) Orlikowski then argued that the contemporary social sciences were not well equipped to explain complex organizational realities where "the social and the material are constitutively entangled in everyday life" (Orlikowski 2010). She therefore called for inter-mingling of materiality and "perspectives that are grounded in ontological and epistemological sensibilities that take seriously the sociomateriality of organizing" (Orlikowski 2007, p.1445). Instead of studying technology design and use in organization, driven by ontological distinction between technology artefacts and human agency, sociomateriality enables researchers to conduct research on the social and material relationships (Feldman and Orlikowski 2011).

According to Leonardi (2013), the social is defined as "(a)bstract concepts such as norms, policies, communication patterns, etc." (p.74), while the material denotes "(t)he arrangement of an artifact's physical and/or digital materials into particular forms that endure across differences in place and time" (p.74).

The scholars who study sociomateriality view technology as not valuable or meaningful on its own, but only through human agency and that "technologies are artifacts whose operation and outcomes are neither fixed nor given a priori, but always temporally emergent through interaction with humans in practice" (Feldman \& Orlikowski 2011, p 1246). Therefore, it is important to study "sociomaterial practices that perform social and material relations together" (Feldman \& Orlikowski 2011, p.1248). Technological affordances, or technological performances, depend on human interpretations, enactment and contexts and human agency is performed materially. (Jarrahi \& Sawyer 2013) This constitutive entanglement of the social and 
material led to agential realism where "there is no social that is separate from material, there is only the sociomaterial". (Leonardi 2013)

In the discussion on empirical and philosophical characteristics of sociomateriality, Leonardi (2013) acknowledged difficulties in engaging empirical data, operationalizing empirical constructs and considering temporality within agential realism, in particular balancing the perspectives of the social and the material without tilting to one side. Furthermore, Leonardi pointed out a challenge in agential realism which may not adequately explain the internal, constitutive relationship between the social and the material and when phenomena lead to relationships with each other.

In order to address the shortcomings, Leronardi (2013) proposed to employ critical realism with analytical dualism and empirical constructivism, which treats structure and agency separate but interacting with each other. According to him, "the "social" and the "material" are independent entities that become "sociomaterial" when they are merged into each other. He argued that the entanglement be explained as "the gradual overlapping and interlocking of distinct elements into a durable infrastructure" (p. 70).

Sociomateriality, in particular Leonardi's approach to sociomateriality, enables researchers to analyze and understand the unique characteristics of e-compliance as empirical phenomena and a conceptual framework. The case studies in this present research found compliance drivers in the leadership, organizational, social and technological categories. These can be classified into the social (leadership, organizational and social) and the material (technological). All compliance drivers were imbricated to form a durable infrastructure which is the compliance mechanism in e-compliance. Some of the compliance drivers, such as leadership, pre-dated the existence of the material, represented by the technological artefacts in the two case study initiatives. Over time, the compliance drivers overlapped, entangled and interlocked with each other, formed $e$-compliance and eventually produced compliance as we observed in the case of Bhutan.

Therefore, the conceptual framework of e-compliance, more specifically the dependence and inter-dependence of compliance drivers, might be further investigated as an imbrication between the social and the material with the perspective of sociomateriality. The application of sociomaterial lens to e-compliance would also enable a researcher to explain dynamic technological development based on interactions with users as well as the evolution of compliance mechanism and compliance space over time. Leonardi (2013) discussed difficulties in engaging empirical data, operationalizing empirical constructs, considering temporality. The conceptual framework of e-compliance provides the framework to investigate the imbrication 
of the compliance drivers and the process of entanglement of the compliance drivers over a period of time.

This present research on compliance demonstrated that the system design, development and implementation are not linear activities or a priori, but rather a continuous negotiation between users, developers, leaders and technology. The series of negotiations are represented by the dependence and inter-dependence of the social and material which form constitutive entanglements in e-compliance. As such, sociomateriality offers e-compliance the theoretical anchoring which enables to explain the findings of the two case studies and the conceptual framework of e-compliance, as discussed in more detail in the below Section 7.5.2

\subsubsection{EXPLAINING AND APPLYING E-COMPLIANCE WITHIN SO- CIOMATERIALITY THEORY}

The analysis of the two case study initiatives in Chapter 6 found that there were the technological (the material) as well as the social, organizational and leadership compliance drivers (the social) which contributed to compliance in the case of Bhutan. In addition, the analysis discovered the entanglements of the compliance drivers in the form of dependence and inter-dependence among compliance drivers which formed the compliance mechanism. The entangled compliance drivers were found to evolve iteratively: when the technological compliance driver was introduced, it affected the social, organizational, and leadership compliance drivers, which then affected the way the technological solutions were updated and implemented. As detailed in Section 2.2.6, the existing IS theories don't offer suitable tools to analyze and explain the unique features of e-compliance, namely the importance of both the social and the material, the entanglements and iterative evolution of compliance drivers. Sociomateriality was found the best tool to explain the unique features of e-compliance.

This section informs how the conceptual framework of e-compliance can be analyzed and explained within the theory of sociomateriality, together with the implications of anchoring e-compliance in the theory of sociomateriality.

First, e-compliance is conceptualized based on the social (social, leadership and organizational drivers) and the material (technological drivers); it is not possible to explain e-compliance without one another and sociomateriality is the unique tool to enable research on the social and material relationships without distinctions between them (Feldman and Orlikowski 2011). 
Second, sociomateriality provides the tool to explain the process of entanglement. Leonardi (2013) explained the entanglement as "the gradual overlapping and interlocking of distinct elements into a durable infrastructure" (p. 70). In the case of e-compliance, each driver and their mutual reinforcement are expected to make ecompliance as a gradually overlapping, durable mechanism and infrastructure for the normative intervention of anti-corruption.

In the case of $e$-PEMS, for example, the previous PEMS had been adopted technologically but was plagued with frauds and misuses of manual check system. Based on other IS theoretical frameworks, PEMS may be considered as a successful technology adoption case but not a good example of e-compliance, as the technology is not effective to ensure the outcome, which is compliance and prevention of fraud. E-compliance and entanglement materialized with the introduction of e-PEMS when the new technology and other compliance drivers became entangled and started taking effects to reduce fraudulent practices as a result of constitutive engagement of the social and the material.

In the case of ADS, the improvement occurred overtime, and can be considered as an example of gradual entanglement, as the system has been improved over time, and the entanglement has been strengthened as more social and material compliance drivers were added to the entanglement constitutively.

Third, using the sociomaterial tools, e-compliance allows a researcher to capture the effects of entanglement between the social and the material. Social, leadership and organizational compliance drivers have significant influence on how e-governance systems are developed and continuously upgraded, which then influence back other social, leadership and organizational compliance drivers. For example, the ACC team's continuous efforts to engage users in advocacy and sensitization workshops helped improve the functionality of the ADS. Due to the improved system functionality and enhanced visibility and transparency, the users became aware of the possibility that illicit enrichments could be discovered and demonstrated fear for punishment, which is an example of gradual overlapping and interlocking entanglement, argued by Leonardi (2013). The sociomaterial theory thus enables a researcher to explain the reinforcing effects of entanglement of the social and the material which ensures compliance in e-governance implementation and makes e-compliance durable.

Fourth, e-compliance also presents empirical evidence to the question on temporality in sociomaterial discourse and more specifically when the social and the material become sociomaterial from the independent entities of the social and the material (Leonardi 2013). In the case of e-compliance, the process starts when dependence and inter-dependence of compliance drivers occur and produce constitutive 
effects on the outcome and durable infrastructure, as explained in the examples of the ADS and e-PEMS.

The two case studies evidenced the reduction in and prevention of fraudulent practices, such as manipulation of checks in the case of $e$-PEMS and gradually improvements in quality and quantity in asset declarations in the case of ADS, through the entangled social and material. E-compliance as a conceptual framework thus explains how an increase or decrease in entangled compliance drivers leads to a higher or lower compliance, which would eventually lead to an increase or decrease in the level of corruption.

In summary, e-compliance is an instrument to offer a logic and structure the compliance drivers under compliance determinants and analyze their relationships through the compliance mechanism, which allows a researcher to explain the level of compliance in e-governance implementation. The framework helps shed light onto what aspects of entangled compliance drivers are effective, their mechanisms and channels. It further helps understand the dynamics and evolution of the compliance drivers and compliance mechanisms.

\subsection{SUMMARY}

Chapter 7 examined the identified compliance drivers against the existing literature detailed in Chapter 2. The comparisons with the existing literature focused on the 4 categories of compliance drivers, namely organizational, leadership, social and technological categories. The existing literature does refer to leadership in the government. However, the role of His Majesty the King and the dual leadership model were not found in the existing literature. Similarly, there was no horizontal or vertical leadership in the context of compliance in e-governance implementation discussed in the existing IS or compliance literature. While social compliance drivers found alignments with the existing literature, the concept and application of ownership was found missing. The organizational compliance drivers, found largely in the case of ADS, were adequately explained by the existing compliance literature. The technological compliance drivers played an important role in ensuring compliance in the two case study initiatives, yet the existing literature did not adequately explain the technological compliance drivers or compliance in the context of e-governance implementation. This present research also recognized the absence of various compliance determinants in the case of Bhutan, such as access to 
information, anti-corruption policies, regulations and frameworks as well as international instruments, such as international conventions and standards.

Chapter 7 then discussed relevant compliance models found in the existing literature, such as the Outcome and Output model. The comparison clarified that the compliance drivers identified in this present research, such as technology and ownership, could not be well explained by the existing compliance models.

Building on the identified gaps between the case study initiatives and literature and in recognition of the lack of appropriate models, Section 7.4 proposed a new conceptual framework of e-compliance. This section explored the construction of a concept, which integrates technology and ownership with other compliance drivers in e-governance implementation. Section 7.4 proposed the development of ecompliance which consists of 1) rule-based, 2) trust-based and 3) technology-based compliance determinants. This conceptual framework is expected to help explain the mechanism and space of compliance in e-governance implementation within the overall framework of anti-corruption efforts.

Section 7.5 then discussed the theoretical anchoring of e-compliance in the context of sociomateriality as a tool by which e-compliance can be explained. Especially relevant to e-compliance was the constitutive entanglement of the social and the material. The entanglement of the social and the material into sociomateriality helps explain the phenomena at hand and dependence and inter-dependence of compliance drivers as constitutive entanglement to form e-compliance. Based on the empirical data and analysis, this section discussed essential parameters required for future studies on e-compliance and the implications of theoretical anchoring in sociomateriality in the Information System (IS) literature. 
"Of course the government is trying to do its best. That's where IT is being widely used. Hopefully, maybe in the near future, due to the intervention of IT services, hopefully a lot of these (corrupt) practices will be stopped. We are hoping. We are very positive". (O2)

This exploratory, inductive research aimed to answer the research questions on what are the determinants of compliance among government employee users in egovernance implementations? It explored the use of compliance as a conduit and mechanism to understand the phenomena of compliance in the e-governance implementation in the case of Bhutan. In addition to the novel approach of applying compliance, this research added to the existing literature the empirical evidence from the case study of Bhutan on which little research has been conducted in the past as well as a new conceptual framework of e-compliance.

This present Chapter begins with a summary of this present research in Section 8.1, followed by the summary of empirical findings in Section 8.2. The theoretical contributions of this research are then summarised in Section 8.3. The Chapter concludes with the discussion on research limitations in Section 8.4 and policy recommendations emanating from the investigation of case study initiatives in Section 8.5 .

\subsection{SUMMARY}

E-governance initiatives are increasingly seen as a vehicle to tackle corruption across the globe. E-governance initiatives offer an unprecedented amount and visibility of data and information which can be aggregated, disaggregated and analyzed to identify patterns and help improve policies, procedures, and processes. But the information systems alone would be insufficient to actually reduce corruption. Otherwise, we would have seen corresponding decreases in corruption along with the increasing number and scale of e-governance initiatives worldwide. Furthermore, despite the fact that similar e-governance functions and initiatives have been implemented across the world, the evidenced outcomes seem to vary markedly from country to country. 
In this exploratory inductive research, compliance is identified as a conduit and part of mechanism to explain the phenomena of e-governance implementation which aims to control corruption. When government employee users comply with the e-governance system requirements, it is expected that the system will achieve the objectives the system is designed for and contribute to overall control of systemic corruption in the government. In this background, this present research aims to answer the following questions:

\section{How does compliance manifest in e-governance implementation?}

\section{What are the determinants of compliance among government employee users in e-governance implementation?}

To answer the research questions, this research used qualitative inductive methods, based on constructivist/interpretivist approach. A comparative case study helped provide a detailed description of each case and theme within a case and across cases (cross-case analysis) for interpretation. The context of the case study country, including its laws and norms, was held constant and introduced variation in each case.

Data collection methods included document analysis, observations and semi-structured interviews. The fieldwork was conducted from September 2019 to January 2020 and conducted semi-structured interviews of 32 government officials and experts in Bhutan. The data collected from the case study initiatives and triangulated across different data sources produced rich descriptions which enabled in-depth interpretation of compliance drivers in each case study initiative. Using two rounds of coding and partial pattern matching, similar and dissimilar compliance drivers were identified for cross-case synthesis. In analyzing data, actor analysis and process tracing methods were applied to establish more nuanced perspectives of various actors and understand the institutional dynamics. The analysed data helped to understand the phenomena under review and explore the how and why of compliance levels attained in each initiative.

The case study county was selected based on a set of pre-determined criteria of egovernment maturity and level of control of corruption. Out of the 13 possible case study countries, Bhutan was selected, based also on the country ranking of Transparency International Perception Survey 2018 (25 th out of 180 countries in 2019) and language requirement. Bhutan is generally not the country of first choice for this type of studies, but the fact that the government provided access and objectively fits the criteria for case study country makes Bhutan a compelling case. 
One distinctive aspect of the case study country is the fact that Bhutan is one of the least developed countries and at the same time landlocked developed country, with the approximate population size of 800,000 . Thus, the available human and financial resources are limited to advance anti-corruption and implement the latest technologies across the government. Out of the 30 e-government initiatives listed in the Bhutan E-government Master Plan, the Asset Declaration System (ADS) of the Anti-Corruption Commission (ACC) and the electronic Public Expenditure Management System (e-PEMS) of the Ministry of Finance (MoF) were selected as case study initiatives based on pre-set criteria.

\subsection{EMPIRICAL FINDINGS}

Across the two case study initiatives examined in Chapter 4 and Chapter 5, similar and dissimilar compliance divers emerged. In this present research, a compliance driver is defined as a group of inter-linked factors and attributes which are evidenced to have direct impact on compliance of government employee users in using e-governance systems. A compliance driver was developed using triangulation of data from multiple sources. This research identified 13 compliance drivers in each case study and contrasted similar and dissimilar compliance drivers among the government employee users in a cross-case synthesis. The compliance drivers were grouped into the 4 categories of organizational, leadership, social and technological compliance drivers.

It was a surprise that the compliance drivers grouped under the leadership and social categories were very similar, identical or interchangeable. The compliance drivers on technology-enabled ease of use (ADS) and familiarity with the existing system and ease of use /technology and automation (e-PEMS) were also very similar, and so was one challenge, application for advanced technology. Dissimilar compliance drivers showed distinctive features, unique to the respective organizations, initiatives and contexts where the systems were situated in.

The present research then explored the conditions, mechanism and context in which the compliance drivers were situated. The conditions were identified in the relationships of dependence and inter-dependence among the compliance drivers. The relationships derived from the interview accounts, observations, and document analysis. The present research proposed the compliance mechanism as an aggregation of relationships of dependence and inter-dependence among the compliance drivers in the compliance space where all the compliance drivers operated and functioned. 
In the process of discerning dependence and inter-dependence and developing a distilled account of compliance mechanism, two important factors emerged, which had widespread impact on several other compliance drivers and challenges. First, Figure 16 illustrated the impact of technology-related compliance drivers on other compliance drivers as an enabler of other compliance drivers. Second, ownership, as defined by funding source and developer, was instrumental with its wide-ranging indirect influence on several other compliance drivers to explain differences between the ADS and e-PEMS compliance drivers and challenges.

The two rounds of literature reviews concluded that technology, e-governance in particular, did not appear prominently in the existing compliance literature, despite the increasing importance in the context of anti-corruption efforts in both OECD and non-OECD countries. The identified technology-related compliance drivers demonstrated its existence and validity to be considered in the compliance literature. The literature reviews also indicated that very few studies have been conducted on compliance in e-governance implementation, while there were even fewer studies which focused on the government employee users' compliance, despite the increasing importance of e-governance initiatives and expectations to control systemic corruption worldwide.

\subsection{THEORETICAL CONTRIBUTIONS}

Building on Chapter 6, Chapter 7 examined the identified compliance drivers against the existing literature detailed in Chapter 2 and develop a conceptual framework which aims to explain the phenomena of compliance in e-governance implementation. Some good matches were found between the compliance drivers found in the case study initiatives and existing compliance literature, as discussed in Section 7.1. These matches were identified mainly in the social and organizational compliance driver categories. The existing literature did not yield good and suitable matches to adequately explain the compliance drivers under the leadership category. Even more scant were the matches between the technological compliance drivers and the existing literature. The examples and narratives related to ownership did not appear in the existing literature at all.

Interestingly, this present research discovered that various compliance determinants found in the existing compliance literature did not appear in the case study initiatives of Bhutan. Compliance triggered by international instruments, such as the role of foreign entities, international conventions and international standards, was found entirely absent in the case studies in Bhutan. Similarly, access to information and anti-corruption policy, legal and regulatory frameworks were largely 
absent from the case study initiatives. On the other hand, there were compliance drivers which were not found in the existing compliance literature.

It was also evident that the exiting compliance models were insufficient to explain the phenomena of compliance in e-governance implementation in the case of Bhutan. In particular, the technological compliance drivers, leadership model and the concept of ownership did not fit into either rule-based compliance or trust-based dispositional compliance.

In this context, not only the compliance mechanism, which consists of dependent or inter-dependent compliance drivers, but also the compliance space, which consists of the number of compliance driver, would help explain the phenomena of compliance in the e-governance implementation.

Therefore, this research proposed the development of a conceptual framework, $e$ compliance, which consists of

1) rule-based compliance determinants, represented by the organizational compliance drivers

2) trust-based, dispositional compliance determinants, represented by the social and leadership compliance drivers and

3) technology-based compliance determinants, represented by the technological compliance drivers.

The conceptual framework is expected to explain not only the compliance drivers but also the role of technology in increasing or decreasing compliance, which would then be liked to and subsequently explain an increase or decrease in the level of systemic corruption.

Section 7.5 then discussed e-compliance in the context of sociomateriality. The entanglement of the social and the material into sociomateriality helps analyze and explain the phenomena at hand and dependence and inter-dependence of compliance drivers to form e-compliance. This section proposed the theoretical anchoring in the theory of sociomateriality in the Information System (IS) literature and essential parameters required for future studies on e-compliance.

This research used ownership as criteria to select the two case study initiatives. The effects of ownership were found wide-ranging, yet indirect, and had impact on various compliance drivers, through which the effects were channeled. The different levels of ownership among the IT teams and users explained the different range and level of challenges encountered in the two case study initiatives. 
This section discusses research limitations derived from the choices I made in the methodological orientation, data collection and analysis methods as well as remedial measures found the existing literature, followed by discussions on possible future research.

The first limitation is the replicability and transferability of research findings. Qualitative research methods have often been criticized for not being replicable and leaving too much scope and influence to the researcher (Blaikie 2013, p. 191-191). In response, Brinkmann and Kvale (2014) asserted that "the goal of global generalization is replaced by a transferability of knowledge from one situation to another, taking into account the contexuality and heterogeneity of social knowledge" in qualitative research (p. 199). Furthermore, the principles and lessons learned from a case study could be applied to a variety of situations beyond the original case study context (Yin 2013).

As this present research is inductive and exploratory, specific to the context of Bhu$\tan$, the identified compliance drivers may not be generalizable. However, it is believed that the methodology used for data collection can be replicated and the conceptual framework of e-compliance be used in other contexts and countries. This research also produced thick descriptions of case initiatives which could be used to identify similarities and congruence for the transferability to similar contexts and initiatives.

Another limitation in conducting semi-structured interviews was identified as perceived lack of objectivity. Successful interviews, however, enable interviewees to feel comfortable and correct any misinterpretations and errors (Silverman 2016, p. 57). During the semi-structured interviews I conducted, several interviewees qualified and corrected my understandings during the interviews when asked to confirm their statements, which increased the level of objectivity, supported by triangulation with different data sources.

For future research, I suggest that similar research be undertaken on different egovernance initiatives which aim to control corruption in Bhutan. Some of the identified compliance drivers were identical and inter-changeable between case study initiatives, which suggests a likelihood that it exists in other e-governance initiatives in Bhutan. These initiatives could include e-governance initiatives with high and low compliance to compare the presence and absence of compliance drivers. 
Further research could be conducted in a country in different predicaments identified in Table 3. This research was designed as exploratory, inductive research and, therefore, I selected the best case study country, where compliance could be easily found. In the future, this research framework could be tested in different circumstances, where compliance is expected to be lower despite the maturity of e-governance systems.

Furthermore, there is an opportunity for a longitudinal study on the identified compliance drivers and how they evolve along with the dynamically evolving context. Another follow up study in 3 or 5 years would shed light on e-compliance evolution and how improved or deteriorated corruption in Bhutan could be explained from the evolution of the identified compliance drivers.

In particular, both the ADS and e-PEMS were not entirely new to the government employee users. The ADS was established in 2009, 10 years ago at the time of fieldwork, and e-PEMS was an upgrade to PEMS. Therefore, there have been various enabling elements to compliance. If this research focused on a brand new system, the findings could have been different, even in the same context. For this reason, I would suggest to conduct a similar study using a variety of e-governance initiatives and different contexts and circumstances.

\subsection{POLICY RECOMMENDATIONS}

The policy recommendations emanating from this research are categorized into 1) policy recommendations specific to Bhutan and case study initiatives and 2) e-governance policy recommendations.

The policy recommendations specific to the case study initiatives include addressing the challenges identified in Section 4.5 and 5.5. of this present research. Such measures will ensure that compliance mechanism and space are maintained and function optimally. This present research underlined the importance of technology and ownership, namely the government funding and system development by government officials. In this context, the empowerment of IT officers and Department of Information Technology and Telecommunications (DITT) will help address the technical and technological challenges and shortcomings identified in this research and ensure the sustainability of effective IT systems in the government. The government could also pay attention to the identified compliance drivers so as not to reduce e-compliance, while advancing the implementation of e-governance initiatives in the context of anti-corruption efforts. 
Another factor elicited in the interviews was the fact that the high compliance level was associated with the long-term efforts and effects of ADS and e-PEMS in the form of familiarity and ease of use. An assessment and evaluation of such initiatives should take into account not only the short-term achievements but also the long-term outcomes in a larger context, as anti-corruption is a long term development goal. Instead of initiating many systems for anti-corruption, it would make sense to nurture the existing systems for a long time, taking into account the dynamically evolving context.

As to the general e-governance policy recommendations, the attainment of e-compliance is not contingent on available financial resources alone. The research found technology and ownership as key enablers of compliance, which would require additional investment and financial resources. However, other compliance drivers and determinants found effective centered on social and leadership factors. This may mean that many compliance drivers can be developed and expanded in developing countries where available financial and human resources are limited and the factors would require special attention.

The e-governance systems are critical building blocks for governments to explore more advanced technological solutions, such as Big Data analytics, artificial intelligence or blockchain for financial transactions and settlements. The type of support, which is effective to the beneficiary countries, should be carefully identified for any ICT or digital technology initiatives. Not all countries require external consultants to design and implement systems. The UN and partner support could focus more on long-term, advisory role, while building technical and functional capacity within the government and private sector. Often, difficulties are faced in maintaining externally developed systems, due to incompatible technical platforms, programming skillsets, or lack of proper documentation and handover. Instead, like in the ADS, a home-grown system could be encouraged, which blends into the technological landscape of the organisation and development aspiration of the country.

Anti-corruption efforts and sound public financial management among beneficiary countries should remain priority areas of development assistance. When systemic corruptions are addressed and funds are managed transparently and efficiently, the country will have more resources to implement public initiatives to achieve SDGs. At the same time, institutional and human capacity would have been strengthened to cope with any irregularities. Public trust in the government would grow as well. UN and partner support should aim at these multiplier effects, which will create a virtuous circle of development. 
Ademmer, E. \& Börzel, T. A. (2013) Migration, Energy and Good Governance in the EU's Eastern Neighbourhood, Europe-Asia Studies, 65:4, 581608, DOI:

$10.1080 / 09668136.2013 .766038$

Akerlof, R. (2016) Anger and enforcement, JOURNAL OF ECONOMIC BEHAVIOR \& ORGANIZATION Volume: 126 Special Issue: SI Pages: 110-124

DOI:10.1016/j.jebo.2015.10.022 Part: B Published: JUN 2016

Alaaraj, H., \& Hassan S. (2016) Does Good Governance Mediate Relationship between E-government and Public Trust in Lebanon? International Review of Management and Marketing, 2016, 6(3), 500-509.

Aladwani, A. M. (2016) Corruption as a source of e-Government projects failure in developing countries: A theoretical exposition, International Journal of Information Management 36 (2016) 105-112

Ali, M., Fjeldstad, O. \& Sjursen, I. H. (2014) To Pay or Not to Pay? Citizens' Attitudes Toward Taxation in Kenya, Tanzania, Uganda, and South Africa, WORLD DEVELOPMENT Volume: 64 Pages: 828-842

Al-Madi, F. N., Al-Shraideh, B. M., \& Khrais, L. T. (2016) The Role of E-government on Implementing and Enhancing Transparency in Jordan, I J A B E R, Vol. 14, No. 14 (2016): 87-106

Alon, A. \& Hageman, A. M. (2013) The Impact of Corruption on Firm Tax Compliance in Transition Economies: Whom Do You Trust? JOURNAL OF BUSINESS ETHICS Volume: 116 Issue: 3 Pages: 479-494 Published: SEP 2013

Alon, A. \& Hageman, A. M. (2017) An institutional perspective on corruption in transition economies, Corp Govern Int Rev. 2017;25:155-166.

Allay, K. (2016) Gross National Happiness: Philosophy of Development Strategy, Chapter 6 in a book "Bhutan: Contemporary Issues \& Perspectives", edited by Kharat, R. S., ISBN: 978-81-87393-08-5

Almutairi, A, Gardner, G., \& McCarthy, A. (2014) Practical guidance for the use of a pattern-matching technique in casestudy research: A case presentation. Nursing and Health Sciences, 16(2), pp. 239-244 
Amr, M. S. M. (2003) The Role of the International Court of Justice as the Principal Judicial Organ of the United Nations (Legal Aspects of International Organization) at

https://books.google.co.th/books?id=ra9vI0V QoEC\&pg=PA129\&dq=\%22institutional+instrument $\% 22 \& h \mathrm{l}=$ th\&sa $=X \& v e d=0$ ahUKEwjesp7h6oT-

jAhXn7HMBHZheAqw4ChDoAQgnMAA\#v=onepage\&q=\%22institutional $\% 20$ instrument $\% 22 \& \mathrm{f}=$ false

Andersen, T. B. (2009) E-Government as an Anti-Corruption Strategy, Information Economics and Policy, 21, 201-210

Anti-Corruption Commission (2011a) Anti-Corruption Act of Bhutan (ACAB), available at https://www.acc.org.bt/sites/default/files/ACA\%202011 1.pdf

Anti-Corruption Commission (2011b) Asset Verification Protocol, available at https://www.acc.org.bt/sites/default/files/Asset\%20Verification\%20Protocol.pdf

Anti-Corruption Commission (2012) Compliance Report of Asset Declaration for the year 2012, available at https://www.acc.org.bt/node/587

Anti-Corruption Commission (2013) National AntiCorruption Strategy (NACS) of Bhutan 2008-13, evaluation report, available at https://www.acc.org.bt/sites/default/files/NACS\%20evaluation\%20report $\% 20$ for $\% 20$ print.pdf

Anti-Corruption Commission (2015a) Review of the Ethics and Integrity Infrastructure in Bhutan, available at https://www.acc.org.bt/sites/default/files/ACC\%20Report.pdf

Anti-Corruption Commission (2015b) Compliance Report of Asset Declaration for the year 2015, available at https://www.acc.org.bt/?q=node/1601

Anti-Corruption Commission (2016) Anti-Corruption Commission Annual Report, available at https://www.acc.org.bt/sites/default/files/AR2016.pdf

Anti-Corruption Commission (2017a) Anti-Corruption Commission Asset Declaration Rules 2017 available at https://www.acc.org.bt/sites/de-

fault/files/rules/ADR2017.pdf 
Anti-Corruption Commission (2017b) Anti-Corruption Commission User Manual for Online Asset Declaration System (ADS), available at

https://www.acc.org.bt/sites/AD\%20User\%20Manual.pdf

Anti-Corruption Commission (2017c) Compliance Report of Asset Declaration for the year 2017, available at https://www.acc.org.bt/?q=node/1891.

Anti-Corruption Commission (2017d) National Integrity Assessment 2016, available at https://www.acc.org.bt/pdf/NIA2017.pdf

Anti-Corruption Commission (2017e) Anti-Corruption Commission Annual Report, available at https://www.acc.org.bt/sites/default/files/2017AnnualReport Eng.pdf

Anti-Corruption Commission (2018) Anti-Corruption Commission Annual Report, available at https://www.acc.org.bt/images/AnnualRepor2018Eng.pdf

Anti-Corruption Commission (2019), National Integrity and Anti-Corruption Strategy (2019-2023): Developing Accountable, Moral and Transparent Systems and Individuals, available at https://www.acc.org.bt/pdf/NIACS\%2020192023.pdf

Anti-Corruption Commission (2019a) ACC Organizational Structure, available at https://www.acc.org.bt/sites/default/files/Organogram $\% 20 \% 28$ Aug $\% 206 \% 2 C \% 202019 \% 29$.pdf

Anti-Corruption Commission (NA), Institutional Development Plan 2011-2020, available at https://www.acc.org.bt/sites/default/files/Final\%20IDP.pdf

Anti-Corruption Commission (N/A) Online Asset Declaration System SRS (Draft) for Anti-Corruption Commission

Avgerou, C., Ciborra, C., Cordella, A., Kallinikos, J. and Smith, M. (2005) The Role of Information and Communication Technology in Building Trust in Governance: Towards Effectiveness and Results, Inter-American Development Bank

Bac, M. (2018) Wages, performance and harassment, Journal of Economic Behavior \& Organization 145 (2018) 232-248

Bannister, F. \& Connolly, R. (2012) Defining e-Governance, e-Service Journal, Volume 8, Number 2, Winter 2012, pp. 3-25 (Article) 
Bannister, F. \& Connolly, R. (2014) ICT, public values and transformative government: A framework and programme for research, Government Information Quarterly 31 (2014) 119-128

Basil Institute of Governance (2013) National AntiCorruption Strategy (NACS) of Bhutan 2008-13: Evalaution report, at https://www.acc.org.bt/sites/default/files/NACS\%20evaluation\%20report\%20for\%20print.pdf

Batory, A. (2012) Why do anti-corruption laws fail in Central Eastern Europe? A target compliance perspective, Regulation \& Governance (2012) 6, 66-82

Baum, A., Gupta, S., Kimani, E. \& Tapsoba, S. J. (2017) Corruption, Taxes and Compliance, EJOURNAL OF TAX RESEARCH Volume: 15 Issue: 2 Special Issue: SI Pages: 190-216 Published: DEC 2017

Bearfield, D. A. \& Bowman, A. O. (2017) Can You Find It on the Web? An Assessment of Municipal E-Government Transparency, American Review of Public Administration 2017, Vol. 47(2) $172-188$

Bennett, A. \& Checkel, J. T. (2014) Process Tracing: From philosophical roots to best practices, in a publication entitled Process Tracing: From Metaphor to Analytic Tool, p.3-37, Cambridge University Press

Benson, E., Torres, L., Royo, S. and Flores, F. (2012) Local e-government 2.0: Social media and corporate transparency in municipalities, Government Information Quarterly, 29, 123-132

Bertot J., Jaeger, P. and Grimes, J. (2010) Using ICTs to create a culture of transparency: E-government and social media as openness and anti-corruption tools for societies, Government Information Quarterly, 27, 264-271

Berghoff, H. (2018) "Organised irresponsibility"? The Siemens corruption scandal of the 1990s and 2000s, Business History, 60:3, 423-445, DOI:

10.1080/00076791.2017.1330332

Bhargava, V. (2006) Curing the Cancer of Corruption, Chapter 18 of the World Bank publication "Global issues for Global Citizens" ISBN 978-0-8213-6731-5 
Bhuiyan, S. H. (2011) Modernizing Bangladesh public administration through egovernance: Benefits and challenges, Government Information Quarterly 28 (2011) 54-65

Bhutan Broadcasting System (BBS) (2018) Bhutan's LDC graduation likely to be deferred to 2023, on 17 August 2018 at http://www.bbs.bt/news/?p=102105

Bhutan Transparency Initiative (2020) National Corruption Barometer Report 2020, available at http://bhutantransparency.org/wp-content/uploads/2020/07/NCBSR-2020.pdf

Bina, X. \& Yinghong, H. (2016). The Political Impetus behind the Construction of Anti-corruption Institutions in Developing Countries: An Analysis of the Process Leading up to India's Lokpal and Lokayuktas Act (LALA). Social Sciences in China. 37. 75-92. 10.1080/02529203.2016.1194629.

Blaikie, N. (2010) Designing Social Research, second edition, ISBN 978-0-74564338-0

Boisvert, A., Dent, P., and Quraishi, O. (2014) Corruption in Canada: Definitions and Enforcement, ISBN No.: 978-1-100-23797-8

Bolivar, M. P. R., Perez, M. C C., \& Lopez-Hernandez, A. M. (2015) Online Budget Transparency in OECD Member Countries and Administrative Culture, Administration \& Society 2015

Bryman, A. (2016) Social Research Methods, $5^{\text {th }}$ edition, Oxford Press, ISBN 978-0$19-968945-3$

Byrne, E. (2007) The Moral and Legal Development of Corruption: Ninetieth and Twentieth Century Corruption in Ireland. PhD Thesis, University of Limerick.

Bu, Q. (2018) The Culture Variable Vis-à-Vis Anti-bribery Law: A Grey Area in Transnational Corporate Criminal Liability, Eur Bus Org Law Rev (2018) 19:183213, DOI 10.1007/s40804-017-0089-8

Business Bhutan (2018a) Eight Immigration Officials Charged For Embezzlement, available at https://www.businessbhutan.bt/2018/03/07/eight-immigration-officials-charged-for-embezzlement/ 
Business Bhutan (2018b) Thimphu, Paro And Punakha Civil Servants Claim Nu. 1.110mn On Table Tours: Audit Report, available at https://www.businessbhutan.bt/2018/07/11/thimphu-paro-and-punakha-civil-servants-claim-nu-1-110mnon-table-tours-audit-report/

Business Bhutan (2019a) Former Finance Minister Involved In Alleged Encroachment Of Government Land, 21 March 2019, available at https://www.businessbhutan.bt/2019/03/21/former-finance-minister-involved-in-alleged-encroachmentof-government-land/

Business Bhutan (2019b) Former Labor Minister And Director General Slapped With Four Charges By OAG, available at https://www.businessbhutan.bt/2019/08/29/former-labor-minister-and-director-general-slapped-with-fourcharges-by-oag/

Camaj, L. (2016) From 'window dressing' to 'door openers'? Freedom of Information legislation, public demand, and state compliance in South East Europe, GOVERNMENT INFORMATION QUARTERLY Volume: 33 Issue: 2 Pages: 346357 DOI: 10.1016/j.giq.2016.03.001 Published: APR 2016

Cho, S., Dreher, A. \& Neumayer, E. (2014) Determinants of Anti-Trafficking Policies: Evidence from a New Index, SCANDINAVIAN JOURNAL OF ECONOMICS Volume: 116 Issue: 2 Pages: 429-454

Cleveland, M., Favo, C.M., Frecka, T.J, \& Owens, C. L. (2009) Trends in the International Fight Against Bribery and Corruption, Journal of Business Ethics (2009) 90:199-244

Coicaud, J. (2016) Administering and Governing with Technology; The Question of Information Communication Technology and E-Governance, Global Policy Volume 7. Issue 2. May 2016

Cordella, A. \& Innacci, F. (2010) Information systems in the public sector: The eGovernment enactment framework, J. Strateg. Inform. Syst. 2010, doi:10.1016/j.jsis.2010.01.001

Creswell, J. W., \& Poth, C. N. (2016). Qualitative Inquiry and Research Design: Choosing Among Five Approaches 
Cyan, M. R., Koumpias, A. M \& Martinez-Vazquez, J. (2016) The determinants of tax morale in Pakistan, JOURNAL OF ASIAN ECONOMICS Volume: 47 Pages: 23-34 DOI: 10.1016/j.asieco.2016.09.002 Published: DEC 2016

Darden, K. (2008) The Integrity of Corrupt States: Graft as an Informal State Institution, POLITICS \& SOCIETY, Vol. 36 No. 1, March 2008 35-60, DOI: $10.1177 / 0032329207312183$

D'Attoma, J., Volintiru, C., \& Steinmo, S. (2017) Willing to share? Tax compliance and gender in Europe and America, RESEARCH \& POLITICS Volume: 4 Issue: 2 Article Number: UNSP 2053168017707151 DOI: 10.1177/2053168017707151 Published: APRJUN 2017

De Figueiredo, J. N. (2013) Are corruption levels accurately identified? The case of US states, JOURNAL OF POLICY MODELING Volume: 35 Issue: 1 Pages: 134-149 DOI: 10.1016/j.jpolmod.2012.01.006 Published: JAN-FEB 2013

DeNardis, L. (2010) E-governance Policies for Interoperability and Open Standards, available at: http://ssrn.com/abstract $=1629833$

Denzin, N. K. \& Lincoln, Y. S. (2012) Introduction: The Discipline and Practice of Qualitative Research, The SAGE Handbook for Qualitative Research, available at https://uk.sagepub.com/sites/default/files/upm-binaries/40425_Chapter1.pdf

Dietrich, S (2011) The Politics of Public Health Aid: Why Corrupt Governments Have Incentives to Implement Aid Effectively, WORLD DEVELOPMENT Volume: 39 Issue: 1 Pages: 55-63

Dwivedi, Y. K., Rana, N. P., Jeyaraj, A., Clement, M. \& Williams, M. D. (2017) Reexamining the Unified Theory of Acceptance

and Use of Technology (UTAUT): Towards a Revised Theoretical Model, Inf Syst Front (2019) 21:719-734

Elbahnasawy, N. (2014) E-Government, Internet Adoption, and Corruption: An Empirical Investigation, World Development, 57, 114-126

Feldman, M. S. \& Orlikowski, W. J. (2011) Theorizing Practice and Practicing Theory, OrganizationScience Vol. 22, No. 5, September-October 2011, pp. 1240-1253

Fenster, M. (2012) The Transparency Fix: Advocating Legal Rights and Their Alternatives in the Pursuit of a Visible State, 73 U. Pitt. L. Rev. 443, 504 (2012) 
Fountain, J. E. (2007) Bureaucratic Reform and E-Government in the United States: An Institutional Perspective, National Center for Digital Government (NCDG) Working Paper No. 07-006, Submitted September 18, 2007

Fukuyama, F. (2004) State-Building: Governance and World Order in the 21st Century, published by Cornell University Press, ISBN-13: 978-0801442926

Fusch, P. I. \& Ness, L. R. (2015) Are We There Yet? Data Saturation in Qualitative Research, The Qualitative Report 2015 Volume 20, Number 9, How To Article 1, 1408-1416 http://www.nova.edu/ssss/QR/QR20/9/fusch1.pdf

Gallenkamp, M. (2013) Triumph of Democracy Bhutan Elections 2013, Institute of Peace and Conflict Studies (IPCS) Special Report \# 144 September 2013

Garcia-Tabuyo, M., Saez-Martin, A. \& Caba-Perez, M. D. C. (2015) PROACTIVE TRANSPARENCY POLICY IN THE MERCOSUR LOCAL GOVERNMENTS: REGULATION VS. SELF-REGULATION, TRANSYLVANIAN REVIEW OF ADMINISTRATIVE SCIENCES Issue: 46E Pages: 71-90 Published: OCT 2015

Garcia-Tabuyo, M., Saez-Martin, A. \& Caba-Perez, M. D. C. (2016) Mandatory versus voluntary disclosures: Drivers of proactive information provision by local governments in Central America, INFORMATION DEVELOPMENT Volume: 32 Issue: 4 Pages: 1199-1215 DOI: 10.1177/0266666915595260 Published: SEP 2016

Galiot, M. (2017) Confiscation of Pecuniary Gain in the Context of International Regulations and Combatting Bribery, ZBORNIK PRAVNOG FAKULTETA SVEUCILISTA U RIJECI Volume: 38 Issue: 1 Pages: 547-571 Published: 2017

Gelderman, C. J., Ghijsen, P. W., \& Bruman, M. J. (2006) Public procurement and EU tendering directives - explaining non-compliance, International Journal of Public Sector Management, Vol. 19 Issue: 7, pp.702-714, https://doi.org/10.1108/09513550610704716

Giesbrecht, T., Scholl, H. J. \& Schwabe, G. (2016) Smart advisors in the front office: Designing employee-empowering and citizen-centric services, Government Information Quarterly 33 (2016) 669-684

Gilbert, J. \& Sharman, J. C. (2016) Turning a Blind Eye to Bribery: Explaining Failures to Comply with the International Anti-corruption Regime, POLITICAL 
STUDIES Volume: 64 Issue: 1 Pages: 74-89 DOI: 10.1111/1467-9248.12153 Published: MAR 2016

Goodrick, D. (2014) Comparative Case Studies: Methodological Briefs - Impact Evaluation No. 9, innpub754, Methodological Briefs

Grindle, M. S. (2007) Good Enough Governance Revisited, Development Policy Review, 2007, 25 (5): 553-574

Gu, Q., Hu, D. \& Hemple, P. (2021) Team reward interdependence and team performance: roles of shared leadership and psychological ownership, Emerald Insights at https://www.emerald.com/insight/0048-3486.htm

Guba, E. G., \& Lincoln, Y. S. (1994) Competing paradigms in qualitative research. Handbook of qualitative research, 2(163-194), 105, available at https://www.researchgate.net/profile/Sandra_Richardson2/post/What_does_it_means_to_strengthen_theoretical_links/attachment/59d6213e79197b807797fa52/AS:295415858647041@1447444037342/download/10-guba_lincoln_94.pdf

Guest, G., Bunce, A. \& Johnson, L. (2006) How Many Interviews Are Enough? An Experiment with Data Saturation and Variability, Field Methods, Vol. 18, No. 1, February 2006 59-82 DOI: 10.1177/1525822X05279903

Halachmi, A. \& Greiling, D. (2013) Transparency, E-government and Accountability, Some Issues and Considerations, Public Performance \& Management Review, Vol. 36, No. 4, June 2013, pp. 562-584.

Hassan, W., \& Logrippo, L. (2008) Requirements and compliance in legal systems: a logic approach, Requirements Engineering and Law, 2008. RELAW '08. Pages $40-44$

Heeks, R. (2002) Information Systems and Developing Countries: Failure, Success, and Local Improvisations, The Information Society, 18:101-112, 2002, DOI: 10.1080/0197224029007503 9

Heeks, R. \& Bailur, S. (2007) Analyzing eGovernment Research: Perspectives, Philosophies, Theories, Methods and Practice, Government Information Quarterly, 24(2), 243265, 2007 
Hermans, L. M. \& Thissen, W. A. H. (2009) Actor analysis methods and their use for public policy analysts, European Journal of Operational Research 196 (2009) 808-818

Hough, D. (2017) ANTICORRUPTION A Case of "Good, but Could Do Better", GERMAN POLITICS AND SOCIETY Volume: 35 Issue: 1 Pages: 63-82 DOI: 10.3167/gps.2017.350104 Published: MAR 2017

Hwang, Y., Al-Arabait, M. \& Shin, Dong-Hee (2015) Understanding technology acceptance in a mandatory environment: A literature review, Information Development 2016, Vol. 32(4) 1266-1283

International Monetary Fund (2016) Expenditure Control: Key Features, Stages, and Actors, technical notes and manuals available at https://www.imf.org/external/pubs/ft/tnm/2016/tnm1602a.pdf

Jarrahi, M. H. \& Sawyer, S. (2013) Social Technologies, Informal Knowledge Practices, and the Enterprise, Journal of Organizational Computing and Electronic Commerce, 23:1-2, 110-137

Jiang, D. (2017) Does China Need an Anti-Foreign Bribery Statutes? Some Lessons from the FCPA of US, FRONTIERS OF LAW IN CHINA Volume: 12 Issue: 3 Pages: 355-371 DOI: 10.3868/s050-006-017-0020-9 Published: 2017

Jokonya, O. (2017) Critical Literature Review of Theory of Planned Behavior in the Information Systems Research, 2017, 2nd International Conference on Advances in Management Engineering and Information Technology (AMEIT 2017) ISBN: 978-1-60595-457-8

Jun, K. Wang, F. \& Wang, D. (2014) E-GOVERNMENT USE AND PERCEIVED GOVERNMENT TRANSSPARENCY AND SERVICE CAPACITY: Evidence from a Chinese Local Government, Public Performance \& Management Review, Vol. 38, No. 1, September 2014, pp. 125-151.

Kalsi, N. S. \& Kiran, R. (2015) A strategic framework for good governance through e-governance optimization: A case study of Punjab in India, Program, Vol. 49 Issue: 2, pp.170-204

Kantsir, I. \& Plekan, M. (2017) REFORM OF REGULATORY POLICY IN THE FIELD OF SUPERVISION OF AUDIT ACTIVITY, BALTIC JOURNAL OF 
ECONOMIC STUDIES Volume: 3 Issue: 5 Pages: 170-174 DOI: 10.30525/22560742/2017-3-5-170-174 Published:

2017

Kim, S., Kim, H., Lee, H. (2009) An institutional analysis of an e-government system for anti-corruption: The case of Open, Government Information Quarterly, 26, 42-50

Kotzian, P. (2011) Cosi fan tutte: Information, Beliefs, and Compliance with Norms, ZEITSCHRIFT FUR SOZIOLOGIE Volume: 40 Issue: 4 Pages: 158-173 Published: AUG 2011

Krishnan, S,; Teo, T. \& Lim, V. (2013) Examining the relationships among e-government maturity, corruption, economic prosperity and Environmental degradation: A cross-country analysis, Information and Management, 50, 638 - 649

Kuensel (2016a) NC recommends inter-agency information sharing, available at http://www.kuenselonline.com/nc-recommends-inter-agency-information-sharing/

Kuensel (2016b) Training to implement paperless initiative commences, available at http://www.kuenselonline.com/training-to-implement-paperless-initiativecommences/

Kuensel (2017a) Policy will require all Govt. agencies to make services online, available at http://www.kuenselonline.com/policy-will-require-all-govt-agenciesto-make-services-online/

Kuensel (2017b) New asset declaration rules in the offing, available at http://www.kuenselonline.com/new-asset-declaration-rules-in-the-offing/

Kuensel (2018a) Non - compliance to audit observations, available at http://www.kuenselonline.com/non-compliance-to-audit-observations/

Kuensel (2018b) 37 schedule I public servants did not declare their assets, available at http://www.kuenselonline.com/37-schedule-i-public-servants-did-not-declare-their-assets/

Kuensel (2018c) ACC charges former labour minister of false asset declaration, https://kuenselonline.com/acc-charges-former-labour-minister-of-false-asset-declaration/ 
Kuensel (2019a) Baby dies in BHU waiting for ambulance, available at http://www.kuenselonline.com/baby-dies-in-bhu-waiting-for-ambulance/

Kuensel (2019b) Glitches in ePEMS, banks face issues, available at http://www.kuenselonline.com/glitches-in-epems-banks-face-issues/

Kuensel (2019c) RAA recovers $\mathrm{Nu}$ 106.3M from irregularities, available at http://www.kuenselonline.com/raa-recovers-nu-106-3m-from-irregularities/

Kuensel (2019d) Digitisation drive in banking reaches new heights, available at http://www.kuenselonline.com/digitisation-drive-in-banking-reaches-newheights/

Kuensel (2019e) OAG takes former labour minister, wife, niece and accomplice to court, https://kuenselonline.com/oag-takes-former-labour-minister-wife-nieceand-two-others-to-court/

Kuensel (2020a) Accountant leaves gaping holes in budget for 4 gewogs, available athttps://kuenselonline.com/accountant-leaves-gaping-holes-in-budget-for-4-gewogs/

Kuensel (2020b) Accountant embezzles more than $\mathrm{Nu} 8.4 \mathrm{M}$, available at https://kuenselonline.com/accountant-embezzles-more-than-nu-8-4m/

Kumar, R. \& Best, M.L. (2006) Impact and sustainability of e-government services in developing countries: Lessons learned from Tamil Nadu, India, The Information Society, 22:1, 1-12, DOI: 10.1080/01972240500388149

Lanzara, G. F. (2009) Building digital institutions: ICT and the rise of assemblages in government, ICT and Innovation in the Public Sector: European Studies in the Making of E-Government, published 2009 by PALGRAVE MACMILLAN, ISBN 978-1349-30970-2

Lee, J. (2010) 10 Year Retrospect on State Models of eGovernment: A Qualitative Metasynthesis, Government Information Quarterly, 27, 220-230

Leonardi, P. M. (2013) Theoretical foundations for the study of sociomateriality, Information and Organization 23 (2013) 59-76 
Lio, M., Liu, M. \& Qu, Y. (2011) Can the Internet Reduce Corruption? A CrossCountry Study Based on Dynamic Panel Data Models, Government Information Quarterly, 28, 47-53

Lokshin, M. \& Yemtsov, R. (2008) Who bears the cost of Russia's military draft?, ECONOMICS OF TRANSITION Volume: 16 Issue: 3 Pages: 359-387 Published: 2008

Maruping, M. L., Zhang, X. \& Venkatesh, V. (2009) Role of collective ownership and coding standards in coordinating expertise in software project teams, European Journal of Information Systems, Vol 18, 2009, Issue 4

Mazzarella, W. (2006) Internet X-Ray: E-Governance, Transparency, and the Politics of Immediation in India, Public Culture 18:3 doi 10.1215/08992363-2006-016

Matthews, B. \& Ross, L. (2010) Research Methods: A practical guide for the social sciences, Pearson Education Limited, ISBN 978-1-4058-5850-2

Mendez, F. \& Sepulveda, F. (2013) OPTIMAL GOVERNMENT REGULATIONS AND RED TAPE IN AN ECONOMY WITH CORRUPTION, HITOTSUBASHI JOURNAL OF ECONOMICS Volume: 54 Issue: 1 Pages: 51-77 Published: JUN 2013

Michael, B. (2012) Issues in Anti-Corruption Law: How Can Code of Conduct Laws Be Drafted in Order to Reduce Corruption in a Public Sector like Romania's, EUROPEAN LAW JOURNAL Volume: 18 Issue: 2 Pages: 289-322 DOI:

10.1111/j.1468-0386.2011.00598.x Published: MAR 2012

Miles, M. B., Huberman, A. M. \& Saldana, J. (2018) Qualitative Data Analysis: A Method Sourcebook, SAGE Publication,

Mingaleva, Z., and Mirskikh, I. (2014) The main institutional instruments of intellectual property protection, Life Science Journal 2014;11(12s)

Ministry of Finance (2019a) Electronic Public Expenditure Management System Business Requirement Document version 05

Ministry of Finance (2019b) e-PEMS (electronic Public Expenditure Management System) Brochure, available at https://www.mof.gov.bt/wp-content/uploads/2019/07/e-PEMSe-Brochure.pdf 
Ministry of Finance (2019c) National Budget Financial Year 2019-20 at https://www.mof.gov.bt/wp-content/uploads/2019/05/BR2019 20 ENG.pdf

Ministry of Finance (2019d) Electronic Public Expenditure Management System (PEMS)

USER MANUAL Party Master, version 0.3, June 2019

Ministry of Finance (2019e) Electronic Public Expenditure Management System (PEMS)

USER MANUAL User Management version 0.3, July 2019

Ministry of Finance (2019f) Electronic Public Expenditure Management System (PEMS)

USER MANUAL Account Payee Master, version 0.3, May 2019

Ministry of Information and Communication (2014) Bhutan e-Government Master Plan, at https://www.moic.gov.bt/wp-content/uploads/2016/05/bhutan_e_gov_master_plan_14953.pdf

Mitra, S. and Jeong, H.Y. (2017) Bhutan: New Pathways to Growth, ISBN 0-19947401-X

Miyata, M. (2011) Measuring impacts of e-government support in least developed countries: a case study of the vehicle registration service in Bhutan, Information Technology for Development, 17:2, 133-152, DOI: 10.1080/02681102.2010.537251

Moses, J. \& Knutsen, T. (2012) Ways of Knowing: Competing Methodologies in Social and Political Research. Palgrave Macmillan, 2012.

National Statistical Bureau (NSB) (2018) Bhutan at a Glance 2018 at http://www.nsb.gov.bt/publication/files/pub3kw5078sm.pdf, Royal Government of Bhutan

Navarra, D. D. and Cornford, T. (2011) The State and Democracy After New Public Management: Exploring Alternative Models of E-Governance, The Information Society, 28:1, 37-45, DOI: 10.1080/01972243.2012.632264

Okuda, A. (2020) Digital Transformation for a Sustainable Bhutan, The Druk Journal Spring Edition 2020 at http://drukjournal.bt/digital-transformation-for-a-sustainable-bhutan/ 
Okuda, A. (2020a) E-Governance and Anti-Corruption in Bhutan: emerging roles of multi-layered leaderships, Conference Paper, Development Studies Association (DSA) 2020 New Leadership for Global Challenges: Panel 42: Digital Development Leadership, available at https://nomadit.co.uk/conference/dsa2020/paperdownload/paper/54041

Organisation on Economic Co-operation and Development (OECD) (2020) The potential of online learning for adults: Early lessons from the COVID-19 crisis, available at https://www.oecd.org/coronavirus/policy-responses/the-potential-ofonline-learning-for-adults-early-lessons-from-the-covid-19-crisis-ee040002/

Orlikowski, W. J. (2007) Sociomaterial Practices: Exploring Technology at Work, Organization Studies 28(09): 1435-1448 ISSN 0170-8406

Orlikowski, W. J. (2010) The sociomateriality of organisational life: considering technology in management research, Cambridge Journal of Economics 2010, 34, 125-141

Osipian, A. L. (2010) Corruption in the politicized university: lessons for Ukraine's 2010 presidential elections, INNOVATION-THE EUROPEAN JOURNAL OF SOCIAL SCIENCE RESEARCH Volume: 23 Issue: 2 Pages: 101-114 Article Number: PII 928668990 Published: 2010

Ozarslan, O. E. (2016) JUST ABOUT TIME: DEFENDING DEMOCRACY AND THE FIGHT AGAINST CORRUPTION, TURKISH POLICY QUARTERLY Volume: 15 Issue: 2 Pages: 107-116 Published: SUM 2016

Panke, D. (2018). Research Design \& Method Selection: Making Good Choices in the Social Sciences

Papyrakis, E.; Rieger, M. \& Gilberthorpe, E. (2017) Corruption and the Extractive Industries Transparency Initiative, The Journal of Development Studies, 53:2, 295-309, DOI: 10.1080/00220388.2016.1160065

Paré, G., Sicotte, C. \& Jacque, H. (2006) The Effects of Creating Psychological Ownership on Physicians' Acceptance of Clinical Information Systems, Journal of the American Medical Informatics Association Volume 13 Number 2 Mar / Apr 2006 
Parliament of Bhutan (2011) Penal Code (Amendment) Act of Bhutan, available at https://www.nab.gov.bt/assets/uploads/docs/acts/2014/The_Penal_Code(Amendment)_Act_of_Bhutan_2011eng7th.pdf

Payan, J., M. and McFarland, R., G., (2005) Decomposing Influence Strategies: Argument Structure and Dependence as Determinants of the Effectiveness of Influence Strategies in Gaining Channel Member, Journal of Marketing, Vol. 69, No. 3 (Jul., 2005), pp. 66-79

Peristeras, V. \& Tarabanis, K. (2004) Governance Enterprise Architecture (GEA): Domain Models for e-governance, Conference Paper for the ICEC'04, Sixth International Conference on Electronic Commerce

Perez-Magro, M., Millan-Tapia, J. M., Millan-Tapia, A. \& Roman-Diaz, C. (2017) The Underground Economy in Times of Crisis: An Analysis of Undeclared Work in Europe, REVISTA DE ESTUDIOS ANDALUCES Volume: 34 Issue: 1 Pages: 453-501 DOI: 10.12795/rea.2017. i34.16 Published: 2017

Popescu, A., Onofrei, M. \& Kelley, C. (2016) An overview of European good practices in public procurement, EASTERN JOURNAL OF EUROPEAN STUDIES Volume: 7 Issue: 1 Pages: 81-91 Published: JUN 2016

Rad, M. S., Nilashi, M. \& Dahlan, H. M. (2017) Information technology adoption: a review of the literature and classification, Univ Access Inf Soc (2018) 17:361-390

Rana, N. P., Dwivedi, Y. K., Williams, M. D., Weerakkody, V. (2015) Investigating success of an e-government initiative: Validation of an integrated IS success model, InfSyst Front (2015) 17:127-142

Radhikaashree, M. \& Balakrishnan, C. S. (2015) E -Governance: A Successful Implementation of Government Policies using Cloud Computing, International Journal of Applied Environmental Sciences (IJAES) ISSN 0973-6077 Vol. 10 No.1 (2015)

Rodriguez, V. M. C. (2016) An Inquiry on Public Corruption and its Determinants, REVISTA MEXICANA DE CIENCIAS POLITICAS Y SOCIALES Volume: 61 Issue: 227 Pages: 103-135 Published: MAY-AUG 2016

Rodriguez-Arana, J. M. (2017) Self-cleaning in public procurement: operational potentiality and regulation in the European Union, A\&C-REVISTA DE DIREITO 
ADMINISTRATIVO \& CONSTITUCIONAL Volume: 17 Issue: 70 Pages: 25-44 DOI: 10.21056/aec.v17i70.815 Published: OCT-DEC 2017

Rosid, A., Evans, C. \& Binh, T. (2016) Do perceptions of corruption influence personal income taxpayer reporting behaviour? Evidence from Indonesia, EJOURNAL OF TAX RESEARCH Volume: 14 Issue: 2 Pages: 387-+ Published: NOV 2016

Royal Audit Authority (2016) IT Audit of Public Expenditure Management System (August 2016), available at http://www.bhutanaudit.gov.bt/audit-cnt/raafiles/pa-reports/IT-Audit\%20Report-on-PEMS\%202016.pdf

Royal Audit Authority (2018) Report on Review of In-country Travels: Audit conducted in 2017, available at http://www.bhutanaudit.gov.bt/audit-cnt/raa-files/pareports/Report\%20on\%20Review\%20of\%20In-country\%20Travel\%20(English).pdf

Saldana, J. (2015) The Coding Manual for Qualitative Researchers

Samuel, A. \& Lowen, A. (2010) Bribery and inspection technology, ECONOMICS OF GOVERNANCE Volume: 11 Issue: 4 Pages: 333-350 DOI: 10.1007/s10101-0100080-0 Published: NOV 2010

Sari, A. (2016) E-Government Attempts in Small Island Developing States: The Rate of Corruption with Virtualization, Sci Eng Ethics, DOI 10.1007/s11948-0169848-0

Saunders, B., Sim, J., Kingstone, T., Baker, S., Waterfield, J., Bartlam, B., Burroughs, H., \& Jinks, C. (2017) Saturation in qualitative research: exploring its conceptualization and operationalization, Qual Quant DOI 10.1007/s11135-017-0574-8

Schlenther, B. (2017) The impact of corruption on tax revenues, tax compliance and economic development: Prevailing trends and mitigation actions in Africa, eJournal of Tax Research (2017) vol 15, no. 2, pp. 217-242

Schueth, S. (2012) Apparatus of capture: Fiscal state formation in the republic of Georgia, POLITICAL GEOGRAPHY Volume: 31 Issue: 3 Pages: 133-143 Published: MAR 2012

Sebastian, S. (2015) Parliamentary Democracy in Bhutan: A Journey from Tradition to Modernity, ISBN: 978-81-87393-15-3

Shareef, M. A., Kumar, V., Kumar, U. \& Dwivedi, Y. K. (2011) e-Government Adoption Model (GAM): Differing service maturity levels, Government Information Quarterly 28 (2011) 17-35 
Shim, D; Eom T. (2009) Anticorruption Effects of Information and Communication Technology (ICT) and Social Capital, International Review of Administrative Sciences, 75;99

Silverman, D. (2016) Qualitative Research, Sage Publication, ISBN 978-1-47391656-2

Sinkovics, N. (2018) Pattern matching in qualitative analysis, available at https://www.researchgate.net/publication/323856200

Sok, S. (2014) Limited state and strong social forces: Fishing lot management in Cambodia, JOURNAL OF SOUTHEAST ASIAN STUDIES Volume: 45 Issue: 2 Pages: 174-193 Published: JUN 2014

Sokol, D. (2012) Cartels, Corporate Compliance and What Practitioners Really Think about Enforcement, 78 Antitrust L.J. 201 (2012)

Søreide, T. (2009) Too risk averse to stay honest? Business corruption, uncertainty and attitudes toward risk, International Review of Law and Economics 29 (2009) 388-395

Sovacool, B.K., Walter, G. \& van de Graaf, T. et al.(2016) Energy Governance, Transnational Rules, and the Resource Curse: Exploring the Effectiveness of the Extractive Industries Transparency Initiative (EITI), WORLD DEVELOPMENT Volume: 83 Pages: 179-192

Srivastava, S. C., Teo, T.S.H., Devaraj, S. (2016) You Can't Bribe a Computer: Dealing with the Societal Challenge of Corruption through ICT, MIS Quarterly Vol. 40 No. 2, pp. 511-526/June 2016

Starke, C., Naab, T. K. \& Scherer, H. (2016) Free to Expose Corruption: The Impact of Media Freedom, Internet Access and Governmental Online Service Delivery on Corruption, International Journal of Communication 10(2016), 4702-4722

Sundstrom, A. (2016) Corruption and Violations of Conservation Rules: A Survey Experiment with Resource Users, WORLD DEVELOPMENT Volume: 85 Pages: 73-83 Published: SEP 2016

Tanzi, V. (1998) Corruption Around the World: Causes, Consequences, Scope and Curses, IMF working paper, WP/98/63 at https://www.imf.org/external/pubs/ft/wp/wp9863.pdf 
Tavits, M. (2010) Why do people engage in corruption - The case of Estonia, 88 Soc. F. 1257 (2010)

The Bhutanese (2016) OAG drops Trongsa land case but ACC disagrees, 31 December 2016, available at https://thebhutanese.bt/11014-2/

The Bhutanese (2018) Social Media: no longer a knight in shining armor but a mirror and amplifier, 19 May 2018, available at https://thebhutanese.bt/social-mediano-longer-a-knight-in-shining-armor-but-a-mirror-and-amplifier/

The Bhutanese (2019) RAA review finds flaws in pool vehicles \& quota, available at https://thebhutanese.bt/raa-review-finds-flaws-in-pool-vehicles-quota/

Timmons, J. F. \& Garfias, F. (2015) Revealed Corruption, Taxation, and Fiscal Accountability: Evidence from Brazil, World Development Vol. 70, pp. 13-27, 2015

Tjen, C. \& Evans, C. (2017) Causes and consequences of corruption in tax administration: An Indonesian case study, eJournal of Tax Research (2017) vol 15, no. 2, pp. 243-261

Transparency International (2017) Strengthening Anti-Corruption Agencies in Asia Pacific: Reginal Synthesis Report, available at https://www.transparency.org/en/publications/strengthening-anti-corruption-agencies-in-asia-pacific

UNDESA (2016) UN E-government Survey 2016 at https://publicadministration.un.org/egovkb/en-us/Reports/UN-E-Government-Survey-2016

UNESCO (2005) E-government Toolkit for Developing Countries, Chapter 1, at https://www.pdfdrive.com/e-government-toolkit-for-developing-countriesunesdoc-unesco-d12896461.html

Van del Wal, Z., Graycar, A. \& Kelly, K. (2016) See No Evil, Hear No Evil? Assessing Corruption Risk Perceptions and Strategies of Victorian Public Bodies, AUSTRALIAN JOURNAL OF PUBLIC ADMINISTRATION Volume: 75 Issue: 1 Pages: 3-17 DOI: 10.1111/1467-8500.12163 Published: MAR 2016

Varvarigos, D. (2017) Cultural norms, the persistence of tax evasion, and economic growth, ECONOMIC THEORY Volume: 63 Issue: 4 Pages: 961-995 DOI: 10.1007/s00199-016-0976-1 Published: APR 2017

Vadlamannati, K. C., Cooray, A. \& Brazys, S. (2018) Nothing to hide: Commitment to, compliance with, and impact of the special data dissemination standard, 
ECONOMICS \& POLITICS Volume: 30 Issue: 1 Pages: 55-77 DOI:

10.1111/ecpo.12100 Published: MAR 2018

Villagrasa, O. C. (2016) ANTICORRUPTION BODIES AND THE USE OF SANCTIONING POWERS: LIMITS AND PROPOSALS FOR PREVENTING CORRUPTION. IN PARTICULAR, THE CASE OF CATALONIA'S ANTI-FRAUD OFFICE, EVISTA CATALANA DE DRET PUBLIC Issue: 53 Pages: 13-30 DOI:

10.2436/rcdp.i53.2016.2821 Published: DEC 2016

Wangchuk, L (2017) Facts about Bhutan: The Land of the Thunder Dragon, ISBN 99936-760-0-4

Watson-Grant, S., Xiong, K. \& Thomas, J. (2017) Achieving sustainability in health information systems: a field tested measure of country ownership, Globalization and Health (2017) 13:36

Webb, W. N. (2012) Ethical Culture and the Value-based Approach to Integrity Management: A Case Study of the Department of Correctional Services, Public Admin. Dev. 32, 96-108 (2012)

Weismann, M. F., Buscaglia, C. A. \& Peterson, J. (2014) The Foreign Corrupt Practices Act: Why It Fails to Deter Bribery as a Global Market Entry Strategy, JOURNAL OF BUSINESS ETHICS Volume: 123 Issue: 4 Special Issue: SI Pages: 591-619 Published: SEP 2014

Williams, C. C. \& Horodnic, I. A. (2015) Tackling the informal economy in Southeast

Europe: an institutional approach, Southeast European and Black Sea Studies, 15:4, 519-539, DOI: 10.1080/14683857.2015.1056980

Williams, C. C. \& Krasniqi, B. (2017) Evaluating the individual- and country-level variations in tax morale Evidence from 35 Eurasian countries, JOURNAL OF ECONOMIC STUDIES Volume: 44 Issue: 5 Pages: 816-832 DOI: 10.1108/JES-092016-0182 Published: 2017

World Bank (2016) Bhutan: Public Financial Management Performance Report: Based on Public Expenditure and Financial Accountability 2016 Framework, available at https://www.mof.gov.bt/wp-content/uploads/2015/07/PEFA2016Report.pdf

World Bank (2019) Bhutan bets on digital payments to improve services, available at https://medium.com/world-of-opportunity/bhutan-bets-on-digital-paymentsto-improve-services-12aaabc58a46 
Yilmaz, G. \& Soyaltin, D. (2014) Zooming into the 'Domestic' in Europeanization: Promotion of Fight against Corruption and Minority Rights in Turkey, JOURNAL OF BALKAN AND NEAR EASTERN STUDIES Volume: 16 Issue: 1 Special Issue: SI Pages: 11-29 Published: 2014

Xinli, H. (2015) Effectiveness of information technology in reducing corruption in China: A validation of the DeLone and McLean information systems success model, The Electronic Library, Vol. 33 Issue: 1, pp.52-64.

Yin, R. (2013) Case Study Research: Design and Methods (Applied Social Research Methods)

Yukl, G., (1989) Managerial Leadership: A Review of Theory and Research, Journal of Management 1989. Vol. 15, No. 2, 251-289 
ANNEX 1: LITERATURE REVIEW: E-GOVERNANCE AND CORRUPTION

TOPIC: (E-GOVERNANCE) OR TOPIC: (E-GOVERNMENT) AND TOPIC: (CORRUPTION) AND TOPIC: (GOVERNMENT*)

REFINED BY: PUBLICATION YEARS=( 2015 OR 2010 OR 2006 OR 2017 OR 2016 OR 2009 OR 2012 OR 2007 OR 2008 OR 2011 OR 2014 OR 2013 OR 2005) AND [EXCLUDING] WEB OF SCIENCE CATEGORIES=(GENETICS HEREDITY OR BIODIVERSITY CONSERVATION OR PUBLIC ENVIRONMENTAL OCCUPATIONAL HEALTH OR GEOSCIENCES MULTIDISCIPLINARY OR OPERATIONS RESEARCH MANAGEMENT SCIENCE OR ENGINEERING CIVIL OR BIOLOGY OR ENGINEERING AEROSPACE OR ENVIRONMENTAL SCIENCES OR ECOLOGY OR ENVIRONMENTAL STUDIES OR METALLURGY METALLURGICAL ENGINEERING OR MARINE FRESHWATER BIOLOGY) AND [EXCLUDING] WEB OF SCIENCE CATEGORIES=( EDUCATION EDUCATIONAL RESEARCH OR WATER RESOURCES )

TIMESPAN=2005-2017, INDEXES=SCI-EXPANDED, SSCI, A\&HCI, ESCI.

Results found:

187

Sum of the Times Cited:

1685

Average Citations per Item:

h-index:

9.01

21 


\begin{tabular}{|c|c|c|c|c|}
\hline No & Title of article & Authors & Year & Summary \\
\hline 1 & $\begin{array}{l}\text { Using ICTs to } \\
\text { create a cul- } \\
\text { ture of trans- } \\
\text { parency: E- } \\
\text { government } \\
\text { and social } \\
\text { media as } \\
\text { openness and } \\
\text { anti-corrup- } \\
\text { tion tools for } \\
\text { societies }\end{array}$ & $\begin{array}{l}\text { Bertot, } \\
\text { John C.; } \\
\text { Jaeger, } \\
\text { Paul T.; } \\
\text { Grimes, } \\
\text { Justin M. }\end{array}$ & 2010 & $\begin{array}{l}\text { This research, based on literature } \\
\text { review, aims to answer the question } \\
\text { on the role of ICT-enabled initia- } \\
\text { tives in creating social and cultural } \\
\text { change towards transparency. } \\
\text { The research provided important } \\
\text { pointers to narrow the scope of my } \\
\text { study and justify my approach. The } \\
\text { authors claim that ICT-enabled ini- } \\
\text { tiatives, such as e-governance, are } \\
\text { evidenced successful in reducing } \\
\text { corruption, especially in areas of } \\
\text { taxation and government contracts } \\
\text { among larger and wealthier coun- } \\
\text { tries. This study cited three existing } \\
\text { approaches to anti-corruption: } \\
\text { 1) administrative reform, } \\
\text { 2) law enforcement and } \\
\text { 3) social change. } \\
\text { The study also states that e-govern- } \\
\text { ance may favor those already in } \\
\text { power, and even after the introduc- } \\
\text { tion of e-governance initiatives, cor- } \\
\text { rupt officials upscale and outma- } \\
\text { neuver those who are not. Accord- } \\
\text { ing to the authors, two e-govern- } \\
\text { ance success factors include: } 1 \text { ) a } \\
\text { culture of transparency embedded } \\
\text { in the government and } 2 \text { ) existence } \\
\text { of transparency readiness factors, } \\
\text { such as technological access and ca- } \\
\text { pabilities. } \\
\text { Despite pertinent insights and find- } \\
\text { ings, the research gaps and unan- } \\
\text { swered questions from this study } \\
\text { include: }\end{array}$ \\
\hline
\end{tabular}


1. Social change in this study focuses on the one among citizens, with the assumption that they can hold governments accountable.

2. Government officials are largely portrayed as bystander or suspects, not as a central protagonist, despite bureaucratic acceptance being cited as a key success factor, together with leadership and political will.

3. Efforts by government officials towards transparency and anticorruption are largely ignored and they are categorized as a homogenous group of possibly corrupt people.

4. ICT-enabled efforts were evidenced successful in countries already with transparency and openness, translated into relevant legislations and policies in place.

5. The mentioned approach of empowering citizens with access to information might work only in countries with democratic institutions with oversight and accountability frameworks.

6. Furthermore, Korea's OPEN initiative was cited as a success story in reducing corruption, when it was actually not, as revealed by the country's latest presidential scandal. Thus, OPEN initiative can address petty corruptions but not systematic government and 


\begin{tabular}{|c|c|c|c|c|}
\hline & & & & $\begin{array}{l}\text { political corruptions, which do } \\
\text { not concern citizens. } \\
\text { 7. Social media and WikiLeaks are } \\
\text { cited as more effective means of } \\
\text { promoting transparency, alt- } \\
\text { hough this research does not } \\
\text { elaborate how. } \\
\text { 8. } \\
\text { The question is, if the identified } \\
\text { success factors are universally } \\
\text { applicable and sufficient to en- } \\
\text { sure e-governance success in } \\
\text { countries with less openness } \\
\text { and transparency, under what } \\
\text { circumstances does e-govern- } \\
\text { ance succeed? }\end{array}$ \\
\hline 4 & $\begin{array}{l}\text { An institu- } \\
\text { tional analy- } \\
\text { sis of an } \\
\text { e-govern- } \\
\text { ment } \\
\text { system for } \\
\text { anti-corrup- } \\
\text { tion: } \\
\text { The case of } \\
\text { OPEN }\end{array}$ & $\begin{array}{l}\text { Kim, } \\
\text { Seong- } \\
\text { cheol; } \\
\text { Kim, } \\
\text { Hyun } \\
\text { Jeong; } \\
\text { Lee, Hee- } \\
\text { jin }\end{array}$ & 2009 & $\begin{array}{l}\text { A single case study conducted by } \\
\text { Kim, Kim and Lee (2009) analysed } \\
\text { the case of the Online Procedures } \\
\text { ENhancement (OPEN) for Civil Ap- } \\
\text { plication of the Seoul Metropolitan } \\
\text { Administration in South Korea. The } \\
\text { authors conclude that regula- } \\
\text { tory/coercive factors were most ef- } \\
\text { fective to the success of this anti- } \\
\text { corruption initiative, guided by the } \\
\text { political leadership of the Mayor. } \\
\text { Other success factors include ena- } \\
\text { bling IT infrastructure, training, re- } \\
\text { sources and Internet literacy among } \\
\text { citizens. } \\
\text { The case study on OPEN is most in- } \\
\text { teresting, as it illustrates the strug- } \\
\text { gle between the organisation's lead- } \\
\text { ership (Mayor of the Seoul City) } \\
\text { and employees, in the introduction } \\
\text { and implementation of the system. } \\
\text { The study found that the audit au- } \\
\text { thority and regulatory interven- } \\
\text { tions were most effective in }\end{array}$ \\
\hline
\end{tabular}




\begin{tabular}{|c|c|c|c|c|}
\hline & & & & $\begin{array}{l}\text { ensuring the initiative's success and } \\
\text { reducing corrupt behaviors, mean- } \\
\text { ing that leadership and a strong } \\
\text { regulatory environment could be } \\
\text { key good governance enablers. } \\
\text { However, the role of civil servants } \\
\text { in promoting transparency and ad- } \\
\text { dressing corruption within the pub- } \\
\text { lic administration is not researched } \\
\text { adequately in this study. The au- } \\
\text { thors define e-government as "the } \\
\text { use of technology to enhance access } \\
\text { to and delivery of government ser- } \\
\text { vices in order to benefit citizens, } \\
\text { businesses and employees" but so } \\
\text { far, most existing research have fo- } \\
\text { cused on citizens and businesses, } \\
\text { not government employees. } \\
\text { Lastly, OPEN is a transparent inter- } \\
\text { face between citizens and low rung } \\
\text { government officials, where space } \\
\text { for corruption has been reduced. } \\
\text { However, such a system would not } \\
\text { catch illegal political contributions } \\
\text { or business to government bribes, } \\
\text { which do not directly involve citi- } \\
\text { zens, as the latest scandal in the } \\
\text { country revealed. Thus, to address } \\
\text { transparency, endogenous capabili- } \\
\text { ties within the public sector to ad- } \\
\text { dress such invisible cases would be } \\
\text { of critical. }\end{array}$ \\
\hline 6 & $\begin{array}{l}\text { 10-year retro- } \\
\text { spect on } \\
\text { stage models } \\
\text { of e Govern- } \\
\text { ment: A qual- } \\
\text { itative meta- } \\
\text { synthesis }\end{array}$ & $\begin{array}{l}\text { Lee, Jung- } \\
\text { woo }\end{array}$ & 2010 & $\begin{array}{l}\text { This research compiled e-govern- } \\
\text { ment development models devel- } \\
\text { oped for the last } 10 \text { years, compar- } \\
\text { ing various methods and their char- } \\
\text { acteristics. } \\
\text { Although, from the technology } \\
\text { point of view, stages and models }\end{array}$ \\
\hline
\end{tabular}




\begin{tabular}{|c|c|c|c|c|}
\hline & & & & $\begin{array}{l}\text { are important, assessment on the } \\
\text { impact and interactions with end } \\
\text { users as well as what the system } \\
\text { does to achieve the objectives are } \\
\text { largely missing. }\end{array}$ \\
\hline 7 & $\begin{array}{l}\text { Impact and } \\
\text { sustainabil- } \\
\text { ity of } \\
\text { e-govern- } \\
\text { ment } \\
\text { services in } \\
\text { developing } \\
\text { countries: } \\
\text { Les- } \\
\text { sons learned } \\
\text { from Tamil } \\
\text { Nadu, India }\end{array}$ & $\begin{array}{l}\text { Ku- } \\
\text { mar, R; } \\
\text { Best, ML }\end{array}$ & 2006 & $\begin{array}{l}\text { The authors examine an e-govern- } \\
\text { ment initiative, which supported } \\
\text { village Internet facilities that pro- } \\
\text { vide various e-government ser- } \\
\text { vices, such as issuing birth certifi- } \\
\text { cate and application of old age pen- } \\
\text { sions in India. A correlation was } \\
\text { found between the presence of fa- } \\
\text { cilities and services used and posi- } \\
\text { tive impact, such as reduced cor- } \\
\text { ruption, was evidenced. However, } \\
\text { the study shows that after a while, } \\
\text { political and administrative sup- } \\
\text { port waned and eventually consid- } \\
\text { ered a failure. The authors conclude } \\
\text { the initiative was not "politically } \\
\text { and institutionally sustainable due } \\
\text { to people, management, cultural } \\
\text { and structural factors." } \\
\text { The authors cite another } 2003 \text { study } \\
\text { conducted in India, indicating that } \\
\text { user satisfaction over e-services } \\
\text { were high, although the use was } \\
\text { low and unused among the desti- } \\
\text { tute section of the population. It is } \\
\text { summarised that: } \\
\text { "Researchers have argued that most } \\
\text { of these projects fail, either totally } \\
\text { or partially, due to 'design-actual- } \\
\text { ity' (Heeks, 2002) or 'design-reality' } \\
\text { gaps (Heeks, 2003a), long-term sus- } \\
\text { tainability problems (Aichholzer, } \\
\text { 2004), or lack of commitment on the }\end{array}$ \\
\hline
\end{tabular}




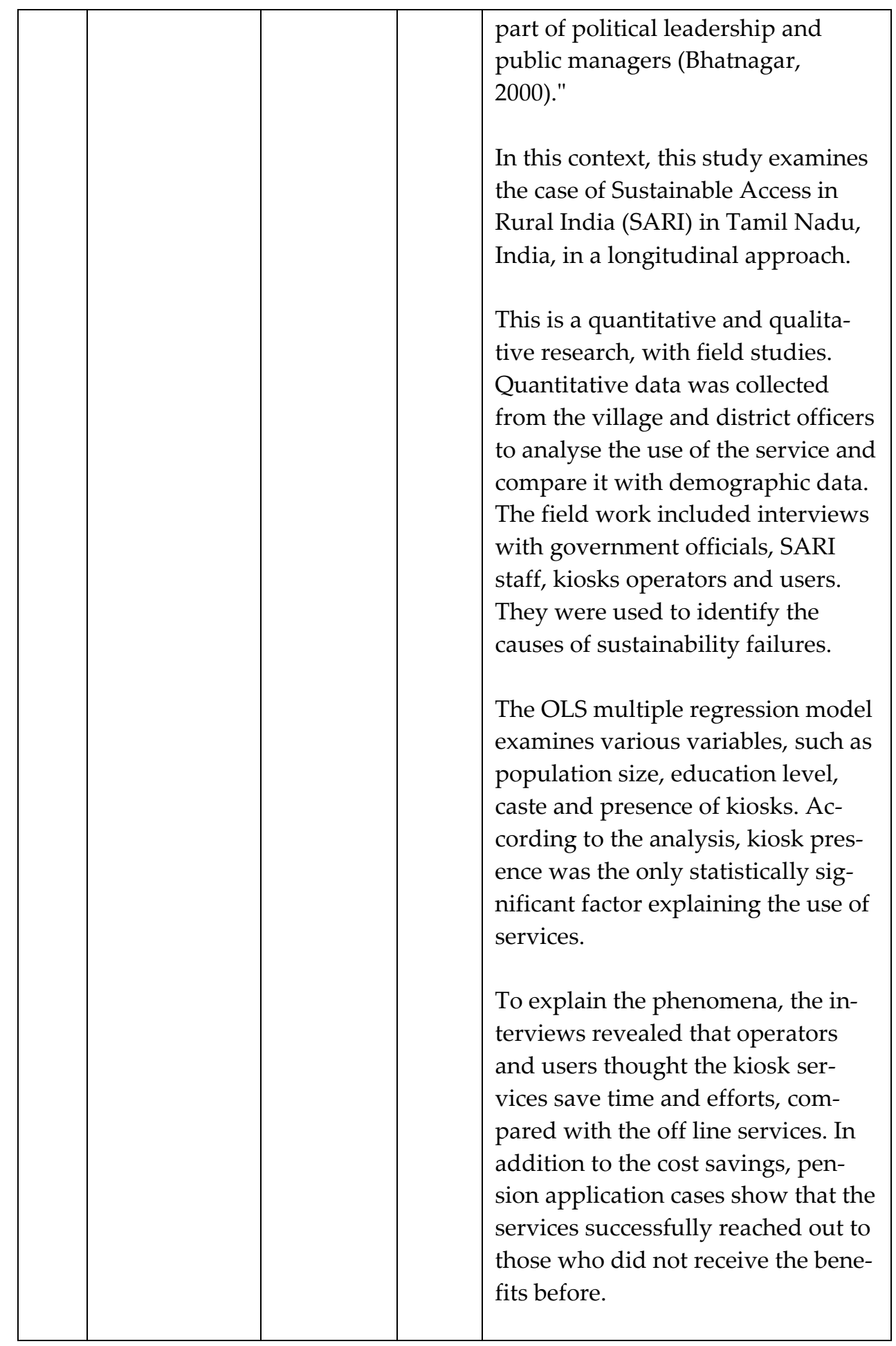




\begin{tabular}{|l|l|l|}
\hline $\mid$ & $\begin{array}{l}\text { One interesting finding of this } \\
\text { study is the reported opposition } \\
\text { and resistance from field officials in } \\
\text { processing some of the applica- } \\
\text { tions. The authors suspect dimin- } \\
\text { ished opportunities for corruption } \\
\text { and rent seeking by officials as the } \\
\text { possible cause. They may have per- } \\
\text { ceived that the opportunities to re- } \\
\text { ceive bribery was diminished from } \\
\text { introduction of the kiosks, fueled } \\
\text { by lack of institutionalisation and } \\
\text { top-down approach. The study also } \\
\text { found that the commitment of the } \\
\text { government office head was an im- } \\
\text { portant factor, and his transfer to } \\
\text { another office led to the ultimate } \\
\text { collapse of the project. Control over } \\
\text { staff and monitoring them was also } \\
\text { an important success factor. De- } \\
\text { spite initial success, time on appli- } \\
\text { cations slackened and efficiency } \\
\text { gains began eroding. } \\
\text { Heeks and Bhatnagar (1999) pro- } \\
\text { posed a model called Critical Fail- } \\
\text { ure Factors, using information, } \\
\text { technical, people, management, cul- } \\
\text { ture, structure, politics, and envi- } \\
\text { ronment. Bhatnagar (2004) docu- } \\
\text { mented effects of reduced bribery } \\
\text { due to e-government, but it was } \\
\text { clear in this study that government } \\
\text { officials can put significant re- } \\
\text { sistance because of the power shift. } \\
\text { The critical failure factors identified } \\
\text { in the interview included lack of ca- } \\
\text { pacity among government officials. } \\
\text { In addition to the resistance, } \\
\text { trained officers were routinely }\end{array}$ \\
\end{tabular}




\begin{tabular}{|c|c|c|c|c|}
\hline & & & & $\begin{array}{l}\text { transferred to another location, to- } \\
\text { gether with lack of resources for } \\
\text { training. Involvement of all stake- } \\
\text { holders was also cited as needed. }\end{array}$ \\
\hline 9 & $\begin{array}{l}\text { Inter- } \\
\text { net X-ray: } \\
\text { E-govern- } \\
\text { ance, } \\
\text { transparency, } \\
\text { and the poli- } \\
\text { tics of imme- } \\
\text { diation in } \\
\text { India }\end{array}$ & $\begin{array}{l}\text { Maz- } \\
\text { zarella, W } \\
\text { illia }\end{array}$ & 2006 & $\begin{array}{l}\text { This is an essay to analyse the cor- } \\
\text { ruption scandal and reporting } \\
\text { online in India, called Operation } \\
\text { West End in 2001. After revealing } \\
\text { corruption attempt among high } \\
\text { level politicians, the website and } \\
\text { journalists were subjected to legal } \\
\text { and other types of harassments. } \\
\text { What is interesting in this essay is } \\
\text { the question the author asks as to } \\
\text { why this incident is different from } \\
\text { TV exposes. He points out that be- } \\
\text { cause it was reported on the Inter- } \\
\text { net, it became an instant global } \\
\text { news. }\end{array}$ \\
\hline 12 & $\begin{array}{l}\text { E-Govern- } \\
\text { ment as } \\
\text { an anti- } \\
\text { corruption } \\
\text { strategy }\end{array}$ & $\begin{array}{l}\text { Ander- } \\
\text { sen, } \\
\text { Thomas } \\
\text { Barnebec }\end{array}$ & 2009 & $\begin{array}{l}\text { This article aims to understand the } \\
\text { impact of e-government on control } \\
\text { of corruption of Worldwide Gov- } \\
\text { ernance Indicators (WGI), using the } \\
\text { panel data of } 149 \text { countries in } 1996 \\
\text { and } 2006 \text {. It found that improve- } \\
\text { ments from } 10 \text { th percentile to } 90 \text { th } \\
\text { percentile in e-government had cor- } \\
\text { relating improvement in reduction } \\
\text { of corruption from 10th to } 23 \text { rd per- } \\
\text { centile. } \\
\text { The author rightly pointed out that } \\
\text { there have been anecdotal success } \\
\text { stories but they have yet to come } \\
\text { under empirical scrutiny. Another } \\
\text { valid point is that there might be } \\
\text { general equilibrium effects in } \\
\text { which, e-government is not reduc- } \\
\text { ing corruption at the macro level, as }\end{array}$ \\
\hline
\end{tabular}




\begin{tabular}{|l|l|l|}
\hline $\mid$ & $\begin{array}{l}\text { it may be shifting to some other } \\
\text { parts of society. Therefore, the } \\
\text { study addressed micro evaluation } \\
\text { using randomised impact evalua- } \\
\text { tion and softer anecdotal evidence. } \\
\text { The research also highlighted that } \\
\text { the level of GDP per capita was the } \\
\text { most crucial predictor of the cor- } \\
\text { ruption levels, followed by demo- } \\
\text { cratic institutions, in particular, free } \\
\text { press that are evidenced to be } \\
\text { linked to corruption reduction. The } \\
\text { author also introduces the concept } \\
\text { of urban density, where concentra- } \\
\text { tion of ICT access is taken into ac- } \\
\text { count. However, the author also in- } \\
\text { cludes telephone line density be- } \\
\text { cause it is assumed to be an im- } \\
\text { portant means for the Internet ac- } \\
\text { cess, but it may be an old mode. } \\
\text { The study also references West } \\
\text { (2006) on the number of e-govern- } \\
\text { ment initiatives, which have func- } \\
\text { tions on reporting corruption and } \\
\text { fraud. Fifty seven countries were } \\
\text { reported to have the function, while } \\
\text { 91 percent of government sites have } \\
\text { functions to e-mail government of- } \\
\text { ficials other than web masters. } \\
\text { The research confirms that OCED } \\
\text { countries have less corruption with } \\
\text { greater growth in e-government. It } \\
\text { is also noted that since OECD coun- } \\
\text { tries will not decrease corruption } \\
\text { significantly, the impact of e-gov- } \\
\text { ernment might appear insignifi- } \\
\text { cant. Therefore, the importance of } \\
\text { analysing OECD and non-OECD } \\
\text { countries separately is logical. }\end{array}$ \\
\hline
\end{tabular}


It is interesting that e-government seems to have clearer impact on non-OECD countries. The author also suspects that the Internet has both direct and indirect impact on corruption, the latter via e-government. In this case, the Internet might be more important than egovernment itself. There are three examples of how the Internet exposed corruption and almost toppled the Indian government. However, apart from the empirical side of the analysis, success stories cited in the research might need critical analysis. For instance, Bhoomi, the land management system in India, is cited as a success story based on a World Bank report. However, a report by Panos in 2003 point out cases of massive land grabs when Bhoomi was introduced and the poor actually lost their titles. Sometimes, the organisations are the funders and have a stake in promoting the initiative, in addition to the fact that the success should be measured long term instead of at the beginning.

The research concludes that increased use of e-government reduced corruption among nonOECD countries from 1996 to 2006 after bringing under control other propensities of corrupt government. 


\begin{tabular}{|c|c|c|c|c|}
\hline 22 & $\begin{array}{l}\text { Anti-corrup- } \\
\text { tion } \\
\text { effects of } \\
\text { information } \\
\text { communica- } \\
\text { tion } \\
\text { and technol- } \\
\text { ogy } \\
\text { (ICT) and } \\
\text { social capital }\end{array}$ & $\begin{array}{l}\text { Shim, Do } \\
\text { ng } \\
\text { Chul; Eo } \\
\text { m, } \\
\text { Tae Ho }\end{array}$ & 2009 & $\begin{array}{l}\text { This quantitative research exam- } \\
\text { ined ICT and social capital as major } \\
\text { factors in reducing corruption. It } \\
\text { concluded that ICT is evidenced to } \\
\text { reduce corruption, including some } \\
\text { aspects of social capital. It is as- } \\
\text { sumed that corruption will reduce } \\
\text { in a densely connected environ- } \\
\text { ment. } \\
\text { While the empirical analysis is of } \\
\text { value, there are some assumptions } \\
\text { that need careful examination. For } \\
\text { instance, one assumption about this } \\
\text { research is that, low human inter- } \\
\text { vention, by introducing IT systems, } \\
\text { will lower opportunities for corrup- } \\
\text { tion. Another assumption is that, } \\
\text { with high social capital accumula- } \\
\text { tion, people are more involved in } \\
\text { policy making that it reduces cor- } \\
\text { ruption. } \\
\text { It is hard to imagine that automa- } \\
\text { tion through IT systems will have } \\
\text { long lasting effects on corruption. } \\
\text { While other studies also evidenced } \\
\text { that ICT reduces corruption, under- } \\
\text { standing mechanisms that make } \\
\text { this happen are unclear, including } \\
\text { the types of corruption that it helps } \\
\text { reduce and the conditions under } \\
\text { which ICT reduces them. }\end{array}$ \\
\hline 26 & $\begin{array}{l}\text { Can the } \\
\text { internet re- } \\
\text { duce } \\
\text { corrup- } \\
\text { tion? A } \\
\text { cross-country }\end{array}$ & $\begin{array}{l}\text { Lio, Mon- } \\
\text { Chi; Liu, } \\
\text { Meng- } \\
\text { Chun; Ou } \\
\text { 'Yi-Pey }\end{array}$ & 2011 & $\begin{array}{l}\text { This quantitative study analyses the } \\
\text { relationship between ICT and cor- } \\
\text { ruption using panel data of } 70 \\
\text { countries from } 1998 \text { to } 2005 \text { with } \\
\text { Granger causality test. While the re- } \\
\text { search concludes that the Internet } \\
\text { has statistically significant effects }\end{array}$ \\
\hline
\end{tabular}




\begin{tabular}{|c|c|c|c|c|}
\hline & $\begin{array}{l}\text { study based } \\
\text { on } \\
\text { dy- } \\
\text { namic panel } \\
\text { data models }\end{array}$ & & & $\begin{array}{l}\text { on corruption reduction, the au- } \\
\text { thors conclude that its full potential } \\
\text { is yet to be realised. } \\
\text { The authors note that some case } \\
\text { studies led to conclusions about the } \\
\text { Internet reducing corruption, alt- } \\
\text { hough they were selected from de- } \\
\text { veloped countries. Therefore, it is } \\
\text { unclear if the same applies to devel- } \\
\text { oping countries or if the countries } \\
\text { of case studies had all the condi- } \\
\text { tions already in place for the Inter- } \\
\text { net to effect corruption reducetion. } \\
\text { Furthermore, it is unclear what it } \\
\text { means for corruption to be reduced, } \\
\text { or for incidents of corruption to ac- } \\
\text { tually be sustainably reduced, or if } \\
\text { they are just people's perceptions, } \\
\text { or of the types of corruptions re- } \\
\text { duced by which e-governance sys- } \\
\text { tems. } \\
\text { Another potential shortcoming of } \\
\text { this research may be that many e- } \\
\text { governance systems were put in } \\
\text { place after } 2000 \text { and that it may be } \\
\text { premature to measure the impact } \\
\text { using the data between } 1998 \text { and } \\
\text { 2005. Seventy countries selected } \\
\text { must have much better governance } \\
\text { systems than the rest, hence better } \\
\text { data availability. In explaining bi- } \\
\text { directionality between Internet and } \\
\text { corruption, the authors struggle to } \\
\text { explain how corruption hinders the } \\
\text { introduction of the Internet. }\end{array}$ \\
\hline 35 & $\begin{array}{l}\text { E-Govern- } \\
\text { ment, } \\
\text { Internet }\end{array}$ & $\begin{array}{l}\text { Elbahna- } \\
\text { sawy, Nas } \\
\text { r }\end{array}$ & 2014 & $\begin{array}{l}\text { This study empirically analyses the } \\
\text { relationship of e-government, Inter- } \\
\text { net adoption and corruption, using }\end{array}$ \\
\hline
\end{tabular}




\begin{tabular}{|l|l|l|}
\hline $\begin{array}{l}\text { Adop- } \\
\text { tion, and } \\
\text { Corruption: } \\
\text { An Empiri- } \\
\text { cal } \\
\text { Investigation }\end{array}$ & $\begin{array}{l}\text { a large panel dataset. The Granger } \\
\text { causality tests reveal the unidirec- } \\
\text { tional causality between e-govern- } \\
\text { ment, corruption reduction and the } \\
\text { bilateral causality between Internet } \\
\text { adoption and corruption. } \\
\text { The author also makes interesting } \\
\text { observations, such as government } \\
\text { officials learning to illegally benefit } \\
\text { from e-government initiatives even } \\
\text { after its introduction and how it is } \\
\text { not necessarily a panacea. The au- } \\
\text { thor explains corruptions through } \\
\text { the model of principle-agent-client, } \\
\text { but in reality, the relationships } \\
\text { might be more nuanced with possi- } \\
\text { ble collusion between principles } \\
\text { and agents. Even if more infor- } \\
\text { mation is made available online to } \\
\text { citizens, they will have no means to } \\
\text { influence enforcements of rules and } \\
\text { regulations unless democratic insti- } \\
\text { tutions are functioning and other } \\
\text { political agenda do not override de- } \\
\text { bates and discussions on corrup- } \\
\text { tion. Furthermore, in many coun- } \\
\text { tries, NGOs and CSOs are funded } \\
\text { and supported by the regime, } \\
\text { which divides citizens' reactions } \\
\text { and voices on the matter and di- } \\
\text { lutes the focus. As to the data, } \\
\text { proxy data from Transparency In- } \\
\text { ternational (TI) and E-government } \\
\text { Survey might not accurately evalu- } \\
\text { ate what the author claims to meas- } \\
\text { ure. For example, TI's corruption } \\
\text { perceptions may not actually match } \\
\text { the number of incidents of corrup- } \\
\text { tion, type and magnitude, while e- } \\
\text { government survey uses too wide a }\end{array}$ \\
\hline
\end{tabular}




\begin{tabular}{|c|c|c|c|c|}
\hline & & & & $\begin{array}{l}\text { range of proxy data, such as adult } \\
\text { literacy, gross enrollment ratio, ex- } \\
\text { pected years and mean years of } \\
\text { schooling53 to measure e-govern- } \\
\text { ment capacity in a country. } \\
\text { While the findings are certainly in- } \\
\text { teresting, it doesn't give a nuanced } \\
\text { view of why e-government initia- } \\
\text { tives have unidirectional causality } \\
\text { to corruption while Internet adop- } \\
\text { tion has bilateral causality. Nor } \\
\text { does it give a granular picture of } \\
\text { which types of corruptions are re- } \\
\text { duced by e-government, where, } \\
\text { how, by whom and for how long, } \\
\text { which are critical questions to } \\
\text { deepen our understanding of the } \\
\text { topic, on top of emerging trends of } \\
\text { using social media and its impact } \\
\text { on government institutions and ac- } \\
\text { tors. }\end{array}$ \\
\hline 36 & $\begin{array}{l}\text { Examin- } \\
\text { ing the } \\
\text { relationships } \\
\text { among E- } \\
\text { government } \\
\text { maturity, } \\
\text { corruption, } \\
\text { economic } \\
\text { prosper- } \\
\text { ity and envi- } \\
\text { ronmental } \\
\text { degradation: } \\
\text { Across-coun- } \\
\text { try } \\
\text { analysis }\end{array}$ & $\begin{array}{l}\text { Krishnan, } \\
\text { Satish; } \\
\text { Teo, } \\
\text { Thomp- } \\
\text { son S. H.; } \\
\text { Lim, } \\
\text { Vivien K. } \\
\text { G }\end{array}$ & 2013 & $\begin{array}{l}\text { In this quantitative analysis, the au- } \\
\text { thors analyse the relationships be- } \\
\text { tween e-government, economic de- } \\
\text { velopment and environmental deg- } \\
\text { radation through corruption as a } \\
\text { moderator. } \\
\text { The study validated the assump- } \\
\text { tion that e-government initiatives } \\
\text { reduce corruption, although they } \\
\text { were found to not contribute di- } \\
\text { rectly to economic development } \\
\text { and environmental degradation. }\end{array}$ \\
\hline
\end{tabular}

${ }^{53} \mathrm{https}$ ///publicadministration.un.org/egovkb/Portals/egovkb/Documents/un/2016-Survey/Annexes.pdf 


\begin{tabular}{|l|l|l|}
\hline $\mid$ & $\begin{array}{l}\text { The study lacks enough justifica- } \\
\text { tion on economic prosperity and } \\
\text { environmental degradation as hav- } \\
\text { ing high-level impact but not oth- } \\
\text { ers. } \\
\text { Education and health could be a } \\
\text { more relevant variable. Further- } \\
\text { more, e-government maturity is not } \\
\text { a relevant proxy, as some e-govern- } \\
\text { ment systems are sophisticated and } \\
\text { technologically advanced. Few may } \\
\text { be using them and user perspec- } \\
\text { tives are not taken into account. } \\
\text { Furthermore, corruption is argued } \\
\text { from a narrow economic and busi- } \\
\text { ness perspective, instead of socio, } \\
\text { economic and political perspec- } \\
\text { tives. Hence, the argument that } \\
\text { some corruptions bring about posi- } \\
\text { tive economic benefits. The differ- } \\
\text { ence between taxation and corrup- } \\
\text { tion is vital, as the former is legiti- } \\
\text { mate and the latter affects the poor } \\
\text { and women disproportionately. } \\
\text { Furthermore, corruption is not de- } \\
\text { fined well in this research and it } \\
\text { gives an impression that with the } \\
\text { introduction of e-government, cor- } \\
\text { ruption is tackled, instead of a more } \\
\text { dynamic approach of corruption, } \\
\text { possibly a moving target. } \\
\text { In addition, the 2004-2008 dataset } \\
\text { may be too old in the field, which } \\
\text { advances swiftly. As in other stud- } \\
\text { ies, the authors use E-government } \\
\text { Survey for the dataset, but the way } \\
\text { e-government content and services } \\
\text { are measured is questionable and } \\
\text { subjective. The way the World }\end{array}$ \\
\end{tabular}




\begin{tabular}{|l|l|l|l|}
\hline & & $\begin{array}{l}\text { Governance Indicators aggregates } \\
\text { data may need a more careful ex- } \\
\text { amination. }\end{array}$ \\
$\begin{array}{l}\text { Finally, if the findings are true, all } \\
\text { countries, regardless of whether } \\
\text { they are developing or developed, } \\
\text { with mature e-government initia- } \\
\text { tives, should have reduced corrup- } \\
\text { tions by now and it is interesting to } \\
\text { see if this proves the case. In my re- } \\
\text { search, I will take the above into } \\
\text { consideration when selecting and } \\
\text { analysing case studies. }\end{array}$ \\
\hline $\begin{array}{l}\text { Transpar- } \\
\text { ency, } \\
\text { E-govern- } \\
\text { ment, } \\
\text { and account- } \\
\text { ability } \\
\text { some Issues } \\
\text { and } \\
\begin{array}{l}\text { Considera- } \\
\text { tions }\end{array}\end{array}$ & $\begin{array}{l}\text { Arie; } \\
\text { Greiling, } \\
\text { Dorothea }\end{array}$ & 2013 & $\begin{array}{l}\text { This qualitative research poses a } \\
\text { pertinent question on how much } \\
\text { transparency is good, enough and } \\
\text { meaningful, as ICT and e-govern- } \\
\text { ment initiatives make more data } \\
\text { and information available online. It } \\
\text { aims to develop theories and mod- } \\
\text { els to balance the need for business- } \\
\text { like efficient public sector and, at } \\
\text { the same time, for more transparent } \\
\text { and open government. This re- } \\
\text { quires diversion of resources from } \\
\text { core government functions to pub- } \\
\text { lishing information and data for the } \\
\text { public and responding to requests. } \\
\text { The author identified information } \\
\text { overload, administrative costs, de- } \\
\text { lay and politicisation as a conse- } \\
\text { quence of publishing more infor- } \\
\text { mation for the public. However, his } \\
\text { examples of German e-government } \\
\text { do not address the challenge of } \\
\text { striking a balance between provid- } \\
\text { ing more information (more effi- } \\
\text { ciently through e-government) and }\end{array}$ \\
\hline
\end{tabular}




\begin{tabular}{|c|c|c|c|c|}
\hline & & & & $\begin{array}{l}\text { more efficient e-government (with } \\
\text { less information). This question is } \\
\text { particularly pertinent to developing } \\
\text { countries with less resources and } \\
\text { less stable democratic institutions. }\end{array}$ \\
\hline 64 & $\begin{array}{l}\text { Accountabil- } \\
\text { ity } \\
\text { and } \\
\text { accessibility: } \\
\text { ensuring the } \\
\text { evidence of } \\
\text { e-govern- } \\
\text { ance } \\
\text { in Australia }\end{array}$ & $\begin{array}{l}\text { Cunning- } \\
\text { ham, A; P } \\
\text { hillips, M }\end{array}$ & 2005 & $\begin{array}{l}\text { The authors examine the role of li- } \\
\text { braries and archives in Australia in } \\
\text { preserving and capturing long term } \\
\text { access to government records and } \\
\text { publications. The methodology } \\
\text { used is case study-based concept } \\
\text { analysis and the case is the Na- } \\
\text { tional Library of Australia and the } \\
\text { National Archive of Australia. The } \\
\text { challenge identified in the study is } \\
\text { that while Australia has made sig- } \\
\text { nificant progress, digital preserva- } \\
\text { tion of government publications } \\
\text { and records, including large } \\
\text { amounts of data, is still at risk of } \\
\text { loss. The study is relevant in the } \\
\text { way that preservation of records is } \\
\text { important for the functioning of de- } \\
\text { mocracy in a country and for trans- } \\
\text { parent and accountable govern- } \\
\text { ance. }\end{array}$ \\
\hline 68 & $\begin{array}{l}\text { E- } \\
\text { GOVERN- } \\
\text { MENT } \\
\text { USEAND } \\
\text { PER- } \\
\text { CEIVED } \\
\text { GOVERN- } \\
\text { MENT } \\
\text { TRANSPAR- } \\
\text { ENCY AND- } \\
\text { SERVICE }\end{array}$ & $\begin{array}{l}\text { Jun, Kyu- } \\
\text { Nahm;Wa } \\
\text { ng, Feng; } \\
\text { Wang, Da } \\
\text { peng }\end{array}$ & 2014 & $\begin{array}{l}\text { The authors examine the e-govern- } \\
\text { ment services implemented in a lo- } \\
\text { cal administration in China to de- } \\
\text { termine citizen's satisfaction and } \\
\text { perception towards transparency, } \\
\text { which is expected to trigger service- } \\
\text { oriented government. } \\
\text { This study is pertinent to my re- } \\
\text { search questions, in a way that it } \\
\text { presents another model of e-gov- } \\
\text { ernance in a limited democratic so- } \\
\text { ciety. What drives improvements in }\end{array}$ \\
\hline
\end{tabular}




\begin{tabular}{|l|l|l|}
\hline $\begin{array}{l}\text { CAPACITY } \\
\text { Evi- } \\
\text { dence from a } \\
\text { Chinese Lo- } \\
\text { cal } \\
\text { Government }\end{array}$ & $\begin{array}{l}\text { various sphere of governance with- } \\
\text { out democratic accountability } \\
\text { would be an important question. } \\
\text { However, the case of China might } \\
\text { be more complex, due to the size of } \\
\text { the country and diversity across the } \\
\text { territory. } \\
\text { The authors set the scene by ex- } \\
\text { plaining that "the research summa- } \\
\text { rized in this article explores the re- } \\
\text { lationship between government } \\
\text { website usage, citizens' perceptions } \\
\text { of local government transparency, } \\
\text { and government's capacity for ser- } \\
\text { vice delivery-all in the context of a } \\
\text { Chinese local government that has } \\
\text { undertaken administrative reforms } \\
\text { to build a service-oriented govern- } \\
\text { ment. Among the various strategies } \\
\text { used to achieve such a transfor- } \\
\text { mation, e-government is a core ap- } \\
\text { proach (Seifert \& chung, 2009)." } \\
\text { The research method is a large- } \\
\text { scale survey conducted in F (???) } \\
\text { city of Guandong province. In 2007, } \\
\text { the data collection was conducted } \\
\text { with a 79 percent response rate } \\
\text { from 949 respondents. } \\
\text { The literature review included the } \\
\text { quote below, which might be rele- } \\
\text { vant to my research: } \\
\text { "Justice, Melitski, and Smith (2006) } \\
\text { argue that the implementation of e- } \\
\text { government will improve manage- } \\
\text { rial capacity, which includes both } \\
\text { administrative and governance ca- } \\
\text { pacity." }\end{array}$ \\
\hline
\end{tabular}




\begin{tabular}{|c|c|c|c|c|}
\hline & & & & $\begin{array}{l}\text { Interestingly, the study finds that } \\
\text { users rely more on traditional me- } \\
\text { dia for information, while a genera- } \\
\text { tion gap was also identified. Age is } \\
\text { correlated to the perception on gov- } \\
\text { ernment capacity for service deliv- } \\
\text { ery. E-government is found to have } \\
\text { a positive correlation with percep- } \\
\text { tions of government capacity. } \\
\text { While the study also finds that e- } \\
\text { government was not linked to the } \\
\text { two-way communication between } \\
\text { government and citizens, it might } \\
\text { be possible that the underlying as- } \\
\text { sumption in China might be differ- } \\
\text { ent from the actual assumption of } \\
\text { the model. The authors also raise } \\
\text { the question below: } \\
\text { "the findings raise the question of } \\
\text { the predictability of the stage } \\
\text { model of e-government, which ex- } \\
\text { pects that governments will move } \\
\text { stepwise toward the adoption of } \\
\text { more sophisticated e-government } \\
\text { offerings, moving from information } \\
\text { to transactions to integration and } \\
\text { ultimately to transformation" } \\
\text { (coursey \& Norris, 2008, p. } 532 \text { )." } \\
\text { Thus, the conclusion of the authors } \\
\text { is that, "the establishment of e-gov- } \\
\text { ernment does not, in itself, lead nat- } \\
\text { urally to a citizen-centric, service- } \\
\text { oriented government". }\end{array}$ \\
\hline 71 & $\begin{array}{l}\text { Corrup- } \\
\text { tion as a } \\
\text { source of } \\
\text { e-Govern- } \\
\text { ment }\end{array}$ & $\begin{array}{l}\text { Alad- } \\
\text { wani, } \\
\text { Adel M }\end{array}$ & 2016 & $\begin{array}{l}\text { The author examines the influence } \\
\text { of corruption on the e-government } \\
\text { initiative, in particular, project fail- } \\
\text { ures. In this study, he aims to }\end{array}$ \\
\hline
\end{tabular}




\begin{tabular}{|l|l|l|}
\hline $\begin{array}{l}\text { projects fail- } \\
\text { ure } \\
\text { in develop- } \\
\text { ing } \\
\text { countries: } \\
\begin{array}{l}\text { A theoretical } \\
\text { exposition }\end{array}\end{array}$ & $\begin{array}{l}\text { propose a theoretical framework to } \\
\text { analyse the phenomenon. } \\
\text { Despite heightened attention by the } \\
\text { academia and practitioners on the } \\
\text { causes of e-government failures, } \\
\text { there hasn't been much attention on } \\
\text { the role of corruption in the pro- } \\
\text { cess. In this backdrop, this study } \\
\text { explains "how corruption can act as } \\
\text { a source of e-Government project } \\
\text { failures in developing countries". } \\
\text { The author added: "This is unfortu- } \\
\text { nate because pervasive corruption } \\
\text { has been shown to be one of the } \\
\text { most important contextual factors } \\
\text { that could influence the maturity of } \\
\text { e-Government initiatives (Singh, } \\
\text { Das, \& Joseph, 2007); important re- } \\
\text { search and practical insights could } \\
\text { be missed if researchers continue to } \\
\text { overlook the other possible ways } \\
\text { through which e-Government and } \\
\text { corruption might be related." } \\
\text { This angle is a pertinent one to my } \\
\text { research as institutional capacity is } \\
\text { influenced by corruption in the } \\
\text { background and through the medi- } \\
\text { ating/moderating factors, affect the } \\
\text { behavior of the civil servants. } \\
\text { The study estimates the conduit of } \\
\text { the process as follows: } \\
\text { "The article argues that e-Govern- } \\
\text { ment failure in developing econo- } \\
\text { mies comes to exist, in part, be- } \\
\text { cause of the role played by corrup- } \\
\text { tion forces. It proposes that e-Gov- } \\
\text { ernment projects fail because of cul- } \\
\text { tural, economic, political and }\end{array}$ \\
\hline
\end{tabular}




\begin{tabular}{|l|l|l|}
\hline & $\mid \begin{array}{l}\text { judicial corruption effects, which } \\
\text { distort information processing ca- } \\
\text { pabilities of administrative systems } \\
\text { (e.g. capability to deal with moral } \\
\text { and governance needs) that ulti- } \\
\text { mately cause e-Government to stop } \\
\text { short from meeting stakeholders' } \\
\text { expectations." } \\
\text { In addition to external factors, the } \\
\text { author quotes previous studies on } \\
\text { internal causes of e-government } \\
\text { failure. The study quotes Heeks re- } \\
\text { search, which concludes that 85 } \\
\text { percent of e-government projects } \\
\text { failed. The causes of failures were } \\
\text { attributed to individual characteris- } \\
\text { tics such as age, gender and educa- } \\
\text { tion among others (e.g., Akman, } \\
\text { Yazici, Mishra, \& Arifoglu, 2005; } \\
\text { Aladwani, 2013a; Choudrie and } \\
\text { Dwivedi, 2005; Dwivedi and Wil- } \\
\text { liams, 2008; Fu, Chao, \& Farn, 2004; } \\
\text { Gauld, Goldfinch, \& Horsburgh, } \\
\text { 2010). Other scholars identified or- } \\
\text { ganisational culture as a cause } \\
\text { (Aladwani, 2011; Luk, 2009; } \\
\text { Wachira, 2012). The other causes } \\
\text { were identified as technology } \\
\text { (Aladwani, 2013b, 2013c; Carter } \\
\text { and Belanger, 2005) and political } \\
\text { environment (Kamal, Hackney, and } \\
\text { Sarwar 2013; Weerakkody, ElHad- } \\
\text { dadeh, Sabol, Ghoneim, and } \\
\text { Dzupka 2012). } \\
\text { "Given this broad view, corruption } \\
\text { can refer to many types of ille- } \\
\text { gal/disapproved financial and ad- } \\
\text { ministrative behaviors in the con- } \\
\text { text of public jobs, such as, bribery }\end{array}$ \\
\\
\hline
\end{tabular}




\begin{tabular}{|l|l|l|}
\hline $\mid$ & $\begin{array}{l}\text { (kickbacks, pay-offs), embezzle- } \\
\text { ment (misappropriation), nepotism } \\
\text { (favoritism, preferential treatment), } \\
\text { abusing authority and extortion } \\
\text { (profiting through coercive means), } \\
\text { to name a few (Caiden, 2001; } \\
\text { Caiden and Caiden, 1977; Rose- } \\
\text { Ackerman, 1975, 1978, 1996, 1999; } \\
\text { United Nations, 1999)." } \\
\text { Corruption is most prevalent } \\
\text { among developing countries, ac- } \\
\text { cording to the author, and has sig- } \\
\text { nificant economic, social and cul- } \\
\text { tural impacts. In particular, } \\
\text { "Corruption could have detrimental } \\
\text { effects on administrative systems } \\
\text { overseeing eGovernment projects } \\
\text { since it limits their capability to op- } \\
\text { erate in accord with good govern- } \\
\text { ance and morality standards." } \\
\text { In this background, "The proposed } \\
\text { theoretical framework consists of } \\
\text { three major parts: corruption types } \\
\text { (cultural, economic, political and } \\
\text { judicial), internal effects (deteriora- } \\
\text { tion of the moral compass and dete- } \\
\text { rioration of governance standards), } \\
\text { and e-Government project failure } \\
\text { dimensions (technical, content, so- } \\
\text { cial and service)." } \\
\text { The author identifies some internal } \\
\text { factors, such as e-government man- } \\
\text { agers and officials, including deci- } \\
\text { sion makers as important for the } \\
\text { project to succeed, however, on } \\
\text { condition that they do not cave in } \\
\text { to political interference. The ability } \\
\text { of government officials to plan and }\end{array}$ \\
\hline
\end{tabular}




\begin{tabular}{|l|l|l|}
\hline & $\mid \begin{array}{l}\text { implement activities in a profes- } \\
\text { sional way would be hampered in } \\
\text { an environment that allows politi- } \\
\text { cal interference. The cost of such } \\
\text { compromised e-government initia- } \\
\text { tives would be higher, while evalu- } \\
\text { ation and taking corrective actions } \\
\text { would also become difficult. } \\
\text { Corruption in the judiciary system } \\
\text { is identified as having significant } \\
\text { multiplier impact: "A recent corrup- } \\
\text { tion report affirms: “ijn 20 coun- } \\
\text { tries, people believe the judiciary to } \\
\text { be the most corrupt institution. In } \\
\text { these countries, an average of } 30 \\
\text { per cent of people, who came into } \\
\text { contact with the judiciary, report } \\
\text { having paid a bribe" (Hardoon and } \\
\text { Heinrich, 2013 p. 17); and, there- } \\
\text { fore, the prevalence of such kind of } \\
\text { corruption always has far reaching } \\
\text { effects on all governmental con- } \\
\text { texts, including that of e-Govern- } \\
\text { ment's." } \\
\text { Therefore, officials in the judiciary } \\
\text { system may attempt various } \\
\text { measures to control and limit the } \\
\text { influence of e-government initia- } \\
\text { tives, such as limiting access to ju- } \\
\text { dicial case files and rulings or } \\
\text { causes. } \\
\text { The consequences are illustrated } \\
\text { below: } \\
\text { "The prevalence of violations of } \\
\text { public trust will eventually discour- } \\
\text { age some e-Government officials } \\
\text { and specialists from paying ade- } \\
\text { quate attention to breaching inner } \\
\text { ethical norms and to encoding ac- } \\
\text { countability and transparency }\end{array}$ \\
\end{tabular}




\begin{tabular}{|c|c|c|c|c|}
\hline & & & & $\begin{array}{l}\text { principles into e-Government sys- } \\
\text { tems based on technically sound } \\
\text { choices. As suggested by the work } \\
\text { of Caiden and Caiden (1977), when } \\
\text { corruption becomes widespread in } \\
\text { a society, it encourages organisa- } \\
\text { tions to present contradictory exter- } \\
\text { nal and internal codes of ethics; } \\
\text { hide violations of the external code, } \\
\text { penalise non-violators and reward } \\
\text { violators; and excuse corruption as } \\
\text { isolated incidents. Such corruption } \\
\text { could put the administrative sys- } \\
\text { tem overseeing an e-Government } \\
\text { project under an unforgiving mo- } \\
\text { rality test. This would certainly } \\
\text { cause deterioration in the perceived } \\
\text { information accuracy and com- } \\
\text { pleteness as well as the integrity } \\
\text { and fairness of the services pro- } \\
\text { vided by e-Government to the pub- } \\
\text { lic and other stakeholders." } \\
\text { Considering the above, maybe } \\
\text { some e-government initiatives } \\
\text { should be considered as a higher } \\
\text { priority initiative - those that } \\
\text { should stem the systemic corrup- } \\
\text { tion within the government. } \\
\text { Although the author emphasised } \\
\text { the external factor, such as political } \\
\text { interference, the corrupt forces } \\
\text { could be found internal to govern- } \\
\text { ment. In particular, in undemo- } \\
\text { cratic societies, such forces manifest } \\
\text { in diverse ways and will have detri- } \\
\text { mental impact. }\end{array}$ \\
\hline 73 & $\begin{array}{l}\text { Examin- } \\
\text { ing the }\end{array}$ & Rana, & 2015 & $\begin{array}{l}\text { The authors examined the level of } \\
\text { success of e-grievance system in }\end{array}$ \\
\hline
\end{tabular}




\begin{tabular}{|c|c|c|}
\hline $\begin{array}{l}\text { Success of the } \\
\text { Online Pub- } \\
\text { lic Grievance } \\
\text { Redressal } \\
\text { Systems: An } \\
\text { Extension of } \\
\text { the IS Suc- } \\
\text { cess Model }\end{array}$ & $\begin{array}{l}\text { Nripen- } \\
\text { dra P.; D } \\
\text { wivedi, } \\
\text { Yogesh K. } \\
\text {; Wil- } \\
\text { liams, } \\
\text { Michael D } \\
\text {; } \\
\text { et al }\end{array}$ & 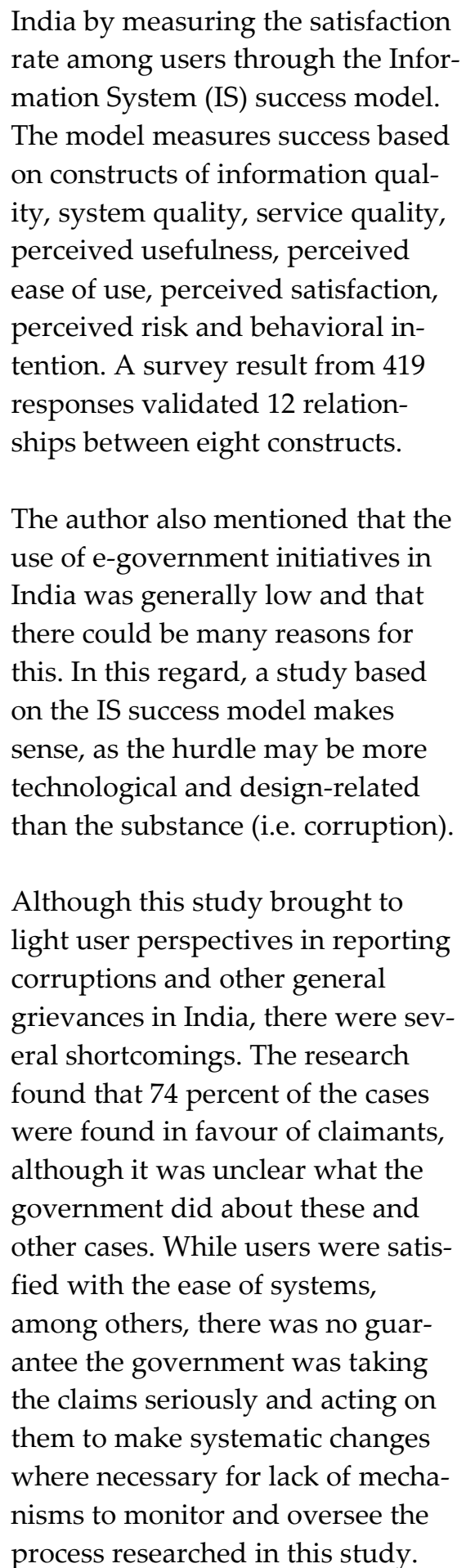 \\
\hline
\end{tabular}




\begin{tabular}{|c|c|c|c|c|}
\hline & & & & $\begin{array}{l}\text { Additionally, this system, like } \\
\text { OPEN in Korea, is effective in ad- } \\
\text { dressing petty corruption, where } \\
\text { citizens are involved. More system- } \\
\text { atic corruptions can't be addressed } \\
\text { by this system, unless there is a } \\
\text { back end online, offline monitoring } \\
\text { system. Another challenge in this } \\
\text { study was the survey sampling. Re- } \\
\text { spondents were more educated and } \\
\text { earned higher income than the vast } \\
\text { majority of the population in the } \\
\text { country, and in no way, were they } \\
\text { representative of the population, in } \\
\text { addition to the gender imbalance. } \\
\text { These were the people unafraid of } \\
\text { speaking up and complaining but it } \\
\text { may not apply to the vast majority. } \\
\text { While the study was relevant and } \\
\text { interesting to my research ques- } \\
\text { tions, it also leaves many more } \\
\text { questions on short-term and long- } \\
\text { term impact of the e-grievance sys- } \\
\text { tem, especially on how effective it } \\
\text { is in reducing corruption and } \\
\text { among a vast majority of popula- } \\
\text { tion in the context of a developing } \\
\text { country. }\end{array}$ \\
\hline 92 & $\begin{array}{l}\text { Online Budge } \\
t \\
\text { Transpar- } \\
\text { ency in } \\
\text { OECD Mem- } \\
\text { ber } \\
\text { Coun- } \\
\text { tries and } \\
\text { Administra- } \\
\text { tive } \\
\text { Culture }\end{array}$ & $\begin{array}{l}\text { Rodrigue } \\
\text { z } \\
\text { Bolivar, } \\
\text { Manuel P } \\
\text { edro; Cab } \\
\text { a Perez, } \\
\text { Maria del } \\
\text { Carmen; } \\
\text { Lopez- } \\
\text { Hernande } \\
\text { z }\end{array}$ & 2015 & $\begin{array}{l}\text { This OECD study examines the role } \\
\text { of e-government as a tool to in- } \\
\text { crease budget transparency among } \\
\text { its member countries. Using the ap- } \\
\text { proach of New Public Management } \\
\text { and administrative culture ap- } \\
\text { proach, the article analyses new } \\
\text { technologies. The findings indicate } \\
\text { that differences emerge across } \\
\text { countries under different adminis- } \\
\text { trative cultures. }\end{array}$ \\
\hline
\end{tabular}




\begin{tabular}{|c|c|c|c|c|}
\hline & & $\begin{array}{l}\text { Antonio } \\
\mathrm{M}\end{array}$ & & $\begin{array}{l}\text { The basic assumption for budgetary } \\
\text { transparency is that once citizens } \\
\text { have access to such information, } \\
\text { they can hold government account- } \\
\text { able; in a democratic environment, } \\
\text { where various legal and legislative } \\
\text { instruments are available. }\end{array}$ \\
\hline 101 & $\begin{array}{l}\text { A strate- } \\
\text { gic frame- } \\
\text { work for goo } \\
\text { d } \\
\text { governance } \\
\text { through e- } \\
\text { governance } \\
\text { optimization }\end{array}$ & $\begin{array}{l}\text { Kalsi, Nir } \\
\text { maljeet Si } \\
\text { ngh; } \\
\text { Kiran, Ra } \\
\text { vi }\end{array}$ & 2015 & $\begin{array}{l}\text { The authors examine the contribu- } \\
\text { tions of ICT, in particular e-govern- } \\
\text { ance initiatives, to good governance } \\
\text { in the State of Punjab, India. The } \\
\text { study identifies factors important } \\
\text { for the conducive environment in } \\
\text { implementing successful e-govern- } \\
\text { ance initiatives and barriers. The } \\
\text { findings feed into the proposed } \\
\text { strategic policy framework for the } \\
\text { State. } \\
\text { The methodology is based on the } \\
\text { participatory stakeholders' assess- } \\
\text { ment, using descriptive statistics, } \\
\text { perception gap, ANOVA and factor } \\
\text { analysis. Using the random strati- } \\
\text { fied sampling technique, a survey } \\
\text { was conducted with a response rate } \\
\text { of } 29.27 \text { percent or } 849 \text { responses. } \\
\text { The research found that while the } \\
\text { importance of ICT is widely recog- } \\
\text { nised, the challenges were identi- } \\
\text { fied as "unreasonable delay, multi- } \\
\text { ple visits even for small services, } \\
\text { poor public infrastructure and its } \\
\text { maintenance in government offices" } \\
\text { While the empirical data obtained } \\
\text { at the state level is valuable, the } \\
\text { questions seem to concern more the }\end{array}$ \\
\hline
\end{tabular}




\begin{tabular}{|c|c|c|c|c|}
\hline & & & & $\begin{array}{l}\text { service diversity than e-governance } \\
\text { or good governance as a whole. In- } \\
\text { teractions with citizens was the cen- } \\
\text { tral theme. } \\
\text { However, it is interesting that the } \\
\text { identified pitfalls are topped by "re- } \\
\text { sistance by political masters and } \\
\text { bureaucracy" and "resistance by cit- } \\
\text { izen, government staff to change". }\end{array}$ \\
\hline 103 & $\begin{array}{l}\text { Evaluat- } \\
\text { ing the } \\
\text { role of } \\
\text { online data } \\
\text { availabil- } \\
\text { ity: The } \\
\text { case of eco- } \\
\text { nomic and in- } \\
\text { stitutional } \\
\text { transpar- } \\
\text { ency in six- } \\
\text { teen Latin } \\
\text { American na- } \\
\text { tions }\end{array}$ & $\begin{array}{l}\text { Murillo, } \\
\text { Martin J }\end{array}$ & 2015 & $\begin{array}{l}\text { The author examines the central } \\
\text { governments of } 16 \text { Latin American } \\
\text { countries and their efforts to pro- } \\
\text { vide information online, where cor- } \\
\text { ruption and inefficiency generally } \\
\text { exist. } \\
\text { Using the principal-agent frame- } \\
\text { work and the theory of asymmetry } \\
\text { of information as a basis for corrup- } \\
\text { tion and inefficiency, the study } \\
\text { finds that policy and mandates to } \\
\text { make information available as well } \\
\text { as sophistication of technology are } \\
\text { important. While the importance of } \\
\text { ICT as means to contributing to } \\
\text { transparency and closing } \\
\text { knowledge divide is acknowl- } \\
\text { edged, its full potentials are yet to } \\
\text { be realised among the } 16 \text { countries. } \\
\text { This study supports my research } \\
\text { questions, in particular the im- } \\
\text { portance of e-governance institu- } \\
\text { tional instrument. While the princi- } \\
\text { pal-agent framework is an interest- } \\
\text { ing one, my research focuses on } \\
\text { limited democratic environment, } \\
\text { where the framework may be inap- } \\
\text { plicable. }\end{array}$ \\
\hline
\end{tabular}




\begin{tabular}{|l|l|l|l|}
\hline 114 & $\begin{array}{l}\text { Bribery and } \\
\text { inspection } \\
\text { technology } \\
\text { Andrew; } \\
\text { Lowen, } \\
\text { Aaron }\end{array}$ & $\begin{array}{l}\text { Samuel, } \\
\text { And }\end{array}$ & $\begin{array}{l}\text { This is an interesting quantitative } \\
\text { study with objectives given below: } \\
\text { "The e-government movement ad- } \\
\text { vocates increased use of technology } \\
\text { to improve government efficiency } \\
\text { and reduce corruption by reducing } \\
\text { the discretionary power of govern- } \\
\text { ment officials. This paper studies } \\
\text { the relationship between improve- } \\
\text { ments in inspection technology } \\
\text { within a Principal-Supervisor- } \\
\text { Agent model, where the supervisor } \\
\text { is an inspector who is hired by the } \\
\text { principal to investigate the agent's } \\
\text { potentially illegal actions." } \\
\text { "We show that when technology in- } \\
\text { creases the marginal or total } \\
\text { productivity of the supervisor's ef- } \\
\text { fort, improvements in inspection } \\
\text { technology encourage some types } \\
\text { of bribery. Although such techno- } \\
\text { logical improvements induce an } \\
\text { equilibrium with bribery, compli- } \\
\text { ance and social welfare can still } \\
\text { rise. However, when techology } \\
\text { and supervisory effort are } \\
\text { sufficiently substitutable, improve- } \\
\text { ments in technology may reduce } \\
\text { compliance when bribery occurs in } \\
\text { equilibrium even when those same } \\
\text { technological improvements would } \\
\text { have raised compliance in the ab- } \\
\text { sence of bribery. We also character- } \\
\text { ize the relationship between the } \\
\text { principal's socially optimal technol- } \\
\text { ogy and the anti-corruption policy } \\
\text { available to the principal and find } \\
\text { that the socially optimal inspection } \\
\text { technology may be a substitute for }\end{array}$ \\
\hline
\end{tabular}




\begin{tabular}{|l|l|l|}
\hline $\mid$ & $\begin{array}{l}\text { or a complement to the anti-corrup- } \\
\text { tion policy." } \\
\text { This sounds counter-intuitive and } \\
\text { may present a limit of quantitative } \\
\text { approach to such a complex topic } \\
\text { as bribery and corruption. } \\
\text { "The e-government movement ad- } \\
\text { vocates using improved inspection } \\
\text { technologies to enhance efficiency, } \\
\text { reduce corruption among govern- } \\
\text { ment regulators, and improve mon- } \\
\text { itoring and compliance. For exam- } \\
\text { ple, transport companies in the } \\
\text { state of Gujurat, India, frequently } \\
\text { load trucks beyond the permissible } \\
\text { axle-load. Inspections at weigh sta- } \\
\text { tions were slow and inefficient, and } \\
\text { by bribing transportation inspec- } \\
\text { tors, truckers were able to avoid } \\
\text { paying a fine for their non-compli- } \\
\text { ance. Thus, compliance with axle- } \\
\text { load regulations was extremely } \\
\text { low. The department of transporta- } \\
\text { tion introduced improved monitor- } \\
\text { ing devices, such as electronic } \\
\text { weighbridges, in order to improve } \\
\text { efficiency and reduce bribery at } \\
\text { these weigh stations in the hope } \\
\text { that it would improve overall com- } \\
\text { pliance with axle-load regulations. } \\
\text { Specifically, they claimed that in- } \\
\text { troducing electronic weighbridges } \\
\text { would: (1) improve efficiency and } \\
\text { reduce red-tape, and (2) lower the } \\
\text { discretionary power of weigh-sta- } \\
\text { tion inspectors, which would in } \\
\text { turn reduce their ability to extract } \\
\text { bribes from truckers. Although } \\
\text { their intuition seemed reasonable, } \\
\text { this policy did not decrease the }\end{array}$ \\
\hline
\end{tabular}




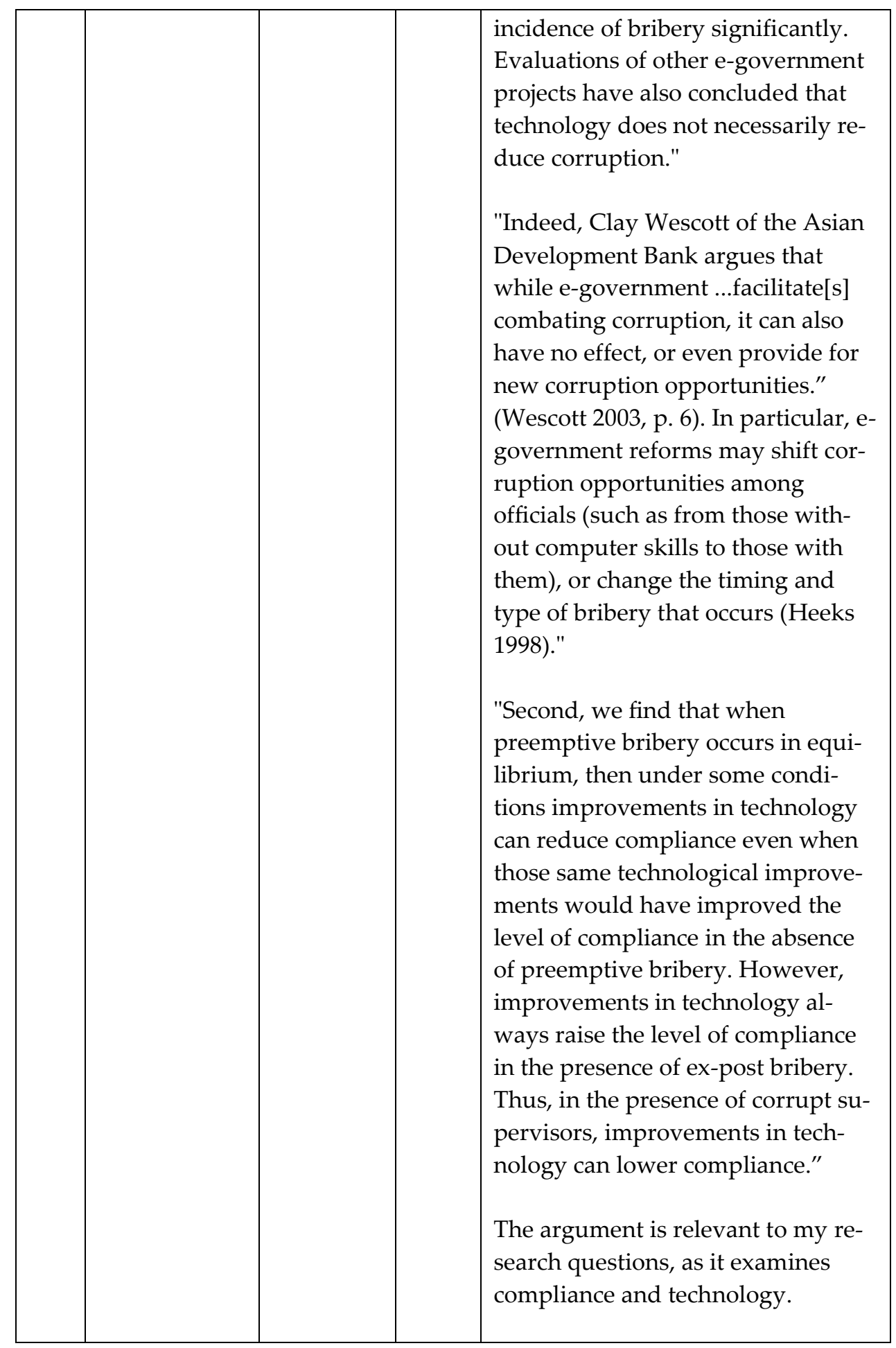




\begin{tabular}{|c|c|c|c|c|}
\hline 117 & $\begin{array}{l}\text { Can You Fin } \\
\text { d It } \\
\text { on the Web? } \\
\text { An Assess- } \\
\text { ment of } \\
\text { Municipal E- } \\
\text { Government } \\
\text { Transpar- } \\
\text { ency }\end{array}$ & $\begin{array}{l}\text { Bearfield, } \\
\text { Do- } \\
\text { monic A.; } \\
\text { Bowman, } \\
\text { Ann O'M }\end{array}$ & 2017 & $\begin{array}{l}\text { This qualitative study conducts lit- } \\
\text { erature review to derive a model to } \\
\text { test five explanations to determine } \\
\text { the propensity of cities for transpar- } \\
\text { ency. It concludes that local govern- } \\
\text { ments are more likely to publish } \\
\text { budget and administrative infor- } \\
\text { mation online than HR related mat- } \\
\text { ters. The authors state: } \\
\text { "Our analysis suggests that com- } \\
\text { munity demand and a city's organi- } \\
\text { zational networks play an im- } \\
\text { portant role in fostering transpar- } \\
\text { ency, regardless of city size. Im- } \\
\text { portant differences do exist be- } \\
\text { tween large and small cities: Trans- } \\
\text { parency in larger cities is spurred } \\
\text { by political competition; in smaller } \\
\text { cities, governmental resources and } \\
\text { administrative professionalism in- } \\
\text { fluence transparency." } \\
\text { The definition of transparency and } \\
\text { assumption that citizens and media } \\
\text { will hold government accountable } \\
\text { are applied in this study conducted } \\
\text { for the United States, but it may not } \\
\text { be applicable in countries without } \\
\text { democratic institutions. } \\
\text { In terms of combination of ele- } \\
\text { ments, which are supposed to facil- } \\
\text { itate openness in administrative } \\
\text { culture, the authors cite that "A } \\
\text { study of New Jersey local govern- } \\
\text { ments identified five possible ex- } \\
\text { planations for a city's commitment } \\
\text { to openness: a supportive adminis- } \\
\text { trative culture; sufficient govern- } \\
\text { mental resources; ample political }\end{array}$ \\
\hline
\end{tabular}




\begin{tabular}{|l|l|l|}
\hline & $\begin{array}{l}\text { competition; an active and profes- } \\
\text { sional media, particularly local } \\
\text { newspapers; and the presence of } \\
\text { good government watchdogs (Pi- } \\
\text { otrowski, 2011)". } \\
\text { The author concludes that based on } \\
\text { the findings of existing research, } \\
\text { more studies are called for. Based } \\
\text { on prior research findings, the au- } \\
\text { thor identified "governmental re- } \\
\text { sources, political competition, ad- } \\
\text { ministrative professionalism, com- } \\
\text { munity demand, and organiza- } \\
\text { tional networks" as determining } \\
\text { factors. } \\
\text { Lack of resources was found to be a } \\
\text { barrier in providing e-government } \\
\text { services. But in other circum- } \\
\text { stances, e-government enables gov- } \\
\text { ernments to provide services with } \\
\text { less resources. While political com- } \\
\text { petition may not apply universally } \\
\text { in the context of promoting trans- } \\
\text { parency in developing countries, } \\
\text { education and administrative pro- } \\
\text { fessionalism might be an important } \\
\text { factor to commit to managerial best } \\
\text { practices. The length of service } \\
\text { among managers was also taken } \\
\text { into account, wherein, new manag- } \\
\text { ers seem more inclined to introduc- } \\
\text { ing new techniques and ap- } \\
\text { proaches. } \\
\text { In explaining demand for transpar- } \\
\text { ency, the authors explain that edu- } \\
\text { cation and income of citizens have } \\
\text { an impact. Another factor taken } \\
\text { into account is the organisational }\end{array}$ \\
\hline
\end{tabular}




\begin{tabular}{|c|c|c|c|c|}
\hline & & & & $\begin{array}{l}\text { network, where cities learn from } \\
\text { each other. This is expected to re- } \\
\text { duce uncertainty in implementa- } \\
\text { tion. In the case of a country, this } \\
\text { should then mean that neighboring } \\
\text { countries, or countries with same } \\
\text { linguistic, cultural and historical } \\
\text { ties, should develop in tandem. } \\
\text { The research gaps identified in- } \\
\text { clude, 1) whether the information } \\
\text { made available led to monitoring } \\
\text { and assessment and 2) if social me- } \\
\text { dia provides additional means to } \\
\text { engage citizens, which is the new } \\
\text { paradigm of engagement. }\end{array}$ \\
\hline 134 & $\begin{array}{l}\text { YOU CAN'T } \\
\text { BRIBE A } \\
\text { COM- } \\
\text { PUTER: } \\
\text { DEAL- } \\
\text { ING WITH } \\
\text { THE SOCIE- } \\
\text { TAL CHAL- } \\
\text { LENGE OF } \\
\text { CORRUP- } \\
\text { TION } \\
\text { THROUGH } \\
\text { ICT }\end{array}$ & $\begin{array}{l}\text { Sri- } \\
\text { vastava, } \\
\text { Shirish C.; } \\
\text { Teo, } \\
\text { Thomp- } \\
\text { son S. H.; } \\
\text { Devaraj, } \\
\text { Sarv }\end{array}$ & 2016 & $\begin{array}{l}\text { The authors find that the theoretical } \\
\text { understanding of how ICT, in par- } \\
\text { ticular e-government, affects cor- } \\
\text { ruption is still limited despite the } \\
\text { research on the role of ICT in en- } \\
\text { hancing transparency and fairness. } \\
\text { Using an institutional perspective, } \\
\text { the authors theorised the relation- } \\
\text { ships between corruption and e- } \\
\text { government at two levels: } \\
\text { "(1) base corruption observed in na- } \\
\text { tional institutions (political, legal, } \\
\text { and media institutions), and (2) } \\
\text { permeated corruption in the na- } \\
\text { tional stakeholders service systems } \\
\text { (business and citizen systems)." } \\
\text { More specifically, } \\
\text { "building on institutional theory, } \\
\text { this study conceptualises corrup- } \\
\text { tion in a nation as corruption in }\end{array}$ \\
\hline
\end{tabular}




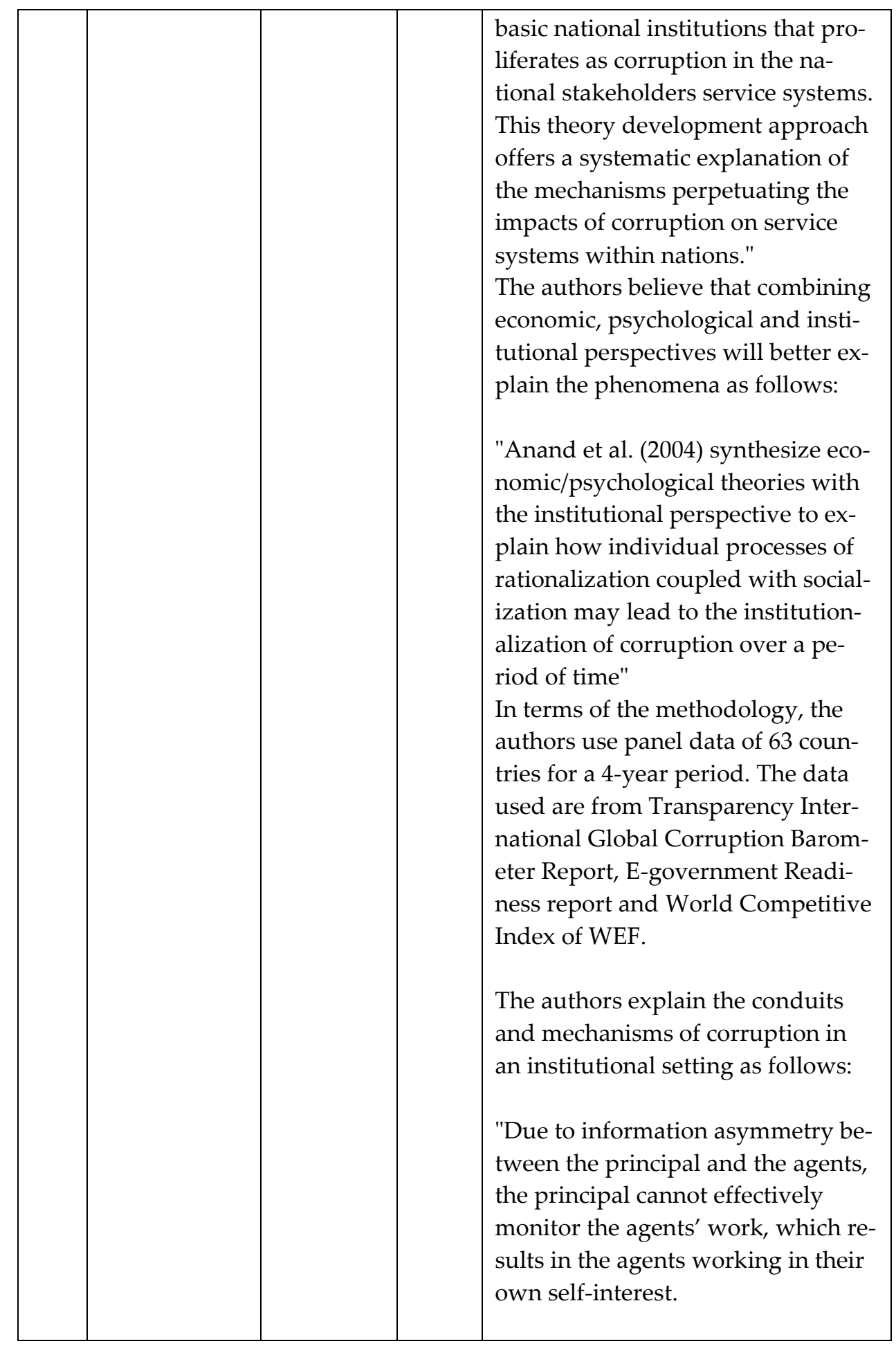




\begin{tabular}{|l|l|l|}
\hline $\mid$ & $\begin{array}{l}\text { Thus, in such a situation of infor- } \\
\text { mation asymmetry between the } \\
\text { government (principal) and public } \\
\text { officials (agents), where the public } \\
\text { officials have access to a monopoly } \\
\text { and also have discretion in admin- } \\
\text { istering it without sufficient ac- } \\
\text { countability, corruption manifests } \\
\text { (Mahmood 2004; Mistry 2012). To } \\
\text { mitigate corruption, the infor- } \\
\text { mation flows should be designed to } \\
\text { reduce the agents' monopoly and } \\
\text { power of discretion or to increase } \\
\text { their level of accountability (DiRi- } \\
\text { enzo et al. 2007)." } \\
\text { This explanation of why e-govern- } \\
\text { ment initiatives should be designed } \\
\text { around information sharing may or } \\
\text { may not work in different contexts. } \\
\text { Even when information asymmetry } \\
\text { is addressed, and people get to } \\
\text { know, there might be power imbal- } \\
\text { ance and culture of impunity, } \\
\text { which prevent any corrective ac- } \\
\text { tion. Power of discretion becomes } \\
\text { an ambiguous concept if they are } \\
\text { not defined well in a weak institu- } \\
\text { tional setting and many transac- } \\
\text { tions take place in an ad hoc man- } \\
\text { ner. } \\
\text { Furthermore, accountability and as- } \\
\text { sumption that information asym- } \\
\text { metry can be addressed by making } \\
\text { information public, again theorises } \\
\text { functioning democratic oversight } \\
\text { and instruments. Providing access } \\
\text { to rules and procedures may not be } \\
\text { practical, as they are complex and } \\
\text { change often and how they apply }\end{array}$ \\
\hline
\end{tabular}




\begin{tabular}{|l|l|l|}
\hline & $\begin{array}{l}\text { can only be explained by govern- } \\
\text { ment officials. } \\
\text { The results of the analysis reveal } \\
\text { that the e-government development } \\
\text { is negatively associated with the } \\
\text { level of corruption in legal, political } \\
\text { and media institutions. Further- } \\
\text { more, corruption in legal and me- } \\
\text { dia institutions are found to be cor- } \\
\text { related with corruption in service } \\
\text { systems, which have direct interac- } \\
\text { tions with businesses and citizens. } \\
\text { Thus, the analysis underlines the } \\
\text { importance of judiciary in address- } \\
\text { ing corruption in the national stake- } \\
\text { holders systems as a mediating fac- } \\
\text { tor. The same applies to media. } \\
\text { For future research, the authors } \\
\text { conclude: } \\
\text { "We have also suggested the mech- } \\
\text { anisms through which this hap- } \\
\text { pens, and future research can ex- } \\
\text { amine them in greater detail. Spe- } \\
\text { cifically, future studies can explore } \\
\text { the processes through which e-gov- } \\
\text { ernment actually reduces the dis- } \\
\text { cretionary power and monopoly of } \\
\text { public officials and enhances their } \\
\text { accountability. Researchers can also } \\
\text { extend the model to incorporate } \\
\text { other variables affecting corrup- } \\
\text { tion." } \\
\text { "Future research can specifically ex- } \\
\text { amine how ICT can transform ra- } \\
\text { ther than reinforce existing corrup- } \\
\text { tion-propagating structures" }\end{array}$ \\
\hline
\end{tabular}




\begin{tabular}{|c|c|c|c|c|}
\hline & & & & $\begin{array}{l}\text { "Corruption is a cultural variant, } \\
\text { and the perception of corruption } \\
\text { across cultures can be different. } \\
\text { Our cross-country study, which is } \\
\text { macro in orientation, does not take } \\
\text { into account the richness of specific } \\
\text { contexts. Future research can take } \\
\text { the situating contexts into account } \\
\text { for a more nuanced understanding } \\
\text { of corruption, possibly through the } \\
\text { use of qualitative research methods } \\
\text { (see Johns 2006; Markus et al. } \\
\text { 2002)." } \\
\text { "Fourth, we have taken an institu- } \\
\text { tional perspective, implying the key } \\
\text { role of institutions in shaping the } \\
\text { behavior of different stakeholders. } \\
\text { It is also plausible that an individ- } \\
\text { ual agency with behavioral and } \\
\text { economic motivations is instrumen- } \\
\text { tal in shaping the corruption-re- } \\
\text { lated practices in a nation. Future } \\
\text { research can examine the role of e- } \\
\text { government in impacting the prolif- } \\
\text { eration of corruption in a nation } \\
\text { from alternate perspectives." }\end{array}$ \\
\hline 135 & $\begin{array}{l}\text { Administer- } \\
\text { ing } \\
\text { and Govern- } \\
\text { ing } \\
\text { with Tech- } \\
\text { nol- } \\
\text { ogy: The Que } \\
\text { stion of } \\
\text { Information } \\
\text { Communica- } \\
\text { tion } \\
\text { Technology } \\
\text { and }\end{array}$ & $\begin{array}{l}\text { Coicaud, } \\
\text { Jean-Marc }\end{array}$ & 2016 & $\begin{array}{l}\text { The author starts his summary of } \\
\text { current research approach and } \\
\text { shortcomings at the beginning of } \\
\text { the essay: } \\
\text { 1. the current approach to e-gov- } \\
\text { ernment is generally positive, } \\
\text { and may not highlight problem- } \\
\text { atic and negative aspects of e- } \\
\text { governance. } \\
\text { 2. the development of e-govern- } \\
\text { ance is taking place at a time } \\
\text { when government institutions }\end{array}$ \\
\hline
\end{tabular}




\begin{tabular}{|c|c|c|c|c|}
\hline & $\begin{array}{l}\text { E-Govern- } \\
\text { ance }\end{array}$ & & & $\begin{array}{l}\text { are weakened by transnational } \\
\text { forces. } \\
\text { 3. } \text { maybe more focus on the public } \\
\text { goods in the discussion on e- } \\
\text { governance might be needed. } \\
\text { 4. } \\
\text { The author further explains his } \\
\text { views: } \\
\text { "... this does not mean that e-gov- } \\
\text { ernance is more open than before to } \\
\text { the participation and engagement } \\
\text { of administered people and citizens } \\
\text { in the decision-making processes of } \\
\text { public administration and govern- } \\
\text { ance. E-governance is not neces- } \\
\text { sarily part of a more open, of a less } \\
\text { traditional and one-way street mo- } \\
\text { dality of administrating and gov- } \\
\text { erning." } \\
\text { "The enthusiasm with which e-gov- } \\
\text { ernment and e-governance, the In- } \\
\text { ternet and ICT in general, are } \\
\text { viewed as supporting tools of de- } \\
\text { mocratization and democracy is in- } \\
\text { deed far from being justified. In } \\
\text { fact, while recognizing the benefits } \\
\text { generated by ICT in the context of } \\
\text { e-government/e-governance, one } \\
\text { has to refrain from making it a } \\
\text { 'magic bullet' when it comes to de- } \\
\text { mocracy and democratization." }\end{array}$ \\
\hline 139 & $\begin{array}{l}\text { Free to Ex- } \\
\text { pose } \\
\text { Corrup- } \\
\text { tion: The } \\
\text { Im- } \\
\text { pact of Me- } \\
\text { dia Freedom, }\end{array}$ & $\begin{array}{l}\text { Starke, } \\
\text { Christoph } \\
\text { er; Naab, } \\
\text { Teresa K.; } \\
\text { Scherer, } \\
\text { Helmut }\end{array}$ & 2016 & $\begin{array}{l}\text { The authors examine the effects of } \\
\text { free media, Internet access and e- } \\
\text { government as factors to curb cor- } \\
\text { ruption. Using the secondary data } \\
\text { of } 157 \text { countries between } 2003 \text { and } \\
2013 \text {, the study finds that the effect } \\
\text { of the Internet access remains }\end{array}$ \\
\hline
\end{tabular}




\begin{tabular}{|l|l|l|}
\hline $\begin{array}{l}\text { Internet Ac- } \\
\text { cess, and Gov } \\
\text { ernmen- } \\
\text { tal Online } \\
\text { Service De- } \\
\text { liv- } \\
\text { ery on Cor- } \\
\text { ruption }\end{array}$ & $\begin{array}{l}\text { constant from 2003. The impact of } \\
\text { e-government emerges in 2013. In } \\
\text { particular, the authors mention the } \\
\text { power of media as follows: }\end{array}$ \\
& $\begin{array}{l}\text { "These naming and shaming cam- } \\
\text { paigns influence the reputation of a } \\
\text { corrupt actor and can increase law } \\
\text { compliance (Fisman \& Miguel, } \\
\text { 2008)." } \\
\text { "..to successfully deter corruption } \\
\text { among public officials, media expo- } \\
\text { sure, strict anti-corruption laws, } \\
\text { and effective prosecution from } \\
\text { strong institutions of justice need to } \\
\text { complement one another. If offi- } \\
\text { cially sanctioned institutions are } \\
\text { weak or even corrupt themselves, } \\
\text { potential perpetrators do not have } \\
\text { to fear punishment (Persson, Roth- } \\
\text { stein, \& Teorell, 2013)." } \\
\text { "Empirical studies support this } \\
\text { claim by showing that information } \\
\text { supply has a positive impact on } \\
\text { government responsiveness (Besley } \\
\text { \& Burgess, 2002) and accountability } \\
\text { (Khazaeli \& Stockemer, 2013) and } \\
\text { that public access to information is } \\
\text { a powerful deterrent of local cap- } \\
\text { ture (Reinikka \& Svensson, 2004)." } \\
\text { The authors continue that, "Empiri- } \\
\text { cal evidence highlights the im- } \\
\text { portance of a general anti-corrup- } \\
\text { tion culture (Fisman \& Miguel, } \\
\text { 2008), corruption awareness (Goel, } \\
\text { Nelson, \& Naretta, 2012), and per- } \\
\text { ceived social norms (Köbis, van } \\
\text { Prooijen, Righetti, \& van Lange, }\end{array}$ \\
\hline
\end{tabular}




\begin{tabular}{|l|l|l|}
\hline & $\mid \begin{array}{l}\text { 2015) as important means to } \\
\text { fighting corruption." } \\
\text { Social media is important as media } \\
\text { freedom might not be in place, es- } \\
\text { pecially in an undemocratic society, } \\
\text { and people's access to media might } \\
\text { be limited. } \\
\text { "For journalists to expose corrup- } \\
\text { tion, media must be free from legal, } \\
\text { political, and economic constraints } \\
\text { (Freedom House, 2015). However, } \\
\text { media freedom is a fragile com- } \\
\text { modity, often abolished by totali- } \\
\text { tarian states, and, even in demo- } \\
\text { cratic countries, it can be sup- } \\
\text { pressed in times of crisis (Dosen- } \\
\text { rode, 2010)." } \\
\text { Regarding social media, the au- } \\
\text { thors' assertion below is important: } \\
\text { "Second, aside from the Internet's } \\
\text { allowing access to professional } \\
\text { journalistic information, the onset } \\
\text { of social media over the last decade } \\
\text { has created new opportunities to } \\
\text { accelerate the dissemination of in- } \\
\text { formation by amateurs. Citizen } \\
\text { journalists, political bloggers, and } \\
\text { lay communicators add to the vari- } \\
\text { ety of information sources and can } \\
\text { create transparency (Bertot et al., } \\
\text { 2010). } \\
\text { Thus, social media have the poten- } \\
\text { tial to uncover corruption even } \\
\text { when traditional media fail to do } \\
\text { so. Sullivan (2013) points out that } \\
\text { "netizen-led initiatives have facili- } \\
\text { tated the mobilization of online }\end{array}$ \\
\hline
\end{tabular}




\begin{tabular}{|l|l|l|}
\hline $\mid$ & $\begin{array}{l}\text { public opinion and forced the cen- } \\
\text { tral government to intervene to re- } \\
\text { dress acts of lower level malfea- } \\
\text { sance" (p. 24). For instance, blog- } \\
\text { gers "routinely uncover corruption, } \\
\text { help solve social problems, and } \\
\text { even pressure state officials to } \\
\text { change policy," (Hassid, 2012, p. } \\
\text { 212). } \\
\text { Furthermore, social networking } \\
\text { sites (SNS) such as Facebook and } \\
\text { Twitter can be used to organize of- } \\
\text { fline demonstrations against cor- } \\
\text { rupt political actors, as it did dur- } \\
\text { ing the Arab Spring in 2011 } \\
\text { (Tufekci \& Wilson, 2012). The emer- } \\
\text { gence of civic technology move- } \\
\text { ments such as ipaidabribe.com, } \\
\text { bribespot.com, sunlightfounda- } \\
\text { tion.com, and others are dedicated } \\
\text { to anti-corruption efforts. By } \\
\text { providing platforms to aggregate } \\
\text { data about single acts of corruption, } \\
\text { they help to foster transparency } \\
\text { and to pressure corrupt actors into } \\
\text { resigning their public offices." } \\
\text { "Others claim that in countries with } \\
\text { limited media freedom, social me- } \\
\text { dia can only contribute to curbing } \\
\text { corruption when no interests of } \\
\text { high political elites are at stake } \\
\text { (Toepfl, 2011)." } \\
\text { Various authors empirically found } \\
\text { that the Internet reduces corrup- } \\
\text { tion. However, all elements and as- } \\
\text { sumptions is that making infor- } \\
\text { mation public is the conduit be- } \\
\text { tween media/Internet/e-govern- } \\
\text { ment and corruption. }\end{array}$ \\
\end{tabular}


"the required standard procedures necessary in the delivery of every digital service show transparent rules and reduce arbitrary case-bycase decision making by potentially corrupt actors. They also reduce discretion about procedures because detailed data about transactions are tracked and stored, increasing the chances to expose acts of corruption (Andersen, 2009; Andersen et al., 2011; Bhatnagar, 2003)."

The study uses the TI's Corruption Perception Index, Press Freedom Index of Freedom House, and ITU data on Internet access to conduct analysis.

In conclusion, the study found strong correlation between free media and corruption at three points in time. The online government services and information is found negatively correlating to corruption. On the relationship between social media and corruption, the authors state:

"Due to the rapid global increase of Internet access over the last decade and the emergence of new technologies such as social media, we assumed that the effect of Internet access on corruption would increase over time. However, our results show that the size of the negative impact is relatively stable and has instead decreased from 2008 to 


\begin{tabular}{|l|l|l|}
\hline & $\mid \begin{array}{l}\text { 2013. Due to the rather large time } \\
\text { interval, we need to interpret longi- } \\
\text { tudinal results with caution. A pos- } \\
\text { sible explanation for this finding is } \\
\text { that the potential impact of social } \\
\text { media may have been overesti- } \\
\text { mated when they first emerged. } \\
\text { It could be argued that the expecta- } \\
\text { tions about the power of social me- } \\
\text { dia alone deterred public officials } \\
\text { from engaging in corruption be- } \\
\text { cause they feared exposure on a } \\
\text { large scale. Over the years, how- } \\
\text { ever, the Internet may not have } \\
\text { lived up to the high expectations so } \\
\text { that its deterring impact on corrup- } \\
\text { tion decreased. Additionally, auto- } \\
\text { cratic and corrupt regimes may } \\
\text { have learned how to use the Inter- } \\
\text { net to their advantage by imposing } \\
\text { further restrictions, managing pub- } \\
\text { lic outrage, and defusing accusa- } \\
\text { tions of corruption (MacKinnon, } \\
\text { 2007; Rød \& Weidmann, 2015; } \\
\text { Toepfl, 2011)." } \\
\text { For future research, the authors } \\
\text { noted that, "This article provides } \\
\text { theoretical arguments for why ac- } \\
\text { cess to the Internet might contrib- } \\
\text { ute to lower levels of corruption } \\
\text { within countries, but the empirical } \\
\text { analyses reveal neither which spe- } \\
\text { cific aspects account for this impact } \\
\text { nor conclude to what degree the } \\
\text { impacts occur. Future research is } \\
\text { needed on the factors that suppos- } \\
\text { edly shape the role of new technol- } \\
\text { ogies in reducing corruption and on }\end{array}$ \\
\hline
\end{tabular}




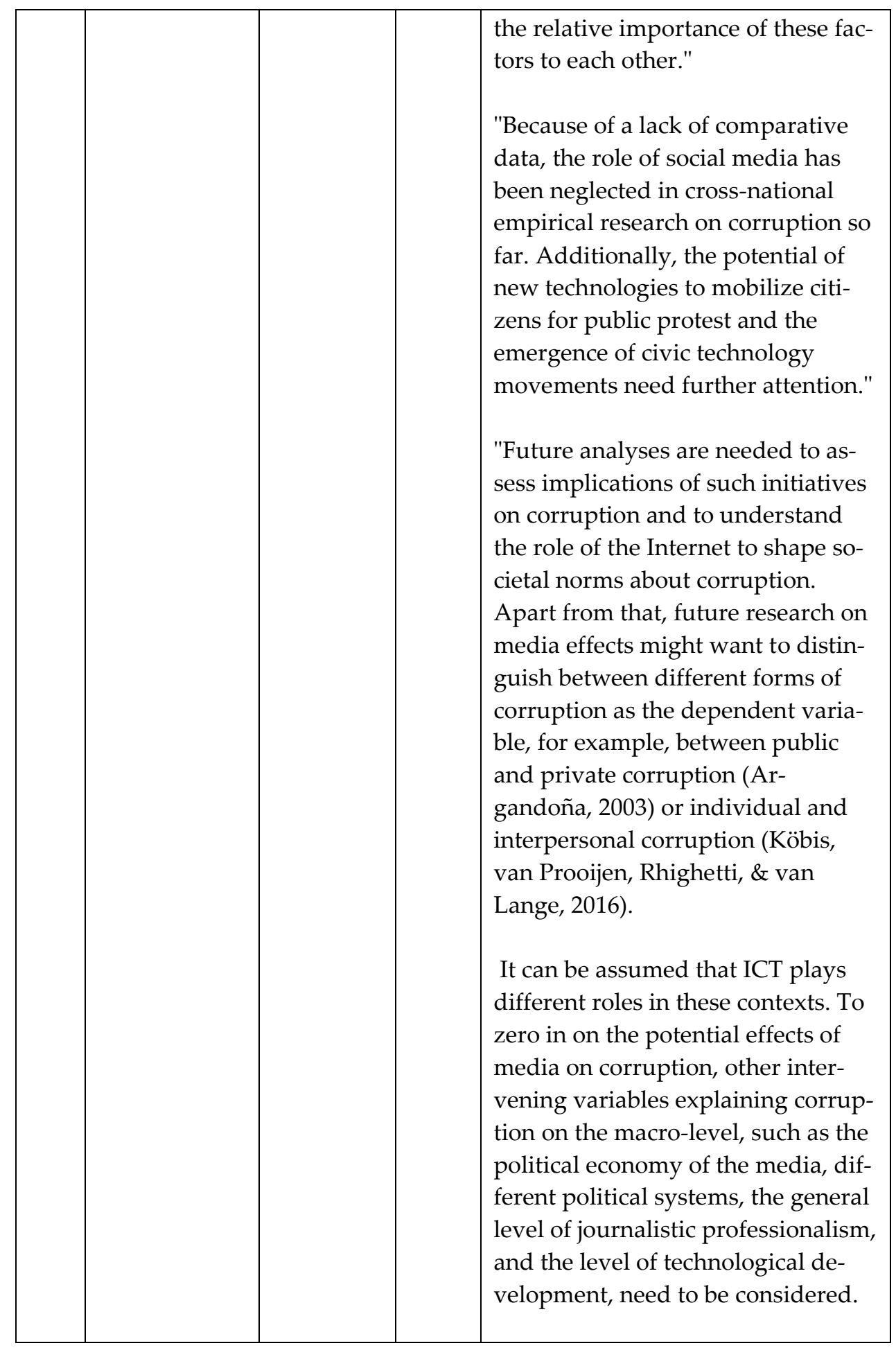




\begin{tabular}{|c|c|c|c|c|}
\hline & & & & $\begin{array}{l}\text { However, for many important con- } \\
\text { trol variables, comparative data } \\
\text { with global scope are lacking." }\end{array}$ \\
\hline 140 & $\begin{array}{l}\text { Virtual Ver- } \\
\text { sus } \\
\text { Physical } \\
\text { Government } \\
\text { Decentraliza- } \\
\text { tion: Ef- } \\
\text { fects on } \\
\text { Corruption } \\
\text { and the Shad } \\
\text { ow Economy }\end{array}$ & $\begin{array}{l}\text { Goel, } \\
\text { Ra- } \\
\text { jeev K.; } \\
\text { Sauno- } \\
\text { ris, } \\
\text { James W }\end{array}$ & 2016 & $\begin{array}{l}\text { This study examines the effective- } \\
\text { ness of cross-national virtual and } \\
\text { physical decentralisation. "While } \\
\text { virtual decentralization reduces } \\
\text { both corruption and the shadow } \\
\text { economy, physical decentralization } \\
\text { reduces only the shadow econ- } \\
\text { omy". }\end{array}$ \\
\hline 149 & $\begin{array}{l}\text { Determining } \\
\text { Factors of } \\
\text { Transpar- } \\
\text { ency } \\
\text { And } \\
\text { Accountabil- } \\
\text { ity in Local } \\
\text { Govern- } \\
\text { ments: } \\
\text { A Meta- } \\
\text { Ana- } \\
\text { lytic Study }\end{array}$ & $\begin{array}{l}\text { Alcaide } \\
\text { Munoz, } \\
\text { Laura; } \\
\text { Rodri- } \\
\text { guez } \\
\text { Bolivar } \\
\text { Manuel } \\
\text { Pedro }\end{array}$ & 2015 & $\begin{array}{l}\text { The authors examined information } \\
\text { transparency in improving public } \\
\text { accountability and conducted meta- } \\
\text { analysis of previous empirical stud- } \\
\text { ies to identify factors for higher dis- } \\
\text { closure level of economic-financial } \\
\text { information by local governments. } \\
\text { The authors find heterogeneity in } \\
\text { the analyses, but identified causes } \\
\text { of the differences. }\end{array}$ \\
\hline 157 & $\begin{array}{l}\text { Effective- } \\
\text { ness of } \\
\text { Information } \\
\text { technol- } \\
\text { ogy in } \\
\text { reducing } \\
\text { corruption in } \\
\text { China A } \\
\text { valida- } \\
\text { tion of the De } \\
\text { Lone and } \\
\text { clean } \\
\text { information } \\
\text { systems suc- } \\
\text { cess model }\end{array}$ & Hu Xinli & 2015 & $\begin{array}{l}\text { The author examines the influence } \\
\text { of electronic monitoring systems } \\
\text { (EMS) used in five Chinese cities } \\
\text { based on the information systems } \\
\text { (IS) success model. } \\
\text { The author started by listing previ- } \\
\text { ous studies, which examine the role } \\
\text { of ICT in reducing corruption. The } \\
\text { drivers, such as timely disclosure of } \\
\text { true, accurate and complete infor- } \\
\text { mation, are found to enhance trans- } \\
\text { parency, supported by public ac- } \\
\text { cess to it. Public can also monitor } \\
\text { corruption by tracking government }\end{array}$ \\
\hline
\end{tabular}




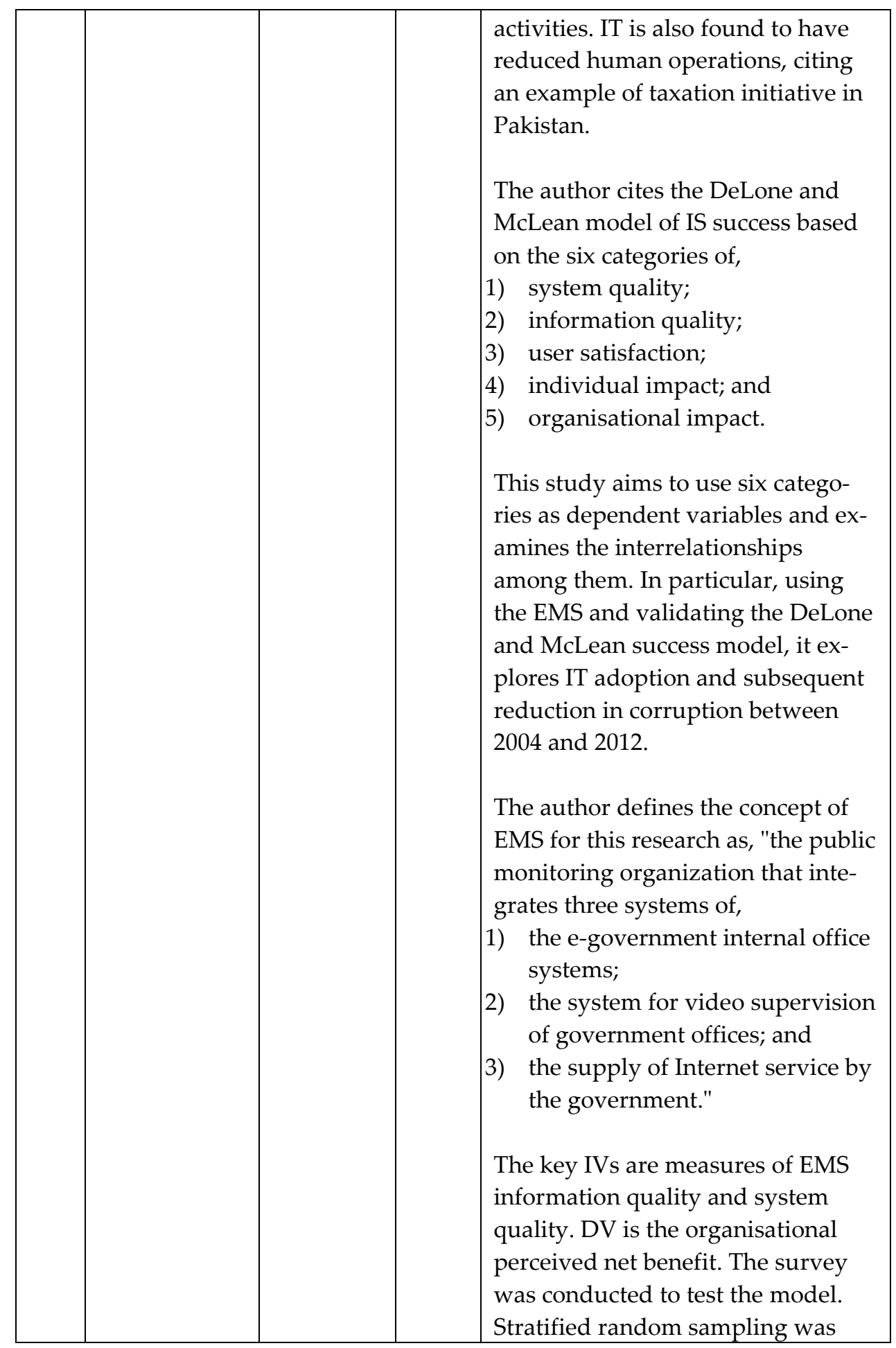




\begin{tabular}{|c|c|c|c|}
\hline & & & $\begin{array}{l}\text { used. The } 500 \text { distributed question- } \\
\text { naires in three cities received } 387 \\
\text { responses. } \\
\text { The research findings indicate that } \\
\text { leadership support is critical, fol- } \\
\text { lowed by the focus on corruption- } \\
\text { prone areas. Some municipalities } \\
\text { focused on procurements, while } \\
\text { others on project construction and } \\
\text { procurement. The research con- } \\
\text { cludes that, "...there is still a long } \\
\text { way to go to perfect the EMS, as } \\
\text { now there is still lack of law and } \\
\text { policy to regulate the use of EMS." } \\
\text { This highlights the importance of e- } \\
\text { governance institutional instru- } \\
\text { ments in the implementation pro- } \\
\text { cess. The author also identifies this } \\
\text { as potential future research focus. } \\
\text { "In future studies, the degree of } \\
\text { EMS's effect on corruption reduc- } \\
\text { tion, how to better use the EMS reg- } \\
\text { ulatory and how the EMS can be ef- } \\
\text { fectively used to achieve better } \\
\text { anti-corruption effectiveness will be } \\
\text { analyzed." }\end{array}$ \\
\hline $\begin{array}{l}\text { Local e-gov- } \\
\text { ernment } \\
\text { 2.0: Social } \\
\text { media and } \\
\text { corporate } \\
\text { transparency } \\
\text { in municipal- } \\
\text { ities }\end{array}$ & $\begin{array}{l}\text { Benson, } \\
\text { E., Torres, } \\
\text { L. Royo, } \\
\text { S. Flores, } \\
\text { F. }\end{array}$ & 2012 & $\begin{array}{l}\text { It provides an overview of the use } \\
\text { of social media tools by local ad- } \\
\text { ministrations in EU countries to en- } \\
\text { hance transparency and citizen par- } \\
\text { ticipation. The authors conclude } \\
\text { that the effect of these tools on } \\
\text { transparency is discernable, but its } \\
\text { impact on e-participation is un- } \\
\text { clear. They also mention that "the } \\
\text { introduction of ICTs without the } \\
\text { corresponding changes in leader- } \\
\text { ship, political and governance is }\end{array}$ \\
\hline
\end{tabular}




\begin{tabular}{|l|l|l|l|}
\hline & & $\begin{array}{l}\text { unlikely to result in a more consul- } \\
\text { tative, participatory, collaborative } \\
\text { and transparent government". This } \\
\text { also confirms my assumption that } \\
\text { ICT initiatives, such as e-govern- } \\
\text { ance, should be accompanied with } \\
\text { the existence of relevant govern- } \\
\text { ance enablers. }\end{array}$ \\
\hline $\begin{array}{l}\text { The role of } \\
\text { ICT in Build- } \\
\text { Governance: } \\
\text { Towards Ef- } \\
\text { fectiveness } \\
\text { and Results }\end{array}$ & $\begin{array}{l}\text { Avgerou, } \\
\text { C. } \\
\text { Claudio, } \\
\text { C. }\end{array}$ & $\begin{array}{l}\text { Cordella, } \\
\text { Kallinikos } \\
\text { J, Smith, } \\
\text { M }\end{array}$ & $\begin{array}{l}\text { The study aims to identify how } \\
\text { ICT-based services can contribute } \\
\text { to enhancing trust in democratic in- } \\
\text { stitutions, using five case studies in } \\
\text { Latin America. The Inter-American } \\
\text { Development Bank-funded study } \\
\text { distinguishes trust and trustworthi- } \\
\text { ness, the latter being a precondition } \\
\text { of trust and trust being an outcome } \\
\text { of experiences of interactions. ICT- } \\
\text { based reforms aim to affect the rela- } \\
\text { tionship between government and } \\
\text { citizens. }\end{array}$ \\
\hline $\begin{array}{l}\text { Trustworthiness is deemed essen- } \\
\text { tial since this is where e-govern- } \\
\text { ment can intervene and manipu- } \\
\text { late, and since it can succeed or fail, } \\
\text { it is considered necessary but not } \\
\text { sufficient condition for trust. Em- } \\
\text { pirical data and observations led to } \\
\text { the conclusion that trustworthiness } \\
\text { is a joint outcome of four factors: } \\
\text { technological, organisational, insti- } \\
\text { tutional and infrastructure. The } \\
\text { study also acknowledges that trust } \\
\text { or outcome of interactions is } \\
\text { formed over a long period of time, } \\
\text { and can't be changed by one initia- } \\
\text { tive. }\end{array}$ \\
\hline
\end{tabular}




\begin{tabular}{|l|l|l|}
\hline $\mid$ & $\begin{array}{l}\text { Trustworthiness, through e-govern- } \\
\text { ment implementation, can be meas- } \\
\text { ured. The authors further make a } \\
\text { distinction between 1) background } \\
\text { initiative which create institutional } \\
\text { and infrastructural conditions and } \\
\text { 2) foreground organisational and } \\
\text { technological factors to be mobi- } \\
\text { lised. Accordingly, this study uses } \\
\text { quantitative and qualitative meth- } \\
\text { ods in an attempt to identify cate- } \\
\text { gories of conditions and factors, } \\
\text { which conform to the requirements } \\
\text { of trustworthiness. } \\
\text { In the literature review, the authors } \\
\text { note that the literature tends to ex- } \\
\text { trapolate certain aspects of e-gov- } \\
\text { ernment based on sporadic evi- } \\
\text { dence and how ICT initiatives in } \\
\text { developing countries have scalabil- } \\
\text { ity and sustainability issues. Fur- } \\
\text { thermore, e-government research } \\
\text { tends to focus on interface, which } \\
\text { provides information instead of ser- } \\
\text { vices. The authors observed that } \\
\text { many e-government systems re- } \\
\text { quire not only technologies but also } \\
\text { organisational reforms in the long } \\
\text { term. Granovetter is quoted saying } \\
\text { how some theories are under-so- } \\
\text { cialised and others over-socialised, } \\
\text { meaning the former focused on } \\
\text { self-interest and economic gains, } \\
\text { while the latter on human interac- } \\
\text { tions. } \\
\text { The authors emphasise the point } \\
\text { that social dimensions are im- } \\
\text { portant in building trust. They say } \\
\text { it is created out of positive }\end{array}$ \\
\hline
\end{tabular}




\begin{tabular}{|l|l|l|}
\hline & & $\begin{array}{l}\text { interactions among individuals, in- } \\
\text { stitutions and artifacts in formal } \\
\text { and informal processes. Thus, the } \\
\text { impact of ICT should be placed in } \\
\text { such social context. } \\
\text { The methodology focuses mainly } \\
\text { on qualitative methods, with four } \\
\text { steps of identifying measurements } \\
\text { and requirements of trustworthi- } \\
\text { ness. It considers the background } \\
\text { and foreground factors, the condi- } \\
\text { tions and finally, which factors af- } \\
\text { fect the most in enhancing trust- } \\
\text { worthiness. The case studies in- } \\
\text { clude tax filing and other financial } \\
\text { management systems in Brazil and } \\
\text { Chile. }\end{array}$ \\
\hline
\end{tabular}


ANNEX 2: LITERATURE REVIEW: COMPLIANCE AND TECHNOLOGY

This round of literature review was conducted to understand the dimensions, attributes and relationships between compliance and corruption. The search was conducted on 20 June 2018 with the below parameters:

TOPIC: (compliance) AND TOPIC: (corruption)

Refined by: WEB OF SCIENCE CATEGORIES: ( ECONOMICS OR ASIAN STUDIES OR LAW OR GEOGRAPHY OR COMPUTER SCIENCE HARDWARE ARCHITECTURE OR BUSINESS OR INFORMATION SCIENCE LIBRARY SCIENCE OR POLITICAL SCIENCE OR MULTIDISCIPLINARY SCIENCES OR PHILOSOPHY OR ETHICS OR HISTORY PHILOSOPHY OF SCIENCE OR CRIMINOLOGY PENOLOGY OR MANAGEMENT OR COMPUTER SCIENCE SOFTWARE ENGINEERING OR INTERNATIONAL RELATIONS OR PLANNING DEVELOPMENT OR SOCIAL SCIENCES INTERDISCIPLINARY OR GREEN SUSTAINABLE SCIENCE TECHNOLOGY OR BUSINESS FINANCE OR HISTORY OF SOCIAL SCIENCES OR AREA STUDIES OR INDUSTRIAL RELATIONS LABOR OR OPERATIONS RESEARCH MANAGEMENT SCIENCE OR PUBLIC ADMINISTRATION OR SOCIOLOGY OR SOCIAL ISSUES OR PUBLIC ENVIRONMENTAL OCCUPATIONAL HEALTH OR URBAN STUDIES OR SOCIAL SCIENCES MATHEMATICAL METHODS OR AGRICULTURAL ECONOMICS POLICY OR ANTHROPOLOGY ) AND WEB OF SCIENCE CATEGORIES: ( ECONOMICS OR SOCIOLOGY OR URBAN STUDIES OR LAW OR BUSINESS OR POLITICAL SCIENCE OR GEOGRAPHY OR ASIAN STUDIES OR ETHICS OR INFORMATION SCIENCE LIBRARY SCIENCE OR MULTIDISCIPLINARY SCIENCES OR MANAGEMENT OR COMPUTER SCIENCE SOFTWARE ENGINEERING OR PLANNING DEVELOPMENT OR SOCIAL SCIENCES INTERDISCIPLINARY OR HISTORY OF SOCIAL SCIENCES OR BUSINESS FINANCE OR INDUSTRIAL RELATIONS LABOR OR AREA STUDIES OR OPERATIONS RESEARCH MANAGEMENT SCIENCE OR SOCIAL SCIENCES MATHEMATICAL METHODS OR PUBLIC ADMINISTRATION OR SOCIAL ISSUES ) AND [excluding] WEB OF SCIENCE CATEGORIES: ( MATHEMATICS INTERDISCIPLINARY APPLICATIONS OR PHARMACOLOGY PHARMACY OR PSYCHOLOGY CLINICAL OR SOCIAL SCIENCES MATHEMATICAL METHODS ) AND [excluding]WEB OF SCIENCE CATEGORIES: ( INDUSTRIAL RELATIONS LABOR OR PHILOSOPHY OR COMPUTER SCIENCE HARDWARE ARCHITECTURE OR PSYCHOLOGY MULTIDISCIPLINARY OR COMPUTER SCIENCE SOFTWARE ENGINEERING ) AND [excluding] WEB OF SCIENCE CATEGORIES: ( CRIMINOLOGY PENOLOGY OR 
ENVIRONMENTAL SCIENCES OR INTERNATIONAL RELATIONS OR ENERGY FUELS ) AND [excluding] WEB OF SCIENCE CATEGORIES: ( ENVIRONMENTAL STUDIES ) AND DOCUMENT TYPES: ( ARTICLE ) Indexes=SCI-EXPANDED, SSCI, A\&HCI, ESCI Timespan=All years

Records; 142

The Summary column below justifies reasons for inclusion or exclusion of articles for further analysis in my research based on the focus of the research questions (public sector, compliance, corruption and institutional instruments). Articles, which focus primarily on the private sector and specific technical and legal issues and those without reference to compliance, government or corruption, are excluded. The included articles are highlighted in shade.

\begin{tabular}{|c|c|c|c|c|c|}
\hline No & Tittle & Authors & $\begin{array}{l}\text { Publi- } \\
\text { cation } \\
\text { Year }\end{array}$ & Source & $\begin{array}{l}\text { Summary (explains in- } \\
\text { clusion and exclusion of } \\
\text { articles) }\end{array}$ \\
\hline 1 & $\begin{array}{l}\text { The integ- } \\
\text { rity of cor- } \\
\text { rupt states: } \\
\text { Graft as an } \\
\text { informal } \\
\text { state insti- } \\
\text { tution }\end{array}$ & $\begin{array}{l}\text { Darden, } \\
\text { Keith }\end{array}$ & 2008 & $\begin{array}{l}\text { POLITICS } \\
\text { \& SOCI- } \\
\text { ETY Vol- } \\
\text { ume: } 36 \\
\text { Issue: } 1 \\
\text { Pages: } 35- \\
59\end{array}$ & $\begin{array}{l}\text { The author examined } \\
\text { bribery and embezzle- } \\
\text { ment in Ukraine. In par- } \\
\text { ticular, the informal insti- } \\
\text { tution of grafts in Ukraine } \\
\text { is argued as an informal } \\
\text { payment, which provides } \\
\text { state organisations the } \\
\text { means to provide public } \\
\text { services. }\end{array}$ \\
\hline 2 & $\begin{array}{l}\text { Multina- } \\
\text { tional cor- } \\
\text { poration } \\
\text { codes of } \\
\text { conduct: } \\
\text { Governance } \\
\text { tools for } \\
\text { corporate } \\
\text { social re- } \\
\text { sponsibil- } \\
\text { ity? }\end{array}$ & $\begin{array}{l}\text { Bondy, } \\
\text { Krista; } \\
\text { Matten, } \\
\text { Dirk; } \\
\text { Moon, } \\
\text { Jeremy }\end{array}$ & 2008 & $\begin{array}{l}\text { CORPO- } \\
\text { RATE } \\
\text { GOV- } \\
\text { ERN- } \\
\text { ANCE- } \\
\text { AN IN- } \\
\text { TERNA- } \\
\text { TIONAL } \\
\text { REVIEW } \\
\text { Volume: } \\
\text { 16 Issue: } 4\end{array}$ & $\begin{array}{l}\text { This empirical research } \\
\text { investigated the linkage } \\
\text { between code of conduct } \\
\text { and corporate social re- } \\
\text { sponsibility, using data of } \\
150 \text { companies in three } \\
\text { countries. As this research } \\
\text { focuses on private sector } \\
\text { alone, this study is ex- } \\
\text { cluded. }\end{array}$ \\
\hline
\end{tabular}




\begin{tabular}{|c|c|c|c|c|c|}
\hline & & & & $\begin{array}{l}\text { Pages: } \\
294-311\end{array}$ & \\
\hline 3 & $\begin{array}{l}\text { Beyond } \\
\text { compliance } \\
\text { - below ex- } \\
\text { pectations? } \\
\text { CSR in the } \\
\text { context of } \\
\text { interna- } \\
\text { tional de- } \\
\text { velopment }\end{array}$ & $\begin{array}{l}\text { Barkem } \\
\text { eyer, } \\
\text { Ralf }\end{array}$ & 2009 & $\begin{array}{l}\text { BUSI- } \\
\text { NESS } \\
\text { ETHICS- } \\
\text { A EURO- } \\
\text { PEAN } \\
\text { REVIEW } \\
\text { Volume: } \\
\text { 18 Issue: } 3 \\
\text { Pages: } \\
\text { 273-289 }\end{array}$ & $\begin{array}{l}\text { This article empirically } \\
\text { analysed data of } 416 \text { case } \\
\text { studies of the UN Global } \\
\text { Compact to determine the } \\
\text { nature of corporate social } \\
\text { responsibility. It focused } \\
\text { primarily on behaviors of } \\
\text { corporations and, there- } \\
\text { fore, is excluded for fur- } \\
\text { ther analysis in my study. }\end{array}$ \\
\hline 4 & $\begin{array}{l}\text { Why do } \\
\text { anti-corrup- } \\
\text { tion laws } \\
\text { fail in Cen- } \\
\text { tral Eastern } \\
\text { Europe? A } \\
\text { target com- } \\
\text { pliance per- } \\
\text { spective }\end{array}$ & $\begin{array}{l}\text { Batory, } \\
\text { Agnes }\end{array}$ & 2012 & $\begin{array}{l}\text { REGULA- } \\
\text { TION \& } \\
\text { GOV- } \\
\text { ERN- } \\
\text { ANCE } \\
\text { Volume: } 6 \\
\text { Issue: } 1 \\
\text { Pages: } 66- \\
82\end{array}$ & $\begin{array}{l}\text { The article aimed to find } \\
\text { out incentives and norms, } \\
\text { which are skewed to- } \\
\text { wards non-compliance } \\
\text { and bribery in Hungary. } \\
\text { As this article focused on } \\
\text { the public sector and in- } \\
\text { stitutional instruments, it } \\
\text { is included. }\end{array}$ \\
\hline 5 & $\begin{array}{l}\text { Migration, } \\
\text { Energy and } \\
\text { Good Gov- } \\
\text { ernance in } \\
\text { the EU's } \\
\text { Eastern } \\
\text { Neighbour- } \\
\text { hood }\end{array}$ & $\begin{array}{l}\text { Ademm } \\
\text { er, } \\
\text { Esther; } \\
\text { Boerzel, } \\
\text { Tanja A. }\end{array}$ & 2013 & $\begin{array}{l}\text { EUROPE- } \\
\text { ASIA } \\
\text { STUDIES } \\
\text { Volume: } \\
65 \text { Issue: } 4 \\
\text { Special Is- } \\
\text { sue: SI } \\
\text { Pages: } \\
\text { 581-608 }\end{array}$ & $\begin{array}{l}\text { This qualitative study ex- } \\
\text { amined the level of com- } \\
\text { pliance of Georgia and } \\
\text { Armenia with EU direc- } \\
\text { tives in areas of migra- } \\
\text { tion, energy and corrup- } \\
\text { tion. This article is in- } \\
\text { cluded. }\end{array}$ \\
\hline 6 & $\begin{array}{l}\text { CARTELS, } \\
\text { CORPO- } \\
\text { RATE } \\
\text { COMPLI- } \\
\text { ANCE, } \\
\text { AND } \\
\text { WHAT }\end{array}$ & $\begin{array}{l}\text { Sokol, } \\
\text { D. Dan- } \\
\text { iel }\end{array}$ & 2012 & $\begin{array}{c}\text { ANTI- } \\
\text { TRUST } \\
\text { LAW } \\
\text { JOUR- } \\
\text { NAL Vol- } \\
\text { ume: } 78 \\
\text { Issue: } 1\end{array}$ & $\begin{array}{l}\text { This article aimed to ex- } \\
\text { amine the gap between } \\
\text { cartel enforcement re- } \\
\text { quirements and actual } \\
\text { outcomes. The study used } \\
\text { qualitative and quantita- } \\
\text { tive survey targeting } \\
\text { practitioners who }\end{array}$ \\
\hline
\end{tabular}




\begin{tabular}{|c|c|c|c|c|c|}
\hline & $\begin{array}{l}\text { PRACTI- } \\
\text { TIONERS } \\
\text { REALLY } \\
\text { THINK } \\
\text { ABOUT } \\
\text { ENFORCE- } \\
\text { MENT }\end{array}$ & & & $\begin{array}{l}\text { Pages: } \\
\text { 201-240 }\end{array}$ & $\begin{array}{l}\text { participated in cartel. This } \\
\text { article is included. }\end{array}$ \\
\hline 7 & $\begin{array}{l}\text { Trends in } \\
\text { the Interna- } \\
\text { tional Fight } \\
\text { Against } \\
\text { Bribery and } \\
\text { Corruption }\end{array}$ & $\begin{array}{l}\text { Cleve- } \\
\text { land, } \\
\text { Margot; } \\
\text { Favo, } \\
\text { Christo- } \\
\text { pher M.; } \\
\text { Frecka, } \\
\text { Thomas } \\
\text { J.; et al. }\end{array}$ & 2009 & $\begin{array}{c}\text { JOUR- } \\
\text { NAL OF } \\
\text { BUSI- } \\
\text { NESS } \\
\text { ETHICS } \\
\text { Volume: } \\
90 \text { Sup- } \\
\text { plement: } \\
2 \text { Pages: } \\
\text { 199-244 }\end{array}$ & $\begin{array}{l}\text { This article focused on in- } \\
\text { ternational instruments } \\
\text { and its enforcement and } \\
\text { effectiveness in address- } \\
\text { ing bribery from Multi- } \\
\text { National Corporation } \\
\text { (MNC) to foreign govern- } \\
\text { ment officials. This article } \\
\text { analysed soft and hard in- } \\
\text { struments and defined the } \\
\text { characteristics of each in- } \\
\text { strument for the purpose } \\
\text { of summarizing interna- } \\
\text { tional efforts to combat } \\
\text { corruption. This article is } \\
\text { included. }\end{array}$ \\
\hline 8 & $\begin{array}{l}\text { How global } \\
\text { is the } \\
\text { Global } \\
\text { Compact? }\end{array}$ & $\begin{array}{l}\text { Bremer, } \\
\text { Jennifer } \\
\text { Ann }\end{array}$ & 2008 & $\begin{array}{c}\text { BUSI- } \\
\text { NESS } \\
\text { ETHICS- } \\
\text { A EURO- } \\
\text { PEAN } \\
\text { REVIEW } \\
\text { Volume: } \\
\text { 17 Issue: } 3 \\
\text { Pages: } \\
227-244\end{array}$ & $\begin{array}{l}\text { This study was developed } \\
\text { to examine the global } \\
\text { compact and corporate } \\
\text { social responsibility. With } \\
\text { focus on the private sec- } \\
\text { tor, this research is not di- } \\
\text { rectly relevant to my re- } \\
\text { search. }\end{array}$ \\
\hline 9 & $\begin{array}{l}\text { Why Do } \\
\text { People En- } \\
\text { gage in } \\
\text { Corrup- } \\
\text { tion? The }\end{array}$ & $\begin{array}{l}\text { Tavits, } \\
\text { Margit }\end{array}$ & 2010 & $\begin{array}{c}\text { SOCIAL } \\
\text { FORCES } \\
\text { Volume: } \\
88 \text { Issue: } 3\end{array}$ & $\begin{array}{l}\text { Using } 2004 \text { survey data, } \\
\text { the article identified the } \\
\text { determinants of corrup- } \\
\text { tion among the public } \\
\text { and government officials }\end{array}$ \\
\hline
\end{tabular}




\begin{tabular}{|c|c|c|c|c|c|}
\hline & $\begin{array}{l}\text { Case of Es- } \\
\text { tonia }\end{array}$ & & & $\begin{array}{c}\text { Pages: } \\
1257-1279\end{array}$ & $\begin{array}{l}\text { in Estonia. This article is } \\
\text { relevant to my research } \\
\text { and, therefore, included. }\end{array}$ \\
\hline 10 & $\begin{array}{l}\text { Political } \\
\text { and Eco- } \\
\text { nomic Ar- } \\
\text { guments for } \\
\text { Corporate } \\
\text { Social Re- } \\
\text { sponsibility: } \\
\text { Analysis } \\
\text { and a Prop- } \\
\text { osition Re- } \\
\text { garding the } \\
\text { CSR } \\
\text { Agenda }\end{array}$ & $\begin{array}{l}\text { Weyzig, } \\
\text { Francis }\end{array}$ & 2009 & $\begin{array}{l}\text { JOUR- } \\
\text { NAL OF } \\
\text { BUSI- } \\
\text { NESS } \\
\text { ETHICS } \\
\text { Volume: } \\
\text { 86 Issue: } 4 \\
\text { Pages: } \\
\text { 417-428 }\end{array}$ & $\begin{array}{l}\text { This study examined be- } \\
\text { haviors of large corpora- } \\
\text { tion and CSR. This article } \\
\text { is not included in my } \\
\text { study. }\end{array}$ \\
\hline 11 & $\begin{array}{l}\text { Why Do } \\
\text { Developing } \\
\text { Countries } \\
\text { Tax So Lit- } \\
\text { tle? }\end{array}$ & $\begin{array}{l}\text { Besley, } \\
\text { Timo- } \\
\text { thy; } \\
\text { Persson, } \\
\text { Torsten }\end{array}$ & 2014 & $\begin{array}{c}\text { JOUR- } \\
\text { NAL OF } \\
\text { ECO- } \\
\text { NOMIC } \\
\text { PER- } \\
\text { SPEC- } \\
\text { TIVES } \\
\text { Volume: } \\
28 \text { Issue: } 4 \\
\text { Pages: 99- } \\
120\end{array}$ & $\begin{array}{l}\text { The authors tried to find } \\
\text { out why low-income } \\
\text { countries had lower tax } \\
\text { compared with developed } \\
\text { countries. While some of } \\
\text { the elements could be } \\
\text { useful, the focus on taxa- } \\
\text { tion and economic struc- } \\
\text { ture, including political } \\
\text { factors are less relevant to } \\
\text { my study. Therefore, this } \\
\text { article is not included in } \\
\text { my research. }\end{array}$ \\
\hline 12 & $\begin{array}{l}\text { Ethical and } \\
\text { Unethical } \\
\text { Leadership: } \\
\text { A Cross- } \\
\text { Cultural } \\
\text { and Cross- } \\
\text { Sectoral } \\
\text { Analysis }\end{array}$ & $\begin{array}{l}\text { Ei- } \\
\text { senbeiss } \\
\text {, Silke } \\
\text { Astrid; } \\
\text { Brod- } \\
\text { beck, } \\
\text { Felix }\end{array}$ & 2014 & $\begin{array}{l}\text { JOUR- } \\
\text { NAL OF } \\
\text { BUSI- } \\
\text { NESS } \\
\text { ETHICS } \\
\text { Volume: } \\
\text { 122 Issue: } \\
2 \text { Pages: } \\
\text { 343-359 }\end{array}$ & $\begin{array}{l}\text { The authors examined } \\
\text { ethical leadership and be- } \\
\text { haviors among executives } \\
\text { in private and public/so- } \\
\text { cial sectors. Although } \\
\text { some findings could be } \\
\text { relevant, it would be diffi- } \\
\text { cult to identify aspects } \\
\text { specific to private or }\end{array}$ \\
\hline
\end{tabular}




\begin{tabular}{|c|c|c|c|c|c|}
\hline & & & & & $\begin{array}{l}\text { public sectors. Therefore, } \\
\text { it is excluded from my } \\
\text { study. }\end{array}$ \\
\hline 13 & $\begin{array}{l}\text { Energy } \\
\text { Govern- } \\
\text { ance, Trans- } \\
\text { national } \\
\text { Rules, and } \\
\text { the Re- } \\
\text { source } \\
\text { Curse: } \\
\text { Exploring } \\
\text { the Effec- } \\
\text { tiveness of } \\
\text { the Extrac- } \\
\text { tive Indus- } \\
\text { tries } \\
\text { Transpar- } \\
\text { ency Initia- } \\
\text { tive (EITI) }\end{array}$ & $\begin{array}{l}\text { Sovacoo } \\
\text { l, } \\
\text { Benjami } \\
\text { n K.; } \\
\text { Walter, } \\
\text { Gotz; } \\
\text { van de } \\
\text { Graaf, } \\
\text { Thijs; et } \\
\text { al. }\end{array}$ & 2016 & $\begin{array}{c}\text { WORLD } \\
\text { DEVEL- } \\
\text { OPMENT } \\
\text { Volume: } \\
\text { 83 Pages: } \\
\text { 179-192 }\end{array}$ & $\begin{array}{l}\text { The article focused on the } \\
\text { level of compliance } \\
\text { among developing coun- } \\
\text { tries with the Extractive } \\
\text { Industries Transparency } \\
\text { Initiative (EITI) and iden- } \\
\text { tifies determinants of the } \\
\text { country's behaviors. This } \\
\text { article is included in my } \\
\text { study. }\end{array}$ \\
\hline 14 & $\begin{array}{l}\text { Determi- } \\
\text { nants of } \\
\text { Anti-Traf- } \\
\text { ficking Poli- } \\
\text { cies: Evi- } \\
\text { dence from } \\
\text { a New } \\
\text { Index }\end{array}$ & $\begin{array}{l}\text { Cho, } \\
\text { Seo- } \\
\text { Young; } \\
\text { Dreher, } \\
\text { Axel; } \\
\text { Neu- } \\
\text { mayer, } \\
\text { Eric }\end{array}$ & 2014 & $\begin{array}{l}\text { SCANDI- } \\
\text { NAVIAN } \\
\text { JOUR- } \\
\text { NAL OF } \\
\text { ECO- } \\
\text { NOMICS } \\
\text { Volume: } \\
\text { 116 Issue: } \\
2 \text { Pages: } \\
\text { 429-454 }\end{array}$ & $\begin{array}{l}\text { The authors examined } \\
\text { factors determining anti- } \\
\text { trafficking policies, com- } \\
\text { pliance and corruption in } \\
180 \text { countries. This article } \\
\text { is included in the study. }\end{array}$ \\
\hline 15 & $\begin{array}{l}\text { Transpar- } \\
\text { ency to Re- } \\
\text { duce Cor- } \\
\text { ruption? }\end{array}$ & $\begin{array}{l}\text { Halter, } \\
\text { Maria } \\
\text { Virginia; } \\
\text { Coutinh } \\
\text { o de } \\
\text { Arruda, } \\
\text { Maria } \\
\text { Cecilia; }\end{array}$ & 2009 & $\begin{array}{c}\text { JOUR- } \\
\text { NAL OF } \\
\text { BUSI- } \\
\text { NESS } \\
\text { ETHICS } \\
\text { Volume: } \\
\text { 84 Sup- } \\
\text { plement: }\end{array}$ & $\begin{array}{l}\text { This article focused on } \\
\text { corruption in the private } \\
\text { sector and, therefore, is } \\
\text { not included in my study. }\end{array}$ \\
\hline
\end{tabular}




\begin{tabular}{|c|c|c|c|c|c|}
\hline & & $\begin{array}{l}\text { Halter, } \\
\text { Ralph } \\
\text { Bruno }\end{array}$ & & $\begin{array}{l}3 \text { Pages: } \\
373-385\end{array}$ & \\
\hline 16 & $\begin{array}{l}\text { The not so } \\
\text { dark side of } \\
\text { trust: Does } \\
\text { trust in- } \\
\text { crease the } \\
\text { size of the } \\
\text { shadow } \\
\text { economy? }\end{array}$ & $\begin{array}{l}\text { D'Herno } \\
\text { ncourt, } \\
\text { Johanna; } \\
\text { Meon, } \\
\text { Pierre- } \\
\text { Guil- } \\
\text { laume }\end{array}$ & 2012 & $\begin{array}{c}\text { JOUR- } \\
\text { NAL OF } \\
\text { ECO- } \\
\text { NOMIC } \\
\text { BEHAV- } \\
\text { IOR \& } \\
\text { ORGANI- } \\
\text { ZATION } \\
\text { Volume: } \\
81 \text { Issue: } 1 \\
\text { Pages: } \\
\text { 97-121 }\end{array}$ & $\begin{array}{l}\text { This article examined the } \\
\text { size of shadow economy } \\
\text { and general trust and is } \\
\text { excluded from my study. }\end{array}$ \\
\hline 17 & $\begin{array}{l}\text { The Politics } \\
\text { of Public } \\
\text { Health Aid: } \\
\text { Why Cor- } \\
\text { rupt Gov- } \\
\text { ernments } \\
\text { Have Incen- } \\
\text { tives to Im- } \\
\text { plement } \\
\text { Aid Effec- } \\
\text { tively }\end{array}$ & $\begin{array}{l}\text { Dietrich, } \\
\text { Simone }\end{array}$ & 2011 & $\begin{array}{l}\text { WORLD } \\
\text { DEVEL- } \\
\text { OPMENT } \\
\text { Volume: } \\
\text { 39 Issue: } 1 \\
\text { Pages: } 55- \\
63\end{array}$ & $\begin{array}{l}\text { The author examined cor- } \\
\text { ruption and compliance } \\
\text { from the perspective of } \\
\text { international aid to tackle } \\
\text { HIV in developing coun- } \\
\text { tries. This study is in- } \\
\text { cluded. }\end{array}$ \\
\hline 18 & $\begin{array}{l}\text { Importing } \\
\text { corruption } \\
\text { culture } \\
\text { from over- } \\
\text { seas: Evi- } \\
\text { dence from } \\
\text { corporate } \\
\text { tax evasion } \\
\text { in the } \\
\text { United } \\
\text { States }\end{array}$ & $\begin{array}{l}\text { DeBacke } \\
\text { r, Jason; } \\
\text { Heim, } \\
\text { Bradley } \\
\text { T.; Anh } \\
\text { Tran }\end{array}$ & 2015 & $\begin{array}{c}\text { JOUR- } \\
\text { NAL OF } \\
\text { FINAN- } \\
\text { CIAL } \\
\text { ECO- } \\
\text { NOMICS } \\
\text { Volume: } \\
\text { 117 Issue: } \\
1 \text { Special } \\
\text { Issue: SI } \\
\text { Pages: } \\
\text { 122-138 }\end{array}$ & $\begin{array}{l}\text { The focus of the article is } \\
\text { the cultural norms and } \\
\text { enforcement policies in } \\
\text { the corporate sector. } \\
\text { Therefore, this article is } \\
\text { not included. }\end{array}$ \\
\hline
\end{tabular}




\begin{tabular}{|c|c|c|c|c|c|}
\hline 19 & $\begin{array}{l}\text { To Pay or } \\
\text { Not to Pay? } \\
\text { Citizens' } \\
\text { Attitudes } \\
\text { Toward } \\
\text { Taxation in } \\
\text { Kenya, Tan- } \\
\text { zania, } \\
\text { Uganda, } \\
\text { and South } \\
\text { Africa }\end{array}$ & $\begin{array}{l}\text { Ali, } \\
\text { Merima; } \\
\text { Fjeldsta } \\
\text { d, Odd- } \\
\text { Helge; } \\
\text { Sjursen, } \\
\text { Ingrid } \\
\text { Hoem }\end{array}$ & 2014 & $\begin{array}{l}\text { WORLD } \\
\text { DEVEL- } \\
\text { OPMENT } \\
\text { Volume: } \\
64 \text { Pages: } \\
828-842\end{array}$ & $\begin{array}{l}\text { The authors investigated } \\
\text { the relationship between } \\
\text { tax compliance and } \\
\text { knowledge/awareness } \\
\text { among citizens in Kenya, } \\
\text { Tanzania, Uganda and } \\
\text { South Africa. This article } \\
\text { is included in my study. }\end{array}$ \\
\hline 20 & $\begin{array}{l}\text { SOLICITA- } \\
\text { TION, EX- } \\
\text { TORTION, } \\
\text { AND THE } \\
\text { FCPA }\end{array}$ & $\begin{array}{l}\text { Yockey, } \\
\text { Joseph } \\
\text { W. }\end{array}$ & 2011 & $\begin{array}{l}\text { NOTRE } \\
\text { DAME } \\
\text { LAW RE- } \\
\text { VIEW } \\
\text { Volume: } \\
\text { 87 Issue: } 2 \\
\text { Pages: } \\
\text { 781-839 }\end{array}$ & $\begin{array}{l}\text { The author looked into } \\
\text { the FCPA compliance } \\
\text { among MNC and exam- } \\
\text { ined compliance chal- } \\
\text { lenges. Although the topic } \\
\text { is pertinent, the focus on } \\
\text { private sector is out of } \\
\text { scope of my study. }\end{array}$ \\
\hline 21 & $\begin{array}{l}\text { Tax Tolera- } \\
\text { tion and } \\
\text { Tax Com- } \\
\text { pliance: } \\
\text { How Gov- } \\
\text { ernment Af- } \\
\text { fects the } \\
\text { Propensity } \\
\text { of Firms to } \\
\text { Enter the } \\
\text { Unofficial } \\
\text { Economy }\end{array}$ & $\begin{array}{l}\text { Hibbs, } \\
\text { Douglas } \\
\text { A.; Pi- } \\
\text { culescu, } \\
\text { Violeta }\end{array}$ & 2010 & $\begin{array}{l}\text { AMERI- } \\
\text { CAN } \\
\text { JOUR- } \\
\text { NAL OF } \\
\text { POLITI- } \\
\text { CAL SCI- } \\
\text { ENCE } \\
\text { Volume: } \\
54 \text { Issue: } 1 \\
\text { Pages: 18- } \\
33\end{array}$ & $\begin{array}{l}\text { The article examined the } \\
\text { relationship between tax- } \\
\text { ation and firms' decisions } \\
\text { to enter unofficial markets } \\
\text { and tax evasion. This } \\
\text { study will not be included } \\
\text { in my research. }\end{array}$ \\
\hline 22 & $\begin{array}{l}\text { The Mortal- } \\
\text { ity Cost of } \\
\text { Political } \\
\text { Connec- } \\
\text { tions }\end{array}$ & $\begin{array}{l}\text { Fisman, } \\
\text { Ray- } \\
\text { mond; } \\
\text { Wang, } \\
\text { Yongxia } \\
\text { ng }\end{array}$ & 2015 & $\begin{array}{l}\text { REVIEW } \\
\text { OF ECO- } \\
\text { NOMIC } \\
\text { STUDIES } \\
\text { Volume: } \\
82 \text { Issue: } 4\end{array}$ & $\begin{array}{l}\text { The authors examined the } \\
\text { relationship between } \\
\text { firms' political connec- } \\
\text { tions and workplace fatal- } \\
\text { ities. This study will not } \\
\text { be included in my study. }\end{array}$ \\
\hline
\end{tabular}




\begin{tabular}{|c|c|c|c|c|c|}
\hline & & & & $\begin{array}{c}\text { Pages: } \\
1346-1382\end{array}$ & \\
\hline 23 & $\begin{array}{l}\text { Context-de- } \\
\text { pendent } \\
\text { cheating: } \\
\text { Experi- } \\
\text { mental evi- } \\
\text { dence from } \\
16 \text { countries }\end{array}$ & $\begin{array}{l}\text { Pascual- } \\
\text { Ezama, } \\
\text { David; } \\
\text { Fosgaar } \\
\text { d, Toke } \\
\text { R.; } \\
\text { Camilo } \\
\text { Car- } \\
\text { denas, } \\
\text { Juan; et } \\
\text { al. }\end{array}$ & 2015 & $\begin{array}{c}\text { JOUR- } \\
\text { NAL OF } \\
\text { ECO- } \\
\text { NOMIC } \\
\text { BEHAV- } \\
\text { IOR \& } \\
\text { ORGANI- } \\
\text { ZATION } \\
\text { Volume: } \\
\text { 116 Pages: } \\
\text { 379-386 }\end{array}$ & $\begin{array}{l}\text { This study focused on the } \\
\text { honesty of citizens in } 16 \\
\text { countries as indicative of } \\
\text { institutional honesty. This } \\
\text { study is excluded from } \\
\text { the study for its pointed } \\
\text { focus on citizens' beliefs } \\
\text { and behaviors. }\end{array}$ \\
\hline 24 & $\begin{array}{l}\text { Beyond the } \\
\text { formal/in- } \\
\text { formal jobs } \\
\text { divide: } \\
\text { evaluating } \\
\text { the preva- } \\
\text { lence of hy- } \\
\text { brid 'under- } \\
\text { declared' } \\
\text { employ- } \\
\text { ment in } \\
\text { south-east- } \\
\text { ern Europe }\end{array}$ & $\begin{array}{l}\text { Wil- } \\
\text { liams, } \\
\text { Colin C. }\end{array}$ & 2010 & $\begin{array}{c}\text { INTER- } \\
\text { NA- } \\
\text { TIONAL } \\
\text { JOUR- } \\
\text { NAL OF } \\
\text { HUMAN } \\
\text { RE- } \\
\text { SOURCE } \\
\text { MAN- } \\
\text { AGE- } \\
\text { MENT } \\
\text { Volume: } \\
\text { 21 Issue: } \\
\text { 14 Special } \\
\text { Issue: SI } \\
\text { Pages: } \\
\text { 2529-2546 }\end{array}$ & $\begin{array}{l}\text { The article investigated } \\
\text { the employment and de- } \\
\text { clared wages in South- } \\
\text { eastern Europe. This } \\
\text { study is excluded from } \\
\text { my study. }\end{array}$ \\
\hline 25 & $\begin{array}{l}\text { Catalyzing } \\
\text { Corporate } \\
\text { Commit- } \\
\text { ment to } \\
\text { Combating } \\
\text { Corruption }\end{array}$ & $\begin{array}{l}\text { Hess, } \\
\text { David }\end{array}$ & 2009 & $\begin{array}{c}\text { JOUR- } \\
\text { NAL OF } \\
\text { BUSI- } \\
\text { NESS } \\
\text { ETHICS } \\
\text { Volume: } \\
88\end{array}$ & $\begin{array}{l}\text { The author examined the } \\
\text { policy reforms needed for } \\
\text { corporate commitment to- } \\
\text { wards anti-corruption. } \\
\text { This article is excluded } \\
\text { from my study. }\end{array}$ \\
\hline
\end{tabular}




\begin{tabular}{|c|c|c|c|c|c|}
\hline & & & & $\begin{array}{c}\text { Supple- } \\
\text { ment: } 4 \\
\text { Pages: } \\
781-790\end{array}$ & \\
\hline 26 & $\begin{array}{l}\text { Illegitimate } \\
\text { wage prac- } \\
\text { tices in } \\
\text { Eastern Eu- } \\
\text { rope: The } \\
\text { case of "en- } \\
\text { velope } \\
\text { wages" }\end{array}$ & $\begin{array}{l}\text { Wil- } \\
\text { liams, } \\
\text { Colin. C. }\end{array}$ & 2008 & $\begin{array}{c}\text { JOUR- } \\
\text { NAL FOR } \\
\text { EAST EU- } \\
\text { ROPEAN } \\
\text { MAN- } \\
\text { AGE- } \\
\text { MENT } \\
\text { STUDIES } \\
\text { Volume: } \\
\text { 13 Issue: } 3 \\
\text { Pages: } \\
\text { 253-270 } \\
\text { Pub- } \\
\text { lished: } \\
2008\end{array}$ & $\begin{array}{l}\text { This paper focused } \\
\text { mainly on illegitimate } \\
\text { wages in Eastern Europe } \\
\text { and is, therefore, ex- } \\
\text { cluded from my research. }\end{array}$ \\
\hline 27 & $\begin{array}{l}\text { Informal } \\
\text { Entrepre- } \\
\text { neurship in } \\
\text { Developing } \\
\text { Economies: } \\
\text { The Im- } \\
\text { pacts of } \\
\text { Starting Up } \\
\text { Unregis- } \\
\text { tered on } \\
\text { Firm Per- } \\
\text { formance }\end{array}$ & $\begin{array}{l}\text { Wil- } \\
\text { liams, } \\
\text { Colin C.; } \\
\text { Mar- } \\
\text { tinez- } \\
\text { Perez, } \\
\text { Alvaro; } \\
\text { Kedir, } \\
\text { Abbi M. }\end{array}$ & 2017 & $\begin{array}{c}\text { ENTRE- } \\
\text { PRE- } \\
\text { NEUR- } \\
\text { SHIP } \\
\text { THEORY } \\
\text { AND } \\
\text { PRAC- } \\
\text { TICE Vol- } \\
\text { ume: } 41 \\
\text { Issue: } 5 \\
\text { Pages: } \\
\text { 773-799 } \\
\text { Pub- } \\
\text { lished: } \\
\text { SEP 2017 }\end{array}$ & $\begin{array}{l}\text { The authors examined the } \\
\text { entrepreneurship pro- } \\
\text { cesses and cost of regis- } \\
\text { tration in } 127 \text { countries } \\
\text { and is not included in my } \\
\text { research. }\end{array}$ \\
\hline 28 & $\begin{array}{l}\text { The "Peter } \\
\text { Pan Syn- } \\
\text { drome" in } \\
\text { Emerging } \\
\text { Markets: }\end{array}$ & $\begin{array}{l}\text { Sudhir, } \\
\text { K.; Ta- } \\
\text { lukdar, }\end{array}$ & 2015 & $\begin{array}{l}\text { MAR- } \\
\text { KETING } \\
\text { SCIENCE } \\
\text { Volume: } \\
\text { 34 Issue: } 4\end{array}$ & $\begin{array}{l}\text { The focus of this article is } \\
\text { the introduction of IT in } \\
\text { firms and their effects on } \\
\text { transparency and produc- } \\
\text { tivity in India. This article }\end{array}$ \\
\hline
\end{tabular}




\begin{tabular}{|c|c|c|c|c|c|}
\hline & $\begin{array}{l}\text { The } \\
\text { Productiv- } \\
\text { ity- Trans- } \\
\text { parency } \\
\text { Trade-off in } \\
\text { IT Adop- } \\
\text { tion }\end{array}$ & $\begin{array}{l}\text { Debabra } \\
\text { ta }\end{array}$ & & $\begin{array}{c}\text { Pages: } \\
\text { 500-521 } \\
\text { Pub- } \\
\text { lished: } \\
\text { JUL-AUG } \\
2015\end{array}$ & $\begin{array}{l}\text { is not included in my re- } \\
\text { search. }\end{array}$ \\
\hline 29 & $\begin{array}{l}\text { Zooming } \\
\text { into the } \\
\text { 'Domestic' } \\
\text { in Europe- } \\
\text { anization: } \\
\text { Promotion } \\
\text { of Fight } \\
\text { against Cor- } \\
\text { ruption and } \\
\text { Minority } \\
\text { Rights in } \\
\text { Turkey }\end{array}$ & $\begin{array}{l}\text { Yilmaz, } \\
\text { Gozde; } \\
\text { Soyaltin, } \\
\text { Digdem }\end{array}$ & 2014 & $\begin{array}{c}\text { JOUR- } \\
\text { NAL OF } \\
\text { BALKAN } \\
\text { AND } \\
\text { NEAR } \\
\text { EAST- } \\
\text { ERN } \\
\text { STUDIES } \\
\text { Volume: } \\
\text { 16 Issue: } 1 \\
\text { Special Is- } \\
\text { sue: SI } \\
\text { Pages: 11- } \\
\text { 29 Pub- } \\
\text { lished: } \\
\text { 2014 }\end{array}$ & $\begin{array}{l}\text { In the context of meeting } \\
\text { the EU requirements, Tur- } \\
\text { key has made efforts to } \\
\text { tackle corruption. The ar- } \\
\text { ticle examined determi- } \\
\text { nants of policy reform. } \\
\text { This article is included. }\end{array}$ \\
\hline 30 & $\begin{array}{l}\text { The Impact } \\
\text { of Corrup- } \\
\text { tion on } \\
\text { Firm Tax } \\
\text { Compliance } \\
\text { in Transi- } \\
\text { tion Econo- } \\
\text { mies: } \\
\text { Whom Do } \\
\text { You Trust? }\end{array}$ & $\begin{array}{l}\text { Alon, } \\
\text { Anna; } \\
\text { Hage- } \\
\text { man, } \\
\text { Amy M. }\end{array}$ & 2013 & $\begin{array}{c}\text { JOUR- } \\
\text { NAL OF } \\
\text { BUSI- } \\
\text { NESS } \\
\text { ETHICS } \\
\text { Volume: } \\
\text { 116 Issue: } \\
\text { 3 Pages: } \\
\text { 479-494 } \\
\text { Pub- } \\
\text { lished: } \\
\text { SEP } 2013\end{array}$ & $\begin{array}{l}\text { Although the article ex- } \\
\text { amined taxation, includ- } \\
\text { ing corporate tax, it evalu- } \\
\text { ated the context and fac- } \\
\text { tors driving compliance in } \\
\text { general. Therefore, this } \\
\text { article is included. }\end{array}$ \\
\hline
\end{tabular}




\begin{tabular}{|c|c|c|c|c|c|}
\hline 31 & $\begin{array}{l}\text { Corruption } \\
\text { and firm } \\
\text { tax evasion }\end{array}$ & $\begin{array}{l}\text { Alm, } \\
\text { James; } \\
\text { Mar- } \\
\text { tinez- } \\
\text { Vazquez } \\
\text {, Jorge; } \\
\text { McClel- } \\
\text { lan, } \\
\text { Chan- } \\
\text { dler }\end{array}$ & 2016 & $\begin{array}{c}\text { JOUR- } \\
\text { NAL OF } \\
\text { ECO- } \\
\text { NOMIC } \\
\text { BEHAV- } \\
\text { IOR \& } \\
\text { ORGANI- } \\
\text { ZATION } \\
\text { Volume: } \\
\text { 124 Spe- } \\
\text { cial Issue: } \\
\text { SI Pages: } \\
\text { 146-163 } \\
\text { Pub- } \\
\text { lished: } \\
\text { APR 2016 }\end{array}$ & $\begin{array}{l}\text { To decipher firms' tax } \\
\text { evasion decisions, the au- } \\
\text { thors examined their be- } \\
\text { haviors and firm-level in- } \\
\text { formation. Therefore, this } \\
\text { article is not included in } \\
\text { my study. }\end{array}$ \\
\hline 32 & $\begin{array}{l}\text { Corruption } \\
\text { in the polit- } \\
\text { icized uni- } \\
\text { versity: les- } \\
\text { sons for } \\
\text { Ukraine's } \\
2010 \text { presi- } \\
\text { dential elec- } \\
\text { tions }\end{array}$ & $\begin{array}{l}\text { Osipian, } \\
\text { Ararat } \\
\text { L. }\end{array}$ & 2010 & $\begin{array}{c}\text { INNO- } \\
\text { VATION- } \\
\text { THE EU- } \\
\text { ROPEAN } \\
\text { JOUR- } \\
\text { NAL OF } \\
\text { SOCIAL } \\
\text { SCIENCE } \\
\text { RE- } \\
\text { SEARCH } \\
\text { Volume: } \\
23 \text { Issue: } 2 \\
\text { Pages: } \\
\text { 101-114 } \\
\text { Article } \\
\text { Number: } \\
\text { PII } \\
928668990 \\
\text { Pub- } \\
\text { lished: } \\
2010\end{array}$ & $\begin{array}{l}\text { The author examined the } \\
\text { level of corruption in ad- } \\
\text { ministrative control from } \\
\text { the center to local levels } \\
\text { in Ukraine. This article is } \\
\text { included in my study. }\end{array}$ \\
\hline 33 & $\begin{array}{l}\text { How Busi- } \\
\text { ness is } \\
\text { Done in the }\end{array}$ & $\begin{array}{l}\text { Hall- } \\
\text { ward- }\end{array}$ & 2015 & $\begin{array}{l}\text { JOUR- } \\
\text { NAL OF }\end{array}$ & $\begin{array}{l}\text { The study investigated } \\
\text { the firms' behavior in op- } \\
\text { erating under weak }\end{array}$ \\
\hline
\end{tabular}




\begin{tabular}{|c|c|c|c|c|c|}
\hline & $\begin{array}{l}\text { Developing } \\
\text { World: } \\
\text { Deals ver- } \\
\text { sus Rules }\end{array}$ & $\begin{array}{l}\text { Drie- } \\
\text { meier, } \\
\text { Mary; } \\
\text { Pritch- } \\
\text { ett, Lant }\end{array}$ & & $\begin{array}{c}\text { ECO- } \\
\text { NOMIC } \\
\text { PER- } \\
\text { SPEC- } \\
\text { TIVES } \\
\text { Volume: } \\
29 \text { Issue: } 3 \\
\text { Pages: } \\
\text { 121-140 } \\
\text { Pub- } \\
\text { lished: } \\
\text { SUM 2015 }\end{array}$ & $\begin{array}{l}\text { institutional settings. It is } \\
\text { not included in my study. }\end{array}$ \\
\hline 34 & $\begin{array}{l}\text { Apparatus } \\
\text { of capture: } \\
\text { Fiscal state } \\
\text { formation } \\
\text { in the re- } \\
\text { public of } \\
\text { Georgia }\end{array}$ & $\begin{array}{l}\text { Schueth, } \\
\text { Samuel }\end{array}$ & 2012 & $\begin{array}{l}\text { POLITI- } \\
\text { CAL GE- } \\
\text { OGRA- } \\
\text { PHY Vol- } \\
\text { ume: } 31 \\
\text { Issue: } 3 \\
\text { Pages: } \\
\text { 133-143 } \\
\text { Pub- } \\
\text { lished: } \\
\text { MAR } \\
2012\end{array}$ & $\begin{array}{l}\text { This research used ethno- } \\
\text { graphic fieldwork to ana- } \\
\text { lyse the formation of } \\
\text { Georgian state with focus } \\
\text { on tax compliance, anti- } \\
\text { corruption etc. This is in- } \\
\text { cluded in my research. }\end{array}$ \\
\hline 35 & $\begin{array}{l}\text { Freeport- } \\
\text { McMoRan } \\
\text { Copper \& } \\
\text { Gold, Inc.: } \\
\text { An Innova- } \\
\text { tive Volun- } \\
\text { tary Code } \\
\text { of Conduct } \\
\text { to Protect } \\
\text { Human } \\
\text { Rights, Cre- } \\
\text { ate Employ- } \\
\text { ment Op- } \\
\text { portunities, } \\
\text { and Eco- } \\
\text { nomic }\end{array}$ & $\begin{array}{l}\text { Sethi, S. } \\
\text { Prakash; } \\
\text { Lowry, } \\
\text { David } \\
\text { B.; } \\
\text { Veral, } \\
\text { Emre } \\
\text { A.; et al. }\end{array}$ & 2011 & $\begin{array}{c}\text { JOUR- } \\
\text { NAL OF } \\
\text { BUSI- } \\
\text { NESS } \\
\text { ETHICS } \\
\text { Volume: } \\
103 \text { Issue: } \\
1 \text { Pages: } \\
\text { 1-30 Pub- } \\
\text { lished: } \\
\text { SEP 2011 }\end{array}$ & $\begin{array}{l}\text { This study examined the } \\
\text { case of Freeport-Mcmo- } \\
\text { Ran mining operation in } \\
\text { Indonesia and how the } \\
\text { company proactively es- } \\
\text { tablished a participatory } \\
\text { code of conduct. As this } \\
\text { focused on company be- } \\
\text { havior, it is excluded. }\end{array}$ \\
\hline
\end{tabular}




\begin{tabular}{|c|c|c|c|c|c|}
\hline & $\begin{array}{l}\text { Develop- } \\
\text { ment of the } \\
\text { Indigenous } \\
\text { People }\end{array}$ & & & & \\
\hline 36 & $\begin{array}{l}\text { Too risk } \\
\text { averse to } \\
\text { stay hon- } \\
\text { est? Busi- } \\
\text { ness cor- } \\
\text { ruption, un- } \\
\text { certainty } \\
\text { and atti- } \\
\text { tudes to- } \\
\text { ward risk }\end{array}$ & $\begin{array}{l}\text { Soreide, } \\
\text { Tina }\end{array}$ & 2009 & $\begin{array}{l}\text { INTER- } \\
\text { NA- } \\
\text { TIONAL } \\
\text { REVIEW } \\
\text { OF LAW } \\
\text { AND } \\
\text { ECO- } \\
\text { NOMICS } \\
\text { Volume: } \\
29 \text { Issue: } 4 \\
\text { Pages: } \\
\text { 388- 395 } \\
\text { Pub- } \\
\text { lished: } \\
\text { DEC 2009 }\end{array}$ & $\begin{array}{l}\text { The author examined the } \\
\text { presence of anti-corrup- } \\
\text { tion policies and firms' } \\
\text { behavior, in particular, } \\
\text { bribery. This article will } \\
\text { not be included in my re- } \\
\text { search. }\end{array}$ \\
\hline 37 & $\begin{array}{l}\text { Tackling } \\
\text { the infor- } \\
\text { mal econ- } \\
\text { omy in } \\
\text { Southeast } \\
\text { Europe: an } \\
\text { institutional } \\
\text { approach }\end{array}$ & $\begin{array}{l}\text { Wil- } \\
\text { liams, } \\
\text { Colin C.; } \\
\text { Horod- } \\
\text { nic, Io- } \\
\text { ana A. }\end{array}$ & 2015 & $\begin{array}{c}\text { SOUTH- } \\
\text { EAST EU- } \\
\text { ROPEAN } \\
\text { AND } \\
\text { BLACK } \\
\text { SEA } \\
\text { STUDIES } \\
\text { Volume: } \\
\text { 15 Issue: } 4 \\
\text { Pages: } \\
\text { 519- 539 } \\
\text { Pub- } \\
\text { lished: } \\
\text { OCT } 2 \\
2015\end{array}$ & $\begin{array}{l}\text { The authors tackled the } \\
\text { issue of informal econ- } \\
\text { omy, tax evasion and cod- } \\
\text { ified laws and regulations } \\
\text { in formal institutions in } \\
\text { Southeastern Europe. This } \\
\text { study is included in my } \\
\text { research. }\end{array}$ \\
\hline 38 & $\begin{array}{l}\text { Revealed } \\
\text { Corruption, } \\
\text { Taxation, } \\
\text { and Fiscal }\end{array}$ & $\begin{array}{l}\text { Tim- } \\
\text { mons, } \\
\text { Jeffrey } \\
\text { F.; Gar- } \\
\text { fias, }\end{array}$ & 2015 & $\begin{array}{l}\text { WORLD } \\
\text { DEVEL- } \\
\text { OPMENT } \\
\text { Volume: } \\
70 \text { Pages: }\end{array}$ & $\begin{array}{l}\text { The article examined the } \\
\text { relationship between cor- } \\
\text { ruption reporting and the } \\
\text { level of tax compliance in }\end{array}$ \\
\hline
\end{tabular}




\begin{tabular}{|c|c|c|c|c|c|}
\hline & $\begin{array}{l}\text { Accounta- } \\
\text { bility: Evi- } \\
\text { dence from } \\
\text { Brazil }\end{array}$ & $\begin{array}{l}\text { Fran- } \\
\text { cisco }\end{array}$ & & $\begin{array}{c}\text { 13-27 } \\
\text { Pub- } \\
\text { lished: } \\
\text { JUN 2015 }\end{array}$ & $\begin{array}{l}\text { Brazil. This article is in- } \\
\text { cluded. }\end{array}$ \\
\hline 39 & $\begin{array}{l}\text { Causes of } \\
\text { Noncompli- } \\
\text { ance with } \\
\text { Interna- } \\
\text { tional Law: } \\
\text { A Field } \\
\text { Experiment } \\
\text { on Anony- } \\
\text { mous Incor- } \\
\text { poration }\end{array}$ & $\begin{array}{l}\text { Findley, } \\
\text { Michael } \\
\text { G.; Niel- } \\
\text { son, } \\
\text { Daniel } \\
\text { L.; Shar- } \\
\text { man, J. } \\
\text { C. }\end{array}$ & 2015 & $\begin{array}{l}\text { AMERI- } \\
\text { CAN } \\
\text { JOUR- } \\
\text { NAL OF } \\
\text { POLITI- } \\
\text { CAL SCI- } \\
\text { ENCE } \\
\text { Volume: } \\
\text { 59 Issue: } 1 \\
\text { Pages: } \\
\text { 146-161 } \\
\text { Pub- } \\
\text { lished: } \\
\text { JAN 2015 }\end{array}$ & $\begin{array}{l}\text { The authors investigated } \\
\text { the efficacy of interna- } \\
\text { tional rules in incorpora- } \\
\text { tion services, using six ex- } \\
\text { perimental conditions. } \\
\text { The focus being behavior } \\
\text { of corporations, this arti- } \\
\text { cle is not included in my } \\
\text { research. }\end{array}$ \\
\hline 40 & $\begin{array}{l}\text { Through a } \\
\text { Glass, } \\
\text { Darkly: The } \\
\text { Rhetoric } \\
\text { and Reality } \\
\text { of Cam- } \\
\text { paign Fi- } \\
\text { nance Dis- } \\
\text { closure }\end{array}$ & $\begin{array}{l}\text { Heer- } \\
\text { wig, } \\
\text { Jennifer } \\
\text { A.; } \\
\text { Shaw, } \\
\text { Kathe- } \\
\text { rine }\end{array}$ & 2014 & $\begin{array}{l}\text { GEORGE } \\
\text { TOWN } \\
\text { LAW } \\
\text { JOUR- } \\
\text { NAL Vol- } \\
\text { ume: } 102 \\
\text { Issue: } 5 \\
\text { Pages: } \\
\text { 1443-1500 } \\
\text { Pub- } \\
\text { lished: } \\
\text { JUN 2014 }\end{array}$ & $\begin{array}{l}\text { The article focused on the } \\
\text { US election and the fi- } \\
\text { nancing requirements, in- } \\
\text { cluding disclosures. Alt- } \\
\text { hough compliance is men- } \\
\text { tioned in the study, it is } \\
\text { not directly linked to gov- } \\
\text { ernment and corruption } \\
\text { and is, therefore, ex- } \\
\text { cluded. }\end{array}$ \\
\hline 41 & $\begin{array}{l}\text { Drift and } \\
\text { Adjustment } \\
\text { in Organi- } \\
\text { zational } \\
\text { Rule Com- } \\
\text { pliance: Ex- } \\
\text { plaining the } \\
\text { "Regulatory } \\
\text { Pendulum" }\end{array}$ & $\begin{array}{l}\text { Martine } \\
\text { z- } \\
\text { Moyano } \\
\text {, Ignacio } \\
\text { J.; } \\
\text { McCaffr } \\
\text { ey, } \\
\text { David } \\
\text { P.; }\end{array}$ & 2014 & $\begin{array}{l}\text { ORGANI- } \\
\text { ZATION } \\
\text { SCIENCE } \\
\text { Volume: } \\
\text { 25 Issue: } 2 \\
\text { Pages: } \\
\text { 321-338 } \\
\text { Pub- } \\
\text { lished: }\end{array}$ & $\begin{array}{l}\text { While the article's empha- } \\
\text { sis on rules, compliance } \\
\text { and organisational change } \\
\text { is pertinent to my re- } \\
\text { search, the unit of analy- } \\
\text { sis is financial market in } \\
\text { the US. Therefore, this }\end{array}$ \\
\hline
\end{tabular}




\begin{tabular}{|c|c|c|c|c|c|}
\hline & $\begin{array}{l}\text { in Financial } \\
\text { Markets }\end{array}$ & $\begin{array}{l}\text { Oliva, } \\
\text { Rogelio }\end{array}$ & & $\begin{array}{c}\text { MAR- } \\
\text { APR } 2014\end{array}$ & $\begin{array}{l}\text { article is not included in } \\
\text { my research. }\end{array}$ \\
\hline 42 & $\begin{array}{l}\text { ETHICAL } \\
\text { CULTURE } \\
\text { AND THE } \\
\text { VALUE- } \\
\text { BASED AP- } \\
\text { PROACH } \\
\text { TO INTEG- } \\
\text { RITY MAN- } \\
\text { AGEMENT: } \\
\text { A CASE } \\
\text { STUDY OF } \\
\text { THE DE- } \\
\text { PART- } \\
\text { MENT OF } \\
\text { CORREC- } \\
\text { TIONAL } \\
\text { SERVICES }\end{array}$ & $\begin{array}{l}\text { Webb, } \\
\text { Werner } \\
\text { Nicho- } \\
\text { laas }\end{array}$ & 2012 & $\begin{array}{c}\text { PUBLIC } \\
\text { ADMIN- } \\
\text { ISTRA- } \\
\text { TION } \\
\text { AND DE- } \\
\text { VELOP- } \\
\text { MENT } \\
\text { Volume: } \\
32 \text { Issue: } 1 \\
\text { Special Is- } \\
\text { sue: SI } \\
\text { Pages: 96- } \\
\text { 108 Pub- } \\
\text { lished: } \\
\text { FEB 2012 }\end{array}$ & $\begin{array}{l}\text { This article examined the } \\
\text { case of South Africa in ap- } \\
\text { plying compliance-based } \\
\text { and value-based ap- } \\
\text { proaches and explained } \\
\text { the phenomena at the De- } \\
\text { partment of Correctional } \\
\text { Services. This article is in- } \\
\text { cluded. }\end{array}$ \\
\hline 43 & $\begin{array}{l}\text { Bribe Pay- } \\
\text { ments and } \\
\text { Innovation } \\
\text { in Develop- } \\
\text { ing Coun- } \\
\text { tries: Are } \\
\text { Innovating } \\
\text { Firms Dis- } \\
\text { proportion- } \\
\text { ately Af- } \\
\text { fected? }\end{array}$ & 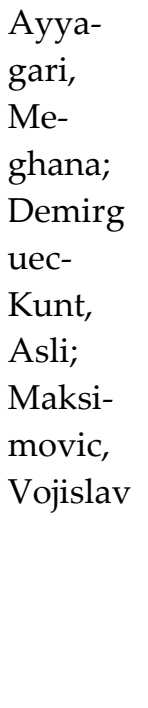 & 2014 & $\begin{array}{l}\text { JOUR- } \\
\text { NAL OF } \\
\text { FINAN- } \\
\text { CIAL } \\
\text { AND } \\
\text { QUANTI- } \\
\text { TATIVE } \\
\text { ANALY- } \\
\text { SIS Vol- } \\
\text { ume: } 49 \\
\text { Issue: } 1 \\
\text { Pages: } 51- \\
75 \text { Pub- } \\
\text { lished: } \\
\text { FEB } 2014\end{array}$ & $\begin{array}{l}\text { The authors examined } \\
\text { bribe payments among in- } \\
\text { novating and non-inno- } \\
\text { vating firms. This article } \\
\text { is not included in my re- } \\
\text { search. }\end{array}$ \\
\hline 44 & $\begin{array}{l}\text { Corruption } \\
\text { and the Ex- } \\
\text { tractive }\end{array}$ & $\begin{array}{l}\text { Papyra- } \\
\text { kis, Elis- } \\
\text { saios; }\end{array}$ & 2017 & $\begin{array}{l}\text { JOUR- } \\
\text { NAL OF }\end{array}$ & $\begin{array}{l}\text { The articles identified the } \\
\text { drivers and conditions of } \\
\text { compliance with the EITI }\end{array}$ \\
\hline
\end{tabular}




\begin{tabular}{|c|c|c|c|c|c|}
\hline & $\begin{array}{l}\text { Industries } \\
\text { Transpar- } \\
\text { ency Initia- } \\
\text { tive }\end{array}$ & $\begin{array}{l}\text { Rieger, } \\
\text { Mat- } \\
\text { thias; } \\
\text { Gil- } \\
\text { berthorp } \\
\text { e, Emma }\end{array}$ & & $\begin{array}{c}\text { DEVEL- } \\
\text { OPMENT } \\
\text { STUDIES } \\
\text { Volume: } \\
53 \text { Issue: } 2 \\
\text { Special Is- } \\
\text { sue: SI } \\
\text { Pages: } \\
\text { 295-309 } \\
\text { Pub- } \\
\text { lished: } \\
2017\end{array}$ & $\begin{array}{l}\text { requirements by member } \\
\text { countries. This article is } \\
\text { included. }\end{array}$ \\
\hline 45 & $\begin{array}{l}\text { Corruption, } \\
\text { governance } \\
\text { and firm } \\
\text { perfor- } \\
\text { mance: Evi- } \\
\text { dence from } \\
\text { Indian en- } \\
\text { terprises }\end{array}$ & $\begin{array}{l}\text { Sharma, } \\
\text { Chan- } \\
\text { dan; Mi- } \\
\text { tra, } \\
\text { Arup }\end{array}$ & 2015 & $\begin{array}{l}\text { JOUR- } \\
\text { NAL OF } \\
\text { POLICY } \\
\text { MODEL- } \\
\text { ING Vol- } \\
\text { ume: } 37 \\
\text { Issue: } 5 \\
\text { Pages: } \\
835-851 \\
\text { Pub- } \\
\text { lished: } \\
\text { SEP-OCT } \\
2015\end{array}$ & $\begin{array}{l}\text { The paper investigated } \\
\text { the case of India in tax } \\
\text { payment and corruption, } \\
\text { with focus on firm's be- } \\
\text { haviors. Therefore, it is } \\
\text { not included in my re- } \\
\text { search. }\end{array}$ \\
\hline 46 & $\begin{array}{l}\text { Can corrup- } \\
\text { tion foster } \\
\text { regulatory } \\
\text { compli- } \\
\text { ance? }\end{array}$ & $\begin{array}{l}\text { Mendez, } \\
\text { Fabio }\end{array}$ & 2014 & $\begin{array}{c}\text { PUBLIC } \\
\text { CHOICE } \\
\text { Volume: } \\
\text { 158 Issue: } \\
\text { 1-2 Pages: } \\
\text { 189-207 } \\
\text { Pub- } \\
\text { lished: } \\
\text { JAN 2014 }\end{array}$ & $\begin{array}{l}\text { This research argued that } \\
\text { an increase in corruption } \\
\text { fosters compliance, using } \\
\text { the firm-level data of } 26 \\
\text { economies. This article is } \\
\text { not included. }\end{array}$ \\
\hline 47 & $\begin{array}{l}\text { "Ethics Hot- } \\
\text { lines" in } \\
\text { Transna- } \\
\text { tional Com- } \\
\text { panies: A }\end{array}$ & $\begin{array}{l}\text { Calde- } \\
\text { ron- } \\
\text { Cuad- } \\
\text { rado, } \\
\text { Reyes; }\end{array}$ & 2009 & $\begin{array}{l}\text { JOUR- } \\
\text { NAL OF } \\
\text { BUSI- } \\
\text { NESS } \\
\text { ETHICS }\end{array}$ & $\begin{array}{l}\text { The topic of hotline and } \\
\text { reporting wrong-doing is } \\
\text { pertinent to my research, } \\
\text { but this article is not in- } \\
\text { cluded in my research }\end{array}$ \\
\hline
\end{tabular}




\begin{tabular}{|c|c|c|c|c|c|}
\hline & $\begin{array}{l}\text { Compara- } \\
\text { tive Study }\end{array}$ & $\begin{array}{l}\text { Luis Al- } \\
\text { varez- } \\
\text { Arce, } \\
\text { Jose; Ro- } \\
\text { driguez- } \\
\text { Tejedo, } \\
\text { Isabel; } \\
\text { et al. }\end{array}$ & & $\begin{array}{l}\text { Volume: } \\
\text { 88 Issue: } 1 \\
\text { Pages: } \\
\text { 199-210 } \\
\text { Pub- } \\
\text { lished: } \\
\text { AUG 2009 }\end{array}$ & $\begin{array}{l}\text { because of its focus on } \\
\text { corporation. }\end{array}$ \\
\hline 48 & $\begin{array}{l}\text { Who bears } \\
\text { the cost of } \\
\text { Russia's } \\
\text { military } \\
\text { draft? }\end{array}$ & $\begin{array}{l}\text { Lokshin, } \\
\text { Michael; } \\
\text { Yemtso } \\
\text { v, } \\
\text { Ruslan }\end{array}$ & 2008 & $\begin{array}{c}\text { ECO- } \\
\text { NOMICS } \\
\text { OF } \\
\text { TRANSI- } \\
\text { TION } \\
\text { Volume: } \\
\text { 16 Issue: } 3 \\
\text { Pages: } \\
\text { 359-387 } \\
\text { Pub- } \\
\text { lished: } \\
2008\end{array}$ & $\begin{array}{l}\text { The article uniquely ad- } \\
\text { dressed the challenge of } \\
\text { military conscription and } \\
\text { conditions for non-com- } \\
\text { pliance in Russia. This ar- } \\
\text { ticle is included. }\end{array}$ \\
\hline 49 & $\begin{array}{l}\text { Determi- } \\
\text { nants of } \\
\text { risk disclo- } \\
\text { sure com- } \\
\text { pliance in } \\
\text { Malawi: a } \\
\text { mixed } \\
\text { method ap- } \\
\text { proach }\end{array}$ & $\begin{array}{l}\text { Taurin- } \\
\text { gana, } \\
\text { Ve- } \\
\text { nancio; } \\
\text { Chitham } \\
\text { bo, } \\
\text { Lyton }\end{array}$ & 2016 & $\begin{array}{c}\text { Journal of } \\
\text { Account- } \\
\text { ing in } \\
\text { Emerging } \\
\text { Econo- } \\
\text { mies Vol- } \\
\text { ume: } 6 \text { Is- } \\
\text { sue: } 2 \\
\text { Pages: } \\
\text { 111-137 } \\
\text { Pub- } \\
\text { lished: } \\
2016\end{array}$ & $\begin{array}{l}\text { The article investigated } \\
\text { compliance with risk dis- } \\
\text { closure requirements by } \\
\text { Malawian Stock Market } \\
\text { listed companies. This ar- } \\
\text { ticle is not included in my } \\
\text { research. }\end{array}$ \\
\hline 50 & $\begin{array}{l}\text { The ethical } \\
\text { commit- } \\
\text { ment of in- } \\
\text { dependent } \\
\text { directors in } \\
\text { different }\end{array}$ & $\begin{array}{l}\text { Maria } \\
\text { Garcia- } \\
\text { Sanchez, } \\
\text { Isabel; } \\
\text { Frias } \\
\text { Aceitun }\end{array}$ & 2015 & $\begin{array}{l}\text { BRQ- } \\
\text { BUSI- } \\
\text { NESS RE- } \\
\text { SEARCH } \\
\text { QUAR- } \\
\text { TERLY }\end{array}$ & $\begin{array}{l}\text { The authors compared } \\
\text { different legal environ- } \\
\text { ments to improve corpo- } \\
\text { rate ethical behaviors by } \\
\text { designing code of }\end{array}$ \\
\hline
\end{tabular}




\begin{tabular}{|c|c|c|c|c|c|}
\hline & $\begin{array}{l}\text { contexts of } \\
\text { investor } \\
\text { protection }\end{array}$ & $\begin{array}{l}\text { o, Jose } \\
\text { Valerian } \\
\text { o; } \\
\text { Rodrigu } \\
\text { ez } \\
\text { Doming } \\
\text { uez, } \\
\text { Luis }\end{array}$ & & $\begin{array}{c}\text { Volume: } \\
\text { 18 Issue: } 2 \\
\text { Pages: 81- } \\
94 \text { Pub- } \\
\text { lished: } \\
\text { APR-JUN } \\
2015 \text { Se- } \\
\text { lect Page }\end{array}$ & $\begin{array}{l}\text { conduct. This article is not } \\
\text { included in my research. }\end{array}$ \\
\hline 51 & $\begin{array}{l}\text { The Effect } \\
\text { of Deferred } \\
\text { and Non- } \\
\text { Prosecution } \\
\text { Agreements } \\
\text { on Corpo- } \\
\text { rate Gov- } \\
\text { ernance: } \\
\text { Evidence } \\
\text { from 1993- } \\
2013\end{array}$ & $\begin{array}{l}\text { Kaal, } \\
\text { Wulf A.; } \\
\text { Lacine, } \\
\text { Timothy } \\
\text { A. }\end{array}$ & 2014 & $\begin{array}{c}\text { BUSI- } \\
\text { NESS } \\
\text { LAWYER } \\
\text { Volume: } \\
70 \text { Issue: } 1 \\
\text { Pages: 61- } \\
\text { 119 Pub- } \\
\text { lished: } \\
\text { WIN } 2014\end{array}$ & $\begin{array}{l}\text { The articles investigated } \\
\text { deferred and non-prose- } \\
\text { cution agreement among } \\
\text { corporations. This article } \\
\text { is not included in my re- } \\
\text { search. }\end{array}$ \\
\hline 52 & $\begin{array}{l}\text { Deception } \\
\text { choice and } \\
\text { self-selec- } \\
\text { tion - The } \\
\text { importance } \\
\text { of being } \\
\text { earnest }\end{array}$ & $\begin{array}{l}\text { Konrad, } \\
\text { Kai A.; } \\
\text { Lohse, } \\
\text { Tim; } \\
\text { Qari, } \\
\text { Salmai }\end{array}$ & 2014 & $\begin{array}{c}\text { JOUR- } \\
\text { NAL OF } \\
\text { ECO- } \\
\text { NOMIC } \\
\text { BEHAV- } \\
\text { IOR \& } \\
\text { ORGANI- } \\
\text { ZATION } \\
\text { Volume: } \\
\text { 107 Spe- } \\
\text { cial Issue: } \\
\text { SI Pages: } \\
\text { 25-39 } \\
\text { Part: A } \\
\text { Pub- } \\
\text { lished: } \\
\text { NOV 2014 }\end{array}$ & $\begin{array}{l}\text { While the topic of tax } \\
\text { payer behavior is interest- } \\
\text { ing, as it concerns compli- } \\
\text { ance, this article does not } \\
\text { focus on the public sector. } \\
\text { Therefore, it is not in- } \\
\text { cluded in my study. }\end{array}$ \\
\hline 53 & $\begin{array}{l}\text { Does busi- } \\
\text { ness regula- } \\
\text { tion matter }\end{array}$ & $\begin{array}{l}\text { Kalyvas, } \\
\text { Anto- } \\
\text { nios }\end{array}$ & 2014 & $\begin{array}{l}\text { JOUR- } \\
\text { NAL OF }\end{array}$ & $\begin{array}{l}\text { The article offered a com- } \\
\text { prehensive analysis on } \\
\text { the impact of regulations }\end{array}$ \\
\hline
\end{tabular}




\begin{tabular}{|c|c|c|c|c|c|}
\hline & $\begin{array}{l}\text { for banks in } \\
\text { the Euro- } \\
\text { pean Un- } \\
\text { ion? }\end{array}$ & $\begin{array}{l}\text { Niko- } \\
\text { laos; } \\
\text { Mamatz } \\
\text { akis, } \\
\text { Emman- } \\
\text { uel }\end{array}$ & & $\begin{array}{c}\text { INTER- } \\
\text { NA- } \\
\text { TIONAL } \\
\text { FINAN- } \\
\text { CIAL } \\
\text { MAR- } \\
\text { KETS IN- } \\
\text { STITU- } \\
\text { TIONS \& } \\
\text { MONEY } \\
\text { Volume: } \\
32 \text { Pages: } \\
\text { 278-324 } \\
\text { Pub- } \\
\text { lished: } \\
\text { SEP 2014 }\end{array}$ & $\begin{array}{l}\text { on banks in the EU over } \\
\text { 2004- } 2010 \text { period. It is not } \\
\text { included in my study. }\end{array}$ \\
\hline 54 & $\begin{array}{l}\text { Limited } \\
\text { state and } \\
\text { strong so- } \\
\text { cial forces: } \\
\text { Fishing lot } \\
\text { manage- } \\
\text { ment in } \\
\text { Cambodia }\end{array}$ & Sok, Say & 2014 & $\begin{array}{c}\text { JOUR- } \\
\text { NAL OF } \\
\text { SOUTH- } \\
\text { EAST } \\
\text { ASIAN } \\
\text { STUDIES } \\
\text { Volume: } \\
\text { 45 Issue: } 2 \\
\text { Pages: } \\
\text { 174-193 } \\
\text { Pub- } \\
\text { lished: } \\
\text { JUN 2014 }\end{array}$ & $\begin{array}{l}\text { The author analysed the } \\
\text { Cambodian fisheries and } \\
\text { compliance with regula- } \\
\text { tions among different so- } \\
\text { cial forces. This article is } \\
\text { included in the study. }\end{array}$ \\
\hline 55 & $\begin{array}{l}\text { To build } \\
\text { above the } \\
\text { limit? Im- } \\
\text { plementa- } \\
\text { tion of land } \\
\text { use regula- } \\
\text { tions in ur- } \\
\text { ban China }\end{array}$ & $\begin{array}{l}\text { Cai, } \\
\text { Hongbi } \\
\text { n; } \\
\text { Wang, } \\
\text { Zhi; } \\
\text { Zhang, } \\
\text { Qing- } \\
\text { hua }\end{array}$ & 2017 & $\begin{array}{l}\text { JOUR- } \\
\text { NAL OF } \\
\text { URBAN } \\
\text { ECO- } \\
\text { NOMICS } \\
\text { Volume: } \\
98 \text { Pages: } \\
\text { 223-233 }\end{array}$ & $\begin{array}{l}\text { The article selected a case } \\
\text { of Chinese urban land use } \\
\text { regulations and identified } \\
\text { gaps between the rules } \\
\text { and actual implementa- } \\
\text { tion. As this article fo- } \\
\text { cused on behaviors of de- } \\
\text { velopers, it is excluded } \\
\text { from my study. }\end{array}$ \\
\hline
\end{tabular}




\begin{tabular}{|c|c|c|c|c|c|}
\hline & & & & $\begin{array}{c}\text { Pub- } \\
\text { lished: } \\
\text { MAR } \\
2017\end{array}$ & \\
\hline 56 & $\begin{array}{l}\text { Do percep- } \\
\text { tions of cor- } \\
\text { ruption in- } \\
\text { fluence per- } \\
\text { sonal in- } \\
\text { come tax- } \\
\text { payer re- } \\
\text { porting be- } \\
\text { haviour? } \\
\text { Evidence } \\
\text { from Indo- } \\
\text { nesia }\end{array}$ & $\begin{array}{l}\text { Rosid, } \\
\text { Arifin; } \\
\text { Evans, } \\
\text { Chris; } \\
\text { Binh } \\
\text { Tran- } \\
\text { Nam }\end{array}$ & 2016 & $\begin{array}{c}\text { EJOUR- } \\
\text { NAL OF } \\
\text { TAX RE- } \\
\text { SEARCH } \\
\text { Volume: } \\
\text { 14 Issue: } 2 \\
\text { Pages: } \\
\text { 387-+ } \\
\text { Pub- } \\
\text { lished: } \\
\text { NOV 2016 }\end{array}$ & $\begin{array}{l}\text { This Indonesian case } \\
\text { study examined the per- } \\
\text { ception of corruption and } \\
\text { its impact on taxpayers' } \\
\text { compliance and reporting } \\
\text { behavior. This study is in- } \\
\text { cluded in my research. }\end{array}$ \\
\hline 57 & $\begin{array}{l}\text { Corruption } \\
\text { and Viola- } \\
\text { tions of } \\
\text { Conserva- } \\
\text { tion Rules: } \\
\text { A Survey } \\
\text { Experiment } \\
\text { with Re- } \\
\text { source Us- } \\
\text { ers }\end{array}$ & $\begin{array}{l}\text { Sundstr } \\
\text { om, } \\
\text { Aksel }\end{array}$ & 2016 & $\begin{array}{c}\text { WORLD } \\
\text { DEVEL- } \\
\text { OPMENT } \\
\text { Volume: } \\
85 \text { Pages: } \\
\text { 73-83 } \\
\text { Pub- } \\
\text { lished: } \\
\text { SEP 2016 }\end{array}$ & $\begin{array}{l}\text { In this study, the author } \\
\text { concluded that corruption } \\
\text { has negative impacts on } \\
\text { conservation manage- } \\
\text { ment, using data of South } \\
\text { African small-scale fisher- } \\
\text { ies. This is included. }\end{array}$ \\
\hline 58 & $\begin{array}{l}\text { The Foreign } \\
\text { Corrupt } \\
\text { Practices } \\
\text { Act: Why It } \\
\text { Fails to De- } \\
\text { ter Bribery } \\
\text { as a Global } \\
\text { Market En- } \\
\text { try Strategy }\end{array}$ & $\begin{array}{l}\text { Weis- } \\
\text { mann, } \\
\text { Miriam } \\
\text { F.; } \\
\text { Busca- } \\
\text { glia, } \\
\text { Christo- } \\
\text { pher A.; } \\
\text { Peter- } \\
\text { son, Ja- } \\
\text { son }\end{array}$ & 2014 & $\begin{array}{c}\text { JOUR- } \\
\text { NAL OF } \\
\text { BUSI- } \\
\text { NESS } \\
\text { ETHICS } \\
\text { Volume: } \\
123 \text { Issue: } \\
4 \text { Special } \\
\text { Issue: SI } \\
\text { Pages: } \\
\text { 591- 619 }\end{array}$ & $\begin{array}{l}\text { The article focuses on the } \\
\text { FCPA and its implemen- } \\
\text { tation and prosecution in } \\
\text { the US and concluded } \\
\text { that FCPA is ineffective in } \\
\text { addressing bribery in for- } \\
\text { eign markets. This article } \\
\text { is included. }\end{array}$ \\
\hline
\end{tabular}




\begin{tabular}{|c|c|c|c|c|c|}
\hline & & & & $\begin{array}{c}\text { Pub- } \\
\text { lished: } \\
\text { SEP } 2014\end{array}$ & \\
\hline 59 & $\begin{array}{l}\text { Pre-emp- } \\
\text { tive Cor- } \\
\text { ruption, } \\
\text { Hold-up } \\
\text { and Re- } \\
\text { peated In- } \\
\text { teractions }\end{array}$ & $\begin{array}{l}\text { Dechena } \\
\text { ux, Em- } \\
\text { manuel; } \\
\text { Samuel, } \\
\text { Andrew }\end{array}$ & 2012 & $\begin{array}{c}\text { ECO- } \\
\text { NOMICA } \\
\text { Volume: } \\
\text { 79 Issue: } \\
\text { 314 Pages: } \\
\text { 258-283 } \\
\text { Pub- } \\
\text { lished: } \\
\text { APR 2012 }\end{array}$ & $\begin{array}{l}\text { This article applied a } \\
\text { model to analyse firms' } \\
\text { compliance behaviors. It } \\
\text { is not included in my } \\
\text { study. }\end{array}$ \\
\hline 60 & $\begin{array}{l}\text { Tax pro- } \\
\text { gressivity, } \\
\text { income dis- } \\
\text { tribution } \\
\text { and tax } \\
\text { non-compli- } \\
\text { ance }\end{array}$ & $\begin{array}{l}\text { Damja- } \\
\text { novic, } \\
\text { Tatiana; } \\
\text { Ulph, } \\
\text { David }\end{array}$ & 2010 & $\begin{array}{c}\text { EURO- } \\
\text { PEAN } \\
\text { ECO- } \\
\text { NOMIC } \\
\text { REVIEW } \\
\text { Volume: } \\
\text { 54 Issue: } 4 \\
\text { Pages: } \\
\text { 594-607 } \\
\text { Pub- } \\
\text { lished: } \\
\text { MAY } \\
2010\end{array}$ & $\begin{array}{l}\text { The article analysed the } \\
\text { role of tax advisory indus- } \\
\text { try in determining tax } \\
\text { non-compliance. It is not } \\
\text { included in my research. }\end{array}$ \\
\hline $61^{54}$ & $\begin{array}{l}\text { The Culture } \\
\text { Variable } \\
\text { Vis-a-Vis } \\
\text { Anti-brib- } \\
\text { ery Law: A } \\
\text { Grey Area } \\
\text { in Transna- } \\
\text { tional Cor- } \\
\text { porate }\end{array}$ & $\begin{array}{l}\text { Bu, } \\
\text { Qingxiu }\end{array}$ & 2018 & $\begin{array}{c}\text { EURO- } \\
\text { PEAN } \\
\text { BUSI- } \\
\text { NESS OR- } \\
\text { GANIZA- } \\
\text { TION } \\
\text { LAW RE- } \\
\text { VIEW } \\
\text { Volume: } \\
19 \text { Issue: }\end{array}$ & $\begin{array}{l}\text { The author investigated } \\
\text { the relationship between } \\
\text { culture and compliance in } \\
\text { China from MNC per- } \\
\text { spectives. This is not in- } \\
\text { cluded in my research. }\end{array}$ \\
\hline
\end{tabular}

${ }^{54}$ After $60^{\text {th }}$, ranking in citation indicator was not found relevant, as the difference among articles is small. Therefore, the rest of the articles are listed in anti-chronological order. 


\begin{tabular}{|c|c|c|c|c|c|}
\hline & $\begin{array}{l}\text { Criminal Li- } \\
\text { ability }\end{array}$ & & & $\begin{array}{c}\text { 1 Pages: } \\
\text { 183-213 } \\
\text { DOI: } \\
\text { 10.1007/s4 } \\
0804-017- \\
0089-8 \\
\text { Pub- } \\
\text { lished: } \\
\text { MAR } \\
2018\end{array}$ & \\
\hline 62 & $\begin{array}{l}\text { Nothing to } \\
\text { hide: Com- } \\
\text { mitment to, } \\
\text { compliance } \\
\text { with, and } \\
\text { impact of } \\
\text { the special } \\
\text { data dis- } \\
\text { semination } \\
\text { standard }\end{array}$ & $\begin{array}{l}\text { Vadlam } \\
\text { annati, } \\
\text { Krishna } \\
\text { Chaitan } \\
\text { ya; } \\
\text { Cooray, } \\
\text { Arusha; } \\
\text { Brazys, } \\
\text { Samuel }\end{array}$ & 2018 & $\begin{array}{c}\text { ECO- } \\
\text { NOMICS } \\
\text { \& POLI- } \\
\text { TICS Vol- } \\
\text { ume: } 30 \\
\text { Issue: } 1 \\
\text { Pages: 55- } \\
77 \text { DOI: } \\
\text { 10.1111/ec } \\
\text { po.12100 } \\
\text { Pub- } \\
\text { lished: } \\
\text { MAR } \\
2018\end{array}$ & $\begin{array}{l}\text { The author examined the } \\
\text { logics behind decisions of } \\
\text { countries, which opted for } \\
\text { compliance with interna- } \\
\text { tional standards, such as } \\
\text { the Special Data Dissemi- } \\
\text { nation Standard. This is } \\
\text { included in my research. }\end{array}$ \\
\hline 63 & $\begin{array}{l}\text { Tax compli- } \\
\text { ance with } \\
\text { uncertain } \\
\text { income: a } \\
\text { stochastic } \\
\text { control } \\
\text { model }\end{array}$ & $\begin{array}{l}\text { Sparta, } \\
\text { Gaetano } \\
\text { T.; } \\
\text { Stabile, } \\
\text { Gabriele }\end{array}$ & 2018 & $\begin{array}{c}\text { ANNALS } \\
\text { OF OPER- } \\
\text { ATIONS } \\
\text { RE- } \\
\text { SEARCH } \\
\text { Volume: } \\
\text { 261 Issue: } \\
\text { 1-2 Pages: } \\
\text { 289-301 } \\
\text { DOI: } \\
\text { 10.1007/s1 } \\
0479-017- \\
2618-9\end{array}$ & $\begin{array}{l}\text { The paper examined tax } \\
\text { payer behavior and com- } \\
\text { pliance with a stochastic } \\
\text { income. This does not in- } \\
\text { volve the government or } \\
\text { corruption and, therefore, } \\
\text { is not included in my } \\
\text { study. }\end{array}$ \\
\hline
\end{tabular}




\begin{tabular}{|c|c|c|c|c|c|}
\hline & & & & $\begin{array}{c}\text { Pub- } \\
\text { lished: } \\
\text { FEB } 2018\end{array}$ & \\
\hline 64 & $\begin{array}{l}\text { Sustainable } \\
\text { global pur- } \\
\text { chasing: as- } \\
\text { sessing the } \\
\text { relative im- } \\
\text { pact of sus- } \\
\text { tainability } \\
\text { goals and } \\
\text { programs }\end{array}$ & $\begin{array}{l}\text { von } \\
\text { Haartm } \\
\text { an, } \\
\text { Robin; } \\
\text { Bengts- } \\
\text { son, } \\
\text { Lars }\end{array}$ & 2018 & $\begin{array}{c}\text { INTER- } \\
\text { NA- } \\
\text { TIONAL } \\
\text { JOUR- } \\
\text { NAL OF } \\
\text { BUSI- } \\
\text { NESS } \\
\text { PERFOR- } \\
\text { MANCE } \\
\text { MAN- } \\
\text { AGE- } \\
\text { MENT } \\
\text { Volume: } \\
\text { 19 Issue: } \\
2 \text { Pages: } \\
\text { 169-188 } \\
\text { DOI: } \\
\text { 10.1504/IJ } \\
\text { BPM.2018 } \\
\text { 10010265 } \\
\text { Pub- } \\
\text { lished: } \\
\text { 2018 }\end{array}$ & $\begin{array}{l}\text { The article focused on fi- } \\
\text { nancial firms in areas of } \\
\text { offshoring. It is not in- } \\
\text { cluded in my research. }\end{array}$ \\
\hline 65 & $\begin{array}{l}\text { "Organised } \\
\text { irresponsi- } \\
\text { bility"? The } \\
\text { Siemens } \\
\text { corruption } \\
\text { scandal of } \\
\text { the 1990s } \\
\text { and 2000s }\end{array}$ & $\begin{array}{l}\text { Berghoff } \\
\text {, Hart- } \\
\text { mut }\end{array}$ & 2018 & $\begin{array}{c}\text { BUSI- } \\
\text { NESS } \\
\text { HISTORY } \\
\text { Volume: } \\
60 \text { Issue: } \\
3 \text { Special } \\
\text { Issue: SI } \\
\text { Pages: } \\
\text { 423-445 } \\
\text { DOI: } \\
\text { 10.1080/00 } \\
076791.20 \\
\text { 17.133033 } \\
2\end{array}$ & $\begin{array}{l}\text { The article traced the his- } \\
\text { tory of Siemens scandal in } \\
\text { the } 1990 \text { s and } 2000 \text { s. Alt- } \\
\text { hough the focus of the ar- } \\
\text { ticle is on a private sector } \\
\text { company, it also reviewed } \\
\text { the national and interna- } \\
\text { tional instruments, prose- } \\
\text { cution and evolution in } \\
\text { responding to the scan- } \\
\text { dal. Therefore, it is in- } \\
\text { cluded in my research. }\end{array}$ \\
\hline
\end{tabular}




\begin{tabular}{|c|c|c|c|c|c|}
\hline & & & & $\begin{array}{l}\text { Pub- } \\
\text { lished: } \\
2018\end{array}$ & \\
\hline 66 & $\begin{array}{l}\text { Wages, per- } \\
\text { formance } \\
\text { and harass- } \\
\text { ment }\end{array}$ & $\begin{array}{l}\text { Bac, } \\
\text { Mehmet }\end{array}$ & 2018 & $\begin{array}{c}\text { OURNAL } \\
\text { OF ECO- } \\
\text { NOMIC } \\
\text { BEHAV- } \\
\text { IOR \& } \\
\text { ORGANI- } \\
\text { ZATION } \\
\text { Volume: } \\
145 \\
\text { Pages: } \\
\text { 232-248 } \\
\text { DOI: } \\
\text { 10.1016/j.j } \\
\text { ebo.2017.1 } \\
1.008 \\
\text { Pub- } \\
\text { lished: } \\
\text { JAN 2018 }\end{array}$ & $\begin{array}{l}\text { The author investigated } \\
\text { the relationship between } \\
\text { wages and harassment } \\
\text { and concluded they were } \\
\text { correlated. This is in- } \\
\text { cluded in my study. }\end{array}$ \\
\hline 67 & $\begin{array}{l}\text { Corruption, } \\
\text { taxes and } \\
\text { compliance }\end{array}$ & $\begin{array}{l}\text { Baum, } \\
\text { Anja; } \\
\text { Gupta, } \\
\text { Sanjeev; } \\
\text { Kimani, } \\
\text { Elijah; } \\
\text { Tap- } \\
\text { soba, } \\
\text { Sam- } \\
\text { pawend } \\
\text { e Jules }\end{array}$ & 2017 & $\begin{array}{c}\text { EJOUR- } \\
\text { NAL OF } \\
\text { TAX RE- } \\
\text { SEARCH } \\
\text { Volume: } \\
15 \text { Issue: } \\
2 \text { Special } \\
\text { Issue: SI } \\
\text { Pages: } \\
\text { 190-216 } \\
\text { Pub- } \\
\text { lished: } \\
\text { DEC 2017 }\end{array}$ & $\begin{array}{l}\text { The article examined the } \\
\text { relationship between cor- } \\
\text { ruption and tax compli- } \\
\text { ance using the global data } \\
\text { of } 147 \text { economies. The es- } \\
\text { tablishment of large tax- } \\
\text { payers' offices was identi- } \\
\text { fied as one way to reduce } \\
\text { perception of corruption. } \\
\text { This article is included. }\end{array}$ \\
\hline 68 & $\begin{array}{l}\text { The impact } \\
\text { of corrup- } \\
\text { tion on tax } \\
\text { revenues, } \\
\text { tax }\end{array}$ & $\begin{array}{l}\text { Schlen- } \\
\text { ther, } \\
\text { Bernd }\end{array}$ & 2017 & $\begin{array}{l}\text { EJOUR- } \\
\text { NAL OF } \\
\text { TAX RE- } \\
\text { SEARCH } \\
\text { Volume: }\end{array}$ & $\begin{array}{l}\text { The author analysed the } \\
\text { level of corruption and } \\
\text { development in Africa } \\
\text { from institutional point of }\end{array}$ \\
\hline
\end{tabular}




\begin{tabular}{|c|c|c|c|c|c|}
\hline & $\begin{array}{l}\text { compliance } \\
\text { and eco- } \\
\text { nomic de- } \\
\text { velopment: } \\
\text { Prevailing } \\
\text { trends and } \\
\text { mitigation } \\
\text { actions in } \\
\text { Africa }\end{array}$ & & & $\begin{array}{l}15 \text { Issue: } \\
2 \text { Special } \\
\text { Issue: SI } \\
\text { Pages: } \\
\text { 217-242 } \\
\text { Pub- } \\
\text { lished: } \\
\text { DEC } 2017\end{array}$ & $\begin{array}{l}\text { view. This article is in- } \\
\text { cluded. }\end{array}$ \\
\hline 69 & $\begin{array}{l}\text { Causes and } \\
\text { conse- } \\
\text { quences of } \\
\text { corruption } \\
\text { in tax ad- } \\
\text { ministra- } \\
\text { tion: An In- } \\
\text { donesian } \\
\text { case study }\end{array}$ & $\begin{array}{l}\text { Tjen, } \\
\text { Chris- } \\
\text { tine; Ev- } \\
\text { ans, } \\
\text { Chris }\end{array}$ & 2017 & $\begin{array}{c}\text { EJOUR- } \\
\text { NAL OF } \\
\text { TAX RE- } \\
\text { SEARCH } \\
\text { Volume: } \\
15 \text { Issue: } \\
2 \text { Special } \\
\text { Issue: SI } \\
\text { Pages: } \\
\text { 243-261 } \\
\text { Pub- } \\
\text { lished: } \\
\text { DEC 2017 }\end{array}$ & $\begin{array}{l}\text { The authors researched } \\
\text { the background and im- } \\
\text { pact of the Gayus case in } \\
\text { Indonesia and institu- } \\
\text { tional changes the gov- } \\
\text { ernment introduced as a } \\
\text { consequence. This article } \\
\text { is included. }\end{array}$ \\
\hline 70 & $\begin{array}{l}\text { Corporate } \\
\text { Social Re- } \\
\text { sponsibility, } \\
\text { Institutional } \\
\text { Environ- } \\
\text { ments, and } \\
\text { Tax Avoid- } \\
\text { ance: Evi- } \\
\text { dence from } \\
\text { a Subna- } \\
\text { tional Com- } \\
\text { parison in } \\
\text { China }\end{array}$ & $\begin{array}{l}\text { Lin, } \\
\text { Kenny } \\
\text { Z; } \\
\text { Cheng, } \\
\text { Suwina; } \\
\text { Zhang, } \\
\text { Fang }\end{array}$ & 2017 & $\begin{array}{c}\text { INTER- } \\
\text { NA- } \\
\text { TIONAL } \\
\text { JOUR- } \\
\text { NAL OF } \\
\text { AC- } \\
\text { COUNT- } \\
\text { ING Vol- } \\
\text { ume: } 52 \\
\text { Issue: } 4 \\
\text { Pages: } \\
\text { 303-318 } \\
\text { DOI: } \\
\text { 10.1016/j.i } \\
\text { ntacc. } 2017 \\
.11 .002\end{array}$ & $\begin{array}{l}\text { The article looked into the } \\
\text { relationship between cor- } \\
\text { porate social responsibil- } \\
\text { ity disclosure and eco- } \\
\text { nomic contribution in } \\
\text { China. This is not in- } \\
\text { cluded. }\end{array}$ \\
\hline
\end{tabular}




\begin{tabular}{|c|c|c|c|c|c|}
\hline & & & & $\begin{array}{c}\text { Pub- } \\
\text { lished: } \\
\text { DEC } 2017\end{array}$ & \\
\hline 71 & $\begin{array}{l}\text { Self-clean- } \\
\text { ing in pub- } \\
\text { lic procure- } \\
\text { ment: oper- } \\
\text { ational po- } \\
\text { tentiality } \\
\text { and regula- } \\
\text { tion in the } \\
\text { European } \\
\text { Union }\end{array}$ & $\begin{array}{l}\text { Rodri- } \\
\text { guez- } \\
\text { Arana } \\
\text { Munoz, } \\
\text { Jaime }\end{array}$ & 2017 & $\begin{array}{c}\text { A\&C-RE- } \\
\text { VISTA } \\
\text { DE } \\
\text { DIREITO } \\
\text { ADMIN- } \\
\text { ISTRA- } \\
\text { TIVO \& } \\
\text { CON- } \\
\text { STITUCI- } \\
\text { ONAL } \\
\text { Volume: } \\
\text { 17 Issue: } \\
70 \text { Pages: } \\
\text { 25-44 } \\
\text { DOI: } \\
10.21056 / a \\
\text { ec.v17i70. } \\
\text { 815 Pub- } \\
\text { lished: } \\
\text { OCT-DEC } \\
\text { 2017 }\end{array}$ & $\begin{array}{l}\text { In this article, the author } \\
\text { examined public procure- } \\
\text { ment and self-cleaning } \\
\text { mechanisms of the EU. } \\
\text { This article is included. }\end{array}$ \\
\hline 72 & $\begin{array}{l}\text { A roadmap } \\
\text { for smart } \\
\text { city services } \\
\text { to address } \\
\text { challenges } \\
\text { faced by } \\
\text { small busi- } \\
\text { nesses in } \\
\text { South Af- } \\
\text { rica }\end{array}$ & $\begin{array}{l}\text { du Ples- } \\
\text { sis, } \\
\text { Haydn; } \\
\text { Marnew } \\
\text { ick, } \\
\text { Annlize } \\
\text { L. }\end{array}$ & 2017 & $\begin{array}{c}\text { SOUTH } \\
\text { AFRI- } \\
\text { CAN } \\
\text { JOUR- } \\
\text { NAL OF } \\
\text { ECO- } \\
\text { NOMIC } \\
\text { AND } \\
\text { MAN- } \\
\text { AGE- } \\
\text { MENT } \\
\text { SCI- } \\
\text { ENCES } \\
\text { Volume: } \\
20 \text { Issue: } \\
1 \text { Article }\end{array}$ & $\begin{array}{l}\text { The high failure rate of } \\
\text { SMEs in South Africa, } \\
\text { among others, is at- } \\
\text { tributed to regulatory } \\
\text { compliance in this article. } \\
\text { As the focus of this paper } \\
\text { is on SMEs, it is not in- } \\
\text { cluded. }\end{array}$ \\
\hline
\end{tabular}




\begin{tabular}{|c|c|c|c|c|c|}
\hline & & & & $\begin{array}{c}\text { Number: } \\
\text { a1631 } \\
\text { DOI: } \\
\text { 10.4102/sa } \\
\text { jems.v20i } \\
1.1631 \\
\text { Pub- } \\
\text { lished: } \\
\text { SEP 29 } \\
2017\end{array}$ & \\
\hline 73 & $\begin{array}{l}\text { Firm-level } \\
\text { determi- } \\
\text { nants of tax } \\
\text { evasion in } \\
\text { transition } \\
\text { economies }\end{array}$ & $\begin{array}{l}\text { Abdix- } \\
\text { hiku, } \\
\text { Lumir; } \\
\text { Kras- } \\
\text { niqi, } \\
\text { Besnik; } \\
\text { Pugh, } \\
\text { Geoff; } \\
\text { Hashi, } \\
\text { Iraj }\end{array}$ & 2017 & $\begin{array}{c}\text { ECO- } \\
\text { NOMIC } \\
\text { SYSTEMS } \\
\text { Volume: } \\
\text { 41 Issue: } \\
\text { 3 Pages: } \\
\text { 354-366 } \\
\text { DOI: } \\
\text { 10.1016/j.e } \\
\text { co- } \\
\text { sys.2016.1 } \\
\text { 2.004 } \\
\text { Pub- } \\
\text { lished: } \\
\text { SEP 2017 }\end{array}$ & $\begin{array}{l}\text { The article examined the } \\
\text { determinants of firm-level } \\
\text { tax evasion. It is not in- } \\
\text { cluded in my research. }\end{array}$ \\
\hline 74 & $\begin{array}{l}\text { CORRUP- } \\
\text { TION IN } \\
\text { THE } \\
\text { PHARMA- } \\
\text { CEUTICAL } \\
\text { SECTOR. } \\
\text { ANALYSIS } \\
\text { OF ITS IM- } \\
\text { PACT IN } \\
\text { THE EU- } \\
\text { ROPEAN } \\
\text { CONTEXT } \\
\text { AND ITS } \\
\text { IM- } \\
\text { PORTANC }\end{array}$ & $\begin{array}{l}\text { Men- } \\
\text { doza } \\
\text { Calde- } \\
\text { ron, Sil- } \\
\text { via }\end{array}$ & 2017 & $\begin{array}{c}\text { REVISTA } \\
\text { GEN- } \\
\text { ERAL DE } \\
\text { DERECH } \\
\text { O PENAL } \\
\text { Issue: } 27 \\
\text { Article } \\
\text { Number: } \\
418561 \\
\text { Pub- } \\
\text { lished: } \\
\text { MAY } \\
2017\end{array}$ & $\begin{array}{l}\text { The article focused on dif- } \\
\text { ferent forms of corruption } \\
\text { in the pharmaceutical in- } \\
\text { dustry in Europe and the } \\
\text { case of Spain. It is not in- } \\
\text { cluded in my research. }\end{array}$ \\
\hline
\end{tabular}




\begin{tabular}{|c|c|c|c|c|c|}
\hline & $\begin{array}{l}\text { E IN SPAN- } \\
\text { ISH CRIMI- } \\
\text { NAL LAW }\end{array}$ & & & & \\
\hline 75 & $\begin{array}{l}\text { An institu- } \\
\text { tional per- } \\
\text { spective on } \\
\text { corruption } \\
\text { in transition } \\
\text { economies }\end{array}$ & $\begin{array}{l}\text { Alon, } \\
\text { Anna; } \\
\text { Hage- } \\
\text { man, } \\
\text { Amy M }\end{array}$ & 2017 & $\begin{array}{c}\text { CORPO- } \\
\text { RATE } \\
\text { GOV- } \\
\text { ERN- } \\
\text { ANCE- } \\
\text { AN IN- } \\
\text { TERNA- } \\
\text { TIONAL } \\
\text { REVIEW } \\
\text { Volume: } \\
\text { 25 Issue: } \\
3 \text { Special } \\
\text { Issue: SI } \\
\text { Pages: } \\
\text { 155-166 } \\
\text { DOI: } \\
\text { 10.1111/co } \\
\text { rg.12199 } \\
\text { Pub- } \\
\text { lished: } \\
\text { MAY } \\
\text { 2017 }\end{array}$ & $\begin{array}{l}\text { Based on the data from } \\
5,000 \text { firms in transition } \\
\text { economies, the article ex- } \\
\text { amined the environment, } \\
\text { where dispositional trust } \\
\text { was found varying, with } \\
\text { the focus on institutional } \\
\text { landscape. It is included. }\end{array}$ \\
\hline 76 & $\begin{array}{l}\text { Willing to } \\
\text { share? Tax } \\
\text { compliance } \\
\text { and gender } \\
\text { in Europe } \\
\text { and Amer- } \\
\text { ica }\end{array}$ & $\begin{array}{l}\text { D'Attom } \\
\text { a, John; } \\
\text { Volintir } \\
\text { u, Clara; } \\
\text { Steinmo } \\
\text {, Sven }\end{array}$ & 2017 & $\begin{array}{c}\text { RE- } \\
\text { SEARCH } \\
\text { \& POLI- } \\
\text { TICS Vol- } \\
\text { ume: } 4 \text { Is- } \\
\text { sue: } 2 \text { Ar- } \\
\text { ticle } \\
\text { Number: } \\
\text { UNSP } \\
\text { 205316801 } \\
7707151 \\
\text { DOI: } \\
\text { 10.1177/20 } \\
531680177 \\
07151\end{array}$ & $\begin{array}{l}\text { The article investigated } \\
\text { the gender difference in } \\
\text { tax compliance in the US, } \\
\text { UK, Sweden and Italy. It } \\
\text { is included. }\end{array}$ \\
\hline
\end{tabular}




\begin{tabular}{|c|c|c|c|c|c|}
\hline & & & & $\begin{array}{c}\text { Pub- } \\
\text { lished: } \\
\text { APRJUN } \\
2017\end{array}$ & \\
\hline 77 & $\begin{array}{l}\text { Cultural } \\
\text { norms, the } \\
\text { persistence } \\
\text { of tax eva- } \\
\text { sion, and } \\
\text { economic } \\
\text { growth }\end{array}$ & $\begin{array}{l}\text { Varvari- } \\
\text { gos, Di- } \\
\text { mitrios }\end{array}$ & 2017 & $\begin{array}{c}\text { ECO- } \\
\text { NOMIC } \\
\text { THEORY } \\
\text { Volume: } \\
\text { 63 Issue: } \\
\text { 4 Pages: } \\
\text { 961-995 } \\
\text { DOI: } \\
\text { 10.1007/s0 } \\
0199-016- \\
\text { 0976-1 } \\
\text { Pub- } \\
\text { lished: } \\
\text { APR 2017 }\end{array}$ & $\begin{array}{l}\text { The author studied the } \\
\text { cultural influence on tax } \\
\text { compliance. It is included } \\
\text { in my research. }\end{array}$ \\
\hline 78 & $\begin{array}{l}\text { ANTI-COR- } \\
\text { RUPTION } \\
\text { A Case of } \\
\text { "Good, but } \\
\text { Could Do } \\
\text { Better" }\end{array}$ & $\begin{array}{l}\text { Hough, } \\
\text { Dan }\end{array}$ & 2017 & $\begin{array}{c}\text { GER- } \\
\text { MAN } \\
\text { POLITICS } \\
\text { AND SO- } \\
\text { CIETY } \\
\text { Volume: } \\
35 \text { Issue: } \\
1 \text { Pages: } \\
63-82 \\
\text { DOI: } \\
\text { 10.3167/g } \\
\text { ps.2017.35 } \\
0104 \text { Pub- } \\
\text { lished: } \\
\text { MAR } \\
2017\end{array}$ & $\begin{array}{l}\text { The article shed light on } \\
\text { Germany's anti-corrup- } \\
\text { tion infrastructure and re- } \\
\text { form efforts. It is in- } \\
\text { cluded. }\end{array}$ \\
\hline
\end{tabular}




\begin{tabular}{|c|c|c|c|c|c|}
\hline 79 & $\begin{array}{l}\text { FUNDA- } \\
\text { MENTAL } \\
\text { THEORETI- } \\
\text { CAL IS- } \\
\text { SUES ON } \\
\text { CRIMINAL } \\
\text { COMPLI- } \\
\text { ANCE }\end{array}$ & $\begin{array}{l}\text { Pablo } \\
\text { Montiel, } \\
\text { Juan }\end{array}$ & 2017 & $\begin{array}{c}\text { EN } \\
\text { LETRA } \\
\text { Volume: } \\
4 \text { Issue: } 7 \\
\text { Pages: 21- } \\
\text { 47 Pub- } \\
\text { lished: } \\
\text { MAR } \\
2017\end{array}$ & $\begin{array}{l}\text { This article focused on } \\
\text { economic criminal law } \\
\text { and corporate self-regula- } \\
\text { tion. It is not included in } \\
\text { my research. }\end{array}$ \\
\hline 80 & $\begin{array}{l}\text { REFORM } \\
\text { OF REGU- } \\
\text { LATORY } \\
\text { POLICY IN } \\
\text { THE FIELD } \\
\text { OF SUPER- } \\
\text { VISION OF } \\
\text { AUDIT AC- } \\
\text { TIVITY }\end{array}$ & $\begin{array}{l}\text { Kantsir, } \\
\text { Iryna; } \\
\text { Plekan, } \\
\text { Marija }\end{array}$ & 2017 & $\begin{array}{c}\text { BALTIC } \\
\text { JOUR- } \\
\text { NAL OF } \\
\text { ECO- } \\
\text { NOMIC } \\
\text { STUDIES } \\
\text { Volume: } \\
3 \text { Issue: } 5 \\
\text { Pages: } \\
\text { 170-174 } \\
\text { DOI: } \\
\text { 10.30525/2 } \\
256- \\
0742 / 2017 \\
-3-5-170- \\
174 \text { Pub- } \\
\text { lished: } \\
2017\end{array}$ & $\begin{array}{l}\text { The article examined } \\
\text { Ukraine's reforms in reg- } \\
\text { ulatory system and audit } \\
\text { activity to prepare for EU } \\
\text { accession. It is included. }\end{array}$ \\
\hline 81 & $\begin{array}{l}\text { DEVELOP- } \\
\text { MENT OF } \\
\text { THE SO- } \\
\text { CIALLY- } \\
\text { ORIENTED } \\
\text { ECONOMY } \\
\text { IN } \\
\text { UKRAINE: } \\
\text { PREREQUI- } \\
\text { SITES AND }\end{array}$ & $\begin{array}{l}\text { Kravchu } \\
\text { k, Nata- } \\
\text { liia; Tar- } \\
\text { asovych, } \\
\text { Liudmyl } \\
\text { a; Yare- } \\
\text { mova, } \\
\text { Maryna }\end{array}$ & 2017 & $\begin{array}{c}\text { BALTIC } \\
\text { JOUR- } \\
\text { NAL OF } \\
\text { ECO- } \\
\text { NOMIC } \\
\text { STUDIES } \\
\text { Volume: } \\
3 \text { Issue: } 2 \\
\text { Pages: 66- } \\
72 \text { Pub- } \\
\text { lished: } \\
2017\end{array}$ & $\begin{array}{l}\text { The authors studied pre- } \\
\text { requisites and prospects } \\
\text { of developing socially ori- } \\
\text { ented economy and de- } \\
\text { mocracy in Ukraine. It is } \\
\text { not included in my re- } \\
\text { search. }\end{array}$ \\
\hline
\end{tabular}




\begin{tabular}{|c|c|c|c|c|c|}
\hline & $\begin{array}{l}\text { STRATE- } \\
\text { GIC FORE- } \\
\text { CASTING }\end{array}$ & & & & \\
\hline 82 & $\begin{array}{l}\text { MORAL } \\
\text { RISK IN } \\
\text { CIVIL LIA- } \\
\text { BILITY IN- } \\
\text { SURANCE } \\
\text { CON- } \\
\text { TRACTS } \\
\text { "D\&O" (Di- } \\
\text { rectors and } \\
\text { Officers Li- } \\
\text { ability In- } \\
\text { surance) }\end{array}$ & 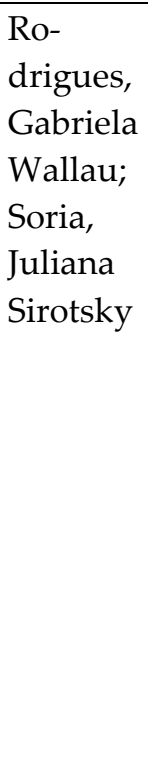 & 2017 & $\begin{array}{l}\text { REVISTA } \\
\text { DO } \\
\text { CURSO } \\
\text { DE } \\
\text { DIREITO } \\
\text { DO UNI- } \\
\text { FOR Vol- } \\
\text { ume: } 8 \text { Is- } \\
\text { sue: } 2 \\
\text { Pages: } 23- \\
39 \text { DOI: } \\
10.24862 / r \\
\text { cdu.v8i2.5 } \\
49 \text { Pub- } \\
\text { lished: } \\
2017\end{array}$ & $\begin{array}{l}\text { Based on the new regula- } \\
\text { tion on insurance in Bra- } \\
\text { zil, the article examined } \\
\text { insurance payments and } \\
\text { corruption. It is not in- } \\
\text { cluded in my research. }\end{array}$ \\
\hline 83 & $\begin{array}{l}\text { The Under- } \\
\text { ground } \\
\text { Economy in } \\
\text { Times of } \\
\text { Crisis: An } \\
\text { Analysis of } \\
\text { Undeclared } \\
\text { Work in Eu- } \\
\text { rope }\end{array}$ & $\begin{array}{l}\text { Perez- } \\
\text { Magro, } \\
\text { Monica; } \\
\text { Maria } \\
\text { Millan- } \\
\text { Tapia, } \\
\text { Jose; } \\
\text { Millan- } \\
\text { Tapia, } \\
\text { Ana; } \\
\text { Roman- } \\
\text { Diaz, } \\
\text { Concepc } \\
\text { ion }\end{array}$ & 2017 & $\begin{array}{l}\text { REVISTA } \\
\text { DE ESTU- } \\
\text { DIOS } \\
\text { ANDA- } \\
\text { LUCES } \\
\text { Volume: } \\
\text { 34 Issue: } \\
1 \text { Pages: } \\
\text { 453-501 } \\
\text { DOI: } \\
\text { 10.12795/r } \\
\text { ea.2017.i3 } \\
4.16 \text { Pub- } \\
\text { lished: } \\
2017\end{array}$ & $\begin{array}{l}\text { The authors looked into } \\
\text { undeclared work as part } \\
\text { of the shadow economy } \\
\text { and non-compliance in } \\
\text { the EU and its institu- } \\
\text { tional setting. It is in- } \\
\text { cluded in my research. }\end{array}$ \\
\hline 84 & $\begin{array}{l}\text { DOES } \\
\text { CHINA } \\
\text { NEED AN } \\
\end{array}$ & $\begin{array}{l}\text { Jiang, } \\
\text { Dong }\end{array}$ & 2017 & $\begin{array}{l}\text { FRON- } \\
\text { TIERS OF } \\
\text { LAW IN }\end{array}$ & $\begin{array}{l}\text { The article evaluated } \\
\text { China's response to US } \\
\text { FCPA and possible }\end{array}$ \\
\hline
\end{tabular}




\begin{tabular}{|c|c|c|c|c|c|}
\hline & $\begin{array}{l}\text { ANTI-FOR- } \\
\text { EIGN BRIB- } \\
\text { ERY STAT- } \\
\text { UTE? } \\
\text { SOME LES- } \\
\text { SONS } \\
\text { FROM THE } \\
\text { FCPA OF } \\
\text { US }\end{array}$ & & & $\begin{array}{c}\text { CHINA } \\
\text { Volume: } \\
12 \text { Issue: } \\
3 \text { Pages: } \\
355-371 \\
\text { DOI: } \\
\text { 10.3868/s0 } \\
50-006- \\
017-0020- \\
9 \text { Pub- } \\
\text { lished: } \\
2017\end{array}$ & $\begin{array}{l}\text { enactment of its own anti- } \\
\text { corruption framework. It } \\
\text { is included in my study. }\end{array}$ \\
\hline 85 & $\begin{array}{l}\text { How expat- } \\
\text { riates work } \\
\text { in danger- } \\
\text { ous envi- } \\
\text { ronments of } \\
\text { pervasive } \\
\text { corruption }\end{array}$ & $\begin{array}{l}\text { Grep- } \\
\text { pin, } \\
\text { Carl; } \\
\text { Carls- } \\
\text { son, Bo; } \\
\text { Wolf- } \\
\text { berg, } \\
\text { Adrian; } \\
\text { Ufere, } \\
\text { Nnaoke }\end{array}$ & 2017 & $\begin{array}{c}\text { JOUR- } \\
\text { NAL OF } \\
\text { GLOBAL } \\
\text { MOBIL- } \\
\text { ITY-THE } \\
\text { HOME } \\
\text { OF EX- } \\
\text { PATRI- } \\
\text { ATE } \\
\text { MAN- } \\
\text { AGE- } \\
\text { MENT } \\
\text { RE- } \\
\text { SEARCH } \\
\text { Volume: } \\
5 \text { Issue: } 4 \\
\text { Special } \\
\text { Issue: SI } \\
\text { Pages: } \\
443-460 \\
\text { DOI: } \\
\text { 10.1108/J } \\
\text { GM-07- } \\
\text { 2017-0030 } \\
\text { Pub- } \\
\text { lished: } \\
\text { 2017 }\end{array}$ & $\begin{array}{l}\text { Based on interviews with } \\
30 \text { US executives, the arti- } \\
\text { cle aimed to answer ques- } \\
\text { tions on corruption and } \\
\text { working environment. } \\
\text { This is not included in my } \\
\text { research. }\end{array}$ \\
\hline
\end{tabular}




\begin{tabular}{|c|c|c|c|c|c|}
\hline 86 & $\begin{array}{l}\text { Practices of } \\
\text { corporate } \\
\text { integrity } \\
\text { and ac- } \\
\text { countability } \\
\text { of non- } \\
\text { profit or- } \\
\text { ganizations } \\
\text { in Malaysia }\end{array}$ & $\begin{array}{l}\text { Atan, } \\
\text { Ruhaya; } \\
\text { Alam, } \\
\text { Md. } \\
\text { Mahmu } \\
\text { dul; } \\
\text { Said, Ja- } \\
\text { maliah }\end{array}$ & 2017 & $\begin{array}{c}\text { INTER- } \\
\text { NA- } \\
\text { TIONAL } \\
\text { JOUR- } \\
\text { NAL OF } \\
\text { SOCIAL } \\
\text { ECO- } \\
\text { NOMICS } \\
\text { Volume: } \\
44 \text { Issue: } \\
12 \text { Pages: } \\
2271-2286 \\
\text { DOI: } \\
\text { 10.1108/IJ } \\
\text { SE-09- } \\
2016-0260 \\
\text { Pub- } \\
\text { lished: } \\
\text { 2017 }\end{array}$ & $\begin{array}{l}\text { The intention of this arti- } \\
\text { cle is to examine the cor- } \\
\text { porate integrity system in } \\
\text { NPOs in Malaysia. It is } \\
\text { not included in my study. }\end{array}$ \\
\hline 87 & $\begin{array}{l}\text { CONFIS- } \\
\text { CATION } \\
\text { OF PECU- } \\
\text { NIARY } \\
\text { GAIN IN } \\
\text { THE CON- } \\
\text { TEXT OF } \\
\text { INTERNA- } \\
\text { TIONAL } \\
\text { REGULA- } \\
\text { TIONS } \\
\text { AND COM- } \\
\text { BATING } \\
\text { BRIBERY }\end{array}$ & $\begin{array}{l}\text { Galiot, } \\
\text { Mijo }\end{array}$ & 2017 & $\begin{array}{c}\text { ZBORNI } \\
\text { K } \\
\text { PRAVNO } \\
\text { G } \\
\text { FAKULT } \\
\text { ETA } \\
\text { SVEU- } \\
\text { CILISTA } \\
\text { U RIJECI } \\
\text { Volume: } \\
\text { 38 Issue: } \\
1 \text { Pages: } \\
\text { 547-571 } \\
\text { Pub- } \\
\text { lished: } \\
\text { 2017 }\end{array}$ & $\begin{array}{l}\text { The article examined the } \\
\text { confiscation of pecuniary } \\
\text { gains by criminal offenses } \\
\text { and relevant international } \\
\text { and national regulations. } \\
\text { It is included in my pa- } \\
\text { per. }\end{array}$ \\
\hline 88 & $\begin{array}{l}\text { Evaluating } \\
\text { the individ- } \\
\text { ual- and } \\
\text { country- } \\
\text { level }\end{array}$ & $\begin{array}{l}\text { Wil- } \\
\text { liams, } \\
\text { Colin C; }\end{array}$ & 2017 & $\begin{array}{l}\text { JOUR- } \\
\text { NAL OF } \\
\text { ECO- } \\
\text { NOMIC } \\
\text { STUDIES }\end{array}$ & $\begin{array}{l}\text { Using } 2010 \text { survey, the ar- } \\
\text { ticle identified a group of } \\
\text { tax payers with low tax } \\
\text { moral to identify individ- } \\
\text { ual and country level }\end{array}$ \\
\hline
\end{tabular}




\begin{tabular}{|c|c|c|c|c|c|}
\hline & $\begin{array}{l}\text { variations } \\
\text { in tax mo- } \\
\text { rale Evi- } \\
\text { dence from } \\
35 \text { Eurasian } \\
\text { countries }\end{array}$ & $\begin{array}{l}\text { Kras- } \\
\text { niqi, } \\
\text { Besnik }\end{array}$ & & $\begin{array}{c}\text { Volume: } \\
\text { 44 Issue: } \\
5 \text { Pages: } \\
816-832 \\
\text { DOI: } \\
\text { 10.1108/JE } \\
\text { S-09-2016- } \\
0182 \text { Pub- } \\
\text { lished: } \\
2017\end{array}$ & $\begin{array}{l}\text { variations. This article is } \\
\text { included. }\end{array}$ \\
\hline 89 & $\begin{array}{l}\text { Does the } \\
\text { corruption } \\
\text { perception } \\
\text { level of a } \\
\text { country af- } \\
\text { fect listed } \\
\text { firms' IFRS } \\
7 \text { risk dis- } \\
\text { closure } \\
\text { compli- } \\
\text { ance? }\end{array}$ & $\begin{array}{l}\text { Agyei- } \\
\text { Mensah, } \\
\text { Ben } \\
\text { Kwame }\end{array}$ & 2017 & $\begin{array}{c}\text { CORPO- } \\
\text { RATE } \\
\text { GOV- } \\
\text { ERN- } \\
\text { ANCE- } \\
\text { THE IN- } \\
\text { TERNA- } \\
\text { TIONAL } \\
\text { JOUR- } \\
\text { NAL OF } \\
\text { BUSI- } \\
\text { NESS IN } \\
\text { SOCIETY } \\
\text { Volume: } \\
\text { 17 Issue: } \\
4 \text { Pages: } \\
\text { 727-747 } \\
\text { DOI: } \\
\text { 10.1108/C } \\
\text { G-10- } \\
\text { 2016-0195 } \\
\text { Pub- } \\
\text { lished: } \\
\text { 2017 }\end{array}$ & $\begin{array}{l}\text { The authors reviewed the } \\
\text { relationships among cor- } \\
\text { porate governance, com- } \\
\text { pliance and corruption. It } \\
\text { is not included in my re- } \\
\text { search. }\end{array}$ \\
\hline 90 & $\begin{array}{l}\text { Tax havens: } \\
\text { conduits for } \\
\text { corporate } \\
\text { tax malfea- } \\
\text { sance }\end{array}$ & $\begin{array}{l}\text { Jalan, } \\
\text { Akank- } \\
\text { sha; }\end{array}$ & 2017 & $\begin{array}{l}\text { JOUR- } \\
\text { NAL OF } \\
\text { FINAN- } \\
\text { CIAL } \\
\text { REGULA- } \\
\text { TION }\end{array}$ & $\begin{array}{l}\text { The purpose of this article } \\
\text { is to demystify tax havens } \\
\text { from MNC point of view. } \\
\text { It is not included in my } \\
\text { study. }\end{array}$ \\
\hline
\end{tabular}




\begin{tabular}{|c|c|c|c|c|c|}
\hline & & $\begin{array}{l}\text { Vaidya- } \\
\text { nathan, } \\
\text { R }\end{array}$ & & $\begin{array}{c}\text { AND } \\
\text { COMPLI- } \\
\text { ANCE } \\
\text { Volume: } \\
25 \text { Issue: } \\
1 \text { Pages: } \\
\text { 86-104 } \\
\text { DOI: } \\
\text { 10.1108/JF } \\
\text { RC-04- } \\
\text { 2016-0039 } \\
\text { Pub- } \\
\text { lished: } \\
\text { 2017 }\end{array}$ & \\
\hline 91 & $\begin{array}{l}\text { Structuring } \\
\text { supervisory } \\
\text { board for } \\
\text { an anti-cor- } \\
\text { ruption } \\
\text { strategy: a } \\
\text { new appli- } \\
\text { cation of a } \\
\text { compliance } \\
\text { system }\end{array}$ & $\begin{array}{l}\text { Previ- } \\
\text { tali, } \\
\text { Pietro; } \\
\text { Cerchi- } \\
\text { ello, } \\
\text { Paola }\end{array}$ & 2017 & $\begin{array}{c}\text { CORPO- } \\
\text { RATE } \\
\text { GOV- } \\
\text { ERN- } \\
\text { ANCE- } \\
\text { THE IN- } \\
\text { TERNA- } \\
\text { TIONAL } \\
\text { JOUR- } \\
\text { NAL OF } \\
\text { BUSI- } \\
\text { NESS IN } \\
\text { SOCIETY } \\
\text { Volume: } \\
\text { 17 Issue: } \\
1 \text { Pages: } \\
\text { 48-63 } \\
\text { DOI: } \\
10.1108 / C \\
\text { G-09- } \\
\text { 2015-0126 } \\
\text { Pub- } \\
\text { lished: } \\
\text { 2017 }\end{array}$ & $\begin{array}{l}\text { The article analysed the } \\
\text { innovation in corporate } \\
\text { supervisory body and } \\
\text { anti-corruption measures. } \\
\text { It is not included in my } \\
\text { study. }\end{array}$ \\
\hline
\end{tabular}




\begin{tabular}{|c|c|c|c|c|c|}
\hline 92 & $\begin{array}{l}\text { The deter- } \\
\text { minants of } \\
\text { tax morale } \\
\text { in Pakistan }\end{array}$ & $\begin{array}{l}\text { Cyan, } \\
\text { Mushar- } \\
\text { raf R; } \\
\text { Koumpi } \\
\text { as, An- } \\
\text { tonios } \\
\text { M; Mar- } \\
\text { tinez- } \\
\text { Vazquez } \\
\text {, Jorge }\end{array}$ & 2016 & $\begin{array}{c}\text { JOUR- } \\
\text { NAL OF } \\
\text { ASIAN } \\
\text { ECO- } \\
\text { NOMICS } \\
\text { Volume: } \\
\text { 47 Pages: } \\
23-34 \\
\text { DOI: } \\
\text { 10.1016/j.a } \\
\text { sieco.2016 } \\
.09 .002 \\
\text { Pub- } \\
\text { lished: } \\
\text { DEC 2016 }\end{array}$ & $\begin{array}{l}\text { The authors shed light on } \\
\text { determinants of tax moral } \\
\text { in Pakistan. It is included. }\end{array}$ \\
\hline 93 & $\begin{array}{l}\text { ANTI-COR- } \\
\text { RUPTION } \\
\text { BODIES } \\
\text { AND THE } \\
\text { USE OF } \\
\text { SANC- } \\
\text { TIONING } \\
\text { POWERS: } \\
\text { LIMITS } \\
\text { AND PRO- } \\
\text { POSALS } \\
\text { FOR PRE- } \\
\text { VENTING } \\
\text { CORRUP- } \\
\text { TION. IN } \\
\text { PARTICU- } \\
\text { LAR, THE } \\
\text { CASE OF } \\
\text { CATALO- } \\
\text { NIA'S } \\
\text { ANTI- } \\
\text { FRAUD } \\
\text { OFFICE }\end{array}$ & $\begin{array}{l}\text { Capdefe } \\
\text { rro } \\
\text { Villa- } \\
\text { grasa, } \\
\text { Oscar }\end{array}$ & 2016 & $\begin{array}{c}\text { EVISTA } \\
\text { CATA- } \\
\text { LANA } \\
\text { DE DRET } \\
\text { PUBLIC } \\
\text { Issue: } 53 \\
\text { Pages: 13- } \\
\text { 30 DOI: } \\
\text { 10.2436/rc } \\
\text { dp.i53.201 } \\
\text { 6.2821 } \\
\text { Pub- } \\
\text { lished: } \\
\text { DEC 2016 }\end{array}$ & $\begin{array}{l}\text { The article centered } \\
\text { around the role of control } \\
\text { bodies as part of the fight } \\
\text { against corruption and } \\
\text { their sanctioning power } \\
\text { in Spain. It is included in } \\
\text { my study. }\end{array}$ \\
\hline
\end{tabular}




\begin{tabular}{|c|c|c|c|c|c|}
\hline 94 & $\begin{array}{l}\text { Ceci n'est } \\
\text { pas une } \\
\text { pipe! Cor- } \\
\text { porate Gov- } \\
\text { ernance } \\
\text { practices } \\
\text { under two } \\
\text { political re- } \\
\text { gimes in } \\
\text { Bangladesh: } \\
\text { A political } \\
\text { economy } \\
\text { perspective }\end{array}$ & $\begin{array}{l}\text { Nurunn } \\
\text { abi, } \\
\text { Moham } \\
\text { mad; } \\
\text { Hossain, } \\
\text { Monirul } \\
\text { Alam; } \\
\text { Al- } \\
\text { Mosa, } \\
\text { Saad A }\end{array}$ & 2016 & $\begin{array}{c}\text { INTER- } \\
\text { NA- } \\
\text { TIONAL } \\
\text { JOUR- } \\
\text { NAL OF } \\
\text { DISCLO- } \\
\text { SURE } \\
\text { AND } \\
\text { GOV- } \\
\text { ERN- } \\
\text { ANCE } \\
\text { Volume: } \\
\text { 13 Issue: } \\
4 \text { Pages: } \\
\text { 329-363 } \\
\text { DOI: } \\
\text { 10.1057/s4 } \\
\text { 1310-016- } \\
\text { 0001- } \\
\text { 8 Pub- } \\
\text { lished: } \\
\text { NOV 2016 }\end{array}$ & $\begin{array}{l}\text { The authors examined the } \\
\text { case of Bangladesh and its } \\
\text { corporate governance. It } \\
\text { is not included in my } \\
\text { study. }\end{array}$ \\
\hline 95 & $\begin{array}{l}\text { Cultural Di- } \\
\text { mensions of } \\
\text { Power/Kno } \\
\text { wledge: The } \\
\text { Challenges } \\
\text { of Measur- } \\
\text { ing Vio- } \\
\text { lence } \\
\text { against } \\
\text { Women }\end{array}$ & $\begin{array}{l}\text { Merry, } \\
\text { Sally } \\
\text { Engle }\end{array}$ & 2016 & $\begin{array}{c}\text { SOCIO- } \\
\text { LOGIE } \\
\text { DU TRA- } \\
\text { VAIL Vo- } \\
\text { lume: } 58 \\
\text { Issue: } 4 \\
\text { Pages: } \\
\text { 370-380 } \\
\text { DOI: } \\
\text { 10.1016/j.s } \\
\text { oc- } \\
\text { tra.2016.0 } \\
\text { 9.017 Pu- } \\
\text { blished: } \\
\text { OCT-DEC } \\
2016\end{array}$ & $\begin{array}{l}\text { The article focused on in- } \\
\text { ternational governance } \\
\text { from the perspective of } \\
\text { violence against women. } \\
\text { With little linkage to cor- } \\
\text { ruption, it is not included } \\
\text { in my study. }\end{array}$ \\
\hline
\end{tabular}




\begin{tabular}{|c|c|c|c|c|c|}
\hline 96 & $\begin{array}{l}\text { I Know } \\
\text { What You } \\
\text { Did Last } \\
\text { Cycle: Im- } \\
\text { proving the } \\
\text { Detection of } \\
\text { State Cam- } \\
\text { paign Fi- } \\
\text { nance Vio- } \\
\text { lations }\end{array}$ & $\begin{array}{l}\text { Seljan, } \\
\text { Ellen C; } \\
\text { Loch- } \\
\text { ner, } \\
\text { Todd; } \\
\text { Gold, } \\
\text { Maya; } \\
\text { Davis, } \\
\text { Walker }\end{array}$ & 2016 & $\begin{array}{c}\text { ELEC- } \\
\text { TION } \\
\text { LAW } \\
\text { JOUR- } \\
\text { NAL Vol- } \\
\text { ume: } 15 \\
\text { Issue: } 3 \\
\text { Pages: } \\
\text { 197-213 } \\
\text { DOI: } \\
\text { 10.1089/elj } \\
.2015 .0348 \\
\text { Pub- } \\
\text { lished: } \\
\text { SEP 2016 }\end{array}$ & $\begin{array}{l}\text { The authors examined the } \\
\text { political campaign financ- } \\
\text { ing regulatory agencies } \\
\text { and regulates in the US. } \\
\text { While the topic may have } \\
\text { some linkages, this is not } \\
\text { included in my study. }\end{array}$ \\
\hline 97 & $\begin{array}{l}\text { Mandatory } \\
\text { versus vol- } \\
\text { untary dis- } \\
\text { closures: } \\
\text { Drivers of } \\
\text { proactive } \\
\text { information } \\
\text { provision } \\
\text { by local } \\
\text { govern- } \\
\text { ments in } \\
\text { Central } \\
\text { America }\end{array}$ & $\begin{array}{l}\text { Garcia- } \\
\text { Tabuyo, } \\
\text { Manoli; } \\
\text { Saez- } \\
\text { Martin, } \\
\text { Alejandr } \\
\text { o; Del } \\
\text { Carmen } \\
\text { Caba- } \\
\text { Perez, } \\
\text { Maria }\end{array}$ & 2016 & $\begin{array}{c}\text { INFOR- } \\
\text { MATION } \\
\text { DEVEL- } \\
\text { OPMENT } \\
\text { Volume: } \\
\text { 32 Issue: } \\
4 \text { Pages: } \\
\text { 1199-1215 } \\
\text { DOI: } \\
\text { 10.1177/02 } \\
\text { 666669155 } \\
\text { 95260 } \\
\text { Pub- } \\
\text { lished: } \\
\text { SEP 2016 }\end{array}$ & $\begin{array}{l}\text { Focusing on Central } \\
\text { America, the article inves- } \\
\text { tigated online proactive } \\
\text { information disclosure } \\
\text { and factors influencing } \\
\text { the decision. It is included } \\
\text { in my study. }\end{array}$ \\
\hline 98 & $\begin{array}{l}\text { The hidden } \\
\text { compliance } \\
\text { cost of } \\
\text { VAT: An } \\
\text { exploration } \\
\text { of psycho- } \\
\text { logical and } \\
\text { corruption } \\
\text { costs of } \\
\text { VAT in a }\end{array}$ & $\begin{array}{l}\text { Faridy, } \\
\text { Nahida; } \\
\text { Freuden } \\
\text { berg, } \\
\text { Brett, } \\
\text { Sarker, } \\
\text { Tapan; } \\
\text { Copp, } \\
\text { Richard }\end{array}$ & 2016 & $\begin{array}{l}\text { EJOUR- } \\
\text { NAL OF } \\
\text { TAX RE- } \\
\text { SEARCH } \\
\text { Volume: } \\
14 \text { Issue: } \\
\text { 1 Pages: } \\
\text { 166-205 }\end{array}$ & $\begin{array}{l}\text { The authors looked into } \\
\text { psychological costs of } \\
\text { VAT for SMEs. It is not } \\
\text { included in my research. }\end{array}$ \\
\hline
\end{tabular}




\begin{tabular}{|c|c|c|c|c|c|}
\hline & $\begin{array}{l}\text { developing } \\
\text { country }\end{array}$ & & & $\begin{array}{c}\text { Pub- } \\
\text { lished: } \\
\text { JUL } 2016\end{array}$ & \\
\hline 99 & $\begin{array}{l}\text { JUST } \\
\text { ABOUT } \\
\text { TIME: DE- } \\
\text { FENDING } \\
\text { DEMOC- } \\
\text { RACY } \\
\text { AND THE } \\
\text { FIGHT } \\
\text { AGAINST } \\
\text { CORRUP- } \\
\text { TION }\end{array}$ & $\begin{array}{l}\text { Ozarsla } \\
\text { n, E. } \\
\text { Oya }\end{array}$ & 2016 & $\begin{array}{c}\text { TURKISH } \\
\text { POLICY } \\
\text { QUAR- } \\
\text { TERLY } \\
\text { Volume: } \\
\text { 15 Issue: } \\
2 \text { Pages: } \\
\text { 107-116 } \\
\text { Pub- } \\
\text { lished: } \\
\text { SUM } 2016\end{array}$ & $\begin{array}{l}\text { Examining the case of } \\
\text { Turkey, the article ex- } \\
\text { plained the country's } \\
\text { fight against corruption. It } \\
\text { is included in my re- } \\
\text { search. }\end{array}$ \\
\hline 100 & $\begin{array}{l}\text { An over- } \\
\text { view of Eu- } \\
\text { ropean } \\
\text { good prac- } \\
\text { tices in pub- } \\
\text { lic procure- } \\
\text { ment }\end{array}$ & $\begin{array}{l}\text { Popescu } \\
\text {, Ada; } \\
\text { Onofrei, } \\
\text { Mihaela; } \\
\text { Kelley, } \\
\text { Christo- } \\
\text { pher }\end{array}$ & 2016 & $\begin{array}{c}\text { EAST- } \\
\text { ERN } \\
\text { JOUR- } \\
\text { NAL OF } \\
\text { EURO- } \\
\text { PEAN } \\
\text { STUDIES } \\
\text { Volume: } \\
7 \text { Issue: } 1 \\
\text { Pages: } 81- \\
91 \text { Pub- } \\
\text { lished: } \\
\text { JUN 2016 }\end{array}$ & $\begin{array}{l}\text { The article covered public } \\
\text { procurement and associ- } \\
\text { ated corruption in Eu- } \\
\text { rope. This is included in } \\
\text { my study. }\end{array}$ \\
\hline 101 & $\begin{array}{l}\text { Anger and } \\
\text { enforce- } \\
\text { ment }\end{array}$ & $\begin{array}{l}\text { Akerlof, } \\
\text { Robert }\end{array}$ & 2016 & $\begin{array}{c}\text { JOUR- } \\
\text { NAL OF } \\
\text { ECO- } \\
\text { NOMIC } \\
\text { BEHAV- } \\
\text { IOR \& } \\
\text { ORGANI- } \\
\text { ZATION } \\
\text { Volume: } \\
\text { 126 Spe- } \\
\text { cial Issue: } \\
\text { SI Pages: }\end{array}$ & $\begin{array}{l}\text { Focusing on anger and } \\
\text { enforcement, the articles } \\
\text { examined rule violations. } \\
\text { It is included in my study. }\end{array}$ \\
\hline
\end{tabular}




\begin{tabular}{|c|c|c|c|c|c|}
\hline & & & & $\begin{array}{c}\text { 110-124 } \\
\text { DOI: } \\
\text { 10.1016/j.j } \\
\text { ebo.2015.1 } \\
0.022 \text { Part: } \\
\text { B Pub- } \\
\text { lished: } \\
\text { JUN 2016 }\end{array}$ & \\
\hline 102 & $\begin{array}{l}\text { An Inquiry } \\
\text { on Public } \\
\text { Corruption } \\
\text { and its De- } \\
\text { terminants }\end{array}$ & $\begin{array}{l}\text { Cas- } \\
\text { taneda } \\
\text { Rodri- } \\
\text { guez, } \\
\text { Victor } \\
\text { Mauri- } \\
\text { cio }\end{array}$ & 2016 & $\begin{array}{c}\text { REVISTA } \\
\text { MEXI- } \\
\text { CANA } \\
\text { DE CIEN- } \\
\text { CIAS PO- } \\
\text { LITICAS } \\
\text { Y SO- } \\
\text { CIALES } \\
\text { Volume: } \\
\text { 61 Issue: } \\
227 \\
\text { Pages: } \\
\text { 103-135 } \\
\text { Pub- } \\
\text { lished: } \\
\text { MAY- } \\
\text { AUG 2016 }\end{array}$ & $\begin{array}{l}\text { The author identified fac- } \\
\text { tors limiting the scope of } \\
\text { corruption in the public } \\
\text { sector. It is included. }\end{array}$ \\
\hline 103 & $\begin{array}{l}\text { From 'win- } \\
\text { dow dress- } \\
\text { ing' to 'door } \\
\text { openers'? } \\
\text { Freedom of } \\
\text { Information } \\
\text { legislation, } \\
\text { public de- } \\
\text { mand, and } \\
\text { state com- } \\
\text { pliance in } \\
\text { South East } \\
\text { Europe }\end{array}$ & $\begin{array}{l}\text { Camaj, } \\
\text { Lindita }\end{array}$ & 2016 & $\begin{array}{c}\text { GOV- } \\
\text { ERN- } \\
\text { MENT } \\
\text { INFOR- } \\
\text { MATION } \\
\text { QUAR- } \\
\text { TERLY } \\
\text { Volume: } \\
\text { 33 Issue: } \\
2 \text { Pages: } \\
\text { 346-357 } \\
\text { DOI: } \\
\text { 10.1016/j. } \\
\text { giq.2016.0 } \\
3.001\end{array}$ & $\begin{array}{l}\text { The article examined the } \\
\text { freedom of information } \\
\text { laws and compliance in } \\
\text { Albania, Kosovo and } \\
\text { Montenegro. This is in- } \\
\text { cluded in my study. }\end{array}$ \\
\hline
\end{tabular}




\begin{tabular}{|c|c|c|c|c|c|}
\hline & & & & $\begin{array}{c}\text { Pub- } \\
\text { lished: } \\
\text { APR } 2016\end{array}$ & \\
\hline 104 & $\begin{array}{l}\text { The Chi- } \\
\text { nese Com- } \\
\text { munist } \\
\text { Party and } \\
\text { People's } \\
\text { Courts: Ju- } \\
\text { dicial De- } \\
\text { pendence in } \\
\text { China }\end{array}$ & Li, Ling & 2016 & $\begin{array}{l}\text { AMERI- } \\
\text { CAN } \\
\text { JOUR- } \\
\text { NAL OF } \\
\text { COM- } \\
\text { PARA- } \\
\text { TIVE } \\
\text { LAW } \\
\text { Volume: } \\
\text { 64 Issue: } \\
\text { 1 Pages: } \\
\text { 37-74 } \\
\text { DOI: } \\
\text { 10.5131/A } \\
\text { JCL.2016. } \\
\text { 0002 Pub- } \\
\text { lished: } \\
\text { SPR 2016 }\end{array}$ & $\begin{array}{l}\text { The article elaborated the } \\
\text { relationship between } \\
\text { China's Communist party } \\
\text { and the court. It is not in- } \\
\text { cluded in my study. }\end{array}$ \\
\hline 105 & $\begin{array}{l}\text { See No Evil, } \\
\text { Hear No } \\
\text { Evil? As- } \\
\text { sessing Cor- } \\
\text { ruption } \\
\text { Risk Per- } \\
\text { ceptions } \\
\text { and Strate- } \\
\text { gies of Vic- } \\
\text { torian Pub- } \\
\text { lic Bodies }\end{array}$ & $\begin{array}{l}\text { van der } \\
\text { Wal, } \\
\text { Zeger; } \\
\text { Graycar, } \\
\text { Adam; } \\
\text { Kelly, } \\
\text { Kym }\end{array}$ & 2016 & $\begin{array}{c}\text { AUS- } \\
\text { TRAL- } \\
\text { IAN } \\
\text { JOUR- } \\
\text { NAL OF } \\
\text { PUBLIC } \\
\text { ADMIN- } \\
\text { ISTRA- } \\
\text { TION } \\
\text { Volume: } \\
75 \text { Issue: } \\
1 \text { Pages: } \\
\text { 3-17 DOI: } \\
\text { 10.1111/14 } \\
\text { 67- } \\
\text { 8500.1216 } \\
3 \text { Pub- } \\
\text { lished: }\end{array}$ & $\begin{array}{l}\text { The article examined the } \\
36 \text { Victorian public school } \\
\text { bodies and their percep- } \\
\text { tion of corruption in Aus- } \\
\text { tralia. It is included. }\end{array}$ \\
\hline
\end{tabular}




\begin{tabular}{|c|c|c|c|c|c|}
\hline & & & & $\begin{array}{c}\text { MAR } \\
2016\end{array}$ & \\
\hline 106 & $\begin{array}{l}\text { Turning a } \\
\text { Blind Eye to } \\
\text { Bribery: Ex- } \\
\text { plaining } \\
\text { Failures to } \\
\text { Comply } \\
\text { with the In- } \\
\text { ternational } \\
\text { Anti-cor- } \\
\text { ruption Re- } \\
\text { gime }\end{array}$ & $\begin{array}{l}\text { Gilbert, } \\
\text { Jo- } \\
\text { Anne; } \\
\text { Shar- } \\
\text { man, J. } \\
\text { C. }\end{array}$ & 2016 & $\begin{array}{c}\text { POLITI- } \\
\text { CAL } \\
\text { STUDIES } \\
\text { Volume: } \\
\text { 64 Issue: } \\
\text { 1 Pages: } \\
74-89 \\
\text { DOI: } \\
\text { 10.1111/14 } \\
\text { 67- } \\
\text { 9248.1215 } \\
\text { 3 Pub- } \\
\text { lished: } \\
\text { MAR } \\
2016\end{array}$ & $\begin{array}{l}\text { The authors investigated } \\
\text { the British and Australian } \\
\text { governments' stance on } \\
\text { compliance with interna- } \\
\text { tional anti-bribery instru- } \\
\text { ments. It is included. }\end{array}$ \\
\hline 107 & $\begin{array}{l}\text { The politics } \\
\text { of anti-cor- } \\
\text { ruption re- } \\
\text { forms and } \\
\text { reversals in } \\
\text { Uganda's } \\
\text { changing } \\
\text { political ter- } \\
\text { rain }\end{array}$ & $\begin{array}{l}\text { Muhu- } \\
\text { muza, } \\
\text { William }\end{array}$ & 2016 & $\begin{array}{c}\text { ECO- } \\
\text { NOMIC } \\
\text { AND PO- } \\
\text { LITICAL } \\
\text { STUDIES- } \\
\text { EPS Vol- } \\
\text { ume: } 4 \text { Is- } \\
\text { sue: } 1 \\
\text { Pages: } 62- \\
84 \text { DOI: } \\
\text { 10.1080/20 } \\
954816.20 \\
16.115209 \\
5 \text { Pub- } \\
\text { lished: } \\
2016\end{array}$ & $\begin{array}{l}\text { Using the case of Uganda, } \\
\text { the author discussed an } \\
\text { increasing level of corrup- } \\
\text { tion despite reform efforts } \\
\text { with focus on politics and } \\
\text { political actors. Although } \\
\text { relevant, politics is be- } \\
\text { yond the scope of this ar- } \\
\text { ticle and, therefore, is not } \\
\text { included. }\end{array}$ \\
\hline 108 & $\begin{array}{l}\text { The Politi- } \\
\text { cal Impetus } \\
\text { behind the } \\
\text { Construc- } \\
\text { tion of Anti- } \\
\text { corruption }\end{array}$ & $\begin{array}{l}\text { Xiao } \\
\text { Bina; } \\
\text { Huang } \\
\text { Ying- } \\
\text { hong }\end{array}$ & 2016 & $\begin{array}{l}\text { SOCIAL } \\
\text { SCI- } \\
\text { ENCES } \\
\text { IN } \\
\text { CHINA } \\
\text { Volume: }\end{array}$ & $\begin{array}{l}\text { The article examined In- } \\
\text { dia's Lokpal and Lo- } \\
\text { kayuktas, a tripartite anti- } \\
\text { corruption model. This is } \\
\text { included in my study. }\end{array}$ \\
\hline
\end{tabular}




\begin{tabular}{|c|c|c|c|c|c|}
\hline & $\begin{array}{l}\text { Institutions } \\
\text { in Develop- } \\
\text { ing Coun- } \\
\text { tries: An } \\
\text { Analysis of } \\
\text { the Process } \\
\text { Leading up } \\
\text { to India's } \\
\text { Lokpal and } \\
\text { Lokayuktas } \\
\text { Act (LALA) }\end{array}$ & & & $\begin{array}{c}37 \text { Issue: } \\
3 \text { Pages: } \\
75-92 \\
\text { DOI: } \\
10.1080 / 02 \\
529203.20 \\
16.119462 \\
9 \text { Pub- } \\
\text { lished: } \\
2016\end{array}$ & \\
\hline 109 & $\begin{array}{l}\text { Assessment } \\
\text { of internal } \\
\text { control sys- } \\
\text { tems to } \\
\text { curb corpo- } \\
\text { rate fraud - } \\
\text { evidence } \\
\text { from Brazil }\end{array}$ & $\begin{array}{l}\text { Imonian } \\
\text { a, } \\
\text { Joshua } \\
\text { Onome; } \\
\text { de } \\
\text { Feitas, } \\
\text { Eduardo } \\
\text { Costa; } \\
\text { Jacob } \\
\text { Perera, } \\
\text { Luiz } \\
\text { Carlos }\end{array}$ & 2016 & $\begin{array}{c}\text { AFRI- } \\
\text { CAN } \\
\text { JOUR- } \\
\text { NAL OF } \\
\text { AC- } \\
\text { COUNT- } \\
\text { ING AU- } \\
\text { DITING } \\
\text { AND FI- } \\
\text { NANCE } \\
\text { Volume: } \\
\text { 5 Issue: } 1 \\
\text { Pages: 1- } \\
\text { 24 DOI: } \\
\text { 10.1504/A } \\
\text { JAAF.201 } \\
6.077592 \\
\text { Pub- } \\
\text { lished: } \\
\text { 2016 }\end{array}$ & $\begin{array}{l}\text { In this case of Brazil, the } \\
\text { articles focused on corpo- } \\
\text { rate fraud. It is not in- } \\
\text { cluded. }\end{array}$ \\
\hline 110 & $\begin{array}{l}\text { The banal- } \\
\text { ity of bad } \\
\text { leadership } \\
\text { and follow- } \\
\text { ership }\end{array}$ & $\begin{array}{l}\text { Solas, } \\
\text { John }\end{array}$ & 2016 & $\begin{array}{c}\text { SOCIETY } \\
\text { AND } \\
\text { BUSI- } \\
\text { NESS RE- } \\
\text { VIEW } \\
\text { Volume: } \\
11 \text { Issue: } \\
1 \text { Pages: } \\
\text { 12-23 } \\
\end{array}$ & $\begin{array}{l}\text { The author investigated } \\
\text { leadership in the business } \\
\text { community. It is ex- } \\
\text { cluded. }\end{array}$ \\
\hline
\end{tabular}




\begin{tabular}{|c|c|c|c|c|c|}
\hline & & & & $\begin{array}{c}\text { DOI: } \\
\text { 10.1108/S } \\
\text { BR-09- } \\
\text { 2015-0049 } \\
\text { Pub- } \\
\text { lished: } \\
2016\end{array}$ & \\
\hline 111 & $\begin{array}{l}\text { Evolution } \\
\text { of interna- } \\
\text { tional and } \\
\text { Chinese } \\
\text { anti-bribery } \\
\text { and corrup- } \\
\text { tion compli- } \\
\text { ance pro- } \\
\text { grams }\end{array}$ & $\begin{array}{l}\text { Schon- } \\
\text { felder, } \\
\text { Karen; } \\
\text { Ve- } \\
\text { lamuri, } \\
\text { S. Ra- } \\
\text { ma- } \\
\text { krishna; } \\
\text { Liu, } \\
\text { Wilson }\end{array}$ & 2016 & $\begin{array}{c}\text { CORPO- } \\
\text { RATE } \\
\text { GOV- } \\
\text { ERN- } \\
\text { ANCE- } \\
\text { THE IN- } \\
\text { TERNA- } \\
\text { TIONAL } \\
\text { JOUR- } \\
\text { NAL OF } \\
\text { BUSI- } \\
\text { NESS IN } \\
\text { SOCIETY } \\
\text { Volume: } \\
\text { 16 Issue: } \\
3 \text { Pages: } \\
\text { 437-451 } \\
\text { DOI: } \\
\text { 10.1108/C } \\
\text { G-07- } \\
\text { 2015-0097 } \\
\text { Pub- } \\
\text { lished: } \\
\text { 2016 }\end{array}$ & $\begin{array}{l}\text { The article focused on } \\
\text { China's anti-corruption } \\
\text { framework and MNCs. It } \\
\text { is excluded. }\end{array}$ \\
\hline 112 & $\begin{array}{l}\text { GOOD } \\
\text { CORPO- } \\
\text { RATE } \\
\text { GOVERN- } \\
\text { ANCE: OB- } \\
\text { SERVA- } \\
\text { TIONS } \\
\text { AND }\end{array}$ & $\begin{array}{l}\text { Gracia } \\
\text { de } \\
\text { Castro, } \\
\text { Julia } \\
\text { Maria }\end{array}$ & 2016 & $\begin{array}{l}\text { QUAES- } \\
\text { TIO IU- } \\
\text { RIS Vol- } \\
\text { ume: } 9 \text { Is- } \\
\text { sue: } 2 \\
\text { Pages: } \\
\text { 1012-1030 } \\
\text { DOI: } \\
\text { 10.12957/r }\end{array}$ & $\begin{array}{l}\text { The author examined the } \\
\text { case of non-profit organi- } \\
\text { sation and effective com- } \\
\text { pliance. It is not included. }\end{array}$ \\
\hline
\end{tabular}




\begin{tabular}{|c|c|c|c|c|c|}
\hline & $\begin{array}{l}\text { RECOM- } \\
\text { MENDA- } \\
\text { TIONS FOR } \\
\text { THE NON- } \\
\text { GOVERN- } \\
\text { MENTAL } \\
\text { ORGANI- } \\
\text { ZATIONS } \\
\text { SECTOR. } \\
\text { THE IM- } \\
\text { PORTANC } \\
\text { E OF IM- } \\
\text { PLEMENT- } \\
\text { ING AN E } \\
\text { FFECTIVE } \\
\text { COMPLI- } \\
\text { ANCE } \\
\text { PROGRAM } \\
\text { IN ORDER } \\
\text { TO ABIDE } \\
\text { BY LAW N. } \\
12.846 / 2015\end{array}$ & & & $\begin{array}{c}\text { qi.2016.22 } \\
\text { 574 Pub- } \\
\text { lished: } \\
2016\end{array}$ & \\
\hline 113 & $\begin{array}{l}\text { Mobilising } \\
\text { internally } \\
\text { generated } \\
\text { funds to fi- } \\
\text { nance de- } \\
\text { velopment } \\
\text { projects in } \\
\text { Ghana's } \\
\text { Northern } \\
\text { Region }\end{array}$ & $\begin{array}{l}\text { Puopiel, } \\
\text { Felix; } \\
\text { Chimsi, } \\
\text { Musah }\end{array}$ & 2015 & $\begin{array}{c}\text { COM- } \\
\text { MON- } \\
\text { WEALTH } \\
\text { JOUR- } \\
\text { NAL OF } \\
\text { LOCAL } \\
\text { GOV- } \\
\text { ERN- } \\
\text { ANCE Is- } \\
\text { sue: } 18 \\
\text { Pages: } \\
\text { 147-160 } \\
\text { DOI: } \\
\text { 10.5130/cjl } \\
\text { g.v0i18.48 } \\
\text { 48 Pub- } \\
\text { lished: } \\
\text { DEC 2015 }\end{array}$ & $\begin{array}{l}\text { The article focused on } \\
\text { mobilising internal funds } \\
\text { to finance development } \\
\text { projects in Ghana. It is not } \\
\text { included. }\end{array}$ \\
\hline
\end{tabular}




\begin{tabular}{|c|c|c|c|c|c|}
\hline 114 & $\begin{array}{l}\text { PROAC- } \\
\text { TIVE } \\
\text { TRANS- } \\
\text { PARENCY } \\
\text { POLICY IN } \\
\text { THE MER- } \\
\text { COSUR } \\
\text { LOCAL } \\
\text { GOVERN- } \\
\text { MENTS: } \\
\text { REGULA- } \\
\text { TION VS. } \\
\text { SELF-REG- } \\
\text { ULATION }\end{array}$ & $\begin{array}{l}\text { Garcia- } \\
\text { Tabuyo, } \\
\text { Manoli; } \\
\text { Saez- } \\
\text { Martin, } \\
\text { Alejandr } \\
\text { o; } \\
\text { Carmen } \\
\text { Caba- } \\
\text { Perez, } \\
\text { Mariade } \\
1\end{array}$ & 2015 & $\begin{array}{c}\text { TRAN- } \\
\text { SYLVA- } \\
\text { NIAN } \\
\text { REVIEW } \\
\text { OF AD- } \\
\text { MINIS- } \\
\text { TRATIVE } \\
\text { SCI- } \\
\text { ENCES } \\
\text { Issue: 46E } \\
\text { Pages: } 71- \\
\text { 90 Pub- } \\
\text { lished: } \\
\text { OCT } 2015\end{array}$ & $\begin{array}{l}\text { The authors discussed in- } \\
\text { formation disclosures by } \\
\text { local authorities, as rec- } \\
\text { ommended by the Organ- } \\
\text { ization of American } \\
\text { States, and transparency. } \\
\text { It is included. }\end{array}$ \\
\hline 115 & $\begin{array}{l}\text { Pharma ad- } \\
\text { vertising- Is } \\
\text { it decep- } \\
\text { tive? }\end{array}$ & $\begin{array}{l}\text { Amudh } \\
\text { a, R; } \\
\text { Alamelu } \\
\text {, R; } \\
\text { Motha, } \\
\text { Cresent } \\
\text { a } \\
\text { Shakila } \\
\text { L; } \\
\text { Badrinat } \\
\text { h, V }\end{array}$ & 2015 & $\begin{array}{c}\text { RE- } \\
\text { SEARCH } \\
\text { JOUR- } \\
\text { NAL OF } \\
\text { PHAR- } \\
\text { MACEU- } \\
\text { TICAL BI- } \\
\text { OLOGI- } \\
\text { CAL } \\
\text { AND } \\
\text { CHEMI- } \\
\text { CAL SCI- } \\
\text { ENCES } \\
\text { Volume: } \\
\text { 6 Issue: } 5 \\
\text { Pages: } \\
\text { 1158-1167 } \\
\text { Pub- } \\
\text { lished: } \\
\text { SEP-OCT } \\
\text { 2015 }\end{array}$ & $\begin{array}{l}\text { The article focused on ad- } \\
\text { vertising in pharmaceuti- } \\
\text { cal companies. It is ex- } \\
\text { cluded. }\end{array}$ \\
\hline 116 & $\begin{array}{l}\text { BRIEF } \\
\text { NOTES ON } \\
\text { THE BRA- } \\
\text { ZILIAN } \\
\text { ANTI- }\end{array}$ & $\begin{array}{l}\text { Fiorese } \\
\text { Reis, } \\
\text { Julia }\end{array}$ & 2015 & $\begin{array}{c}\text { EN } \\
\text { LETRA } \\
\text { Volume: } \\
2 \text { Issue: } 4 \\
\text { Pages: }\end{array}$ & $\begin{array}{l}\text { Although the topic of } \\
\text { FCPA is relevant, the arti- } \\
\text { cle focuses on anti-cor- } \\
\text { ruption laws, which affect }\end{array}$ \\
\hline
\end{tabular}




\begin{tabular}{|c|c|c|c|c|c|}
\hline & $\begin{array}{l}\text { CORRUP- } \\
\text { TION ACT }\end{array}$ & & & $\begin{array}{c}\text { 123-151 } \\
\text { Pub- } \\
\text { lished: } \\
\text { AUG } 2015\end{array}$ & $\begin{array}{l}\text { companies. Therefore, it is } \\
\text { not included. }\end{array}$ \\
\hline 117 & $\begin{array}{l}\text { Supplier In- } \\
\text { tegrity Due } \\
\text { Diligence in } \\
\text { Public Pro- } \\
\text { curement: } \\
\text { Limiting } \\
\text { the Crimi- } \\
\text { nal Risk to } \\
\text { Australia }\end{array}$ & $\begin{array}{l}\text { de } \\
\text { Koker, } \\
\text { Louis; } \\
\text { Harwoo } \\
\text { d, } \\
\text { Kayne }\end{array}$ & 2015 & $\begin{array}{l}\text { SYDNEY } \\
\text { LAW RE- } \\
\text { VIEW } \\
\text { Volume: } \\
\text { 37 Issue: } \\
2 \text { Pages: } \\
\text { 217-241 } \\
\text { Pub- } \\
\text { lished: } \\
\text { JUN 2015 }\end{array}$ & $\begin{array}{l}\text { The authors investigated } \\
\text { the cultural norms, en- } \\
\text { forcement policies and il- } \\
\text { licit corporate activities. It } \\
\text { is excluded. }\end{array}$ \\
\hline 118 & $\begin{array}{l}\text { Impacts of } \\
\text { corruption } \\
\text { on the fun- } \\
\text { damental } \\
\text { right to a } \\
\text { fair trail in } \\
\text { compliance } \\
\text { to constitu- } \\
\text { tional jus- } \\
\text { tice }\end{array}$ & $\begin{array}{l}\text { Leal, } \\
\text { Rogerio } \\
\text { Gesta }\end{array}$ & 2015 & $\begin{array}{l}\text { REVISTA } \\
\text { DE IN- } \\
\text { VESTI- } \\
\text { GACOES } \\
\text { CON- } \\
\text { STITU- } \\
\text { CION- } \\
\text { AIS- } \\
\text { JOUR- } \\
\text { NAL OF } \\
\text { CONSTI- } \\
\text { TU- } \\
\text { TIONAL } \\
\text { RE- } \\
\text { SEARCH } \\
\text { Volume: } \\
2 \text { Issue: } 2 \\
\text { Pages: } \\
\text { 169-187 } \\
\text { DOI: } \\
\text { 10.5380/ri } \\
\text { nc.v2i2.44 } \\
515 \text { Pub- } \\
\text { lished: }\end{array}$ & $\begin{array}{l}\text { The articles focused on } \\
\text { the impact of corruption } \\
\text { on fair trial. Despite some } \\
\text { linkages, it focused more } \\
\text { on how registry works. It } \\
\text { is excluded. }\end{array}$ \\
\hline
\end{tabular}




\begin{tabular}{|c|c|c|c|c|c|}
\hline & & & & $\begin{array}{c}\text { MAY- } \\
\text { AUG } 2015\end{array}$ & \\
\hline 119 & $\begin{array}{l}\text { ON THE } \\
\text { INTERNAL } \\
\text { REVENUE } \\
\text { SERVICE'S } \\
\text { SERVICE } \\
\text { AND EN- } \\
\text { FORCE- } \\
\text { MENT }\end{array}$ & $\begin{array}{l}\text { Tsai, } \\
\text { Tsung- } \\
\text { Sheng; } \\
\text { Yang, C. } \\
\text { C }\end{array}$ & 2015 & $\begin{array}{c}\text { ECO- } \\
\text { NOMIC } \\
\text { INQUIRY } \\
\text { Volume: } \\
53 \text { Issue: } \\
2 \text { Pages: } \\
889-905 \\
\text { DOI: } \\
\text { 10.1111/ec } \\
\text { in.12160 } \\
\text { Pub- } \\
\text { lished: } \\
\text { APR 2015 }\end{array}$ & $\begin{array}{l}\text { Based on the case of the } \\
\text { US, the authors consid- } \\
\text { ered the model of tax } \\
\text { compliance in IRS. As this } \\
\text { does not deal with cor- } \\
\text { ruption, it is excluded. }\end{array}$ \\
\hline 120 & $\begin{array}{l}\text { Does Au- } \\
\text { thoritarian- } \\
\text { ism Breed } \\
\text { Corrup- } \\
\text { tion? Re- } \\
\text { considering } \\
\text { the Rela- } \\
\text { tionship Be- } \\
\text { tween Au- } \\
\text { thoritarian } \\
\text { Governance } \\
\text { and Cor- } \\
\text { rupt Ex- } \\
\text { changes in } \\
\text { Bureaucra- } \\
\text { cies }\end{array}$ & $\begin{array}{l}\text { Zaloz- } \\
\text { naya, } \\
\text { Marin }\end{array}$ & 2015 & $\begin{array}{c}\text { LAW } \\
\text { AND SO- } \\
\text { CIAL IN- } \\
\text { QUIRY- } \\
\text { JOUR- } \\
\text { NAL OF } \\
\text { THE } \\
\text { AMERI- } \\
\text { CAN } \\
\text { BAR } \\
\text { FOUN- } \\
\text { DATION } \\
\text { Volume: } \\
40 \text { Issue: } \\
2 \text { Pages: } \\
345-376 \\
\text { DOI: } \\
\text { 10.1111/lsi } \\
.12076 \\
\text { Pub- } \\
\text { lished: } \\
\text { SPR 2015 }\end{array}$ & $\begin{array}{l}\text { The article applied ethno- } \\
\text { graphic and historical } \\
\text { study to explain corrup- } \\
\text { tion. As the setting of my } \\
\text { study is contemporary, it } \\
\text { is excluded. }\end{array}$ \\
\hline
\end{tabular}




\begin{tabular}{|c|c|c|c|c|c|}
\hline 121 & $\begin{array}{l}\text { The weak- } \\
\text { ness of the } \\
\text { rule of law } \\
\text { in Latin } \\
\text { America: a } \\
\text { factor to un- } \\
\text { derstand } \\
\text { the implan- } \\
\text { tation of the } \\
\text { organized } \\
\text { crime }\end{array}$ & $\begin{array}{l}\text { Alda } \\
\text { Mejias, } \\
\text { Sonia }\end{array}$ & 2015 & $\begin{array}{c}\text { REVISTA } \\
\text { ES- } \\
\text { PANOLA } \\
\text { DE CIEN- } \\
\text { CIA PO- } \\
\text { LITICA- } \\
\text { RECP Is- } \\
\text { sue: } 37 \\
\text { Pages: } 63- \\
88 \text { Pub- } \\
\text { lished: } \\
\text { MAR } \\
2015\end{array}$ & $\begin{array}{l}\text { As the focus of this article } \\
\text { is on organised crime and } \\
\text { violence, it is excluded. }\end{array}$ \\
\hline 122 & $\begin{array}{l}\text { MULTIPLE } \\
\text { IMPACTS } \\
\text { OF } \\
\text { GLOBAL } \\
\text { ELECTRIC } \\
\text { COMPA- } \\
\text { NIES. THE } \\
\text { CASE OF } \\
\text { IBERDROL } \\
\text { A IN MEX- } \\
\text { ICO }\end{array}$ & $\begin{array}{l}\text { Uharte } \\
\text { Pozas, } \\
\text { Luis Mi- } \\
\text { guel }\end{array}$ & 2015 & $\begin{array}{c}\text { ANDULI } \\
\text { Issue: } 14 \\
\text { Pages: } \\
\text { 121-133 } \\
\text { Pub- } \\
\text { lished: } \\
2015\end{array}$ & $\begin{array}{l}\text { The article analysed nega- } \\
\text { tive social impacts of } \\
\text { global companies in the } \\
\text { developing region. It is } \\
\text { excluded. }\end{array}$ \\
\hline 123 & $\begin{array}{l}\text { Does coun- } \\
\text { try-level } \\
\text { governance } \\
\text { enhance } \\
\text { ethical be- } \\
\text { haviour of } \\
\text { firms? An } \\
\text { African per- } \\
\text { spective }\end{array}$ & $\begin{array}{l}\text { Agyema } \\
\text { ng, } \\
\text { Otuo } \\
\text { Serebou } \\
\text { r; } \\
\text { Fantini, } \\
\text { Giulia; } \\
\text { Frimpon } \\
\text { g, Joyce }\end{array}$ & 2015 & $\begin{array}{c}\text { INTER- } \\
\text { NA- } \\
\text { TIONAL } \\
\text { JOUR- } \\
\text { NAL OF } \\
\text { LAW } \\
\text { AND } \\
\text { MAN- } \\
\text { AGE- } \\
\text { MENT } \\
\text { Volume: } \\
\text { 57 Issue: } \\
6 \text { Pages: } \\
\text { 582-599 } \\
\text { DOI: } \\
\text { 10.1108/IJ }\end{array}$ & $\begin{array}{l}\text { The article explained the } \\
\text { relationship between gov- } \\
\text { ernance at country level } \\
\text { and ethical behaviors of } \\
\text { firms in Africa. It is ex- } \\
\text { cluded. }\end{array}$ \\
\hline
\end{tabular}




\begin{tabular}{|c|c|c|c|c|c|}
\hline & & & & $\begin{array}{l}\text { LMA-12- } \\
\text { 2014-0063 } \\
\text { Pub- } \\
\text { lished: } \\
2015\end{array}$ & \\
\hline 124 & $\begin{array}{l}\text { The "need } \\
\text { to know" } \\
\text { and the lack } \\
\text { of online } \\
\text { transpar- } \\
\text { ency among } \\
\text { political } \\
\text { parties }\end{array}$ & $\begin{array}{l}\text { Cuad- } \\
\text { rado- } \\
\text { Balles- } \\
\text { teros, } \\
\text { Beatriz; } \\
\text { Andres } \\
\text { Vaquero } \\
\text {-Cacho, } \\
\text { Luis }\end{array}$ & 2015 & $\begin{array}{c}\text { TRANS- } \\
\text { FORM- } \\
\text { ING } \\
\text { GOV- } \\
\text { ERN- } \\
\text { MENT- } \\
\text { PEOPLE } \\
\text { PROCESS } \\
\text { AND } \\
\text { POLICY } \\
\text { Volume: } \\
9 \text { Issue: } 1 \\
\text { Pages: 85- } \\
\text { 103 DOI: } \\
\text { 10.1108/T } \\
\text { G-09- } \\
\text { 2014-0039 } \\
\text { Pub- } \\
\text { lished: } \\
\text { 2015 }\end{array}$ & $\begin{array}{l}\text { The authors elaborated on } \\
\text { the transparency in the } \\
\text { Spanish political parties } \\
\text { and political systems. As } \\
\text { it is not government-re- } \\
\text { lated, it is excluded. }\end{array}$ \\
\hline 125 & $\begin{array}{l}\text { Tax evasion } \\
\text { and public } \\
\text { expendi- } \\
\text { tures on tax } \\
\text { revenue } \\
\text { services in } \\
\text { an endoge- } \\
\text { nous } \\
\text { growth } \\
\text { model }\end{array}$ & $\begin{array}{l}\text { Kaflalas, } \\
\text { Sifis; } \\
\text { Kalaitzi } \\
\text { dakis, } \\
\text { Pantelis; } \\
\text { Tzouvel } \\
\text { ekas, } \\
\text { Vangelis }\end{array}$ & 2014 & $\begin{array}{c}\text { EURO- } \\
\text { PEAN } \\
\text { ECO- } \\
\text { NOMIC } \\
\text { REVIEW } \\
\text { Volume: } \\
70 \text { Pages: } \\
\text { 438-453 } \\
\text { DOI: } \\
\text { 10.1016/j.e } \\
\text { uroe- } \\
\text { corev.201 } \\
4.06 .014\end{array}$ & $\begin{array}{l}\text { The article examined the } \\
\text { relationship between an- } \\
\text { nounced tax rate and } \\
\text { share of the tax revenue. } \\
\text { It is not included. }\end{array}$ \\
\hline
\end{tabular}




\begin{tabular}{|c|c|c|c|c|c|}
\hline & & & & $\begin{array}{c}\text { Pub- } \\
\text { lished: } \\
\text { AUG } 2014\end{array}$ & \\
\hline 126 & $\begin{array}{l}\text { Choosing } \\
\text { Between } \\
\text { Saw and } \\
\text { Scalpel: } \\
\text { FCPA Re- } \\
\text { form and } \\
\text { the Compli- } \\
\text { ance De- } \\
\text { fense }\end{array}$ & $\begin{array}{l}\text { Livshiz, } \\
\text { Tamara }\end{array}$ & 2014 & $\begin{array}{l}\text { COLUM- } \\
\text { BIA } \\
\text { JOUR- } \\
\text { NAL OF } \\
\text { LAW } \\
\text { AND SO- } \\
\text { CIAL } \\
\text { PROB- } \\
\text { LEMS } \\
\text { Volume: } \\
\text { 47 Issue: } \\
\text { 4 Pages: } \\
\text { 417-452 } \\
\text { Pub- } \\
\text { lished: } \\
\text { SUM } 2014\end{array}$ & $\begin{array}{l}\text { This article discussed the } \\
\text { US Chamber of Com- } \\
\text { merce initiative called } \\
\text { Compliance Defense to } \\
\text { inoculate corporations } \\
\text { from FCPA liabilities. It is } \\
\text { not included. }\end{array}$ \\
\hline 127 & $\begin{array}{l}\text { CARROTS } \\
\text { AND } \\
\text { STICKS: } \\
\text { PLACING } \\
\text { REWARDS } \\
\text { AS WELL } \\
\text { AS PUN- } \\
\text { ISHMENT } \\
\text { IN REGU- } \\
\text { LATORY } \\
\text { AND TORT } \\
\text { LAW }\end{array}$ & $\begin{array}{l}\text { Schwart } \\
\text { z, Victor } \\
\text { E; } \\
\text { Goldber } \\
\text { g, Phil }\end{array}$ & 2014 & $\begin{array}{c}\text { HAR- } \\
\text { VARD } \\
\text { JOUR- } \\
\text { NAL ON } \\
\text { LEGISLA- } \\
\text { TION } \\
\text { Volume: } \\
51 \text { Issue: } \\
2 \text { Pages: } \\
\text { 315-363 } \\
\text { Pub- } \\
\text { lished: } \\
\text { SUM 2014 }\end{array}$ & $\begin{array}{l}\text { The authors focused on } \\
\text { the topic of corporate } \\
\text { bribery and enforcement } \\
\text { mechanism in the US. It is } \\
\text { not included in my re- } \\
\text { search. }\end{array}$ \\
\hline 128 & $\begin{array}{l}\text { Announced } \\
\text { vs. surprise } \\
\text { inspections } \\
\text { with tip- } \\
\text { ping-off }\end{array}$ & $\begin{array}{l}\text { Dechena } \\
\text { ux, Em- } \\
\text { manuel; } \\
\text { Samuel, } \\
\text { Andrew }\end{array}$ & 2014 & $\begin{array}{l}\text { EURO- } \\
\text { PEAN } \\
\text { JOUR- } \\
\text { NAL OF } \\
\text { POLITI- } \\
\text { CAL }\end{array}$ & $\begin{array}{l}\text { The focus of the article is } \\
\text { a model in which a super- } \\
\text { visor monitors a corpo- } \\
\text { rate compliance with reg- } \\
\text { ulation. It is excluded. }\end{array}$ \\
\hline
\end{tabular}




\begin{tabular}{|c|c|c|c|c|c|}
\hline & & & & $\begin{array}{c}\text { ECON- } \\
\text { OMY } \\
\text { Volume: } \\
34 \text { Pages: } \\
\text { 167-183 } \\
\text { DOI: } \\
\text { 10.1016/j.e } \\
\text { jpoleco.20 } \\
\text { 14.01.001 } \\
\text { Pub- } \\
\text { lished: } \\
\text { JUN 2014 }\end{array}$ & \\
\hline 129 & $\begin{array}{l}\text { Let's be } \\
\text { clear: com- } \\
\text { pliance } \\
\text { with new } \\
\text { transpar- } \\
\text { ency re- } \\
\text { quirements } \\
\text { is going to } \\
\text { be challeng- } \\
\text { ing for re- } \\
\text { source com- } \\
\text { panies }\end{array}$ & $\begin{array}{l}\text { Hughes, } \\
\text { Carl D; } \\
\text { Pen- } \\
\text { dred, } \\
\text { Oliver }\end{array}$ & 2014 & $\begin{array}{c}\text { JOUR- } \\
\text { NAL OF } \\
\text { WORLD } \\
\text { ENERGY } \\
\text { LAW \& } \\
\text { BUSI- } \\
\text { NESS } \\
\text { Volume: } \\
7 \text { Issue: } 1 \\
\text { Special } \\
\text { Issue: SI } \\
\text { Pages: 36- } \\
\text { 45 DOI: } \\
\text { 10.1093/j } \\
\text { welb/jwt0 } \\
\text { 23 Pub- } \\
\text { lished: } \\
\text { MAR } \\
\text { 2014 }\end{array}$ & $\begin{array}{l}\text { The article examined the } \\
\text { extractive industries and } \\
\text { transparency require- } \\
\text { ments in the EU with fo- } \\
\text { cus on companies. It is } \\
\text { not included. }\end{array}$ \\
\hline 130 & $\begin{array}{l}\text { DOES SAY- } \\
\text { ING 'YES' } \\
\text { TO CAPI- } \\
\text { TAL IN- } \\
\text { FLOWS } \\
\text { NECES- } \\
\text { SARILY } \\
\text { MEAN } \\
\text { GOOD }\end{array}$ & $\begin{array}{l}\text { Elisa } \\
\text { Farias, } \\
\text { Maria; } \\
\text { de } \\
\text { Almeida } \\
\text {, Monica } \\
\text { Arruda }\end{array}$ & 2014 & $\begin{array}{c}\text { ECO- } \\
\text { NOMICS } \\
\text { \& POLI- } \\
\text { TICS Vol- } \\
\text { ume: } 26 \\
\text { Issue: } 1 \\
\text { Pages: } 96- \\
\text { 127 DOI: } \\
\text { 10.1111/ec }\end{array}$ & $\begin{array}{l}\text { While the topic of anti- } \\
\text { money laundering efforts } \\
\text { and economic perfor- } \\
\text { mance is interesting, it } \\
\text { does not focus specifically } \\
\text { on the government. It is } \\
\text { not included. }\end{array}$ \\
\hline
\end{tabular}




\begin{tabular}{|c|c|c|c|c|c|}
\hline & $\begin{array}{l}\text { BUSINESS? } \\
\text { THE EF- } \\
\text { FECT OF } \\
\text { ANTIMO- } \\
\text { NEY } \\
\text { LAUNDER- } \\
\text { ING REGU- } \\
\text { LATIONS } \\
\text { IN THE } \\
\text { LATIN } \\
\text { AMERI- } \\
\text { CAN AND } \\
\text { THE CAR- } \\
\text { IBBEAN } \\
\text { ECONO- } \\
\text { MIES }\end{array}$ & & & $\begin{array}{l}\text { po.12028 } \\
\text { Pub- } \\
\text { lished: } \\
\text { MAR } \\
2014\end{array}$ & \\
\hline 131 & $\begin{array}{l}\text { INFOR- } \\
\text { MAL SEC- } \\
\text { TOR TAX } \\
\text { ADMIN- } \\
\text { ISTRA- } \\
\text { TION IN } \\
\text { ZIMBA- } \\
\text { BWE }\end{array}$ & $\begin{array}{l}\text { Dube, } \\
\text { Godwin }\end{array}$ & 2014 & $\begin{array}{c}\text { PUBLIC } \\
\text { ADMIN- } \\
\text { ISTRA- } \\
\text { TION } \\
\text { AND DE- } \\
\text { VELOP- } \\
\text { MENT } \\
\text { Volume: } \\
34 \text { Issue: } \\
1 \text { Pages: } \\
48-62 \\
\text { DOI: } \\
10.1002 / p \\
\text { ad.1673 } \\
\text { Pub- } \\
\text { lished: } \\
\text { FEB 2014 }\end{array}$ & $\begin{array}{l}\text { The author analysed the } \\
\text { case of Zimbabwe and ef- } \\
\text { forts to collect tax from } \\
\text { the informal sector. It is } \\
\text { not included in my study. }\end{array}$ \\
\hline 132 & $\begin{array}{l}\text { Selective } \\
\text { Adaptation } \\
\text { in Treaty } \\
\text { Compli- } \\
\text { ance: The } \\
\text { Implica- } \\
\text { tions of }\end{array}$ & $\begin{array}{l}\text { Wang, } \\
\text { Chao }\end{array}$ & 2014 & $\begin{array}{l}\text { ASIA PA- } \\
\text { CIFIC } \\
\text { LAW RE- } \\
\text { VIEW } \\
\text { Volume: } \\
22 \text { Issue: } \\
1 \text { Pages: }\end{array}$ & $\begin{array}{l}\text { The article investigated } \\
\text { the case of Japan's selec- } \\
\text { tive adaption of the agree- } \\
\text { ment on government pro- } \\
\text { curement. While compli- } \\
\text { ance is a central theme, } \\
\text { this article does not }\end{array}$ \\
\hline
\end{tabular}




\begin{tabular}{|c|c|c|c|c|c|}
\hline & $\begin{array}{l}\text { Japan's Im- } \\
\text { plementa- } \\
\text { tion of the } \\
\text { World } \\
\text { Trade Or- } \\
\text { ganization's } \\
\text { Agreement } \\
\text { on Govern- } \\
\text { ment Pro- } \\
\text { curement }\end{array}$ & & & $\begin{array}{l}\text { 103-117 } \\
\text { Pub- } \\
\text { lished: } \\
2014\end{array}$ & $\begin{array}{l}\text { concern corruption or } \\
\text { government officials. It is } \\
\text { not included. }\end{array}$ \\
\hline 133 & $\begin{array}{l}\text { MINIMIZ- } \\
\text { ING THE } \\
\text { MENACE } \\
\text { OF THE } \\
\text { FOREIGN } \\
\text { CORRUPT } \\
\text { PRAC- } \\
\text { TICES ACT }\end{array}$ & $\begin{array}{l}\text { Isaac- } \\
\text { son, } \\
\text { Kristin }\end{array}$ & 2014 & $\begin{array}{l}\text { UNIVER- } \\
\text { SITY OF } \\
\text { ILLINOIS } \\
\text { LAW RE- } \\
\text { VIEW Is- } \\
\text { sue: } 2 \\
\text { Pages: } \\
597-627 \\
\text { Pub- } \\
\text { lished: } \\
2014\end{array}$ & $\begin{array}{l}\text { This note discusses the } \\
\text { disadvantages FCPA cre- } \\
\text { ated among US compa- } \\
\text { nies. It is not included. }\end{array}$ \\
\hline 134 & $\begin{array}{l}\text { Transform- } \\
\text { ing Vi- } \\
\text { etnam: a } \\
\text { quest for } \\
\text { improved } \\
\text { efficiency } \\
\text { and trans- } \\
\text { parency in } \\
\text { central gov- } \\
\text { ernment } \\
\text { procure- } \\
\text { ment }\end{array}$ & $\begin{array}{l}\text { Khorana } \\
\text {, Sang- } \\
\text { eeta; } \\
\text { Mishra, } \\
\text { Nishi- } \\
\text { kant; } \\
\text { Kerr, } \\
\text { William } \\
\text { A. }\end{array}$ & 2014 & $\begin{array}{c}\text { POLICY } \\
\text { AND } \\
\text { POLITICS } \\
\text { Volume: } \\
\text { 42 Issue: } \\
1 \text { Pages: } \\
\text { 109-129 } \\
\text { DOI: } \\
\text { 10.1332/03 } \\
0557312 X \\
\text { 655611 } \\
\text { Pub- } \\
\text { lished: } \\
\text { JAN 2014 }\end{array}$ & $\begin{array}{l}\text { With focus on Vietnam, } \\
\text { the article examined the } \\
\text { relationship between } \\
\text { WTO government pro- } \\
\text { curement agreement and } \\
\text { its cost benefit approach. } \\
\text { It is not included in my } \\
\text { research. }\end{array}$ \\
\hline 135 & $\begin{array}{l}\text { OPTIMAL } \\
\text { GOVERN- } \\
\text { MENT }\end{array}$ & $\begin{array}{l}\text { Mendez, } \\
\text { Fabio; }\end{array}$ & 2013 & $\begin{array}{c}\text { HI- } \\
\text { TOTSUB } \\
\text { ASHI }\end{array}$ & $\begin{array}{l}\text { The article examined opti- } \\
\text { mal levels of regulations } \\
\text { and red tape to test }\end{array}$ \\
\hline
\end{tabular}




\begin{tabular}{|c|c|c|c|c|c|}
\hline & $\begin{array}{l}\text { REGULA- } \\
\text { TIONS } \\
\text { AND RED } \\
\text { TAPE IN } \\
\text { AN ECON- } \\
\text { OMY WITH } \\
\text { CORRUP- } \\
\text { TION }\end{array}$ & $\begin{array}{l}\text { Sepul- } \\
\text { veda, } \\
\text { Facundo }\end{array}$ & & $\begin{array}{c}\text { JOUR- } \\
\text { NAL OF } \\
\text { ECO- } \\
\text { NOMICS } \\
\text { Volume: } \\
54 \text { Issue: } \\
1 \text { Pages: } \\
51-77 \\
\text { Pub- } \\
\text { lished: } \\
\text { JUN } 2013\end{array}$ & $\begin{array}{l}\text { regulatory compliance. It } \\
\text { is included. }\end{array}$ \\
\hline 136 & $\begin{array}{l}\text { Are corrup- } \\
\text { tion levels } \\
\text { accurately } \\
\text { identified? } \\
\text { The case of } \\
\text { US states }\end{array}$ & $\begin{array}{l}\text { de } \\
\text { Figueire } \\
\text { do, Joao } \\
\text { Neiva }\end{array}$ & 2013 & $\begin{array}{c}\text { JOUR- } \\
\text { NAL OF } \\
\text { POLICY } \\
\text { MODEL- } \\
\text { ING Vol- } \\
\text { ume: } 35 \\
\text { Issue: } 1 \\
\text { Pages: } \\
\text { 134-149 } \\
\text { DOI: } \\
\text { 10.1016/j.j } \\
\text { polmod.2 } \\
012.01 .006 \\
\text { Pub- } \\
\text { lished: } \\
\text { JAN-FEB } \\
2013\end{array}$ & $\begin{array}{l}\text { The article examined the } \\
\text { case of the US states and } \\
\text { public official corruption } \\
\text { and non-compliance. It is } \\
\text { included. }\end{array}$ \\
\hline 137 & $\begin{array}{l}\text { Issues in } \\
\text { Anti-Cor- } \\
\text { ruption } \\
\text { Law: How } \\
\text { Can Code } \\
\text { of Conduct } \\
\text { Laws Be } \\
\text { Drafted in } \\
\text { Order to } \\
\text { Reduce } \\
\text { Corruption } \\
\text { in a Public }\end{array}$ & $\begin{array}{l}\text { Michael, } \\
\text { Bryane }\end{array}$ & 2012 & $\begin{array}{c}\text { EURO- } \\
\text { PEAN } \\
\text { LAW } \\
\text { JOUR- } \\
\text { NAL Vol- } \\
\text { ume: } 18 \\
\text { Issue: } 2 \\
\text { Pages: } \\
\text { 289-322 } \\
\text { DOI: } \\
\text { 10.1111/j.1 } \\
468-\end{array}$ & $\begin{array}{l}\text { The author investigated } \\
\text { the case of Romania and } \\
\text { its Code of Conduct Law. } \\
\text { It is included. }\end{array}$ \\
\hline
\end{tabular}




\begin{tabular}{|c|c|c|c|c|c|}
\hline & $\begin{array}{l}\text { Sector like } \\
\text { Romania's }\end{array}$ & & & $\begin{array}{c}0386.2011 . \\
\text { 00598.x } \\
\text { Pub- } \\
\text { lished: } \\
\text { MAR } \\
2012\end{array}$ & \\
\hline 138 & $\begin{array}{l}\text { Cosi fan } \\
\text { tutte: Infor- } \\
\text { mation, Be- } \\
\text { liefs, and } \\
\text { Compliance } \\
\text { with Norms }\end{array}$ & $\begin{array}{l}\text { Kotzian, } \\
\text { Peter }\end{array}$ & 2011 & $\begin{array}{c}\text { ZEITSCH } \\
\text { RIFT FUR } \\
\text { SOZIOLO } \\
\text { GIE } \\
\text { Volume: } \\
\text { 40 Issue: } \\
\text { 4 Pages: } \\
\text { 158-173 } \\
\text { Publishe } \\
\text { d: AUG } \\
2011\end{array}$ & $\begin{array}{l}\text { The author studied the ef- } \\
\text { fect of norm compliance } \\
\text { of information. It is in- } \\
\text { cluded. }\end{array}$ \\
\hline 139 & $\begin{array}{l}\text { Bribery and } \\
\text { inspection } \\
\text { technology }\end{array}$ & $\begin{array}{l}\text { Samuel, } \\
\text { An- } \\
\text { drew; } \\
\text { Lowen, } \\
\text { Aaron }\end{array}$ & 2010 & $\begin{array}{c}\text { ECO- } \\
\text { NOMICS } \\
\text { OF GOV- } \\
\text { ERN- } \\
\text { ANCE } \\
\text { Volume: } \\
\text { 11 Issue: } \\
\text { 4 Pages: } \\
\text { 333-350 } \\
\text { DOI: } \\
\text { 10.1007/s1 } \\
0101-010- \\
\text { 0080-0 } \\
\text { Pub- } \\
\text { lished: } \\
\text { NOV 2010 }\end{array}$ & $\begin{array}{l}\text { The article advocated the } \\
\text { use of technology to re- } \\
\text { duce discretionary power } \\
\text { of government officials } \\
\text { and increase efficiency. It } \\
\text { is included. }\end{array}$ \\
\hline 140 & $\begin{array}{l}\text { Fighting } \\
\text { Corruption } \\
\text { in Croatia } \\
\text { with the } \\
\text { Prospect of } \\
\text { European }\end{array}$ & $\begin{array}{l}\text { Hardy, } \\
\text { Angel- } \\
\text { ique }\end{array}$ & 2010 & $\begin{array}{l}\text { ROMA- } \\
\text { NIAN } \\
\text { JOUR- } \\
\text { NAL OF } \\
\text { POLITI- } \\
\text { CAL }\end{array}$ & $\begin{array}{l}\text { The article focused on EU } \\
\text { pre-accession conditional- } \\
\text { ity and fight against cor- } \\
\text { ruption, in particular, } \\
\text { backsliding. It mainly } \\
\text { concerns compliance with }\end{array}$ \\
\hline
\end{tabular}




\begin{tabular}{|c|c|c|c|c|c|}
\hline & $\begin{array}{l}\text { Union } \\
\text { Member- } \\
\text { ship On the } \\
\text { non-sus- } \\
\text { tainability } \\
\text { of EU con- } \\
\text { ditionality } \\
\text { in policy } \\
\text { fields gov- } \\
\text { erned by } \\
\text { the soft ac- } \\
\text { quis com- } \\
\text { munautaire } \\
\text { and lessons } \\
\text { learned } \\
\text { from the } \\
\text { previous } \\
\text { enlarge- } \\
\text { ments to } \\
\text { Slovenia, } \\
\text { Bulgaria } \\
\text { and Roma- } \\
\text { nia }\end{array}$ & & & $\begin{array}{l}\text { SCIENCE } \\
\text { Volume: } \\
\text { 10 Special } \\
\text { Issue: SI } \\
\text { Pages: 63- } \\
95 \text { Pub- } \\
\text { lished: } \\
\text { SEP } 2010\end{array}$ & $\begin{array}{l}\text { the EU accession and con- } \\
\text { ditionality. This, however, } \\
\text { is not included in my } \\
\text { study. }\end{array}$ \\
\hline 141 & $\begin{array}{l}\text { Bribery in } \\
\text { Islam-Otto- } \\
\text { man Penal } \\
\text { Codes and } \\
\text { Examples } \\
\text { From The } \\
\text { Bursa } \\
\text { Shari'a } \\
\text { Court Rec- } \\
\text { ords of } \\
\text { 18(th) Cen- } \\
\text { tury }\end{array}$ & $\begin{array}{l}\text { Duzba- } \\
\text { kar, } \\
\text { Omer }\end{array}$ & 2009 & $\begin{array}{l}\text { BILIG Is- } \\
\text { sue: } 51 \\
\text { Pages: } 55- \\
84 \text { Pub- } \\
\text { lished: } \\
\text { FAL 2009 }\end{array}$ & $\begin{array}{l}\text { This historical account of } \\
\text { Ottoman Empire is inter- } \\
\text { esting, but my study fo- } \\
\text { cuses on the contempo- } \\
\text { rary context and, there- } \\
\text { fore, it is not included. }\end{array}$ \\
\hline 142 & $\begin{array}{l}\text { Determi- } \\
\text { nants of } \\
\text { business tax } \\
\text { compliance }\end{array}$ & $\begin{array}{l}\text { Nur- } \\
\text { tegin, } \\
\text { Kanybe } \\
\text { k D }\end{array}$ & 2008 & $\begin{array}{l}\text { B E } \\
\text { JOUR- } \\
\text { NAL OF } \\
\text { ECO- } \\
\text { NOMIC }\end{array}$ & $\begin{array}{l}\text { This article examined the } \\
\text { determinants of tax eva- } \\
\text { sion by firms. It is not in- } \\
\text { cluded. }\end{array}$ \\
\hline
\end{tabular}




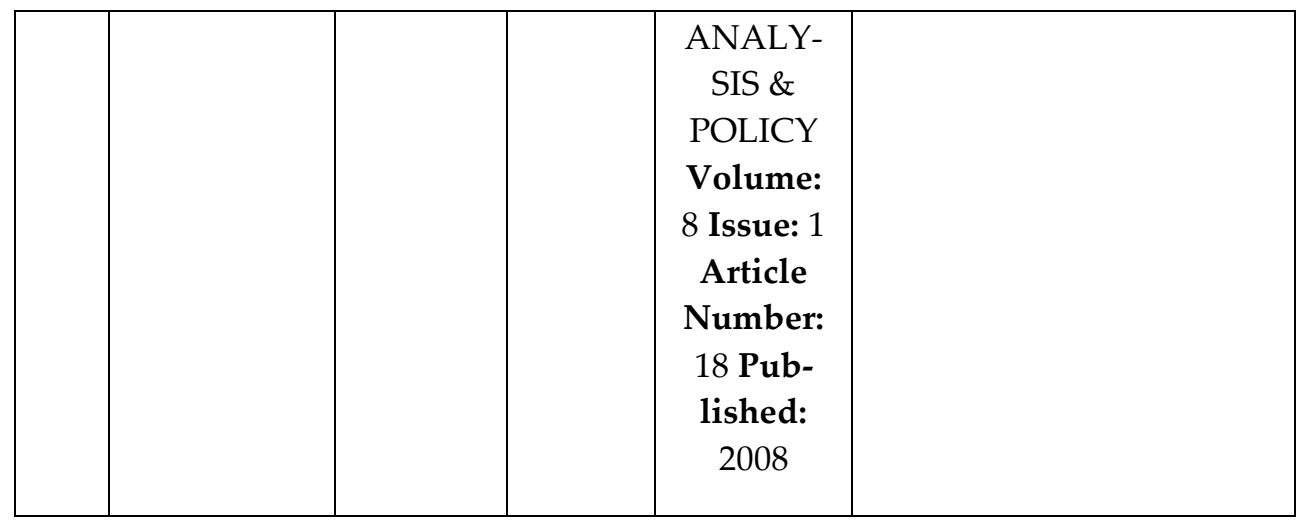


Text in bold indicates the key factors, while text in red indicates the specific role of e-governance and ICT.

\begin{tabular}{|c|c|c|}
\hline $\begin{array}{l}\text { Cate- } \\
\text { gory }\end{array}$ & $\begin{array}{l}\text { Attributes of } \\
\text { institutional } \\
\text { instruments }\end{array}$ & $\begin{array}{l}\text { Elements of compliance determinants emanating } \\
\text { from the literature review }\end{array}$ \\
\hline $\begin{array}{l}\text { Trans- } \\
\text { parency }\end{array}$ & $\begin{array}{l}\text { Collecting } \\
\text { and dissemi- } \\
\text { nating infor- } \\
\text { mation about } \\
\text { corrupt prac- } \\
\text { tices }\end{array}$ & $\begin{array}{l}\text { Cleveland, Favo, Frecka, et al. (2010) cite that } \\
\text { "NGOs and other groups can play an extremely im- } \\
\text { portant role by strengthening their reporting and } \\
\text { tracking of specific bribery cases" (p.223) such as } \\
\text { Transparency International's (TI) foreign bribery } \\
\text { cases and investigations. NGOs, such as TI and } \\
\text { World Economic Forum, have been the whistle } \\
\text { blowers and proven effective in monitoring and } \\
\text { reporting cases, which have significantly in- } \\
\text { creased the potential to catch offences. The most } \\
\text { important tool for the NGOs is identified as the In- } \\
\text { ternet, as it allows information sharing globally and } \\
\text { transparently (Cleveland, Favo, Frecka, et al. 2010). } \\
\text { Webb (2012) elaborates on the virtue of transpar- } \\
\text { ency by which "managers are able to observe the } \\
\text { unethical conduct of the employees and its conse- } \\
\text { quences, and vice versa" (p. 99), thus serving as a } \\
\text { deterrent to unethical behaviors. } \\
\text { Garcia-Tabuyo, Saez-Marin, Caba-Perez (2015) cites } \\
\text { previous studies to conclude that access to infor- } \\
\text { mation facilitated citizens participation in public } \\
\text { management and reduced opportunities for cor- } \\
\text { ruption. ICT was found to have positive effect on } \\
\text { voluntary information disclosure, by reducing } \\
\text { costs, and municipal managers are aware that, with } \\
\text { size, socioeconomic development level and educa- } \\
\text { tion level of municipality were found associated }\end{array}$ \\
\hline
\end{tabular}




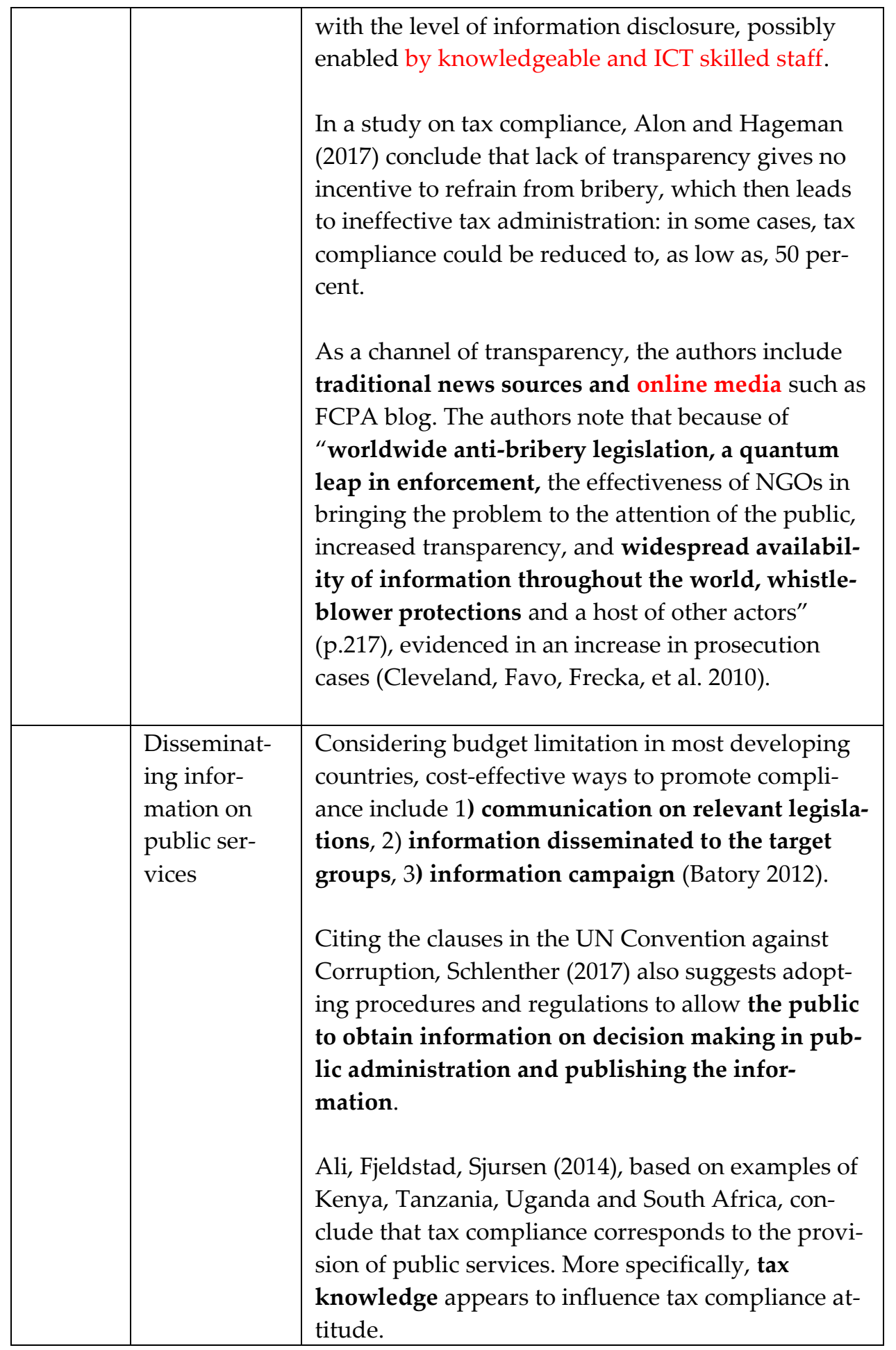




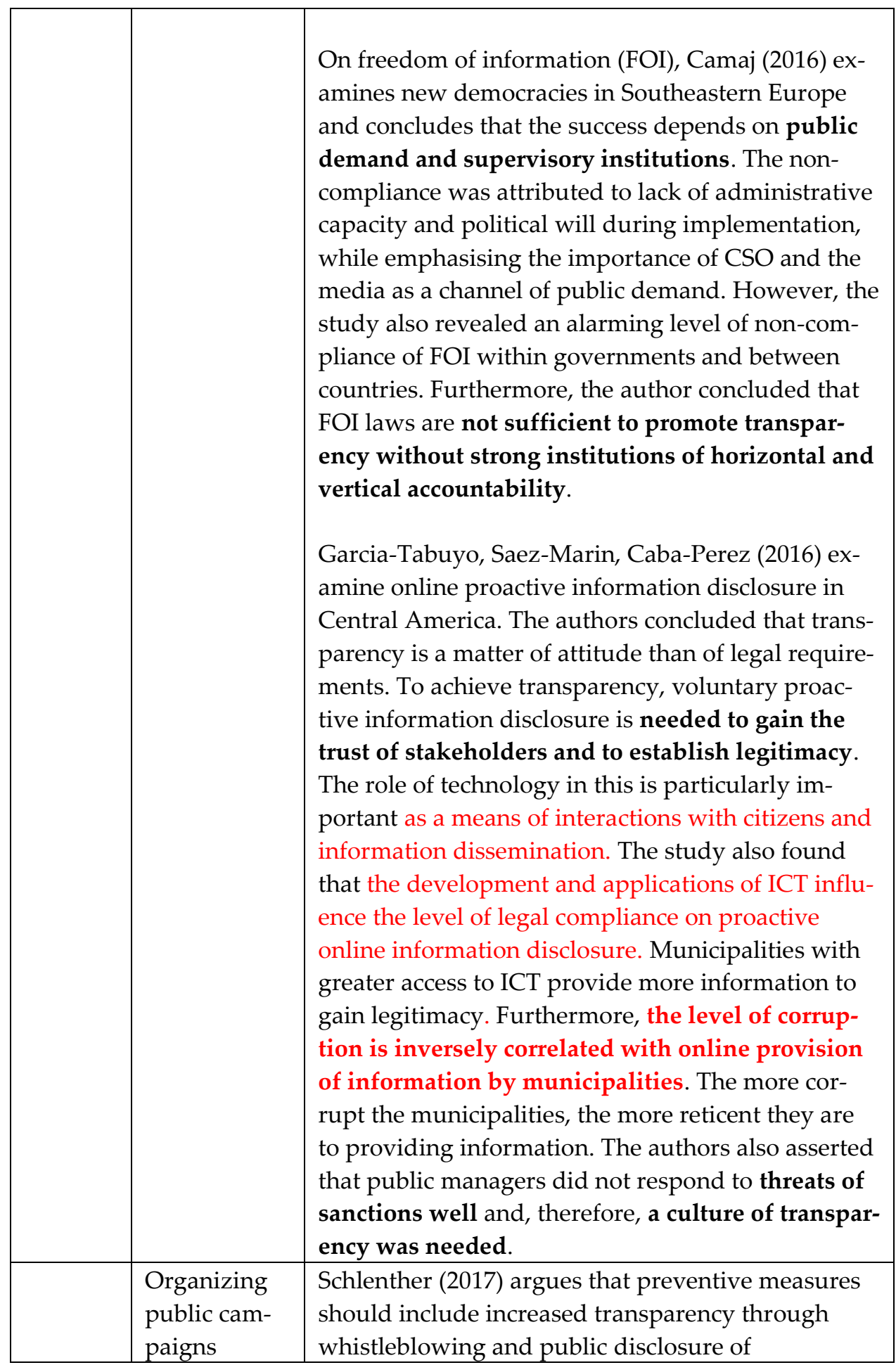




\begin{tabular}{|c|c|c|}
\hline & $\begin{array}{l}\text { against cor- } \\
\text { ruption }\end{array}$ & $\begin{array}{l}\text { information, as symbolised in the Luxemburg } \\
\text { Leaks, Panama Papers and Paradise Papers. Whis- } \\
\text { tleblowing and other institutional instruments } \\
\text { rely on public awareness and understanding, as } \\
\text { "transparency supports measures to combat cor- } \\
\text { ruption and importantly increases public pressure } \\
\text { on the government to fully address the problem of } \\
\text { corruption" (p.231). Schlenther refers to the case of } \\
\text { Swaziland, which launched a campaign, "I refuse to } \\
\text { be silenced" by the Internal Affair's Division of the } \\
\text { Revenue Authority to raise public awareness and } \\
\text { encourage people to come forward in case of sus- } \\
\text { pected instances of corruption. } \\
\text { Sokol (2014) notes that limited public awareness } \\
\text { on cartel/anti-trust made the enforcement difficult, } \\
\text { as "(t)he lack of public awareness and the resulting } \\
\text { lack of social penalties impact deterrence and de- } \\
\text { tection" (p.203). } \\
\text { Bina and Yinghong (2016) add that in the case of } \\
\text { LALA in India, all three parties recognised the sig- } \\
\text { nificant mass movement as a democratic channel, } \\
\text { which results in self-improvement of democratic } \\
\text { systems. } \\
\text { Akerlof (2017) cites that the perception of corrup- } \\
\text { tion being "reasonable" should be changed through } \\
\text { a "big push". Citing examples of the US, Sweden, } \\
\text { Denmark, Hong Kong and Singapore, dramatic de- } \\
\text { clines in corruption were evidenced to coincide } \\
\text { with anti-corruption campaigns. }\end{array}$ \\
\hline $\begin{array}{l}\text { Anti- } \\
\text { Corrup- } \\
\text { tion } \\
\text { policy, } \\
\text { legal } \\
\text { and reg- } \\
\text { ulatory } \\
\text { frame- } \\
\text { works }\end{array}$ & $\begin{array}{l}\text { Anti-Corrup- } \\
\text { tion policies, } \\
\text { laws and reg- } \\
\text { ulations }\end{array}$ & $\begin{array}{l}\text { Another factor is the legislative and legal environ- } \\
\text { ment. According to OECD, the lack of clarity in le- } \\
\text { gal and regulatory framework is identified as a } \\
\text { driver of corruption together with the absence of } \\
\text { well-functioning tax administration (Schlenther } \\
\text { 2017). } \\
\text { Tjen and Evans (2017) study the Gayus case in In- } \\
\text { donesia, and identify ethical policies and practices }\end{array}$ \\
\hline
\end{tabular}




\begin{tabular}{|l|l|}
\hline $\mid$ & $\begin{array}{l}\text { and statutory changes as key for anti-corruption } \\
\text { strategies. } \\
\text { Citing a South African case, Webb (2012) states that } \\
\text { "the anti-corruption and anti-fraud policies are } \\
\text { formulated at the head office and do not reach the } \\
\text { 'ground level'. Officials reported that they had not } \\
\text { even seen these policies, nor was any form of train- } \\
\text { ing provided" (p. 98). The normative expectations } \\
\text { would be clear with "concrete, comprehensive and } \\
\text { understandable guidelines that direct their behav- } \\
\text { iors" (p.99). } \\
\text { Travits (2010) cites a study on Eastern Europe indi- } \\
\text { cating that "condemnation of bribery is associated } \\
\text { with increased resistance to both accepting and } \\
\text { paying bribery" (P.1260) }\end{array}$ \\
$\begin{array}{l}\text { Considering budget limitations in most developing } \\
\text { countries, cost-effective ways to promote compli- } \\
\text { ance include policy reversal and termination. Con- } \\
\text { cerning the last point, if ignored, laws would have } \\
\text { more negative impact on compliance, as such be- } \\
\text { havior undermines the credibility of the entire le- } \\
\text { gal system (Batory 2012). } \\
\text { Popescu, Onofrei \& Kelley (2016) analysed the EU } \\
\text { efforts to reduce corruption in public procurement } \\
\text { through legal rules to enhance compliance with } \\
\text { procurement standards and prosecution of offend- } \\
\text { ers. The authors also reported that "the gap be- } \\
\text { tween legislative goals and actual outcomes, a gap } \\
\text { partially attributable to the differences in the op- } \\
\text { tics of national legislators and the efficiency of } \\
\text { enforcement authorities." (p. 83) }\end{array}$ \\
$\begin{array}{l}\text { Schueth (2012) looked at the example of Georgia, } \\
\text { where the Rose Revolution of 2003 led to the re- } \\
\text { form-oriented government and tripled central gov- } \\
\text { ernment tax revenue from seven percent to 23 per- } \\
\text { cent of GDP between 2004 and 2007. The }\end{array}$ \\
\hline
\end{tabular}




\begin{tabular}{|c|c|}
\hline & $\begin{array}{l}\text { government also introduced effecting anti-corrup- } \\
\text { tion and anti-tax evasion policies. The new tax } \\
\text { laws and enforcement procedures were intro- } \\
\text { duced, together with the civil service reform. The } \\
\text { new tax regime's instrument of coercion was the fi- } \\
\text { nancial police, created in } 2004 \text { under the President's } \\
\text { control. } \\
\text { Yilmaz (2014) investigated the case of Turkey's } \\
\text { anti-corruption reforms, including the new Penal } \\
\text { Code in 2005, definition of corrupt activities and } \\
\text { bribery offences and associated penalties. New } \\
\text { legislations included the Public Procurement Law, } \\
\text { the Law on the Right to Information and Code of } \\
\text { Conduct for Civil Servants. Corresponding insti- } \\
\text { tutional and enforcement frameworks were set } \\
\text { up. Lastly, the countries joined various interna- } \\
\text { tional groups and international conventions, inde- } \\
\text { pendent of the EU accession requirements. } \\
\text { Ozarslan (2016) cites the case of Turkey, where the } \\
\text { government developed the Anti-Corruption Strat- } \\
\text { egy and Plan in 2010, but without transparency, } \\
\text { no significant improvements and achievements } \\
\text { were reported six years after the announcement. } \\
\text { The author identified better policies, including } \\
\text { transparency, integrity and accountability, and re- } \\
\text { ducing the impunity on corruption related cases to } \\
\text { stiffen the fight against corruption. }\end{array}$ \\
\hline $\begin{array}{l}\text { Administra- } \\
\text { ble compli- } \\
\text { ance guide- } \\
\text { lines and } \\
\text { code of con- } \\
\text { duct }\end{array}$ & $\begin{array}{l}\text { In a study on cartel and compliance, Sokol (2014) } \\
\text { identifies a need for cartel-related compliance } \\
\text { guidelines, so that employees know what the } \\
\text { compliance entails. They could also show the type } \\
\text { of behaviors and methods, which are considered } \\
\text { compliant and not. Other organisations established } \\
\text { codes of conduct to improve governance and com- } \\
\text { pliance. Over time, it is expected that these guide- } \\
\text { lines would change the norms and enhance com- } \\
\text { pliance. In addition, regulating processes, com- } \\
\text { pared with outcomes, may be important to change } \\
\text { behavior within the organisation. As guidelines are }\end{array}$ \\
\hline
\end{tabular}




\begin{tabular}{|l|l|}
\hline |l & $\begin{array}{l}\text { enforced, compliance level and changes have been } \\
\text { observed in Canada and the UK. (Sokol 2014). } \\
\text { Van del Wal, Graycar \& Kelly (2016) reviewed the } \\
\text { case of Australia and found that the public bodies } \\
\text { established a broad range of controls, such as gift } \\
\text { disclosure, benefits, hospitality policies and conflict } \\
\text { of interest policies, based on the broad guidelines } \\
\text { of codes of conduct for public sector employees in } \\
\text { the state. The authors found that there was very lit- } \\
\text { tle on corruption in the code of conduct though. } \\
\text { Some respondents revealed that they were develop- } \\
\text { ing fraud and corruption awareness training pro- } \\
\text { grammes as well as training for the Protected Dis- } \\
\text { closure Act requirements. The Code of Conduct } \\
\text { was made public to avoid financial misconduct } \\
\text { and collusion. }\end{array}$ \\
\hline $\begin{array}{l}\text { Anti-Corrup- } \\
\text { tion pro- } \\
\text { grammes }\end{array}$ & $\begin{array}{l}\text { Van del Wal, Graycar \& Kelly (2016) examined the } \\
\text { international best practices in integrity manage- } \\
\text { ment in developed countries. The three pillars of } \\
\text { such attempts include i) specific corruption preven- } \\
\text { tion programs and strategies, ii) anti-corruption } \\
\text { training and effective leadership engagement and } \\
\text { iii) commitment to an ethical culture. In countries } \\
\text { with less corruptions, compliance measures were } \\
\text { found needing regular training, awareness on eth- } \\
\text { ics and leadership. The focus is to shift from Integ- } \\
\text { rity 1.0 (legal, hard controls) to 2.0 (training, } \\
\text { awareness and ethical leaderships as per the } \\
\text { value-based approach) to ultimately 3.0 (ingrained } \\
\text { integrity as regular professional responsibility) to } \\
\text { avoid complacence and naivety. One approach is to } \\
\text { develop integrated integrity management systems } \\
\text { with enabling organisational structure and culture. } \\
\text { The focus is the senior management commitment } \\
\text { to an ethical culture and corruption free organisa- } \\
\text { tion. } \\
\text { Tjen and Evans (2017) study the Gayus case in In- } \\
\text { donesia. The compliance regime has preventive and } \\
\text { reactive systems: the former including compliance }\end{array}$ \\
\hline
\end{tabular}




\begin{tabular}{|c|c|}
\hline & $\begin{array}{l}\text { examination, monitoring of the employee code of } \\
\text { conduct, managing whistleblowing system and } \\
\text { civil servants' wealth reporting system and a Cor- } \\
\text { porate Value Internalization Program. }\end{array}$ \\
\hline $\begin{array}{l}\text { Risk assess- } \\
\text { ment and } \\
\text { management }\end{array}$ & $\begin{array}{l}\text { Van del Wal, Graycar \& Kelly (2016) studied the } \\
\text { cases of developed countries, which would benefit } \\
\text { from emphasis on risks analysis and enforcement. } \\
\text { They introduced the views that integrity policies } \\
\text { are often incident-driven and introduces new } \\
\text { measures instead of implementing and institution- } \\
\text { alising existing policies and programmes. Appoint- } \\
\text { ment of specific officer often results in others feel- } \\
\text { ing less responsible and integrity policies may be } \\
\text { seen as additional bureaucracy without adequate } \\
\text { resources. The identified risks included procure- } \\
\text { ment, breach of IT and information security, finan- } \\
\text { cial misconduct by employees, misconduct relating } \\
\text { to recruitment or human resources and theft or mis- } \\
\text { use of resources by employees. Risk management is } \\
\text { defined as "the combination of organisational sys- } \\
\text { tems, processes, procedures and culture that facili- } \\
\text { tate the identification, assessment, evaluation and } \\
\text { treatment of risk to protect the organisation and as- } \\
\text { sist in the successful pursuit of its strategies and } \\
\text { performance objectives." (p. 10) } \\
\text { Cleveland, Favo, Frecka, et al. (2010) suggest that } \\
\text { risk management policies should include "a code } \\
\text { of conduct, gift policy, training policy, political } \\
\text { and charitable contributions policy, delegation of } \\
\text { authority policy, and accounting policies regard- } \\
\text { ing the proper recording of transactions" (p.218). } \\
\text { The authors document the need for risk assessment, } \\
\text { such as FCPA audits, to test the effectiveness of } \\
\text { the compliance programme implementation once it } \\
\text { is instituted. Any issue arising from the audit, po- } \\
\text { tential FCPA violations and risk assessment may } \\
\text { need an investigation proactively, as the costs of vi- } \\
\text { olations have increased over the years. Risk man- } \\
\text { agement is linked to monitoring as the information }\end{array}$ \\
\hline
\end{tabular}




\begin{tabular}{|l|l|l|}
\hline & & $\begin{array}{l}\text { made available to determine the risk level could } \\
\text { be used to later monitor operations. }\end{array}$ \\
\hline $\begin{array}{l}\text { Tjen and Evans (2017) study the Gayus case in In- } \\
\text { donesia and identify corruption risk mapping as } \\
\text { one of the key features for anti-corruption strate- } \\
\text { gies. }\end{array}$ & $\begin{array}{l}\text { Monitoring } \\
\text { programme }\end{array}$ & $\begin{array}{l}\text { Schlenther (2017) cites the cases of Nigeria and } \\
\text { South Africa, which lack independent and effec- } \\
\text { tive monitoring bodies in the implementation of } \\
\text { anti-corruption policies and initiatives. The author } \\
\text { identifies success factors among countries, which } \\
\text { reduced corruption, such as 1) comprehensive case } \\
\text { management and tracking systems together with } \\
\text { transparent case assignment, 2) administrative re- } \\
\text { forms (i.e. budget, staff, performance management, } \\
\text { rewards and career opportunities for law enforce- } \\
\text { ment officials), 3) inter-agency cooperation and } \\
\text { task team approach and 4) forfeiture of assets in } \\
\text { high-level corruption cases. }\end{array}$ \\
\hline $\begin{array}{l}\text { Anti- } \\
\text { Corrup- } \\
\text { tion- } \\
\text { cen- } \\
\text { tered or- } \\
\text { ganiza- } \\
\text { tional } \\
\text { reforms }\end{array}$ & $\begin{array}{l}\text { Anti-Corrup- } \\
\text { tion bodies } \\
\text { and compli- } \\
\text { ance and dis- } \\
\text { ciplinary of- }\end{array}$ & $\begin{array}{l}\text { According to Schlenther (2017), another institu- } \\
\text { tional instrument well referenced is the establish- } \\
\text { ment of the Anti-Corruption Body as the central } \\
\text { mechanism to prevent corruption and implement } \\
\text { anti-corruption policies and initiatives. It, how- } \\
\text { ever, is not a panacea to corruption. It is evidenced } \\
\text { to require various factors to function optimally, } \\
\text { such as institutional coherence (buy-in), sectoral } \\
\text { and agency cooperation, functional and financial } \\
\text { independence and monitoring functions. Schlen- } \\
\text { ther cites an example of Nigeria, which put in place } \\
\text { a number of institutional instruments. Chief Justice } \\
\text { of Nigeria planned to establish a special court dedi- } \\
\text { cated to corruption charges. For transparency and } \\
\text { accountability purpose, the country introduced an } \\
\text { audit bill to guarantee the independence of the of- } \\
\text { fice of Auditor-General. Another example is the } \\
\text { Anti-Corruption and Transparency Unit, which } \\
\text { was established in the Federal Inland Revenue Ser- } \\
\text { vice. }\end{array}$ \\
\hline
\end{tabular}


Tjen and Evans (2017) study the Gayus case in Indonesia. One of the measures the government took, after the case was revealed, was the establishment of the compliance office. The role of the Directorate of Internal Compliance and Apparatus Transformation was to "formulate and implement policies and technical standardisation in internal compliance and apparatus transformation" (p.256) and the unit implements the code of conduct through such means as random surprise inspection, surveillance, internal control monitoring, risk management monitoring, disciplinary compliance, formulating recommendations on business process improvement.

Van del Wal, Graycar \& Kelly (2016) cite some examples in Australia of having specific officers with Protected Disclosure Act responsibilities, known as a Protected Disclosure Coordinator and a Protected Disclosure Manager. The respondents indicated that senior managers were involved in the oversight of misconduct. These bodies included an audit or risk management committee, fraud control or prevention officer, and/or integrity manager, compliance and risk managers.

Bina and Yinghong (2016) examined the case of India's Lokpal and Lokayuktas Act (LALA) as a tripartite anti-corruption model among government, NGOs and people. Together with the Act, the establishment of independent ombudsman was a result of political impetus, after 45 years of parliamentary debates and popular mobilisation.

By examining the case of Catalan Anti-Fraud Office, its functions and continued trends of corrupt practices in the Spanish State, Villagrasa (2016) concludes that the impact of the office is not optimal without duties for preventing corruption and 


\begin{tabular}{|c|c|}
\hline & $\begin{array}{l}\text { granting sanctioning powers to specialised agen- } \\
\text { cies in the event of non-compliance. } \\
\text { But Baum, Gupta, Kimani et al. (2017) reiterate that } \\
\text { an anti-corruption unit alone would be insufficient } \\
\text { to reduce corruption in India. Independence and } \\
\text { enforcement power are needed to pursue cases: } \\
\text { otherwise such unit would become another layer of } \\
\text { bureaucracy. } \\
\text { Hough (2017) focused on Germany's anti-corrup- } \\
\text { tion infrastructure, but resilient, path-dependency } \\
\text { makes the reform difficult, in the area of regulating } \\
\text { German businesses, meeting international anti-cor- } \\
\text { ruption commitment and transparency agenda. } \\
\text { Ozarslan (2016) noted that "Turkey implemented } \\
\text { some structural changes to address this issue be- } \\
\text { tween } 2003 \text { and } 2005 \text { in accordance with the EU } \\
\text { harmonisation process, such as signing the UNCAC } \\
\text { and OECD Conventions, establishing the Council } \\
\text { of Ethics for public officials, and enacting the } \\
\text { Right to Access Information Act. As a result, Tur- } \\
\text { key's perception was positively affected in that pe- } \\
\text { riod, but subsequent compliance with these interna- } \\
\text { tion-ally binding agreements was poor." (p. 112). }\end{array}$ \\
\hline $\begin{array}{l}\text { Resource al- } \\
\text { location }\end{array}$ & $\begin{array}{l}\text { Webb (2012) adds that resource scarcity and work- } \\
\text { load could be determinants, which may lead to an } \\
\text { environment for cheating to occur. Webb lists "ade- } \\
\text { quate time, budgets, equipment, information and } \\
\text { authority to execute their responsibilities" (p. 99) } \\
\text { as key ingredients. } \\
\text { Van del Wal, Graycar \& Kelly (2016) state that aus- } \\
\text { terity measures due to the financial crises could re- } \\
\text { sult in integrity risks, as time and resources for in- } \\
\text { tegrity management could be affected. }\end{array}$ \\
\hline $\begin{array}{l}\text { Internal ac- } \\
\text { counting and } \\
\text { audit }\end{array}$ & $\begin{array}{l}\text { Kantsir \& Plekan (2017) reviewed the case of regu- } \\
\text { latory system and audit activity in Ukraine as a } \\
\text { condition to the EU accession and as a response to } \\
\text { corporate financial scandals in the US, Europe and }\end{array}$ \\
\hline
\end{tabular}




\begin{tabular}{|l|l|}
\hline |l & $\begin{array}{l}\text { Japan. This prompted the EU directive to ensure } \\
\text { public oversight of auditors and their independence } \\
\text { by monitoring the process of implementation of au- } \\
\text { dit activity. }\end{array}$ \\
$\begin{array}{l}\text { Van del Wal, Graycar \& Kelly (2016) cited the role } \\
\text { of auditors in control and risk management by re- } \\
\text { viewing control and risk management systems and } \\
\text { operations and assessing their effectiveness and ef- } \\
\text { ficiency with value for money. }\end{array}$ \\
\hline $\begin{array}{l}\text { Reducing } \\
\text { compliance } \\
\text { costs }\end{array}$ & $\begin{array}{l}\text { Citing a concept of corruption trap, Akerlof (2017) } \\
\text { also cites that a high rate of corruption tends to lead } \\
\text { to more corruption and it is difficult to undertake } \\
\text { an audit in a highly corrupt society. }\end{array}$ \\
\hline $\begin{array}{l}\text { Tjen and Evans (2017) studied the Gayus case in In- } \\
\text { donesia, and identified reduction in compliance } \\
\text { costs as one of the key schemes for anti-corruption } \\
\text { strategies. } \\
\text { Bac (2018) cites three factors that impact the effec- } \\
\text { tiveness of internal control: 1) cost of filing com- } \\
\text { plaint, 2) probability with which the victims pre- } \\
\text { vail and 3) remedial effects of procedural quality } \\
\text { (speed and accuracy). }\end{array}$ \\
\hline $\begin{array}{l}\text { Tjen and Evans (2017) studied the Gayus case in In- } \\
\text { donesia, and identified e-services as one of the key } \\
\text { instruments for anti-corruption strategies. They } \\
\text { note that it is unlikely that "tax collectors and bail- } \\
\text { iffs would be capable of postponing or cancelling } \\
\text { the seizure of assets without being detected given } \\
\text { the implementation of new real time and compre- } \\
\text { hensive information systems such as the DGT In- } \\
\text { formation System" (p.255). }\end{array}$ \\
$\begin{array}{l}\text { However, Schlenther (2017) cites a case of Kenya, } \\
\text { where the president was suspected to be involved } \\
\text { in a corruption case. An e-payment system is sus- } \\
\text { pected to have been manipulated at the Ministry of } \\
\text { Health and the company associated with the }\end{array}$ \\
\hline
\end{tabular}




\begin{tabular}{|c|c|c|}
\hline & & $\begin{array}{l}\text { president is reported to have received double pay- } \\
\text { ment. In a similar case in Malawi, a computer- } \\
\text { based financial system was compromised by gov- } \\
\text { ernment officials to divert funds and an arrest war- } \\
\text { rant was eventually issued to the former president. } \\
\text { Citing IMF recommendations, the author also sug- } \\
\text { gests "simple transparency and to the extent possi- } \\
\text { ble automated procedures, strong information sys- } \\
\text { tems and high profile prosecutions" (p.234). } \\
\text { Citing a case of Albania, Camaj (2016) refers to the } \\
\text { e-government initiatives as the online infrastruc- } \\
\text { ture for information access. Government web } \\
\text { pages and e-government processes provide infor- } \\
\text { mation regarding legal frameworks, public pro- } \\
\text { curement, tax system, etc. Despite progresses, an } \\
\text { audit report pointed out that some websites do not } \\
\text { work and information is not up to date with limited } \\
\text { awareness among the public on the tool. } \\
\text { According to a survey } 57 \text { percent of the respond- } \\
\text { ents were not aware of the government websites } \\
\text { and } 80 \text { percent did not use the website to access in- } \\
\text { formation. Local governments were also identified } \\
\text { among those left out in the open government initia- } \\
\text { tives. In the case of Kosovo, the introduction of } \\
\text { digital technologies and e-government websites } \\
\text { enabled citizens to request for information online, } \\
\text { although an audit reported selective transparency } \\
\text { and unavailability of comprehensive information. } \\
\text { Fifty-five percent of citizens were unaware of their } \\
\text { local government's websites. The author concluded } \\
\text { that the use of new technologies and creation of } \\
\text { online platforms and online portals would help } \\
\text { facilitate access to information and potentially } \\
\text { solve the limitations in public administrations in } \\
\text { developing countries. } \\
\text { On EU public procurement, Popescu, Onofrei \& } \\
\text { Kelley (2016) noted that one of the most popular } \\
\text { tools to disseminate information and promote }\end{array}$ \\
\hline
\end{tabular}




\begin{tabular}{|l|l|}
\hline & $\begin{array}{l}\text { efficient public procurement, was e-government. } \\
\text { "The Internet and the electronic platforms systems } \\
\text { based on it proved to determine lower transaction } \\
\text { costs, increase competition and decrease corrup- } \\
\text { tion through transparency and easy public pro- } \\
\text { curement monitoring. E-procurement and e-invoic- } \\
\text { ing are successfully used during the bidding stage } \\
\text { in many European countries such as Portugal, Ger- } \\
\text { many, France, Lithuania, Slovakia, and Slovenia, } \\
\text { Estonia. One of the good practices in this respect is } \\
\text { the electronic public procurement platform used in } \\
\text { Portugal. It is an application used for all public pro- } \\
\text { curement stages, including contract management } \\
\text { and payment. The National E-Procurement Portu- } \\
\text { guese Portal, or simply BASE, centralises public } \\
\text { procurement contracts, keeping extended records } \\
\text { on public procurement transactions. Also, the e- } \\
\text { procurement platform offers the possibility of } \\
\text { downloading documentation free of charge } \\
\text { (OECD, 2007). Since its implementation in 2003, the } \\
\text { system has proved its efficiency in saving time and } \\
\text { money for both public and private partners and in } \\
\text { keeping the public informed about spending pub- } \\
\text { lic money. Another good practice is the Open Local } \\
\text { Government Initiative of Slovakia that ranks a } \\
\text { hundred Slovakian towns using a set of criteria } \\
\text { such as "transparency in public procurement, ac- } \\
\text { cess to information, availability of data of public } \\
\text { interest, public participation, professional ethics } \\
\text { and conflicts of interests" (European Commission, } \\
\text { 2014, p. 28)." (p. 87) } \\
\text { Samuel \& Lowen (2010) began their article on in- } \\
\text { spection technology by stating that e-government } \\
\text { aimed to improve government efficiency and re- } \\
\text { duce corruption by reducing the discretional } \\
\text { power of government officials. Within the Princi- } \\
\text { pal-Supervisor-Agent model, the authors showed } \\
\text { that improvement inspection technology increases } \\
\text { marginal or total productivity, while increasing } \\
\text { some types of corruption, as corruption may shift }\end{array}$ \\
\hline
\end{tabular}




\begin{tabular}{|c|c|c|}
\hline & & $\begin{array}{l}\text { from government officials without computer } \\
\text { skills to those with skills, or change the timing } \\
\text { and type of bribery. The authors evidenced that } \\
\text { improvements in inspection technology and super- } \\
\text { visor's productivity increased preemptive corrup- } \\
\text { tion. When preemptive bribery is observed, it re- } \\
\text { duces compliance, where it would have increased, } \\
\text { if not corruption. In the presence of corrupt super- } \\
\text { visors, technological improvements will not nec- } \\
\text { essarily reduce corruption. An improvement in in- } \\
\text { spection technology needs to be accompanied by } \\
\text { an increase in penalties to increase compliance and } \\
\text { discourage corruption. In the case of Korea's } \\
\text { OPEN, the workload on officials increased and } \\
\text { could open up a new avenue for bribery. }\end{array}$ \\
\hline $\begin{array}{l}\text { Anti- } \\
\text { Corrup- } \\
\text { tion re- } \\
\text { porting } \\
\text { and en- } \\
\text { force- } \\
\text { ment }\end{array}$ & $\begin{array}{l}\text { Whistle- } \\
\text { blower pro- } \\
\text { tection }\end{array}$ & $\begin{array}{l}\text { In a study on cartel enforcement, Sokol (2014) fo- } \\
\text { cuses on the need to entice behavioral changes } \\
\text { among employees and embed the anti-trust culture } \\
\text { in the organisation as the most detection incidents } \\
\text { come from employees. It is necessary to create } \\
\text { enough incentives for whistleblowers to come for- } \\
\text { ward by changing the cost and benefit calculation. } \\
\text { This finding is echoed in the case of Uganda, which } \\
\text { reports that } 30 \text { percent of investigation cases are } \\
\text { brought by whistleblowers (Schlenter 2017). } \\
\text { However, in a study on South Africa, Webb (2012) } \\
\text { reports that officials "were generally afraid to re- } \\
\text { port corruption as management could not be } \\
\text { trusted. Whistle-blowing was ineffective as officials } \\
\text { did not believe that reports would be kept confi- } \\
\text { dential and this could be victimized", in addition } \\
\text { to the fact that "no one even answered the whistle- } \\
\text { blowing line". (p.99) } \\
\text { Schlenther (2017) argues that preventive measures } \\
\text { should include increased transparency through } \\
\text { whistleblowing and public disclosure of infor- } \\
\text { mation. Whistleblowing and other institutional in- } \\
\text { struments rely on public awareness and }\end{array}$ \\
\hline
\end{tabular}




\begin{tabular}{|c|c|}
\hline & $\begin{array}{l}\text { understanding. Transparency will help inform the } \\
\text { public as a means to combatting corruption and } \\
\text { pressurising governments to act. } \\
\text { Whistleblower protection is a way to influence the } \\
\text { cost-benefits calculus but one case was reported in } \\
\text { Hungary due to the fear for reprisal against whis- } \\
\text { tleblowers. Therefore, target groups have been un- } \\
\text { able to comply with rules and requirements, also } \\
\text { exasperated by low awareness of their own rights, } \\
\text { opportunities to redress, information deficits } \\
\text { among target groups (Batory 2012). } \\
\text { Gilbert and Sharman (2016) cited the case of British } \\
\text { Aerospace scandal based on the account of whistle- } \\
\text { blower, involving the British Prime Minister, Mar- } \\
\text { garet Thatcher, for the supply of military aircraft to } \\
\text { Saudi Arabia. Despite the pressure, the investiga- } \\
\text { tion was terminated. The last case of Note Printing } \\
\text { Australia and Securency involves AU\$ } 50 \text { million in } \\
\text { kickbacks for contracts. "The RBA and the Austral- } \\
\text { ian government's reactions to the allegations were } \\
\text { characterised by a mix of denial, inaction, blame } \\
\text { avoidance and foot-dragging" (p.85). It was the } \\
\text { whistleblower and media pressure, not the gov- } \\
\text { ernment, which triggered the response. } \\
\text { Michael (2012) mentions the Whistleblowers Law } \\
\text { in Romania that "stresses 'the integrity, impartiality } \\
\text { and efficiency of public authorities and institutions' } \\
\text { as comprising the public interest" (p. } 311 \text { ). }\end{array}$ \\
\hline $\begin{array}{l}\text { Confidential } \\
\text { reporting }\end{array}$ & $\begin{array}{l}\text { Schlenther (2017) refers to the Swaziland case, } \\
\text { which launched a campaign "I refuse to be si- } \\
\text { lenced" by the Internal Affair's Division of the Rev- } \\
\text { enue Authority to raise public awareness and en- } \\
\text { courages people to come forward regarding sus- } \\
\text { pected corrupt cases. A toll free number was set up } \\
\text { as part of the campaign. } \\
\text { Citing the cases of forest nationalisations and re- } \\
\text { verse effects the policies had, Akerlof (2017) }\end{array}$ \\
\hline
\end{tabular}




\begin{tabular}{|c|c|}
\hline & $\begin{array}{l}\text { concludes that observers will not report non-com- } \\
\text { pliance or violations because they consider the rule } \\
\text { illegitimate with a high non-compliance rate. In an } \\
\text { honest society, corruption triggers an indignation } \\
\text { and reporting, but when corrupt behaviors are } \\
\text { common place, this does not happen. Furthermore, } \\
\text { the author refers to the reporting and retaliation by } \\
\text { the offender. } \\
\text { In the case of Turkey, Ozarslan (2016) cited Trans- } \\
\text { parency International 2015-2016 report, indicating } \\
\text { that " } 45 \text { percent (60 percent in } 2015 \text { ) believe report- } \\
\text { ing bribery and improper solicitation of gifts by } \\
\text { public officials does little to improve these prob- } \\
\text { lems, and in fact, could result in negative out- } \\
\text { comes." (p. 112) } \\
\text { Van del Wal, Graycar \& Kelly (2016) analysed the } \\
\text { case of Australian schools and concluded that the } \\
\text { most common ways to commence investigations } \\
\text { was to follow complaints from the public, manag- } \\
\text { ers and colleagues. In some rare cases, suppliers } \\
\text { complained about irregularities in staff conduct. } \\
\text { Most respondents reported that they have mecha- } \\
\text { nisms to lodge complaints. }\end{array}$ \\
\hline $\begin{array}{l}\text { Rewards and } \\
\text { penalties }\end{array}$ & $\begin{array}{l}\text { The detection rate is evidenced to increase together } \\
\text { with the leniency programme and fines (Sokol } \\
\text { 2014). On the question of perception of impunity, } \\
\text { Webb (2012) states that "if employees perceive that } \\
\text { they will not be rewarded for ethical conduct, they } \\
\text { will be less likely to act ethically" (p. 99). Therefore, } \\
\text { "a visible imposition of sanctions and rewards" } \\
\text { (p. 107) would be a factor to influence employee be- } \\
\text { haviors. } \\
\text { Considering budget limitations in most developing } \\
\text { countries, cost-effective ways to promote compli- } \\
\text { ance include rewards for rule conforming behav- } \\
\text { ior. She notes that a typical policy reaction is deter- } \\
\text { rence "to try to change the individual's strategic } \\
\text { calculus by increasing the costs of socially harmful }\end{array}$ \\
\hline
\end{tabular}




\begin{tabular}{|c|c|}
\hline & $\begin{array}{l}\text { behavior as well as the likelihood that those costs } \\
\text { will indeed need to be borne" (p.72) (Batory 2012). } \\
\text { Berghoff (2018) also notes that one factor fueling } \\
\text { corrupt behavior was "(a)uthorities had been } \\
\text { dormant and lenient in the last, fines had been ex- } \\
\text { tremely low" (p.433). Because of the bribery case, } \\
\text { Siemens was fined a record } \$ 1.6 \text { billion by the US } \\
\text { and German authorities. The investigation was con- } \\
\text { ducted as a major FCPA case. It was also noted that } \\
\text { the efficiency of a compliance system was evi- } \\
\text { denced in a prompt detection and response by rig- } \\
\text { orous sanctions. } \\
\text { Akerlof (2017) cites the concept of graduated sanc- } \\
\text { tions. One reason for escalating punishment is that } \\
\text { the anger triggered by repeated offenses is greater } \\
\text { than the first-time offender. } \\
\text { Jiang (2017) depicted an increasing pressure on } \\
\text { multinational corporations for compliance. Enforce- } \\
\text { ment agencies are imposing substantial penalties, } \\
\text { as exemplified in the case of VimpelCom for a com- } \\
\text { bined fine of US\$ } 795 \text { million by US and Dutch au- } \\
\text { thorities in 2016. } \\
\text { Galiot (2017) identified that confiscation of pecuni- } \\
\text { ary gains is one of the effective means to address } \\
\text { bribery criminal offenses. } \\
\text { Sokol (2014) elaborates that "(i)f antitrust were to } \\
\text { empower individuals through rewards for whistle- } \\
\text { blowing, this might lead to greater detection than } \\
\text { through the use of leniency alone" (p.230.) }\end{array}$ \\
\hline $\begin{array}{l}\text { Control of vi- } \\
\text { olations }\end{array}$ & $\begin{array}{l}\text { Corruption is a classic collective action problem, } \\
\text { where the social cost is high and diffused and no } \\
\text { immediate personal unitality is identified. In this } \\
\text { context, the deterrence should try to change the in- } \\
\text { dividuals' calculus by increasing costs and likeli- } \\
\text { hoods of penalty, while increasing moral satisfac- } \\
\text { tion. In the case of Hungary, lenient penalties, }\end{array}$ \\
\hline
\end{tabular}




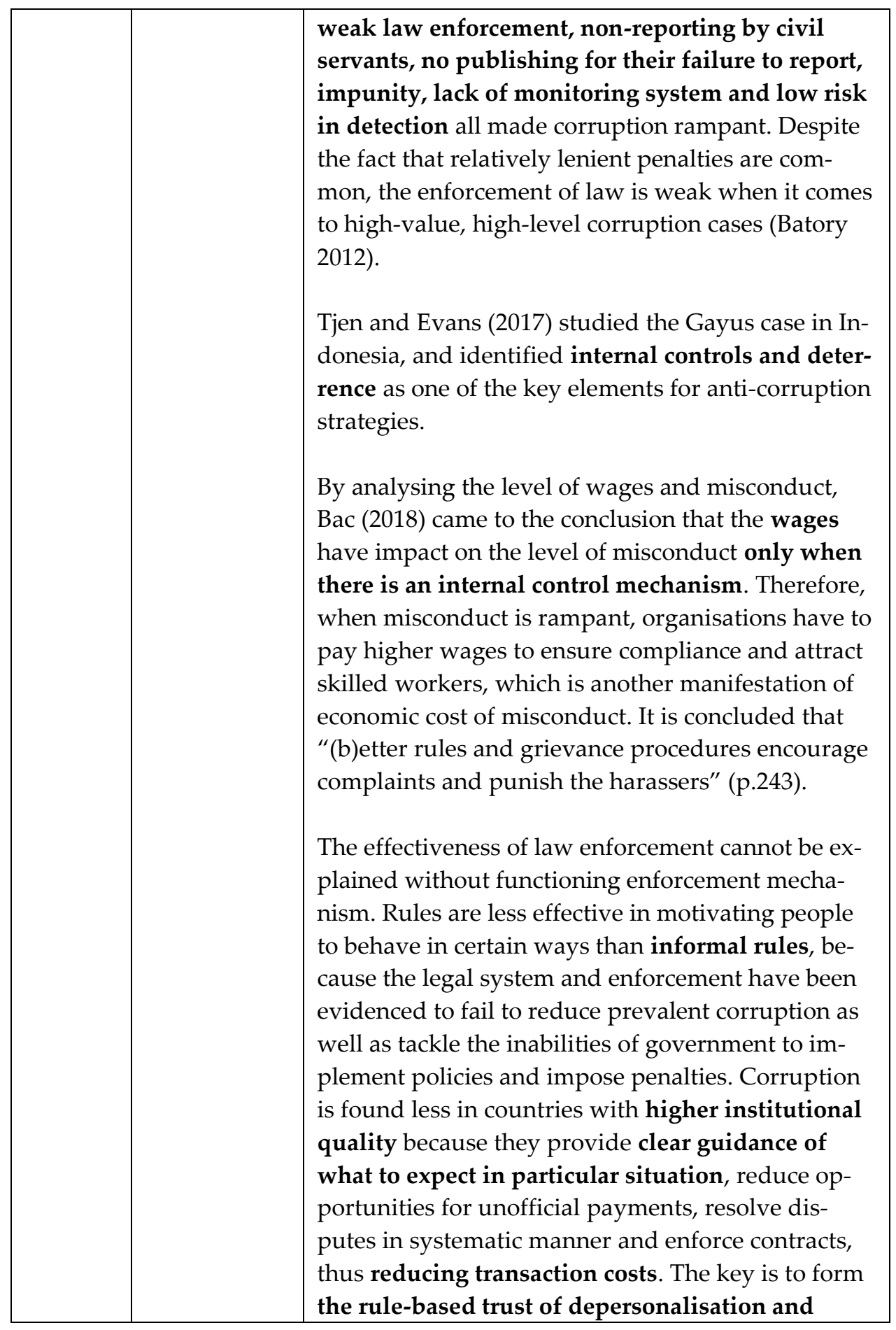




\begin{tabular}{|c|c|}
\hline & $\begin{array}{l}\text { predictability through institutionalisation (Alon } \\
\text { and Hageman 2017). } \\
\text { Akerlof (2017) explored the phenomena of rule vio- } \\
\text { lations from the angle of legitimacy in enforcement, } \\
\text { specifically on "corruption traps; graduated sanc- } \\
\text { tions for repeated offenders; and tolerance of self- } \\
\text { interestedness". (p.110) A rule is considered legiti- } \\
\text { mate "if there is a widespread feeling that there is a } \\
\text { duty to comply". (P.111) Lack of legitimacy makes } \\
\text { rule compliance more difficult, leading to the need } \\
\text { for coercive forces. They would then lead to re- } \\
\text { sistance, which can take the form of not only rule } \\
\text { violations but also non-reporting of such violations } \\
\text { to authorities. It then leads to a "noncompliance } \\
\text { trap" with high non-compliance, resulting in more } \\
\text { non-compliance. } \\
\text { Ali, Fjeldstad, Sjursen (2014) assert that when there } \\
\text { is a perception that enforcement makes tax evasion } \\
\text { difficult, people in South Africa and Kenya re- } \\
\text { sponded that they comply with taxation, although } \\
\text { the size of informal economy, illiteracy, uncer- } \\
\text { tainty, lack of trust in government, which may af- } \\
\text { fect the level of tax compliance. } \\
\text { Gilbert \& Sharman (2016) examined the cases of } \\
\text { British and Australian corruption scandals and con- } \\
\text { cluded that failures were not due to the lack of abil- } \\
\text { ities but willful blindness towards the OECD con- } \\
\text { vention. }\end{array}$ \\
\hline $\begin{array}{l}\text { Detection, in- } \\
\text { vestigation } \\
\text { and prosecu- } \\
\text { tion }\end{array}$ & $\begin{array}{l}\text { Sokol (2014) mentioned that cartel behaviors were } \\
\text { detected by auditors ( } 10 \text { percent), media (13 per- } \\
\text { cent), regulators ( } 13 \text { percent) and employees ( } 17 \\
\text { percent) among others. } \\
\text { Webb (2012) also notes that without capacity for } \\
\text { investigation, whistle-blowing would be ineffec- } \\
\text { tive. Cleveland, Favo, Frecka, et al. (2010) also high- } \\
\text { light the need to train officers to conduct corrup- } \\
\text { tion investigations. }\end{array}$ \\
\hline
\end{tabular}


Gilbert and Sharman (2016) cited the British Aerospace scandal case, where the government terminated its investigation for commercial and diplomatic concerns, which was later addressed by the US Department of Justice for accounting offense. In the case of Australian Wheat Board scandal, "the government long resisted any investigation so as to protect the country's economic interests, and then, when further stalling became impossible, designed the investigation to minimise adverse media coverage and electoral damage rather than promote accountability" (p. 84). "The failure of democratic governments to investigate crimes of their powerful corporate citizens properly suggests that improving compliance depends on protecting whistle-blowers better, augmenting the capacity of anti-corruption NGOs and investigative journalists, and substantially toughening the review process carried out by intergovernmental organisations like the OECD." (p. 87)

In the case of Turkey, Ozarslan (2016) pointed out that despite Turkey's subscription to the OECD Convention, the enforcement was found weak: there has not been a foreign bribery conviction in the 11 years since the Convention took effect in the country. Turkey is also party to the UN Convention against Corruption since 2014. According to Transparency International, the country's legal system is compliant with the Convention requirements, but the overall enforcement is poor with non-responsive government officials, lack of data collection and analysis and open public access. The author also concluded that "the most common methods used in impunity cases, secrecy orders and the blanket press ban on court trials, as well as the wide range of immunities granted to politicians and bureaucrats are systematically applied in corruption cases in Turkey. Unfortunately, Turkey is one of few countries in the world that still grants 


\begin{tabular}{|c|c|c|}
\hline & & $\begin{array}{l}\text { political immunity to members of Parliament in } \\
\text { corruption crimes, as well as a wide range of im- } \\
\text { munities for bureaucrats in some corruption-related } \\
\text { offences." (p. 114) }\end{array}$ \\
\hline $\begin{array}{l}\text { Public } \\
\text { sector } \\
\text { reform }\end{array}$ & $\begin{array}{l}\text { Efficient ju- } \\
\text { diciary }\end{array}$ & $\begin{array}{l}\text { Williams and Horodnic (2015) elaborate the two ap- } \\
\text { proaches of compliance. One is characterised as } \\
\text { "cop and robber", where employers and employ- } \\
\text { ees use tight rules and procedures with close su- } \\
\text { pervision and monitoring in centralised struc- } \\
\text { tures. This tends to lead to a low-trust, low-com- } \\
\text { mitment adversarial environment. The other softer } \\
\text { approach of high trust and high commitment cul- } \\
\text { ture generates self-regulated control. The formal } \\
\text { approach works with three changes of, 1) proce- } \\
\text { dural justice (treat citizens with respect), 2) proce- } \\
\text { dural fairness and 3) redistributive justice. } \\
\text { Ozarslan (2016) concluded that "in a recent study } \\
\text { by TI Turkey, the National Integrity System (NIS) } \\
\text { re-veals the long shadow of executive power over } \\
\text { the pillars of the system and the fundamental insti- } \\
\text { tutions of the regime. While the "separation of } \\
\text { powers," principle has turned into "unification of } \\
\text { powers", the institutions that are essential for a } \\
\text { democratic system to function, such as the legisla- } \\
\text { ture, judiciary, and the media, appear to have been } \\
\text { rendered ineffective by this shadow. Of the } 15 \text { insti- } \\
\text { tutions the NIS report assessed, } 11 \text { were classified } \\
\text { as "weak" and only four rated as high as "moder- } \\
\text { ate". The fact that none of the institutions in the } \\
\text { system could be identified as "strong" provides } \\
\text { crucial insight about the functionality of the state. } \\
\text { The deficiencies in the main institutions are mostly } \\
\text { the result of political polarization, partisanship, } \\
\text { and the imbalance in checks and balances mecha- } \\
\text { nisms." (p. 115) } \\
\text { By reviewing the case of South African natural re- } \\
\text { source management regulations, Sundstrum (2016) } \\
\text { corruption affects various aspects of institutions. It } \\
\text { may constrain policy-makers from enacting stricter }\end{array}$ \\
\hline
\end{tabular}




\begin{tabular}{|c|c|}
\hline & $\begin{array}{l}\text { regulations and reduce the effectiveness of regula- } \\
\text { tions during implementation. He believes the com- } \\
\text { pliance is also impacted by the rules and how they } \\
\text { are formulated, including if citizens were in- } \\
\text { volved in the decision-making processes from dis- } \\
\text { tributive and procedural justice point of view. }\end{array}$ \\
\hline $\begin{array}{l}\text { Less interac- } \\
\text { tions with } \\
\text { government } \\
\text { officials, in- } \\
\text { cluding auto- } \\
\text { mation }\end{array}$ & $\begin{array}{l}\text { Corruption is evidenced to harm the culture of } \\
\text { compliance. In the sphere of tax administration, it } \\
\text { tends to undermine trust in government and com- } \\
\text { pliance efforts with tax laws, thus increasing tax } \\
\text { evasion. Indirect tax collection is found particularly } \\
\text { vulnerable to corruption as it requires interactions } \\
\text { with tax authorities. Improvements in tax compli- } \\
\text { ance would require building necessary institutions } \\
\text { (Baum, Gupta, Kimani et al. 2017). } \\
\text { In particular, manual registration and process of fil- } \\
\text { ing and payment, which involves person to person } \\
\text { transactions, were found to be an opportunity for } \\
\text { corruption. Thus, simple, transparent automated } \\
\text { procedures and strong information systems were } \\
\text { found effective to reduce corrupt practices } \\
\text { (Schlenther 2017). } \\
\text { Tjen and Evans (2017) studied the Gayus case in In- } \\
\text { donesia, and identified minimising taxpayer/tax au- } \\
\text { thority interactions and automation as key for anti- } \\
\text { corruption strategies. }\end{array}$ \\
\hline $\begin{array}{l}\text { Institutional } \\
\text { and individ- } \\
\text { ual capacity }\end{array}$ & $\begin{array}{l}\text { Citing a case of Kenya, Schlenther (2017) notes "the } \\
\text { deliberate undermining of the basic institutions that } \\
\text { underpin and support the rule of law and good } \\
\text { government" (P.224) to explain a high-level and } \\
\text { pervasive corruption in the country. Therefore, } \\
\text { "(i)nstitutional responses to corruption have also } \\
\text { come in the form of anti-corruption bodies, } \\
\text { whereby, states attempt to enhance their institu- } \\
\text { tional capacity to prevent corruption" (p.232) } \\
\text { On EU public procurement, Popescu, Onofrei \& } \\
\text { Kelley (2016) noted that "the European challenge } \\
\text { remains the enforcement of public procurement }\end{array}$ \\
\hline
\end{tabular}




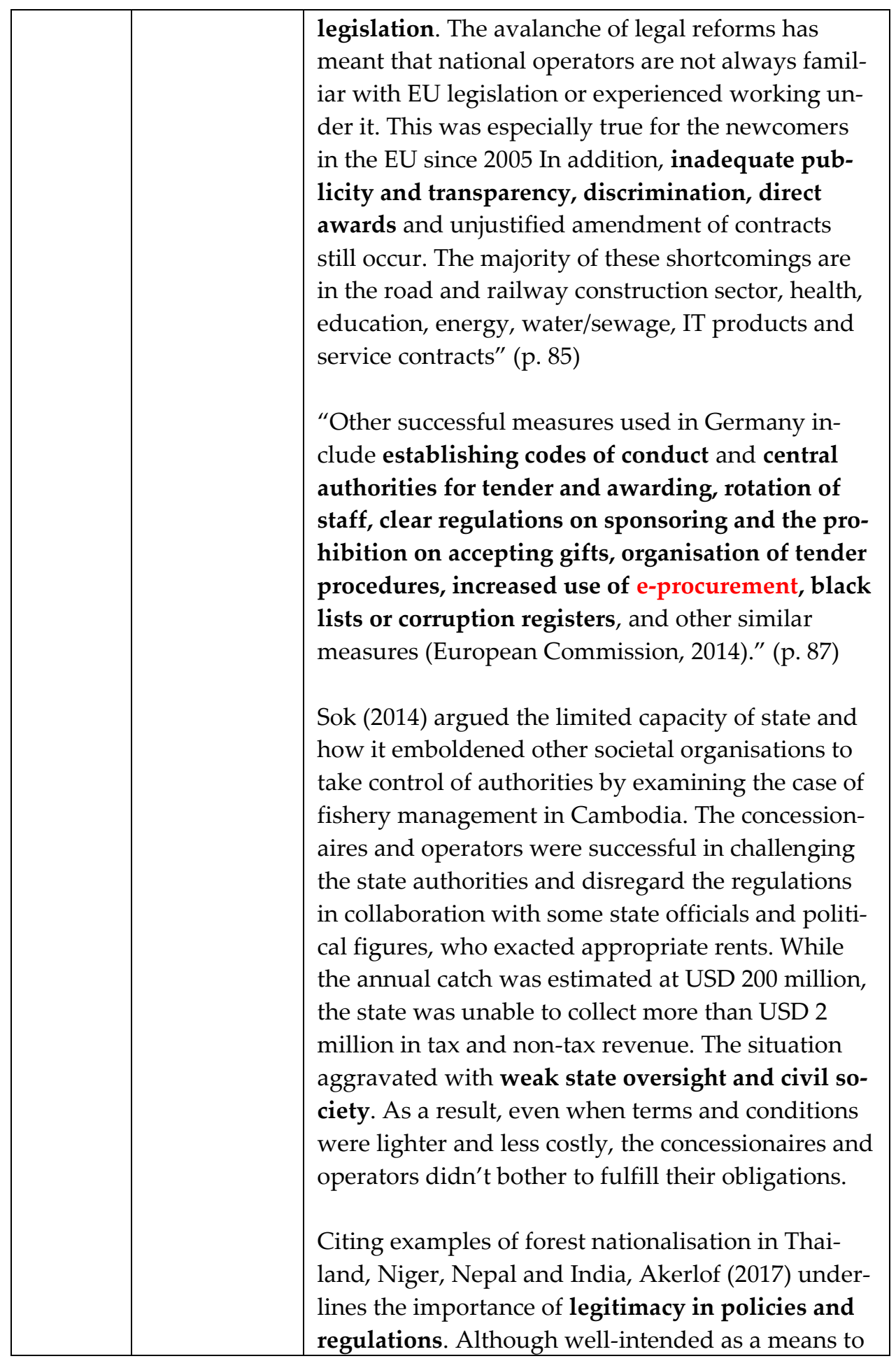




\begin{tabular}{|l|l|}
\hline & $\begin{array}{l}\text { protecting forests, the nationalisation policies had } \\
\text { contrary effects, as the residents disagreed with the } \\
\text { legitimacy of the policies and government policing. }\end{array}$ \\
$\begin{array}{l}\text { Cho, Dreher \& Neumayer (2014) assert that compli- } \\
\text { ance with anti-trafficking prosecution policy is } \\
\text { highest among developed countries. The study also } \\
\text { reveals that compliance with anti-trafficking poli- } \\
\text { cies decreases with corruption and is high among } \\
\text { countries, which respect women's rights. The au- } \\
\text { thors quantitatively evidenced that one point in- } \\
\text { crease in democracy index increases prosecution, } \\
\text { protection and prevention (3Ps) by 0.07 points. Sim- } \\
\text { ilarly, one point increase in control of corruption } \\
\text { increases 3Ps by as much as 0.4 point. The authors } \\
\text { also identified emulation effect, which means that } \\
\text { countries with similar political views take cues } \\
\text { from other similar countries in policy design and } \\
\text { diffusions. } \\
\text { Ozarslan (2016) analysed the case of Turkey and } \\
\text { identified the rampant grand corruption, deeply } \\
\text { rooted in society, including the public sector, is a } \\
\text { major challenge, despite the fact that Turkey is } \\
\text { party to the OECD convention. According to Trans- } \\
\text { parency International's 2013 Global Corruption Ba- } \\
\text { rometer, "54 percent of the respondents in the pub- } \\
\text { licly conducted survey in Turkey indicate that cor- } \\
\text { ruption has increased in the past two years. Re- } \\
\text { spondents identified political parties (66 percent), } \\
\text { the media (56 percent), the Parliament (55 per- } \\
\text { cent), and businesses (50 percent) as the most cor- } \\
\text { rupt institutions. Furthermore, } 68 \text { percent felt that } \\
\text { corruption was either a problem or a serious prob- } \\
\text { lem in the public sector." (p. 112) }\end{array}$ \\
$\begin{array}{l}\text { In the context of freedom of information, Camaj } \\
\text { (2016) identified the need for material resources, } \\
\text { such as bureaucratic capacity, officer training and } \\
\text { external requirements pertaining to laws, supervi- } \\
\text { sory institutions and international obligations. }\end{array}$ \\
\hline
\end{tabular}




\begin{tabular}{|l|l|l|}
\hline & $\begin{array}{l}\text { In a study on cartel, Sokol (2014) notes that better } \\
\text { training seems corresponding to fewer cartel be- } \\
\text { haviors. }\end{array}$ \\
\hline $\begin{array}{l}\text { Simpler pro- } \\
\text { cedures }\end{array}$ & $\begin{array}{l}\text { Tjen and Evans (2017) studied the Gayus case in In- } \\
\text { donesia and identified simplified and standard- } \\
\text { ised procedures as one of the key aspects for anti- } \\
\text { corruption strategies. }\end{array}$ \\
\hline $\begin{array}{l}\text { Citing the clauses in the UN Convention against } \\
\text { Corruption, Schlenther (2017) also suggests simpli- } \\
\text { fying administrative procedures to allow public ac- } \\
\text { cess to the competent decision making authorities. } \\
\text { Dietrich (2011) asserted that industry and trade are } \\
\text { the sectors, where compliance costs could be high, } \\
\text { while transportation, energy and mining sectors of- } \\
\text { fer corruption opportunities. Construction of roads, } \\
\text { telecommunications network, railways and power } \\
\text { grids all require significant paperwork, thus mak- } \\
\text { ing it susceptible to corruption, such as kickbacks } \\
\text { and procurement frauds. }\end{array}$ \\
\hline $\begin{array}{l}\text { On EU public procurement, Popescu, Onofrei \& } \\
\text { Kelley (2016) reported that "improved provisions } \\
\text { address a number of key issues, including the fol- } \\
\text { lowing: prevention of conflict of interests, e-pro- } \\
\text { curement, simplification of documentation, better } \\
\text { access to the market for small companies, monitor- } \\
\text { ing and reporting on public procurement activity } \\
\text { by member states for a rigorous and uniform en- } \\
\text { forcement of European Union law." (p. 85) How- } \\
\text { ever, the results have been mixed with weak en- } \\
\text { forcement in some countries and some sectors. }\end{array}$ \\
$\begin{array}{l}\text { Schlenther cites some success factors among coun- } \\
\text { tries, which successfully reduced corruption, such } \\
\text { as administrative reforms (i.e. budget, staff, per- } \\
\text { formance management, rewards and career oppor- } \\
\text { tunities for law enforcement officials), and inter- } \\
\text { agency cooperation and task team approach } \\
\text { (Schenther 2017) }\end{array}$ \\
\hline
\end{tabular}




\begin{tabular}{|c|c|}
\hline & $\begin{array}{l}\text { The improvement in relationships between tax pay- } \\
\text { ers and institutions should be based on trust } \\
\text { through the supply of public goods, among others. } \\
\text { The synergy of compliance is expected to transform } \\
\text { into social norms and common practices, and } \\
\text { eventually change behaviors and perceptions. } \\
\text { Based on examples of Kenya, Tanzania, Uganda } \\
\text { and South Africa, Ali, Fjeldstad, Sjursen (2014) con- } \\
\text { cluded that tax compliance corresponds to provi- } \\
\text { sion of public services. More specifically, tax } \\
\text { knowledge appears to influence tax compliance } \\
\text { attitude, while the level of informal payments to } \\
\text { non-state actors and government treatments of their } \\
\text { ethnic group were found having negative impacts } \\
\text { on tax compliance. The article confirmed that, 1) } \\
\text { compliance is more likely if tax evasion is found } \\
\text { harder and 2) the individuals are satisfied with } \\
\text { public services in all four countries. } \\
\text { Cyan, Koumpias \& Martinez-Vazquez (2016) con- } \\
\text { cluded that current failure of tax administration } \\
\text { and horizontal inequality from administrative } \\
\text { weaknesses need to be addressed to improve vol- } \\
\text { untary tax compliance using Pakistan's case. The } \\
\text { authors cited previous studies, which evidenced } \\
\text { satisfaction with government and public services, } \\
\text { trust in government institutions, government ef- } \\
\text { fectiveness and procedural justice influence tax } \\
\text { morale. } \\
\text { Van del Wal, Graycar \& Kelly (2016) noted that de- } \\
\text { volution of responsibilities create freedom in de- } \\
\text { ciding how integrity policies are implement, alt- } \\
\text { hough it may not be conducive or coherent. }\end{array}$ \\
\hline $\begin{array}{l}\text { Introducing } \\
\text { value-based } \\
\text { approach }\end{array}$ & $\begin{array}{l}\text { Webb (2012) proposes that compliance-based ap- } \\
\text { proach to be supplemented by value-based ap- } \\
\text { proach to reduce public service malfeasance, using } \\
\text { analysis on South Africa's Department of Correc- } \\
\text { tional Services. His study evidenced that compli- } \\
\text { ance-based approach of creating more regulations }\end{array}$ \\
\hline
\end{tabular}




\begin{tabular}{|c|c|}
\hline & $\begin{array}{l}\text { and oversights impact public service efficiency } \\
\text { and effectiveness, and creates additional opportu- } \\
\text { nities for corruption. The value-based approach } \\
\text { aims to create an ethical culture within the organi- } \\
\text { sation and enhances implementation of anti-cor- } \\
\text { ruption policies. Such an approach includes "com- } \\
\text { municating moral expectations with employees, } \\
\text { visible punishing offenders, ethics training, and } \\
\text { appraising ethics performance of employees by } \\
\text { making it a stand-alone key performance area" (p. } \\
\text { 97). } \\
\text { Van del Wal, Graycar \& Kelly (2016) contrasted the } \\
\text { compliance-based approach and the integrity or } \\
\text { value-based approach. The former focuses on laws, } \\
\text { rules and regulations through supervision, control } \\
\text { and punishment of offenders. The associated insti- } \\
\text { tutional instruments include asset declaration, } \\
\text { screening of employees, penal code on corruption } \\
\text { and disciplinary measures and procedures. The } \\
\text { latter strategy focuses on bottom-up formulation } \\
\text { of organisational aspirations, promotion of ethical } \\
\text { behaviors and code of conduct, ethical behaviors } \\
\text { and training. Most studies identified the combina- } \\
\text { tion of both approaches as being most effective to } \\
\text { scale up from Integrity } 1.0 \text { to } 2.0 \text { and } 3.0 \text {. The more } \\
\text { implicit, culture-oriented approach include behav- } \\
\text { iors of peers and supervisors, creation of shared } \\
\text { values, fair renumeration, appraisal and promo- } \\
\text { tion systems, which reward good behaviors. The } \\
\text { direct, more formal approach creates the struc- } \\
\text { tures and standards in support of ethical conducts } \\
\text { of employees. }\end{array}$ \\
\hline $\begin{array}{l}\text { Civil service } \\
\text { reform }\end{array}$ & $\begin{array}{l}\text { Webb (2012) also reflects on human aspects. "If } \\
\text { people are clever and sufficiently motivated by per- } \\
\text { sonal gain, they can always find a way to reinter- } \\
\text { pret the rules to their advantage or simply to ignore } \\
\text { the rules with impunity. A better tool for confront- } \\
\text { ing corruption could be for society to develop }\end{array}$ \\
\hline
\end{tabular}




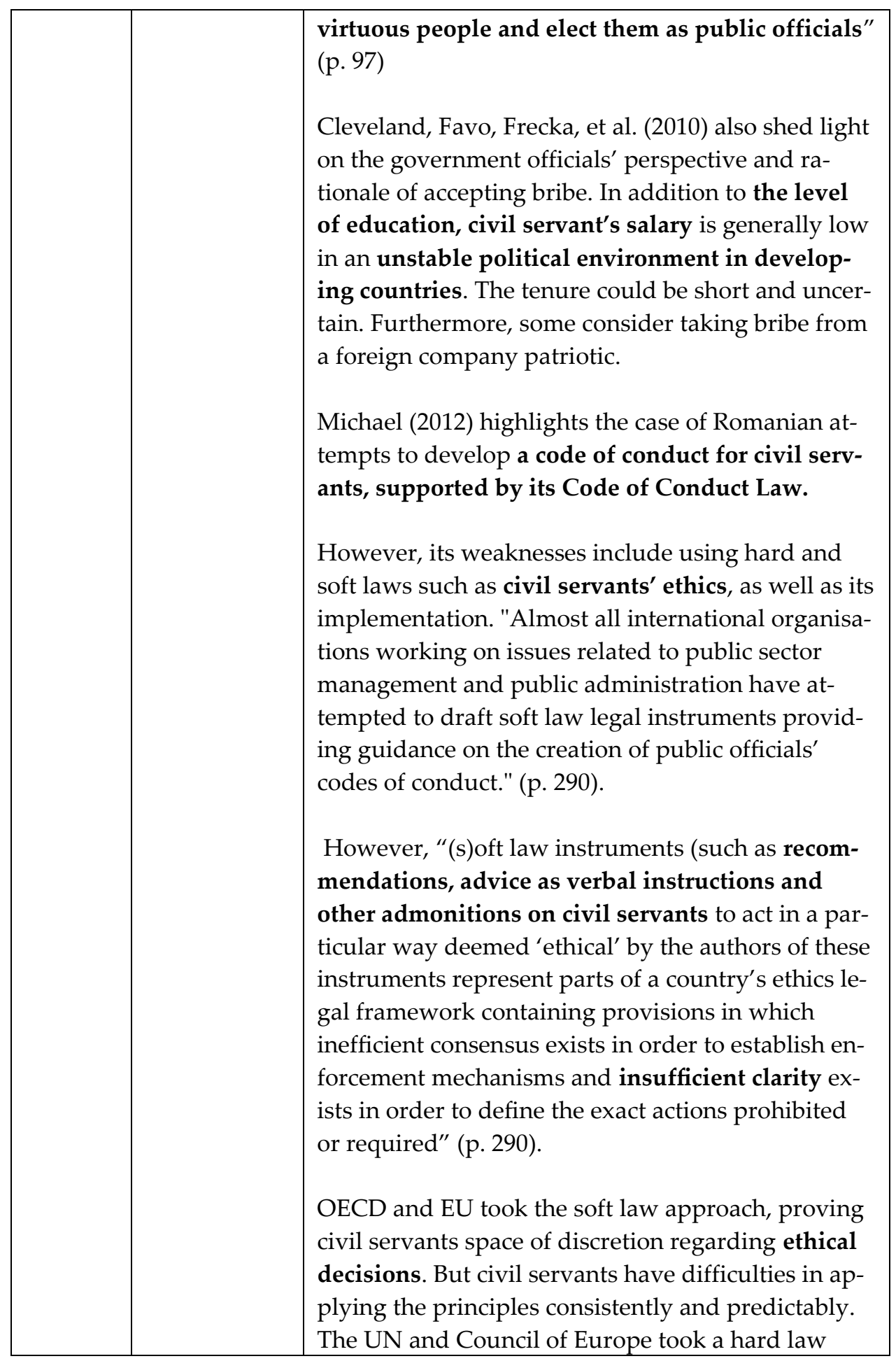




\begin{tabular}{|l|l|}
\hline & $\begin{array}{l}\text { approach by defining obligations and monitoring } \\
\text { compliance. The effective implementation would } \\
\text { need the multi-agency adoption of ethics regula- } \\
\text { tions. } \\
\text { Schueth (2012) looked at the example of Georgia, } \\
\text { where the Rose Revolution of } 2003 \text { led to the re- } \\
\text { form-oriented government and tripled central gov- } \\
\text { ernment tax revenue from seven percent to 23 per- } \\
\text { cent of GDP between 2004 and 2007. The interna- } \\
\text { tional donors, such as UNDP and Open Society } \\
\text { Foundation supported the salary payment of 11,000 } \\
\text { civil servants in 2004, which enabled the govern- } \\
\text { ment to focus on reforms and civil service reforms } \\
\text { from top down. It led to the elimination of 50,000 } \\
\text { civil service jobs, including interior ministry, law } \\
\text { enforcement personnel and militia. In total 250,000 } \\
\text { public sector employments were estimated to be } \\
\text { eliminated. New employment in the civil service } \\
\text { required strict adherence to new official proce- } \\
\text { dures. The budgetary support from international } \\
\text { donors alleviated the need for corruption among } \\
\text { civil servants and financed training of new offi- } \\
\text { cials, coupled with punishment for bribery. Tax } \\
\text { officials were personally held responsible for any } \\
\text { missing revenues, thus resulting in fear, antipathy, } \\
\text { guilt and resignation among civil servants. } \\
\text { By examining corruptions in universities in } \\
\text { Ukraine, Osipian (2010) identified that low salaries } \\
\text { among professors and faculty staff added incen- } \\
\text { tives to corruption. "College professors, who lost } \\
\text { the bulk of their savings to inflation in early 1990s } \\
\text { and are now grossly underpaid, adjust their profes- } \\
\text { sional ethics and behavior accordingly by accepting } \\
\text { bribes and numerous other benefits and utilizing } \\
\text { their privileged position and control over access to } \\
\text { higher education." (p. 106) While the budget for } \\
\text { universities is decreasing, alternative funding } \\
\text { mechanisms could help alleviate the problem. }\end{array}$ \\
\hline
\end{tabular}




\begin{tabular}{|c|c|c|}
\hline & $\begin{array}{l}\text { Less organi- } \\
\text { zational com- } \\
\text { plexity }\end{array}$ & $\begin{array}{l}\text { Camaj (2016) discussed that one of the obstacles to } \\
\text { FOI is the clear uniform rules and instructions on } \\
\text { the implementation of access to information law as } \\
\text { well as political instability and frequent change of } \\
\text { government. The factors led to the reorganization } \\
\text { or abolition of ministries and re-deployment of } \\
\text { senior officials in the case of Albania. } \\
\text { Mendez \& Sepulveda (2013) aimed to identify opti- } \\
\text { mal levels of regulations and red tapes to reduce } \\
\text { the welfare losses corruption caused. Typically, de- } \\
\text { veloped countries with low corruption are charac- } \\
\text { terised by high level of regulations and low level } \\
\text { of red tapes, while the opposite is observed among } \\
\text { corruption-ridden countries. Furthermore, "stricter } \\
\text { regulation of entry is not associated with better } \\
\text { public goods across countries, but is associated } \\
\text { with higher corruption" (p. 54). Therefore, to find } \\
\text { the right policy mix is important, as "in highly cor- } \\
\text { rupt economies the correlations between corrup- } \\
\text { tion, regulations, and red tape need to be under- } \\
\text { stood as a political economy equilibrium, where } \\
\text { corrupt bureaucrats seek to manipulate institu- } \\
\text { tional rules to their advantage" (p.69). } \\
\text { Darden (2008) demonstrates the importance of con- } \\
\text { text and conditions of institutions and the fact that } \\
\text { corrupt state may not necessarily be a dysfunctional } \\
\text { state using the case of Ukraine. In particular, transi- } \\
\text { tion economies and developing countries may be } \\
\text { placed in an institutional vacuum during transition } \\
\text { to democracy and institutional changes, which } \\
\text { might be creating additional impediments. }\end{array}$ \\
\hline Trust & $\begin{array}{l}\text { Trust in gov- } \\
\text { ernment }\end{array}$ & $\begin{array}{l}\text { Tavits (2010) refers to empirical research on compli- } \\
\text { ance, which shows that "the more individuals trust } \\
\text { government and their fellow citizens, the more } \\
\text { likely they will comply with government demands } \\
\text { and regulations, including paying taxes, accepting } \\
\text { court authority and complying with the military } \\
\text { services requirement" (p.1259) }\end{array}$ \\
\hline
\end{tabular}




\begin{tabular}{|l|l|}
\hline & $\begin{array}{l}\text { In the same vein, Timmons and Garfias (2015) ex- } \\
\text { amine the case of Brazil and conclude that "new in- } \\
\text { formation about corruption affects municipal } \\
\text { property tax collection and the structure of fiscal } \\
\text { institutions" (p. 13) and that "property tax revenue } \\
\text { rises with clean audit reports and falls as revealed } \\
\text { corruption increases" (p. 13). } \\
\text { Webb (2012) notes "organizational trust as a pre- } \\
\text { requisite for whistle-blowing to be effective in } \\
\text { public institutions" (p. 100). } \\
\text { Anti-corruption efforts are a function of incentives } \\
\text { and social norms and legitimacy. In terms of social } \\
\text { norms, many people in Hungary obey the rules as } \\
\text { they believe 1) "the law is just", 2) the authority } \\
\text { has the right to dictate behaviors and 3) obedience, } \\
\text { driven by procedural fairness, perceived fairness of } \\
\text { the content of the law and perception that law was } \\
\text { formulated with full authority. Thus, social norms } \\
\text { and legitimacy of the sources of legal obligations } \\
\text { are the basis for rule-conforming behavior. The } \\
\text { target should be convinced that corruption is } \\
\text { wrong and that it's a widespread notion and acted } \\
\text { upon, as people are conditional cooperator. Com- } \\
\text { pliance takes place when there is cooperation of cit- } \\
\text { izens with the authorities in reaching policy objec- } \\
\text { tives. Penalties could be in place, but they them- } \\
\text { selves are weak deterrence as corruption may not } \\
\text { be uncovered with low incentives to report wrong } \\
\text { doings. Thus, Batory concludes that raising aware- } \\
\text { ness among target groups, addressing exiting so- } \\
\text { cial norms, communicating the benefits and relay- } \\
\text { ing on positive incentives (than penalties) were } \\
\text { identified as key ingredients. In her view, norma- } \\
\text { tive commitment is an ideal type of compliance as } \\
\text { it doesn't require state apparatus. On the other } \\
\text { hand, if social belief does not change and political } \\
\text { class is perceived as illegitimate, the default policy } \\
\text { should be based on deterrence and cost-benefit } \\
\text { calculation. However, as many studies indicate, }\end{array}$ \\
\hline
\end{tabular}




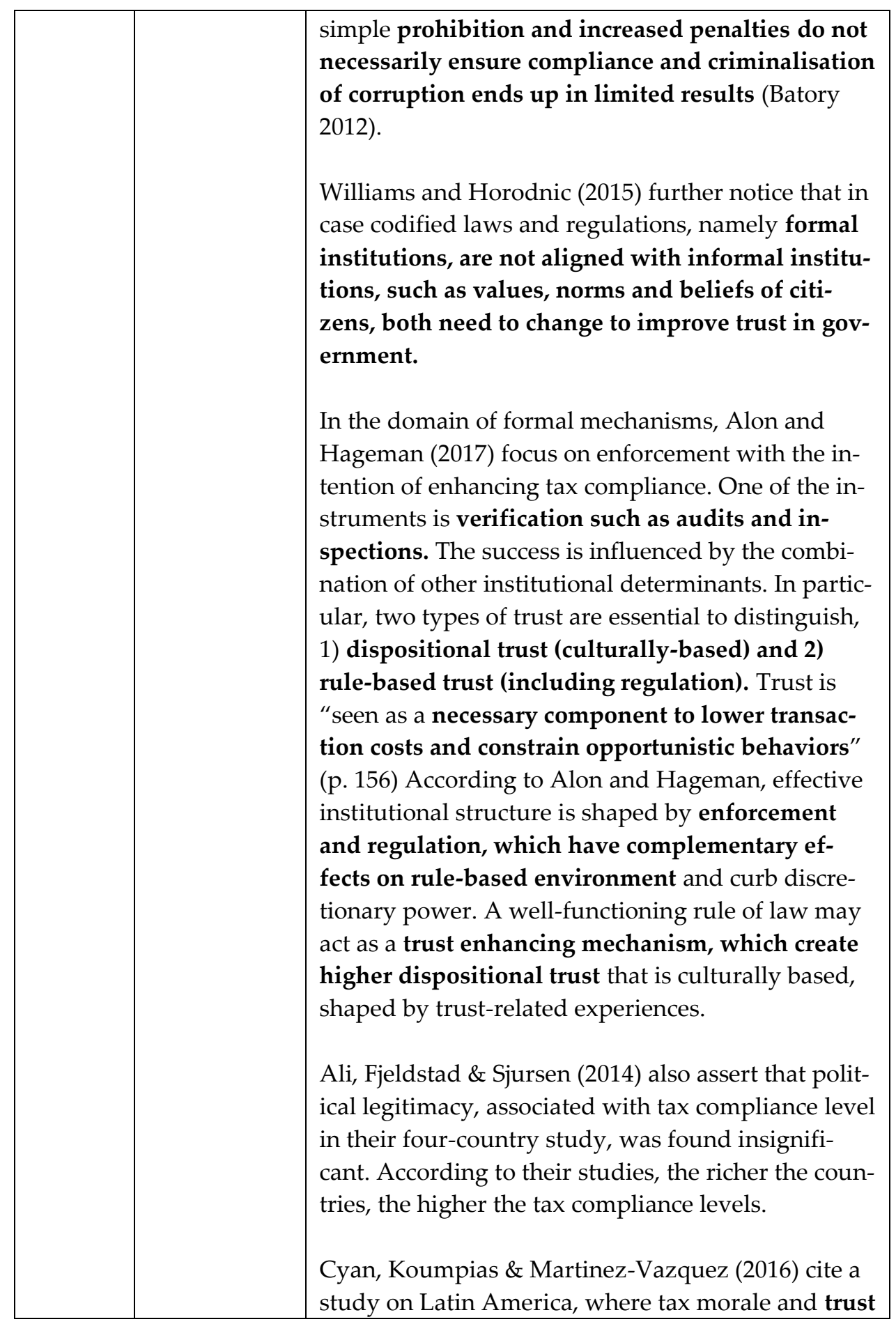




\begin{tabular}{|c|c|c|}
\hline & & $\begin{array}{l}\text { in government, the rule of law and pro-democracy } \\
\text { attitudes, were identified as being associated. } \\
\text { Citing example of forest nationalisation in Thai- } \\
\text { land, Niger, Nepal and India, Akerlof (2017) high- } \\
\text { lights the importance of legitimacy in policies and } \\
\text { regulations. Although well-intended to protect for- } \\
\text { ests, the nationalisation policies had contrary ef- } \\
\text { fects, as the residents disagreed with the policies } \\
\text { and government policing. }\end{array}$ \\
\hline & $\begin{array}{l}\text { Trust heuris- } \\
\text { tics }\end{array}$ & $\begin{array}{l}\text { Using social learning theory, Tavits (2010) ap- } \\
\text { proaches corruption as a collective action problem; } \\
\text { behavior is acquired and sustained through imitat- } \\
\text { ing others and positive reinforcement. According to } \\
\text { the study, when bribery is condemned, resistance to } \\
\text { bribery tends to increase. Thus, once the clear defi- } \\
\text { nition and message are communicated and mod- } \\
\text { elled by others, supported by trust heuristics (gen- } \\
\text { eralised trust in others), it may lead to a path to } \\
\text { corruption reduction. "Generalized trust, including } \\
\text { trust in political institutions, increases tax compli- } \\
\text { ance more significantly than fear of punishment" } \\
\text { (p.1259) } \\
\text { Sundstrum (2016) explained features of trust heu- } \\
\text { ristics to explain the behaviors and compliance in } \\
\text { horizontal and vertical relationships. In addition to } \\
\text { the relationship between citizens and agents, the } \\
\text { perception of everyone else's compliance is criti- } \\
\text { cal. The perceived corruption on the authority has a } \\
\text { detrimental impact in the process. }\end{array}$ \\
\hline $\begin{array}{l}\text { Social } \\
\text { norms }\end{array}$ & $\begin{array}{l}\text { Peer influ- } \\
\text { ence and } \\
\text { stigma }\end{array}$ & $\begin{array}{l}\text { Using Hungary's example, Batory (2012) examines } \\
\text { incentive and normative judgement on corrupt be- } \\
\text { haviors. Based on the theory of "target compli- } \\
\text { ance", Batory explores why laws, intended to } \\
\text { change behaviors, fail. While the transitional con- } \\
\text { text of Hungary created a special condition, the } \\
\text { country has developed a legislative framework but } \\
\text { no significant improvements have been observed } \\
\text { when it comes to corruption. }\end{array}$ \\
\hline
\end{tabular}




\begin{tabular}{|l|l|}
\hline & $\begin{array}{l}\text { Batory segmented the channel of compliance into } \\
\text { compliance (outcome based on the conformity of } \\
\text { behaviors) and implementation (process). After } \\
\text { identifying reasons for compliance and non-compli- } \\
\text { ance, Batory also identified two factors: 1) instru- } \\
\text { mental (people act as dictated by self-interest, re- } \\
\text { wards and punishments) and 2) normative (moral } \\
\text { judgements). }\end{array}$ \\
$\begin{array}{l}\text { Tavits (2010) refers to social behavior to be "ac- } \\
\text { quired and sustained through imitation or model- } \\
\text { ling of others' behaviors" (p.1260) Using social } \\
\text { learning theory, Travits explains how people ac- } \\
\text { quire behaviors through, 1) definition, 2) imitat- } \\
\text { ing behaviors and 3) positive reinforcement. }\end{array}$ \\
$\begin{array}{l}\text { Akerlof (2017) also refers to how legitimacy impacts } \\
\text { internal values of law enforcement officials as } \\
\text { well as social stigma associated with crimes. The } \\
\text { author cites studies, which found that people are } \\
\text { more willing to engage in corruption when others } \\
\text { are believed to be doing the same. Akerlof uses the } \\
\text { definition of norms as “internalized views regard- } \\
\text { ing duty and obligations". (P. 112) He argues that } \\
\text { the feeling of duty triggers compliance as well as } \\
\text { motivations for punishments for others non-com- } \\
\text { pliance. } \\
\text { Cyan, Koumpias \& Martinez-Vazquez (2016) cite } \\
\text { previous studies, which indicated that perceived } \\
\text { tax evasion and corruption have negative and sta- } \\
\text { tistically significant effect on tax morale in Eastern } \\
\text { Europe. }\end{array}$ \\
$\begin{array}{l}\text { In addition to norms, social control and rational cal- } \\
\text { culation, Kotzian (2011) introduced the role of in- } \\
\text { formation in compliance with norms. The author } \\
\text { proved that individuals will comply when others } \\
\text { cooperate, as beliefs about the validity of norms are } \\
\text { based on public and private information. Individu- } \\
\text { als will, therefore, be able to adjust their beliefs }\end{array}$ \\
\hline
\end{tabular}




\begin{tabular}{|l|l|}
\hline & $\begin{array}{l}\text { according to information. Although formal norms } \\
\text { are sanctioned by the authorities, the fear of pun- } \\
\text { ishment was found to be ineffective in enhancing } \\
\text { law-abidance. Sociologists have argued that "com- } \\
\text { pliance with norms is not a result of rational cal- } \\
\text { culation, but occurs because the norm is internal- } \\
\text { ized" (p. 159) and expectation of reciprocity. The } \\
\text { author argues that the role of information in the } \\
\text { process of updating one's beliefs and cooperation is } \\
\text { critical. The author asserts that "there are no effects } \\
\text { of social trust on norm compliance. What makes } \\
\text { people comply with norms is not blind trust, which } \\
\text { is by definition the absence of knowledge and cer- } \\
\text { tainty, but belief based on information that a } \\
\text { norm is effective and that it is hence rational to } \\
\text { comply with it." (p. 170) } \\
\text { Rosid, Evans \& Binh (2016) examined tax compli- } \\
\text { ance in Indonesia. The study concluded that a high } \\
\text { level of perception of corruption undermine tax } \\
\text { compliance. Coined as "echo chamber" problem, } \\
\text { the corruption perception among peers and indi- } \\
\text { viduals reinforces and create a vicious circle with- } \\
\text { out evidence. } \\
\text { Sundstrum (2016) looked at the South African con- } \\
\text { servation efforts and concluded that resource users } \\
\text { are more likely to defy compliance if they perceive } \\
\text { that inspectors are corrupt and that the negative ef- } \\
\text { fect of corruption is stronger among those who } \\
\text { didn't support the rules. This suggests that the rule } \\
\text { compliance would be encouraged by a reduction in } \\
\text { corruption among inspectors and rangers, who en- } \\
\text { force the natural resource conservation regulations. }\end{array}$ \\
$\begin{array}{l}\text { Ali, Fjeldstad \& Sjursen (2014) discuss that behav- } \\
\text { iors and attitudes would be influenced by those of } \\
\text { their reference groups. In addition to the social in- } \\
\text { fluence theory, herd behaviors are also evidenced } \\
\text { to influence compliance, possibly through the per- } \\
\text { ceived probability of detection. Those who comply }\end{array}$ \\
\hline
\end{tabular}




\begin{tabular}{|l|l|}
\hline Leadership & $\begin{array}{l}\text { with taxation have peers and friends who also com- } \\
\text { ply, and vice versa. }\end{array}$ \\
\hline $\begin{array}{l}\text { Webb (2012) believes that leadership is one of the } \\
\text { key variables of ethics policy implementation and } \\
\text { "management behavior as a source of moral guid- } \\
\text { ance" (p. 99). When normative expectations con- } \\
\text { tradict the management behaviors, employees per- } \\
\text { ceive moral ambiguity. Furthermore, he empha- } \\
\text { sises the importance of congruence of supervisors } \\
\text { and managers in not only ensuring compliance } \\
\text { with policies but also promoting ethical culture in } \\
\text { the organisation. }\end{array}$ \\
$\begin{array}{l}\text { Schlenther (2017) cites an example of Botswana, } \\
\text { which is a top performer in terms of anti-corrup- } \\
\text { tion, judging from the Corruption Perception Index. } \\
\text { The success is attributed to "the implementation of } \\
\text { ethics and anti-corruption initiatives that are sup- } \\
\text { ported by the country's leaders" or the value of so- } \\
\text { cially rooted leadership (p.223). The leadership } \\
\text { and political will is "supported by a dedicated anti- } \\
\text { corruption agency that has been able to translate } \\
\text { political talk into action" (p.223) }\end{array}$ \\
\hline $\begin{array}{l}\text { On the point of individual motivations, Tavits } \\
\text { (2010) examines the citizens and government offi- } \\
\text { cials' perspectives to analyse corruption in a transi- } \\
\text { tion period of Estonia, as corruption is in essence } \\
\text { "the direct result of decisions, choices and behav- } \\
\text { ior at the individual level" (p. 1257). Webb (2012) } \\
\text { reiterates that "(e)mployees that feel they are } \\
\text { treated poorly will attempt to balance the scales of } \\
\text { justice by deliberately damaging the institution" (p. } \\
\text { 99) }\end{array}$ \\
$\begin{array}{l}\text { D'Attoma, Volintiru \& Steinmo (2017) examined } \\
\text { gender in honesty, deceptive behavior, pro-sociality } \\
\text { and risk aversion as part of study on tax compli- } \\
\text { ance in the US, UK, Sweden and Italy. The study } \\
\text { found that women are significantly more compli- } \\
\text { ant than men in all countries and the trend is con- } \\
\text { sistent. }\end{array}$ \\
\hline
\end{tabular}


By examining corruption cases in the United States, De Figueiredo (2013) concluded that non-compliance levels among the population and public officials do not always correspond. Furthermore, the study alluded that the traditional measures of corruption per capita might be an inaccurate measurement.

Rosid, Evans \& Binh (2016) examined tax compliance in Indonesia. The authors used four categories of tax payers based on their compliance behavior,

1) the disengaged,

2) the resisters,

3) the triers and

4) the supporters.

Behaviors are characterised by

1) deliberate or intentional compliant,

2) accidental or unintentional non-compliance,

3) accidental or unintentional compliant and

4) deliberate or intentional non-compliant.

Perception is linked to a belief, which is defined as "subjective probabilities" (p. 397) According to the article, "behavioural beliefs represent the subjective probabilities, in which conducting certain behaviour produces a particular outcome. Second, normative beliefs consist of injunctive and descriptive normative beliefs. Injunctive normative beliefs are concerned with the subjective probabilities that certain group of referents encourage or discourage performance of a given behaviour. Descriptive normative beliefs refer to subjective probabilities that important referents are doing or not doing the behaviour. Third, the subjective probabilities that certain factors can support or prevent the performance of a behaviour are elements of control beliefs. Once beliefs associated with a certain behaviour have been developed, these beliefs then provide the 


\begin{tabular}{|l|l|}
\hline |l & $\begin{array}{l}\text { basis for the attitudes, subjective norms, and per- } \\
\text { ceived control, which in turn lead to the formation } \\
\text { of intention and a given behaviour (Fishbein \& } \\
\text { Ajzen, 2010)" (p. 397). The study found that the per- } \\
\text { ception of petty corruption didn't have significant } \\
\text { impact but the perception on grand corruption } \\
\text { did. } \\
\text { Williams \& Krasniqi (2017) analysed tax compli- } \\
\text { ance and tax morale among Eurasian countries and } \\
\text { found that tax morale is high among the middle- } \\
\text { aged, the married, homeowners with children, } \\
\text { those with university degree and employed. Other } \\
\text { factors favourable included countries with less cor- } \\
\text { ruption and strong legal systems, as well as high } \\
\text { state interventions, taxation and expenditures. The } \\
\text { assumption of this study was that tax morale can't } \\
\text { be fully explained by a rational economic actor } \\
\text { model, as many comply despite the unfavorable } \\
\text { economic calculations. The social actor model } \\
\text { emerged to explain such a situation as "civil duty". }\end{array}$ \\
\hline $\begin{array}{l}\text { Orgniza- } \\
\text { tional culture }\end{array}$ \\
$\begin{array}{l}\text { In astudy on cartel enforcement, Sokol (2014) fo- } \\
\text { among employees and embed the anti-trust culture } \\
\text { in the organisation as most detection incidents } \\
\text { come from employees. Webb (2012) believes that } \\
\text { culture is one of the key variables of ethics policy } \\
\text { implementation. He states that "organisational cul- } \\
\text { ture is a shared understanding by employees of } \\
\text { how they do things within the institution" (p. 97). } \\
\text { Webb asserts that "policy - once adopted- is sub- } \\
\text { jected to a range of institutional influences, in- } \\
\text { cluding values, relationships, power structures } \\
\text { and standard operating procedures" (p.97). }\end{array}$ \\
$\begin{array}{l}\text { Schlenther (2017) also considers culture as an im- } \\
\text { portant element. In the context of tax administra- } \\
\text { tion in Africa, revenue authorities would be re- } \\
\text { quired to build integrity, ethics and anti-corrup- } \\
\text { tion into corporate culture. Schlenther examines } \\
\text { the case of Mozambique, which in addition to laws }\end{array}$ \\
\hline
\end{tabular}




\begin{tabular}{|l|l|}
\hline & $\begin{array}{l}\text { and supportive legal framework to prosecute and } \\
\text { sanction officials, aimed to change culturally en- } \\
\text { trenched attitudes. } \\
\text { In the case of Ukraine, Osipian (2010) asserted that } \\
\text { when a strong institution is corrupt, government } \\
\text { officials, especially at lower levels, are placed in a } \\
\text { vulnerable position with systematic blackmailing, } \\
\text { kompromat, selective applications of criminal law } \\
\text { and other measures and widespread grafts etc. cre- } \\
\text { ating self-sustaining corrupt regimes. Thus, such a } \\
\text { corrupt system is difficult to change from within. }\end{array}$ \\
\hline Training and & $\begin{array}{l}\text { In tax compliance, tax education and integrity ef- } \\
\text { forts are found effective in influencing compliance } \\
\text { behavior and reducing incidents (Schlenther 2017). } \\
\text { Cleveland, Favo, Frecka, et al. (2010) also echoed } \\
\text { the importance of education and training in reduc- } \\
\text { ing bribery, accompanied by robust ethics and } \\
\text { compliance programme. }\end{array}$ \\
$\begin{array}{l}\text { Tjen and Evans (2017) studied the Gayus case in In- } \\
\text { donesia, and found that taxpayer outreach and ed- } \\
\text { ucation was one of the key prospects for anti-cor- } \\
\text { ruption strategies. } \\
\text { Examining the case of Pakistan's tax morale, Cyan, } \\
\text { Koumpias \& Martinez-Vazquez (2016) concluded } \\
\text { that educated respondents were more tax compli- } \\
\text { ant than the illiterate group and that those with } \\
\text { very low or high degrees had higher tax moral than } \\
\text { those with bachelor's degree. The tax moral was } \\
\text { highest among the most industrialised parts of the } \\
\text { country. Women tend to have higher tax moral, } \\
\text { which then declines with age. The findings help tar- } \\
\text { get more cost-effective interventions, according } \\
\text { the characteristics of the group, with target com- } \\
\text { munication strategies to improve tax moral in Pa- } \\
\text { kistan. }\end{array}$ \\
\hline
\end{tabular}




\begin{tabular}{|l|l|l|}
\hline & & $\begin{array}{l}\text { Van del Wal, Graycar \& Kelly (2016) mentioned } \\
\text { that the Australian government provides public in- } \\
\text { formation and training on corruption or fraud, but } \\
\text { no agency reported on a mechanism to assess the } \\
\text { effectiveness of these efforts. Education for the } \\
\text { public was cited as expensive but would bring } \\
\text { significant benefits. }\end{array}$ \\
\hline $\begin{array}{l}\text { Interna- } \\
\text { instru- } \\
\text { ments }\end{array}$ & $\begin{array}{l}\text { Role of for- } \\
\text { eign entities }\end{array}$ & $\begin{array}{l}\text { Schlenther (2017) also notes that foreign company } \\
\text { investments and requirements by foreign govern- } \\
\text { ment laws "may motivate developing host coun- } \\
\text { tries to improve domestic administrative practices } \\
\text { and laws to avoid future disputes and for coun- } \\
\text { tries to better deal with negative externalities } \\
\text { caused by foreign involvement" (p.232). }\end{array}$ \\
\hline $\begin{array}{l}\text { International } \\
\text { conventions } \\
\text { and foreign } \\
\text { laws and leg- } \\
\text { islations }\end{array}$ & $\begin{array}{l}\text { Dietrich (2011) analysed strategic compliance in de- } \\
\text { veloping countries, which comply with donor re- } \\
\text { quirements in some selected sectors, where com- } \\
\text { pliance is cheap, such as health. Using the case of } \\
\text { Bangladesh, where corruption scores are high, the } \\
\text { author argues that the recipient country has the in- } \\
\text { centive to cooperate in strategic sectors of donor } \\
\text { priority, such as public health and demonstrate sec- } \\
\text { tor aid success and international legitimacy. The } \\
\text { authors concluded that in the case of Australia, cor- } \\
\text { ruption was not on the radar of the responding } \\
\text { agencies, as there was considerable level of aware- } \\
\text { ness of fraud and misconduct. } \\
\text { ternal reforms, and Oanst Corruption, which requires the } \\
\text { eign Account Tax Compliance Act (FACTA) and } \\
\text { UK Bribery Act of 2010 have impacts outside their } \\
\text { own jurisdictions when multinational corporations } \\
\text { are involved, which "put any real pressure on na- } \\
\text { tions to institute internal reforms" (p.232) (Schlen- } \\
\text { ther 2017). }\end{array}$ \\
\hline
\end{tabular}




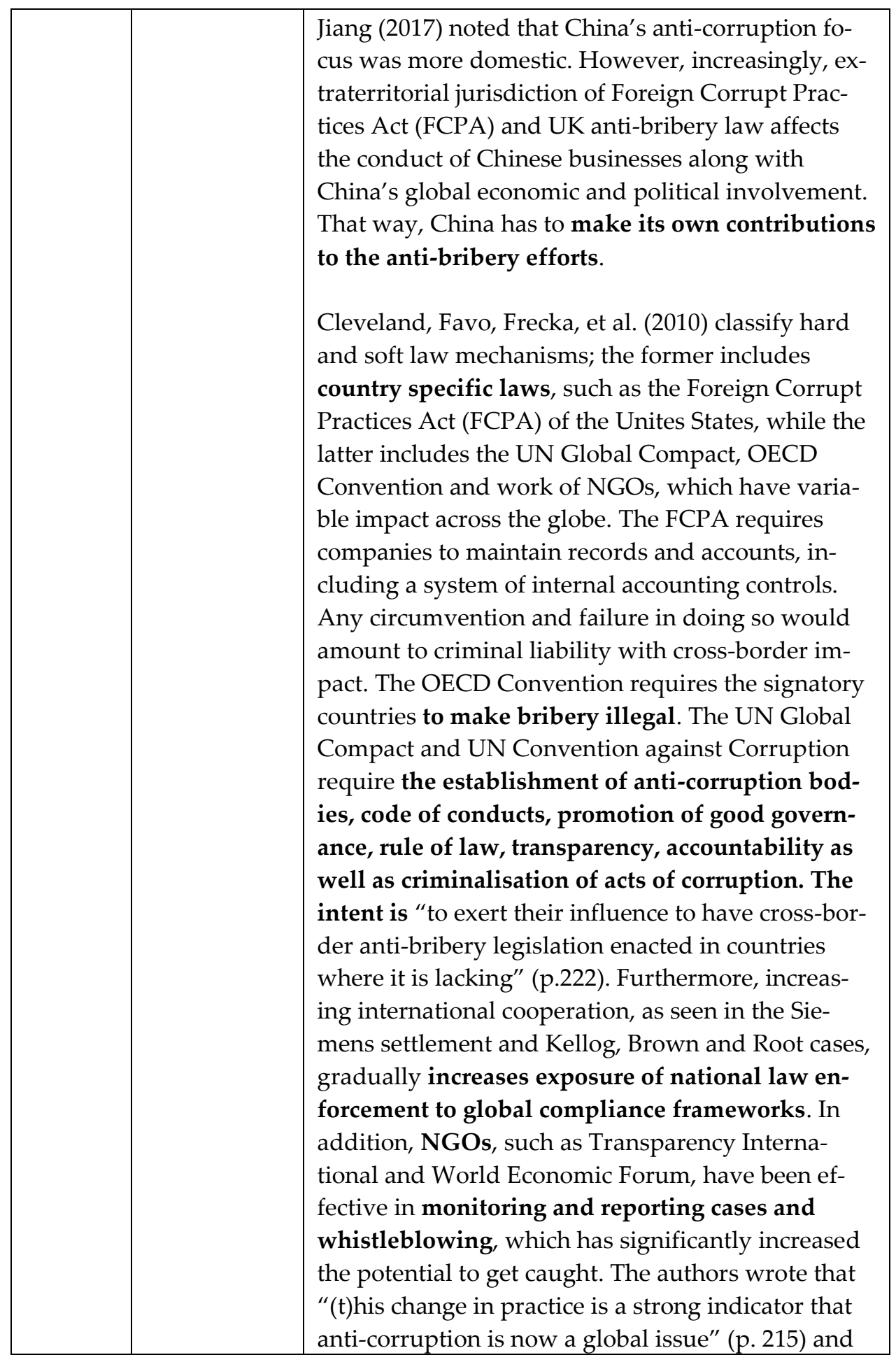




\begin{tabular}{|l|l|}
\hline & $\begin{array}{l}\text { international law enforcement agencies readily } \\
\text { communicate and cooperate with each other. }\end{array}$ \\
$\begin{array}{l}\text { Gilbert and Sharman (2016) analysed British and } \\
\text { Australian corruption scandals and concluded that } \\
\text { even democratic governments opt for electoral in- } \\
\text { centives over compliance with OECD convention. } \\
\text { Media exposure was identified as another incentive } \\
\text { to opt for damage control instead of genuine inves- } \\
\text { tigations for transparency and accountability. A } \\
\text { conventional constructivist and rationalist ap- } \\
\text { proach is that compliance with OCED convention } \\
\text { takes place when a large sum of foreign bribery is } \\
\text { involved with long-time, repeated malfeasance and } \\
\text { strong evidence in a country with low domestic cor- } \\
\text { ruption, but strong press and civil society. }\end{array}$ \\
$\begin{array}{l}\text { The examination of the three cases prompted the } \\
\text { authors to conclude that non-compliance is ob- } \\
\text { served in a country with supportive factors, it is as- } \\
\text { sumed prevalent in countries with weaker institu- } \\
\text { tions and OECD convention might be less effective } \\
\text { than previously thought. A government may wish } \\
\text { to genuinely comply but can't (inability) or deliber- } \\
\text { ately chooses not to comply (unwillingness); alt- } \\
\text { hough the result is the same, the mechanics and } \\
\text { context are largely different. The authors assert that } \\
\text { the international conventions are not necessarily } \\
\text { making states law-abiding, but law-abiding coun- } \\
\text { tries subscribe to international conventions; thus, } \\
\text { endogeneity and selection effects as great issues in } \\
\text { compliance research and building genuine compli- } \\
\text { ance. The scholars emphasised the merit of interna- } \\
\text { tional conventions by changing the climate of pub- } \\
\text { lic opinions and making corruption less accepta- } \\
\text { ble. Rationalists on the other hand explains the } \\
\text { power of the US government within the framework } \\
\text { of utility-maximising rational actors. The conven- } \\
\text { tion monitoring procedures of peer assessment } \\
\text { prompt peer pressure, shaming and reputational } \\
\text { concerns, while making sure that their foreign }\end{array}$ \\
\hline
\end{tabular}




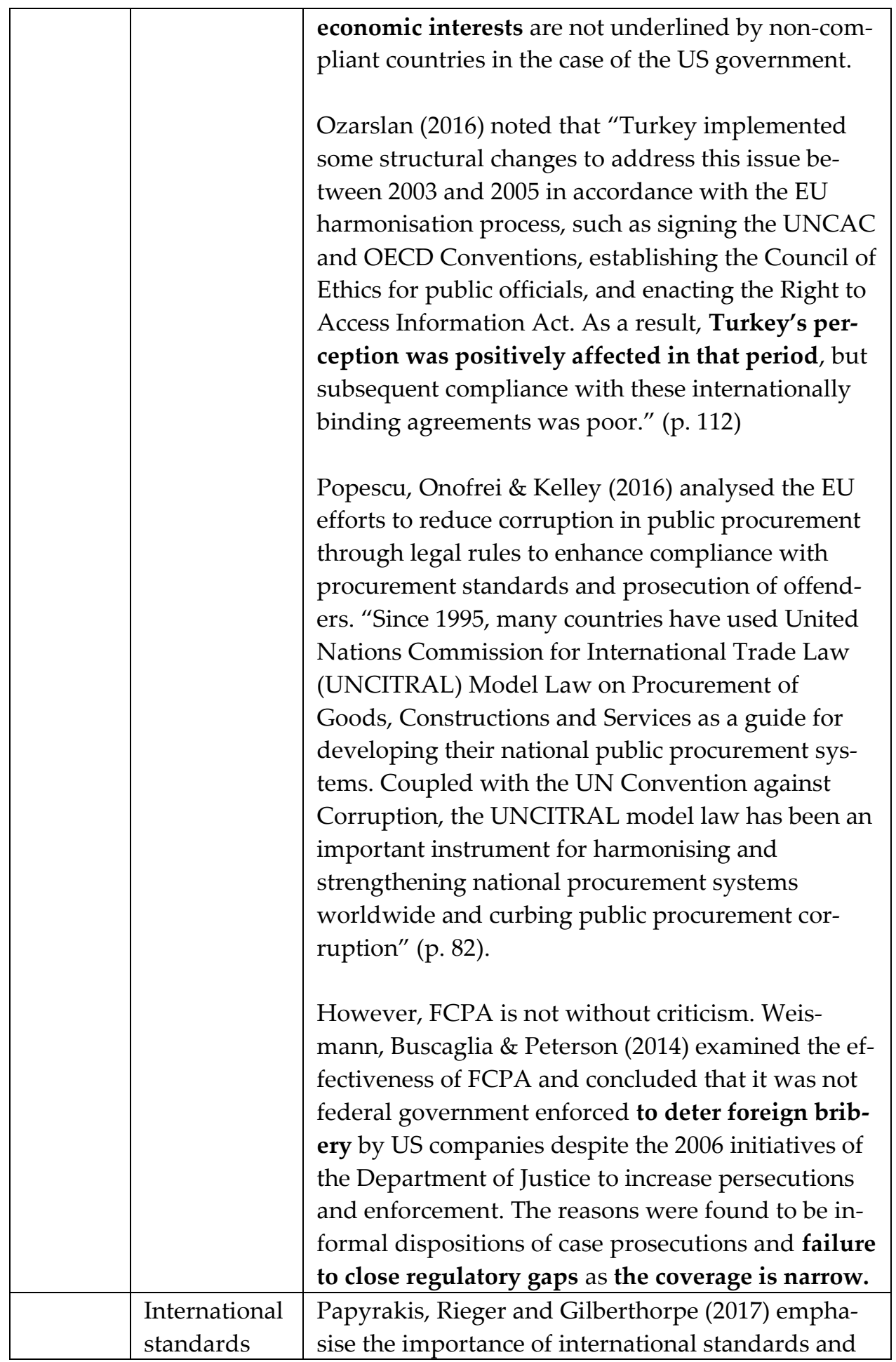




\begin{tabular}{|l|l|}
\hline & $\begin{array}{l}\text { framework. The Extractive Industries Transpar- } \\
\text { ency Initiative (EITI) membership "offers, on a } \\
\text { whole, a shielding mechanism against the general } \\
\text { tendency of mineral-rich countries to experience in- } \\
\text { creases in corruption over time" (p. 295). The study } \\
\text { shows that "countries that reach the third stage of } \\
\text { the EITI implementation, and are hence declared } \\
\text { compliant, experience further improvements in re- } \\
\text { ducing corruption" (p. 300) as "countries need to } \\
\text { intensify effort and take series of measures as a } \\
\text { prerequisite for full compliance" (p., 305). } \\
\text { Sovacool et al. (2016) analysed the effectiveness of } \\
\text { the EITI, which aims to increase revenue transpar- } \\
\text { ency through promotion of voluntary standards } \\
\text { among extracting companies and countries. Despite } \\
\text { global recognition, the EITI countries were found } \\
\text { not performing better than their status before com- } \\
\text { pliance or better than other countries against the } \\
\text { EITI metrics. The authors agree that "the right to } \\
\text { information is not accountability in itself but is } \\
\text { instrumental to it, and transparency does not auto- } \\
\text { matically produce accountability but is a neces- } \\
\text { sary but insufficient condition for it." (p. 180) }\end{array}$ \\
$\begin{array}{l}\text { Furthermore, transparency depends on the public- } \\
\text { ity condition, such as people's capacity to under- } \\
\text { stand and use information, and accountability } \\
\text { condition, such as enforcement and deterrence of } \\
\text { non-compliance. It was found that this did not al- } \\
\text { ways promote better decision making, reduce cor- } \\
\text { ruption and improve effectiveness. As a global } \\
\text { norm in international law, "(t)his "opening up of } \\
\text { the books" can build trust between stakeholders, } \\
\text { hold governments more accountable for billions of } \\
\text { dollars of revenue, improve corporate image and } \\
\text { the national investment climate, and empower } \\
\text { communities - all leading to "greater political and } \\
\text { social stability." (p. 186) In reality, however, the } \\
\text { public is not actively involved in EITI due to illit- } \\
\text { eracy, livelihood concerns, lack of interest and }\end{array}$ \\
\hline
\end{tabular}




\begin{tabular}{|l|l|}
\hline & $\begin{array}{l}\text { cultural and political factors. Civil society should } \\
\text { also be effective, but in many countries, they are } \\
\text { disorganised or non-existent to convert infor- } \\
\text { mation into accountability. }\end{array}$ \\
$\begin{array}{l}\text { Vadlamannati, Cooray \& Brazys (2018) examine the } \\
\text { commitments to compliance with the IMF Special } \\
\text { Data Dissemination Standards (SDDS) and con- } \\
\text { cludes that compliance happens when the costs to } \\
\text { state is low and there is material reward or pun- } \\
\text { ishment domestically and internationally with } \\
\text { normative and ideational logic. Furthermore, } \\
\text { "countries which were already more transparent, } \\
\text { typically rich and democratic, were more likely to } \\
\text { join the SDDS as they faced lower material costs } \\
\text { and reaped larger material and normative benefits } \\
\text { compared to less transparent states" (p.70). The } \\
\text { compliance is also seen by investors as a commit- } \\
\text { ment by the government to macroeconomic } \\
\text { health, among others. } \\
\text { Camaj (2016) added that the FOI initiatives were } \\
\text { developed by Southeastern European countries as } \\
\text { part of the integration with the EU and Council of } \\
\text { Europe. Because of the external pressure, the author } \\
\text { argues that there were delays, without political } \\
\text { leadership, orientations towards transparency and } \\
\text { no pressure from CSOs and the media. }\end{array}$ \\
$\begin{array}{l}\text { Garcia-Tabuyo, Saez-Marin, Caba-Perez (2015) fo- } \\
\text { cused on technologies such as the Internet as a } \\
\text { means of information dissemination without } \\
\text { prior requests. The Organization of American } \\
\text { States (OAS) developed a Model Inter-American } \\
\text { Law to assist the drafting of national laws to en- } \\
\text { courage proactive disclosure using ICT. Such ac- } \\
\text { cess to information would help combat corruption } \\
\text { among public servants. }\end{array}$ \\
\hline
\end{tabular}




\title{
Interview Protocol for ICT Officers
}

Purpose of study - The information obtained in this interview will be used to conduct a research study for the UNU/Maastricht Graduate School of Governance.

Topic -determinants of compliance among government employee users in e-governance implementation

Duration of interview - 45 - 60 minutes.

Procedure - Interview will take place face-to-face either in person or via a videoconference call (Skype; Google Hangout).

Confidentiality - Respondent will be asked to sign a consent form/confidentiality statement, informing them that the information shared will be confidential, only to be used for the purpose of research and his/her name will not be used. In case of online interviews, the interviewer will ask participants to confirm consent on tape, if recorded, and send them the form electronically to be signed and scanned.

Place to hold the interview - Interviews could take place inside any government offices, café, home or hotels; responses should be based on individual's opinions.

Recording interview - Respondent will be asked if he/she agrees with the conversation being recorded. The interviewer will also be taking notes, but since it is not possible to write everything, allowing her to record will ensure that she obtains all the information provided.

Right to stop interview/avoid a subject - Respondent will be told that he/she retains the right to not speak about any topic that he/she does not feel comfortable; interview can end at any point.

Interviewer's information:

\author{
Atsuko Okuda \\ PhD Fellow, Maastricht Graduate School of Governance/University of \\ Maastricht \\ Tel: +1-305-606-8641 \\ E-mail: a.okuda@maastrichtuniversity.nl
}


Academic Institution's information:

Maastricht Graduate School of Governance/University of Maastricht

Contact: Dr. Mindel van de Laar

Tel: +31-43-3884660

E-mail: mindel.vandelaar@maastrichtuniversity.nl

Clarification - Respondent will be asked before starting the interview if there any questions regarding what the interviewer explained.

Agreement to participate - Respondent will be asked to confirm that he/she is willing to participate in this interview.

\section{Interview Guide}

\section{ICT Officers}

\section{E-governance initiative}

1. Your agency is using the online Asset Declaration System and e-PEMS. What is your role in supporting the use of these two systems? Do you provide technical support?

2. Were you involved in the designing, testing and/or implementation of the systems?

3. In your opinion, are the systems performing the way they are intended and delivering the expected outcomes?

a. If no, why do you think so?

b. If yes, why does he think so?

4. What are the concrete benefits you perceive by using the ADS and e-PEMS?

a. What are the feedback you receive from users?

b. What do you think about the visibility and traceability both systems provide?

5. What kind of issues have you and your ministry/agency colleagues encountered so far?

a. Do you work with finance officers/accountants and ADA?

b. How were they resolved?

c. Have you discussed the issues with other ICT officers in other ministries and DITT? 
6. How do you receive functional changes and update, since the system was implemented? Do you follow user manuals?

7. How do you assess the level of compliance among your agency's users?

a. Were there any work arounds which require offline parallel steps and procedures?

b. If the compliance is high, why do you think is the case?

c. If it is low, why do you think is the case?

8. Do you think that the fact that the system was developed with government budget and human resources or with external funding and consultant makes a difference in terms of confidence and trust?

a. If yes, why so?

b. If no, why so?

9. Do you think the systems make it difficult to commit abuse and fraud and personally and illicitly gain from the positions and functions of government officials?

a. If yes, why do you think so?

b. If no, why do you think so?

\section{Dispositional compliance}

10. Do you think relevant training, advocacy and sensitization would be effective in ensuring compliance among government employee users?

a. If yes, in what way do you think it was helpful?

b. If not, why not?

11. What is the feedback from the head of the agency? Are there encouragements, or they consider them as administrative tools?

12. Do you think media coverage and social media affect how government officials think and behave in using the systems?

a. If yes, what kind of media coverage and social media would be influential?

b. Why do you think they are influential?

c. If not, why do you think media coverage and social media do not affect government officials? 
13. Which factor do you think is most important to ensure government officials' compliance with the systems?

14. Do you have any other comments?

Thank the respondent for his/her time.

\section{Interview Protocol for HR Offices (ADA)}

Purpose of study - The information obtained in this interview will be used to conduct a research study for the UNU/Maastricht Graduate School of Governance.

Topic -determinants of compliance among government employee users in e-governance implementation

Duration of interview - 45 - 60 minutes.

Procedure - Interview will take place face-to-face either in person or via a videoconference call (Skype; Google Hangout).

Confidentiality - Respondent will be asked to sign a consent form/confidentiality statement, informing them that the information shared will be confidential, only to be used for the purpose of research and his/her name will not be used. In case of online interviews, the interviewer will ask participants to confirm consent on tape, if recorded, and send them the form electronically to be signed and scanned.

Place to hold the interview - Interviews could take place inside any government offices, café, home or hotels; responses should be based on individual's opinions.

Recording interview - Respondent will be asked if he/she agrees with the conversation being recorded. The interviewer will also be taking notes, but since it is not possible to write everything, allowing her to record will ensure that she obtains all the information provided.

Right to stop interview/avoid a subject - Respondent will be told that he/she retains the right to not speak about any topic that he/she does not feel comfortable; interview can end at any point. 
Interviewer's information:

Atsuko Okuda

Maastricht

PhD Fellow, Maastricht Graduate School of Governance/University of

Tel: +1-305-606-8641

E-mail: a.okuda@maastrichtuniversity.nl

Academic Institution's information:

Maastricht Graduate School of Governance/University of Maastricht

Contact: Dr. Mindel van de Laar

Tel: +31-43-3884660

E-mail: mindel.vandelaar@maastrichtuniversity.nl

Clarification - Respondent will be asked before starting the interview if there any questions regarding what the interviewer explained.

Agreement to participate - Respondent will be asked to confirm that he/she is willing to participate in this interview.

$\underline{\text { Interview Guide }}$

$\underline{\text { ADA/HR Officers }}$

\section{E-governance initiative}

15. Your agency is using the online Asset Declaration System. As ADA, what do you do? How many ADS and declarants are there in the ministry/agency?

16. In your opinion, is the system performing the way they are intended and delivering the expected outcomes?

a. If no, why do you think so?

b. If yes, why does he think so?

17. What are the concrete benefits you perceive by using the ADS?

a. What are the feedback you receive from declarants?

b. What do you think about the visibility and traceability ADS provides?

18. What kind of issues have you and your ministry/agency colleagues encountered so far? 
a. How did you communicate them to the ACC?

b. How did you communicate them to the Ministry/agency management?

c. Did you work with IT Officer?

d. How were they resolved?

e. Have you discussed the issues with other ADAs in other ministries?

19. How do you receive functional changes and update, since the system was implemented? Do you follow user manuals?

20. How do you assess the level of compliance among your agency's declarants?

a. Were there any work arounds which require offline parallel steps and procedures?

b. If the compliance is high, why do you think is the case?

c. Would fines be an effective deterrent to non-compliance?

21. Were there any repeaters of late and non-declarants?

a. Did they all pay fines or they were waivered?

b. Does it affect their and your performance ranting?

c. How does the head of the agency react to late or non-declarants?

22. Do you think that the fact that the system was developed within the government with government budget and human resources increased the confidence and trust in the system?

a. If yes, why so?

b. If no, why so?

c. What if the system was developed by external consultants?

23. Do you think the ADS makes it difficult to commit abuse and fraud and personally and illicitly gain from the positions and functions of government officials?

a. If yes, why do you think so?

b. If no, why do you think so?

c. In a hypothetical scenario, if you observed undeclared assets or conflict of interest, whom do you report to? Ministry/Agency or ACC? 
24. Do you think relevant training, advocacy and sensitization would be effective in ensuring compliance among government employee users of ADS?

a. If yes, can you describe the details of examples of the training?

b. In what way do you think it was helpful?

c. If not, why not?

25. What is the feedback from the head of the agency? Are there encouragements, or they consider ADS as an administrative tool?

26. Why do you think some ADAs are proactive and following up with declarants, while the others are not?

27. Do you think media coverage and social media affect how government officials think and behave in using ADS?

a. If yes, what kind of media coverage and social media would be influential?

b. Why do you think they are influential?

c. If not, why do you think media coverage and social media do not affect government officials?

\section{Factors affecting their compliance behavior}

28. Which factor do you think is most important to ensure government officials' compliance with the ADS?

29. Do you have any other comments?

Thank the respondent for his/her time.

\section{Interview Protocol for Finance Officers}

Purpose of study - The information obtained in this interview will be used to conduct a research study for the UNU/Maastricht Graduate School of Governance. 
Topic -determinants of compliance among government employee users in e-governance implementation

Duration of interview - 45 - 60 minutes.

Procedure - Interview will take place face-to-face either in person or via a videoconference call (Skype; Google Hangout).

Confidentiality - Respondent will be asked to sign a consent form/confidentiality statement, informing them that the information shared will be confidential, only to be used for the purpose of research and his/her name will not be used. In case of online interviews, the interviewer will ask participants to confirm consent on tape, if recorded, and send them the form electronically to be signed and scanned.

Place to hold the interview - Interviews could take place inside any government offices, café, home or hotels; responses should be based on individual's opinions.

Recording interview - Respondent will be asked if he/she agrees with the conversation being recorded. The interviewer will also be taking notes, but since it is not possible to write everything, allowing her to record will ensure that she obtains all the information provided.

Right to stop interview/avoid a subject - Respondent will be told that he/she retains the right to not speak about any topic that he/she does not feel comfortable; interview can end at any point.

Interviewer's information:

Atsuko Okuda

PhD Fellow, Maastricht Graduate School of Governance/University of Maastricht

Tel: +1-305-606-8641

E-mail: a.okuda@maastrichtuniversity.nl

Academic Institution's information:

Maastricht Graduate School of Governance/University of Maastricht

Contact: Dr. Mindel van de Laar

Tel: +31-43-3884660

E-mail: mindel.vandelaar@maastrichtuniversity.nl

Clarification - Respondent will be asked before starting the interview if there any questions regarding what the interviewer explained. 
Agreement to participate - Respondent will be asked to confirm that he/she is willing to participate in this interview.

\section{Interview Guide}

\section{Finance Officers}

\section{E-governance initiative}

30. Your agency is using e-PEMS. Can you describe your role in the planning, testing, consultation and implementation of the system prior to the launching?

31. What do you do with the system? How many e-PEMS users are there in the ministry/agency?

32. In your opinion, is the system performing the way they are intended and delivering the expected outcomes?
a. If no, why do you think so?
b. If yes, why does he think so?

33. What are the concrete benefits you perceive by using the e-PEMS (compared with before)?

a. Were the Ministry/agency employees enthusiastic to embrace the changes and use e-PEMS?

b. What are the feedback you receive from other employees?

c. What do you think about the visibility and traceability e-PEMS provides?

34. What kind of issues have you and your ministry colleagues encountered so far?

a. How did you communicate them to the MoF?

b. How did you communicate them to the Ministry/agency management?

c. Did you work with IT Officer?

d. How were they resolved?

e. Have you discussed the issues with other finance officers in other ministries?

35. How do you receive functional changes and update, since the system was implemented? Do you follow user manuals? 
36. How do you assess the level of compliance with the user manuals and MoF instructions among your agency's e-PEMS users who are processing the payments?

a. What are the concrete examples?

b. Were there any work arounds which require offline parallel steps and procedures?

c. If the compliance is high, why do you think is the case?

37. How does your agency implement the maker checker concept and internal control?

38. Do you think that the fact that an external consultant was onboard in the system development increased confidence and trust in the system?
a. If yes, why so?
b. If no, why so?
c. What if the system was developed purely within Bhutan with government funds and government officers?

39. Do you think e-PEMS makes it difficult to commit abuse and fraud (i.e. payment instructions to a personal account, travel claim without travel)?
a. If yes, why do you think so?
b. If no, why do you think so?
c. In a hypothetical scenario, if there was an alleged abuse or fraud, whom do you report to? Ministry/Agency or MoF?

\section{Dispositional compliance}

40. Do you think relevant training would be effective in ensuring compliance among government employee users of e-PEMS?

a. If yes, can you describe the details of examples of the training?

b. In what way do you think it was helpful?

c. If not, why not?

41. What is the feedback from the head of the agency? Are there encouragements, or they consider e-PEMS as an administrative tool?

42. Do you think media coverage and social media affect how government officials think and behave in using e-PEMS? 
a. If yes, what kind of media coverage and social media would be influential?

b. Why do you think they are influential?

c. If not, why do you think media coverage and social media do not affect government officials?

\section{Factors affecting their compliance behavior}

43. Which factor do you think is most important to ensure government officials' compliance with the e-PEMS?

44. Do you have any other comments?

Thank the respondent for his/her time. 
- Remove "uh", "mm" and other transition sounds from the transcript unless they may mean pronounced hesitation or other indication of emotions, doubt or uncertainty.

- Correct obvious grammatical errors so far as the correction would not divert the nuances and emphasis expressed by the interviewees.

- Remove the repeat words wherever possible.

- Add note such as pause, laughter, interruptions as well as end note to capture the impression and unrecorded peculiar features after the interviews.

- Wherever appropriate, separate a sentence and add a comma to make sure that the meaning of the sentence is conveyed as accurately as possible.

- Complete a sentence wherever possible.

- Missing words were added in parenthesis.

- Incorrect use of words were also corrected in parenthesis.

- Some sentences were shortened in the quote used in this present research to enhanced the readability. 
This codebook details the definitions of both ADS and e-PEMS compliance drivers. The code was named based on inductive coding and definitions derived from the interviews. The list is also accompanied by what is excluded from the compliance drivers.

\begin{tabular}{|l|l|l|}
\hline Code & Definition & Exclude \\
\hline $\begin{array}{l}\text { Credibility } \\
\text { and trust in } \\
\text { the organi- } \\
\text { zation/ } \\
\text { ADS }\end{array}$ & $\begin{array}{l}\text { This code captures respect, fear, support, } \\
\text { trust and belief the government employee } \\
\text { users hold towards the ACC as a constitu- } \\
\text { tional and rule-based body. People be- } \\
\text { lieve that ACC is doing a good job and } \\
\text { therefore need to comply with the ADS } \\
\text { requirements. }\end{array}$ & $\begin{array}{l}\text { Bustem require- } \\
\text { systs, staff com- } \\
\text { mitment, organiza- } \\
\text { tional structure, } \\
\text { leadership }\end{array}$ \\
\hline $\begin{array}{l}\text { Organiza- } \\
\text { tional } \\
\text { setup/ ADS }\end{array}$ & $\begin{array}{l}\text { This code represents the actions and } \\
\text { measures implemented by the ADS user } \\
\text { organizations to facilitate the ADA's work } \\
\text { and submission of declarations among } \\
\text { government employee users. These are } \\
\text { extra measures being designed and imple- } \\
\text { mented by the user organizations, such as } \\
\text { appointment of additional ADAs, organ- } \\
\text { izing annual conferences and allocating } \\
\text { resources. }\end{array}$ & $\begin{array}{l}\text { Training, aware- } \\
\text { ness raising and } \\
\text { sensitization, lead- } \\
\text { ership, personal } \\
\text { commitments of } \\
\text { ADAs }\end{array}$ \\
\hline $\begin{array}{l}\text { Peer sup- } \\
\text { port/ADS }\end{array}$ & $\begin{array}{l}\text { This code includes informal peer support } \\
\text { and its mechanisms established among } \\
\text { ADAs to facilitate the work of ADAs and } \\
\text { compliance among government employee } \\
\text { users. Such peer support was instrumen- } \\
\text { tal in sharing information, rules and regu- } \\
\text { lations and what is expected of ADAs in } \\
\text { the agencies. }\end{array}$ & $\begin{array}{l}\text { Social media and } \\
\text { media in providing } \\
\text { public information, } \\
\text { more individual- } \\
\text { ized personal com- } \\
\text { mitment, organiza- } \\
\text { tional setups, train- } \\
\text { ing, sensitization } \\
\text { and awareness rais- } \\
\text { ing. }\end{array}$ \\
\hline
\end{tabular}




\begin{tabular}{|c|c|c|}
\hline $\begin{array}{l}\text { Personal } \\
\text { commit- } \\
\text { ment/ } \\
\text { ADS }\end{array}$ & $\begin{array}{l}\text { This code captures personal commitment } \\
\text { of various government officials as a com- } \\
\text { pliance driver. It was demonstrated in } \\
\text { positive and negative cases where the for- } \\
\text { mer leads to high compliance and the lat- } \\
\text { ter leads to low. compliance. It includes } \\
\text { their proactiveness and sending remind- } \\
\text { ers, following up with declarants and } \\
\text { making sure that the declarations are of } \\
\text { good quality, beyond the call of duty. }\end{array}$ & $\begin{array}{l}\text { Formal responsibil- } \\
\text { ity and function as } \\
\text { ADAs, peer sup- } \\
\text { port, organizational } \\
\text { setup, training, sen- } \\
\text { sitization and } \\
\text { awareness raising. }\end{array}$ \\
\hline $\begin{array}{l}\text { Training } \\
\text { and aware- } \\
\text { ness/ ADS }\end{array}$ & $\begin{array}{l}\text { This code aims to capture training, advo- } \\
\text { cacy, awareness raising and sensitization } \\
\text { sessions conducted by ACC targeted at } \\
\text { ADAs and end users for the ultimate ob- } \\
\text { jective of ensuring compliance among the } \\
\text { government employee users. It also in- } \\
\text { cludes official messages from ACC to } \\
\text { ADAs and from ACC to end users via } \\
\text { mass media. Some proactive agencies also } \\
\text { requested the ACC for additional training } \\
\text { and support. }\end{array}$ & $\begin{array}{l}\text { Informal peer sup- } \\
\text { port, personal com- } \\
\text { mitment, organiza- } \\
\text { tional setups, in- } \\
\text { cluding annual con- } \\
\text { ferences and regu- } \\
\text { lar meetings on as- } \\
\text { set declarations } \\
\text { within the user or- } \\
\text { ganizations. }\end{array}$ \\
\hline $\begin{array}{l}\text { The role of } \\
\text { His Majesty } \\
\text { the King }\end{array}$ & $\begin{array}{l}\text { This codes include the words, resolve and } \\
\text { commitment of His Majesty the King to- } \\
\text { wards digitization and anti-corruption ef- } \\
\text { forts which have an overarching impact } \\
\text { on the government employee users. }\end{array}$ & $\begin{array}{l}\text { Leadership in the } \\
\text { government which } \\
\text { include elected offi- } \\
\text { cials as well as } \\
\text { other high-level of- } \\
\text { ficials in the gov- } \\
\text { ernment }\end{array}$ \\
\hline $\begin{array}{l}\text { Leader- } \\
\text { ship/ADS }\end{array}$ & $\begin{array}{l}\text { The code captures the leadership within } \\
\text { the government which facilitates the work } \\
\text { of ADAs and creates an enabling and sup- } \\
\text { portive environment for declarants. It } \\
\text { takes the form of verbal encouragement, } \\
\text { taking responsibilities and demonstrating } \\
\text { commitment to anti-corruption in their ac- } \\
\text { tions. }\end{array}$ & $\begin{array}{l}\text { His Majesty the } \\
\text { King }\end{array}$ \\
\hline $\begin{array}{l}\text { Technol- } \\
\text { ogy-ena- } \\
\text { bled ease of } \\
\text { use/ ADS }\end{array}$ & $\begin{array}{l}\text { This code captures the technology-ena- } \\
\text { bled ease of use of the ADS, simple de- } \\
\text { sign, import function of previous records, } \\
\text { familiarity with the system among the us- } \\
\text { ers, automated password generation and }\end{array}$ & $\begin{array}{l}\text { Technical support } \\
\text { and responsiveness } \\
\text { of the ACC team to } \\
\text { the user requests }\end{array}$ \\
\hline
\end{tabular}




\begin{tabular}{|c|c|c|}
\hline & $\begin{array}{l}\text { notification, which drives compliance } \\
\text { among the users. }\end{array}$ & \\
\hline $\begin{array}{l}\text { Technical } \\
\text { support } \\
\text { and re- } \\
\text { sponsive- } \\
\text { ness of the } \\
\text { ACC Team/ } \\
\text { ADS }\end{array}$ & $\begin{array}{l}\text { This code summarizes the compliance } \\
\text { driver which is associated with the tech- } \\
\text { nical support and responsiveness of the } \\
\text { ACC's ICT and functional team. This also } \\
\text { includes the responsiveness which leads } \\
\text { to system update and upgrades and fixing } \\
\text { system bugs. }\end{array}$ & $\begin{array}{l}\text { System design, de- } \\
\text { velopment, auto- } \\
\text { mation. }\end{array}$ \\
\hline $\begin{array}{l}\text { Monitor- } \\
\text { ing, verifi- } \\
\text { cation and } \\
\text { follow-up/ } \\
\text { ADS }\end{array}$ & $\begin{array}{l}\text { This code categorizes the elements of } \\
\text { compliance driver which are associated } \\
\text { with the ACC's work in monitoring, veri- } \\
\text { fying and following up on the submitted } \\
\text { declarations. It also includes the ACC's } \\
\text { work in the ADS to monitor illicit enrich- } \\
\text { ment of assets and follow up calls with } \\
\text { the concerned declarants to check the rea- } \\
\text { son for sudden increase in assets in decla- } \\
\text { rations. }\end{array}$ & $\begin{array}{l}\text { Fear for punish- } \\
\text { ment }\end{array}$ \\
\hline $\begin{array}{l}\text { Naming } \\
\text { and sham- } \\
\text { ing/ ADS }\end{array}$ & $\begin{array}{l}\text { The code captures the fact that non and } \\
\text { late declarants may be named on the web- } \\
\text { site and media and their negative expo- } \\
\text { sure would deter non-and late declaration } \\
\text { and thus, encourage compliance. Famous } \\
\text { politicians and high-level government of- } \\
\text { ficials are particularly sensitive to being } \\
\text { named. }\end{array}$ & $\begin{array}{l}\text { Formal proceeding } \\
\text { of being implicated } \\
\text { in fraud and irregu- } \\
\text { larities such as in- } \\
\text { vestigation, prose- } \\
\text { cution and punitive } \\
\text { measures, the role } \\
\text { of media and social } \\
\text { media, fear for } \\
\text { punishment. }\end{array}$ \\
\hline $\begin{array}{l}\text { The role of } \\
\text { media and } \\
\text { social me- } \\
\text { dia/ ADS }\end{array}$ & $\begin{array}{l}\text { This code covers the specific role of media } \\
\text { and social media as compliance driver, in- } \\
\text { cluding investigative reporting of corrup- } \\
\text { tion cases and providing a platform to } \\
\text { whistleblowers to share materials on alle- } \\
\text { gations and wrong doings, which often } \\
\text { lead to ACC investigation later on. }\end{array}$ & $\begin{array}{l}\text { Naming and sham- } \\
\text { ing, fear for punish- } \\
\text { ment, peer support }\end{array}$ \\
\hline
\end{tabular}




\begin{tabular}{|c|c|c|}
\hline $\begin{array}{l}\text { Fear for } \\
\text { punish- } \\
\text { ment/ ADS }\end{array}$ & $\begin{array}{l}\text { This code captures various types of fear } \\
\text { the ADS users have in case of non-and } \\
\text { late declaration. Including fear for pen- } \\
\text { alty, fine and prosecution. }\end{array}$ & $\begin{array}{l}\text { Naming and sham- } \\
\text { ing }\end{array}$ \\
\hline $\begin{array}{l}\text { The role of } \\
\text { His Majesty } \\
\text { the King/ e- } \\
\text { PEMS }\end{array}$ & $\begin{array}{l}\text { The code summarizes the reverence peo- } \\
\text { ple hold towards His Majesty the Kind, } \\
\text { his words, resolve and commitment to } \\
\text { anti-corruption. It was evidenced to have } \\
\text { an overarching effect on the government } \\
\text { employee users to comply. }\end{array}$ & $\begin{array}{l}\text { Leadership in the } \\
\text { government }\end{array}$ \\
\hline $\begin{array}{l}\text { Leadership/ } \\
\text { e-PEMS }\end{array}$ & $\begin{array}{l}\text { This code captures the leadership-related } \\
\text { compliance driver in the implementation } \\
\text { of e-PEMS. It includes trust the users have } \\
\text { in leadership. The government employee } \\
\text { users decided to comply, as the leadership } \\
\text { advocated for the use and benefits of } e \text { - } \\
\text { PEMS. }\end{array}$ & $\begin{array}{l}\text { Efficiency gains, } \\
\text { training and aware- } \\
\text { ness raising, actual } \\
\text { technological de- } \\
\text { sign. }\end{array}$ \\
\hline $\begin{array}{l}\text { Efficiency } \\
\text { gains/ e- } \\
\text { PEMS }\end{array}$ & $\begin{array}{l}\text { This code collects elements related to effi- } \\
\text { ciency gains brought about by the } e \text { - } \\
\text { PEMS. It includes elimination of complex } \\
\text { financial operations and manual checks, } \\
\text { instant online payment, cost cutting, im- } \\
\text { proved service delivery to citizens and } \\
\text { vendors, reduced workload. }\end{array}$ & $\begin{array}{l}\text { Automation, tech- } \\
\text { nology-induced } \\
\text { ease of use, famili- } \\
\text { arity with the exist- } \\
\text { ing system }\end{array}$ \\
\hline $\begin{array}{l}\text { Familiarity } \\
\text { with the ex- } \\
\text { isting sys- } \\
\text { tem/ e- } \\
\text { PEMS }\end{array}$ & $\begin{array}{l}\text { This code describes the elements related } \\
\text { to familiarity government employee users } \\
\text { feel in using the e-PEMS as a compliance } \\
\text { driver. The e-PEMS was built on the pre- } \\
\text { vious PEMS, and the majority of steps and } \\
\text { functions are similar. }\end{array}$ & $\begin{array}{l}\text { Technology-ena- } \\
\text { bled ease of use, } \\
\text { automation and ef- } \\
\text { ficiency gains }\end{array}$ \\
\hline $\begin{array}{l}\text { Technology } \\
\text { and auto- } \\
\text { mation/e- } \\
\text { PEMS }\end{array}$ & $\begin{array}{l}\text { This code describes features of e-PEMS re- } \\
\text { lated to technology and automation } \\
\text { which drive compliance among govern- } \\
\text { ment employee users. It includes the auto- } \\
\text { mation of bank statement reconciliation } \\
\text { and utility payment. }\end{array}$ & $\begin{array}{l}\text { Efficiency gains, } \\
\text { technology-enabled } \\
\text { ease of use }\end{array}$ \\
\hline $\begin{array}{l}\text { Transpar- } \\
\text { ency, visi- } \\
\text { bility and } \\
\text { traceability/ } \\
\text { e-PEMS }\end{array}$ & $\begin{array}{l}\text { This code identifies elements of transpar- } \\
\text { ency, visibility and traceability that com- } \\
\text { pel users to comply with e-PEMS. The ele- } \\
\text { ments include the system functions which } \\
\text { captures who create, verify and approves }\end{array}$ & $\begin{array}{l}\text { Efficiency gains, } \\
\text { technology-enabled } \\
\text { ease of use, auto- } \\
\text { mation }\end{array}$ \\
\hline
\end{tabular}




\begin{tabular}{|c|c|c|}
\hline & $\begin{array}{l}\text { vouchers as well as keeps track of govern- } \\
\text { ment employee and payments so as to } \\
\text { avoid duplicate records and double pay- } \\
\text { ments. }\end{array}$ & \\
\hline $\begin{array}{l}\text { Centralized } \\
\text { master data } \\
\text { manage- } \\
\text { ment and } \\
\text { monitor- } \\
\text { ing/ e- } \\
\text { PEMS }\end{array}$ & $\begin{array}{l}\text { This code aims to summarize the elements } \\
\text { of compliance driver emanating from cen- } \\
\text { tralized master data management and the } \\
\text { role of DPA to centrally monitor it. In the } \\
\text { previous decentralized model, payees } \\
\text { could be manipulated by agencies. In the } \\
\text { current system, the entry of payees and } \\
\text { employee data is centrally managed and } \\
\text { monitored. }\end{array}$ & $\begin{array}{l}\text { Efficiency gains, } \\
\text { automation, tech- } \\
\text { nology-enabled } \\
\text { ease of use. }\end{array}$ \\
\hline $\begin{array}{l}\text { e-PEMS IT } \\
\text { support/e- } \\
\text { PEMS }\end{array}$ & $\begin{array}{l}\text { This code identifies the compliance driver } \\
\text { of } e \text {-PEMS IT support without which us- } \\
\text { ers would be discouraged and find work- } \\
\text { arounds. The IT support team responded } \\
\text { to user request to fix system bugs and in- } \\
\text { troduce solution improvements. }\end{array}$ & $\begin{array}{l}\text { Automation, tech- } \\
\text { nology-enabled } \\
\text { ease of use, trans- } \\
\text { parency, visibility } \\
\text { and traceability }\end{array}$ \\
\hline $\begin{array}{l}\text { Peer sup- } \\
\text { port and } \\
\text { parenting } \\
\text { arrange- } \\
\text { ment/ } e^{-} \\
\text {PEMS }\end{array}$ & $\begin{array}{l}\text { This code collects elements related to } e \text { - } \\
\text { PEMS peer support among finance offic- } \\
\text { ers and accountants as well as parenting } \\
\text { arrangement implemented by MoF. The } \\
\text { peer support included the creation of in- } \\
\text { formal WeChat group based on commit- } \\
\text { ment to their professional groups, tradi- } \\
\text { tion, and culture. It was supported by } \\
\text { parenting arrangement of transfer, pro- } \\
\text { motion and various study opportunities, } \\
\text { managed by MoF. }\end{array}$ & $\begin{array}{l}\text { Personal commit- } \\
\text { ment }\end{array}$ \\
\hline $\begin{array}{l}\text { Personal } \\
\text { commit- } \\
\text { ment/ } e- \\
\text { PEMS }\end{array}$ & $\begin{array}{l}\text { This code captures the personal commit- } \\
\text { ment expressed by e-PEMS users as a } \\
\text { compliance driver. It includes commit- } \\
\text { ment to do jobs well, remaining true to } \\
\text { the mandate of finance officers and ac- } \\
\text { countants, following rules and regulations } \\
\text { despite disagreements in working agen- } \\
\text { cies. It also appeared in their personal } \\
\text { commitment to resolve technical issues }\end{array}$ & $\begin{array}{l}\text { Peer support and } \\
\text { parenting arrange- } \\
\text { ment. }\end{array}$ \\
\hline
\end{tabular}




\begin{tabular}{|c|c|c|}
\hline & $\begin{array}{l}\text { and ensure smooth functions of the sys- } \\
\text { tem. }\end{array}$ & \\
\hline $\begin{array}{l}\text { Fear for } \\
\text { punish- } \\
\text { ment/ e- } \\
\text { PEMS }\end{array}$ & $\begin{array}{l}\text { This code collects the elements associated } \\
\text { with fear for punishment in case of non- } \\
\text { compliance. It includes fear for being } \\
\text { caught for their misuse or non-compliance } \\
\text { in audits, audit clearance not obtained, } \\
\text { which affects various opportunities, such } \\
\text { as transfer, promotion and studying } \\
\text { abroad, recovery of misused funds, crimi- } \\
\text { nal charges and disciplinary actions. }\end{array}$ & $\begin{array}{l}\text { Naming and sham- } \\
\text { ing }\end{array}$ \\
\hline $\begin{array}{l}\text { Naming } \\
\text { and sham- } \\
\text { ing/e- } \\
\text { PEMS }\end{array}$ & $\begin{array}{l}\text { This code summarises the factors associ- } \\
\text { ated with naming and shaming as e- } \\
\text { PEMS compliance driver. It includes be- } \\
\text { ing implicated in a misuse, misappropria- } \\
\text { tion and non-compliance in media and so- } \\
\text { cial media. The impact of naming and } \\
\text { shaming also extends to the fact that the } \\
\text { parent agency of MoF getting to know the } \\
\text { problem and names of the implicated fi- } \\
\text { nance officers and accountants. }\end{array}$ & $\begin{array}{l}\text { Fear for punish- } \\
\text { ment }\end{array}$ \\
\hline
\end{tabular}




\begin{tabular}{|c|c|c|}
\hline No & $\begin{array}{l}\text { Parent } \\
\text { Agency }\end{array}$ & Agencies \\
\hline 1 & \multirow{3}{*}{$\begin{array}{l}\text { Armed } \\
\text { Force }\end{array}$} & Royal Bhutan Army \\
\hline 2 & & Royal Bhutan Police \\
\hline 3 & & Royal Body Guard \\
\hline 4 & \multirow{15}{*}{$\begin{array}{l}\text { Autono- } \\
\text { mous } \\
\text { Agencies }\end{array}$} & 4th King Secretariat \\
\hline 5 & & Alternative Dispute Resolution Centre \\
\hline 6 & & Agency for Promotion of Indigenous Craft \\
\hline 7 & & Bar Council \\
\hline 8 & & Bhutan Chamber for Commerce and Industry \\
\hline 9 & & $\begin{array}{l}\text { Bhutan Council for School Examination and Assess- } \\
\text { ment }\end{array}$ \\
\hline 10 & & Bhutan Electricity Authority \\
\hline 11 & & Bhutan Health Trust Fund \\
\hline 12 & & Bhutan Info-comm and Media Authority \\
\hline 13 & & Bhutan Medical and Health Council \\
\hline 14 & & Bhutan Narcotic Control Agency \\
\hline 15 & & Bhutan National Legal Institute \\
\hline 16 & & Bhutan Olympic Committee \\
\hline 17 & & Bhutan Standard Bureau \\
\hline 18 & & Cabinet Secretariat \\
\hline
\end{tabular}




\begin{tabular}{|c|c|}
\hline 19 & Centre for Bhutan Studies \\
\hline 20 & Construction Development Board \\
\hline 21 & Dratshang Lhentshog \\
\hline 22 & Drug Regulatory Authority \\
\hline 23 & Druk Holding and Investments \\
\hline 24 & Dzongkha Development Commission \\
\hline 25 & Gross National Happiness Commission \\
\hline 26 & His Majesty's Secretariat \\
\hline 27 & Jigme Singye School of Law \\
\hline 28 & Khesar Gyalpo University of Bhutan \\
\hline 29 & National Assembly Secretariat \\
\hline 30 & National Centre for Hydrology and Meteorology \\
\hline 31 & National Commission for Women and Children \\
\hline 32 & National Council Secretariat \\
\hline 33 & National Environment Commission \\
\hline 34 & National Land Commission Secretariat \\
\hline 35 & National Pension and Provident Fund \\
\hline 36 & National Statistical Bureau \\
\hline 37 & Office of the Attorney General \\
\hline 38 & Privy Council of Bhutan \\
\hline 39 & Royal Education Council \\
\hline 40 & Royal Institute of Management \\
\hline 41 & Royal Securities Exchange of Bhutan Limited \\
\hline
\end{tabular}




\begin{tabular}{|c|c|c|}
\hline 42 & & Royal University of Bhutan \\
\hline 43 & & Tourism Council of Bhutan \\
\hline 44 & \multirow{6}{*}{$\begin{array}{l}\text { Constitu- } \\
\text { tional of- } \\
\text { fice }\end{array}$} & Anti-Corruption Commission \\
\hline 45 & & Election Commission of Bhutan \\
\hline 46 & & Royal Audit Authority \\
\hline 47 & & Royal Civil Service Commission \\
\hline 48 & & Supreme Court \\
\hline 49 & & High Court \\
\hline 50 & \multirow{15}{*}{$\begin{array}{l}\text { Corpora- } \\
\text { tions }\end{array}$} & Army Welfare Project \\
\hline 51 & & Basochhu Hydropower Plant \\
\hline 52 & & Bhutan Agro Industry Ltd. \\
\hline 53 & & Bhutan Board Product Ltd. \\
\hline 54 & & Bhutan Automation and Engineering Ltd. \\
\hline 55 & & Bhutan Broadcasting Service Ltd. \\
\hline 56 & & Bhutan Carbide Chemical Ltd. \\
\hline 57 & & Bhutan Duty Free Ltd. \\
\hline 58 & & Bhutan Ferro Alloys Ltd. \\
\hline 59 & & Bhutan Hydropower Service Ltd. \\
\hline 60 & & Bhutan Livestock Development Corporation Ltd. \\
\hline 61 & & Bhutan Polymers and Company Ltd. \\
\hline 62 & & Bhutan Postal Corporation Ltd. \\
\hline 63 & & Bhutan Power Corporation Ltd. \\
\hline 64 & & Bhutan Telecom Ltd. \\
\hline
\end{tabular}




\begin{tabular}{|c|c|}
\hline 65 & Bhutan Times Ltd. \\
\hline 66 & Bhutan Tourism Corporation Ltd. \\
\hline 67 & Construction Development Corporation Ltd \\
\hline 68 & Chhukha Hydro Power Energy Ltd. \\
\hline 69 & Dagachhu Hydro Power Corporation \\
\hline 70 & Druk Air Corporation Ltd. \\
\hline 71 & Druk Ferro Alloys Ltd. \\
\hline 72 & Druk Green Power Corp. Ltd. \\
\hline 73 & Druk Horticulture Pvt Ltd \\
\hline 74 & Druk Plaster and Chemical Ltd. \\
\hline 75 & Druk Satair Corporation Ltd. \\
\hline 76 & Druk Wang Alloys \\
\hline 77 & Dungsam Cement Corporation Ltd \\
\hline 78 & Dungsam Polymers Ltd. \\
\hline 79 & Farm Machinery Corporation Ltd. \\
\hline 80 & Financial Institution Training Institute Ltd. \\
\hline 81 & Food Corporation of Bhutan Ltd. \\
\hline 82 & Green Bhutan Corporation Ltd. \\
\hline 83 & Jigmi Mining Corporation Ltd. \\
\hline 84 & Kholongchhu Hydro Energy Ltd. \\
\hline 85 & Koufuku international Ltd. \\
\hline 86 & Kuensel Corporation Ltd. \\
\hline 87 & Kurichhu Hydropower Plant \\
\hline
\end{tabular}




\begin{tabular}{|c|c|c|}
\hline 88 & & Mangdechhu Hydroelectric Project Authority \\
\hline 89 & & Menjong Sorig Pharmaceuticals Corp Ltd. \\
\hline 90 & & National Housing Development Corporation Ltd. \\
\hline 91 & & Natural Resources Development Corporation Ltd. \\
\hline 92 & & Penden Cement Authority Ltd. \\
\hline 93 & & PHPA I \\
\hline 94 & & PHPA II \\
\hline 95 & & $\begin{array}{l}\text { Royal Bhutan Helicopter Services Ltd. } \\
\text { Old Hangar, Paro International Airport }\end{array}$ \\
\hline 96 & & Royal Bhutan Lottery Ltd. \\
\hline 97 & & Rural Enterprise Development Corporation Ltd. \\
\hline 98 & & S.D. Eastern Bhutan Coal Company Ltd. \\
\hline 99 & & State Mining Corporation Ltd. \\
\hline 100 & & State Trading Corporation of Bhutan Ltd. \\
\hline 101 & & Tala Hydro Power Corporation \\
\hline 102 & & Tangsibji Hydro Energy Ltd. \\
\hline 103 & & Wood Craft Centre Ltd. \\
\hline 104 & & Thimphu TechPark Ltd \\
\hline 105 & \multirow{6}{*}{ CSO/NGOs } & Ability Bhutan Society \\
\hline 106 & & Association of Bhutan Tour Operators \\
\hline 107 & & Association of Bhutanese Industries \\
\hline 108 & & Bhutan Association of Women Entrepreneur \\
\hline 109 & & Bhutan Cancer Society \\
\hline 110 & & Bhutan Centre for Media \& Democracy \\
\hline
\end{tabular}




\begin{tabular}{|c|c|}
\hline 111 & Bhutan Ecological Society \\
\hline 112 & Bhutan Film Association \\
\hline 113 & Bhutan Kidney Foundation \\
\hline 114 & Bhutan Network for Empowering Women \\
\hline 115 & Bhutan Transparency Initiative \\
\hline 116 & Bhutan Trust Fund for Environment Conservation \\
\hline 117 & Bhutan Youth Development Fund \\
\hline 118 & Construction Association of Bhutan (CAB) \\
\hline 119 & Chithuen Phendhey Association \\
\hline 120 & Disabled Person Association of Bhutan \\
\hline 121 & $\begin{array}{l}\text { Draktsho Vocational Centre for Special Children \& } \\
\text { Youth }\end{array}$ \\
\hline 122 & GNH Centre Bhutan \\
\hline 123 & Guide Association of Bhutan \\
\hline 124 & Gyalyum Charitable Trust \\
\hline 125 & Handicraft Association of Bhutan \\
\hline 126 & Journalists Association of Bhutan \\
\hline 127 & LHAK-SAM \\
\hline 128 & Menjong Foundation \\
\hline 129 & Music of Bhutan Research Centre \\
\hline 130 & Phuntsholing Sports Association \\
\hline 131 & RENEW \\
\hline 132 & Royal Society for Senior Citizens \\
\hline 133 & Royal Textile Academy \\
\hline
\end{tabular}




\begin{tabular}{|c|c|c|}
\hline 134 & & RSPN \\
\hline 135 & & SABAH-Bhutan \\
\hline 136 & & Tarayana Foundation \\
\hline 137 & & The Lhomon Society/SJ initiatives \\
\hline 138 & & Loden Foundation \\
\hline 139 & & VAST Bhutan \\
\hline 140 & \multirow{17}{*}{$\begin{array}{l}\text { Dzongkhag } \\
\text { Court }\end{array}$} & Bumthang \\
\hline 141 & & Chukha Court \\
\hline 142 & & Dagana Court \\
\hline 143 & & Gasa Court \\
\hline 144 & & Haa Court \\
\hline 145 & & Lhuntse Court \\
\hline 146 & & Mongar Court \\
\hline 147 & & Paro Court \\
\hline 148 & & Pema Gatshel Court \\
\hline 149 & & Punakha Court \\
\hline 150 & & Samdrupjongkhar Court \\
\hline 151 & & Samtse Court \\
\hline 152 & & Sarpang Court \\
\hline 153 & & Trongsa Court \\
\hline 154 & & Trashigang Court \\
\hline 155 & & Trashi Yangtse Court \\
\hline 156 & & Tsirang Court \\
\hline
\end{tabular}




\begin{tabular}{|c|c|c|}
\hline 157 & & Thimphu Court \\
\hline 158 & & Wangdue Court \\
\hline 159 & & Zhemgang Court \\
\hline 160 & & Gelephu Dungkhag Court \\
\hline 161 & & Phuntsholing Court \\
\hline 162 & & Bhutan Insurance Ltd. \\
\hline 163 & & Tashi Bank Ltd. \\
\hline 164 & & Bank Of Bhutan \\
\hline 165 & & Bhutan National Bank \\
\hline 166 & Financial & Credit Information Bureau \\
\hline 167 & Institutions & Royal Monetary Authority \\
\hline 168 & & Royal Insurance Corporation of Bhutan Ltd. \\
\hline 169 & & Druk Punjab National Bank \\
\hline 170 & & GIC Bhutan Re Ltd. \\
\hline 171 & & Bhutan Development Bank Ltd. \\
\hline 172 & \multirow{8}{*}{$\begin{array}{c}\text { Dzongkhag } \\
\text { Admin- } \\
\text { istrations }\end{array}$} & Bumthang \\
\hline 173 & & Chhukha \\
\hline 174 & & Dagana \\
\hline 175 & & Gasa \\
\hline 176 & & Haа \\
\hline 177 & & Lhuntse \\
\hline 178 & & Mongar \\
\hline 179 & & Paro \\
\hline
\end{tabular}




\begin{tabular}{|c|c|c|}
\hline 180 & & Pema Gatshel \\
\hline 181 & & Punakha \\
\hline 182 & & Samdrupjongkhar \\
\hline 183 & & Samtse \\
\hline 184 & & Sarpang \\
\hline 185 & & Thimphu \\
\hline 186 & & Trongsa \\
\hline 187 & & Trashigang \\
\hline 188 & & Trashi Yangtse \\
\hline 189 & & Tsirang \\
\hline 190 & & Wangdue Phodrang \\
\hline 191 & & Zhemgang \\
\hline 192 & \multirow{11}{*}{ Ministries } & Ministry of Agriculture and Forests \\
\hline 193 & & Ministry of Economic Affairs \\
\hline 194 & & Ministry of Education \\
\hline 195 & & Ministry of Finance \\
\hline 196 & & Ministry of Foreign Affairs \\
\hline 197 & & Ministry of Health \\
\hline 198 & & Ministry of Home and Cultural Affairs \\
\hline 199 & & Ministry of Information and Communications \\
\hline 200 & & Ministry of Labour and Human Resources \\
\hline 201 & & Ministry of Works and Human Settlement \\
\hline 202 & & JDWNRH \\
\hline
\end{tabular}




\begin{tabular}{|c|c|c|}
\hline 203 & & Mongar Regional Referral Hospital \\
\hline 204 & & Gelephu Central Region Referral Hospital \\
\hline 205 & & Phuntsholing Hospital \\
\hline 206 & \multirow{4}{*}{ Thromde } & Thimphu Thromde \\
\hline 207 & & Phunthsoling Thromde \\
\hline 208 & & Gelephu Thromde \\
\hline 209 & & Samdrupjongkhar Thromde \\
\hline
\end{tabular}

Source: ACC; Okuda (2020a) 
E-governance initiatives are increasingly seen as a vehicle to tackle corruption across the globe. E-governance initiatives offer an unprecedented amount and visibility of data and information which can be aggregated, disaggregated and analyzed to identify patterns and help improve policies, procedures, and processes. But the information systems alone would be insufficient to actually reduce corruption. Otherwise, we would have seen corresponding decreases in corruption along with the increasing number and scale of e-governance initiatives worldwide. Furthermore, despite the fact that similar e-governance functions and initiatives have been implemented across the world, the evidenced outcomes seem to vary markedly from country to country.

In this exploratory inductive research, compliance is identified as a conduit and part of mechanism to explain the phenomena of e-governance implementation which aims to control corruption. When government employee users comply with the e-governance system requirements, it is expected that the system will achieve the objectives the system is designed for and contribute to overall control of corruption in the government. In this background, this present research aims to answer the following questions:

\section{How does compliance manifest in e-governance implementation?}

\section{What are the determinants of compliance among government employee users in e-governance implementation?}

To answer the research questions, this exploratory research used qualitative inductive methods, based on constructivist/interpretivist approach. A comparative case study helped provide a detailed description of each case and theme within a case and across cases (cross-case analysis) for interpretation.

Data collection methods included document analysis, observations and semi-structured interviews. The fieldwork was conducted from September 2019 to January 2020 and conducted semi-structured interviews of 32 government officials and experts in Bhutan. The data collected from the case study initiatives and triangulated across different data sources produced rich descriptions which enabled in-depth interpretation of compliance drivers in each case study initiative. Using two rounds of coding and partial pattern matching, similar and dissimilar compliance drivers were identified in cross-case synthesis. In analyzing data, actor analysis and process tracing methods were applied to establish more nuanced perspectives of 
various actors and understand the institutional dynamics. The analysed data helped understand the phenomena under review and explain the how and why of compliance levels attained in each initiative.

The case study county was selected based on a set of pre-determined criteria of egovernment maturity and level of control of corruption. Out of the 13 possible case study countries, Bhutan was selected, based on the UNDESA E-Government Survey 2016, Transparency International Perception Survey 2018 (25 $5^{\text {th }}$ out of 180 countries in 2019) and language requirement.

One distinctive aspect of the case study country is the fact that Bhutan is one of the least developed countries and at the same time landlocked developing country, with the approximate population size of 800,000 . Thus, the available human and financial resources are limited to advance anti-corruption and implement the latest technologies across the government. Out of the 30 e-government initiatives listed in the Bhutan E-government Master Plan, the Asset Declaration System of the AntiCorruption Commission (ACC) and the electronic Public Expenditure Management System (e-PEMS) of the Ministry of Finance (MoF) were selected as case study initiatives based on pre-set criteria.

Across the two case study initiatives examined in Chapter 4 and Chapter 5, similar and dissimilar compliance drivers emerged. Some drivers were identical and interchangeable between the case study initiatives, despite the different organizational contexts and case configurations. They include the role of His Majesty the King, leadership, peer support, technology-enabled east of use, such as automation, naming and shaming, the role of media and social media and fear for punishment. The others were similar but not identical or interchangeable, including credibility and trust in organization, organizational setup, personal commitment, transparency, visibility and traceability as well as responsive technical support. Some drivers appeared both in positive and negative examples, but nonetheless, pointing to the same effect as a compliance driver.

Some of the compliance drivers were technology-enabled and induced, and the others were institutional or social drivers. Some of them were dependent on other drivers and the others were independent and inter-dependent. Together, the identified compliance drivers and their dependence and inter-dependence have created a compliance mechanism and compliance space where the compliance drivers function optimally and compliance is high. If compliance is low, the functioning compliance mechanism might not be in place, with limited and ineffective compliance drivers, and the compliance space too narrow. 
At the same time, it is expected that the compliance drivers evolve in response to a dynamically evolving context and background. New drivers may emerge, while other drivers may disappear when there are some incidents or changes in the context. If there are many inter-linked compliance drivers, a disappearance of a compliance driver or the diminished importance might not affect the overall compliance level much. However, if there is only one compliance driver in the country, such as leadership, and it disappears, it can safely be assumed that compliance will be reduced accordingly.

In this context, not only the compliance mechanism, which consists of inter-linked and mutually supportive compliance drivers, but also the compliance space, which consists of the number of compliance driver, would help explain the phenomena of compliance in the e-governance implementation.

Chapter 7 examined the identified compliance drivers against the existing literature detailed in Chapter 2. The technological compliance drivers played an important role in ensuring compliance in the two case study initiatives, yet the existing literature did not adequately explain the technological compliance drivers or compliance in the context of e-governance implementation.

Building on the identified gaps between the case study initiatives and literature and in recognition of the lack of appropriate compliance models, this present research proposed a new conceptual framework of e-compliance which integrates technology with other compliance drivers in e-governance implementation.

This present research elaborated how sociomateriality provides the theoretical foundation to explain e-compliance, as constitutive entanglement of the social and the material. E-compliance provides empirical data and operationalization of how the constitutive entanglement takes place. 
Ms. Atsuko Okuda is the Regional Director of the International Telecommunication Union (ITU) Regional Office for Asia and the Pacific.

Until April 2020, she was the Chief of the ICT and Development Section of the ICT and Disaster Risk Reduction Division (IDD) of the United Nations Economic and Social Commission for Asia and the Pacific (ESCAP), in Bangkok, Thailand.

Before joining ESCAP, Ms. Okuda served the United Nations Economic and Social Commission for Western Asia (ESCWA) in Beirut as the Chief of the Governance and Statebuilding Section and as the Team Leader responsible for ESCWA Knowledge Management. Prior to it, she contributed to the Umoja project, the Enterprise Resource Planning (ERP) initiative, as the testing manager at the Department of Management of UNHQ. From 2002 to 2010, she held various positions responsible for promoting a wide range of ICT for development initiatives at ESCAP and the United Nations Economic Commission for Africa (ECA) as Senior IT Officer, after contributing to the ICT for development programmes at UNDP (New York and Bhutan) for 6 years.

Ms. Okuda obtained a BA from Kyoto University (Japan), MA from Helsinki University (Finland), and has currently been enrolled as a research fellow on e-governance and anti-corruption at the United Nations University - Maastricht Economic and Social Research Institute on Innovation and Technology (UNU-MERIT) in the Netherlands.

Her academic articles on artificial intelligence and broadband connectivity were published by the Lee Kwan Yew School of Public Policy of Singapore. She also authored a chapter on digital government and e-resilience in the UN E-government Survey 2018, published by the United Nations Department of Economic and Social Affairs (DESA) in New York. Her article on emerging technologies and digital transformation in Bhutan was published in Druk Journal in 2020. Across the duty stations, she authored and managed the development of numerous reports and publications on ICT for development, including e-government.

She is married to Karma Sangay Phuntsho and has two daughters, Sonam Pelzon Misaki Okuda and Samdrup Dolma Miyuki Okuda. 


\section{UNU-MERIT/MGSoG Dissertation Series}

2021

Rafael Lemaitre Carabias

Public Sector Innovation in the United

Arab Emirates

How innovation occurs and the outcomes it delivers

UNU-MERIT/MGSoG Dissertation

Series № 268

\section{Maria Klara Kuss}

The Negotiations of Zambia's Welfare

Regime

The Transformative Potential of Social

Cash Transfers

UNU-MERIT/MGSoG Dissertation

Series № 267

\section{Michelle S. M. Momo}

A Multidimensional Perspective on

Education in Developing Countries

UNU-MERIT/MGSoG Dissertation

Series № 266

\section{Gideon Onyewuchi Ndubuisi}

Essays on International Trade: The Role of Institutions and Imported Intermediate Inputs

UNU-MERIT/MGSoG Dissertation

Series № 265

\section{Solomon Owusu}

Powering Structural Transformation and Economic Development in Africa: The Role of Services, Manufacturing and Global Value Chains

UNU-MERIT/MGSoG Dissertation Series № 264

\section{Halefom Yigzaw Nigus}

Markets and Human Behavior: Evidence

from Artefactual Field Experiments

UNU-MERIT/MGSoG Dissertation

Series № 263

\section{Iulia Falcan}

Transition towards a renewable European electricity system

What are the implications for the power technology mix, pan-European power trade and the electricity market?

UNU-MERIT/MGSoG Dissertation Series № 262

\section{Anne-Lore Fraikin}

The effect of financial retirement incentives originating from the social security system on the retirement behavior of older Belgian workers

UNU-MERIT/MGSoG Dissertation

Series № 261

\section{Bart Kleine Deters}

A Quantitative approach to the right to education: Concept, Measurement, and Effects

UNU-MERIT/MGSoG Dissertation

Series № 260

Eliana Rubiano-Matulevich

Essays on Conflict-Induced Displacement and Gender in Colombia

UNU-MERIT/MGSoG Dissertation

Series № 259

\section{Njagi Purity Muthoni}

Financial Risk, Vulnerability and Equity of Access to Healthcare Services in Kenya UNU-MERIT/MGSoG Dissertation

Series № 258 


\section{María José Espinosa-Romero}

The Shadow of Hierarchy in Marine

Fisheries Governance

UNU-MERIT/MGSoG Dissertation

Series № 257

\section{Lorena Rivera León}

Unveiling the Determinants of Scientific

Productivity in Middle-Income Countries:

An Economics of Science Perspective

UNU-MERIT/MGSoG Dissertation

Series № 256

\section{Racky Balde}

Essays on Informal versus formal Economy

Choices

UNU-MERIT/MGSoG Dissertation

Series № 255

\section{Caio Torres Mazzi}

Learning, Capabilities and Governance in

Global Value Chains

UNU-MERIT/MGSoG Dissertation

Series № 254

\section{Giulia Rossello}

Social Transformations and Labour Market

Entry

An Investigation into University Systems

in Emerging Economies

UNU-MERIT/MGSoG Dissertation

Series № 253

2020

\section{Rose Camille Vincent}

Essays in Public Economics

Multi-Layer Tax Structure and

Implications

UNU-MERIT/MGSoG Dissertation

Series № 252

\section{Emmanuel Mensah}

Structural change in developing countries: patterns, causes, and consequences

UNU-MERIT/MGSoG Dissertation

Series № 251

\section{Ornsaran Manuamorn}

Governance of International Adaptation

Finance for local Climate Change

Adaptation: An Analysis of Adaptation

Fund Projects

UNU-MERIT/MGSoG Dissertation

Series № 250

\section{Gillian McFarland}

Doing policy in Further Education

An exploration of the enactment of the

GCSE resits policy in Further Education

colleges in England

UNU-MERIT/MGSoG Dissertation

Series № 249

\section{Omar Rodriguez Torres}

Essays on Entrepreneurship in Colombia UNU-MERIT/MGSoG Dissertation

Series № 248

\section{Elaine Lebon-McGregor}

International Organizations and Global Migration Governance

UNU-MERIT/MGSoG Dissertation

Series № 247

Janyl Moldalieva

Playing the 'Game' of Transparency and

Accountability in Kyrgyzstan's Resource

Governance

UNU-MERIT/MGSoG Dissertation

Series № 246

Kaleab Kebede Haile

Essays on Rural Household Decision-

Making under Climate Risk

UNU-MERIT/MGSoG Dissertation

Series № 245 


\section{Nora Jasmin Ragab}

Diaspora Mobilisation in a Conflict Setting

UNU-MERIT/MGSoG Dissertation

Series № 244

\section{Mary Kaltenberg}

From Micro to Macro: Essays on

Technological Change and Income

Divergence

UNU-MERIT/MGSoG Dissertation

Series № 243

\section{Ayla E. Bonfiglio}

Student migrant, refugee or both?

Exploring Refugee Agency and Mobility

through Tertiary Education in Kenya,

South Africa and Uganda

UNU-MERIT/MGSoG Dissertation

Series № 242

\section{Danilo Sartorello Spinola}

Cycles, Economic Structures and External Constraints.

A Structuralist study on the causes of economic volatility in Latin America UNU-MERIT/MGSoG Dissertation Series № 241

2019

\section{Jemal Adem}

Livelihood Vulnerability to Shocks, Behaviour and Investment in Education:

Essays in Behavioural Development

Economics

UNU-MERIT/MGSoG Dissertation

Series № 240

\section{Davina Osei}

Corrupt or corrupted networks?

An empirical enquiry UNU-MERIT/MGSoG Dissertation

Series № 239

\section{Patima Chongcharoentanawat}

Beyond Static Inequality

Public policies and economic mobility in

Thailand

UNU-MERIT/MGSoG Dissertation

Series № 238

\section{Charlotte Guillard}

Rethinking economic growth

and structural change.

The role of boundaries and linkages between industries

UNU-MERIT/MGSoG Dissertation

Series № 237

\section{Nicolas Echarti}

Employment Effects or Vocational

Rehabilitation in Germany:

A quantitative analysis

UNU-MERIT/MGSoG Dissertation

Series № 236

\section{Shellie E. Solomon}

Neighborhoods Matter:

Crime, collective efficacy and foreclosures in Miami

UNU-MERIT/MGSoG Dissertation

Series № 235

\section{Michał Kazimierczak}

Regional Innovation and Entrepreneurship Patents, trade marks, entry and entrants' growth in European manufacturing industries

UNU-MERIT/MGSoG Dissertation

Series № 234

\section{Fernanda Soares}

The Influence of Within School and Across Schools' Collaborative Practices on Student Learning and Teaching Outcomes in West Africa

UNU-MERIT/MGSoG Dissertation Series № 233 


\section{Mira Bierbaum}

New Mindsets to Innovate Activation

UNU-MERIT/MGSoG Dissertation

Series № 232

\section{Norman Dytianquin}

Technology in the Asian Miracle and Crisis Debates: Applications of and Insights from the Field of Influence Approach to InputOutput Analysis

UNU-MERIT/MGSoG Dissertation

Series № 231

\section{Nga Le}

The implications of health insurance for the labour market and patient satisfaction with medical care in Vietnam

UNU-MERIT/MGSoG Dissertation

Series № 230

\section{Jinhyuck Park}

Intellectual Property right protection and cross-border RED investments by multinational enterprises

UNU-MERIT/MGSoG Dissertation

Series № 229

\section{Richard de Groot}

Show me the Money:

Essays on the Impact of Cash Transfers on Child Nutrition and the Role of Intra-

Household Dynamics

UNU-MERIT/MGSoG Dissertation

Series № 228

\section{Catie Lott}

Diamonds are a Women's Best Friend Broadening Measures of Women's Access to Formal Political Decision-Making UNU-MERIT/MGSoG Dissertation Series № 227

\section{Ana Cristina Calderon Ramirez \\ Public Management Reforms \\ Three stories about public procurement agencification in Latin America UNU-MERIT/MGSoG Dissertation Series № 226}

\section{Camilo Nicanor Carrillo Purin}

Teachers' in-service training and student achievement:

The effect of in-service training of Peruvian teachers on student achievement

UNU-MERIT/MGSoG Dissertation

Series № 225

\section{Hugo Confraria}

Developing scientific capacity in the Global South

UNU-MERIT/MGSoG Dissertation

Series № 224

Alison Cathles

Educational Pathways and Skills:

Past, Present, and Future

UNU-MERIT/MGSoG Dissertation

Series № 223

\section{Ibrahima Sory Kaba}

Aggregate Fluctuations and Development: Essays on Macroeconomic Volatility and

Economic Growth

UNU-MERIT/MGSoG Dissertation

Series № 222

\section{Charlotte Keijser}

Firm Participation, Learning and Innovation in Heterogenous Value Chains of IT-enabled Services UNU-MERIT/MGSoG Dissertation Series № 221 


\section{Salih Çevikarslan}

Innovation Strategies and Their

Implications for Technological Change and

Market Outcomes:

An Evolutionary Multi-Agent Based

Modelling Approach

UNU-MERIT/MGSoG Dissertation

Series № 220

\section{Wondimagegn Mesfin Tesfaye}

Essays on the Impacts of Climate-Smart

Agricultural Innovations on Household

Welfare

UNU-MERIT/MGSoG Dissertation

Series № 219

\section{Tatevik Poghosyan}

How Board Networks Affect Firm

Performance and Innovation Incentives in

Transition Economies: The Case of

Armenia

UNU-MERIT/MGSoG Dissertation

Series № 218

\section{Arip Muttaqien}

Essays on Inequality and Polarization:

Empirical Studies in Developing Asia

UNU-MERIT/MGSoG Dissertation

Series № 217

\section{8}

\section{Katrin Marchand}

Essays on Forced Migration and Labour

Market Participation in Developing

Countries

UNU-MERIT/MGSoG Dissertation

Series № 216

\section{Ortrun Merkle}

The Myth of Gender Neutral Power:

Corruption and Gender Norms

UNU-MERIT/MGSoG Dissertation

Series № 215

\section{Biljana Meshkovska}

Life after Trafficking:

(re)integration processes of women that have been trafficked for the purpose of sexual exploitation in Europe

UNU-MERIT/MGSoG Dissertation

Series № 214

\section{Vincenzo Vinci}

The Relevance of Institutions and People's

Preferences for Social Protection

UNU-MERIT/MGSoG Dissertation

Series № 213

\section{Silke Heuser}

The Effectiveness of Environmental Policies on Reducing Deforestation in the Brazilian Amazon

UNU-MERIT/MGSoG Dissertation

Series № 212

\section{Jennifer Waidler}

Social Assistance and Remittances and Their Role in the Fight Against Poverty UNU-MERIT/MGSoG Dissertation

Series № 211

\section{Choolwe Muzyamba}

The role of community mobilization in the promotion of maternal health of women living with HIV in Zambia

UNU-MERIT/MGSoG Dissertation

Series № 210

\section{Juan Carlos A. Castillo Sánchez}

Assessing the Role of the Export Sector in Mexican Economic Development,19652014

UNU-MERIT/MGSoG Dissertation

Series № 209 


\section{Tareq Abuelhaj}

Food Security Policy Impact Analysis: The

Econometrics of Cash and Food Assistance

Cost Effectiveness

UNU-MERIT/MGSoG Dissertation

Series № 208

Marta Férnandez de Arroyabe Arranz

Essays on MEAS and Innovation

UNU-MERIT/MGSoG Dissertation

Series № 207

\section{Clotilde Mahé}

Essays on Migration and Occupational

Choice

UNU-MERIT/MGSoG Dissertation

Series № 206

\section{Simone Sasso}

Talent on the move. Essays on Human

Capital, Graduate Mobility and Economic

Development

UNU-MERIT/MGSoG Dissertation

Series № 205

\section{Khaled Walid Rajab}

Strategic Planning under Fragility

UNU-MERIT/MGSoG Dissertation

Series № 204

\section{Mutinta Hambayi Nseluke}

A Tall Order: Improving Child Linear Growth

UNU-MERIT/MGSoG Dissertation

Series № 203

\section{Elvis Korku Avenyo}

Innovations and Firm Performance

in sub-Saharan Africa: Empirical Analyses

UNU-MERIT/MGSoG Dissertation

Series № 202

\section{Ni Zhen}

Employment Dynamics, Firm Performance and Innovation Persistence in the Context of Differentiated Innovation Types:

Evidence from Luxembourg

UNU-MERIT/MGSoG Dissertation

Series № 201

\section{Caroline Wehner}

Too Scared to Achieve: The Relation

Between Neuroticism, Conscientiousness

and Socioeconomic Outcomes

UNU-MERIT/MGSoG Dissertation

Series № 200

\section{Stefania Innocenti}

On Institutional Persistence

UNU-MERIT/MGSoG Dissertation

Series № 199

\section{Hassen Abda Wako}

Economic Globalization, Institutions and Development: Essays on Aid, Foreign

Direct Investment and Trade

UNU-MERIT/MGSoG Dissertation

Series № 198

2017

\section{Hans-Erik Edsand}

Winds of Change

UNU-MERIT/MGSoG Dissertation

Series № 197

Ana Patricia Silva Vara

Redressing the Gender Gap

UNU-MERIT/MGSoG Dissertation

Series № 196

\section{Andrés Iván Mideros Mora}

Essays on the Economic Effects of Noncontributory Social Protection UNU-MERIT/MGSoG Dissertation Series № 195 


\section{Tobias Broich}

New Actors in the Global Economy

UNU-MERIT/MGSoG Dissertation

Series № 194

Bernard Nikaj

From No-government to E-government UNU-MERIT/MGSoG Dissertation

Series № 193

Ali Safarnejad

Prioritizing the HIV Response

UNU-MERIT/MGSoG Dissertation

Series № 192

\section{Clovis Freire}

Diversification and Structural Economic

Dynamics

UNU-MERIT/MGSoG Dissertation

Series № 191

\section{Michael Verba}

Innovation and Knowledge Dynamics:

Essays on the Knowledge Economy

UNU-MERIT/MGSoG Dissertation

Series № 190

\section{Pui Hang Wong}

The Hearts and Minds in Conflict and

Peace: The Economics of

Counterinsurgency and the Psychology of

Reconstruction

UNU-MERIT/MGSoG Dissertation

Series № 189

\section{Brenda Yamba}

Schooling Despite All Odds: Evidence from Lesotho on Female Child Carers who Stayed in School

UNU-MERIT/MGSoG Dissertation

Series № 188

\section{Sheng Zhong}

Moving towards An Energy Efficient

Future: Essays on Energy Efficiency,

Technology and Development

UNU-MERIT/MGSoG Dissertation

Series № 187

\section{Julieta Marotta}

Access to Justice and Legal Empowerment of Victims of Domestic Violence through Legal Organizations in the City of Buenos Aires: A Qualitative Empirical Legal Study UNU-MERIT/MGSoG Dissertation Series, № 186

\section{Andrea Franco-Correa}

On the Measurement of Multidimensional Poverty as a Policy Tool: Empirical Applications to Chile, Colombia, Ecuador and Peru

UNU-MERIT/MGSoG Dissertation Series, № 185

2016

\section{Yesuf Awel}

Insurance for Growth: Empirical Essays on Insurance Demand and Impacts in Africa UNU-MERIT Dissertation Series, № 108

\section{Tigist Mekonnen Melesse}

Grow More Food using Fewer Resources: Agricultural Technology Adoption and Innovation Practices for Inclusive and Sustainable Development UNU-MERIT Dissertation Series, № 107

\section{Eleni Yitbarek}

Getting Ahead or left Behind? Essays on Poverty Dynamics and Social Mobility in Africa UNU-MERIT Dissertation Series, № 106 


\section{Thuy Dieu Nguyen}

Firm-Level Theory and Evidence of

Corruption

UNU-MERIT Dissertation Series, № 105

\section{Raquel Tsukada Lehman}

Essays on Household Production with

Labor-Saving Technology

UNU-MERIT Dissertation Series, № 104

\section{Eva Barteková}

Multi-Problem Challenges for a Renewable

Future: Empirical Studies on Competitive

Disadvantages from Electricity Price

Differentials and Mineral Supply Risk in

an Open Economy

UNU-MERIT Dissertation Series, № 103

\section{Jocelyn Olivari}

Entrepreneurial Traits and Innovation:

Evidence from Chile

UNU-MERIT Dissertation Series, № 102

\section{Muhammad Shafique}

Essays on the role of knowledge, $R \mathcal{E} D$, and Technology-based Firms in the Evolution of Socio-techno-economic System

UNU-MERIT Dissertation Series, № 101

\section{Serdar Türkeli}

Governance of Innovation Policy: Empirical Studies on Applied Political Economy by

Multi-Methods Analysis

UNU-MERIT Dissertation Series, № 100

\section{Ayokunu Adedokun}

Pathways to Sustainable Peace building in Divided Societies: Lessons and Experiences from Mozambique MGSoG Dissertation Series, № 75

\section{Luiz Rothier Bautzer}

Organizing Concurrent Engineering through ICT Platforms

Blueprinting Product Lifecycle

Management Platforms across Disciplinary Agencies

MGSoG Dissertation Series, № 74

\section{Natalia Popova}

Migration in the Periphery of the European Union:

Determinants of Successful and

Sustainable Labour Market Integration of

Return Migrants in Albania, Egypt,

Moldova and Tunisia

MGSoG Dissertations Series, № 73

\section{Richard A. Martina}

Uncertainty and Resource Constraint in the Small Island Developing States:

Essays in Entrepreneurial Cognition

MGSoG Dissertations Series, № 72

\section{Cécile Cherrier}

The Expansion of Basic Social Protection in Low-income Countries:

An Analysis of Foreign Aid Actors' Role in the Emergence of Social Transfers in SubSaharan Africa

MGSoG Dissertations series, № 71

\section{Paul Caldron}

The Tacit Bargain in Short-Term Medical Missions: Why U.S. physicians go and what it costs

MGSoG Dissertation Series, № 70

\section{Mahmut Kobal}

Customs \& Excellence: A Comparative Approach on Administrative and Regulatory Compliance Perspectives of the EU-Turkey Customs Union MGSoG Dissertation Series, № 69 


\section{Craig Loschmann}

Essays on Conflict-related Migration and

Development in the Case of Afghanistan

MGSoG Dissertations Series, № 68

\section{Andrea Milan}

Rural Livelihoods, Location and Vulnerable Environments: Approaches to Migration in Mountain areas of Latin America

MGSoG Dissertation Series, № 67

\section{Farida Lada}

On Guarding the Welfare of Clinical Trial

Subjects While Promoting Novel Drug

Innovation

A Game Theoretical Approach

MGSoG Dissertation Series, № 66

\section{5}

\section{Hibret Belete Maemir}

Dissecting Aggregate Productivity:

International Integration and Growth with Heterogeneous Firms

UNU-MERIT Dissertation Series, № 96

\section{Giorgio Triulzi}

Looking for the Right Path: Technology

Dynamics, Inventive Strategies and

Catching-up in the Semiconductor

Industry

UNU-MERIT Dissertation Series, № 95

\section{Abdul Baseer Qazi}

Knowledge flows and networks in the ICT sector: The case of Pakistan

UNU-MERIT Dissertation Series, № 94

\section{Ajay Thutupalli}

Technology Paradigm Shifts in

Agriculture: Drivers of Sustainability and Catch up

UNU-MERIT Dissertation Series, № 93

\section{Eduardo Urias}

Improving access to HIVIAIDS treatment in Brazil: When are Compulsory Licenses effective in Price Negotiations?

UNU-MERIT Dissertation Series, № 92

\section{Francesca Guadagno}

Why have so few Countries Industrialised? UNU-MERIT Dissertation Series, № 91

\section{Daniel Opolot}

The Evolution of Beliefs and Strategic

Behaviour

UNU-MERIT Dissertation Series, № 90

\author{
Alejandro Lavopa \\ Structural Transformation and Economic \\ Development: Can Development Traps be \\ Avoided
}

UNU-MERIT Dissertation Series, № 89

\section{Jinjin Zhao}

Urban water management reform: The Case of China

UNU-MERIT Dissertation Series, № 88

\section{Simona Vezzoli}

Borders, Independence and Post-colonial

Ties: the Role of the State in Caribbean

Migration

MGSoG Dissertation Series, № 65

\section{Silvia Consuelo Gómez Soler}

Civil Conflict and Education: How Does

Exposure to Civil Conflict Affect Human

Capital Accumulation? Evidence from

Standardized Exit Exams in Colombia

MGSoG Dissertation Series, № 64

\section{Paula Nagler}

Occupational Choice in the Developing

World

MGSoG Dissertation Series, № 63 


\section{Jasmin Kientzel}

Determinants of Professional Commitment to Environmental Sustainability

MGSoG Dissertation Series, № 62

\section{Mehmet Güney Celbiş}

Regional Policies: Convergence, Trade, and the Allocation of Public Capital

MGSoG Dissertation Series, № 61

\section{Florian Henning}

Living Up to Standard: Interoperability Governance and Standards Adoption in

Government Information Networks

MGSoG Dissertation Series, № 60

\section{Niels P. Groen}

The Never-Ending Project

Understanding E-Government Project

Escalation

MGSoG Dissertation Series, № 59

\section{Derek Copp}

Teacher-Based Reactivity to Provincial

Large-scale Assessment in Canada

MGSoG Dissertation Series, № 58

\section{Michaella Vanore}

Family-Member Migration and the Psychosocial Health Outcomes of Children in Moldova and Georgia

MGSoG Dissertation Series, № 57

\section{Sonja Fransen}

The Economic and Social Effects of Remittances and Return Migration in Conflict-Affected Areas: The Case of Burundi

MGSoG Dissertation Series, № 56

\section{Ibrahim Khalil Conteh}

The Impact of Floods on Primary School Education in Zambia MGSoG Dissertation Series, № 55

\section{Richard Bluhm}

Growth Dynamics and Development Essays in Applied Econometrics and Political Economy MGSoG Dissertation Series, № 54

\section{Nevena P. Zhelyazkova}

Work-Family Reconciliation and Use of Parental Leave in Luxembourg: Empirical Analysis of Administrative Records MGSoG Dissertation Series, № 53

\section{4}

\section{Dirk Crass}

The Impact of Brands on Innovation and Firm Performance: Empirical Evidence from Germany

UNU-MERIT Dissertation Series, № 87

\section{Samyukta Bhupatiraju}

The Geographic Dimensions of Growth and Development

UNU-MERIT Dissertation Series, № 86

\section{François Lafond}

The Evolution of Knowledge Systems

UNU-MERIT Dissertation Series, № 85

\section{Annalisa Primi}

Promoting Innovation in Latin America:

What Countries Have Learned (and What

They Have Not) in Designing and Implementing Innovation and Intellectual Property Policies

UNU-MERIT Dissertation Series, № 84

Fatoumata Lamarana Diallo

Evaluation of Meal and Deworming Programs for Primary Schools in Rural Senegal

UNU-MERIT Dissertation Series, № 83 


\section{Sachin Kumar Badkas}

Metachoice and Metadata: Innovating with Environmental Policy Analysis in Europe MGSoG Dissertation Series, № 52

\section{Irina S. Burlacu}

An Evaluation of Tax-Benefit Systems Impact on the Welfare of Frontier Worker: The Case of Luxembourg and Belgium MGSoG Dissertation Series, № 51

\section{Özge Bilgili}

Simultaneity in Transnational Migration Research: Links Between Migrants' Host and Home Country Orientation

MGSoG Dissertation Series, № 50

\section{Yulia Privalova Krieger}

Reshaping the Big Agenda: Transnational Politics and Domestic Resistance Financial crisis and social protection reform in Bosnia and Herzegovina

MGSoG Dissertation Series, № 49

\section{Marieke van Houte}

Moving Back or Moving Forward? Return migration after Conflict

MGSoG Dissertation Series, № 48

\section{Oxana Slobozhan}

Global Governance in the Management of

Natural Resources: The Case of the

Extractive Industries Transparency

Initiative (EITI)

MGSoG Dissertation Series, № 47

\section{Luis Bernardo Mejia Guinand}

The Changing Role of the Central Planning

Offices in Latin America: A Comparative

Historical Analysis Perspective (1950-

2013)

MGSoG Dissertation Series, № 46

\section{Cheng Boon Ong}

Ethnic Segregation in Housing, Schools and Neighbourhoods in the Netherlands MGSoG Dissertation Series, № 45

\section{Luciana V. Cingolani}

Bureaucracies for Development: Oxymoron or Reality? Studies on State Capacity in Challenging Governance Contexts MGSoG Dissertation Series, № 44

\section{Carlos Cadena Gaitán}

Green Politics in Latin American Cities -

Sustainable Transport Agendas

MGSoG Dissertation Series, № 43

\section{Katie Kuschminder}

Female Return Migration and

Reintegration Strategies in Ethiopia

MGSoG Dissertation Series, № 42

\section{Metka Hercog}

Highly-Skilled Migration and New

Destination Countries

MGSoG Dissertation Series, № 41

\section{Margaret Agaba Rugadya}

Can Remittances Influence the Tenure and Quality of Housing in Uganda?

MGSoG Dissertation Series, № 40

\section{Ilire Agimi}

New Governance Under Limited Statehood: The Case of Local Government Reform in Kosovo

MGSoG Dissertation Series, № 39

2013

\section{Anant Kamath}

Information Sharing through Informal Interaction in Low-Tech Clusters UNU-MERIT Dissertation Series, № 82 


\section{Flavia Pereira de Carvalho}

What we talk about when we talk about

Brazilian Multinationals: An Investigation on Brazilian FDI, Economic Structure,

Innovation and the Relationship between them

UNU-MERIT Dissertation Series, № 81

\section{Jun Hou}

Complementarity in Innovation and

Development: A Cross-country

Comparison

UNU-MERIT Dissertation Series, № 80

\section{Rufin Baghana}

Impacts of Government Incentives to RED, Innovation and Productivity:

A Microeconometric Analysis of the

Québec Case

UNU-MERIT Dissertation Series, № 79

Lilia I. Stubrin

High-Tech Activities in Emerging

Countries: A Network perspective on the

Argentinean Biotech Activity

UNU-MERIT/MGSoG Dissertation

Series, № 78

\section{Kristine Farla}

Empirical Studies on Institutions, Policies and Economic Development

MGSoG Dissertation Series, № 38

\section{Marina Petrovic}

Social Assistance and Activation in the Pursuit of Happiness: Shedding New Light on Old Policy Solutions to Social Exclusion MGSoG Dissertation Series, № 37

\section{Laura Torvinen}

Assessing Governance Assessments: The Case of Mozambique: Governance Assessments in the Context of Aid Effectiveness Discourse MGSoG Dissertation Series, № 36

\section{Biniam Egu Bedasso}

Institutional Change in the Long Shadow of Elite: Essays on Institutions, Human

Capital and Ethnicity in Developing

Countries

MGSoG Dissertation Series, № 35

\section{Sepideh Yousefzadeh Faal Deghati}

Childhoods Embargoed: Constructing and

Reconstructing Multidimensional Child

Poverty in Iran 1984-2009

MGSoG Dissertation Series, № 34

\section{Robert Bauchmüller}

Investing in Early Childhood Care and

Education: The Impact of Quality on

Inequality

MGSoG Dissertation Series, № 33

\section{Martin Rehm}

Unified Yet Separated: Empirical Study on the Impact of Hierarchical Positions within Communities of Learning

MGSoG Dissertation Series, № 32

\section{2}

\author{
Abdul Waheed \\ Innovation Determinants and Innovation \\ as a Determinant: Evidence from \\ Developing Countries \\ UNU-MERIT Dissertation Series, № 77
}

\section{Bilal Mirza}

Energy Poverty and Rural Energy Markets in Pakistan

UNU-MERIT Dissertation Series, № 76

\section{Benjamin Engelstätter}

Enterprise Software and Video Games: An

Empirical Analysis

UNU-MERIT Dissertation Series, № 75 


\section{Fulvia Farinelli}

Natural Resources, Innovation and Export

Growth: The Wine Industry in Chili and

Argentina

UNU-MERIT Dissertation Series

\section{Rodolfo Lauterbach}

Innovation in Manufacturing: From

Product Variety and Labor Productivity

Growth to Economic Development in Chile

UNU-MERIT Dissertation Series

\section{Kirsten Wiebe}

Quantitative Assessment of Sustainable

Development and Growth in Sub-Saharan

Africa

UNU-MERIT Dissertation Series, № 74

Julio Miguel Rosa

Organizational Strategies, Firms'

Performance and Spatial Spillovers: The

Canadian Case in Research and

Development.

UNU-MERIT Dissertation Series, № 73

\section{Johannes Wilhelmus Marie Boels}

Joseph Schumpeter, Honderd Jaar

Economische Ontwikkeling: Een

Historisch-theoretische Beschouwing.

UNU-MERIT Dissertation Series

\section{Dorcas Mbuvi}

Utility Reforms and Performance of the

Urban Water Sector in Africa

MGSoG Dissertation Series, № 31

\section{Lina Salanauskaite}

Distributional Impacts of Public Policies:

Essays in Ex-Ante and Ex-Post Evaluation

MGSoG Dissertation Series, № 30

\section{Esther Schüring}

To Condition or not - is that the Question?

An Analysis of the Effectiveness of Ex-Ante and Ex-Post Conditionality in Social Cash

Transfer Programs

MGSoG Dissertation Series, № 29

\section{Joe Abah}

Strong Organisations in Weak States:

Atypical Public Sector Performance in

Dysfunctional Environments

MGSoG Dissertation Series, № 28

\section{Zina Samih Nimeh}

Social Citizenship Rights: Inequality and

Exclusion

MGSoG Dissertation Series, № 27

2011

Daniel Vertesy

Interrupted Innovation: Emerging

Economies in the Structure of the Global

Aerospace Industry

UNU-MERIT Dissertation Series, № 72

\section{Tina Saebi}

Successfully Managing Alliance Portfolios: An Alliance Capability View

UNU-MERIT Dissertation Series, № 71

\section{Nora Engel}

Tuberculosis in India: A Case of Innovation and Control

UNU-MERIT/MGSoG Dissertation

Series, № 70

\section{Evans Mupela}

Connectivity and growth in Sub-Saharan

Africa: The Role of Communication

Satellites

UNU-MERIT Dissertation Series, № 69 


\section{Nantawan Kwanjai}

Cross Cultural Intelligence amid Intricate

Cultural Webs: A Tale of the

UnDutchables in the Land of 1002 Smiles

UNU-MERIT Dissertation Series, № 68

\section{Lina Sonne}

Innovation in Finance to Finance

Innovation: Supporting Pro-poor

Entrepreneur-based Innovation

UNU-MERIT Dissertation Series, № 67

\section{Lenka Eisenhamerová}

Legitimacy of 'Humanitarian Military

Intervention'

MGSoG Dissertation Series, № 26

\section{Sonila Tomini}

Informal Payments for Health Care

Services in Albania

MGSoG Dissertation Series, № 25

\section{Jinjing Li}

Dynamic Microsimulation in Public Policy

Evaluation

MGSoG Dissertation Series, № 24

\section{Aziz Atamanov}

Rural Nonfarm Employment and

International Migration as Alternatives to

Agricultural Employment: The Case of

Kyrgyzstan

MGSoG Dissertation Series, № 23

\section{Frieda Vandeninden}

Poverty Alleviation: Aid and Social

Pensions

MGSoG Dissertation Series, № 22

\section{Juliana Nyasha Tirivayi}

The Welfare Effects of Integrating AIDS

Treatment with Food Transfers: Evidence

from Zambia

MGSoG Dissertation Series, № 21

\section{Agnieska Ewa Sowa}

Who's Left Behind? Social Dimensions of

Health Transition and Utilization of

Medical Care in Poland

MGSoG Dissertation Series, № 20

\section{Emmanaouil Sfakianakis}

The Role of Private Actors in the Provision of Public Goods with Applications to Infrastructure and Financial Stability MGSoG Dissertation Series, № 19

\section{Siu Hing Lo}

White Collars Green Sleeves: An Inter-

organizational Comparison of

Determinants of Energy-Related Behaviors among Office Workers

MGSoG Dissertation Series, № 18

\section{Treena $\mathbf{W u}$}

Constraints to Human Capital Investment in Developing Countries:

Using the Asian Financial Crisis in

Indonesia as a Natural Experiment

MGSoG Dissertation Series, № 17

\section{Henry Espinoza Peña}

Impact Evaluation of a Job-Training

Programme for Disadvantaged Youths:

The Case of Projoven

MGSoG Dissertation Series, № 16

2010

\section{Fernando Santiago}

Human Resources Management Practices and Learning for Innovation in Developing Countries: Pharmaceutical Firms in Mexico UNU-MERIT Dissertation Series, № 66

\section{Zakaria Babutsidze}

Essays on Economies with Heterogeneous Interacting Consumers

UNU-MERIT Dissertation Series, № 65 


\section{Bertha Vallejo}

Learning and Innovation Under Changing

Market Conditions: The Auto Parts

Industry in Mexico

UNU-MERIT Dissertation Series, № 64

\section{Donatus Ayitey}

Technical Change, Competitiveness and

Poverty Reduction: A Study of the

Ghanaian Apparel Industry

UNU-MERIT Dissertation Series, № 63

\section{Sergey Filippov}

Multinational Subsidiary Evolution:

Corporate Change in New EU Member

States

UNU-MERIT Dissertation Series, № 62

\section{Asel Doranova}

Technology Transfer and Learning under

the Kyoto Regime: Exploring the

Technological Impact of CDM Projects in

Developing Countries

UNU-MERIT Dissertation Series, № 61

\section{Florian Tomini}

Between Family and Friend:

Understanding the Interdependency of

Private Transfers

MGSoG Dissertation Series, № 15

\section{Michał Polalowski}

The Institutional Transformation of Social Policy in East Central Europe: Poland and Hungary in Comparative and Historical Perspective

MGSoG Dissertation Series, № 14

\section{Maha Ahmed}

Defining, Measuring and Addressing Vulnerability: The Case of Post Conflict

Environments

MGSoG Dissertation Series, № 13

\section{Pascal Beckers}

Local Space and Economic Success: The Role of Spatial Segregation of Migrants in the Netherlands

MGSoG Dissertation Series, № 12

\section{Victor Cebotari}

Conflicting Demands in Ethnically Diverse Societies: Ethno political Contention and Identity Values in Europe MGSoG Dissertation Series, № 11

\section{Dennis Gyllensporre}

Competing and Complementary

Perspectives on the EU as a Crisis

Management Actor:

An Examination of the Common Security and Defence Policy through the Lenses of Idealism and Realism

MGSoG Dissertation Series, № 10

\section{Judit Vall Castello}

Business Cycle and Policy Effects on Labour Market Transitions of Older and Disabled Workers in Spain

MGSoG Dissertation Series, № 9

\section{Keetie Roelen}

False Positives or Hidden Dimensions: The Definition and Measurement of Child Poverty

MGSoG Dissertation Series, № 8

Denisa Maria Sologon

Earning Dynamics in Europe

MGSoG Dissertation Series, № 7

\section{Melissa Siegel}

Money and Mobility: Migration and

Remittances

MGSoG Dissertation Series, № 6 


\section{Jessica S. Hagen-Zanker}

Modest Expectations: Causes and Effects of

Migration on Migrant Households

inSource Countries

MGSoG Dissertation Series, № 5

2009

\section{Alexis Habiyaremye}

From Primary Commodity Dependence to

Diversification and Growth: Absorptive

Capacity and Technological Catch Up in

Botswana and Mauritius.

UNU-MERIT Dissertation Series, № 60

\section{Yoseph Getachew}

The Role of Public Capital in Economic

Development

UNU-MERIT Dissertation Series, № 59

\section{Sandra Leitner}

Embodied Technological Change and

Patterns of Investment in Austrian

Manufacturing

UNU-MERIT Dissertation Series, № 58

\section{Semih Akçomak}

The Impact of Social Capital on Economic and Social Outcomes

UNU-MERIT Dissertation Series, № 57

\section{Abraham Garcia}

The Role of Demand in Technical Change

UNU-MERIT Dissertation Series, № 56

\section{Saurabh Arora}

Coherence in Socio-technical Systems: A

Network Perspective on the Innovation

Process

UNU-MERIT Dissertation Series, № 55

\section{Mirtha R. Muniz Castillo}

Human Development and Autonomy in Project Aid: Experiences from four bilateral projects in Nicaragua and El Salvador

MGSoG Dissertation Series, № 4

\section{Christiane Arndt}

Governance Indicators

MGSoG Dissertation Series, № 3

\section{Britta Augsburg}

Microfinance: Greater Good or Lesser Evil?

MGSoG Dissertation Series, № 2

2008

\section{Rutger Daems}

Medicines for the Developing World

UNU-MERIT Dissertation Series, № 54

Johannes Hanel

Assessing Induced Technology: Sombart's Understanding of Technical Change in the History of Economics

UNU-MERIT Dissertation Series, № 53

\section{Rifka Weehuizen}

Mental Capital: the Economic Significance of Mental Health

UNU-MERIT Dissertation Series, № 52

\section{Danielle Cloodt}

The Relationship between RED

Partnership Formation, Social

Embeddedness and Innovative Performance UNU-MERIT Dissertation Series, № 51

\section{Sabine Fuss}

Sustainable Energy Development under

Uncertainty

UNU-MERIT Dissertation Series, № 50

\section{Geranda Notten}

Measuring and Managing Poverty Risks

MGSoG Dissertation Series, № 1 


\section{Thomas Pogue}

\section{Tobias Kronenberg}

Reconciling Environmental Conservation with Economic Prosperity: The Feasibility of Double Dividends in the Short and Long Run

UNU-MERIT Dissertation Series, № 49

\section{Viktoria Kravtsova}

Assessing the Impact of Foreign Direct Investment in Transition Economies

UNU-MERIT Dissertation Series, № 48

\section{Suhail Sultan}

The Competitive Advantage of Small and Medium Sized Enterprises: The Case of Jordan's Natural Stone Industry

UNU-MERIT Dissertation Series, № 47

2006

\section{Bulat Sanditov}

Essays on Social Learning and Imitation UNU-MERIT Dissertation Series, № 46

\section{Mamata Parhi}

Dynamics of New Technology Diffusion: A Study of the Indian Automotive Industry UNU-MERIT Dissertation Series, № 45

\section{Andreas Reinstaller}

Social Structures and the Innovation

Process: Their Role in the Demand of Firms and Consumers

UNU-MERIT Dissertation Series, № 44

\section{Rose Kiggundu}

Innovation systems and Development: The Journey of a Beleaguered Nile Perch Fishery in Uganda

UNU-MERIT Dissertation Series, № 43

The Evolution of Research Collaboration in South African Gold Mining: 1886-1933 UNU-MERIT Dissertation Series, № 42

\section{Geoffrey Gachino}

Foreign Direct Investment, Spillovers and Innovation: The Case of Kenyan

Manufacturing Industry

UNU-MERIT Dissertation Series, № 41

\section{Önder Nomaler}

Technological Change, International Trade and Growth: An Evolutionary, Multi-

Agents-Based Modeling Approach

UNU-MERIT Dissertation Series, № 40

2005

\section{Samia Satti Osman Mohamed-Nour}

Change and Skill Development in the Arab Gulf Countries

UNU-MERIT Dissertation Series, № 39

\section{Elad Harison}

Intellectual Property Rights: Economics and Policy Analysis

UNU-MERIT Dissertation Series, № 38

\section{Daniel Dalohoun}

Learning to innovate: agricultural innovation and entrepreneurship: the case of Songhaï farmers in Benin

UNU-MERIT Dissertation Series, № 37

\section{Müge Ozman}

Networks, Organizations and Knowledge

UNU-MERIT Dissertation Series, № 36

\section{Bas Straathof}

Product Variety and Economic Growth:

The Counteracting Effects of Scale and Idiosyncrasy

UNU-MERIT Dissertation Series, № 35 


\section{Wilfred Schoenmakers}

Knowledge Flows between Multinational

Companies: A Patent Data Analysis

UNU-MERIT Dissertation Series, № 34

\section{Myriam Cloodt}

Mergers and Acquisitions ( $M$ and $A s$ ) in

High-Tech Industries: Measuring the Post-

$M$ and $A$ Innovative Performance of

Companies

UNU-MERIT Dissertation Series, № 33

2004

\section{Paola Criscuolo}

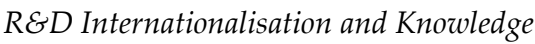

Transfer: Impact on MNEs and their Home Countries

UNU-MERIT Dissertation Series, № 32

\section{Maarten Verkerk}

Trust and Power on the Shop Floor

UNU-MERIT Dissertation Series, № 31

\section{Gottfried Leibbrandt}

Adoption, Harmonization and Succession of Network Technologies across Countries UNU-MERIT Dissertation Series, № 30

\section{Mark Sanders}

Skill Biased Technical change: Its Origins, the Interaction with the Labour Market and Policy Implications

UNU-MERIT Dissertation Series, № 29

2003

Nadine Roijakkers

Inter-firm Cooperation in High-tech Industries: a Study of RED Partnerships in Pharmaceutical Biotechnology UNU-MERIT Dissertation Series, № 28

\section{Viki Sonntag}

Speed, Scale and Sustainability UNU-MERIT Dissertation Series, № 27
Masaru Yarime

From End-of-Pipe Technology to Clean

Technology

UNU-MERIT Dissertation Series, № 26

\section{Stéphane Malo}

The Combinatorial Chemistry Revolution:

Sustaining a Superior Performance

Position through Technological Learning

UNU-MERIT Dissertation Series, № 25

2002

\section{Annelies Hogenbirk}

Determinants of Inward Foreign Direct Investment: the Case of the Netherlands UNU-MERIT Dissertation Series, № 24

\section{Bastiaan Johan terWeel}

The Computerization of the Labour Market UNU-MERIT Dissertation Series

2001

John Adeoti

Technology Investment in Pollution Control in Sub-Saharan Africa: The Case of the Nigerian Manufacturing Industry UNU-MERIT Dissertation Series, № 23

\section{Edward Huizenga}

Innovation Management: How

Frontrunners Stay Ahead: An Empirical

Study on Key Success Factors in the ICT sector

UNU-MERIT Dissertation Series, № 22

2000

\section{Machiel van Dijk}

Technological Change and the Dynamics of Industries: Theoretical Issues and Empirical evidence from Dutch Manufacturing UNU-MERIT Dissertation Series, № 21 
1999

\section{Jan Cobbenhagen}

Managing Innovation at the Company

Level: A Study on Non-Sector-Specific

Success Factors

UNU-MERIT Dissertation Series, № 20

\section{Marjolein Caniëls}

Regional Growth Differentials: The Impact of Locally Bounded Knowledge Spillovers

UNU-MERIT Dissertation Series, № 19

1998

\section{Aldo Geuna}

Resource Allocation and Knowledge

production: Studies in the Economics of

University Research

UNU-MERIT Dissertation Series, № 18

1996

\section{Reinoud Joosten}

Dynamics, Equilibria, and Values

UNU-MERIT Dissertation Series, № 17

\section{Hugo Kruiniger}

Investment, $R \mathcal{E} D$, and the Financing

Decisions of the Firm

UNU-MERIT Dissertation Series, № 16

1995

\section{Hans van Meijl}

Endogenous Technological Change: The

Case of Information Technology,

Theoretical Considerations and Empirical

Results

UNU-MERIT Dissertation Series, № 15

\section{René Kemp}

Environmental Policy and Technical

Change: A Comparison of the Technological Impact of Policy Instruments

UNU-MERIT Dissertation Series, № 14

\section{Rohini Acharya}

The Impact of New Technologies on

Economic Growth and Trade: A Case Study of Biotechnology

UNU-MERIT Dissertation Series, № 13

\section{Geert Duysters}

The Evolution of Complex Industrial Systems: The Dynamics of Major IT

Sectors

UNU-MERIT Dissertation Series, № 12

\section{Marjan Groen}

Technology, Work and Organisation: A

Study of the Nursing Process in Intensive

Care Units

UNU-MERIT Dissertation Series, № 11

1994

\section{Huub Meijers}

On the Diffusion of Technologies in a Vintage Framework: Theoretical

Considerations and Empirical Results

UNU-MERIT Dissertation Series, № 10

\section{Theon van Dijk}

The Limits of Patent Protection: Essays on the Economics of Intellectual Property Rights

UNU-MERIT Dissertation Series, № 9

\section{Hans Voordijk}

Naar Integrale Logistiek in Bedrijfsketens:

Ontwikkelingen in de Bouw

UNU-MERIT Dissertation Series, № 8

1993

\section{Paul Diederen}

Technological Progress in Enterprises and Diffusion of Innovation: Theoretical

Reflections and Empirical Evidence

UNU-MERIT Dissertation Series, № 7 


\section{Ben Dankbaar}

Economic Crisis and Institutional Change:

The Crisis of Fordism from the Perspective of the Automobile Industry

UNU-MERIT Dissertation Series, № 6

\section{Hanno Roberts}

Accountability and Responsibility: The

Influence of Organisation Design on

Management Accounting

UNU-MERIT Dissertation Series, № 5

1992

\section{Bart Verspagen}

Uneven Growth between Interdependent

Economies: An Evolutionary View on

Technology Gaps, Trade and Growth

UNU-MERIT Dissertation Series, № 4

\section{Sjoerd Romme}

A Self-organization Perspective on Strategy

Formation

UNU-MERIT Dissertation Series, № 3

1989

\section{John Spangenberg}

Economies of Scale, and Atmosphere in

Research Organisations

UNU-MERIT Dissertation Series, № 2

1988

\section{John Hagedoorn}

Evolutionary and Heterodox Innovation

Analysis: A Study of Industrial and

Technological Development in Process

Control and Information Technology

UNU-MERIT Dissertation Series, № 1 